\title{
VALUE AND RISK EFFECTS OF FINANCIAL DERIVATIVES: EVIDENCE OF CORPORATE GOVERNANCE ON HEDGING, SPECULATION AND SELECTIVE HEDGING STRATEGIES
}

\author{
by \\ RUBEENA TASHFEEN
}

\begin{abstract}
A thesis
submitted to the Victoria University of Wellington in fulfilment of the requirements for the degree of

Doctor of Philosophy
\end{abstract}

Victoria University of Wellington

2016 


\section{FOR MY MOTHER}

\section{FOREVER LOVED, MISSED \& REMEMBERED}




\section{Statement of Original Authorship}

I hereby confirm that the work presented in this thesis is my own and original work that has been carried out through the School of Accounting and Commercial Law, Victoria University of Wellington, during my candidature as a $\mathrm{PhD}$ student. I declare that the material of this thesis has not been submitted either in whole or in part for the award of any other degree or diploma at this or any other university. To the best of my knowledge and belief, it contains no material previously published or written by other persons or institutions except where due reference has been made.

Rubeena Tashfeen 


\section{Acknowledgements}

I wish to express my utmost gratitude to my primary supervisor, Professor Tony van Zijl for his invaluable insights, guidance, and comments throughout the many stages of the development of this thesis. The direction and supervision provided has enabled me to achieve a depth of research presented in this thesis. I am also thankful to Dr. Noor Houqe for his supervision and insights in the execution of my thesis.

I wish to express my sincerest gratitude to PhD Program Director, Andrew Smith for his support through the completion of the thesis - thank you. I am very grateful to Dr. Ian Eggleton and Dr. Carolyn Cordery for their continued guidance and support. I extend my indebtedness to Dr. Philip Colquhoun, for mentoring me through the first three years of my PhD. Dr. Lizzie Towl has a very special place in my PhD journey and I would like to express my heartfelt gratitude for her invaluable support. I also extend my gratitude to Dr. Michael Fraser for believing in me and making this $\mathrm{PhD}$ possible. A special thanks to Dr. Ken Bates and Dr. Rodney Dormer from whom I have learnt so much as a tutor in their course. And, I am grateful to Dr. Phuong Truong and Dr. Martin Lubberink for sharing their statistical techniques with me.

To my family of PhD students, I extend my appreciation for the wonderful times we have shared together. A special thanks to Hannah for sharing her technical and analytical skills with me and for being such a good friend. A thank you to Asma for all the delightful moments we have shared. Ryan, Uyanga, Tariq, Marko, Dimu, Nam, Arie, Farzana, Katie, Sendirella, Claire, Hien, Amy, Yinka and others, I take away so many wonderful memories and experiences of my time with you. Matt Sorola I thoroughly enjoyed our many intellectual discussions and you have helped me so many times and in so many ways. I also thank Oliver, Ilken and Tom (finance and economics department) for sharing their econometric insights. A special note of appreciation to Jane Perry for her cooperation and guidance. 
I wish to express my gratitude to Victoria University of Wellington (VUW) for awarding me the VUW Doctoral Scholarship and PhD Submission Scholarship.

This $\mathrm{PhD}$ would not have been possible without the love and sacrifices made by my family: Tashfeen, Arqum, Serina, Amaad and Atiya. I thank them for giving me the strength to move forward at each stage in my endeavors. And, I am grateful to my siblings for supporting me through the sad demise of my mother. 


\begin{abstract}
This study investigates whether there is a relationship between corporate governance and derivatives, whether corporate governance influence in firms impacts the association between derivatives and firm value, and whether corporate governance influence affects the association between derivatives and cash flow volatility, stock return volatility and market risk. This study uses two different data samples of publicly traded firms listed on the New York Stock Exchange. The first sample comprises a panel of 6900 firm year observations and the other consists of a panel of 6234 firm year observations both over the eight-year period from 2004-2011.
\end{abstract}

With regard to whether there is a relationship between corporate governance and derivatives, the findings from the empirical results show that corporate governance does influence derivatives and therefore is an important determinant in the firm's decisions to use derivatives. Of the thirteen corporate governance variables examined, board size, institutional shareholders, CEO age, CEO bonus, CEO salary, insider shareholders and total CEO compensation show significant association with derivatives.

This study finds that derivative users exhibit higher firm value on account of the corporate governance influence, which is correspondingly largely insignificant for derivative non-users. Further the research indicates that the impact of corporate governance varies according to the different types of risks examined. Generally, the board of directors and CEO governance mechanisms reduce stock return volatility to achieve hedging effectiveness. This supports the view that directors and management take actions to reduce stock return volatility to protect their personal portfolios without having to bear the costs of hedging themselves. 
With respect to cash flow volatility, the board of directors and CEO related corporate governance mechanisms largely exhibit increased risk to show evidence of speculative behavior. It supports the perceptions that managers and directors have a strong motivation to show higher earnings to protect jobs and reputation and to enhance compensation.

All the shareholder governance mechanisms encourage risk taking with respect to stock return volatility, without any increase in firm value. This is in line with research findings of market granularity by institutional and other larger block holders to indicate that these investors increase stock price volatilities and play the markets for their own financial gain. Besides they have little interest in diversifying firm risk as they already have well protected portfolios and would not want to incur additional costs of hedging.

The study finds evidence of association between corporate governance and hedging, speculation and selective hedging. Of the thirteen corporate governance variables examined in the study board diversity consistently shows hedging effectiveness, with accompanying increase in firm value. While board meetings, institutional shareholders, block shareholders, CEO age, CEO base salary and CEO compensation exhibit exclusive speculative behavior. The remaining corporate governance mechanisms: board size, insider shareholding, CEO tenure, CEO bonus and audit committee size, show evidence of selective hedging behavior.

The concurrent hedging and speculative behavior evidenced in this study supports literature in respect of selective hedging by non-financial firms. It also validates the idea that corporate governance delves in risk allocation strategies that have been evidenced by past research. The results remain unchanged, after using alternative measures for firm value and firm risk, and alternative methods of analyses. 


\section{TABLE OF CONTENTS}

STATEMENT OF ORIGINAL AUTHORSHIP .................................................... II

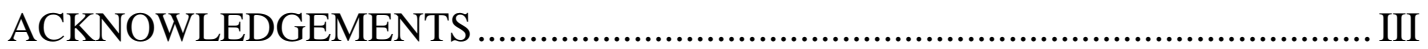

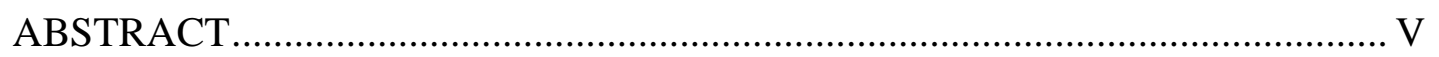

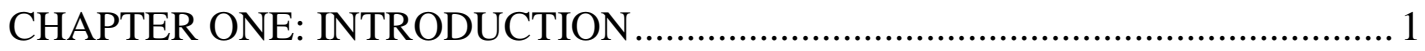

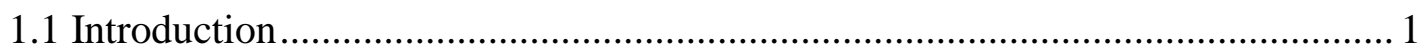

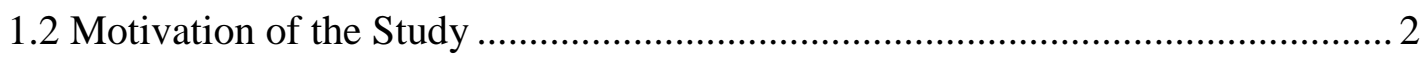

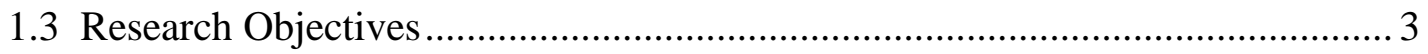

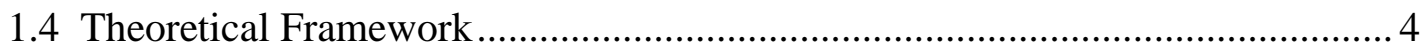

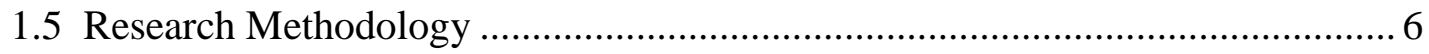

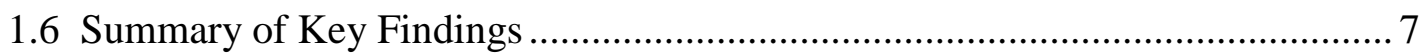

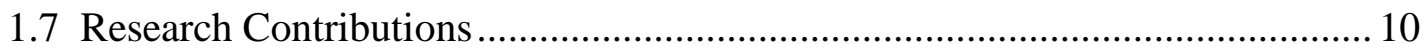

1.8 Structure of the Remainder of the Thesis ........................................................ 12

CHAPTER TWO: OVERVIEW OF INSTITUTIONAL ENVIRONMENT AND

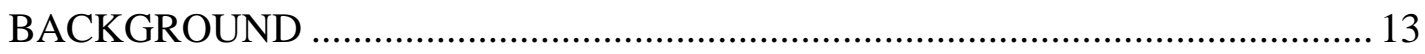

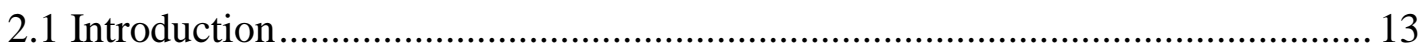

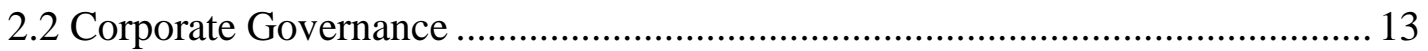

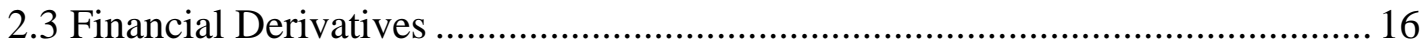

2.4 The Financial Crisis and Corporate Governance ………………...................... 16 


\section{CHAPTER THREE: PRIOR STUDIES ON DERIVATIVES, CORPORATE}

GOVERNANCE, FIRM VALUE AND FIRM RISK ………………………......... 21

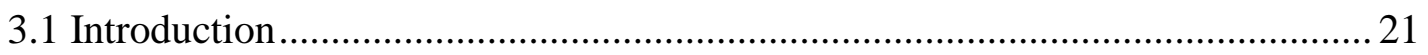

3.2 What are the Determinants of Derivatives? .................................................... 21

3.2.1 Corporate Governance as a Determinant of Derivatives ............................... 34

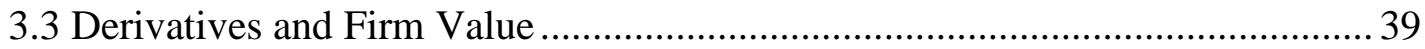

3.3.1 Derivatives, Corporate Governance and Firm Value.................................... 43

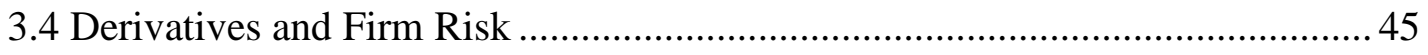

3.4.1 Derivatives, Corporate Governance and Firm Risk .....................................4 48

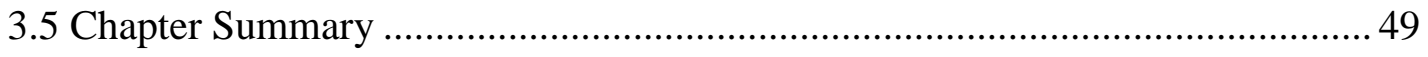

CHAPTER FOUR: THEORETICAL FRAMEWORK AND DEVELOPMENT OF

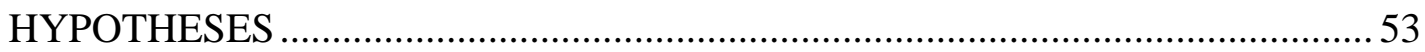

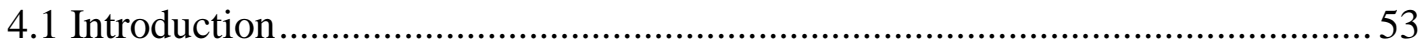

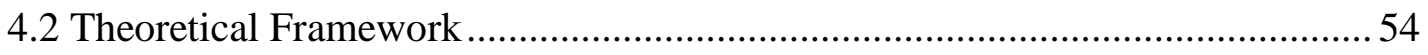

4.2.1. Agency Theory and Corporate Governance ……………………….........5

4.2.2 Corporate Governance Mechanisms ........................................................... 55

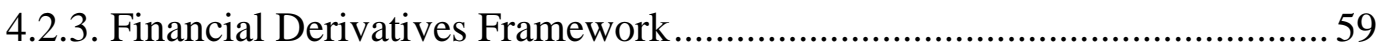

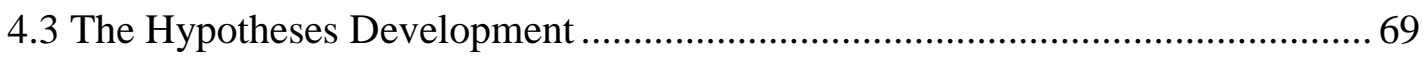

4.4 Hypotheses Development - Board of Directors (board)..................................... 69

4.5 Hypotheses Development - Shareholders ………….......................................... 81

4.6 Hypotheses Development - CEO Executive Remuneration ................................. 88 
4.7 Hypothesis Development - Audit Committee

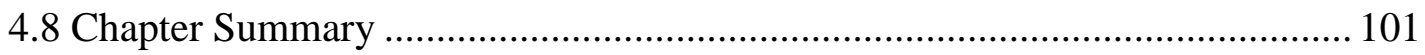

CHAPTER 5: SAMPLE, DATA AND RESEARCH METHODOLOGY ............. 103

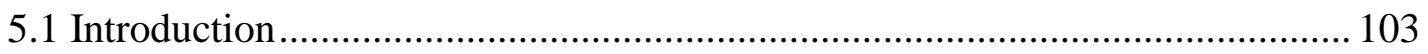

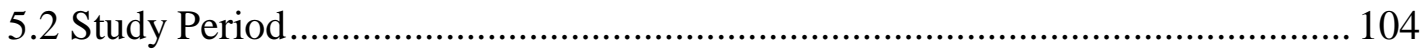

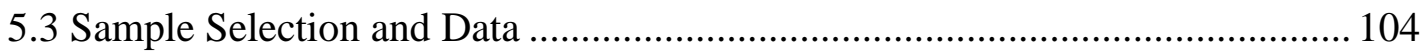

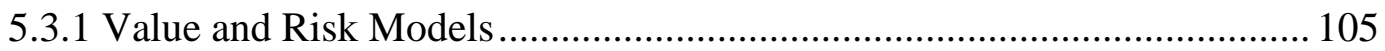

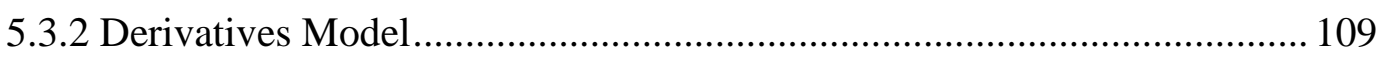

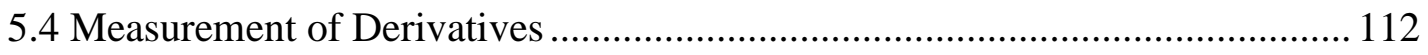

5.5 Measurement of Firm Value .................................................................... 114

5.6 Measurement of Firm Risk ....................................................................... 115

5.7 Measurement of Corporate Governance Variables........................................ 119

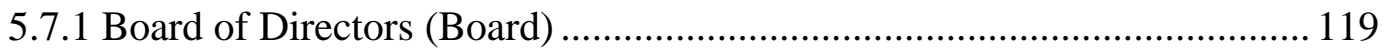

5.7.2 CEO Compensation, Age and Tenure ................................................... 123

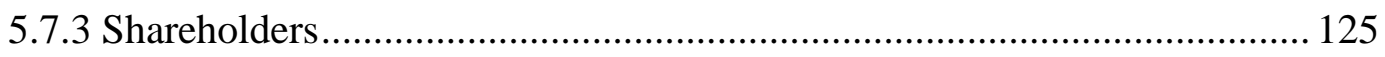

5.7.4 Audit Committee Size ................................................................... 128

5.8 Measurement of Control Variables for Value and Risk Models...................... 133

5.9 Measurement of Control Variables for the Derivatives Model ....................... 136

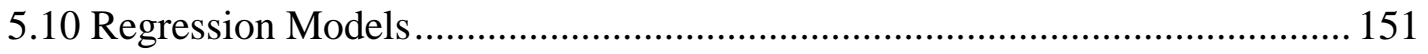

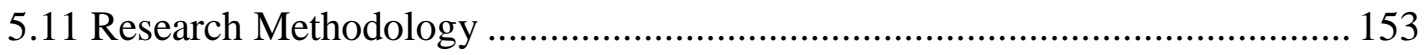

5.12 Sensitivity Analyses and Alternative Tests................................................ 159

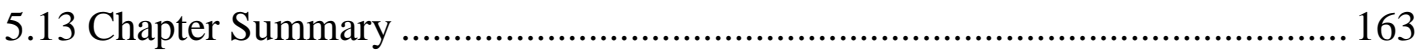


CHAPTER SIX: RESULTS I: FIRM VALUE, FIRM RISK, DERIVATIVES AND

CORPORATE GOVERNANCE

6.1 Introduction

6.2 Descriptive Statistics. 166

6.2.1 Analysis of Differences between Derivative User and Non User Firms ... 173

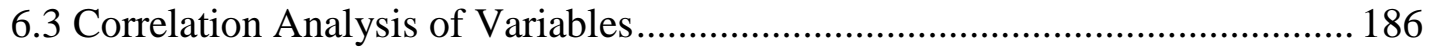

6.3.1 Correlation Analysis of Variables - Value Model ...................................... 186

6.3.2 Multicollinearity Tests for Value and Risk Models.

6.4 Multivariate Analysis for Effect of Corporate Governance on the Value Effect of Derivatives.

6.4.1 Multivariate Analysis on Value for Derivatives Non User Firms.

6.4.2 Comparison of Results from the Multivariate Analysis .205

6.5 Multivariate Analysis on the Effect of Corporate Governance on the Relationship between Derivatives and Cash Flow Volatility Risk.

6.6 Multivariate Analysis of the Effect of Corporate Governance on the Relationship between Derivatives and Stock Return Volatility

6.7 Multivariate Analysis of the Effect of Corporate Governance on the Relationship between Derivatives and Market Risk

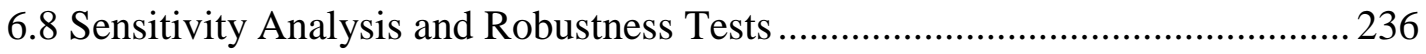

6.8.1 Robustness Tests for Value Model ...................................................... 237

6.8.2 Robustness Tests for Risk Models

6.9 Alternative Tests on the Relationship between Derivatives, Corporate Governance, Firm Value and Firm Risk for Derivative Users and Derivative Non Users 


\section{CHAPTER SEVEN RESULTS II: DERIVATIVES AND CORPORATE}

GOVERNANCE

7.1 Introduction

7.2 Descriptive Statistics.

7.3 Correlation Analysis of Variables

7.4. Multivariate Analysis on the Effect of Corporate Governance Variables on Derivatives.

7.5 Sensitivity Analyses and Robustness Tests

7.6 Chapter Summary

CHAPTER EIGHT: DISCUSSION OF FINDINGS

8.1 Introduction

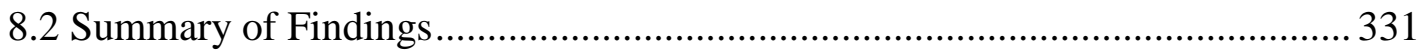

8.2.1 Corporate Governance and Hedging .................................................... 332

8.2.2 Corporate Governance and Speculation.................................................. 333

8.2.3 Corporate Governance and Selective Hedging ......................................... 336

8.2.4 Corporate Governance as a Determinant of Derivatives ........................... 337

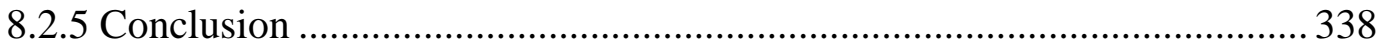

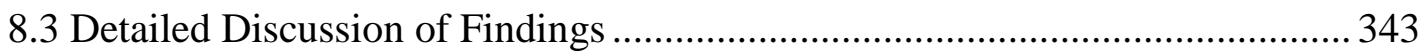

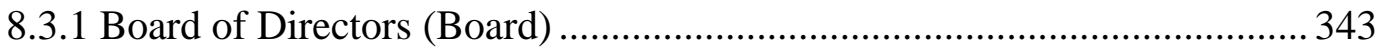

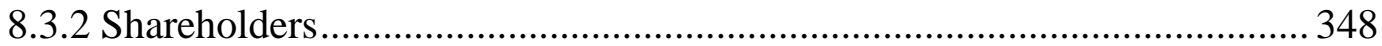

8.3.3 Chief Executive Officer (CEO) ............................................................ 352

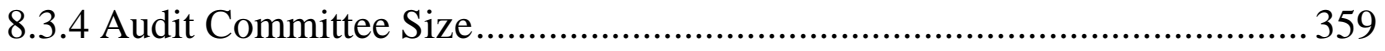

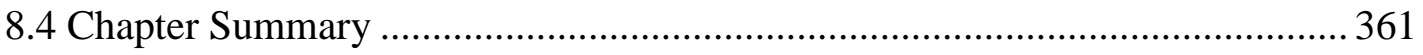

CHAPTER NINE: SUMMARY AND CONCLUSION......................................... 363 
9.1 Introduction

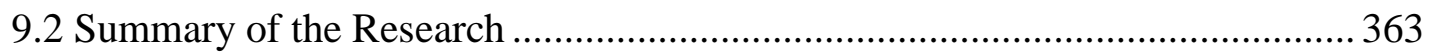

9.2.1 Is Corporate Governance a Determinant of Derivatives? ......................... 364

9.2.2 Does Corporate Governance Impact the Value Effects of Derivatives?.... 364

9.2.3 Does Corporate Governance Impact the Risk Effects of Derivatives?...... 365

9.3 Derivatives and Corporate Governance: Hedging, Speculation, and Selective Hedging 367

9.4 Limitations of the Study 371

9.5 Future Research Suggestions 373

9.6 Contributions .374

REFERENCES .379

APPENDIX 1: DERIVATIVES TRADED ON ORGANIZED EXCHANGES.... 413

APPENDIX 2: GLOBAL OTC DERIVATIVES MARKET . 414

APPENDIX 3 : HEDGING VS NON-HEDGING WITH PUT OPTIONS 415

APPENDIX 4: DERIVATIVE USER AND NON USER COMPARISON OF RESULTS 416

APPENDIX 5: SUMMARY OF RESULTS FOR DERIVATIVE USERS

APPENDIX 6: YEAR-WISE COMPARISON OF CORPORATE GOVERNANCE CHARACTERISTICS 


\section{LIST OF TABLES}

TABLE 4.1: DERIVATIVES: HEDGING AND SPECULATION MATRIX ..... 62

TABLE 5. 1: DERIVATION OF SAMPLE AND INDUSTRY CATEGORY -

VALUE AND RISK MODELS.

TABLE 5. 2: DERIVATION OF SAMPLE AND INDUSTRY CATEGORY -

DERIVATIVES MODEL

TABLE 5. 3 DEFINITION OF CORPORATE GOVERNANCE

VARIABLES.

TABLE 5. 4: DEFINITION OF OTHER INDEPENDENT AND CONTROL

VARIABLES

TABLE 5. 5: EXPECTED RELATIONS BETWEEN EXPLANATORY

VARIABLES AND DERIVATIVES

TABLE 5. 6: EXPECTED RELATIONS BETWEEN EXPLANATORY

VARIABLES AND RISK

TABLE 5. 7: EXPECTED RELATIONS BETWEEN EXPLANATORY

VARIABLES AND VALUE

TABLE 5.8: MODEL SPECIFICATIONS FOR ALL MODELS IN THE STUDY

TABLE 5. 9: SPECIFICATIONS FOR ISUR MODELS

TABLE 6. 1: DESCRIPTIVE STATISTICS FOR VALUE, RISK, DERIVATIVES AND CORPORATE GOVERNANCE

TABLE 6. 2: MEAN DIFFERENCES IN CHARACTERISTICS FOR DERIVATIVE USER \& NON USER FIRMS 176

TABLE 6. 3: TIME SERIES EFFECTS FOR MEAN DIFFERENCES IN DERIVATIVE USER AND NON USER FIRMS 
TABLE 6.4A: PEARSON CORRELATION MATRIX FOR VALUE , CORPORATE GOVERNANCE, CONTROL VARIABLES ......... 188

TABLE 6.4B: CORRELATION MATRIX FOR VALUE, CORPORATE

GOVERNANCE, CONTROL VARIABLES. 188

TABLE 6.4C: CORRELATION MATRIX FOR RISK, CORPORATE

GOVERNANCE, CONTROL VARIABLES.................................. 188

TABLE 6. 5: MULTICOLLINEARITY TESTS - VALUE MODEL.................. 192

TABLE 6. 6: MULTICOLLINEARITY TESTS - RISK MODELS ....................193

TABLE 6. 7: VALUE REGRESSION MODELS FOR DERIVATIVE USER FIRMS

TABLE 6. 8: VALUE REGRESSION MODELS FOR DERIVATIVE NON USER FIRMS. .203

TABLE 6. 9: CASH FLOW VOLATILITY REGRESSION MODELS FOR DERIVATIVE USER FIRMS 211

TABLE 6. 10: CASH FLOW VOLATILITY REGRESSION MODELS FOR DERIVATIVE NON USER FIRMS

TABLE 6. 11: STOCK RETURN VOLATILITY REGRESSION MODELS FOR DERIVATIVE USER FIRMS . 223

TABLE 6. 12: STOCK RETURN VOLATILITY REGRESSION MODELS FOR DERIVATIVE NON USER FIRMS 226

TABLE 6. 13: MARKET RISK REGRESSION MODELS FOR DERIVATIVE USER FIRMS

TABLE 6.14: MARKET RISK REGRESSION MODELS FOR DERIVATIVE

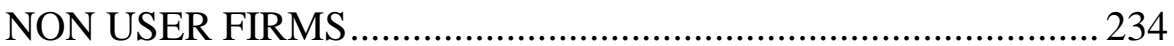

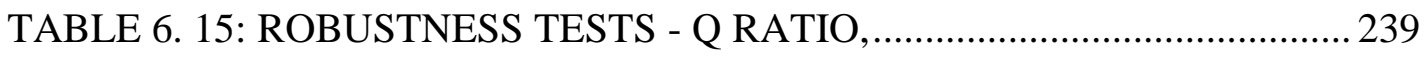

TABLE 6. 16: ROBUSTNESS TESTS - MARKET-BOOK RATIO ..................... 241

TABLE 6. 17: ROBUSTNESS MODEL - VALUE BOOTSTRAP $(10,000)$....... 243

TABLE 6. 18: ROBUSTNESS TESTS - LEVELS OF LEVERAGE IN DERIVATIVE USER FIRMS .246

TABLE 6. 19:ROBUSTNESS TESTS - LEVELS OF LEVERAGE IN DERIVATIVE NON USER FIRMS .248 
TABLE 6. 20: ROBUSTNESS TESTS - Z-SCORE 251

TABLE 6. 21: ROBUSTNESS TESTS - VROE. .253

TABLE 6. 22: ROBUSTNESS TESTS -CASH FLOW VOLATILITY

BOOTSTRAP $(10,000)$...... .256

TABLE 6. 23: ROBUSTNESS TESTS - STOCK RETURN VOLATILITY

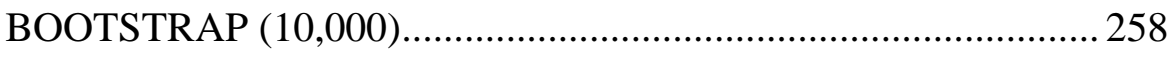

TABLE 6. 24: ROBUSTNESS TESTS - MARKET RISK BOOTSTRAP $(10,000)$ 260

TABLE 6. 25: ALTERNATIVE TESTS (ISUR): VALUE AND CASH FLOW VOLATILITY IN DERIVATIVE USER AND NON USER FIRMS 265

TABLE 6. 26: ALTERNATIVE TESTS (ISUR) VALUE AND STOCK RETURN VOLATILITY. 270

TABLE 6. 27: ALTERNATIVE TESTS (ISUR): VALUE AND MARKET RISK, IN DERIVATIVE USER AND NON USER FIRMS .275

TABLE 7. 1: DESCRIPTION OF DERIVATIVE USERS BY INDUSTRY AND YEAR 283

TABLE 7. 2: DESCRIPTION OF DERIVATIVE USER AND NON-USER FIRMS BY INDUSTRY. .285

TABLE 7. 3: DESCRIPTIVE STATISTICS FOR DERIVATIVES, LEVERAGE AND CORPORATE GOVERNANCE. .291

TABLE 7.4A: PEARSON CORRELATION MATRIX FOR DERIVATIVES, CORPORATE GOVERNANCE AND CONTROL VARIABLES. .296

TABLE 7.4B: SPEARMAN CORRELATION MATRIX FOR DERIVATIVES, CORPORATE GOVERNANCE AND CONTROL VARIABLES. .296 
TABLE 7. 5: MULTICOLLINEARITY TESTS FOR DERIVATIVES

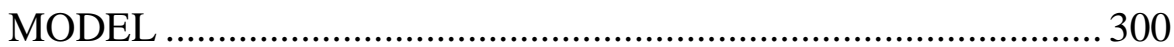

TABLE 7. 6: PROBIT REGRESSION FOR DERIVATIVES MODEL .............. 302

TABLE 7. 7: SIMULTANEOUS EQUATIONS MODEL - DERIVATIVES, LEVERAGE AND CORPORATE GOVERNANCE ……………...308

TABLE 7. 8: DERIVATIVES ROBUSTNESS TESTS - FINANCIAL CONSTRAINT MEASURES

TABLE 7. 9: DERIVATIVES ROBUSTNESS TESTS - GROWTH MEASURES

TABLE 7.10: DERIVATIVES ROBUSTNESS TESTS - INVESTMENT OPPORTUNITIES AND UNDERINVESTMENT COSTS 318

TABLE 7. 11: DERIVATIVES ROBUSTNESS TESTS - LEVELS OF LEVERAGE

TABLE 7. 12:DERIVATIVES ROBUSTNESS TESTS - ALTERNATIVE

VARIABLES

TABLE 7. 13: DERIVATIVES ROBUSTNESS TESTS - FIRM SIZE SUB-

SAMPLES 


\section{LIST OF FIGURES}

FIGURE 4. 1: DERIVATIVES AND CORPORATE GOVERNANCE .....................66

FIGURE 4. 2: DERIVATIVES, CORPORATE GOVERNANCE, FIRMVALUE...67

FIGURE 4. 3: DERIVATIVES, CORPORATE GOVERNANCE, FIRM RISK .......68

FIGURE 6.1 YEAR WISE CASH FLOW VOLATILITY GRAPH................ 184

FIGURE 6.2 YEAR WISE STOCK RETURN VOLATILITYGRAPH...............184

FIGURE 6.3 YEAR WISE MARKET RISK GRAPH........................... 185

FIGURE 6.4 YEAR WISE VALUE GRAPH................................ 185 


\section{CHAPTER ONE: INTRODUCTION}

\subsection{Introduction}

Corporate governance quality is important for effective risk management in companies where the ownership is separated from control of corporate decisions. The agency theory (Jensen and Meckling, 1976; Fama and Jensen, 1983a) suggests that in such circumstances there exists the possibility of agency conflict. This role becomes all the more critical within firms that use financial derivatives since the risky nature of these securities necessitates more effective monitoring and control. Derivatives are sophisticated financial instruments that enable firms to hedge their risk exposure. They provide a cushion against losses and a protection against unforeseen market changes and unpredictable cash flow fluctuations. At the same time due to their complex nature, the financial instruments are not easily understood and require a greater level of expertise and control for their proper management.

It is the high risk and complex nature of derivative instruments that motivated Buffet (2003) to term them as "the lethal weapons of mass destruction". The exotic derivatives: mortgage-backed securities, collateralized debt obligations (CDOs), CDOs squared, synthetic CDOs and other synthetic securitization, are often termed as "toxic" (FCIR, 2011). This is due to the huge losses that can arise from the failure of derivative instruments, where the losses have a roll over effect. It highlights the fact that the risks involved in derivatives are large and any mistake, malpractice or mismanagement in their use would have very dire consequences for the firm. Therefore, the quality of the corporate governance is critical for firms that use derivative instruments to hedge risks. 


\subsection{Motivation of the Study}

This thesis is motivated primarily by losses that occurred during the financial crisis and the role that corporate governance played in the management of derivatives securities at the firm level. Many studies (Roll, 2011; Figlewski, 2009) attribute the misuse, weak control and poor understanding of the complex derivative instruments as contributing to the financial crisis. Bhalla (2009) suggests that the investors (firms) should have more closely scrutinized the risks associated with the securities purchased as this would have provided some sort of a check over the securitization process.

There is a general criticism that there was inadequate control over hedging activities which resulted in firms taking hedging positions that did not match their risk exposure. Some companies ended up speculating inadvertently due to insufficient expertise or deliberately for financial gain (Rossi, 2012), indicating that agency problems, high risk exposures and inadequate hedging strategies enabled speculation with derivatives (Zeidan and Rodrigues, 2013). Likewise, firms with weak management capabilities indulged in hubris and excessive risk ( $\mathrm{Li}$ and Tang, 2010). In his report, Kirkpatrick (2009) concludes that "the financial crisis can to a large extent be attributed to failures and weaknesses in corporate governance" (Kirkpatrick, 2009, p.1) in both financial and non-financial firms.

This raises concerns regarding governance and inadequate risk management. Despite the rich literature on financial institutions, there is limited research on the impact of corporate governance on risk management through derivatives in non-financial companies. Prior studies in this area examine some of the corporate governance mechanisms. Generally, the examination does not cover a comprehensive range of governance mechanisms, and additionally does not include all (together) in one study. Therefore, results of such studies may suffer from omitted variables bias. This could be one of the reasons for the weak results that are observed in current studies in relation to the association between corporate governance and derivatives. 
Another shortcoming, is the lack of an examination of the corporate governancederivatives relationship along with other hedging activities of the firm. External financing and derivatives decisions are both considered while evaluating a firm's financing needs and capital structure requirements. Therefore, studies that ignore other financial hedges when investigating the derivatives hedging effects, may suffer from problems of endogeneity. This thesis is motivated by existing gaps in current studies on the governance-derivatives relationship. Thus, the study investigates a larger range of corporate governance mechanisms and utilizes a simultaneous equations methodology to overcome problems with endogeneity.

There is an abundance of studies that focus on the effect of derivatives on firm performance. However, a void exists in the area of corporate governance, and only two studies have examined some corporate governance elements with respect to the value effect of derivatives. While there is a large gap in the research related to the corporate governance and derivatives association with firm risk. And, the examination of the value and risk effects taken together has been ignored which is important in any study of derivatives hedging impact. This provides a motivation for examining the corporate governance-derivatives impact on both firm value and firm risk and allows evaluation of the hedging effectiveness of corporate governance.

\subsection{Research Objectives}

The primary research question of this study relates to what the effects of corporate governance on derivatives are? Does corporate governance enhance the hedging and risk management activities in the firm to increase value and reduce risk, or, as suggested by Erkens et al. (2009), does it push firms into high-risk activities and the kind of losses experienced during the financial crisis? 
Only a few studies have been conducted within this general area related to nonfinancial firms. The study examines the governance-derivatives relationship via an examination of the effects of corporate governance on two broad areas. The first of these is concerned with the influence of corporate governance on derivatives. The second area of interest is the examination of the influence of corporate governance on the effect of derivatives on both firm risk and firm value. It is these gaps, particularly as it relates to non-financial firms, that the present study explores.

The objective of this study, therefore, is to address the following questions:

1. Is corporate governance a determinant of derivatives in the firm?

2. Does corporate governance influence the effect of derivatives on the value of the firm?

3. Does corporate governance influence the effect of derivatives on the risk of the firm?

Finally, through these research objectives, and examination of the impacts on firm value and firm risk, this study attempts to evaluate the hedging effectiveness of corporate governance on the firm.

\subsection{Theoretical Framework}

The theoretical underpinnings of this thesis are based on the agency theory. An agency relationship arises when the principal, the investor, invests in the firm and engages another person, the agent (normally the manager), to act on his or her behalf. Agency theory deals with the resolution of problems occurring between principal and agents. Agents are entrusted to act in the principal's best interests but on occasion can fail to do so and be concerned instead with furthering their own interests which gives rise to agency conflict. 
The notion that management may have incentives to further their own interests at the cost of shareholders is at the center of the agency conflict. Agency problems arise when the interests of managers are not aligned with those of shareholders. Therefore, various corporate governance mechanisms are put in place to monitor management activities and prevent any opportunistic behavior by management (Shleifer and Vishny, 1977). Within the context of contracting theories and the agency framework, this study assumes that the agency conflicts arise through management opportunistic behaviour that would result in management speculating with derivatives. Management may view speculation as similar to investing in profitable projects that provide higher returns for the company; others may speculate from a sense of their information advantage in the market and/or to project an impression of expertise (Geczy, et al., 2007); sometimes hedging activities serves management's own purposes to protect their personal portfolios; or for financial gain; or to protect their own reputation (Smith and Stulz, 1985; Tufano, 1996) to the detriment of shareholders. Sometimes management of lower ability may refrain from hedging when it should hedge (Breeden and Viswanathan, 1998) and thus undermine firm value. Further management may hedge to hide lack of diversification or simply to safeguard preferred projects (DeMarzo and Duffie, 1995; Smith and Stulz, 1985; Stulz, 1984; Tufano, 1998). Therefore, the potential for agency conflicts is very strong in firms that use derivatives and if management is not properly monitored the firm may become involved in high risk speculation activities.

The theoretical framework is centered on risk management by corporate governance. It builds on the existing theories related to the determinants of derivatives decisions by the firm in respect of financial distress, tax convexity, investment growth opportunities and underinvestment hypotheses, and managerial risk aversion. Corporate governance influences the firms risk management strategies through financial, investment, liquidity and compensation policies and strategies. This suggests that corporate governance is able to potentially increase value through effective and adequate financial policies that include the firm's capital structure decisions; the source and extent of external debt utilization; financing costs and the amount and 
extent of derivatives. Governance monitor the investment and liquidity decisions of the firm which would determine the positive projects that the firm may undertake and therefore add value by reducing underinvestment costs, increasing investment growth opportunities and liquidity through the efficient use of derivatives by managers. Corporate governance is responsible for structure of the compensation structure that would determine whether managers are prone to take more risk or curb risk with use of derivatives. Managers are risk averse and as a result of their compensation and large stock holding, managers would avoid investing in risker long-term projects even with high returns, to the detriment of shareholders (Almazan and Suarez, 2003).

Therefore, agency conflict could be reduced by either constant monitoring by the board or by inducing appropriate risk management through the use of derivatives hedging. Following from this, I develop hypotheses connecting derivatives with corporate governance through the firm's value and risk effects evidenced in the historical data.

Specifically, the hypotheses I develop addresses the question of whether there is a significant relationship between corporate governance and derivatives to impact firm performance.

\subsection{Research Methodology}

The thesis comprises two different sample sets. The first period covers an 8-year period from 2004-2011 and consists of 6900 firm-year observations. This model examines corporate governance factors as a determinant of derivatives decisions within the firm. First I employ a probit regression to test this relationship. Since, there is a strong endogeneity problem related to derivatives and capital structure decisions, therefore, subsequently I use a simultaneous equations model to capture the simultaneity of debt and derivatives financing strategies. All sensitivity analyses use the same simultaneous equations model to test for robustness of results. 
The second sample comprises 6234 firm year observations for an eight-year period from 2004-2011. Here, the total sample is further split into firms that use derivatives and those that do not use derivatives. This part of the study first examines the separate effects of corporate governance factors on firm value. Subsequently it examines the effects of corporate governance mechanisms separately on total risk: cash flow volatility, stock return volatility and market risk. Each model is based on four regression models to ensure the robustness of the results: the basic OLS regression model; the fixed effects OLS regression; regression including the Huber White sandwich robust variance estimator (White 1980) for heteroscedasticity corrected standard errors; and finally the Newey-West (1987) variance estimator for correction of the possible effects of both autocorrelation and heteroscedasticity.

Sensitivity analyses are conducted to test the robustness of the results that includes alternative variables and methods to include bootstrapping methodology. Alternative tests are conducted that use a systems equations model to simultaneously test for the effects of firm value and firm risk. The iterated seemingly unrelated regression (ISUR) model accepts that there may be exogenous correlations but does not require an endogenous relationship between the two equations. This is especially suited for such an examination of firm risk and firm value (without forcing an endogenous relationship) in order to obtain a simultaneous examination of both effects. It employs the systems equations R2 test, to examine for the robustness of the ISUR models.

\subsection{Summary of Key Findings}

There are many likely reasons for the corporate governance behavior evidenced in this study. It could be due to the aligning of derivatives positions to vary with market prices for profits; or stem from the motive of risk allocation to hedge one type of risk in order to enhance another business risk where more benefits are to be derived; or be attributed to weak governance which allows managers to use derivatives for personal motives and gains. Finally, the concurrent hedging and speculation activities reported, could 
also be part of a purposeful profit-increasing risk management strategy, where speculation is accompanied with effective internal controls to monitor derivatives and deter their abuse.

The results presented in this thesis provide evidence of an association between corporate governance and derivatives. Specifically, the empirical results show that corporate governance is an important determinant of derivatives decisions of the firm. However, the impact of the corporate governance mechanisms has varying hedging effects: board size and CEO bonus increase the use of derivatives to exhibit hedging effectiveness with respect to stock return volatility; institutional shareholders, CEO age and CEO salary increase the amount of derivatives but this results in over-hedging activities to undermine firm performance; and insider shareholders and total CEO compensation decrease the use of derivatives to achieve under-hedging that undermines firm performance.

The empirical results from the other models testing, provides support for the premise that corporate governance-derivatives relationship has a significant impact on firm performance through their value and risk effects. The findings show that corporate governance indulges in hedging, speculation and selective hedging behavior in their strategies to manage risk.

The findings of the study indicate that largely the board and CEO governance mechanisms achieve hedging effectiveness through reduction of stock return volatility. It supports derivatives literature which finds that stock awards encourage managers to increase hedging to reduce equity volatility. This is because share price fluctuations reduce gains and increase losses in the stock markets, unlike options that may benefit from increased volatility. Therefore, it would be more natural to see a hedging effectiveness strategy by management and directors with respect to stock return volatility to protect their stock wealth at no personal costs to them. 
In respect of cash flow volatility, the findings indicate that largely the board and CEO characteristics increase earnings volatility to exhibit speculative behavior. This supports the view that the performance and reputation of directors, CEOs and top management alike are gauged on the growth in earnings and cash flows. As these measures are more transparent and more easily understood, managers have more incentives and are able to more easily manipulate these financial statement measures. (While stock price volatility is more opaque and less understood by managers and therefore more difficult to manipulate). Also, cash based compensation and bonuses are linked to profits rather than risk, and therefore would encourage directors and CEOs to increase this at the cost of higher risk, through speculation (Geczy et al., 2007).

In respect of corporate governance shareholder characteristics: institutional shareholders, insider shareholders and block shareholding, the results show that they encourage risk taking with respect of stock return volatility. This supports the findings of David et al. (2015) who suggest that institutional investors (larger investors) increase stock price volatilities that is specifically related to the trading shocks of large investors. Due to the granular nature of their portfolios and their market presence, large institutions trade less with the objective to diversify risk than other smaller firms and have a strong positive impact on stock return volatility in firms (David et al., 2015). Institutions and larger block holders have well diversified portfolios and therefore, would not like to incur additional costs of hedging risks when they are already well protected.

Overall the study provides evidence that corporate governance does influence the impact of derivative use with respect to firm performance. It indicates that corporate governance manage risks in accordance with the particular risk being hedged which may stem from personal motives, lack of expertise or mismanagement. However, it could also stem from a purposeful firm strategy, if other controls are in place to control for derivatives-related risks as suggested by Geczy, et al. (2007). It is possible that the 
value-enhancing speculative activities may be encouraged by firms to compensate for the high costs of implementing an elaborate set of internal controls mandatory under the Sarbanes-Oxley (SOX) amendments.

\subsection{Research Contributions}

The contributions of this research are manifold. Firstly, my research extends the literature on the determinants of derivatives decisions by the firm. Results of such studies are conflicting and this could be a result of omitted factors (Lel, 2012; Geczy et al., 2001; Pantzalis et al., 2001; Guay and Kothari, 2003). This study is among the few that provide insights into a comprehensive set of corporate governance mechanisms such as: board of directors, shareholders, compensation, audit committee and $\mathrm{CEO} /$ management characteristics taken together in one model. The examination of board diversity, board meetings, audit committee size, CEO age, CEO tenure, CEO basic salary and CEO cash compensation components are innovative to such a study.

Secondly, this study extends the literature related to the corporate finance risk management through an examination of both systematic and unsystematic risks: cash flow volatility, stock return volatility and market risk. There is only one recent working paper (to the knowledge of the author) that examines board independence in relation to firm risk in firms that use derivatives in non-financial firms.

An underlying assumption of this study is that an assessment of hedging needs to examine both the effects of firm value and firm risk. As the failure of either would undermine the hedging effect. This is the first study to examine both derivatives value and risk effects in a study of corporate governance hedging effectiveness of derivatives. 
Fourthly, the method used is innovative and the first application in a study of the derivatives-corporate governance relationship in non-financial firms. Zellner's (1962) seemingly unrelated regression method with iterations (ISUR) is suitable to examine a relationship where value and risk need to be seen simultaneously, without forcing an endogenous relationship between the two. It enables the simultaneous examination with the inclusion of some exogenous correlations (through the error terms) that exist due to the common derivatives environment in the value and risk regression models.

Fifthly, the study adds to the thread of corporate governance literature. It extends current literature on corporate governance risk management activities. Though this area has been vastly researched in the financial sector, there is a dearth of such studies in non-financial firms. The research makes contribution in this area and is the first study to document the selective hedging behavior of corporate governance in their use of derivatives in non-financial firms.

Taken as a whole, the evidence presented in this study could be of use to management and shareholders. It builds an awareness for the fact the speculative behavior is evidenced largely with regard to cash flow volatility. This suggests that such activities may be better aligned and discouraged through compensation structures that link cash based bonuses less with profits and more toward risk management. On the other hand, if the speculation activity is intentional, then management needs to be aware of this and ensure that there are strong controls in place related to derivatives and that these are operational.

Researchers and theorists maintain that compensation structures need to be geared to encourage risk-taking by risk-averse managers. Many suggest that this would align the objectives of management with that of the shareholders to increase firm value and wealth, and therefore reduce the agency conflict. If this is true, then it would indicate that compensation structures should encourage high risk taking and speculation. This feature needs to be reviewed by legislative bodies to determine what the overall 
objectives of compensation structures and other governance structures should be with regard to firms using derivatives.

The study further highlights that there are some gaps with respect to the relationship between corporate governance and risk management. Specifically, it underscores that governance mechanisms and compensation requirements under the current system are too general and not customized toward efficient risk management. There is a need for more derivatives-hedging specific governance tools to provide direction to a firm's derivatives use activities within non-financial firms. This would enable corporate governance to be more effective in such an environment.

\subsection{Structure of the Remainder of the Thesis}

The remainder of the thesis is set out as follows. Chapter 2 provides an overview of the institutional environment and background surrounding corporate governance and financial derivatives in the United States of America. A review of the literature related to derivatives and corporate governance is presented in Chapter 3. Chapter 4 provides the theoretical framework, and hypotheses development. In Chapter 5, I describe the research methodology used in this study. The empirical results are reported in Chapters 6 and 7 for the different sample models and a discussion of the findings are

provided in Chapter 8. Finally, in Chapter 9 I present the conclusions of the study, acknowledgement of the limitations of the study and identify issues for future research. Lastly, I expand on the contributions of the study. 


\section{CHAPTER TWO: OVERVIEW OF INSTITUTIONAL ENVIRONMENT AND BACKGROUND}

\subsection{Introduction}

This chapter provides an overview of the institutional environment and the rules and legislation surrounding corporate governance and financial derivatives in the United States of America. It examines the development of corporate governance framework and the entities responsible for their management. It also provides a discussion on the bodies governing financial derivatives, and the markets in which they are traded.

Section 2.2 discusses important features of the Sarbanes-Oxley Act of 2002, The Dodd-Frank Wall Street Reform and Consumer Protection Act 2010 and the Jumpstart Our Business Startups Act of 2012. In section 2.3, an explanation is provided of the mechanisms and administration of the exchanges and markets on which derivatives are traded. This is followed by Section 2.4 which presents an overview related to corporate governance and the financial crisis. Lastly, in Section 2.5 a summary of the chapter is presented.

\subsection{Corporate Governance}

Sarbanes-Oxley Act of 2002 (SOX) and New York Stock Exchange (NYSE) and National Association of Securities Dealers Automated Quotations System (NASDAQ) Rulings

On July 25, 2002 the US Government passed the Sarbanes-Oxley Act of 2002 in response to frauds and misrepresentations by many non-financial firms, and in an attempt to restore investor confidence in corporations and in the capital and financial 
markets. This is one of the most significant legislations passed and has far reaching effects for businesses in the United States of America (USA). It was followed by additional corporate governance enactments: Dodd-Frank Wall Street Reform Act 2010 passed on July 21, 2010 and the Jumpstart Our Business Startups Act of 2012.

In 2002 the Securities Exchange Commission (SEC) required that the exchanges should improve their listing standards further to tighten governance. As a result, NYSE and NASDAQ, issued reforms related to the corporate governance of firms listed on the exchanges and these are discussed in the following sections. These amendments have an important bearing on corporate governance development and implementation in the USA.

\section{Board of Directors}

The board of directors is mainly governed by NYSE and NASDAQ rulings (SEC release No. 34-48745) ${ }^{1}$ which determines the composition and modus operandi of the board of directors. These rulings require that boards be composed of a majority of independent directors. SOX does not stipulate any similar requirements with regard to the board of directors and only makes it mandatory for audit committees to have independent directors.

The SOX definition of "independence" restricts directors from accepting any consulting, advisory or other compensation from the company and also indicates that they should not be affiliated to the company or its subsidiaries. The NYSE and NASDAQ take this definition a step further and suggest that independent directors

1 SEC Release No. 34-48745. NASD and NYSE Rulemaking: Relating to Corporate Governance. Securities and Exchange Commission, November 4, 2003. Available at: http://www.sec.gov/rules/sro/34-48745.htm. 
must have no direct or indirect material relationship with the firm and need to disclose the basis of this in their proxy statements. However, the NYSE and NASDAQ rules allow independent directors to own shares in the firm.

\section{Executive Compensation}

The Dodd-Frank Act 2010 focuses on executive compensation in an attempt to promote more transparency and a compensation package that is based on performance. While NYSE ruling requires that listed firms have compensation committees consisting totally of independent directors. However, it does not give the Committee sole authority for Chief Executive Officer (CEO) compensation that needs to be approved along with the board of directors. Finally, SOX gives SEC the authority to temporarily freeze the pay of officers pending the investigation of securities fraud. NASDAQ requires shareholders to approve most equity compensation plans. Therefore, any new stock or option plans or major modifications to existing incentive plans for the company directors, officers or employees need to be approved by shareholders. This would act as a deterrent to management taking any actions that could be detrimental to current stock holders.

\section{Audit Committee}

Corporate governance reforms have had the most bearing on audit committee composition and operations. SOX does not make it compulsory for public companies to form a separate audit committee but requires the board of directors to either form an audit committee or take on the responsibilities of one. However, NYSE requires listed companies to form separate audit committees comprising totally of independent directors, or otherwise be delisted. The audit committee must have a minimum of three members, with all being independent. Additionally, the audit committee is required to meet regularly with management, internal auditors and external auditors. 
Another important ruling applies to financial expertise requirement. NYSE and NASDAQ require that each member of the audit committee be financially literate or become financially literate within a stipulated time frame. Financial literacy is defined as the ability to read and understand company's annual reports, including all the financial statements. It is mandatory under NYSE and NASDAQ rules that the audit committee has at least one financial expert where financial expert is one who has accounting or financial management expertise either through education or experience or both as qualified by the board of directors.

There is a general consensus that SOX has greatly improved public confidence in governance at the corporate level. It has put in place many reforms to enhance the transparency of financial reporting. At the same time there is some criticism of SOX and the related NYSE and NASDAQ rulings. Hermalin and Weisbach (2007) suggest that there are costs involved to increase transparency, and Section 404 of SOX is such an example. Under Section 404, firms are required to implement and appraise their internal control systems which then needs to be testified by the external auditor. Implementation of this requirement entails excessively high costs for firms.

\subsection{Financial Derivatives}

A derivative instrument is a financial contract between two entities that agree to make payments to one another. The main types of derivatives are related to forward contracts, futures contracts, option contracts and swaps.

There are two types of markets on which derivatives are traded: Organized Exchanges and Over-The-Counter (OTC) markets. Non-financial companies popularly use futures contracts traded on the organized exchanges to hedge risks The company would buy and sell these contracts through brokers, who in turn trade these on the exchanges through traders. These are standardized contracts. The market size of 
exchange-traded derivatives has grown rapidly over the years and at the end of December 2014, the total notional amount of futures outstanding was US\$27,169.3 billion and notional amount of options outstanding for all markets was US\$ 37,688.9 billion (See Appendix 1).

Likewise, other popular derivatives used by non-financial firms are interest rate swaps and forward rate agreements, among others. These are not standardized contracts and have specific settlement price, date and delivery terms and are traded on the OTC. The OTC derivatives market is much larger than the organized exchanges market. In 2013 the notional amount of derivatives outstanding on the OTC market totaled $\$ 692,908$ billion, with a gross value of $\$ 20,158$ billion (See Appendix 2).

The magnitude of the losses during the financial crisis was due to the nature and complexity of financial derivatives. It reinforces the need for vigilant and effective corporate governance over these financial instruments.

\subsection{The Financial Crisis and Corporate Governance}

There are many factors that played a role in the financial crisis. However, the main culprit was the high risk mortgages and financial mortgage securities that were bundled, then re-bundled into complex synthetic securitizations and sold to investors around the globe. Many larger financial institutions began trading in these risky instruments for higher returns. As a result of the high borrowings, high risk investments and lack of transparency, many investment banks were operating with very low capital just prior to the financial crisis. And, the OTC markets were overburdened with atom bombs of toxic risks, that were largely unmonitored.

Researchers have also questioned the adequacy of the accounting standards for derivatives. They criticize the lack of transparency as the accounting disclosures did 
not provide information on how hedging activities are affecting financial positions of the firm. Subsequently, from 2008 there has been an explosion of amendments and accounting standards with regard to financial instruments accounting and disclosure.

Some blamed the financial crisis on corporate governance, both at the government and firm levels. Others indicated that the firms as investors should have exhibited more restraint and disciplining at the firm level. The Financial Crisis Inquiry Commission (FCIC) set up by the US Federal Government concluded in their report that the responsibility lies with the public administrators who were supposed to be watching the financial system and regulatory agencies. The blame could also be placed with the chief executives who had the responsibility for smooth operation of their company. The report by the FCIC indicates that: "Tone at the top does matter and, in this instance, we were let down. No one said 'no'.” (FCIR, 2011, p. xxiii).

\subsection{Chapter Summary}

This chapter provides the background for my study; which mainly focuses on the development of corporate governance practices in the United States of America, the institutional environment surrounding derivatives and the impact of both on the Global Financial Crisis.

The Sarbanes-Oxley Act 2002 was introduced along with the NYSE and NASDAQ rulings. It has been well documented that these are amongst the most important pieces of legislation to impact governance of corporations. There is a general consensus that these corporate governance endeavors have greatly benefitted US corporations in building investor confidence, increasing liquidity and strengthening capital markets. However, there are others who are critical of the heavy costs that companies are burdened with to implement this framework. Their particular focus is on the Section 404 requirement that companies set up elaborate internal control systems. This has 
also been responsible for many companies delisting from the exchanges to avoid the costs.

Derivatives are highly sophisticated, complex financial instruments. The volume of derivatives traded on the exchanges and over-the-counter market have grown rapidly. However, OTC trading is around 11 times more than that of the exchanges. While exchanges are very strictly regulated, the OTC was largely unregulated, until very recently. It is only after the Financial Crisis some form of regulation has been introduced over OTC trading activities. In fact, it was the creation of the many mortgage securities - packaged and repackaged again, credit default swaps and credit default obligations that heightened risk of the OTCs on which they were traded. It was these very "toxic" securities that were responsible for causing a systemic affect to expand the financial crisis into a Global Financial Crisis. 


\section{CHAPTER THREE: PRIOR STUDIES ON DERIVATIVES, CORPORATE GOVERNANCE, FIRM VALUE AND FIRM RISK}

\subsection{Introduction}

This study relates to and develops on three major streams of research: financial derivatives, corporate governance and firm performance - risk and value. This chapter provides a review of the research that underlies my theoretical framework and development of my hypotheses. It also provides a basis for the evidence to support my results.

My study investigates three main areas in the relationship of derivatives and corporate governance: a) corporate governance as a determinant of derivatives b) derivatives, corporate governance and firm value; and c) derivatives, corporate governance and firm risk. Therefore, on the same basis, I divide the literature review into three main sections. Section 3.2 addresses research on the determinants of derivatives and then presents literature on a). Section 3.3 reviews studies in the area of derivatives and firm value, and then provides a literature review on b). Section 3.4 investigates research related to derivatives and firm risk, and then presents research related to c).

Finally, in Section 3.5, I provide a summary of the chapter.

\subsection{What are the Determinants of Derivatives?}

Modigliani and Miller (1958) lay the foundation for the studies related to the determinants of derivatives by showing the importance of taxes and investment decisions of the firm in the maximization of value. Expanding on this, Smith and Stulz (1985) develop the basis of the theories informing the determinants of hedging decisions. They show that taxes, transactions costs of bankruptcy and financial 
distress, managerial compensation and risk aversion provide a strong motivation for firms to hedge with the objective of maximizing the value of the firm. Adding to this and building on the theories of Fazzari et al. (1988), Froot et al. (1993) show that investment growth opportunities and the problem of underinvestment are other factors in a hedging decision.

There is a general consensus that the determinants in the use of derivatives are related to the firm's decisions regarding tax convexity, financial distress costs, investment opportunities and underinvestment costs, and managerial risk aversion. Hence, I discuss the literature and research findings based on each determinant separately. Initially I explain the underlying theory behind each determinant and then I review related research studies.

\section{Convex Tax Structure}

Theory related to risk management indicates that tax structure is an important motivation for firms to hedge. In some circumstances firms are confronted with tax codes that are progressive causing the tax structure to be convex. In this situation when taxable income is low then the marginal rate of tax is low and when income is high then the effective tax rate is high. In these circumstances volatility of income increases tax liability, whereas in situations in which firms face a constant marginal tax rate, fluctuations in taxable income do not affect the tax liability (Graham and Rogers, 2002). Researchers examine this incentive to hedge and show that if a firm can eliminate cash flow volatility through hedging, the firm can reduce its tax liability (Graham and Rogers, 2002). The greater the tax convexity, the larger is the impact of hedging. Further, Mayers and Smith (1982) and Smith and Stulz (1985) contend that the reduction in tax liability by hedging increases the value of the firm to the extent that tax savings at higher income levels exceed the tax savings at lower levels Thus, firms with income more in the tax convex region have a greater motivation to hedge than firms with income in the less convex tax regions. 


\section{Prior Studies on Convex Tax Structure:}

Researchers hypothesize that tax loss carry forward signals the existence of tax convexity. As such researchers use tax loss carry forward or tax credits to test for the motivation of tax reduction through hedging. Berkman and Bradbury (1996) examine 116 non-financial firms from New Zealand during 1993 and use a dummy variable for tax convexity to find a significant positive relationship between tax convexity and derivatives. Dionne and Garand (2003) investigate the hedging activities in the North American gold mining industry. Using a sample of 898 firm year observations they employ a similar variable to Graham and Smith (1999) to simulate tax savings. They find that the values of the tax save variable are very sensitive to a drop of $5 \%$ in the volatility of taxable income, indicating that the tax savings due to tax convexity induces firms to hedge. These studies find a positive relationship between tax convexity and hedging.

Graham and Smith (1999) use a large sample of 84,200 firm-year observations for the years from 1980 to 1994 to examine the impact of tax incentives on hedging. They contend that net operating loss carry forward does not capture tax convexity and in fact provides a tax disincentive to hedge for companies with losses but an incentive for profitable firms. Graham and Smith (1999) and Graham and Rogers, (2002) use a volatility case scenario and then reduce tax liability by $5 \%$ to capture the differences to represent the tax convexity benefit. They suggest that for firms with convex tax structure the tax savings from hedging are an important factor. However, they caution that these are not mutually exclusive from the hedging benefits of controlling underinvestment problems, increasing debt capacity or by reducing the cost differences in the risk-bearing claimholders. Leland (1998) also asserts that hedging enhances debt capacity and thus the benefits from the tax shields on interest would be important considerations. 
Some other studies find mixed support for the tax convexity theory. For example, Nance et al. (1993) conduct a survey and using a data sample of 169 responses for the year 1986, employ three measures to capture tax convexity. They find significant results for investment tax credits, while the measures of tax loss carry forward and income in the progressive region provide insignificant results. Bartram et al. (2009), use a global sample of 50 countries, comprising 7319 firms for the period of 2000 2001 that includes 2231 US firms. The total sample comprises $45.2 \%$ foreign exchange derivatives, $33.1 \%$ interest derivatives and $10 \%$ commodity derivatives. Their results indicate that while income tax credit is positive and significant for the general derivatives and commodity price categories, the tax convexity does not appear to be significant for foreign exchange derivatives and interest rate derivatives. Haulshalter (2000) examines around 97- 98 firms in the oil and gas industry for the years from 1992 and 1994. The author uses two measures for tax convexity and while the tax indicator dummy variable does not provide significant results, generally the variable that simulates the marginal tax rate gives strong results for most of the models. Mian (1996) examine three different types of derivatives in a sample of 771 hedgers and 2,251 non hedgers for the year 1992. The author also finds mixed results, with a positive effect for foreign tax credits and no significant results for tax loss carry forward.

There is a group of studies that does not find support for the tax convexity hypothesis. Gay and Nam (1998) take a sample of approximately 325 derivative users and 161 non-users for the fiscal-year end 1995 from the Swaps Monitor database and they do not find any significant results for any of their models. Tufano (1996) examines a total of 48 firms from the North American gold mining industry for the period 1991 - 1993. The author uses a dummy variable for tax loss carry forward and similarly does not find any significant results for his sample of firms. Geczy et al. (1997) use the same measure in their examination of 372 nonfinancial firms in 1990 and do not find support for the tax convexity hypothesis. 
A review of the literature related to tax convexity suggests that the findings are generally mixed and there is no very strong support for the hypothesis. Graham and Rogers (2002) explain these weak results may suggest that while tax convexity may be partly responsible for hedging, it is the leveraging and the interest tax shields that are the real motives for hedging.

\section{Financial Distress Costs}

Shareholder wealth maximization theory supports the view that firms hedge in order to reduce the costs of fluctuating cash flows. Mayers and Smith (1982) suggest that it is fear of financial distress or bankruptcy that motivates managers to hedge in order to minimize costs arising from cash flow fluctuations and losses. Hedging decreases expected financial distress costs by reducing the effect of management engaging in risky projects in order to promote the interests of equity holders at the expense of debt holders (Bessembinder, 1991; Mayers and Smith, 1987). Warner (1977) notes that bankruptcy costs should include the direct costs of lawyers' fees, other professional fees and managerial costs related to the bankruptcy; and the indirect costs pertaining to lost sales, lost goodwill and other similar costs. Shapiro and Titman (1986) also include the impact on long-term relationships with customers and traders among these indirect costs.

Kaplan and Zingales (1997) suggest that firms are more restricted financially with increased debt as it increases the firm's propensity for bankruptcy and financial distress. However, Pulvino (1998) contends that leverage on its own may not indicate financial distress as a firm with enough cash reserves, is not constrained and so both factors need to be considered together. Nance et al. (1993) adds that the size of a firm's fixed claims is an important consideration in bankruptcy, and indicates that comparatively smaller firms have a larger proportion of fixed claims relative to the value of their assets. So size of the firm is also important in hedging decisions and smaller firms are more likely to hedge against financial distress. 


\section{Prior Studies on Financial Distress Costs:}

Generally, studies use variations of the debt ratio to capture financial distress and find strong results to support the theory. For example, Haushalter (2000) uses two measures: a debt ratio and another measure to include a cash constraint by including a binary variable set to one if the debt ratio is above the sample median and the current ratio is below the sample median. The author observes a strong positive relationship for both the variables. Visvanathan (1998) examines interest rate swaps for nonfinancial firms among the S\&P 500 list of companies, comprising a total sample dataset of 410 firms for 1992 and 1993. The study uses a debt-equity ratio for leverage and concludes that firms that use fixed interest rate swaps have higher financial distress costs and consider debt maturity structure in their decisions to use swaps. Another US study by Graham and Rogers (2002) takes a random sample of 850 firms from the SEC's 10-K filings through the SEC's EDGAR database. They also find strong support for the financial distress hypothesis for hedging in the manner of others ( Dolde, 1995; Gay and Nam, 1998).

A more detailed approach is used by Bartram et al. (2009) who employ several measures indicating that higher leverage, shorter debt maturity, lower interest coverage, and less liquidity increase financial risk. While firms with higher dividend yield would exhibit stable cash flows, and additionally, higher profitability and larger fraction of tangible assets would exhibit lower financial distress and so as a result, firms would hedge less. Their findings strongly support the financial distress costs theory. Similarly, Howton and Perfect (1998) use a Fortune S\&P sample ranging from 451- 461 firms for the year ending in 1994. They measure financial distress costs through interest coverage ratio, debt-asset ratio, liquidity and tangible assets. All results are largely significant and reflect support for the financial distress theory, except for tangible assets that exhibits insignificant results. 
A number of studies examine data from other countries. For example, Nguyen and Faff (2002) study 469 firms from the top 500 non-financial firms listed on the Australian Stock Exchange for the years 1999 and 2000. They also use leverage as proxy for financial distress costs and find a strong positive relationship between leverage and hedging. Judge (2006) examines a sample of $400 \mathrm{UK}$ non-financial firms in 1995 and uses both survey data and data from the annual reports to measure the likelihood of financial distress. The author uses four measures to capture the probability of distress to show that high gearing, low interest cover ratio, low credit rating and high interest payments increase the probability of distress for the firm. Their results provide strong support for financial distress as a motivation to hedge.

On the other hand, there are a number of studies that do not find support for a positive relationship between hedging and leverage. Allayannis and Ofek (2001), study a sample of 378 firms from the S\&P 500 firms in 1993 and examine foreign currency derivatives. They use return on assets and leverage as proxies for financial distress costs and while the results for return on assets are not significant, leverage has a significant negative association with foreign currency derivatives. Geczy et al. (1997) examine currency derivatives and use interest cover ratio and long term debt ratio to capture financial distress. Their results provide support for the theory related to expected costs of financial distress. However, Tufano (1996) focuses on specific industries to study the extent of derivative use, and largely finds insignificant results both for cash costs and leverage.

A review of the research indicates that generally there is strong support for the theory that financial distress and bankruptcy costs are strong motivations for hedging. 


\section{Investment Opportunities and Underinvestment Hypothesis}

Fazzari et al. (1988) argue that when the costs of external financing are higher than internally generated funds and when the internal cash flow decreases, then firms will have to reduce investments. The difference between costs of internal and external funds determine the degree of financial constraint on the firm (Kaplan and Zingales, 1997). Further, Froot et al. (1993) suggest that companies face the problem of underinvestment when firms have many investment opportunities but cash flow is constrained. This gives rise to the underinvestment problem when firms may not be able to undertake positive net present value (NPV) projects. If the internal cash flow is fluctuating this would give rise to a larger requirement for external financing and/or diminish the ability of the firm to invest in projects. The more external financing that the firm avails, the greater the increase in external financing costs. Thus variation in cash flows affects both investment growth opportunities and financing decisions, and hedging enables firms to overcome this problem by stabilizing cash flows and increasing debt capacity.

Firms hedge to minimize the underinvestment costs when they have many investment opportunities (Bessembinder, 1991) and firms that do not manage their risk properly have to cut back on profitable investments (Lessard, 1990; Stulz, 1990). And, the value for firms depends on their opportunities for investment and costs of underinvestment when they cannot invest in viable projects (Myers, 1977; Smith and Watts, 1992).

Therefore, firms will resort to increased hedging in order to stabilize cash flows and be able to realize the value of their investments.

Prior Studies on Investment Growth Opportunities:

Allayannis and Mozumdar (2000) examine whether firms using derivatives are able to reduce dependence of their investments on internal cash flow, thereby eliminating the 
underinvestment problem. They hypothesize that derivatives should reduce the dependence of a firm's investments on its cash flows. They find that the investment and cash flow sensitivity of hedgers is much lower than that for the non-hedgers indicating that firms use currency derivatives to protect their investment from shortrun cash flow variations. Allayannis and Ofek (2001) too find that hedging is able to stabilize cash flow, such that investment and the cash flow sensitivity of the sample of hedgers is considerably lower than that of the non-hedgers.

The market-book ratio is a popular measure used to capture a firm's investment opportunities, however with varying results. Mian (1996) does not find supporting evidence for the premise that there is a positive relationship between hedging and market-to-book value. He obtains a negative result for this proxy and attributes it to the restrictions imposed by financial reporting requirements. Nguyen and Faff (2002) also use the market-to-book ratio as a proxy and similarly obtain a negative association between hedging and the ratio. Therefore, they raise the question that perhaps marketto-book ratio is not a good proxy for the firm's investment opportunities. Judge (2006) uses both archival and survey research, in separate tests, to test the underinvestment hypothesis but neither provides any evidence of support and similarly, Allayannis and Ofek (2001) do not achieve significant results for this measure.

Gay and Nam (1998) assert that a firm will benefit the most from hedging if it faces two conditions: the firm should have a shortage of internally generated cash and it should have high investment opportunities. If the firm does not have sufficient internal funds, it will resort to hedging thereby exhibiting a negative relationship between hedging and the liquidity ratios. Nguyen and Faff (2002) use both the liquidity ratio and current ratio in order to capture short-term constraints. They use operating cash flow variable for the investment and find that if a firm faces liquidity limitations and liquidity increases by $1 \%$, then hedging will decrease by $0.75 \%$, which supports the theory that internal financing constraints make hedging more attractive. However, the 
current ratio is not significant and the authors suggest that this proxy may not be a good measure of the firm's ability to meet short-term commitments.

Gay and Nam (1998) use five measures to capture this relationship: research and development expenses, price-earnings ratio, cumulative abnormal return, market to book value and Tobin's Q. Their findings are positive and significant.

Researchers also contend that research and development (R\&D) expenses are associated with growth opportunities and investments in projects requiring additional financing. Many studies use this proxy, for example, Allayannis and Ofek (2001), Dolde (1995), Geczy et al. (1997) and Nance et al. (1993) obtain a positive relation between research and development expenses and the use of derivatives in support of the investment opportunities hypothesis. Froot et al. (1993) also find that research and development expenses are positively related to currency derivatives. However, the authors contend that such a proxy may be capturing other effects such as the level of intangible assets or information asymmetry. Gay and Nam (1998) are also doubtful about this proxy and suggest that they may be capturing other effects. Agency problems could be the motivating factor behind the association of research and development expenditure with use of derivatives. The suggestion is that good managers have a greater incentive to hedge in order to undertake profitable projects, whereas weak managers invest their capital in $R \& D$ projects and hedge to give appearance of appropriate investment strategy, in order to hide their poor investment portfolios. For these managers R\&D expenses would be a tool to convey incorrect market information.

In contrast to theory where higher R\&D expenses give rise to more hedging, Bartram et al. (2009) and Graham and Rogers (2002) provide evidence of a negative relation between R\&D and hedging. Myers (1977) explain that just as underinvestment costs have a negative association with debt, similarly hedging mitigates underinvestment costs (Myers and Maljuf, 1984). While, Bessembinder (1991) shows that hedging 
eases the underinvestment problem because it enables the debt financing decision to be less related to the investment decisions. Gay and Nam (1998) assert that a strong relationship of investment to its cash flows may indicate higher underinvestment problems and suggest that vice versa, poor investments are likely to result in low cash flows at the same time. Similarly, Nguyen (2011) also indicates that a firm having enough cash for investment would have a lower need to hedge.

Some other studies do not find support for this hypothesis. For example, Tufano (1996) does not find any relationship between hedging and investment opportunities in the gold mining industry in North America and reports a negative result for exploration expenses, suggesting that with reduced expenses the firm would hedge more. Tufano (1996) suggests that hedging leads to overinvestment and finds no support for the theory. Berkman and Bradbury (1996) use the earnings price ratio and ratio of changes in net assets to changes in net income as proxies for the long-term and short-term investment opportunities. However, they do not find any significant relationship between derivative use and growth opportunities.

Researchers use different proxies to measure investment opportunities and financial constraint. Adam (2002) suggest the results may be biased according to the proxy being used and therefore account for the mixed findings.

\section{Managerial Risk Aversion}

Stulz (1984) argues that hedging is the outcome of managers' aversion to risk. While the other shareholders may have the capability to diversify their portfolio in order to minimize their risk, this is not the case with managers who hold large amount of shares in the company. Therefore, managers have the need to hedge to decrease their own portfolio price variance. If their own cost of hedging is higher than the cost of hedging for the firm, then the managers will hedge (Smith and Stulz, 1985; Stulz, 1984; Tufano, 
1996). While Smith and Stulz (1985) indicate that managers having larger stock holdings compared to those with options, prefer to hedge their risks, because stocks have linear payoffs while options have convex payoffs. Options contracts may thus induce managers to take greater risk because greater volatility would increase the value of the options contracts.

Prior Studies on Managerial Risk Aversion:

Most of the researchers therefore use closely held shares and options owned by managers as a proxy to test the managerial risk aversion hypothesis. Nguyen and Faff (2002) use the number of options held by directors and officers and the number of shares held scaled by the total number of shares outstanding to measure this hypothesis. Berkman and Bradbury (1996) in their study of New Zealand firms also find a consistency between the hedging trend and the volume of options/stock held by the managers. Tufano (1996) supports the view that managers have a lower motivation to hedge when they receive stock options. He analyses the use of commodity derivatives in the gold mining industry and finds that use of commodity derivatives is negatively related to the volume of managerial options holdings and positively related to the value of their shareholding. Likewise, Rajgopal and Shevlin (2000) find an inverse relationship between hedging and managers' option holdings.

Rogers (2002) analyses CEO's stock and option holdings to examine the effect of their risk-taking incentives on the extent of derivative use in the firm. The author finds a positive relation for CEO stock - holdings but a negative relation for their options holdings. Knopf et al. (2002) also find a strong relationship between managerial stock option portfolios and corporate hedging. They contend that as the portfolio becomes more sensitive to share prices the firm inclines to increase hedging and as the options portfolio sensitivities increase to stock return fluctuations, the firm reduces hedging. 
In contrast, Haushalter (2000) findings do not support managerial stock holdings and there is a mixed response to the managerial option holding. The author finds a positive relation between CEO stock option holdings and firm hedging, unlike the results for other managerial options holding and he does not support the view that more closely held shares or managerial risk aversion would cause firms to increase hedging. Similarly, Gay and Nam (1998) also find a positive relationship between managerial option holdings and firm's use of derivatives.

On the other hand, there are some studies that do not find support for the theory. Bartram et al. (2009) find little support for the managerial incentives hypothesis (univariate tests) as they observe that hedgers are not closely held firms and are more prone to use stock options as an incentive indicating that executive stock options do reduce the manager's risk aversion. Fok et al. (1997) contrary to expected results find that managers with lower stake in the company hedge more indicating a negative association between managerial stockholding and hedging. Nguyen (2011) does not include any variables related to managerial incentives as he argues, that these are not important determinants of derivatives.

Breeden and Viswanathan (1998) and DeMarzo and Duffie (1995) give a different perspective by focusing on the asymmetric information of the markets. They show that managers hedge to influence the labor market perception of their managerial ability and would hedge with derivatives to avoid financial problems and the fear of being fired. Breeden and Viswanathan (1998) suggest that managers with superior abilities want to communicate their superior abilities to the market and thus hedge the risks over which they have no control as a way of "locking-in" their superior abilities. DeMarzo and Duffie (1995) also argue that managers' hedge to send a signal to the market about their managerial ability. Tufano (1996) shares this view and asserts that higher ability younger managers have a greater tendency to hedge as compared to lower ability young managers. 


\section{Conclusion:}

A review of the existing literature on the determinants of derivatives shows mixed and often conflicting results. This suggests, among other factors, the probability of some important variables that may have been omitted and that are causing noise in the models. Geczy et al. (2001), Guay and Kothari (2003) and Pantzalis et al. (2001) assert that operational hedging is important in any risk management strategy and its exclusion from the studies could be one of the reasons for the mixed research findings. Bartram et al. (2009) attribute the conflicting results in previous research due to the endogenous nature of the decision to use derivatives and other financial and operating decisions. Bartram et al. (2011) and Aretz and Bartram (2010) support this to indicate that derivative use must be looked at along with other financial policies and Leland (1998) shows that there is a relationship between derivatives and agency costs, besides investment and capital structure decisions. While Lel (2006) emphasizes the importance of including corporate governance in any study of derivatives because in his view it affects the risk management decisions of the firm.

\subsubsection{Corporate Governance as a Determinant of Derivatives}

The extant literature indicates that agency conflicts form a strong basis of a link between corporate governance mechanisms and hedging activities. Often corporate hedging strategies are driven by managers' motivation to hedge which arises from their lack of diversification, desire to guard their reputation or need to protect their favorite projects. Therefore, if these managers are not properly managed and risk not adequately monitored, managers would indulge in detrimental hedging behavior for their own purposes.

Lel (2012) hypothesizes that corporate governance could impact derivative use in two respects: 1) it affects a firm's choice to use derivatives for hedging or for speculation 
to maximize value. Strong governance is more likely to contribute to valuemaximizing derivative use while weak governance would result in managers having freedom in use of derivatives, with less or no consequences for their decisions. 2) Managerial self-interest would be more prominent in weakly governed firms and therefore shareholder wealth maximization would not be so important in firms with a weak board of directors. Lel (2012) notes however, that though there is a strong link between corporate governance and the firm's decision to use derivatives there are few, if any, studies that examine the effects of corporate governance on the firm's use of derivatives. He stresses the importance of investigating such effects and suggests that corporate governance may remove some of the uncertainties in the results of existing literature.

\section{Prior Studies on Derivatives and Corporate Governance}

The main purpose of these studies is to shed light on the link between risk management and the quality of corporate governance. The most commonly researched areas relate to ownership structure and board independence. Most studies concentrate on different aspects of the ownership structure and specifically large shareholders, with the assumption that larger shareholders have the resources and higher motivation to monitor managers. Managers who own shares also have a strong incentive to hedge because they are both managers (who earn an income) and shareholders, and thus would hedge to protect their interests.

Fok et al. (1997) examine both managerial shareholding and institutional shareholding components of ownership structure. They collect their data from the off-balance sheet activities from 1990-1992 taken from the Handbook of Users of Off Balance Sheet Instruments, 1993 edition published by Swaps Monitor Publications. The total sample size ranges from 298 to 331 observations and covers the different types of derivatives. In respect of institutional ownership, Fok et al. (1997) find a strong positive effect of institutional shareholders on derivative use. Others (Allayannis et al., 2003; Lel, 2006) 
also find evidence that institutional investors contribute to risk management activities. These findings suggest that institutional investors have stronger financial incentive to monitor management.

In respect of insider shareholding, Fok et al. (1997) findings suggest that managers who hold a high percentage of shares are less likely to hedge. This is contrary to their expectations and they suggest that it could be related to management entrenchment or signaling hypotheses. Others (Allayannis et al., 2003; Lel, 2006) also investigate insider block holders to indicate that the agency costs are higher when managerial block holders exist. Their results suggest that the presence of an insider block holder decreases the likelihood that firms will engage in value enhancing risk management activities.

Lel (2006) is one of the few studies that finds any support between block holder ownership and corporate risk management. The author constructs a governance index comprising ownership structure, board structure and investor protection rights in a global setting using a sample of firms from 30 countries over the period of 1990 to 1999 and provide evidence of effective monitoring by corporate governance. The study divides the sample into strong and weak governance, both at the firm and country levels. On the whole, their results suggest that strong governance induces firms to use currency derivatives when there is greater currency exposure, financial distress costs and growth opportunities. However, firms with weak governance use more currency derivatives to cover weaknesses in undiversified portfolios and use less when the currency exposure is higher (Lel, 2012).

Prior studies have also more frequently examined the role of board independence in monitoring firm derivative use decisions. Marsden and Prevost (2005) investigate the effects of outside directors in a sample of non-financial firms listed on the New Zealand Stock Exchange at end of 1994 and 1997. In their sample data of 185 firm year observations, they find that companies with higher growth opportunities and a 
greater proportion of outside directors are less likely to use financial derivatives following the 1993 Companies Act. This could be an outcome of the increased directors' fiduciary responsibilities and perceived risk of liability on outside directors for poor investment decisions. They examine the effects of ownership structure through block holders and insider shareholders, but do not achieve significant results for either variable to indicate any strong support for their effects on hedging.

Borokhovich et al. (2004) examine a larger array of board characteristics: board insider ownership, options holdings, total block holdings, bank block holdings, board size and board independence using a sample of 370 non-financial firms in the S\&P 500 list of firms for the sample period of 1995. Their results support the positive effect of outside directors on the quantity of interest rate derivatives. However, they do not find any supporting evidence for their other measures of board composition. This is in line with Marsden and Prevost (2005) who do not support the hypothesis that board composition plays an important role in the use of derivatives. In another study on board independence, Dionne and Trikki (2013) focus on the percentage of independent directors on boards and the separation of the CEO and Chairman of the board. Their sample comprises 48 North American gold mining firms during the period 1991-1999. They find a positive significant relationship between derivatives and board independence to suggest that board composition, both for board independence and board chairman independence, is an important determinant of derivative use and increases the extent of hedging.

The emphasis on financial expertise in the SEC and NYSE rulings, have motivated researchers to investigate the link with risk management activities. Dionne and Trikki (2005) analyze the effects of financial expertise on the audit committee and board of directors and take measures of financial expertise such as education, knowledge and experience of directors. They study a panel dataset of 485 observations relative to 36 North American gold mining firms during the period from January 1993 to December 1999. Their results indicate that directors with a financial degree seem to encourage 
corporate hedging, however directors with no financial degree but with financial and accounting experience do not seem to have any impact on hedging policies.

In a relatively recent study, Huang et al. (2013) examine the effects of board independence, audit committee expertise and CEO stock holding on the degree of hedging. They use a unique method of counting the number of times a word appears in the financial statements (through the SEC Proxy 10-K statements) to arrive at their sample of observations related to derivatives. Their findings suggest that firms do not take optimum hedging decisions such that those firms that lack a majority of independent directors are involved in excessive use of derivatives for hedging. While the firms with majority independent boards provide better monitoring through reduced extent of hedging. With regard to CEO equity exposure, they suggest that increased hedging in firms with high shareholding reduces value but has no effect where the shareholding is low. The addition of audit committee expertise also does not appear to impact on derivative use decisions of the firm.

In another study, Geczy et al. (2007) shed light on the risk behavior of firms. This study uses survey data on US non-financial firms for the year 1997 and though their initial sample comprises 1928 firms, the final number of observations is reduced to 341 respondents, due to either missing data or non-respondents. They use a GMI index to capture general monitoring mechanisms through five elements such as: tactics for delaying hostile bidders; voting rights; director/officer protection; other takeover defenses; and state laws. They examine samples of speculators, non-speculators and frequent speculators. Additionally, they also examine firm and internal control characteristics for these firms. The authors find that hedgers may indulge in speculation, but observe that frequent speculation may be associated with weaker governance mechanisms. However, they also observe that speculators seem to have more sophisticated reporting systems with more elaborate and frequent reporting to the board, more sophisticated valuation techniques, more comprehensive policies to limit counterparty risk, and trading activities that are monitored via internal controls. 
This suggests that though firms do speculate they put in place strong internal controls to monitor hedging activities.

Some studies suggest that compensation plays an important role in determining management's speculative or hedging activities. Management that has its compensation linked to profits rather than to risk control would find it more rewarding to speculate for financial gain (Geczy et al., 2007). On the other hand, Geczy et al. (2007) examine the impact of corporate governance on speculation by firms and find that frequent speculation is associated with weaker governance. Therefore, the existing literature indicates that agency conflicts form a strong basis of a link between corporate governance mechanisms and hedging activities. Often corporate hedging strategies are driven by managers' motivation to hedge which arises from their lack of diversification, desire to guard their reputation or need to protect their favorite projects. Hence, if these managers are not properly managed and risk not adequately monitored, managers would indulge in detrimental hedging behavior for their own purposes.

A review of the current literature shows that most of the studies examine governance provisions, aspects of ownership structure and board independence in relation to their impact on derivative use. Generally, the studies employ a governance index. Many of these studies do not control for the effects of other financial and capital structure policies that are related to derivatives in the firm. Thus there is a gap in the current literature in respect of the range of corporate governance mechanisms examined, either combined or in isolation, and also in relation to the methodology employed.

\subsection{Derivatives and Firm Value}

Modigliani and Miller (1958) in their irrelevance proposition suggest that in perfect capital markets firms cannot increase firm value through leverage as stockholders are 
able to match leveraging strategies executed by the firm. In imperfect markets however, it is apparent in most cases that hedging can increase firm value. Smith and Stulz (1985), for instance contend that in the situation of imperfect capital markets, hedging can add value to firms through its impact on the determinants of derivative use that form the basis of hedging theory. Hedging increases value through reducing expected bankruptcy costs and the agency costs of debt arising from conflicts between bondholders and stockholders. Further value is increased through reduction of tax liability, increased debt capacity benefits (Leland, 1998; Stulz, 1996) and by increasing the opportunities to take on more profitable investments.

Researchers, as explained in Section 3.2, investigate the determinants of derivative use and assume that corporate hedging increases shareholder value. However, there is another group of studies that investigate whether hedging does in fact increase firm value through impacting the determinants, as is indicated under existing hedging theories. Thus there are large number of studies that look at the relationship between hedging with derivatives and its effect on firm value.

\section{Prior Studies on Derivatives and Firm Value}

There is strong support for the value effects of hedging and most studies use Tobin's Q to examine this relationship. For example, Belghitar et al. (2008) examine the effect of both foreign currency and interest rate derivatives, using a sample of 412 top 500 non-financial firms in the United Kingdom (UK). They report a significant relationship between hedging and firm value with increase of $14.7 \%$ due to use of foreign currency derivatives and $18.6 \%$ due to interest rate derivatives. Kapitsinas (2008) studies Greek non-financial firms using a sample of 81 companies and also finds a premium hedging effect of $4.6 \%$. Carter et al. (2006) examine hedging activity in the airline industry in the US, by using a sample of 28 companies during 1992-2003. They find a significant impact on firm value and record an increase of 5\%-10\% in value for their different models. 
Many studies focus on foreign currency derivatives (FCD). For example, Allayannis and Weston (2001) examine a sample comprising 720 non-financial US firms from 1990-1995. Their results indicate a positive relationship between firm value and FCD use, with FCD providing a $4.87 \%$ increase in value compared with non-users. Nain (2004) investigates US firms from 1997 to 1999, using a sample of 548 users and 2,711 non-users and finds that foreign currency derivatives increase firm value to show that: if a firm does not hedge its foreign currency risk when its competitors are applying a hedging strategy, it will realize a reduction of 5\% in value. Bartram et al. (2009) also examine the effects of FCD along with interest rate derivatives (IRD) in 50 countries using a sample of 7,319 non-financial companies. Their findings indicate a positive relationship: more specifically they find a $0.32 \%$ increase for FCD; $0.82 \%$ for general derivatives; $1.28 \%$ for IRD and $1.71 \%$ for commodity price derivatives.

Some researchers prefer to study firms from a specific industry since this reduces selection bias. For example, Mackay and Moeller (2007) examine a sample of 34 oil refineries and find a $2 \%$ to $3 \%$ increase in firm value due to hedging when revenues and costs are nonlinearly related to energy prices. Similarly, Lookman (2004) investigates firms in the oil industry with respect to commodity price risk and its effect on firm value and finds there is lower value for undiversified firms compared to diversified companies in this industry. According to Lookman (2004) lower firm value is associated with hedging large risk, while hedging a lesser risk is associated with higher firm value. In effect, hedging the larger risk is a proxy for bad management or high agency costs and Lookman (2004) suggests that once the agency conflicts are reduced, the valuation premium associated with hedging becomes insignificant.

In another study, Nelson et al. (2005) examine 1308 US firms over the period from 1995 to 1999 . Their sample contains around $21.6 \%$ hedgers that are the larger firms in the sample. Unlike other studies they use equity measure to capture firm value and find that stock prices for hedgers are $4.3 \%$ per year higher in comparison to nonhedgers. Gonzalez and Yun (2013) also study the impact of derivatives on firm value, 
investments and leverage. They examine the effectiveness of weather derivatives to hedge weather risks and find a value enhancing effect.

Some researchers posit that there is an endogenous relationship between the different types of hedging/other strategies available to the firm and that there may also exist some substitution effects. In this vein, many studies incorporate aspects of a firm's operational and financial hedging activities into their study of derivatives hedging. Kim et al. (2006) for instance, find that operational hedging increases firm value five times more than financial hedging. Similarly, Allayannis et al. (2001) document value increases for FCDs when operational hedging is combined with derivatives hedging. Campello et al. (2011) examine how hedging impacts the firm's leverage and investment decisions. They contend that hedging results in fewer investment restrictions in debt contracts and lower interest rates. Thus hedging increases firm value through more favorable debt financing. Barton (2001) researches the relationship between accruals and hedging and suggests that the two are used as substitutes by managers to smooth earnings volatility. Using a simultaneous equations approach, when they control for the firm's incentives to hedge, the author finds a negative relationship between hedging and accruals. Pincus and Rajgopal (2002) however, find that managers first use hedging to reduce oil price risk and then in the last quarter substitute between hedging and abnormal accruals to reduce earnings volatility. Both studies suggest that hedging with derivatives and abnormal accruals act as substitutes.

In contrast to the above, there are other studies reporting that hedging has either no effect or a negative effect on value. Guay and Kothari (2003), for instance, find that increase in value is insignificantly related to hedging, especially when considering large derivative positions. Jin and Jorion (2006) examine this relationship in the US oil and gas industry from 1998 to 2001 and do not find any relationship between hedging and firm value. Similarly, Callahan (2002) studies gold hedging activity in 
North American gold mining firms from 1996-2000 through examination of a sample of 20 firms and finds that hedging activity is negatively related to stock price.

Similarly, Koski and Pontif (1999) find that returns of the mutual funds using derivatives are not significantly different from those not using derivatives. This is similar to the results of Hentschel and Kothari (2001) and Guay and Kothari (2003) who show that the cash flow benefits from hedging are quite minimal. In fact, the median firm could only hedge a maximum of 3\% - 6\% of its interest rate and exchange rate risk. The authors contend that the large value effects recorded by researchers may also be attributed to other risk management activities related to derivatives such as operational hedges.

\subsubsection{Derivatives, Corporate Governance and Firm Value}

Risk management theory indicates that hedging adds value through impact on the tax liability, financial distress costs, increased debt capacity, tax-shield benefits and also through impacting the firm's investment growth opportunities. Therefore, corporate governance may influence the value of the firm directly through their impact on the amount and extent of derivatives. It can also impact hedging indirectly through financial, investment, and compensation policies. A major objective of corporate governance is to ensure that shareholders' interests are protected and that they receive adequate return for capital investments (Shleifer and Vishny, 1997). Therefore, it is expected that strong governance structures should reduce agency problems between managers and shareholders by limiting the managers' opportunistic behaviour to maximize their own self-interests. If corporate governance is effective, it should be able to control agency conflict to ensure that managers apply risk management strategies in line with the firm's overall strategies to maximize shareholder wealth. 
There are few studies, only two (to the author's knowledge) that inspect the relationship of corporate governance and derivatives risk management on firm value. Allayannis et al. (2009) is one of the first studies to examine this association in a crosscountry examination. They use a firm-specific index in the manner of Gompers et al. (2003) methodology and similar to that used by Lel (2006). The index comprises seven governance factors ranging from 0 for weak governance and 7 for strong governance and addresses: insider block holders; outside block holder; institutional block holder; separation of CEO and chairman; and cash flow rights of the largest managerial block holder. This study uses a global sample of firms and examines the effect of both internal and external corporate governance on hedging. For the firm specific model, the authors divide their sample into high-low insider ownership and high-low outside ownership and test the effect of foreign currency derivatives on firm value. The authors document that hedging results in a value increasing strategy when coupled with strong corporate governance. Conversely, weak corporate governance leads to a positive but not significant hedging premium. The findings of the study provide evidence that firms use derivatives in a manner consistent with value-maximization, while weakly governed firms use derivatives for managerial utility-maximization. Thus there is a hedging premium where there is strong corporate governance but not for weakly governed firms.

Another recent study by Fauver and Naranjo (2010) investigate the effect of corporate governance on both derivatives and firm value. They examine a sample of 1746 in US firms during the period from 1991 to 2000 and investigate agency costs and monitoring problems related to corporate governance. The authors are interested in measuring agency problems arising from entrenchment and quality of monitoring. They use insider ownership, sales-to-assets and free cash flow as proxies for agency costs to capture agency conflicts, and use institutional shareholding for corporate governance diligence. While the E-index and G-index capture other corporate governance mechanisms. They find that derivative use has mixed effects on firm value and conclude that in firms that exhibit greater agency and monitoring problems, derivative use has a negative impact on value. 


\subsection{Derivatives and Firm Risk}

Researchers have shown a keen interest in exploring the hedging behavior of firms in respect of firm risk. Stulz (1996) suggests that firms who possess private information and/or sufficient financial strength to take the additional risk, may incorporate their market view into their hedging programs to create value. Alternatively, firms may engage sometimes in hedging and sometimes in speculation due to asset substitution motives. Therefore, managers may hedge selectively because they erroneously believe that they can outperform the market and may in reality erode firm value.

Another perspective of firm risk management behavior is provided by Schrand and Unal (1998) and they term this as "risk allocation". The authors contend that firms constrained with respect to total risk, would hedge other risks where they may have no comparative advantage in bearing, to achieve higher returns in new projects where more comparative advantage exists. Therefore, firms take a tradeoff between riskreturn, where a decrease in one risk type could off-set another risk where greater benefits are to be derived, suggesting cross-purposes exist with respect to risks and hedging (Schrand and Unal, 1998). This risk allocation could be prompted by risk strategies for the benefit of the firm, or simply on account of personal motives of management and directors for their own benefits. Therefore, there is a strong motivation for managers to hedge risk exposure or increase firm risk through speculation for financial gain.

\section{Prior Studies on Derivatives and Firm Risk:}

Firms use derivatives to reduce risk but evidence that derivatives actually do reduce risk is somewhat mixed. Guay (1999) uses a sample of 254 non-financial companies to investigate the impact of derivatives on firm risk. His primary focus is on whether firms use derivatives to reduce risk. He finds that risk declines for firms using 
derivatives to hedge: stock-return volatility reduction of $5 \%$ generally across the sample with a reduction of $22 \%$ due to interest rate derivative use and $11 \%$ due to foreign exchange rate hedging. He notes that though derivatives reduce total risk, idiosyncratic risk and interest rate risk, he finds no significant effect on market risk for these firms.

Bartram et al. (2011) evaluate the effect of derivatives on firm risk and use a large global sample of 6,888 non-financial firms from 47 countries. They examine exchange rate, interest rate and commodity price derivatives separately and test their effect on cash flow volatility, standard deviation of stock returns and market betas. They find that over the period from 1998 to 2003 hedgers, when compared to non-hedgers, have lower sensitivity to market returns or market beta. They conclude that hedging firms do reduce cash flow risk, total risk and systematic risk with the use of derivatives. The univariate results indicate a 50\% lower cash flow volatility, $18 \%$ lower return volatility and $6 \%$ lower market betas as compared to non-derivative users.

Bartram et al. (2011) argue that there are problems with endogeneity. They contend that the differences in results for risk of derivative-users and non-derivative users could be due to omission of some control variables affecting firm risk and firm hedging behaviour and which may hide the real differences in risk measures. They hypothesize that hedging behaviour may be driven by risk exposures of the firm, so higher risk firms may hedge to ensure their "risk profile is indistinguishable from inherently less risky non-hedgers" (pp. 2-3). Bartram et al. (2011) use the propensity score matching technique to control for this. After controlling for endogeneity, they find that firms that hedge, when compared to non-hedgers, have $10 \%$ to $25 \%$ lower cash flow volatility, $3 \%$ to $10 \%$ lower standard deviation of returns, $6 \%$ to $22 \%$ lower betas and $1 \%$ to $7 \%$ higher firm value assessed through Tobin's $Q$. Therefore, hedgers do reduce risk. 
Magee (2013) investigates risk and uses Merton's model to construct a distance-todefault proxy as a measure of financial risk. He examines a sample of 401 US firms from 1996 to 2000 and uses an instrumental variables approach to reduce endogeneity between hedging and leverage. The results indicate that hedging does reduce the probability of financial risk. In another recent study, Manchiraju et al. (2014) investigate whether derivatives are used by firms for hedging or non-hedging purposes based on SFAS 161 disclosures. They use a sample of 445 firm-year observations from US oil and gas industry, and measure risk through cash flow volatility, earnings volatility, stock returns volatility and oil/gas beta proxies. Their results indicate that firms use cash flow hedges to decrease risk and this is more evident in the face of high financial contracting costs. They find that the use of derivatives for non-hedging purposes is tied to increased risk exposure. The authors conclude that firms achieve significant gains through hedging and use non-hedging activities to achieve expected market benchmarks. Also results show that firm value increases only for hedging activities.

In contrast there are studies that do not find a significant relationship between firm risk and derivative use. For instance, Hentschel and Kothari (2001) look at the impact of derivatives on firm risk through examination of financial statements data of 425 large US companies and find that there is no association between stock price volatility and derivative positions of the firm, even for firms that hold large derivative positions. They conclude that hedging firms compared to non-hedging firms do not exhibit any measurable difference in risk from use of derivatives. Koski and Pontif (1999) examine the mutual funds industry in the US using a sample of 679 domestic equity mutual funds. They find no differences between funds using derivatives and those not using derivatives: hedgers have the same risk and return compared to non-hedgers and exhibit the same idiosyncratic risk, standard deviation, market risk, skewness and kurtosis as those not using derivatives. 
Another group of researchers find strong support for the selective hedging behavior by non-financial firms in the markets. Dolde (1993) reports that almost $90 \%$ of the 244 firms in Fortune 500 firms surveyed sometimes based their hedging on future market movements; Bodnar et al. (1998) use survey data and find that of the 399 US nonfinancial firms around half of them admit to sometimes hedging based on the markets. While Glaum (2002) finds that the risk management practices of their sample of German firms followed risk management strategies oriented to profit increase. Similarly, Brown et al. (2002) also indicate that for their sample of non-financial firms comprising 44 gold producers, managers market views influence the broader financial policies and decisions. This is further supported by Adam and Fernando (2006) who find that $62 \%$ of the firms in their sample gold mining industry took hedging positions according to future metal prices. There are others who find support for the view that selective hedging is a common practice for nonfinancial firms in the financial markets (Baker and Wurgler, 2002; Faulkender, 2005; Graham and Harvey, 2001). Most of these studies use the hedging ratio to capture the effects of the selective hedging behavior in these firms. Thus, these studies suggest that non-financial firms may use derivatives not only to hedge but also for speculation and may also vary their derivatives positions in accordance with their market expectations.

\subsubsection{Derivatives, Corporate Governance and Firm Risk}

As explained above, many studies provide strong support for the selective hedging behavior by non-financial firms. This raises the question regarding the potential agency conflict and the role of corporate governance in allowing such risk behavior. If firms are indulging in this behavior what is the corporate governance stance on it and is corporate speculation positively related to corporate governance? It is posited that overconfidence leads managers to believe that they have superior information or ability when in reality they do not and this then induces managers to speculate based on their market views, sometimes to the detriment of the firm (Stulz, 1996). Corporate governance has the option to either deter and manage such behavior; encourage or 
ignore it out of personal motives; or increase the hedging and speculation activities as part of their financial strategy for the benefit of the firm.

Risk management theory indicates that there is a natural relationship between corporate governance and risk management over hedging activities. There is an implicit assumption that non-financial firms need to apply derivatives to hedge their risk exposure. It is also expected that these firms should not be speculating for profit, as it is not part of their trade or business. It then follows that corporate governance at the helm of operations needs to ensure that the firm's derivatives risk management strategies are not being directed toward managers' personal objectives.

There is a dearth of studies that investigates the effectiveness of corporate governance in risk management of derivatives. Only one recent study (to the knowledge of the author) examines the corporate governance-derivatives relationship on firm risk and inspects one corporate governance mechanism in this regard: board independence. Huang et al. (2013) study the association between board independence and risk management through derivatives. They derive their sample from the SEC Proxy 10$\mathrm{K}$ statements and the number of firm year observations range from around 2084 to 6968 for their risk models. They examine the effects of board independence and derivatives on unsystematic, systematic and total risk and their results suggest that boards with less independence seem to increase total firm risk and idiosyncratic risk, but do not impact market risk.

\subsection{Chapter Summary}

This chapter reviews existing literature and provides an understanding of the concepts of derivatives hedging, the special features that underlie the determinants of derivative use and corporate governance. It presents the theories surrounding derivative use by firms in their efforts at risk management. Prior studies show that convex tax structure, 
financial distress and bankruptcy costs, investment growth opportunities and the related underinvestment costs, and managerial risk aversion, are the motivations for firms to hedge risk.

The available literature on corporate governance and risk management may be segregated into three main areas of research that examine: a) the link between corporate governance and derivatives; b) the effect of the corporate governancederivatives relationship on firm value; and c) the impact of the corporate governancederivatives relationship on firm risk. These three areas are discussed below.

a) Majority of studies examine the first dimension in the relationship. Generally, these studies center around ownership structure and board independence. In this respect, Lel (2006) is one of the few studies that affirms that some corporate governance mechanisms do impact derivatives decisions in the firm. This study uses a global sample and inspects the governance characteristics through a governance index. They suggest the detrimental impacts of weak governance in managing derivatives hedging activities. Geczy et al. (2007) examines compensation and speculative behavior of non-financial firms. They suggest that frequent speculation by firms is associated with weaker corporate governance, but that more controls are put in place as a result of this.

Overall the findings related to the determinants of derivatives provide weak evidence for many of the theories and often the results are conflicting and mixed. This may indicate some weaknesses in the models due to omitted variables and show that there are other determinants that may have been ignored (Geczy et al., 2001; Guay and Kothari, 2003; Pantzalis et al., 2001). Bartram et al. (2011) and others (Aretz and Bartram, 2010; Bartram et al., 2009) explain that the difference in findings could be due the endogenous nature of the decision to use derivatives and other financial and operating decisions. Leland (1998) indicates that use of derivatives affects investment, capital structure and agency costs and Lel (2006) emphasizes the importance of including corporate governance in any study of derivatives because according to him 
it affects the risk management decisions of the firm.

Current literature indicates that there are many corporate governance mechanisms that have not been examined. Also, many of the studies construct a governance index that may mask the effects of the individual components of governance. Most importantly, some of the studies do not control for the effects of other financial decisions that impact derivatives hedging and may therefore provide a biased view. The weaknesses in existing research studies, lack of investigation into a comprehensive set of governance mechanisms and reliance on governance index provides a strong motivation for further investigation of this relationship in the US. There has been a growing interest in studying the impact of corporate governance on hedging and specifically on derivatives. This has been the outcome of the recent global financial crisis. However, results for existing literature differ and vary for the different governance mechanisms examined.

b) In respect of the second dimension, there are only few studies that examine the relationship of governance and derivatives on firm value. Allayannis et al. (2009) is one of the few studies to provide evidence that corporate governance does provide a hedging premium and they segregate governance into weak and strong governance. Their findings affirm that strong corporate governance does show value enhancing hedging activities. However, they suggest that weakly governed firms do not increase firm value through derivatives. Their study uses a global sample and investigates corporate governance through the construction of a governance index and focusses largely on ownership structure. Another study (Fauver and Naranjo, 2010) investigates agency costs and monitoring problems related to corporate governance in the US and also focusses on shareholder components of corporate governance. There appears to be a gap in the research related to the corporate governance influence on the value effects of derivatives in respect of the range of governance mechanisms examined. 
c) The third dimension of this relationship has not been adequately examined and literature is thin in this area. Existing research indicates that firms apply their hedging programs to hedge, speculate and sometimes switch between the two to exhibit selective hedging. Researchers suggest that this behavior in non-financial firms may stem from either/both managerial personal motivations and shareholder wealth considerations. It raises concerns about corporate governance role in managing risk in non-financial firms. Current literature related to corporate governance and firm risk with respect to derivatives by non-financial firms is quite sparse. One recent study examines how board independence influences the effect of derivatives on firm risk. Therefore, there exists a huge gap and provides a motivation for further research in this area. 


\section{CHAPTER FOUR: THEORETICAL FRAMEWORK AND DEVELOPMENT OF HYPOTHESES}

\subsection{Introduction}

The objectives of this study are to examine (1) whether there is an association between corporate governance and derivatives, (2) whether the influence of corporate governance enhances the effect of derivatives on firm value and (3) whether the impact of corporate governance improves the effect of derivatives on firm risk. Through these objectives, the study endeavours to assess whether corporate governance contributes to the hedging effectiveness of derivatives in non-financial firms.

Initially, in Section 4.2, I discuss the background for the framework and the theory surrounding agency conflict. I also dilate on the governance mechanisms that I examine in this study and the reasons for my selection. Further, I discuss the link between corporate governance and hedging decisions.

I follow this with an explanation of the characteristics and outcomes of derivatives in context of hedging, speculation and arbitrage, and relate it to the effects on firm value and firm risk. At the end of this section, I develop a matrix to show how corporate governance hedging or speculative behaviour could impact firm performance. In Sections 4.3 to 4.7 , I develop the hypotheses related to the study and that form the basis for the regression models. At the end, Section 4.8 provides a summary of the chapter.

In the following sections and chapters: value and firm value; risk and firm risk; derivatives and derivatives use, are used interchangeably and carry the same meaning. 


\subsection{Theoretical Framework}

Agency theory explains the conflicts that exist between management and shareholders. The agency conflicts largely form the basis for the risk management decisions taken by management, specifically with regard derivatives.

\subsubsection{Agency Theory and Corporate Governance}

The Corporate Governance framework has its origins in agency theory derived from the concept of "separation of ownership and control" (Jensen and Meckling, 1976, p. 6). An agency relationship arises when the principal, the investor, invests in the firm and engages another person, the agent (normally the manager), to act on his or her behalf. Agency theory deals with the resolution of problems occurring between principal and agents. Agents are entrusted to act in the principal's best interests but on occasion can fail to do so and be concerned instead with furthering their own interests. The result is agency conflict sometimes referred to as the agency problem. To minimize agency conflict, a contract is commonly executed between the investor and the manager (Coase, 1937; Fama and Jensen, 1983a; Jensen and Meckling, 1976).

The problem, though, cannot be wholly eliminated through a contract as it is not possible to draw up a contract to completely cover every contingent situation (Shleifer and Vishny, 1997). Unforeseen circumstances inevitably occur and managers must be given sufficient investors' residual control rights to allow managers to take independent action. It is this transfer of residual control rights which increases the management problem for through these rights managers gain the freedom to use investor funds as they see fit. Such freedom is easily abused. Managers, for instance, can refrain from paying back free cash to investors and invest it instead in their own pet projects; or worse they can expropriate the funds. 


\subsubsection{Corporate Governance Mechanisms}

I discuss below the corporate governance mechanisms of interest in this study.

\section{Executive Compensation}

In examining agency conflict, Jensen and Meckling (1976) ask the question: why investors do not bribe managers with cash not to undertake unprofitable projects? Coase (1960) and Grossman and Hart (1986) suggest that this is what actually happens in practice. Managerial incentive contracts, by way of example, are intended to induce managers to act on behalf of investors by including share ownership, stock options and other measures that are linked to performance of the firm. Berle and Means (1932) too suggest that there is a positive relationship between pay and performance.

Two views have emerged regarding executive compensation (Bebchuk and Weisbach (2010): the optimal contracting view; and the managerial power view. The former sees incentive contracts as an effective means for reducing agency conflict (Holmstrom, 1979); whereas the latter view incentive contracts as part of the problem rather than a part of the solution (Bebchuck and Fried, 2003, 2004). Incentive contracts, in the last view aggravate managerial conflict by encouraging managerial misbehaviour for example when excessively high paying contracts are negotiated with weak boards of directors. However, the motivation of compensation toward better performance cannot be denied, though incentive contracts cannot completely solve the agency problems.

\section{Board of Directors}

In addition to contracts and incentives, investors can also use other governance mechanisms to put checks on agents. Boards of directors are elected by the 
shareholders to monitor managers but in this context there is a problem again in so far as it is necessary to keep directors' interests aligned with those of investors (Berle and Means, 1932). In this regard, there are a number of issues. Fama (1980) and Fama and Jensen (1983a, b), for instance, note that board composition and structure influence the effectiveness of boards. The expertise of inside directors is needed to gauge performance and contribute to management of the affairs of the company.

At the same time the powers of the inside directors need to be restricted in order to ensure they do not control the boards. Board independence has been suggested as a suitable countermeasure and many studies find a strong relationship between board independence and improved decisions in the firm (Byrd and Hickman, 1992; Gillette et al., 2003; Shivdasani, 1993). The ability of independent directors to perform well however, is also related to their incentives (Ravina and Sapienza, 2009). On the other hand, Hermalin and Weisbach (1998) find that independent directors that are forced on the firm, are less effective than those who have been voted into place and many do not find any association between increased firm value and board independence (Bhagat and Black, 1999; Hermalin and Weisbach, 1991).

Theory suggests that board independence and structure contribute to its effectiveness. However, some studies criticize the requirement for board independence and suggest that demands for board independence have caused problems with regard to board competence, such as the focus on board independence may have reduced the level of expertise and with it the proper monitoring of risk as directors are on multiple boards and do not have the time (Kashyap et al., 2008).

\section{Audit Committee}

The objective of the board of directors is to reduce agency conflict. Toward this objective, they appoint audit committees. The audit committee is responsible for 
overseeing the quality of the financial reporting processes, internal control and audit activities of the firm, both internal and external. In many non-financial firms, the audit committee is also involved in risk management function of the firm.

Kirkpatrick (2009) notes that boards in many instances were not aware of the risk exposure that their companies undertook during the crisis and did not put control mechanisms in place. He attributes this to the board's limited understanding and control over "balance sheet growth and liquidity needs" (Kirkpatrick, 2009, p.8).

Audit committee size would be vital in determining their importance in the firm and the weight they carry to implement significant decisions that affect risk management strategies of the firm. This dimension has cross-sectional explanatory power.

What is the link between hedging theories and corporate governance?

Nelson et al. (2005) suggests that there are three different views regarding hedging and firm value: 1) some indicate that hedging achieves a zero net present value under the assumptions put forward by Modigliani and Miller (1958) where there are no additional costs and markets are perfect; 2) hedging programs are expensive but despite this managers would hedge to reduce their own personal risk and protect their wealth without incurring any costs themselves, therefore achieving negative net present value for the firm (Smith and Stulz, 1985); and 3) some support the view that hedging increases value through reducing the costs of financial distress (Smith and Stulz, 1985), enabling firms to stabilize cash flows and earnings to maintain profitable investments and access lower cost financing costs (Froot et al., 1993; Stulz, 1984), and finally, hedging provides markets with a signal of higher quality management (Breeden and Viswanathan, 1999; DeMarzo and Duffie, 1995) to minimize information asymmetry and lower cost of capital, and thereby increase firm value 
(Nelson, et al., 2005). Therefore, depending on the view point, hedging could have either no impact, negative impact or an increased effect on firm value.

There is a strong link between corporate governance and firm's hedging activities as corporate governance may influence the firm's risk management strategies through financial, investment, liquidity and compensation policies and strategies. This suggests that firstly, boards are able to potentially increase value through effective and adequate financial policies. It is the concern for financial distress or bankruptcy costs that motivates managers to hedge as without hedging the more external financing used by the firm, the greater will be the increase in financing costs. Through the financial strategies the boards determine the firm's capital structure; the source and extent of external debt utilization; financing costs and the amount of derivatives. Effective boards would structure financial policies, to increase debt capacity and reduce financial costs, through the optimum use of derivatives.

Secondly, boards monitor the investment and liquidity decisions of the firm. Froot et al. (1993) suggest that companies face the problem of underinvestment when firms have many investment opportunities but cash flow is constrained (Also: See Bessembinder 1991; Lessard, 1990; Myers 1977; Smith and Watts 1992; Stulz 1990). Thus variation in cash flows affects investment growth opportunities as firms would not be able to undertake positive net present value (NPV) projects. Boards must monitor investments and projects in line with the vision for overall firm growth and expansion vision. Effective boards would add value by reducing underinvestment costs, increasing investment growth opportunities and liquidity through the efficient use of derivatives by managers.

Thirdly, the board has the obligation to establish executive compensation policies geared to reduce agency conflict and increase value. Managers are risk averse and as a result of their compensation and large stock holding, managers would avoid investing in risker long-term projects even with high returns, to the detriment of shareholders 
(Almazan and Suarez, 2003). Managers having larger stock holdings compared to those with options prefer to hedge their risks, because stocks have linear payoffs while options have convex payoffs. Option contracts may thus induce managers to take greater risk because greater volatility would increase the value of the options. Researchers also hypothesize that if risk-averse managers find that their own costs of hedging are higher than the cost of hedging for the firm, then the managers will hedge firm risks (Smith and Stulz 1985; Stulz 1984; Tufano, 1996).

Therefore, agency conflict could be reduced by either constant monitoring by the board or by inducing risk reduction (Lel, 2012) through derivatives hedging to protect compensation and management wealth.

\subsubsection{Financial Derivatives Framework}

Derivatives are multipurpose instruments and may be used for hedging, speculation and arbitrage. Hedgers use derivatives to reduce risks related to assets or investments. Speculators, on the other hand prefer to use derivatives in order to gain through betting on anticipated changes in asset prices and in the market. Arbitrageurs try to benefit from the differences in the prices in two different markets, if at all and take offsetting positions in two or more instruments to lock in a profit (Hull, 2011).

\section{Hedging}

Smith and Stulz (1985) define hedging through:

"We say that firm $a$ hedges more with respect to state variable $i$ than firm $b$ if the absolute value of the covariance of the value of firm $a$ with state variable $i$ is less than 
or equal to that of firm $b$. Therefore, hedging reduces the dependence of firm value on changes in the state variable.” ( p. 392).

The primary objective of hedging is risk reduction and it may not result in the increase in value. Hedging may be used to control price risk and interest rate fluctuations; protect cash values; provide higher yields from investments; and develop effective swap programs, among others. It is not necessary that hedging increases value but should reduce risk. A perfect hedge would absolutely remove the risk, however as Hull (2011) indicates, it is hard to achieve a perfect hedge. Usually non-financial firms use "hedge-and-forget strategies" (page 47) where the hedger takes a hedging position and holds this till end of the contract life which is counter-intuitive to the purpose of hedging. The manager does not adjust the hedge to match risk exposures, as he should do.

Does Hedging Increase Firm Value?

One of the main goals for corporate managers is the maximization of stockholder wealth. However, literature is mixed with regard to this. There is no consensus on whether hedging does in fact increase firm value and empirical evidence is somewhat mixed.

Graham and Rogers (1999) examine the effect of interest rate and currency derivatives on firm value. They take the long and short positions of derivative holdings and net them, to measure the extent of hedging using the net notional values. They find that firms hedge to increase debt capacity and through this, increase firm value. Additionally, the authors find that the increase in value is associated with the increase in debt capacity to a greater extent than with tax convexity, which is another value increasing determinant of hedging. 
Hedging theories (Smith and Stulz, 1985) indicate that taxes, transaction costs of bankruptcy and financial distress, managerial compensation and risk aversion provide the rationale for firms to hedge with the objective of maximizing the value of the firm. Investment growth opportunities and the problem of underinvestment are also factors in a hedging decision and increase value (Froot et al., 1993). However, Lel (2006) cautions that an increase in amount of derivatives does not in itself indicate a hedging premium if the hedging is ineffective, similarly a decrease in amount of derivatives could lead to increased value due to more effective hedging.

\section{Hedging Versus Non-Hedging}

A comparison between the financial impact of hedging versus non-hedging, shows that hedging enables investors to limit their loss, even if the profit is lower than that for the non-hedgers. Appendix 3 shows the different impacts for hedgers and non-hedgers. Hedgers are able to safeguard their portfolios from a reduction in share prices and have the option to avoid a loss, or otherwise make a profit. However, non-hedgers would incur a larger loss, even though they have the potential to make a higher profit. Therefore, derivatives strategies for firms should aim to reduce financing costs and manage risks, as profitably as possible. The main objective of hedging is the reduction of risk and not the increase in value.

\section{Speculation}

The most noticeable difference between the hedger and the speculator is that the former tries to alleviate risk while the speculator seeks profit at the cost of increased risk. But it is easy for a hedger to become a speculator. Speculators are not focused on risk reduction but try to wager on price changes in order to make a profit. For the speculator, futures and forwards would provide the same opportunities for expected gain or loss which can be very large. However, options would limit the extent of 
losses. In fact, speculation increases the magnitude of the financial impact to greatly enhance gains but also dramatically increase losses (Hull, 2011).

\section{Arbitrage}

Management may also use derivatives to arbitrage. Arbitrageurs delve in derivative instruments in order to secure riskless profit by two transactions in two markets. They take advantage of the price differences or transaction cost differences in the markets. Though arbitrage is possible however, the advantage would only be short term, as prices would quickly settle and the price differences would disappear. Therefore, arbitrage would be less visible in the markets (Hull, 2011).

\section{Corporate Governance - Derivatives Matrix}

The role of corporate governance within a firm is to motivate managers to implement hedging strategies that are aligned to the financial, operational and investment strategies and policies that benefit the firm and its shareholders.

As a result, corporate governance should influence and motivate managers to implement hedging strategies in keeping with their overall direction. Table 4.1 depicts a matrix of the derivatives outcomes that are possible for firms with respect to hedging and speculation. There could be either well-planned and purposive hedging or speculation. Or these could simply be a result of inadequate knowledge or expertise resulting in ineffective hedging. The optimum hedging position would result in an increase in firm value and reduction in firm risk, while successful speculation would result in increased value with an accompanying increase in risk. 
Table 4.1: Derivatives: Hedging and Speculation Matrix

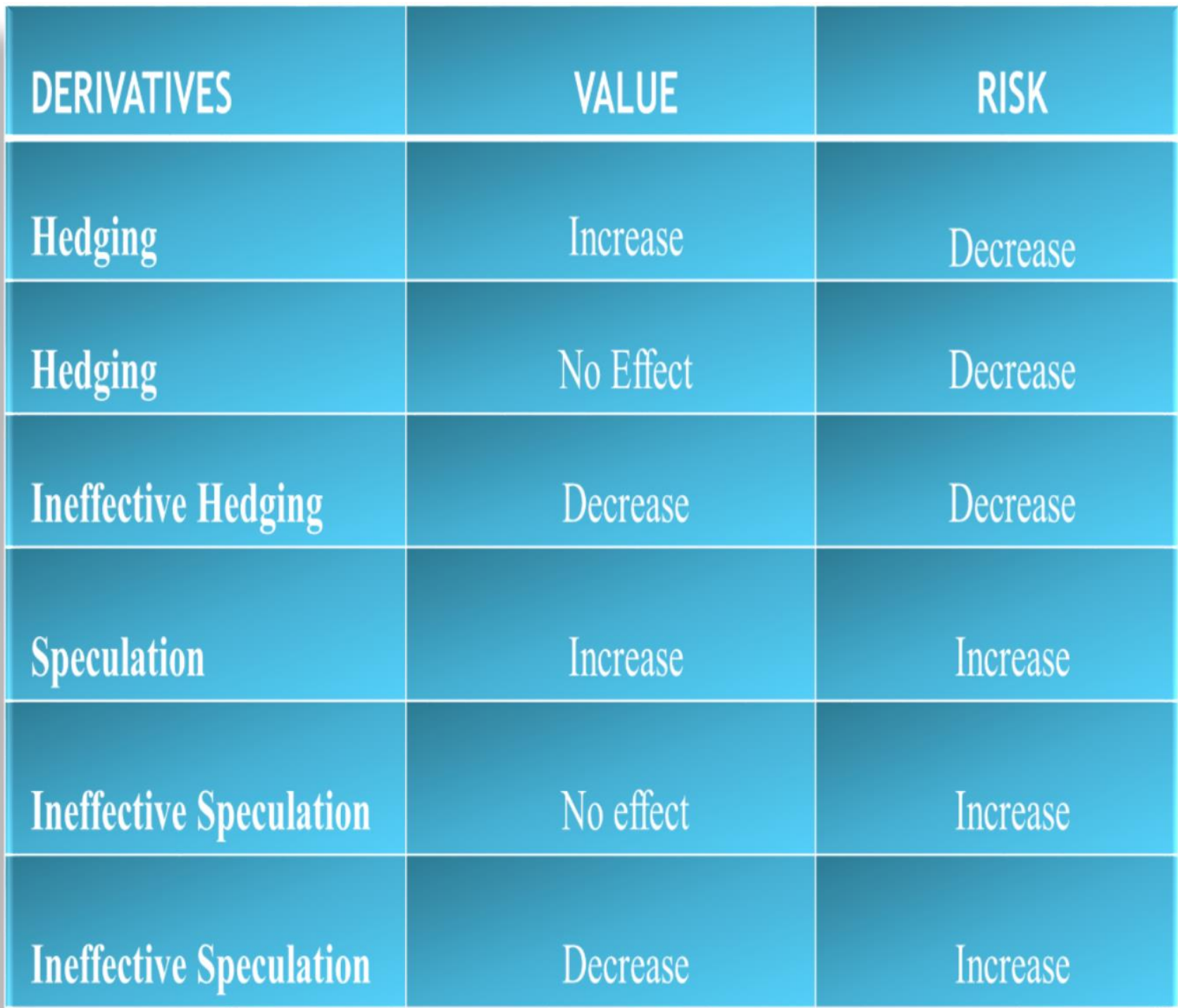

Why do managers hedge or speculate?

There are many reasons why management may speculate or not hedge optimally. Some may view speculation similar to positive NPV projects that provide higher returns for the company; others tend to speculate more from a sense of their information advantage in the market and possibly, to project an impression of expertise (Geczy, et al., 2007). Corporate governance should exercise strong influence over a firm's activities to manage risk. If management is not properly monitored the firm may 
become involved in hedging activities that serves management's own purpose or is designed to protect its own reputation (Smith and Stulz, 1985; Tufano, 1996) to the detriment of shareholders. Gezcy, et al. (2007) find that frequent speculation may be associated with weaker governance mechanisms though speculators seem to have more sophisticated reporting systems with more elaborate and frequent reports to the board, more sophisticated valuation techniques, more comprehensive policies to limit counterparty risk, and trading activities are monitored via internal controls. Sometimes management of lower ability may refrain from hedging when it should hedge (Breeden and Viswanathan, 1998) and thus undermine firm value. Some management may hedge to hide lack of diversification or simply to safeguard preferred projects (DeMarzo and Duffie, 1995; Smith and Stulz, 1985; Stulz, 1984; Tufano, 1998).

Compensation plays an important role in determining management's speculative or hedging activities. Management that has its compensation linked to profits rather than to risk control would find it more rewarding to speculate for financial gain (Geczy et al., 2007; Li and Tang, 2010; Zeidan and Rodrigues, 2013). Finally, many firms lack the expertise to match hedging positions to their risk exposure and therefore may speculate inadvertently. An increase in firm risk either through speculative or mismatched hedging activities may indicate a failure in the governance mechanism.

Derivatives are complex instruments and provide managers incentives to speculate mainly due to the leverage they provide. Also because of their complexity it becomes difficult for investors to understand the consequences of their actions on operations (Bodnar et al., 1998). In a survey of US firms Bodnar et al. (1998) find that 50\% of their sample firms use derivatives of which $41.5 \%$ currency derivatives, and of these $32 \%$ use them for speculation.

The primary role of the board of directors is to exercise decision control and monitor operations. The board's role is all the more important in a derivatives environment as the consequence of ineffectiveness could be severe. This raises concerns that firstly, 
corporate governance is effective in this environment and secondly, that the corporate governance framework is adequate for monitoring the activities of management.

Does an increase in derivatives mean an increase in hedging and therefore increase in value?

If this was true, then firms could increase value by indiscriminately increasing the amount of derivatives. Managers would not have to be bogged down by implementing different hedging strategies to match risk exposure of the underlying assets/liabilities to hedging positions. However, the indiscriminate increase (decrease) of derivatives, would result in over-hedging (under-hedging). On the other hand, if derivatives are employed prudently then it would result in effective hedging to increase value and reduce risk. Lel (2006) observes that generally researchers see the use of derivatives as synonymous with hedging and he contends that derivatives can be used for hedging, speculation and/or both. The author warns that taking derivatives to proxy for hedging can provide spurious results. This study investigates whether corporate governance is a determinant of derivative use decisions (Figure 4.1). Further it examines whether the corporate governance-derivatives relationship has an impact on firm value (Figure 4.2) and firm risk (Figure 4.3). 
Figure 4. 1: Derivatives and Corporate Governance

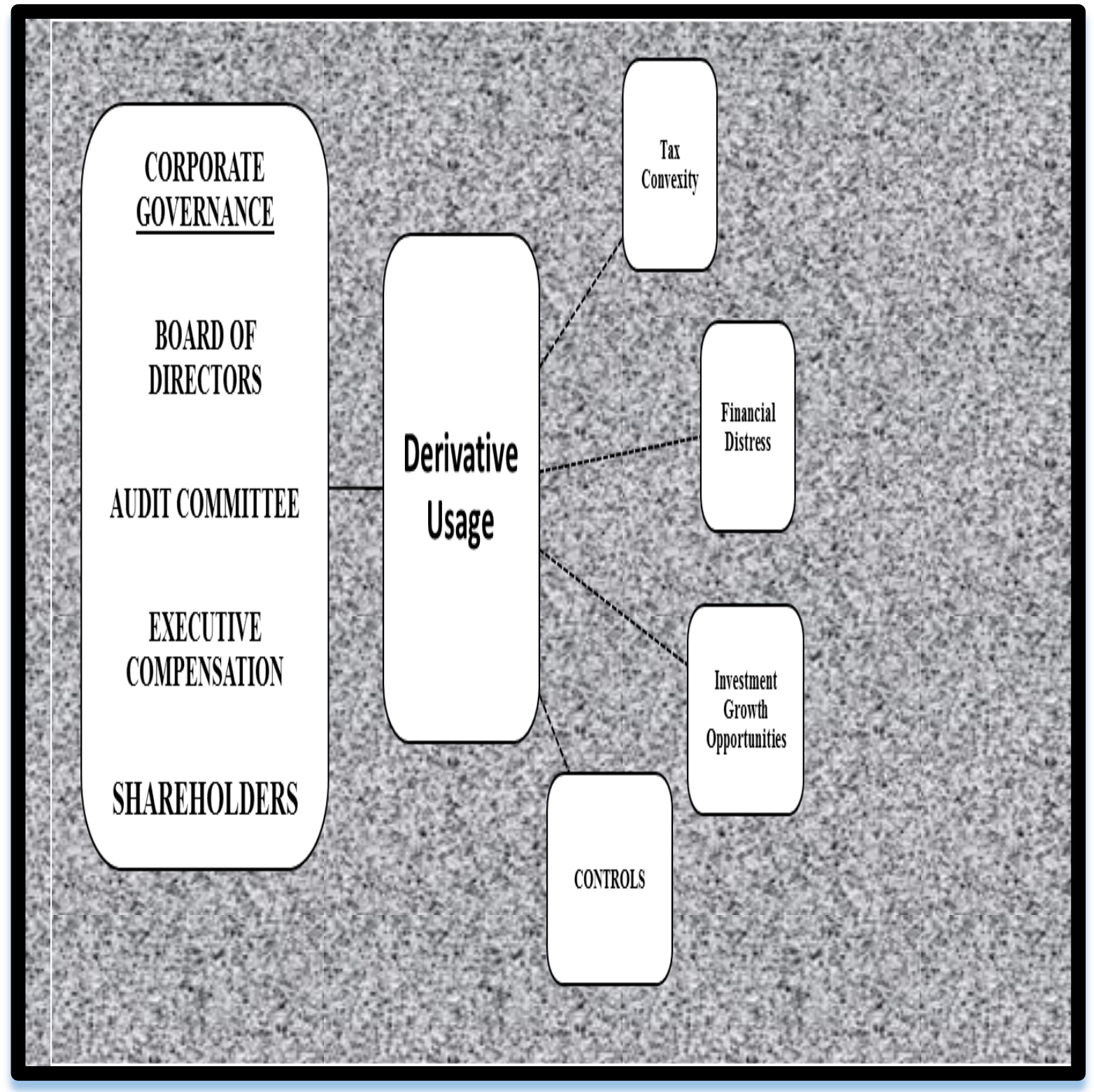


Figure 4. 2: Derivatives, Corporate Governance, Firm Value

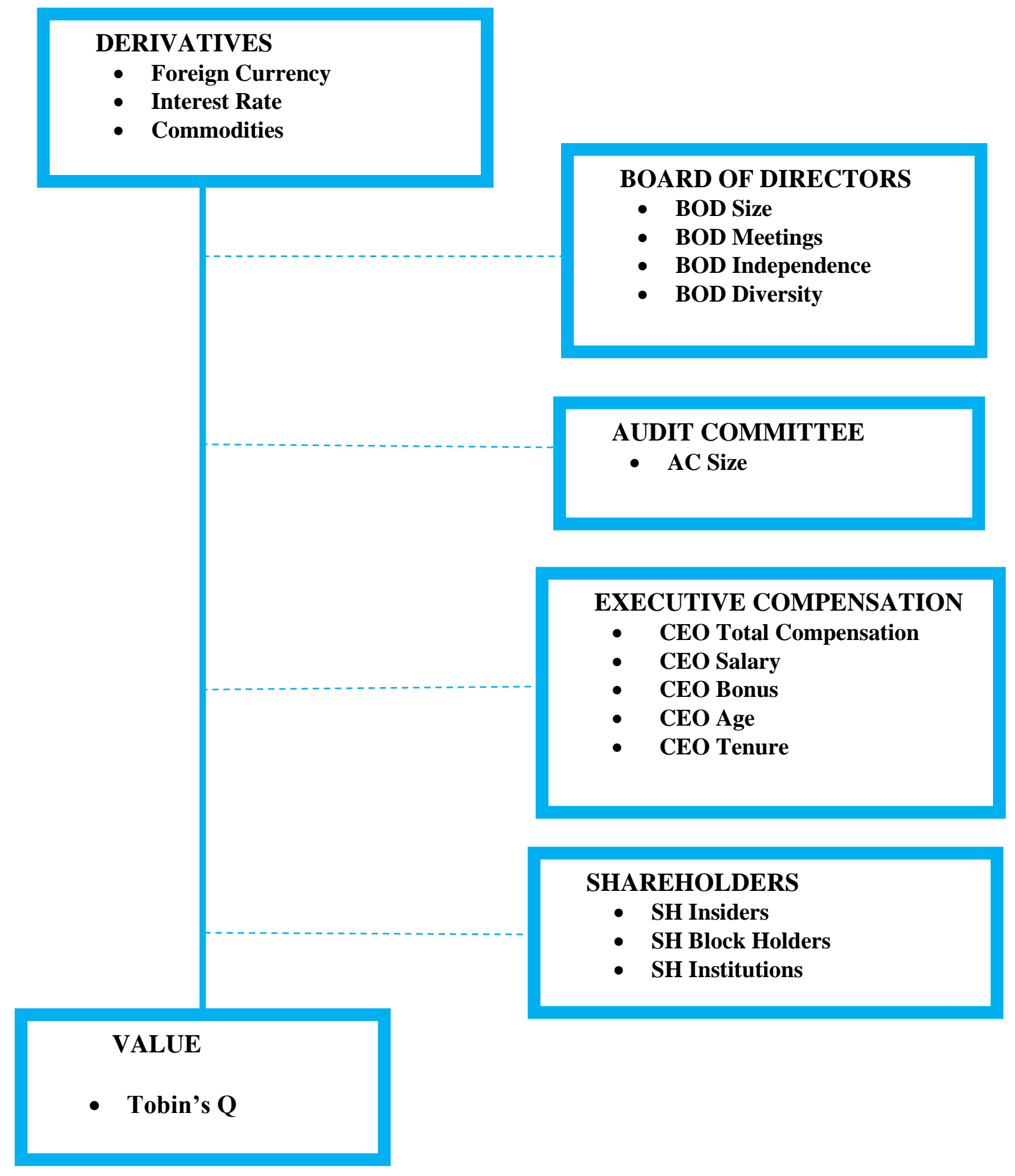


Figure 4. 3: Derivatives, Corporate Governance, Firm Risk

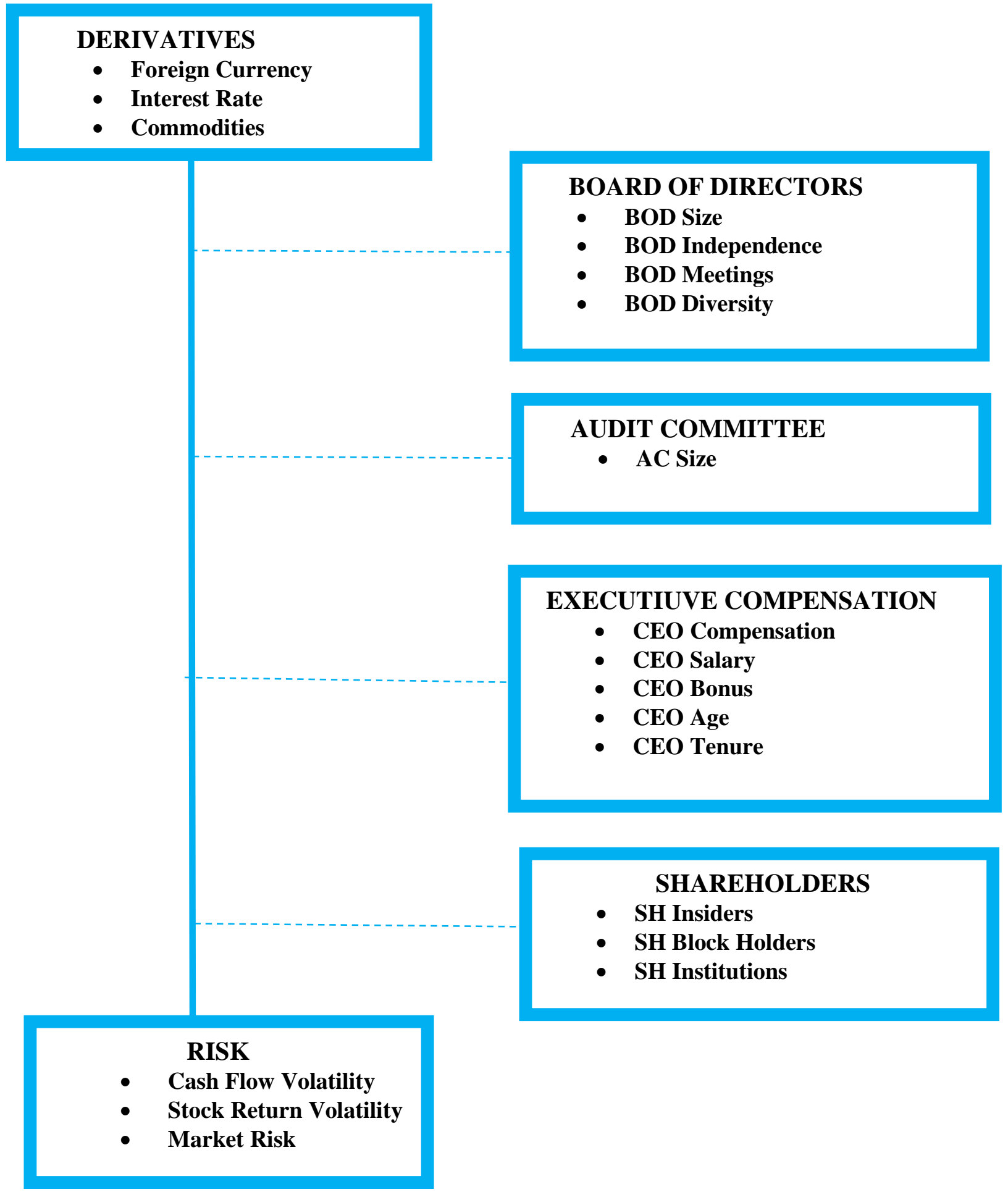




\subsection{The Hypotheses Development}

The most significant realization evolving from section 4.2 is that derivatives may be used for hedging, speculation, arbitrage, selective hedging, ineffective hedging and could easily shift from hedging into speculation. The development of each hypothesis relies on existing literature and findings, in order to form predictions of the results. However, where there is no available research or mixed findings then, a priori, no predictions are made with respect to the direction of the relationships.

In this section and in subsequent chapters, I apply the terms: derivatives and derivatives use; firm value and value; firm risk and risk, as being synonymous.

\subsection{Hypotheses Development - Board of Directors (board)}

\section{Do board meetings impact the value and risk effects of derivatives?}

Board meetings are used to capture the effect of board diligence and monitoring. Generally, there is a perception that if management is active they should better monitor financial activities and better hedge risk exposures. An active board acts as a deterrent against management being involved in speculative activities for personal gain and ensures firm performance is enhanced through proper hedging strategies.

Some researchers (Adams, 2005; Vafeas, 1999) indicate that that the board's monitoring activities are inversely related to prior year experience, as boards appear to increase their activities through more meetings in the face of poor performance. Boards should be relatively inactive and may be forced to maintain higher levels of 
activity in face of poor performance (Jensen, 1993; Vafeas, 1999). Excessive board meetings may be an inkling of the boards own deficiencies. Therefore, board meetings may serve as a fire fighting device and boards that meet more frequently are valued less by the market (Karamanou and Vafeas, 2005; Vafeas, 1999).

It appears that firms with internal control weaknesses are more likely to hold additional meetings to deal with their problems (Zhang et al., 2007). The negative effects of over-monitoring also outweigh the benefits of improved monitoring. When corporate innovation is a significant driver for a firm or the operations are complex, boards that monitor intensely actually diminish corporate innovation (Faleye et al., 2011) and so are less effective. Therefore, there may be detrimental effects of over-monitoring in a more complex hedging environment that also requires innovative strategies. And Adams (2005) finds that boards increase their monitoring efforts when firms are more diversified. Brick and Chidambaran (2010) use two variables to capture board diligence: board monitoring and board meetings, and both contain a variation of board meetings. Though they find a positive impact for these variables on firm performance, they make a distinction between board's activities for purpose of fulfilling regulatory requirements which would only increase costs, without any related benefits. Firms tend to increase their activities as a reaction to poor performance to send a signal that they were "not asleep at the wheel" (Brick and Chidambaran, 2010, p. 534; Brick and Chidambaran, 2008).

In a hedging environment, over monitoring may be putting excessive pressure on management to take actions to increase value which would be accompanied with increased risk. This derives support from Erkens et al. (2009) who suggest that corporate governance put undue pressure on managers to increase short term profits with accompanying increase in firm risk during the financial crisis. 
I expect to find that board meetings would encourage managers to increase risk which may not have a value enhancing impact. Therefore, I hypothesize that:

H01a: Board meetings has no relationship with the value effect of derivatives

H1b: $\quad$ Board meetings increase the risk effect of derivatives

\section{Does board size impact the value and risk effects of derivatives?}

According to the resource dependency theory, the board of directors is an important resource due to its linkages to other entities that are of importance to the firm. Through these linkages and affiliations, the board is able to access external resources such as capital and financing, suppliers, customers and stakeholders (Burt, 1983; Freeman and Evan, 1990; Frooman, 1999; Mizruchi and Sterns, 1988). Many regard this advantage as being stronger with larger boards (Korac-Kakabadse et al., 2001; Zahra and Pearce, 1989). Dalton et al. (1999) show that larger boards have wider knowledge and access to a broader information base collectively, which contributes towards higher performance. Adams and Mehran (2012) and Coles et al. (2008) also find supporting evidence for the positive effect of board size on performance. The greater the number of directors, the more experience they bring to the board and the more they appear to compensate for one another's deficiencies in adding value. Greater numbers also make it possible for more vigilance and alertness.

On the other hand, studies have shown that many problems arise when groups get larger such as reaching consensus becomes more difficult and also their decisions show more concessions (Kogan and Wallach, 1996; Moscovici and Zavalloni, 1969; Sah and Stiglitz, 1986, 1991). Larger board size appears to confound board effectiveness. It becomes more difficult for larger boards to fulfill their monitoring and 
advising role, as larger boards appear to manifest problems of communication and coordination (Jensen, 1993; Lipton and Lorsch,1992; Yermack, 1996). It is more problematic with larger boards to organize board meetings and reach mutually agreeable resolutions resulting in delayed and inefficient decisions (Jensen 1993). Larger boards also exhibit problems in controlling management. Decisions take longer to be made and longer to be implemented, causing actions and decisions to be delayed, if taken at all. Directors would be less unified and would differ with respect to objectives and strategies and not be able to easily communicate their different perspectives undermining board cohesiveness (Lipton and Lorsch, 1992). This is aggravated by the number of free-rider directors that tend to increase with board size as they have a lower chance of being detected (Lipton and Lorsch, 1992). Discordance and divergence in larger boards would ultimately result in confusion, untimely action and ineffective decisions.

Jensen (1993) indicates that this poorer communication and coordination will make it more difficult for managers to have frank discussions on managerial performance and this would facilitate CEO's control over the board. Therefore, "CEO performance incentives provided by the board through compensation and the threat of dismissal operate less strongly as board size increases" (Yermack, 1996, p. 210). Both Eisenberg et al., (1998) and Yermack (1996) find that board size impacts current year performance, unlike others that indicate that past year performance influences the board size.

Eisenberg et al., (1998) and Yermack (1996) show that smaller boards exhibit higher firm performance and there is a trade-off between costs of monitoring and firmspecific benefits (Boone et al., 2007). Bhagat and Black (1999) also find a negative relation between board size and firm performance. It appears that larger boards with more communication problems and diversity of objectives and strategies would either 
take drastic actions or untimely decisions.

When the board takes actions that may impact firm cash flows, they are either not equipped to monitor hedging related risk adequately or their extreme measures may cause heightened derivative risk. Cheng (2008) suggests that board size is a determinant of stock volatility and indicates that corporate performance changes with board size. While others (Coles et al., 2006; Harris and Raviv, 2008; Raheja, 2005) suggest that the negative relation between performance and board size may be due to some exogenous factors.

Board size is an important corporate governance element when evaluating firm hedging activities. Larger board size may increase the risks related to hedging so that smaller boards may be more effective for hedgers, or at least there is an optimum size above which board effectiveness dwindles (Jensen, 1993; Lipton and Lorsch, 1992). However, research also shows that more directors on the boards increase the resources and linkages available to the firm and therefore larger size may be more beneficial. There is inadequate research related to board size and firm risk. Therefore, a priori, I hypothesize:

H02a: Board size has no relationship with the value effect of derivatives

H02b: Board size has no relationship with the risk effect of derivatives

\section{Does board independence impact the value and risk effects of derivatives?}

The expertise of inside directors is important to gauge performance and contribute toward management of company affairs. At the same time the powers of inside 
directors need to be restricted in order to ensure they do not control the boards. Overall board independence has been suggested as a suitable countermeasure and many studies find a strong relationship between board independence and improved decisions in the firm (Byrd and Hickman, 1992; Gillette et al., 2003; Shivdasani, 1993). Some studies show that equity markets more favourably value companies whose boards have a higher proportion of outside directors (Borokhovich et al., 1996; Byrd and Hickman, 1992; Rosenstein and Wyatt, 1990; Weisbach, 1988).

Diverse resources of outside directors enable the firm to access many linkages and networks. Diversity opens the breadth and depth of knowledge from the varied experiences of the many directors. Borokhovich et al. (2004) suggest that this plays an important role when there is a conflict of interest between shareholders and management. While managers may have specific-industry related knowledge they may lack the broader knowledge and expertise related to derivatives that outside directors have access to (Borokhovich et al., 2004).

Outside directors are expected to be better monitors as they are free to make choices without worrying about any personal consequences regarding compensation or job position as is the case with the CEO and possibly other inside directors (Dionne and Trikki, 2005). Also, outside directors are more concerned with their reputation as effective monitors and so would maintain better control over management (Fama,1980; Fama and Jensen, 1983a; 1983b). Similarly, Cotter et al. (1997) and MacAvoy and Millstein (1999) find that board independence is positively related with firm performance. Hermalin and Weisbach (1988) assert that board composition largely determines the effectiveness of the board's monitoring. Outside directors have a more objective perspective of firm operations and so provide better internal control. Fama and Jensen $(1983 a ; 1983 b)$ indicate that independent boards have greater motivation to take decisions that profit shareholders. These directors are more 
concerned for their reputation in the labour market since they are generally important decision-makers in other organizations as well. Huang et al. (2013) study current boards that were non-compliant prior to 2002 and find that these non-compliant (nonindependent) boards increase risk.

In contrast other studies criticize the requirement for board independence and suggest that demands for board independence have caused problems with regard to board competence (OECD, 2009). Others contend that board independence (proxy for monitoring) is ineffective in the face of uncertainty and enhances the principal-agent conflict (Prendergst, 2000; Raheja, 2005). Kashyap et al. (2008) for instance, suggest that the focus on board independence may have reduced the level of expertise and with it the proper monitoring of risk. Ricol (2008) likewise suggests that considerations of board competence should be given preference over considerations of board independence and some point out that, "the question of independent directors might have been pushed too far" (Kirkpatrick, 2009, p.23) with disregard of capabilities. This may indicate that the independent directors could undermine the expertise that is needed for managing derivatives. Inside directors may have more affiliation, expertise and accountability in these firms and therefore may add more value.

Others indicate that there may be a trade-off between increasing shareholder returns through greater risk. Erkens et al. (2009) also suggest that during the crisis, boards with more independent directors encouraged management to raise more equity capital during the crisis that aggravated losses. As a result, firms with higher independent boards performed worse during the crisis. Additionally, with the increase of outside directors the costs of acquiring information increases (Raheja, 2005). There is continuous pressure on firms to reduce agency costs through applying proper controls (Vafeas, 1999) and some (McConnell and Servaes, 1990; Morck et al.,1988) suggest that insider directors are such a control and that increases firm value. Besides inside 
directors expedite the flow of valuable information to the board (Jensen, 1993; Raheja, 2005).

Klein (1998) examines board committees and finds a positive effect of inside directors on finance and investment committees, to accounting performance measures and stock market indicators. This is also evidenced when a firm increases the inside representation on committees when compared to a decrease in insider director percentage. Klein (1998) suggests that firms may need to reevaluate their committee composition to derive more value through insider representation. There are others that do not support the superior monitoring by independent boards (Subrahmanyam et al., 1997), over acquisitions (Harford, 2003), over CEO compensation (Core et al., 1999) and regarding earnings restatements (Agrawal and Chadha, 2005).

On the other hand, others suggest there may not be a strong effect for board independence. Bhagat and Black (1999) find that there is no correlation between board independence and long-term firm performance. Klein (1998) also finds little association between board composition and firm performance. Hermalin and Weisbach (2003) highlight the fact that in the literature there seems to be a lack of significant relationship between board composition and firm performance. They further suggest that board independence may not be very important for day-to-day actions by the board and may be more important in certain situations for example: "particularly those that occur infrequently or only in a crisis situation", (Hermalin and Weisbach, 2003, p.17).

Therefore, a priori, I hypothesize in null form: 
H03a: Board independence has no relationship with the value effect of derivatives

H03b: Board independence has no relationship with the risk effect of derivatives

\section{Does board diversity impact the value and risk effect of derivatives?}

Recent studies have emphasized the role of women on the boards. There are many countries that have made it mandatory to include gender diversity on boards. And gender diversity on boards improve board monitoring for example, Adams and Ferreira (2009) show that women tend to have lower attendance problems than men; a greater proportion of women on boards contribute to the increase in male director attendance; women sit on more monitoring committees than men; and gender diversity makes CEO's accountability and turnover more sensitive to stock returns. Therefore, gender diversity on boards make the boards tougher monitors.

Many researchers (Adler, 2001; Carter et al., 2003) suggest that there is a positive relationship between presence of women on boards and firm performance; that more women on boards seem to increase the reputation of the firm (Bernardi et al., 2006; Brammer et al., 2009); women directors have a positive effect on board decisions (Burgess and Tharenou, 2002; Campbell et. al 2008; Carter et al., 2003; Kang et al., 2007); and generally diversity as a whole impacts firm performance positively (Kramer et al., 2006; Ramirez, 2003; Sellers, 2007). Diversity would be especially pertinent to hedging decisions when these are determined by a dominating group in the board. Harjoto et al. (2014) also suggest that board diversity (including gender

diversity) exhibits more risk aversion with lower capital spending and lower stock return volatilities. They suggest that increase in board diversity would contribute to better risk management. 
Researchers have taken an interest in gender in their examination of overconfident investor models. Odean (1998) suggests that overconfident investors believe that their assessments are more accurate than others assessments, exaggerate the returns they expect, and utilize too much of time and money on investment information which leads to conflicting views. As a result of this they would be involved in more trading activities (Harris and Raviv, 1993; Varian, 1989). While both genders display overconfidence behaviour, men are more overconfident (Deaux and Farris, 1977; Lundberg et al., 1994) and especially in financial matters (Prince, 1993). Gervais and Odean (1999) see this overconfidence stems from "self-serving attribution bias" (Barber and Odean, 2001, p. 265) and many (Beyer, 1990; Deaux and Farris, 1977; Meehan and Overton, 1986) observe that this characteristic is more prevalent in men. Barber and Odean (2001) show that men trade $45 \%$ more than women and that this reduces their profits by 0.93 percentage points per year, more than women.

Others support the view that board diversity decreases risk as women are more risk averse than men (Byrnes et al., 1999) and when delving in lotteries and money matters they show an inclination to discourage risk taking (Fehr-Duda, et. al, 2006; Levin et al., 1988; Powell and Ansic, 1997). Women are also more reserved in their investment decisions (Bernasek and Shwiff, 2001; Sunden and Surette, 1998) and the number of women directors on boards is negatively related to firm bankruptcy (Wilson and Altanlar, 2011). Adams and Ferreira (2004) document that firms exhibiting higher stock return volatility have lower proportion of female directors (Also see: Farrell and Hersch, 2005; Hillman et al., 2007). Women are risk averse and may shirk from taking decisions involving risk or it may stem from a lack of confidence (Barber and Odean, 2001).

Therefore, I predict that women on boards provide better monitoring of hedging activities of the firm and I posit: 
H4a: Female representation on boards increases the value effect of derivatives

H4b: Female representation on boards reduces the risk effect of derivatives

\section{Does board composition and structure: diligence, size, independence and diversity, influence the use of derivatives?}

Researchers assert that outside directors provide better monitoring and advice to the firm (Fields and Keys, 2003). There are only a few studies that examine the impact of boards on derivatives, and none that investigate the monitoring effects of board meetings and board diversity.

Borokhovich et al., (2004) study the monitoring effects of board's composition on interest rate derivatives. The directors are classified into six categories: inside directors, outside directors, gray directors (comprising bank executives, lawyers, consultants, and insurance company executives in the manner of Weisbach 1988), bank executives separately, outside directors less inside directors and total number of directors on the board. Their results show that boards with higher independent directors would use more interest rate derivative instruments for risk management signifying that these directors take a more vigorous role in hedging decisions. However, none of the other board variables are significant and the authors contend that there are two circumstances under which board composition would impact on derivatives. Firstly, if there is a conflict between management and shareholders then the dominating group will influence the use of derivatives. Secondly, if management lack expertise in the management of derivatives or it is lower than that of outside directors, then the board of directors would intervene and play an active role in the hedging activities. Their findings suggest that outside directors do significantly influence the firms' decisions to hedge with interest rate derivatives. Dionne and 
Trikki (2013) study the determinants of risk management through a model that examines hedging and capital structure decisions simultaneously. They also find that outside directors appear to increase hedging.

In a recent study that examines the exogenous impact of the NYSE/NASDAQ listing rule changes, Huang et al., (2013) find that the increase in independence on boards reduces financial hedging. However, they reject that it is due to lack of knowledge but suggest better monitoring resulting in reduced financial hedging. Therefore, here a reduction in hedging stems from stronger corporate governance.

Marsden and Prevost (2005) examine the impact of legislative change on New Zealand listed companies in 1994 and 1997. They find that companies with higher growth opportunities and more outside directors (after introduction of the new 1993 Companies Act) reduce derivatives. They suggest that it demonstrates that internal governance mechanisms play a role in corporate derivatives policy, and that regulation/legislation may affect this role.

The limited research available on the relationship between board of directors and risk management does not provide any basis to positively conclude the direction of the relationship. Therefore a priori, I hypothesize in null form that:

H05a: There is no relationship between board size and derivatives

H05b: There is no relationship between board meetings and derivatives

H05c: There is no relationship between board independence and derivatives

H05d: There is no relationship between board diversity and derivatives 


\subsection{Hypotheses Development - Shareholders}

\section{Does insider shareholding impact the value and risk effects of derivatives?}

"There will be some divergence between the agent's decisions and those decisions which would maximize the welfare of the principal" (Jensen and Meckling, 1976, p. 482) and agency conflicts arise from this difference between shareholders and managers. Research indicates that managers implement hedging programs out of their own personal objectives at the cost of shareholders (Beber and Fabbri, 2005; Dhanajarata et al., 2010; Dolde, 1993; Faulkender, 2005; Geczy et al., 2007). While others propose that when insiders own significant shareholding they become entrenched as they are able exert substantial influence to guarantee their jobs (Demsetz, 1983; Fama and Jensen, 1983a, 1983b; Gibbs, 1992).

Allayannis et al. (2012) investigate whether corporate governance creates value for firms using derivatives. They split their sample into strong and weak governance and find that strongly governed firms use currency derivatives to increase value. The governance index for strong governance assumes the absence of insider shareholding. Therefore, they imply that the absence of managerial shareholding makes for stronger governance and leads to an increase in value. Insiders would have different objectives for hedging as compared to outsiders that would affect the firm's use of derivatives and adversely impact on firm performance (Allayannis et al., 2009). Insiders do not bear the risks of their decisions and they may be prone to use derivatives for their own personal reasons adversely affecting firm value. Further, managers that have inferior abilities may hedge in order to save their reputations and camouflage their abilities, in order to create confusion with regard to their impact on firm performance. Therefore, they would be motivated not to implement effective risk management strategies within the firm. 
McConnell and Servaes (1990) suggest that that insider ownership exacerbates the entrenchment problems and Short and Keasey (1999) also confirm the entrenchment effect of management in United Kingdom firms. Fauver and Naranjo (2010) examine a non-linear relationship between insider shareholding and Tobin's Q in relation to derivatives, and find that insider ownership impacts derivatives to reduce firm value.

Some do not any find any relationship between managerial ownership and firm performance (Himmelberg et al., 1999). Others suggest there is a non-monotonic relationship between insider shareholding and firm performance, exhibiting a value increment when insiders have low ownership, but a decrease in value with a higher shareholding (Stulz, 1988). With respect to risk too researchers take a non-monotonic approach and suggest that smaller shareholding induces higher risk-taking which reduces when the insider ownership expands (Amihud and Lev, 1981; Wright et al., 1996).

Therefore, firm risk may fluctuate according to the already existing level of shareholding.

Therefore, I posit:

H6a: Higher percentage of insider shareholding reduces the value effect of derivatives

H06b: Percentage of insider shareholding has no relationship with the risk effect of derivatives 


\section{Does institutional shareholding impact the value and risk effects of derivatives?}

Erkens et al. (2009) suggest that corporate governance may have pressured management to take short-term actions to increase short-term profits irrespective of the increase in risk. They find that institutional investors focus on short-term performance and bonus plans as opposed to long-term strategies. This has induced corporate managers to take more risk, resulting in larger losses. The authors suggest that firms with more institutional shareholders encouraged managers to take greater risk in their investment policies just before the crisis. Their results show a negative relationship between boards with large institutional shareholders and stock returns. Their findings suggest that firms with higher institutional shareholding assumed greater risk before the crisis that resulted in greater shareholder losses during the crisis. Fauver and Naranjo (2010) also find a negative effect for institutional shareholders on Tobin's Q with respect to derivatives, which however becomes positive when they take the non-linear measure.

Large institutions exhibit granularity, i.e. they differ from smaller independent firms in that they have a distinct institutional presence in the markets. David et al. (2015) examine the trading trends of large institutions and compare them with trading by smaller firms. They indicate that institutional investors increase stock price volatilities that is specifically related to the trading shocks of large institutions. Due to this granular nature and their market presence, large institutions trade less with the objective to diversify risk than other smaller firms and have a strong positive impact on stock return volatility in firms (David et al., 2015).

Others also support the theory that institutions: cannot easily diversify their idiosyncratic risk (Gabaix, 2011); increase market volatility (Gabaix et al., 2006); impact CDS contracts prices when financially constrained (Siriwardane, 2015); and 
impact the behaviour of small traders (Corsetti et al., 2004). Large institutions can also impact asset prices (Barberis et al., 2005; Coval and Stafford, 2007; Greenwood, 2005; Shleifer, 1986; Baker et al., 2011). While, Ferreira and Laux (2007) find evidence of institutions trading activities through merger arbitrage and speculation that increases idiosyncratic risk for firms. However, the risk seems to diminish when the governance effect is removed.

In view of the above, I expect to see a risk-enhancing effect of institutional shareholders in a derivatives environment. Therefore, I posit:

H7a: Higher percentage of institutional shareholding reduces the value effect of derivatives

H7b: Higher percentage of institutional shareholding increases the risk effect of derivatives

\section{Does block holder shareholding impact the value and risk effects of derivatives?}

Block holders are required to file Schedule 13 with the SEC upon acquiring at least 5\% ownership. Block holders are well informed about the firm and implement this information into stock price trading. Many suggest that they negatively affect stock prices through block selling of shares (Kraus and Stoll, 1972; Mikkelson and Partch, 1985; Scholes, 1972; Sias et al., 2006). This decline in value could be a result of block holders off-loading firm's shares which sends a signal to the markets that these informed investors consider firm value to be lower (Dou et al., 2014). 
Belghitar et al. (2011), Heflin and Shaw (2000) and O’Neill and Swisher (2003) contend that more institutional block holders engender higher information asymmetry in the markets, as they lower the degree of informed trading. Elbadry et al. (2015) suggest that while large shareholders can closely monitor management, at the same time they have the power to get managers to act in their best interest to the detriment of other shareholders. This creates uncertainty and insecurity among shareholders that could lead of uncertainty in share prices and higher volatility. Their results indicate a significant positive relation between asymmetry and ownership concentration.

Erkens et al. (2012) also study large shareholders and though they do not find a relationship for the firm value measures, block ownership appears to positively impact stock return volatility, endorsing that block holders increase firm risk.

In keeping with the above studies, I expect to see an increased risk effect by large shareholders, and therefore I hypothesize:

H8a: Higher concentration of ownership reduces the value effect of derivatives

H8b: Higher concentration of ownership increases the risk effect of derivatives

\section{Do institutional, block holder and insider shareholdings influence the use of derivatives?}

Firms can use derivatives for speculation or selective hedging and governance provides a monitoring role to discourage such behaviour. Therefore, well governed firms would not use derivatives for such purposes (Lel, 2006; 2012). Firms do not 
appear to hedge optimally (Huang et al., 2013) and may selectively hedge risk exposure (Faulkender, 2005). Allayannis et al. (2003) document that firms during the East Asian crisis did not hedge interest rate risk on their foreign loans. Bodnar et al. (1998) also provides evidence of this as they find that managers in the US incorporate their own personal views in hedging activities. Huang et al. (2013) suggests that agency problems lead some firms to hedge too much and better governed firms to reduce hedging in order to increase shareholder value. Further they suggest that hedging practices greatly depend on whether firms were over-hedging or underhedging previously (before and after SOX in their study).

Many do not find any significant relationship for these components. Borokhovich et al. (2004) examine total insider ownership, total block holdings and bank block holdings using a S\&P 500 sample of firms on the effect on interest rate derivatives. They do not obtain significant results for any of these variables. Similarly, Marsden and Prevost (2005) do not find any significant effect for block holders and managerial shareholders on derivatives in New Zealand firms. Fauver and Naranjo (2010) too, find that institutional ownership and insider ownership have no significant impact on derivatives decisions by the firm.

Lel (2012) examines foreign currency derivatives with respect to strong and weak governance. The author finds that inside ownership increases foreign currency derivatives in weakly governed firms but reduces their use when corporate governance is stronger. Further, he suggests that managers in weakly governed firms use derivatives more when they hold more of their personal wealth in firms as stock. Hedging due to managerial motives is harmful to shareholders and indicates that when managers' actions are unchecked they may use derivatives differently. 
With respect to insider ownership there are two important theories to consider: the managerial utility-maximizing hedging theory and shareholder value-maximizing theory. Lel $(2006$; 2012) suggests that a firm's derivatives decisions are consistent with the managerial utility-maximizing hedging theories and selective hedging motives when firms are inadequately governed. It appears that shareholder valuemaximizing theories of hedging are less important in weakly governed firms and managerial utility-maximizing theories are less important in strongly governed firms. The author indicates that strong governance may not automatically use more derivatives, but use them more to the benefit shareholders. Therefore, Lel (2006) concludes that in stronger governed firms inside ownership would not result in either an increase or decrease in derivatives by the firm.

Allayannis et al. (2009) examine the effect of strong internal corporate governance and weak corporate governance on foreign currency derivatives. Their results indicate that outside ownership (for both high and low concentrations) increases derivatives. Though the coefficient for high outside ownership is larger. Also lower inside ownership increases hedging within the firm, while higher insider ownership does not seem to impact hedging.

When Allayannis et al. (2009) compare institutional ownership within strongly and weakly governed firms, they find that institutional ownership increases foreign currency derivatives hedging when governance is strong and has no effect for weakly governed firms. At the same time high managerial (largest block holder) cash flow rights in strongly governed firms increase foreign currency derivatives hedging, though results are significant only at a $10 \%$ significance. They conclude that in firms with strong governance structure, hedging adds a value premium. 
In keeping with Allayannis et al. $(2009,2012)$ I predict that institutional and large block holder ownership would increase the use of derivatives which could be aligned with their intent to increase short term profits or to further their own interests. I expect that inside ownership will also increase hedging selectively to further their selfinterest. In the manner of Allayannis et al. (2009) I expect to see that reduced managerial ownership will result in increased hedging and be more aligned with the objectives of the other shareholders.

Therefore, I hypothesize that:

H9a: Larger concentration of institutional shareholders increases derivatives

H9b: Larger concentration of block shareholders increases derivatives

H9c: Lower concentration of insider shareholders increases derivatives

\subsection{Hypotheses Development - CEO Executive Remuneration}

There is a plethora of research that examines the effects of options and stockholdings on risk management in support of the theory of managerial risk aversion. I am interested in investigating executive compensation structure as a corporate governance mechanism that provides a disciplining and monitoring impact on the risk behaviour of executives. I do not take separate measures for the options and shares components of managerial compensation, but examine the impact of total compensation, bonus compensation and basic salary to study their impact on the CEO's risk management effectiveness. 


\section{Does CEO age and tenure impact the value and risk effects of derivatives?}

Management that have a long tenure would indicate an absence of governance problems and higher abilities, as otherwise they would have been removed and have continued only due to their better performance (Hermalin and Weisbach 1991). Alderfer (1986) also suggests that it takes time to understand the company and therefore longer tenured CEOs display a greater understanding of the firm and industry that therefore translates to higher performance. Thus older CEOs with more experience and knowledge in the related industry should provide better monitoring and management of firm operations and over the firm's strategies and policies.

Some see the length of tenure of board and top management as another measure of underlying agency problems. There is a consensus that a CEO should not serve for too long and a period of ten years seems optimal (Vancil, 1987). This relates to the entrenchment theory that suggests longer serving CEOs become contented and may lose the ability to adapt to situations occurring in the longer term. Also, a longer tenure could indicate a desire for power and control. Therefore, CEO age and CEO tenure both capture the entrenchment problem and literature associates CEO age with problems of wealth myopia and CEO tenure with short-term horizon problems. The association of CEO age (and therefore performance) is stronger when the CEO is approaching retirement (Cheng, 2004).

Managers have a limited employment tenure and when they approach retirement they may engross in more unethical and biased behaviour (Berger et al., 1997; Lewellen et al., 1987). CEO's near retirement are not disciplined and therefore have a greater incentive to look for ways to increase their compensation (Gibbons and Murphy, 1992). $\mathrm{Xu}$ (2011) finds that CEO tenure is positively associated with capital expenditure and research and development expenditure, and CEOs do not perform 
better when they have a shorter horizon and an influence on investment. Their findings also seem to affect the risk-taking behaviour of CEOs, as shorter horizons seem to decrease investments.

In contrast younger CEOs are more concerned with career growth and so would be more aligned with shareholders' objectives (Fama, 1980; Gibbons and Murphy 1992). Also, older CEOs may have more personal wealth and would be more prone to take risk and as they lack the incentives provided to younger CEOs in the job market which would contribute more myopic decision-making (Lewellen et al., 1987).

Therefore, I posit:

H10a: Older CEOs reduce the value effect of derivatives

H10b: Older CEOs increase the risk effect of derivatives

Dechow and Sloan (1991) advise that though older CEOs may enhance performance, there is a possibility that CEOs in their final years of service are more prone to manage short-term earnings. Therefore, they suggest that CEO horizon would be a more important factor than tenure, as CEOs would respond differently to firm performance depending on where they stand with respect to their horizon. Since those CEOs nearing retirement would be more prone to manipulating earnings.

Hermalin and Weisbach (1991) use different levels of CEO tenure to examine their effect on Tobin's Q. They find that at low levels CEO tenure does not affect profitability, however, when CEO's have been in service for more than 15 years, it reduces profitability. Hermalin and Weisbach (1991) suggest that at lower levels of 
ownership, an increase in ownership improves both the effects of stock ownership and CEO tenure on firm performance. But beyond the $1 \%$ ownership, performance declines because CEOs are more insulated against disciplining devices and therefore less aligned to the interests of shareholders. This indicates that the effect of CEO tenure on firm performance would differ according to where the CEO stands with respect to his total job horizon.

Therefore, a priori, I hypothesize in null hypothesis that:

H010c: CEO tenure has no relationship with the value effect of derivatives

H010d: CEO tenure has no relationship with the risk effect of derivatives

\section{Does CEO age and CEO tenure impact derivatives?}

There is no literature (in the knowledge of the author) with respect to derivatives that examines the relationship of CEO's entrenchment, short-term horizon and myopia problems, through CEO age and tenure, on risk management. Therefore, I do not make any predictions regarding to the direction of CEO age and CEO tenure with derivative. And, a priori, I hypothesize in null form that:

H010e: There is no relationship between CEO age and derivatives.

H010f: There is no relationship between CEO tenure and derivatives 


\section{Executive Remuneration: Does executive remuneration impact the value and risk effects of derivatives?}

Compensation is a corporate governance tool with which to monitor and channelize the behaviour of management. An effective board would be able to design an optimal pay package to engender the required CEO performance, however, where agency problems exist, CEOs are able to obtain higher pay packages and record underperformance (Core et al., 1999). Bebchuk and Fried (2003) contend that executive compensation may be as much a part of the agency problem as an instrument of corporate governance for addressing this problem.

There has been a continuing debate whether CEO compensation is reasonable (Murphy, 1999). Many have questioned the effectiveness of the excessive pay to suggest that compensation systems are flawed and indicative of deficient corporate governance structures, as even when the firm has low earnings and poor stock market returns, executives receive large annual pay (Bebchuk and Fried, 2004). Compensation packages are not linked to performance and there is criticism about the lack of restraints on the exercising of stock options and off-loading of shares (Core and Guay, 2010). While Dittman and Maug (2007) advocate that CEOs should not hold any stock options, have lower base salaries and receive additional shares in their companies. They suggest that the current compensation practices have many deficiencies. Additionally, contracts based on fixed salaries and restricted stock alone cannot prevent the CEO from making inefficient investment decisions (Dybvig and Zender, 1991).

Some researchers suggest that stocks reduce volatility, while options increase volatility (Rajgopal and Shevlin, 2002; Schrand and Unal, 1998). Stronger equity incentives are associated with less risk taking, whereas portfolio convexity due to 
options encourages more risk taking (Coles et al., 2006; Guay, 1999; Lewellen, 2006; Tufano, 1996). Risk tolerance in executives is positively related to incentive pay levels and there is also a concern that incentive compensation encourages managers to manipulate performance measures (Benmelech et al., 2010; Bolton et al., 2006; Goldman and Slezak, 2006) and some attribute it to the options component and some to the stock component of compensation. Chesney and Asner (2004) also indicate that managers will always have an incentive to cheat and stock options provide a greater incentive to cheat than a compensation structure comprising cash equivalent remuneration and stocks.

There may be a gap between the attitude of shareholders and managers to risk. Shareholders generally are able to diversify the risks in their investment portfolios, however, it is more difficult for managers to do so. Researchers suggest that managers are risk averse and therefore would prefer to take actions that reduce their own compensation risk (Amihud and Lev, 1981; Jensen and Meckling, 1976) and this in turn can detrimentally affect shareholder wealth (Mehran, 1995). Therefore, shareholders would seek to align their interests with those of the managers by providing the right incentives. If compensation is effective, it would enhance firm value and managerial performance. Tying performance to compensation compels managers to make more value-maximizing decisions (Grossman and Hart, 1983; Harris and Raviv, 1979; Holmstrom, 1979). Some indicate that incentive based compensation plans would motivate managers to take on more risk and many find that the impact of CEO pay on shareholder return is large and significant (Boschen and Smith, 1995; Jensen and Murphy, 1990; Joskow and Rose, 1994) while Smith and Stulz (1985) indicate that options are essential to encourage CEOs to take risky projects that increase value and risk. 
Murphy (1999) suggests that stock-based compensation accounts for most of the variation in executive wealth. However, accounting performance is an important measure, as CEOs better understand how their actions affect accounting profits but are less sure about the outcome of their actions on shareholder value. The authors suggest that CEOs would naturally devote their efforts on increasing accounting bonuses that they understand than focus on efforts to increase stock price. Most executive compensation comprises four main components: a basic salary, annual bonus which is linked to accounting performance, stock options and long-term incentive plans. Murphy (1999) suggests that base salary is a key component of contracts, mainly because components of compensation are measured in relation to base salary levels. Target bonuses, option grants defined pension benefits and severance pay all depend on the basic salary structure and so this is important. And, most companies use accounting measures to gage the CEO performance.

With respect to firm risk, Erkens et al. (2009) study CEO annual bonuses and focus less on long-term equity-based compensation. They find evidence that these compensation components encourage a short-term focus and the annual bonuses are associated with increased risk taking. They further suggest that some pay should be withheld until the fruition of investment strategies in order to implement a more longterm focus. Others suggest that compensation structure will impact unsystematic risk if it has a relationship with management performance, and suggest a positive relation between firm specific risk and the use of incentive compensation (Harvey and Shrieves, 2001; Lippert and Moore, 1994). Incentive compensation is less effective when the stock price fluctuation is not under the CEO's control, such as systematic risk (Harvey and Shrieves, 2001). Lewellen et al. (1987) also do not find any association between incentive compensation and beta, but a strong positive relationship for stock return variance. Jin (2002) finds a robust relation between firmspecific risk and level of compensation but no significant relationship between systematic risk and level of incentives. While, Skaife et al. (2006) document that 
CEO's of firms that possess more speculative credit ratings are largely overcompensated as compared to firms with investment-grade ratings. Therefore, it would indicate that CEO compensation may have a positive association with speculative activities.

It appears that derivative users would be more prone to speculation when compensation is benchmarked against profits rather than risk management (Geczy et al., 2007). If speculation increases of cash compensation such as bonuses, and when compensation stock price sensitivity is higher than the options sensitivity, then CEOs would tend to enhance speculation. Geczy et al. (2007) suggest that without proper monitoring and effective controls, management would take excessive risks with derivatives.

Management is generally risk averse and would only take risky decisions when they benefit, and would avoid taking risk from which they reap no benefits. CEO compensation would be designed to reduce CEOs risk aversion so that they invest in risky projects that provide benefits for shareholders. Therefore, boards would ensure compensation is structured such that management are induced to take high risk projects with high return and increased shareholder value. Whether speculation relates to corporate governance failure (as indicated above) or stronger governance evidenced through better internal controls (Geczy et al., 2007) is not clear. Also, a dichotomy exists whether risk taking by managers is more in line with shareholders' objectives (strong governance), or detrimentally aligned to manager self-interest.

Either way, I expect to find a strong relationship between CEO compensation and risk management activities. Therefore, with respect to CEO total compensation, I hypothesize that: 
H11a: CEO total compensation increases the value effect of derivatives

H11b: CEO total compensation increases the risk effect of derivatives

As described above, CEO bonus would vary depending on whether options, stocks, or cash awards dominate. Consequently, I do not make any predictions in regard to the direction of the relationship between CEO bonus and firm risk. Therefore, I hypothesize that:

H11c CEO bonus increases the value effect of derivatives

H011d CEO bonus has no relationship with the risk effect of derivatives

With respect to base salary I posit that:

H11e: CEO salary increases the value effect of derivatives

H11f CEO salary increases the risk effect of derivatives

\section{Does CEO compensation influence the use of derivatives?}

Essentially managers take risk decisions in line with what would further their own interest. Stulz (1984) argues that hedging is the outcome of managers' aversion to risk. While the other shareholders may have the capability to diversify their portfolio in order to minimize their risk, this is not the case with managers who hold large amount of shares in the company.

Managers have the need to hedge to decrease risk and their portfolio price variance. 
Therefore, if their own cost of hedging is higher than the cost of hedging for the firm, then managers will hedge (Smith and Stulz, 1985; Stulz, 1984; Tufano, 1996). If managers have larger stock holdings compared to those with options, they would prefer to hedge their risks, because stocks have linear payoffs while options have convex payoff (Smith and Stulz, 1985). Options contracts may thus induce the managers to take greater risk because greater volatility would increase the value of the options contracts. Most of the researchers therefore use closely held shares and options owned by managers as a proxy to test the managerial risk aversion hypothesis (Berkman and Bradbury, 1996; Nguyen and Faff, 2002; Rajgopal and Shevlin, 2000; Tufano, 1996) and generally find a negative relation with hedging.

In this context, a review of the theories related to managerial utility and wealth convexity and concavity is important. When an investor has a convex utility function he derives a larger proportional increase in satisfaction for each unit increase in wealth. Therefore, convex utility investors would be termed as "risk-seeking investors". On the other hand, if the investor reflects a concave utility function, i.e. the marginal utility of wealth decreases as wealth increases, such investors would be "risk averse". Managers are largely risk averse. Graham and Rogers (1999) indicate that stock options introduce "convexity between managerial wealth and stock value which offsets the concavity in the manager's utility function" (p. 11). This causes managers to become less risk averse and therefore reduce the need to hedge to protect wealth. Therefore, CEO options would have a negative impact on hedging. However, the authors indicate that common stock has a linear relationship with firm value and would therefore not reduce the concavity of the manager's utility function, or risk aversion. Therefore, this would induce managers to increase hedging activity.

Research indicates that managerial hedging is focussed toward the increase in managers' wealth and compensation at the cost of shareholders. With increased 
hedging related to stockholding compensation, and decreased hedging related to stock options, providing the greatest benefit for managers. As indicated in the literature and in the manner of Graham and Rogers (1999), I expect that option awards will have a negative effect and stocks a positive influence on the derivatives. Therefore, depending on the dominating effect of either shares or options, the direction of the relationship of CEO total compensation and CEO bonus with derivatives will vary.

Therefore, I hypothesize that:

H12a: There is a positive relationship between CEO salary and derivatives

H012b: There is no relationship between CEO bonus and derivatives

H012c: There is no relationship between CEO total compensation and derivatives

\subsection{Hypothesis Development - Audit Committee}

\section{Does Audit Committee size impact the value and risk effects of derivatives?}

Audit committee size appears to be the most important audit committee characteristic as it synthesizes all the other attributes (Dhaliwal et. al., 2006) including independence, resources and expertise. Lin et al. (2006) find that increased audit committee size enhances monitoring of the financial reporting process and thereby improves quality of earnings. Others suggest that larger audit committees command more power, status and resources, and therefore provide better monitoring (Kalbers and Fogarty, 1993) and are better placed in detecting problems and fraud (Pincus et al., 1989) and this would result in better internal control. There are two implications with regard to larger audit committees: 1) larger size would indicate more resources 
for better monitoring and 2) it would also indicate access to higher level of financial expertise as all members are required under the new rules to have or equip themselves with some accounting or financial expertise, thereby enhancing the quality of monitoring. Archambeault and DeZoort (2001) contend that larger committees will have access to more experience and larger knowledge base that will enable them to resolve problems without having to depend on outsourcing consultancy services. Similarly, Anderson et al. (2004) find that audit committee size reduces the cost of debt financing indicating a reduction in risk.

The evidence of audit committee size on the firm is mixed. Abbott et al. (2004) find no significant relationship between audit committee size and earnings restatements. Similarly, Mangena and Pike (2005) also do not find any relationship between number of members on the audit committee and interim financial disclosures. However, the sign of the coefficient is negative which they suggest may weakly support the fact that smaller committees improve financial reporting. Likewise, Bedard et al. (2004) and Xie et al. (2003) find no significant relationship between audit committee size and earnings management. While Yang and Krishnan (2005) find a negative relationship between audit committee size and earnings management to indicate that a minimum number of members may influence financial reporting. Chan and Li (1996) results indicate a negative association between audit committee size and Tobin's Q.

Many researchers have suggested that smaller groups provide better group dynamics and synergy, and higher firm value (Yermack, 1996) evidenced through more conducive communication and coordination (Jensen, 1993). Braiotta (1999) and DeZoort et al. (2002) suggest that audit committees should be contained enough to enable valuable dialogue and deliberation between members, but large enough to benefit from their resources. Sharma et al. (2009) find a positive relationship between frequency of audit committee meetings and audit committee size. And, higher audit 
committee meetings frequency has a negative association with independence, but a positive relationship with both independence and financial expertise when there is a higher risk of misreporting. Therefore, larger size and a larger frequency of meetings may have a detrimental effect on the governance impact of the audit committee.

Based on the above, I hypothesize that:

H13a: Smaller audit committees increase the value effect of derivatives

H013b: Audit committee size has no relationship with the risk effect of derivatives

\section{Does Audit Committee size influence the use of derivatives?}

There is a dearth of literature that examines the correlation between audit committee size and hedging. One such study conducted by Dionne and Trikki (2005) investigates whether the NYSE (and SOX) requirements for publicly listed companies to have a minimum of three members is valid and contributes to better risk management. They find support for the argument that audit committees with at least three members would induce increased hedging by the firm. However, unlike Dionne and Trikki (2005), I study the impact of audit committee size and use the total number of audit committee members as a proxy.

Therefore, a priori, I hypothesize in null form:

H13d There is no relationship between audit committee size and derivatives 


\subsection{Chapter Summary}

This chapter provides the theoretical framework for the study and explains the links between corporate governance, derivatives, firm value and firm risk, based on agency theory and financial derivatives-hedging framework. With reference to the theoretical framework, this chapter develops the hypotheses predicting the relationship between the four main variables. As explained in the introduction, this research does not develop any assumptions with respect to strong or weak governance. It examines the impact that corporate governance has on derivatives, and the impact of governance on the effect of derivatives on firm value and firm risk.

Firstly, the study hypothesizes on the impact of corporate governance on the value effect of derivatives. Secondly, hypotheses on the impact of corporate governance on the risk effect of derivatives is developed. Lastly, hypotheses are developed with respect to the relationship between corporate governance and derivatives.

At the end of this section I provide a summary of the hypotheses presented in this chapter. In the subsequent chapter, I discuss the research methodology including the sample selection process, measures for the dependent, independent and control variables and quantitative analyses and the regression models that will be employed to test these hypotheses. 


\section{CHAPTER 5: SAMPLE, DATA AND RESEARCH METHODOLOGY}

\subsection{Introduction}

The previous chapter delineates on the theoretical framework and development of hypotheses. Chapter 5 extends on this and provides specifics of the research methodology applied in the study including sample selection, measurement of variables, regression models and sensitivity analyses. This study basically comprises two data sets: one for examining the impact of corporate governance on the value and risk effects of derivatives; and the other for testing corporate governance effect on derivatives. On this basis, the following sections are further subdivided.

This chapter comprises thirteen main sections. Section 5.2 describes details of the period of study and the different databases that were accessed. Section 5.3 explains the sample selection process for the derivatives model, and the value and risk models. This is followed by Section 5.4 where I discuss the procedure involved in collecting data on derivatives and their measurement. Further in Sections 5.5 and 5.6, I provide the basis for selection of the other dependent variables, firm value and firm risks, and an explication of their measurement techniques.

The process for selection of the corporate governance variables is outlined in Section 5.7. This section is further sub-divided into nine sections that describe the thirteen corporate governance variables used in my research. Further, Section 5.8 outlines the control variables used in the value and risk models, followed by description of the controls that are applied in the derivatives model in Section 5.9. Under each section I explain the bases for each explanatory and control variable, drawing support from literature. This is followed by tables that provide definitions of the variables, sources of data and database codes. Further, in Section 5.10 the regression models of the study 
are presented and this is followed by Section 5.11 that describes the research methodology used to test these regression models. In the end in Section 5.12, I provide a review of the robustness tests and alternative tests used to support the main results of my analysis. Finally, Section 5.13 provides a summary of the chapter.

\subsection{Study Period}

The population for this study comprises non-financial companies listed on the New York Stock Exchange (NYSE) for the period from 2004 to 2011. Non-financial firms are of interest in this study as the primary objective of these firms is to use derivatives

for hedging purposes. The study utilizes an unbalanced panel of firms consisting of 6234 and 6900 firm year observations to examine the relationships between corporate governance, derivatives and firm performance. The data has been derived from the Bloomberg, WRDS Corporate Library, Direct Edgar and WRDS Compustat databases which are defined in Tables 5.3 and 5.4.

\subsection{Sample Selection and Data}

The initial sample period included data for 2003. However, as data for one corporate governance variable - block shareholders was not available, therefore this year was dropped. Further banks and other financial institutions are excluded from the sample since these entities trade in derivative instruments as part of their business and therefore may not exhibit hedging behaviour. All insurance companies are also eliminated to achieve a total exclusion of North American Industry Classification System (NAICS) No. 52 firms. NAICS 52 comprises firms under the Finance and Insurance industry classification: "This sector comprises establishments primarily engaged in financial transactions (that is, transactions involving the creation, 
liquidation, or change in ownership of financial assets) or in facilitating financial transactions". NAICS Code (2007).

I compile two different data samples for: a) Value and Risk models and b) Derivatives model.

\subsubsection{Value and Risk Models}

Table 5.1 panel A outlines my sample selection procedure. Firstly, as at November 2012, I collect sample of non-financial companies listed on the NYSE. I use a list of companies listed on NYSE at end of financial year 2008. I choose 2008 to ensure that my sample has a larger number of firms prior to and subsequent to the financial crisis. Using this sample of firms, I collect data covering period of 2003-2011 which comprises 2741 firms over 9 years to total 24,669 firm year observations. This initial sample from NYSE is taken from the Bloomberg database. However, the Central Index Key (CIK) information for the firms is gathered from the WRDS Compustat database as Bloomberg database does not provide this information. CIK numbers are used on the Securities Exchange Commission's (SEC) computer systems to identify corporations and individual people who have filed disclosures with the SEC. These CIK numbers are necessary for collecting further data from Direct Edgar and the Corporate Library databases.

Secondly, I collect data pertaining to derivatives from the SEC 10-K statements available on the Direct Edgar database. I apply the Direct Edgar filter and extraction software to the SEC 10-K filings over the period 2003-2011 and extract data on firms that use derivatives. The detail process is described under Section 5.4. 
Thirdly, I delete the missing observations for all dependent, independent and control variables, taken from Bloomberg database and therefore eliminate 6,984 observations leaving a total sample of 14,592 observations. The combining of different risk and leverage variable measures significantly affects the sample size at this point.

Lastly, I collect corporate governance data from the WRDS GMI Ratings, Corporate Library database by matching data available for my companies against the individual CIK numbers. The Corporate Library has four different datasets: a) CEO b) Companies c) Directors d) Takeover Defenses. I gather data pertaining to board of directors (BOD) from the "Companies" dataset. However, I also include additional data available from the Bloomberg database for BOD size and BOD meetings. I further collect data related to shareholders also from the "Companies" dataset. CEO information is taken from the "CEO" dataset and this further reduces the sample by 2781 observations.

Audit Committee information is not directly available on the Corporate Library database. Therefore, I consolidate the information pertaining to audit committee size from the "Directors" dataset that provides information on each individual directorship for each company. I use a pivot table to extract information about the directors who are members of the audit committee.

Table 5.1 panel B provides year-wise information and panel $\mathrm{C}$ shows the industry breakdown of data for the value and risk models. The final sample consists of 6234 firm-year observations comprising an unbalanced panel with a minimum of 129 firms in 2004 and maximum of 1492 firms in 2010. 
Table 5. 1: Derivation of Sample and Industry Category - Value and Risk

\section{Panel A: Sample Derivation}

Number of

Observations

Sample from NYSE from 2003-2011

24669

Less year 2003

Less insurance companies

Full sample prior to deleting missing variables

21576

Less missing observations for all dependent and independent variables (excluding corporate governance variables)

Full sample prior to deleting corporate governance variables

Less missing BOD observations

Less missing CEO observations

Less missing Shareholder observations

Less missing Audit Committee observations

Final sample

6234 
Panel B: Sample Firms Year-wise

\begin{tabular}{|c|c|c|}
\hline Year & No.of firms & $\begin{array}{c}\% \text { of } \\
\text { sample }\end{array}$ \\
\hline 2004 & 129 & 02.07 \\
\hline 2005 & 369 & 05.92 \\
\hline 2006 & 652 & 10.46 \\
\hline 2007 & 199 & 03.19 \\
\hline 2008 & 1016 & 16.30 \\
\hline 2009 & 1470 & 23.58 \\
\hline 2010 & 1492 & 23.93 \\
\hline 2011 & 907 & 14.55 \\
\hline Total & 6234 & 100 \\
\hline \multicolumn{3}{|c|}{ Panel C: New York Stock Exchange Industry Categories of Sample Firms } \\
\hline Industry & $\begin{array}{l}\text { No.of } \\
\text { firms }\end{array}$ & $\begin{array}{r}\text { \% of } \\
\text { sample }\end{array}$ \\
\hline Agriculture and Forestry & 24 & 00.38 \\
\hline $\begin{array}{l}\text { Professional Business } \\
\text { Other Services }\end{array}$ & 669 & 10.73 \\
\hline Leisure and Hospitality & 204 & 03.27 \\
\hline Education and Health & 154 & 02.47 \\
\hline Real Estate & 63 & 01.01 \\
\hline Information & 548 & 08.79 \\
\hline Service Provider & 802 & 12.87 \\
\hline Utilities & 341 & 05.47 \\
\hline Construction & 104 & 01.67 \\
\hline Mining, Oil and Gas & 356 & 05.71 \\
\hline Manufacturing & 2969 & 47.63 \\
\hline Total & 6234 & 100 \\
\hline
\end{tabular}




\subsubsection{Derivatives Model}

The second sample pertains to the derivatives model. Table 5.2 shows the sample selection process: the elimination of missing data collected from Bloomberg database regarding the independent, dependent and control variables; further deletion of the missing corporate governance data to give a final sample comprising 6,900 firm year observations.

The data comprises an unbalanced dataset with a minimum of 174 firms and maximum number of 1606 firms. Panel B, shows the number of firms for each year while Panel $\mathrm{C}$ provides the number of firms with industry-wise breakdown. 
Table 5. 2: Derivation of Sample and Industry Category - Derivatives

Panel A: Sample Derivation

Number of

Observations

Sample from NYSE from 2003-2011

24669

Less year 2003

Less insurance companies

Full sample prior to deleting missing variables

21576

Less missing observations for all dependent and independent variables (excluding corporate governance variables)

Full sample prior to deleting missing governance variables

16195

Less missing BOD observations

Less missing CEO observations

Less missing Shareholder observations

Less missing Audit Committee observations

Final sample

6900 
Panel B: Sample Firms Year-wise

\begin{tabular}{ccc}
\hline Year & $\begin{array}{c}\text { Number } \\
\text { of firms }\end{array}$ & $\begin{array}{c}\text { Percentage } \\
\text { of sample }\end{array}$ \\
\hline 2004 & 174 & 02.52 \\
2005 & 531 & 07.70 \\
2006 & 755 & 10.94 \\
2007 & 207 & 03.00 \\
2008 & 1001 & 14.51 \\
2009 & 1606 & 23.28 \\
2010 & 1539 & 22.30 \\
2011 & 1087 & 15.75 \\
Total & 6900 & 100.00 \\
\hline
\end{tabular}

Panel C: New York Stock Exchange Industry Category of the Sample Firms

\begin{tabular}{lcc}
\hline Industry & Number of firms & $\begin{array}{c}\text { Percentage } \\
\text { of sample }\end{array}$ \\
\hline $\begin{array}{l}\text { Agriculture and Forestry } \\
\text { Professional Business }\end{array}$ & 23 & 00.33 \\
and Other Services & 730 & 10.58 \\
Leisure and Hospitality & 211 & 03.06 \\
Education and Health & 182 & 02.64 \\
Real Estate & 71 & 01.03 \\
Information & 588 & 08.52 \\
Service Provider & 924 & 13.39 \\
Utilities & 371 & 05.38 \\
Construction & 121 & 01.75 \\
Mining, Oil and Gas & 405 & 05.87 \\
Manufacturing & 3274 & 47.45 \\
Total & 6900 & 100.00 \\
\hline
\end{tabular}




\subsection{Measurement of Derivatives}

Interest rates, foreign exchange, commodity prices and credit derivative instruments have grown rapidly over the years, both in over-the-counter and exchange-traded derivative markets. The volume of derivatives increased dramatically from the early 1990s to reach a value of US $\$ 64,858.2$ billion by December 2014 traded on organized exchanges (BIS, 2015).

In keeping with this growth in derivatives accounting, regulators have endeavored to bring uniformity to financial reporting of derivatives. The FASB issued Statement 133 in 1998 for application from 2000 and it superseded the requirements of all earlier statements covering aspects of disclosures and/or recognition of various types of specific derivatives. The Statement has been amended a number of times since issue and supplemented by other Statements.

The FASB Statement 133: Accounting for Derivative Instruments and Hedging Activities required firms to identify all derivative positions as either assets or liabilities on the balance sheet at fair values. At the end of the fiscal year the carrying values of the derivative positions were to be adjusted to their fair value. Therefore, derivative instruments were reflected at the mark-to-market value. SFAS 133 introduced many important adjustments in derivatives accounting. However, the accounting standard did not require many of the disclosures that were mandatory under the previous standards. As a result, many firms stopped disclosing the fair values and notional amounts of their derivative positions. Firms also combined the fair values of derivatives with those of other assets and liabilities, which made it difficult to isolate the performance and effects due to derivatives. Thus, under SFAS 133, the gains or losses on certain hedges appear minimally or not at all on the income statement. Manchiraju et al. (2014) indicate that the poor quality of publicly available derivative 
disclosures prior to SFAS 161 was at least partially responsible for the mixed findings in the literature on derivatives.

Subsequently, FASB issued SFAS 161 in 2008 to provide more transparency. SFAS 161 required qualitative disclosures with regard to derivatives and strategies; and quantitative disclosures of the gains and losses (realized and unrealized) on derivative instruments. The new standard required: disclosures relating to hedging positions and performance indicating the location and fair value of derivative instruments included in the balance sheet; a report of derivative gains and losses and related hedged items and where those amounts are reported in the income statement or in the balance sheet. However, SFAS 161 does not specify the form of disclosure of the volume of derivatives such as notional amounts, and the firm may select the manner of these disclosures.

Therefore, as a result of SFAS 133 and SFAS 161, the recognition requirements for derivatives have varied over my study sample period. My study covers the period from 2004 to 2011 and therefore any specific valuation measure of derivative instruments would either not be available for the whole period or provide inconsistent measurements for comparison. Therefore, I use a binary variable to identify the firms in my sample using derivative instruments in the manner of other researchers ( Fok et al., 1997; Marsden and Prevost, 2005; Mian, 1996; Nance et al., 1993).

I gather data pertaining to derivatives from the SEC 10-K statements using the Direct Edgar extraction software to SEC 10-K filings over the period 2003-2011 for the firms that use derivatives. In the manner of Bartram et al., (2011), I use search words: derivativ*, swap*, future, forward, and option to filter out derivatives. The asterisk* is a wildcard that aids a larger search for all words with this prefix. This provides a larger sample of all companies filing $10-\mathrm{K}$ statements that use the search words. 
Thereafter, using the Direct Edgar filter this larger sample is then matched to the firms in my sample of firms, by matching the CIK numbers. I extract four lines on either side of each search word in order to ensure that the search actually indicates the firm used derivatives (as opposed to mere mention of the search words in the report). This yields around 1.2 million rows of search word data. From this data set then I manually obtain my sample of derivatives firms.

Finally, I use a binary measure to classify firms that use derivative instruments from those that do not. If a firm uses any type of derivative instrument it is coded as 1 and non-users are coded as 0 . In my sample, the term derivatives, applies to all types of derivatives: interest rate derivatives, foreign exchange/currency derivatives, and commodity price derivatives. Descriptive statistics related to derivative users and nonusers, and corporate governance are reported in Chapters 6 and 7.

\subsection{Measurement of Firm Value}

Following previous studies (Allayannis et al., 2009; Allayannis and Weston, 2001; Bartram et al. 2011; Belghitar et al, 2008; Jin and Jorion; 2006; Fauver and Naranjo, 2010; Mackay and Moeller, 2007), I measure the quality of firm value using Tobin's Q. The model is based on the assumption that the firm's decision to invest depends on both current and future expected profitability.

Tobin's Q is the ratio of the market value of a firm to the replacement cost of its assets. Chung and Pruitt (1994) suggest some modification to the original formula to make the value measure less complex and easy to calculate. The components of their measure are easily obtainable from a firm's financial statements and is captured as: $Q$ $=(\mathrm{MVE}+\mathrm{PS}+\mathrm{DEBT}) / \mathrm{TA}$, where MVE is the product of a firm's share price and 
number of common stock shares outstanding; PS represents the liquidating value of the firm's outstanding preferred stock; DEBT represents the value of the firm's shortterm liabilities, net of its short term assets, plus book value of the firm long-term debt; and TA is the book value of total assets.

There are some criticisms of Tobin's Q which suggests that this suffers from some deficiencies as a measure for firm value. Nelson et al., (2005) suggest that share price return is a better measure for firm value as it may be directly observed unlike $Q$ that needs to be estimated. Therefore, $\mathrm{Q}$ will vary based on the different estimations used and therefore the model would also need to control for the numerous factors related to these components. Despite this criticism, Tobin's Q has been popularly used in the literature and similarly I use Q to capture firm value (VALUE), as described in Table 5.4 .

\subsection{Measurement of Firm Risk}

Firms are faced with the risk that the consequences of their actions cannot be predicted. One option for the firm is to manage risk through hedging and reduce the extent of uncertainty to the firm. Therefore, it is expected that derivatives use would reduce risk through stabilizing of cash flows. The extant literature on risk management generally considers the reduction of volatility or variance minimization, as one of the main objectives of any risk management program and takes volatility as the principal measure of risk (Stulz, 1996).

Schrand and Unal (1998) suggest that risk management is a function of risk allocation rather than risk reduction. They suggest that risks are bundled together such that a variation in one type of risk may concurrently affect other risks. The authors 
hypothesize that firms constrained with respect to total risk, hedge other risks where they may have no comparative advantage in bearing, to enable investment in new projects where a comparative advantage does exist. So that a reduction in interest rate exposure may be observed without any corresponding reduction in total stock return risk.

Schrand and Unal (1998) suggest that a tradeoff between risk-return exists, such that a decrease of risk in one area may increase risk elsewhere where greater benefits are derived. Therefore, business risk, financial risk, investment risk and the whole range of unsystematic and systematic risks, comprising total firm risk may substitute for one another. This suggests that cross-purposes exist with respect to risks and hedging. It indicates that one risk component could act as a substitute, complement for one another or have indirect effects with respect to risk exposure, and the hedging programs and strategies used. I examine various components of total risk and expect to see the tradeoff, risk allocation effect described by Schrand and Unal (1998) in the hedging strategies and risk exposures of each type of risk.

A firm faces total risk comprising systematic risk and unsystematic risk. Unsystematic risk is specific to the firm and may be diversified through holding of efficient portfolio of stocks, however, systematic risk, also known as market risk may not be diversified away and is more relevant for investment decisions. In this study I examine the effects of corporate governance on hedging activities in reducing firm risks. I apply three types of risk measures in the current study: cash flow volatility, stock return volatility and market risk following Bartram et al., (2011). 


\section{Cash Flow Volatility}

Studies use volatility of firm value to capture aggregate firm risk. Many suggest that cash flow volatility is able to capture effects of earnings volatility (Barton, 2001; Lang et al., 2003; Leuz, et al., 2003) and Rountree et al. (2008) prefer to use this measure as it is easily accessed and more transparent. Froot et al. (1993) and Mayers and Smith (1990) also to use cash flow volatility to proxy for aggregate firm risk.

Therefore, the first risk measure in my study relates to operating cash flow volatility. It is measured through the standard deviation of five years' data in the manner of Bartram et al. (2011) as: $\left.\sigma_{\mathrm{CFi}}=\sqrt{[} \frac{1}{4} \sum_{j=1}^{5}\left(p_{\mathrm{i}}-q_{\mathrm{i}}\right)^{2}\right]$, which represents the standard deviation of five years' data for each firm, where pi is the annual operating margins (operating cash flow scaled by total sales) and qi is the mean of the operating margins. However, Bartram, et al. (2011) suggest that this measure has some weaknesses as operating cash flows may not be measured accurately and are also prone to accounting manipulations. The authors explain that the measure may not account for use of some foreign currency derivatives and commodity price derivatives, if these do not use hedge accounting and also the effects of most interest rate derivatives may not be reflected in operating cash flow. However, despite these limitations, Bartram et al. (2011) use cash flow volatility to capture overall firm risk. Similarly, I use cash flow volatility, with sales as the scaler in the manner of Bartram et al. (2011) and Huang (2009). Huang (2009) provides two reasons why using sales as the scalar is more beneficial. Firstly, it has been used as a measure of firm size in numerous studies (Berk, 1997) and secondly, it captures the seasonality in cash flow. This is in line with studies which suggest that operating variables exhibit seasonality (Brown and Otsuki,, 1993). Rountree et al. (2008) examine both earnings per share volatility and cash flow per share volatility. A similar measure is used by Manchijaru et al. (2014), however they scale operating cash flows by total assets and use eight quarters of data. 


\section{Stock Return Volatility}

The second risk measure of this study is stock return volatility. Bartram et al. (2011) show that it is difficult to disaggregate the exposures related to variation in a firm's assets and liabilities and appeal to market efficiency to suggest stock price volatility as a proxy for this risk. Following Bartram et al. (2011), I use stock return volatility to estimate the firm's assets and liabilities risks, measured as the standard deviation of day-to-day logarithmic price changes for each firm for each year. The previous day 260-day price volatility equals the annualized standard deviation of relative price change of the 260 most recent trading days' closing price, expressed in a percentage for the day prior to the current

\section{Market Risk}

The third measure for risk beta, analyses market risk that the firm faces, by examining the firm's stock return sensitivity to market return through application of the standard market model on daily returns, in the manner of Bartram et al. (2011):

$$
\mathrm{R}_{\mathrm{jt}}-\mathrm{r}_{\mathrm{ft}}=\alpha_{\mathrm{j}}+\beta_{\mathrm{j}}\left(\mathrm{R}_{\mathrm{Mt}}-\mathrm{r}_{\mathrm{ft}}\right)+\varepsilon_{\mathrm{jt}}
$$

where $R_{j t}$ is the return of firm $j$ on day $t, R_{M t}$ is the return on the market index $M$ on day $\mathrm{t}$, and $\mathrm{rft}$ is the daily risk free rate of interest. The overall market risk is then measured by the estimated values of $\beta \mathrm{j}$. However, this is an adjusted beta and is derived from the past two years of weekly data, modified under the assumption that a security's beta moves toward the market average over time. Values are calculated using the Standard and Poor's 500 Index as the relative market index. A full description of the variable is provided in Table 5.4 


\subsection{Measurement of Corporate Governance Variables}

This section presents the measures of corporate governance variables that have been used in the study. It also provides a review of supporting literature that use similar measures. In accordance with the hypotheses developed in Section 4.3-Section 4.7, the proxies for thirteen corporate governance variables: board independence, board size, board diversity, board meetings, insider shareholders, institutional shareholders, block holders, CEO age, CEO tenure, CEO total compensation, CEO bonus, CEO salary and audit committee size, are explained in Section 5.7. The description of source of data and definitions for the corporate governance variables are summarized in Table 5.3 .

\subsubsection{Board of Directors (Board)}

\section{Board Independence}

The New York Stock Exchange (NYSE listings Section 303A.01) require all publicly listed companies to have a majority of independent directors: "Effective boards of directors exercise independent judgment in carrying out their responsibilities. Requiring a majority of independent directors will increase the quality of board oversight and lessen the possibility of damaging conflicts of interest. However, as the concern is independence from management, the Exchange does not view ownership of even a significant amount of stock, by itself, as a bar to an independence finding." (NYSE, 2009).

The board of directors are responsible for overseeing managers' actions to ensure that these actions are aligned with the shareholders' interests (Fama and Jensen, 1983a). 
The monitoring role of the board as an effective corporate governance mechanism is dependent on the degree of independence, among other characteristics (Borokhovich et al., 1996; Karamanou and Vafeas, 2005; Mayers et al., 1997). Larger firms may require more independent directors because bigger companies face more agency problems (Crutchley et al., 2004; Lehn et al., 2005). Independent directors are better able to handle the broader range of activities of the more diversified firms (Anderson et al., 2000; Coles et al., 2008).

Researchers use several variations in the measure of independence, for example, Klein (2002) uses three measures. The first measure captures board independence as a percentage of total outside directors and this has been popularly used in the literature (Cheng, 2008; Adams and Mehran, 2012; Boone et al., 2007). The second measure relates to whether a majority of members are independent of management and the third measure uses a binary variable of 1 if there is a majority of independent members, with $51 \%$ representing a majority. This is in line with Dechow et al. (1996) who consider a board as not independent if at least $50 \%$ of the board members are firm officers. Other studies related to derivatives also investigate board independence as a corporate governance mechanism ${ }^{2}$.

Weisbach (1988) uses the number of independent board members as a function of board activity, while Erkens et al. (2012) classify them as independent, if the directors are non-executive directors. In this study, I take the number of outside directors that

\footnotetext{
${ }^{2}$ Borokhovich et al., (2004) also use another measure taken as outside directors less inside directors and Allayannis et al. (2012) prefer to construct a governance index where independent directors are assigned a score of 1 in a firm-level score ranging from 0 to 7 . Marsden and Provost (2005) segregate outside directors by the 1994 and 1997 boards in order to test the impact of the introduction of the 1993 Companies Act on derivatives. Dionne and Trikki (2013) and Borokhovich et al., (2004) use the percentage of outside directors taken as all not affiliated with the firm as their proxy for board independence.
} 
are considered as totally independent under the NYSE listings, as the measure for board independence (BDINDEP).

\section{Board Size}

Board size enhances board monitoring as the appointment of more relevant directors would enhance the combined knowledge resource and enhance capacity for more directors to share in the monitoring activities (Karamanou and Vafeas, 2005). NYSE does not provide any mandatory requirement for size of the board of directors. However, the Exchange listings suggest that board size should keep in mind the rights of the stockholders, including preferred stockholders. Further, the number of directors on the board should be reviewed from time to time by the board and any resolution adopted should be passed by a majority of the board members.

Generally, studies examine the number of directors on the board to determine whether board monitoring is enhanced when the number of members on the board increases (Beiner et al., 2006; Boone et al., 2007; Brick and Chidambaran, 2010). Borokhovich et al. (2004) examine the effect of board size on interest rate derivatives Barnhart and Rosenstein (1998) also study board size as the number of directors on board, however they use a one-year lag to overcome endogeneity problems in a simultaneous equations model. As in prior studies (Linck et al., 2008; Mak and Kusnadi, 2005; Vafeas, 2005; Yermack, 1996), I use the number of directors on the board of directors, as indicated in the financial statement at the end of the year, to measure board size (BDSIZE). 


\section{Board Diversity}

There is a concern that the whole workforce is not adequately represented on the board of directors and this is reinforced by the notion that gender-diverse boards add value. For example, Davies (2011), suggests that women contribute a larger pool of skills, superior customer-understanding and better quality of corporate governance to positively impact firm performance. Others indicate that board independence is improved (Carter et al., 2003) and the risk of homogeneousness thinking and decisions is reduced (Maznevski, 1994) by board gender diversity. Further women are less prone to take risk and several studies, including those in the areas of psychology and economics support this view (Barber and Odean, 2001). However, SOX and the NYSE listings do not address any diversity requirements or concerns within the overall board structure.

Adams and Ferreira (2009) explore the effects of gender diversity on firm performance and on the board. They use several proxies for gender diversity. The first proxy comprises a dummy variable of 1 if the company has female directors in a given year. The other measure is a dummy variable of one if the firm has only one female director and another variation is taken as the fraction of female directors. Carter et al. (2003) measure both gender diversity and minority diversity, and use percentage of women on the board as a proxy to study the association with firm value. In the current study, I examine board diversity (BDDIVERS) through gender diversity and use a measure of the total number of women directors on the board that is explained in Table 5.3. 


\section{Board Meetings}

NYSE listings place a specific minimum requirement for the frequency of board meetings. The Exchange recommends that boards should not have a minimum of four meetings in a year, indicating that boards should meet more frequently. Additionally, special directors' meetings may take place at the behest of the Board Chairman, Chief Executive Officer or a majority of the directors.

Board meetings represent the time devoted by the board to monitoring the company's management and financial affairs. Vafeas (1999) examines board meetings to study the impact of board activity on corporate performance and suggests that meetings frequency may represent a trouble shooting device for boards. Brick and Chidambaran (2010) also investigate the effect of board activity on performance and use two variations to capture this: the number of annual meetings held by the board of directors; and combining independent directors and annual board meetings to construct the second proxy for "monitor". While Adams and Ferreira (2012) use number of board meetings as proxy in their study of directors' incentives to attend board meetings.

In the manner of Xie et al. (2003) and Vafeas (1999), I use the number of board meetings held during the year and as reported at the end of the financial year, to proxy for board monitoring activities and capture BDMTGS.

\subsubsection{CEO Compensation, Age and Tenure}

The Sarbanes-Oxley Act of 2002 (Act) imposes many changes in the executive compensation provisions. Executive compensation also forms an important feature of 
the Dodd-Frank Wall Street Reform and Consumer Protection Act of 2010. There has been substantial focus on CEO compensation to ensure that compensation structures are geared towards the principle of pay-for-performance.

There are many variations and combinations of executive compensation components that have been researched: CEO compensation sensitivity (vega and delta); market value of stock holdings and options holding, using some asset valuation models. Some studies examine a combination of executive compensation features such as CEO salary, bonus and other compensation. For example, Cyert et al. (2002) study three components of CEO pay: 1) base salary 2) equity compensation including all equitybased awards such as restricted stocks, stock options and stock appreciation rights and 3) total discretionary compensation which includes not only equity-based compensation but also bonus and other compensation. The examination of cash compensation salary, bonus and total direct compensation taken as the sum of the manager's salary, bonus, stock and options grants and other compensation are popularly investigated (Hartzell and Starks, 2003). Beaumont (2015) and Rajgopal and Shevlin (2000) use these measures and investigate their impact on firm value and risk, while Hogan and Lewis (2005) and Kato et al. (2005) study the impact on firm performance taken as return on assets, return on equity and/or cumulative abnormal returns.

It is suggested that older CEOs and those at the end of their tenure exhibit the effects of short-term horizon problems and wealth myopia that may compel them to act in their own interest. Researchers use CEO age and tenure to measure whether an agency conflict does exist (Cornett et al., 2008; Faleye et al., 2011, Harvey and Shrieves, 2001; Ozkan, 2011). Leone et al. (2006) also study CEO age, tenure and years-to-retirement as proxies for short horizon CEOs, to examine whether the pay-performance sensitivity for cash compensation increases for short horizon CEOs. 
Core et al. (1999) study CEO salary, CEO total cash compensation and CEO total compensation to assess the effect on stock return and return on asset taken as firm performance. They also use a measure of CEO age and tenure to capture the effects of managerial entrenchment (Cheng, 2004) ${ }^{3}$. Similar to Core et al. (1999), I use three measures of compensation: total CEO compensation (CEOCOMP) taken as the sum of base salary, annual bonus and other annual compensation; CEO bonus (CEOBONUS) taken as the cash or cash equivalent of any annual incentive award; and CEO base salary (CEOSALARY). I also investigate whether CEO age (CEOAGE) and tenure (CEOTENURE) restrict corporate governance effectiveness and exhibit short-term horizon problems.

\subsubsection{Shareholders}

\section{Block Shareholders}

The board and institutional structures are two of the most important mechanisms in the governance framework (Denis and McConnell, 2003). Gillian and Starks (2007) attribute this to the disciplining and monitoring roles in governance and some researchers (Florackis and Ozkan, 2009; Gul et al., 2010; Shleifer and Vishny, 1997) find evidence to show that large shareholders are better able to monitor management and effectively increase performance (Bozec and Laurin, 2008).

Short and Keasey (1999) investigate the effect of large stock ownership on the marketto-book value of equity and return on equity. They examine three measures:

\footnotetext{
${ }^{3}$ Cheng (2004) uses similar measures for CEO compensation where cash compensation represents total of CEO salary and annual bonus and CEO total compensation is the sum of cash compensation, option compensation, fringe benefits and other incentives. He uses a dummy variable for CEO age to examine the horizon problem.
} 
percentage of shares held by directors; percentage of shares owned by institutions owning $5 \%$ or more shareholding; and percentage of shares held by other external ownership interests. Dou et al. (2014) use another proxy in their study of block holders: Herfindahl Index comprising the number of shares held by a block holder divided by the total number of shares held by all the block holders. While, Bedard et al. (2004) and Raghunandan and Rama (2007) use the percentage of common shares held by shareholders that own more than 5\% shareholding as their proxy for a large block of shareholding. Likewise, Laeven and Levine (2009) use the same measure but apply cut-off of $10 \%$ shareholding to signify block shareholding. Similar to Bedard et al. (2004) and Raghunandan and Rama (2007), this study measures block shareholders (SHBLOCK) as the percentage of common shareholders that own more than $5 \%$ shareholding.

\section{Institutional Shareholders}

Institutional shareholders have an objective interest in the company and a large pool of resources and therefore are better able to control managers. Conversely, Heflin and Shaw (2000) and O'Neill and Swisher (2003) suggest that while these large shareholders provide objectivity they can undermine the selection process and cause problems by influencing management to act in their best interest. Therefore, research is mixed with respect of institutional shareholders. So while studies do find the benefits of large institutional shareholders on firm performance, some (Erkens et al., 2012) indicate that institutional shareholders encouraged extensive short term risk taking for the purpose of high profits during the financial crisis.

Hartzell and Starks (2003) use various proxies for institutional investor holdings. They take: total institutional holdings and another measure of the top 5 largest institutional holdings, all taken as a percentage of shares outstanding and examine their effect on 
executive compensation. David et al. (2015) use many different proxies for their study with the two main measures as: percentage ownership of total ownership by all large institutions; and \% ownership of the large institutions. While Firth et al. (2014) apply a proxy representing the percentage of shares held by institutional investors to study their role in corporate governance. In this study, I use the percentage of institutional shareholders (SHINST) variable, using a binary variable of one, if institutional percentage of shareholders is in majority and otherwise zero.

\section{Insiders Shareholders}

There are some detrimental effects of shareholders who are also managers and directors. For example, Hill and Snell (1988) contend that insider and block ownership influences discourage diversification by the firm. Others suggest that insider shareholders may not pursue value increasing strategies and may be driven by their own personal agenda (Jensen and Murphy, 1990; Wright and Ferris, 1997).

Wright et al. (1996) examine various measures of ownership such as insider percentage ownership, block holders and institutional equity ownership on firm risk. They bifurcate insider ownership into low managerial and high managerial ownership and study the impact on firm risk. While Himmelberg et al. (1999) use two measures of insider holdings such as total common equity holdings of top level managers as a fraction of common equity outstanding; and another nonlinear measures, to capture the determinants of total equity ownership of top managers and their impact on firm value. However, Firth et al. (2014) and Raghunandan and Rama (2007), examine the number of shares held by managers as a percentage of total number of shares outstanding. I use a similar proxy for insider shareholders (SHINSIDER) to measure the shareholding of executives, managers and directors as a percentage of total shareholding. 


\subsubsection{Audit Committee Size}

The NYSE rulings have very rigorous requirements for audit committees. The NYSE Manual requires audit committees to have a minimum of three members ${ }^{4}$ and additionally, all audit committee members must be independent ${ }^{5}$. At least one member of the audit committee must have accounting or related financial management expertise, and each member of the audit committee must be financially literate or become financially literate within a reasonable period of time after his or her appointment to the audit committee. Amongst the other duties and obligations, the audit committee is required to meet to review and discuss the company's annual and quarterly financial statements with management and the independent auditor. They are also required to meet to discuss policies with respect to risk assessment and risk management. Therefore, larger size would improve internal controls and provide better monitoring due to the larger resources and knowledge base that they are able to access.

Zhang et al. (2007) examine size with the expectation that large audit committees enhance audit committee status and power within an organization (Kalbers and Forgarty, 1993) as they receive more resources (Pincus et al., 1989) and lower the cost of debt financing (Anderson et al., 2004). If audit committee members are required to have a certain level of financial expertise, therefore larger committees with more members should be better monitors. The larger number of members would have access to more experience and both financial and non-financial expertise. Archambeault and DeZoort (2001) and Zaman et al. (2011) indicate that larger audit committees will be

\footnotetext{
${ }^{4}$ NYSE Manual Section 303A.07

${ }^{5}$ NYSE Manual Section 303A.02
} 
able to perform their role better through sharing of knowledge and which would require less outsourcing for the required services.

Dionne and Trikki (2013) examine audit committee independence, financial expertise and size. They take a dummy variable of 1 if audit committee has at least three members, and otherwise as zero. Lin et al. (2006) study the effect of audit committee performance on earnings quality and use audit committee size as a measure for audit committee performance. They use a dummy variable of 1 if audit committee consists of at least four members, and 0 otherwise. Some researchers use the natural logarithm of the number of members on the audit committee to proxy for size (Kalbers and Forgarty, 1993; Pincus et al., 1989; Zhang et al., 2007).

Xie et al. (2003) and Raghunandan and Rama (2007) use the number of audit committee members to proxy for audit committee monitoring through size and study their effect on firm performance. In a similar manner to Xie et al. (2003) and Raghunandan and Rama (2007), I use the number of audit committee members reported at the end of the financial year, to measure audit committee size (ACSIZE).

Table 5.3 presents details with regard to definitions, sources of databases and codes for all the governance variables applied in this study. 
Table 5. 3: Definition of Corporate Governance Variables

\begin{tabular}{|c|c|c|c|c|}
\hline Variable & Measure & $\begin{array}{l}\text { Data Base/ } \\
\text { Dataset } \\
\text { Category }\end{array}$ & Field Name & Definitions \\
\hline CEOBONUS & $\mathrm{Ln}$ & $\begin{array}{l}\text { Corporate } \\
\text { Library - CEO }\end{array}$ & CEOBonus & $\begin{array}{l}\text { Represents } \\
\text { natural logarithm } \\
\text { of: the cash or } \\
\text { cash equivalent of } \\
\text { any annual } \\
\text { incentive award to } \\
\text { the Chief } \\
\text { Executive Officer } \\
\text { (CEO). } 1 \text { has been } \\
\text { added to the } \\
\text { original figure in } \\
\text { order to include } \\
\text { any zero values. }\end{array}$ \\
\hline CEOSALARY & $\mathrm{Ln}$ & $\begin{array}{l}\text { Corporate } \\
\text { Library - CEO }\end{array}$ & CEOBaseSalary & $\begin{array}{l}\text { Represents } \\
\text { natural logarithm } \\
\text { of: CEO salary, } \\
\text { which can include } \\
\text { non-cash } \\
\text { elements and } \\
\text { salary taken as } \\
\text { deferred } \\
\text { compensation. }\end{array}$ \\
\hline CEOCOMP & Ln & $\begin{array}{l}\text { Corporate } \\
\text { Library - CEO }\end{array}$ & $\begin{array}{l}\text { CEOTotalAnnua } \\
\text { lComp }\end{array}$ & $\begin{array}{l}\text { Represents } \\
\text { natural logarithm } \\
\text { of: the sum of } \\
\text { base salary, } \\
\text { annual bonus and } \\
\text { other annual } \\
\text { compensation to } \\
\text { CEO. }\end{array}$ \\
\hline CEOAGE & $\begin{array}{l}\text { Number of } \\
\text { Years }\end{array}$ & $\begin{array}{l}\text { Corporate } \\
\text { Library - CEO }\end{array}$ & CEOAge & $\begin{array}{l}\text { Age of current } \\
\text { Chief Executive } \\
\text { Officer. }\end{array}$ \\
\hline CEOTENURE & $\begin{array}{l}\text { Number of } \\
\text { Years }\end{array}$ & $\begin{array}{l}\text { Corporate } \\
\text { Library - CEO }\end{array}$ & CEOTenure & $\begin{array}{l}\text { Number of years } \\
\text { of service of } \\
\text { current Chief } \\
\text { Executive Officer. }\end{array}$ \\
\hline
\end{tabular}




\begin{tabular}{|c|c|c|c|c|}
\hline Variable & Measure & $\begin{array}{l}\text { Data Base/ } \\
\text { Dataset } \\
\text { Category }\end{array}$ & Field Name & Definitions \\
\hline BDINDEP & $\begin{array}{l}\text { Number of } \\
\text { directors }\end{array}$ & $\begin{array}{l}\text { Corporate } \\
\text { Library } \\
\text { Company }\end{array}$ & $\begin{array}{l}\text { DirectorsOutside } \\
\text { Total }\end{array}$ & $\begin{array}{l}\text { Sum of all fully } \\
\text { independent } \\
\text { directors on a } \\
\text { given board. }\end{array}$ \\
\hline BDSIZE & $\begin{array}{l}\text { Number of } \\
\text { directors }\end{array}$ & $\begin{array}{l}\text { Corporate } \\
\text { Library } \\
\text { Company } \\
\text { and Bloomberg }\end{array}$ & DirectorsTotal & $\begin{array}{l}\text { Total number of } \\
\text { directors on a } \\
\text { given board (does } \\
\text { not include } \\
\text { Emeritus or } \\
\text { Advisory member } \\
\text { positions). }\end{array}$ \\
\hline BDDIVERS & $\begin{array}{l}\text { Number of } \\
\text { directors }\end{array}$ & $\begin{array}{l}\text { Corporate } \\
\text { Library } \\
\text { Company }\end{array}$ & DirectorsWomen & $\begin{array}{l}\text { Sum of female } \\
\text { directors on a } \\
\text { given board. }\end{array}$ \\
\hline BDMTGS & $\begin{array}{l}\text { Number of } \\
\text { meetings }\end{array}$ & $\begin{array}{l}\text { Corporate } \\
\text { Library } \\
\text { Company } \\
\text { \& Bloomberg }\end{array}$ & \begin{tabular}{l}
$\underline{\text { BDMtgs }}$ \\
\multicolumn{3}{c}{} \\
BOARD_MEET \\
INGS _PER \\
_YEAR
\end{tabular} & $\begin{array}{l}\text { Number of full } \\
\text { board meetings } \\
\text { held. }\end{array}$ \\
\hline SHINSIDER & Percentage & $\begin{array}{l}\text { Corporate } \\
\text { Library } \\
\text { Company }\end{array}$ & InsidersPctg & $\begin{array}{l}\text { Estimated } \\
\text { percentage of } \\
\text { outstanding } \\
\text { shares held by top } \\
\text { management and } \\
\text { directors. }\end{array}$ \\
\hline SHBLOCK & Percentage & $\begin{array}{l}\text { Corporate } \\
\text { Library } \\
\text { Company }\end{array}$ & $\begin{array}{l}\text { OwnersFivePerc } \\
\text { entPctg }\end{array}$ & $\begin{array}{l}\text { Estimated } \\
\text { percentage of } \\
\text { outstanding } \\
\text { shares held by any } \\
5 \% \text { or greater } \\
\text { shareholders. }\end{array}$ \\
\hline SHINST & Binary & $\begin{array}{l}\text { Corporate } \\
\text { Library } \\
\text { Company }\end{array}$ & $\begin{array}{l}\text { InstitutionalMaj } \\
\text { ority }\end{array}$ & $\begin{array}{l}\text { Indicates whether } \\
\text { or not a majority } \\
\text { of outstanding } \\
\text { shares are held by } \\
\text { institutions. } \\
\text { Taken as dummy } \\
\text { variable } 1 \text { if } \\
\text { institutional }\end{array}$ \\
\hline
\end{tabular}




\begin{tabular}{|l|l|l|l|l|}
\hline Variable & Measure & $\begin{array}{l}\text { Data Base/ } \\
\text { Dataset } \\
\text { Category }\end{array}$ & Field Name & Definitions \\
\hline ACSIZE & $\begin{array}{l}\text { Number of } \\
\text { directors }\end{array}$ & $\begin{array}{l}\text { Corporate } \\
\text { Library } \\
\text { - Directors } \\
\text { (extracted from } \\
\text { individual } \\
\text { director } \\
\text { information) } \\
\text { otherwise 0. }\end{array}$ \\
\hline
\end{tabular}

Ln = Natural logarithm function 


\subsection{Measurement of Control Variables for Value and Risk Models}

Empirical studies suggest that firm performance may be jointly determined by a number of firm characteristics, such as those related to the firm's business and operating environment. Specifically, the studies show that there is a positive association of firm value with profitability and investment growth opportunities, a negative relationship with leverage, and there may exist with either a negative or positive association with firm size. These findings are consistent with existing theories, evidence and intuition. For example, leverage provides tax benefits through interest rate tax savings and could increase value. However, conversely, debt may increase agency conflict between the debt holders and shareholders to reduce profitability (Fama and French, 1998; Jensen and Meckling, 1976; Miller, 1977; Myers, 1977).

An important control for studies that examine firm performance is leverage (LEVERAGE). Higher debt translates into a higher cost of external financing and interest payments. Also, higher leverage would imply a greater level of financial distress. Proper debt management would be needed to reduce the costs associated with financial distress (Shapiro and Titman, 1986; Smith and Stulz, 1985) and to achieve the optimal debt-equity ratio and the tax benefits of debt (Leland, 1998; Myers, 1984) As a consequence, increase in leverage would reduce value and many studies find a negative relationship (Faulkender and Petersen, 2006; Magee, 2008; Rajan and Zingales, 1995) with firm value. With respect to firm risk, leverage increases the need

to pay the fixed interest payments on time which enhances financial distress and increases risk. Total debt and a total debt scaled by total assets are popularly used as a measures for leverage (Coles et al., 2006; Ferreira and Laux, 2007). However, Belghitar et al. (2008) and Guay (1999) prefer to use total debt scaled by size to proxy for 
leverage. In my study, I use the same proxy as Belghitar et al. (2008) and Guay (1999) as defined in Table 5.4, and predict that leverage would have a negative association with value and a positive relationship with risk.

If a firm has many investment growth opportunities, then it is able to undertake profitable net present value (NPV) projects. However, if at the same time the firm faces a financial constraint, it would prevent them from investing in these projects and reduce potential profits, giving rise to problems of underinvestment. Additional projects would also encourage firms to hedge in order to stabilize cash flows to realize the value of their investments and therefore hedgers may generally have larger investment opportunities. Following Allayannis et al. (2012), I use two measures for investment growth opportunities, such as capital expenditure (CAPEX) and research and development expenditure (R\&D) and expect a positive relationship with firm value.

Firms that achieve higher profits provide higher return to shareholders. Therefore, such firms would also have higher firm values. Researchers have controlled for profitability in their studies (Magee, 2008; Yermack, 1996) and even incorporate a control for the profitability from earlier years. For example, Yermack (1996) uses one and two year lags of return on assets to control for the influence of profits on firm value. In the regression model that examines the impact of hedging and governance on firm value, I control for profitability through a measure of return of assets (ROA) in the manner of Bartram et al., (2011) and others (Allayannis and Weston, 2001; Jin and Jorion, 2006; Gonzalez and Yun, 2013; Magee, 2008).

Profitability also affects the firm in other ways as the loss or reduction in income would enhance risk. And studies find an impact of reduced return on assets on current year risk (Ferreira and Laux, 2007; Guay, 1999, Wei and Zhang, 2006). However, prior 
year performance would also have a lagged effect on current year risk and firms would tailor their financing and hedging strategies based on this. Investors prefer to invest in firms with a trend of high profitability and creditors provide financing and adjust the costs of financing, on the basis of past firm performance. Therefore, past profits also impact current year risks and in the manner of Huang et al. (2013) I control for current year return of assets (ROA) and a one-year lag ROA (t-1), and predict a negative relationship for both variables with risk.

There is a long ranging debate on the effect of liquidity on constrained firms. Campbell et al. (2008) indicate that entities with larger cash holdings exhibit lower risk such that there is a negative relationship between cash holdings and financial distress. On the other side there are others who show that with increased financial distress the firm has a propensity to save from cash inflows (Almeida et al., 2004) and therefore increase their cash reserves. This would be the natural outcome from the lack of access to external financing. Firms experiencing high volatility reduce leverage, decrease investments, increase cash holdings, while reducing their non-cash current assets (inventories and account receivables) and curb dividends (Chen et al., 2014). Thus, I predict that liquidity could have either a negative or positive relationship with risk, which would depend on the level of volatility and financial distress of the firm. I use the quick ratio as a measure of liquidity (LIQUIDITY), to capture the relationship between cash reserves and firm risk.

There are two theories that address the effect of size on the firm. Some propose that size represents the bankruptcy costs faced by firms, and therefore larger firms would have greater fixed costs and payments and so incur greater bankruptcy costs. Others see size as representing economies of scale advantage of firms, so that larger firms with added benefits of economies of scale and resources would have a benefit over smaller firms. For example, Nguyen and Faff (2002) argue that larger firms would 
have the resources to put a hedging program in place. Thus, firm size is used in the literature as a proxy both for financial distress and firm resources and therefore results are mixed.

In the current study, in the manner of Allayannis et al. (2009), Bartram et al. (2011), Coles et al. (2006), Dionne and Trikki (2013), and Graham and Rogers (1999) I use sales as a proxy for firm size (SIZE) and study their impact on firm value and firm risk. I predict that if size captures that economies of scales aspect of the firm, then it would increase firm value and reduce firm risk. However, if size represents financial distress and bankruptcy costs, then larger size would induce more distress costs and would reduce firm value and increase firm risk.

\subsection{Measurement of Control Variables for the Derivatives Model}

The extant literature on derivatives shows that convex tax structure, financial distress costs, managerial risk aversion, investment growth opportunities and the underinvestment costs influence a firm's decision to hedge. A detailed explanation of the theories underlying the determinants of derivatives is provided in Section 3.2. Therefore, any study on derivatives, needs to control for the effects of these determinants of derivatives.

Firms use derivatives when they are faced with a convex tax structure in order to reduce their tax liability (Donohoe, 2015). When firms report tax loss carry-forwards, it exhibits the presence of convexity in their tax structure. Therefore, researchers use tax loss carry-forward to capture the effects of tax convexity in their studies (Allayannis and Ofek, 2001; Bartram et al., 2009; Nance et al., 1993). Bartram et al. (2009), Gay and Nam (1998) and others (Berkman and Bradbury, 1996; Mian, 1996; 
Nance et al., 1993) find a positive effect of tax convexity on derivatives by firms. However, Allayannis and Ofek (2001) encounter mixed results which suggests that tax convexity may not be a significant determinant of a firm's hedging activities. In my study, I also use tax loss carry forward to capture tax convexity (TLCF), and apply a dummy variable of 1 to indicate where a firm exhibits tax convexity and otherwise 0 where this effect is not evidenced. However, I do not make any firm predictions about the impact of tax convexity on derivatives use.

Gay and Nam (1998) suggest that firms with higher leverage have a greater probability of financial distress. These firms will increase hedging in order to increase debt capacity and reduce reliance on external financing and related high costs of interest. Many researchers find support for this hypothesis in their studies (Bartram et al., 2009; Graham and Rogers, 2002; Haushalter, 2000; Nguyen and Faff, 2002). As explained in Section 5.8, I use the same measures to proxy for firm leverage (LEVERAGE). I predict that higher debt will increase financial distress resulting in a positive relationship between firm hedging activities and leverage.

Liquidity ratio captures the effects of short-term financial constraints and the problems related to underinvestment. A depletion of cash reserves would not enable firms to take advantage of lucrative investment opportunities available to them. If firms do not have sufficient internal funds, they will resort to hedging in order to increase their financing capacity. Therefore, there is a negative relationship between hedging and liquidity. I use the quick ratio to proxy for short-term constraints in the manner of Nguyen and Faff (2002) and predict a negative relation of liquidity (LIQUIDITY) with hedging.

Investment growth opportunities encourage firms to use derivatives to enable them to invest in profitable projects. Many studies on derivatives, employ research and 
development expenditure to capture the existence of investment growth opportunities within the firm (See Section 5.8). Allayannis and Ofek (2001); Dolde (1995), Geczy et al. (1997) and Nance et al. (1993) obtain a positive relationship between research and development expenditure and the use of derivatives to provide support for the investment opportunities hypothesis. Froot et al. (1993) also find that research and development is positively related to currency derivatives. I use a dummy variable to capture research and development (R\&D) activities of the firm, as explained in Table 5.4 .

This model employs the same measure for firm size (SIZE) as explained in Section 5.8. I do not make any predictions for the relationship between firm size and derivatives use.

In the first equation of the derivatives simultaneous model, debt (LEVERAGE) is the dependent variable. For this model, I use control variables similar to those applied by the other researchers in the manner suggested by Titman and Wessels (1988) and Opler and Titman (1996). I use measures of the controls that have been used by other studies in their simultaneous equations model. Research and development expenditure (R\&D) is taken as a proxy for investment growth opportunities (Borokhovich et al., 2004; Geczy et al., 2007; Graham and Rogers, 1999; Graham and Rogers, 2002); Sales (SIZE) is used as a proxy for firm size (Borokhovich et al, 2004; Geczy et al., 1997; Graham and Rogers, 1999; Graham and Rogers, 2002). I use stock return volatility (VOLATILITY) as it impacts the debt-equity capital structure decisions (Hovakimian et al., 2001; Titman and Wessels, 1988) and profitability also impacts financing decisions (Borokhovich et al., 2004; Dionne and Trikki, 2013) and I use return on assets (ROA) to proxy for profitability (Hovakimian et al., 2001). I predict that DER and VOLATILITY have a positive association with LEVERAGE, while there is a 
negative association for ROA and R\&D with LEVERAGE. I do not make any prediction on the sign of SIZE, as described earlier on.

Based on my arguments described in Chapter 4, the expected relationship between the dependent variables: derivatives, leverage, firm value and firm risk, with the corporate governance independent variables and controls, are illustrated in Tables 5.5, 5.6 and 5.7 . 
Table 5. 4: Definition of Other Independent and Control Variables

\begin{tabular}{|c|c|c|c|}
\hline Variable & $\begin{array}{l}\text { Variable } \\
\text { Measure/ } \\
\text { Transfor- } \\
\text { mation }\end{array}$ & Data Base & Definitions \\
\hline$\overline{\text { DER }}$ & & Direct Edgar & $\begin{array}{l}\text { Binary variable taken as } 1 \text { where } \\
\text { firms use derivatives and } 0 \text {, } \\
\text { otherwise }\end{array}$ \\
\hline VALUE & Ln & $\begin{array}{l}\text { Constructed } \\
\text { from } \\
\text { variables on } \\
\text { Bloomberg }\end{array}$ & $\begin{array}{l}\mathrm{Q}=(\mathrm{MVE}+\mathrm{PS}+\mathrm{DEBT}) / \mathrm{TA} \text {, } \\
\text { where MVE is the product of a } \\
\text { firm's share price (PX_LAST) and } \\
\text { number of common stock shares } \\
\text { outstanding (BS_SH_OUT); PS is } \\
\text { preferred equity (BS_PFD_EQY), } \\
\text { DEBT represents short-term and } \\
\text { long term debt taken as } \\
\text { (SHORT_AND_LONG_TERM_ } \\
\text { DEBT) and TA is the book value } \\
\text { of total assets (BS_TOT_ASSET). }\end{array}$ \\
\hline $\begin{array}{l}\text { CASH FLOW } \\
\text { VOLATILITY }\end{array}$ & Ln & $\begin{array}{l}\text { Constructed } \\
\text { from } \\
\text { variables } \\
\text { available on } \\
\text { Bloomberg }\end{array}$ & $\begin{array}{l}\text { Represents natural logarithm of: } 5 \\
\text { year standard deviation of Cash } \\
\text { from Operations. } \\
\text { Cash from Operations is the total } \\
\text { amount of cash a company } \\
\text { generates from its operations. } \\
\text { (CF_CASH_FROM_OPER). } \\
\text { Generally calculated as: Net } \\
\text { Income + Depreciation and } \\
\text { Amortization + Other Noncash } \\
\text { Adjustments + Changes in Non- } \\
\text { cash Working Capital. } \\
\text { Where: } \\
\text { Net Income (CF_NET_INC) } \\
\text { Depreciation and Amortization } \\
\text { (CF_DEPR_AMORT) } \\
\text { Other Non-cash Adjustments } \\
\text { (CF_OTHER_NON_CASH_ADJ } \\
\text { UST); Changes in Non-cash } \\
\text { Working Capital is (CF_ } \\
\text { CHNG_NON_CASH_CAP). }\end{array}$ \\
\hline $\begin{array}{l}\text { STOCK RETURN } \\
\text { VOLATILITY }\end{array}$ & Ln & $\begin{array}{l}\text { Constructed } \\
\text { from } \\
\text { Bloomberg }\end{array}$ & $\begin{array}{l}\text { Represents natural logarithm of: } \\
\text { Stock Return Volatility which is } \\
\text { the standard deviation of day to }\end{array}$ \\
\hline
\end{tabular}




\begin{tabular}{|c|c|c|c|}
\hline Variable & $\begin{array}{l}\text { Variable } \\
\text { Measure/ } \\
\text { Transfor- } \\
\text { mation }\end{array}$ & Data Base & Definitions \\
\hline & & $\begin{array}{l}\text { (using } \\
\text { formula) }\end{array}$ & $\begin{array}{l}\text { day logarithmic price changes. A } \\
\text { previous day } 260 \text {-day price } \\
\text { volatility equals the annualized } \\
\text { standard deviation of relative price } \\
\text { change of the } 260 \text { most recent } \\
\text { trading days closing price, } \\
\text { expressed in a percentage for the } \\
\text { day prior to the current. }\end{array}$ \\
\hline MARKET RISK & $\mathrm{Ln}$ & Bloomberg & $\begin{array}{l}\text { Represents the natural logarithm } \\
\text { of: Market Risk taken as market } \\
\text { beta. Beta estimate of a security's } \\
\text { future beta. This is an adjusted beta } \\
\text { derived from the past two years of } \\
\text { weekly data, but modified by the } \\
\text { assumption that a security's beta } \\
\text { moves towards the market average } \\
\text { over time. The formula used to } \\
\text { adjust beta is : Adjusted Beta = } \\
(0.66666) * \text { Raw Beta + (0.33333) } \\
\text { * } 1.0 \text {. } \\
\text { Where : Raw Beta } \\
\text { (EQY_RAW_BETA). Equities: } \\
\text { Values are calculated using } \\
\text { Relative Index (REL_INDEX) for } \\
\text { the security. Only the prices for the } \\
\text { stock and its relative index are used } \\
\text { in the calculation. }\end{array}$ \\
\hline ROA & as & Bloomberg & $\begin{array}{l}\text { Represents arsinh (or inverse } \\
\text { hyperbolic sine) of : } \\
\text { Return on Assets taken as a } \\
\text { percentage and indicates how } \\
\text { profitable a company is relative to } \\
\text { its total assets. ROA gives an idea } \\
\text { as to how efficient management is } \\
\text { at using its assets to generate } \\
\text { earnings. Calculated as: (Trailing } \\
12 \text { Months Net Income / Average } \\
\text { Total Assets) *100. }\end{array}$ \\
\hline
\end{tabular}




\begin{tabular}{|c|c|c|c|}
\hline Variable & $\begin{array}{l}\text { Variable } \\
\text { Measure/ } \\
\text { Transfor- } \\
\text { mation }\end{array}$ & Data Base & Definitions \\
\hline & & & $\begin{array}{l}\text { Where: } \\
\text { Trailing 12M Net Income is } \\
\text { income for the year ( TRAIL_ } \\
\text { 12M_NET_INC). } \\
\text { Average Total Assets is the } \\
\text { average of the beginning balance } \\
\text { and ending balance of total assets } \\
\text { (BS_TOT_ASSET). }\end{array}$ \\
\hline CAPEX & $\mathrm{Ln}$ & $\begin{array}{l}\text { Constructed } \\
\text { from } \\
\text { variables } \\
\text { available on } \\
\text { Bloomberg }\end{array}$ & $\begin{array}{l}\text { Represents total capital } \\
\text { expenditure (CAPEX) scaled by } \\
\text { total assets. The separate values of } \\
\text { Capex and Total assets are } \\
\text { obtained from Bloomberg. } \\
\text { CAPEX is the amount the } \\
\text { company spent on purchases of } \\
\text { tangible fixed assets. It excludes } \\
\text { purchases of investments. For } \\
\text { utility companies, capital } \\
\text { expenditures is composed of the } \\
\text { sum of additions to utility plant, } \\
\text { decommissioning funds, and non- } \\
\text { utility capital expenditures. } \\
\text { (CAPITAL_EXPEND). } \\
\text { Total Assets are the total of all } \\
\text { short and long-term assets as } \\
\text { reported on the Balance Sheet. } \\
\text { (BS_TOT_ASSET) }\end{array}$ \\
\hline LEVERAGE & Ratio & $\begin{array}{l}\text { Constructed } \\
\text { from } \\
\text { variables } \\
\text { available on } \\
\text { Bloomberg }\end{array}$ & $\begin{array}{l}\text { Represents total debt scaled by } \\
\text { firm value. } \\
\text { Where: } \\
\text { Total Debt is the sum of short term } \\
\text { debt (BS_ST_BORROW) and } \\
\text { long term debt } \\
\text { (BS_LT_BORROW). } \\
\text { Firm value is constructed as sum of } \\
\text { market value of equity } \\
\text { (CUR_MKT_CAP), total debt (as }\end{array}$ \\
\hline
\end{tabular}




\begin{tabular}{|c|c|c|c|}
\hline Variable & $\begin{array}{l}\text { Variable } \\
\text { Measure/ } \\
\text { Transfor- } \\
\text { mation }\end{array}$ & Data Base & Definitions \\
\hline & & & $\begin{array}{l}\text { above) and preferred equity } \\
\text { (BS_PFD_EQY). }\end{array}$ \\
\hline SIZE & $\mathrm{Ln}$ & Bloomberg & $\begin{array}{l}\text { Represents natural logarithm of : } \\
\text { Sales/Revenue/Turnover - Total of } \\
\text { operating revenues less various } \\
\text { adjustments to gross sales } \\
\text { (SALES_REV_TURN). } \\
\text { Adjustments: Returns, discounts, } \\
\text { allowances, excise taxes, insurance } \\
\text { charges, sales taxes, and value } \\
\text { added taxes (VAT). Includes } \\
\text { revenues from financial } \\
\text { subsidiaries in industrial } \\
\text { companies if the consolidation } \\
\text { includes those subsidiaries } \\
\text { throughout the report. Excludes } \\
\text { inter-company revenue. Excludes } \\
\text { revenues from discontinued } \\
\text { operations. Includes subsidies } \\
\text { from federal or local government } \\
\text { in certain industries (i.e. } \\
\text { transportation or utilities). }\end{array}$ \\
\hline $\operatorname{ROA}(t-1)$ & as & Bloomberg & $\begin{array}{l}\text { Represents one year lag of arsinh } \\
\text { (return on asset value). }\end{array}$ \\
\hline LIQUIDITY & $\mathrm{Ln}$ & $\begin{array}{l}\text { Constructed } \\
\text { from } \\
\text { variables } \\
\text { available on } \\
\text { Bloomberg }\end{array}$ & $\begin{array}{l}\text { Represents natural logarithm of } \\
\text { quick ratio. Calculated as Liquid } \\
\text { Assets/Current Liabilities. } \\
\text { (QUICK_RATIO) } \\
\text { Where: } \\
\text { Liquid Assets= Cash and Near } \\
\text { Cash Items +Marketable Securities } \\
\text { and Short Term Investments + } \\
\text { Accounts Receivable and Notes } \\
\text { Receivable. }\end{array}$ \\
\hline R\&D & Binary & $\begin{array}{l}\text { Constructed } \\
\text { from } \\
\text { variables } \\
\text { available on } \\
\text { Bloomberg } \\
\end{array}$ & $\begin{array}{l}\text { Dummy variable taken as } 1 \text { if } \\
\text { company has research and } \\
\text { development } \\
\text { otherwise zero. } \\
\text { Where: }\end{array}$ \\
\hline
\end{tabular}




\begin{tabular}{|c|c|c|c|}
\hline Variable & $\begin{array}{l}\text { Variable } \\
\text { Measure/ } \\
\text { Transfor- } \\
\text { mation }\end{array}$ & Data Base & Definitions \\
\hline & & & $\begin{array}{l}\text { R\&D is total research and } \\
\text { expenditures } \\
\text { development } \\
\text { incurred which includes R\&D in } \\
\text { profit and loss account and } \\
\text { capitalized R\&D during the period. } \\
\text { In the case where R\&D } \\
\text { expenditure is not disclosed, this } \\
\text { field may only return profit and } \\
\text { loss account only. This figure may } \\
\text { or may not be gross of government } \\
\text { grants, subsidies, tax credits as this } \\
\text { depends on the company } \\
\text { disclosure. (IS_RD_EXPEND). }\end{array}$ \\
\hline TLCF & Binary & $\begin{array}{l}\text { Constructed } \\
\text { from } \\
\text { variables } \\
\text { available on } \\
\text { Compustat }\end{array}$ & $\begin{array}{l}\text { Represents Tax Loss Carry } \\
\text { Forward taken as a dummy } \\
\text { variable of } 1 \text { if company has tax } \\
\text { loss carry forward, otherwise } 0 \text {. }\end{array}$ \\
\hline VOL & Ln & $\begin{array}{l}\text { Constructed } \\
\text { from } \\
\text { Bloomberg } \\
\text { (using } \\
\text { formula) }\end{array}$ & $\begin{array}{l}\text { Represents stock return volatility } \\
\text { and taken as the natural logarithm } \\
\text { of Stock Return Volatility, defined } \\
\text { earlier. }\end{array}$ \\
\hline \multicolumn{4}{|c|}{ Other measures used for the sensitivity analyses } \\
\hline SALES/VALUE & Ratio & $\begin{array}{l}\text { Constructed } \\
\text { from } \\
\text { Bloomberg }\end{array}$ & $\begin{array}{l}\text { This measure is taken as total sales } \\
\text { scaled by firm value. } \\
\text { Sales Represents: } \\
\text { Sales/Revenue/Turnover - Total of } \\
\text { operating revenues less various } \\
\text { adjustments to gross sales } \\
\text { (SALES_REV_TURN). } \\
\text { Firm Value is constructed as: } \\
\text { Market capitalization + Total debt } \\
+ \text { Preferred Equity where: } \\
\text { Firm value is constructed as sum of } \\
\text { market value of equity } \\
\text { (CUR_MKT_CAP), total debt (as }\end{array}$ \\
\hline
\end{tabular}




\begin{tabular}{|c|c|c|c|}
\hline Variable & $\begin{array}{l}\text { Variable } \\
\text { Measure/ } \\
\text { Transfor- } \\
\text { mation }\end{array}$ & Data Base & Definitions \\
\hline & & & $\begin{array}{l}\text { above) and preferred equity } \\
\text { (BS_PFD_EQY). }\end{array}$ \\
\hline CAPEX1 & $\mathrm{Ln}$ & Bloomberg & $\begin{array}{l}\text { Represents total capital } \\
\text { expenditure (CAPEX). } \\
\text { CAPEX is the amount the } \\
\text { company spent on purchases of } \\
\text { tangible fixed assets. It excludes } \\
\text { purchases of investments. For } \\
\text { utility companies, capital } \\
\text { expenditures is composed of the } \\
\text { sum of additions to utility plant, } \\
\text { decommissioning funds, and non- } \\
\text { utility capital expenditures. } \\
\text { (CAPITAL_EXPEND). }\end{array}$ \\
\hline $\mathrm{CASH} / \mathrm{TA}$ & Ratio & $\begin{array}{l}\text { Constructed } \\
\text { from } \\
\text { Bloomberg }\end{array}$ & $\begin{array}{l}\text { Taken as total cash scaled by total } \\
\text { assets where: } \\
\text { Cash represents: } \\
\text { BS_CASH_NEAR_CASH_ITEM } \\
\text { Total Assets are the total of all } \\
\text { short and long-term assets as } \\
\text { reported on the Balance Sheet. } \\
\text { (BS_TOT_ASSET). }\end{array}$ \\
\hline LEVERAGE2 $^{c}$ & $\mathrm{Ln}$ & As above & $\begin{array}{l}\text { This represents the square of the } \\
\text { leverage predicted value. Where } \\
\text { leverage represents total debt } \\
\text { scaled by total market value of } \\
\text { assets. } \\
\text { Where: } \\
\text { Total Debt is the sum of short term } \\
\text { debt (BS_ST_BORROW) and } \\
\text { long term } \\
\text { (BS_LT_BORROW). } \\
\text { Market Value of Total Assets is } \\
\text { constructed as sum of market value } \\
\text { of equity (CUR_MKT_CAP), total }\end{array}$ \\
\hline
\end{tabular}




\begin{tabular}{|c|c|c|c|}
\hline Variable & $\begin{array}{l}\text { Variable } \\
\text { Measure/ } \\
\text { Transfor- } \\
\text { mation }\end{array}$ & Data Base & Definitions \\
\hline & & & $\begin{array}{l}\text { debt (as above) and preferred } \\
\text { equity (BS_PFD_EQY). }\end{array}$ \\
\hline LEVERAGE $^{\mathrm{a}}$ & $\mathrm{Ln}$ & Bloomberg & $\begin{array}{l}\text { Represents the predicted value of } \\
\text { LEVERAGE as defined above. }\end{array}$ \\
\hline $\begin{array}{l}\text { LEVERAGE }^{\mathrm{a}}{ }_{-} \\
1 /(\mathrm{BV} / \mathrm{MV})\end{array}$ & & $\begin{array}{l}\text { Constructed } \\
\text { from } \\
\text { Bloomberg }\end{array}$ & $\begin{array}{l}\text { Represents LEVERAGE predicted } \\
\text { value multiplied into inverse of } \\
\text { BV/MV }\end{array}$ \\
\hline $\begin{array}{l}\text { LEVERAGE2 }^{\mathrm{c}} \\
1 /(\mathrm{BV} / \mathrm{MV})\end{array}$ & & $\begin{array}{l}\text { Constructed } \\
\text { from } \\
\text { Bloomberg }\end{array}$ & $\begin{array}{l}\text { Represents the square of predicted } \\
\text { LEVERAGE value multiplied into } \\
\text { the inverse of BV/MV }\end{array}$ \\
\hline $\mathrm{BV} / \mathrm{MV}$ & Ratio & Bloomberg & $\begin{array}{l}\text { Taken as book value of equity } \\
\text { scaled by market value of equity } \\
\text { Taken as inverse of } \\
\text { (PX_TO_BOOK_RATIO) }\end{array}$ \\
\hline Q & as & Bloomberg & $\begin{array}{l}\text { Taken as Tobins Q. It represents } \\
\text { the ratio of the market value of a } \\
\text { firm to the replacement cost of the } \\
\text { firm's assets. The Q ratio is taken } \\
\text { from TOBIN_Q_Ratio. }\end{array}$ \\
\hline MB & $\mathrm{Ln}$ & Bloomberg & $\begin{array}{l}\text { Taken as the market to book ratio } \\
\text { as market price per share scaled by } \\
\text { book value per share as: } \\
\text { PX_TO_BOOK_RATIO. }\end{array}$ \\
\hline FINCONSTR1 & Binary & $\begin{array}{l}\text { Constructed } \\
\text { from } \\
\text { Bloomberg }\end{array}$ & $\begin{array}{l}\text { Constructed as a dummy variable } \\
\text { with a value of } 1 \text { for those firms } \\
\text { with a cash stock lower than } \\
\text { average and the growth measure } \\
\text { being greater than the mean }\end{array}$ \\
\hline FINCONSTR2 & Binary & As above & $\begin{array}{l}\text { Constructed as a dummy variable } \\
\text { of } 1 \text { if the debt ratio is greater than } \\
\text { the median debt ratio for the } \\
\text { sample and also the current ratio is } \\
\text { less than the median of the sample }\end{array}$ \\
\hline FINCONSTR3 & Ratio & As above & $\begin{array}{l}\text { This represents the book to market } \\
\text { ratio taken as: book value per share }\end{array}$ \\
\hline
\end{tabular}




\begin{tabular}{|c|c|c|c|}
\hline Variable & $\begin{array}{l}\text { Variable } \\
\text { Measure/ } \\
\text { Transfor- } \\
\text { mation }\end{array}$ & Data Base & Definitions \\
\hline & & & $\begin{array}{l}\text { scaled by market price per share } \\
\text { i.e. } \mathrm{BV} / \mathrm{MV} \text {. }\end{array}$ \\
\hline TOTALFIRMSIZE & $\mathrm{Ln}$ & As above & $\begin{array}{l}\text { Constructed as: Market } \\
\text { capitalization + Total debt }+ \\
\text { Preferred Equity where: } \\
\text { Market capitalization is } \\
(\text { CUR_MKT_CAP), total debt (as } \\
\text { above) and preferred equity } \\
(\text { BS_PFD_EQY). Total Debt is the } \\
\text { sum of short term debt } \\
(\text { BS_ST_BORROW) and long } \\
\text { term debt(BS_LT_BORROW). }\end{array}$ \\
\hline ZSCORE & $\mathrm{Ln}$ & Bloomberg & $\begin{array}{l}\text { Indicates the probability of a } \\
\text { company entering bankruptcy } \\
\text { within the next two years. A score } \\
\text { above } 3 \text { indicates bankruptcy is } \\
\text { unlikely, below } 1.8 \text { bankruptcy is } \\
\text { possible. Where: the Z Score is } \\
\text { obtained through: ALTMAN_Z_ } \\
\text { SCORE which is= } 1.2^{*} \text { (Working } \\
\text { Capital/Tangible Assets) + } \\
\text { 1.4*(Retained Earnings/ } \\
\text { TangibleAssets)+0.6*(Market } \\
\text { Value of Equity/Total Liabilities) } \\
+ \text { (Sales/Tangible Assets). }\end{array}$ \\
\hline VROE & & Constructed & $\begin{array}{l}\text { Variance of } 3 \text { years ROE - as } \\
\text { defined above }\end{array}$ \\
\hline Sales & $\mathrm{Ln}$ & Bloomberg & Same as defined as SIZE \\
\hline Earnings Yield & as & Constructed & $\begin{array}{l}\text { Taken as: EPS/Market Share Price } \\
\text { Where EPS is Earnings Per Share } \\
\text { Share and 1/PE Ratio; Market } \\
\text { share price is PX_LAST }\end{array}$ \\
\hline MV of Equity & $\mathrm{Ln}$ & Bloomberg & $\begin{array}{l}\text { Taken as market capitalization and } \\
\text { is (CUR_MKT_CAP). }\end{array}$ \\
\hline
\end{tabular}

$\mathrm{Ln}=$ Natural logarithm function; as = Arc sinh as the inverse hyperbolic sine function. 
Table 5. 5: Expected Relations between Explanatory Variables and Derivatives

\begin{tabular}{|c|c|c|}
\hline Explanatory Variables & $\begin{array}{l}\text { Expected } \\
\text { Sign }\end{array}$ & Derivatives \\
\hline \multicolumn{3}{|c|}{ Corporate Governance Variables } \\
\hline Board Meetings & $+/-$ & Undetermined \\
\hline Board Size & $+/-$ & Undetermined \\
\hline Board Independence & $+/-$ & Undetermined \\
\hline Board Diversity & $+/-$ & Undetermined \\
\hline CEO Total Compensation & $+/-$ & Undetermined \\
\hline CEO Bonus & + & Increase \\
\hline CEO Base Salary & + & Increase \\
\hline CEO Age & $+/-$ & Undetermined \\
\hline CEO Tenure & $+/-$ & Undetermined \\
\hline Shareholders Insiders & - & Decrease \\
\hline Shareholders Block holders & - & Increase \\
\hline Shareholders Institution & $+/-$ & Undetermined \\
\hline Audit Committee Size & $+/-$ & Undetermined \\
\hline \multicolumn{3}{|l|}{ Other Control Variables } \\
\hline $\mathrm{R} \& \mathrm{D}$ & + & Increase \\
\hline Leverage & + & Increase \\
\hline Firm Size & $+/-$ & Undetermined \\
\hline Tax Convexity & $+/-$ & Undetermined \\
\hline Liquidity & - & Decrease \\
\hline
\end{tabular}

Expected Relations Between Explanatory Variables and Leverage

\begin{tabular}{lll}
\hline Explanatory Variables & $\begin{array}{l}\text { Expected } \\
\text { Sign }\end{array}$ & Leverage \\
\hline Derivatives & + & Increase \\
Other Control Variables & & \\
ROA & - & Decrease \\
Size & $+/-$ & Undetermined \\
Volatility & + & Increase \\
R\&D & - & Decrease \\
\hline
\end{tabular}


Table 5. 6: Expected Relations between Explanatory Variables and Risk

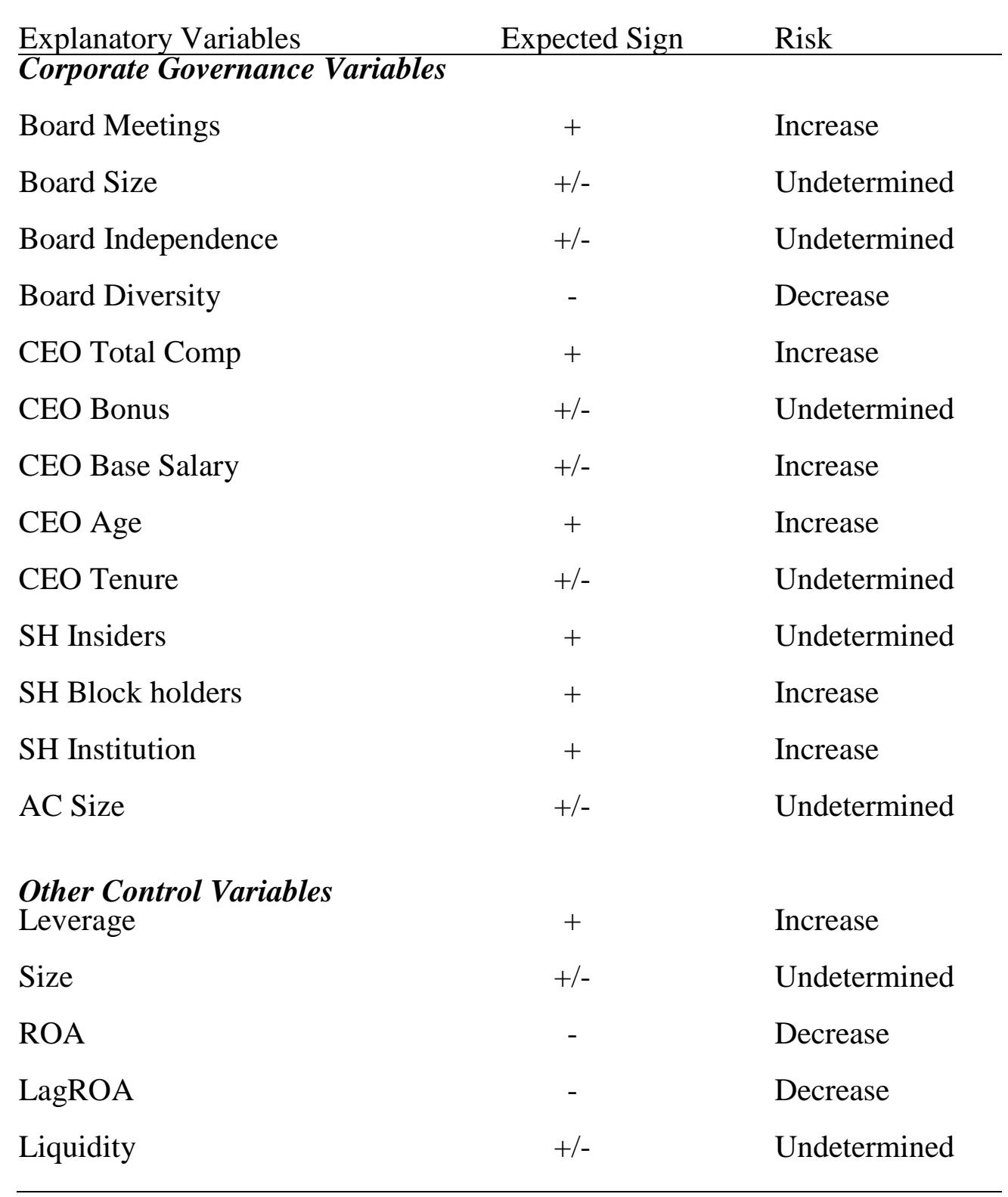


Table 5. 7: Expected Relations between Explanatory Variables and Value

\begin{tabular}{lcl}
\hline Explanatory Variables & Expected Sign & Value \\
\hline Corporate Governance Variables & & \\
Board Meetings & $+/-$ & Undetermined \\
Board Size & $+/-$ & Undetermined \\
Board Independence & $+/-$ & Undetermined \\
Board Diversity & + & Increase \\
CEO Total Comp & + & Increase \\
CEO Bonus & + & Increase \\
CEO Base Salary & + & Increase \\
CEO Age & - & Decrease \\
CEO Tenure & $+/-$ & Undetermined \\
SH Insiders & - & Decrease \\
SH Block holders & - & Decrease \\
SH Institutional Majority & - & Decrease \\
Audit Committee Size & - & Decrease \\
Other Control Variables & + & \\
R\&D & + & Increase \\
Leverage & + & \\
Size & + & Decrease \\
ROA & + & Undetermined \\
CAPEX & + & Increase \\
\hline
\end{tabular}




\subsection{Regression Models}

In Table 5.8, I summarize the regression models used to test the hypotheses of this study.

Table 5.8: Model Specifications for All Models in the Study

\begin{tabular}{|c|c|}
\hline Model 1a & $\begin{aligned} \text { DER }_{i, t}=a_{0}+ & a_{1} \text { BDMTGS }_{i, t}+a_{2} \text { BDSIZE }_{i, t}+a_{3} \text { BDINDEP }_{i, t} \\
& +a_{4} \text { BDDIVERS }_{i, t}+a_{5} \text { SHINSIDER }_{i, t} \\
& +a_{6} \text { SHINST }_{i, t}+a_{7} \text { SHBLOCK }_{i, t}+a_{8} \text { CEOAGE }_{i, t} \\
& +a_{9} \text { CEOTENURE }_{i, t}+a_{10} \text { CEOCOMP }_{i, t} \\
& +a_{11} \text { CEOBONUS }_{i, t}+a_{12} \text { CEOSALARY }_{i, t} \\
& +a_{13} \text { ACSIZE }_{i, t}+a_{14} \text { LEVERAGE }_{i, t}+a_{15} \text { SIZE }_{i, t} \\
& +a_{16} \text { RED }_{i, t}+a_{17} \operatorname{TLCF}_{i, t}+a_{18} \text { LIQUIDITY }_{i, t} \\
& +\alpha_{i, t}\end{aligned}$ \\
\hline \multirow[t]{2}{*}{ Model 1b } & $\begin{aligned} \operatorname{LEVERAGE}_{i, t}^{*} & =b_{0}+b_{1} \operatorname{DERUSE}_{i, t}^{*}+b_{2} R O A_{i, t}+b_{3} \operatorname{SIZE}_{i, t} \\
& +b_{4} V O L_{i, t}+b_{5} R \& D_{i, t}+\beta_{i, t}\end{aligned}$ \\
\hline & $\begin{aligned} \text { DER }_{i, t}^{*}=c_{0}+ & c_{1} \text { BDMTGS }_{i, t}+c_{2} \text { BDSIZE }_{i, t}+c_{3} \text { BDINDEP }_{i, t} \\
& +c_{4} \text { BDDIVERS }_{i, t}+c_{5} \text { SHINSIDER }_{i, t} \\
& +c_{6} \text { SHINST }_{i, t}+c_{7} \text { SHBLOCK }_{i, t}+c_{8} \text { CEOAGE }_{i, t} \\
& +c_{9} \text { CEOTENURE }_{i, t}+c_{10} \text { CEOCOMP }_{i, t} \\
& +c_{11} \text { CEOBONUS }_{i, t}+c_{12} \text { CEOSALARY }_{i, t} \\
& +c_{13} \text { ACSIZE }_{i, t}+c_{14} \text { LEVERAGE }_{i, t}^{*}+c_{15} \operatorname{SIZE}_{i, t} \\
& +c_{16} \text { R\&D }_{i, t}+c_{17} \text { TLCF }_{i, t}+c_{18} \text { LIQUIDITY }_{i, t}+\gamma_{i, t}\end{aligned}$ \\
\hline Model 2 & $\begin{aligned} \text { VALUE }_{i, t}= & d_{0}+d_{1} \text { BDMTGS }_{i, t}+d_{2} \text { BDSIZE }_{i, t}+d_{3} \text { BDINDEP }_{i, t} \\
& +d_{4} \text { BDDIVERS }_{i, t}+d_{5} \text { SHINSIDER }_{i, t} \\
& +d_{6} \text { SHINST }_{i, t}+d_{7} \text { SHBLOCK }_{i, t}+d_{8} \text { CEOAGE }_{i, t} \\
& +d_{9} \text { CEOTENURE }_{i, t}+d_{10} \text { CEOCOMP }_{i, t} \\
& +d_{11} \text { CEOBONUS }_{i, t}+d_{12} \text { CEOSALARY }_{i, t} \\
& +d_{13} \text { ACSIZE }_{i, t}+d_{14} \text { LEVERAGE }_{i, t}+d_{15} R \& D_{i, t} \\
& +d_{16} \text { ROA }_{i, t}+d_{17} \text { SIZE }_{i, t}+d_{18} \text { CAPEX }_{i, t}+\delta_{i, t}\end{aligned}$ \\
\hline
\end{tabular}




\begin{tabular}{|c|c|}
\hline Model 3 & $\begin{aligned} \text { CASHFLOWV } & \text { LATILITYi,t } \\
& =e_{0}+e_{1} \text { BDMTGS }_{i, t}+e_{2} \text { BDSIZE }_{i, t} \\
& +e_{3} \text { BDINDEP }_{i, t}+e_{4} \text { BDDIVERS }_{i, t} \\
& +e_{5} \text { SHINSIDER }_{i, t}+e_{6} \text { SHINST }_{i, t} \\
& +e_{7} \text { SHBLOCK }_{i, t}+e_{8} \text { CEOAGE }_{i, t} \\
& +e_{9} \text { CEOTENURE }_{i, t}+e_{10} \text { CEOCOMP }_{i, t} \\
& +e_{11} \text { CEOBONUS }_{i, t}+e_{12} \text { CEOSALARY }_{i, t} \\
& +e_{13} \text { ACSIZE }_{i, t}+e_{14} \text { LEVERAGE }_{i, t}+e_{15} \text { ROA }_{i, t} \\
& +e_{16} \text { lagROA }_{i, t}+e_{17} \text { SIZE }_{i, t}+e_{18} \text { LIQUIDITY }_{i, t} \\
& +\varepsilon_{i, t}\end{aligned}$ \\
\hline Model 4 & $\begin{aligned} & \text { STOCKRETURNVOLATILITY } i, t \\
&=f_{0}+f_{1} \text { BDMTGS }_{i, t}+f_{2} \text { BDSIZE }_{i, t} \\
&+f_{3} \text { BDINDEP }_{i, t}+f_{4} \text { BDDIVERS }_{i, t} \\
&+f_{5} \text { SHINSIDER }_{i, t}+f_{6} \text { SHINST }_{i, t}+f_{7} \text { SHBLOCK }_{i, t} \\
&+f_{8} \text { CEOAGE }_{i, t}+f_{9} \text { CEOTENURE }_{i, t} \\
&+f_{10} \text { CEOCOMP }_{i, t}+f_{11} \text { CEOBONUS }_{i, t} \\
&+f_{12} \text { CEOSALARY }_{i, t}+f_{13} \text { ACSIZE }_{i, t} \\
&+f_{14} \text { LEVERAGE }_{i, t}+f_{15} \text { ROA }_{i, t}+f_{16} \text { lagROA }_{i, t} \\
&+f_{17} \text { SIZE }_{i, t}+f_{18} \text { LIQUIDITY Y }_{i, t}+\epsilon_{i, t}\end{aligned}$ \\
\hline Model 5 & $\begin{aligned} \text { MARKETRISK }, t & \\
& =g_{0}+g_{1} \text { BDMTGS }_{i, t}+g_{2} \text { BDSIZE }_{i, t} \\
& +g_{3} \text { BDINDEP }_{i, t}+g_{4} \text { BDDIVERS }_{i, t} \\
& +g_{5} \text { SHINSIDER }_{i, t}+g_{6} \text { SHINST }_{i, t} \\
& +g_{7} \text { SHBLOCK }_{i, t}+g_{8} \text { CEOAGE }_{i, t} \\
& +g_{9} \text { CEOTENURE }_{i, t}+g_{10} \text { CEOCOMP }_{i, t} \\
& +g_{11} \text { CEOBONUS }_{i, t}+g_{12} \text { CEOSALARY }_{i, t} \\
& +g_{13} \text { ACSIZE }_{i, t}+g_{14} \text { LEVERAGE }_{i, t}+g_{15} \text { ROA }_{i, t} \\
& +g_{16} \text { lagROA }_{i, t}+g_{17} \text { SIZE }_{i, t}+g_{18} \text { LIQUIDITY }_{i, t} \\
& +\theta_{i, t}\end{aligned}$ \\
\hline
\end{tabular}


To examine for the effect of corporate governance on derivatives, I use Models 1a and 1b. These two equations are used to test for hypotheses described in Chapter 4. Model 1a uses the probit regression methodology and Model $1 \mathrm{~b}$ applies a simultaneous equations model to test the effect of corporate governance on derivatives.

Model 2 is the regression model that tests for the hypotheses related to how corporate governance influences the value effect of derivatives. In order to examine for the hypotheses related to the impact of corporate governance on the risk effect of derivatives, I use Models 3, 4 and 5.

\subsection{Research Methodology}

\section{Split Models for Derivative Users and Derivative Non-Users}

A majority of studies in derivatives literature split their sample into hedgers and nonhedgers. This enables researchers to examine the features of firms that use derivatives and those that do not hedge with derivatives. Studies further support their examination with additional tests such as Mann Whitney (1947), Wilcoxon (1945) and other independent t-tests, that examine the differences in the means of individual firm characteristics. These examinations provide an important insight into the value, risk, assets and liabilities, and other differences in firm characteristics that induce hedging and/or provide advantages from derivatives hedging, or otherwise.

An alternative method to splitting the sample, would be the use of an interaction effect with derivatives. For example, Campello et al. (2011) examine the joint hedging and risk effects on capital expenditure covenant restrictions. Fauver and Naranjo (2010) use the joint effect of hedging and agency factors to study the agency costs and 
monitoring effects on firm value. While, Manchiraju et al., (2014) use an interaction effect to assess whether derivatives are used for hedging or non-hedging purposes, based on the SFAS 161 disclosures. Huang et al. (2013) also examines the joint effect of derivatives and corporate governance on firm risk.

The joint effects of numerous independent variables (with derivatives use) in one regression model causes high problems of multicollinearity and hinders analyses. Thus, this may also be one of the main reasons why researchers favor the splitting of the sample, over joint effects, to compare hedging activities. Hentschel and Kothari (2001) split their sample into non-financial firms and financial firms and then compare all firms with firms hedging with derivatives. They examine their respective risk exposure using equity return volatility. Petersen and Thiagarajan (2000) examine the mining industry in the US. They compare two mines where one uses derivatives to hedge while the other is a non-user of derivatives but relies on operational and financial hedging strategies. Their study examines the differences in the effects on equity, asset, investment and cash flow risk exposures. Another recent study investigates three different samples: derivative non-users, users and new users to study the impact of financial derivatives on corporate tax avoidance (Donohoe, 2015). However, Gonzalez and Yun (2013) are interested in weather derivatives and divide their sample of hedgers into pre-1997 and post-1997 groups to study the impact on firm value and risk management.

Therefore, in the manner used by Bartram et al., (2011), Allayannis and Weston (2001), Jin and Jorion (2006) and Guay (1999), I split the full sample into derivatives users and non-users and study the impact of corporate governance on firm value and risk in both groups. This method enables me to examine the effects of thirteen corporate governance mechanisms in a single regression model, without problems with multicollinearity. I also study differences in the individual firm characteristics 
between hedgers and non-hedgers by applying the Mann Whitney-Wilcoxon (MWW) test. Unlike the Chow Test (1960) that tests whether on the whole the coefficients in two linear regressions are equal, this method has the added advantage of providing the significance in the differences in each individual variable between the two samples, and is widely used in the derivatives literature.

\section{Empirical Models - Ordinary Least Squares (OLS)}

Using the split sample, I conduct OLS regression to test related hypotheses presented in Chapter 4. I use Tobin's Q as the dependent variable to capture firm value and regress this on corporate governance variables for the two samples: firms that hedge with derivatives and those that do not.

Subsequently, I also use OLS regressions to test hypotheses related to cash flow volatility, stock return volatility and market risk as dependent variables for various risks models that have been described earlier in Section 5.6. I examine the effects for corporate governance on each risk element for the two samples of hedgers and nonhedgers.

\section{Derivatives - Simultaneous Equations Model}

Titman (1992) explains how borrowing affects hedging decisions of the firm. He suggests that investors sometimes may borrow short-term and swap for a long-term obligation and likewise they may also borrow long-term and swap for a short-term obligation. Thus firms would swap to gain benefits of better interest rates and

financing costs. Similarly, firms may use the swap market to alter the duration of their liabilities. Titman (1992) shows that the main reasons behind this is firstly, financial 
distress may motivate some firms to decrease their insecurity about future interest charges. Secondly, investors with asymmetric information may encourage firms to borrow short-term so that they can benefit from more favorable rates in the future. Similarly, research suggests indicates there is a simultaneity in the use of debt and derivatives.

Geczy et al. (1997) support this view and contend that there is a simultaneous relationship in a firm's capital structure and derivatives decisions. They use Maddala's (1983) two-stage estimation technique to simultaneously examine the firm's hedging and capital decisions, using specifications proposed by Titman and Wessels (1988) and Opler and Titman (1996). Other researchers also use this model to study similar relationships (Dionne and Trikki, 2013; Graham and Rogers, 2002; Rogers, 2002). Similarly, I use a simultaneous equations model to study the simultaneous effect of debt financing and hedging on corporate governance. In the manner proposed by Maddala (1983), my simultaneous equations model is:

$$
\begin{aligned}
& \text { LEVERAGE }{ }^{*}=b_{0}+b_{1} D E R^{*}+b_{2} X_{1}+\gamma_{1} \\
& \text { DER }^{*}=c_{0}+c_{1} \text { LEVERAGE }+c_{2} X_{2}+\gamma_{2}
\end{aligned}
$$

where:

LEVERAGE* denotes debt, the continuous endogenous variable in equation (1)

$D E R^{*}$ denotes derivatives, the dichotomous endogenous variable in equation (2), and taken as 1 if $D E R^{*}>0$, and 0 otherwise

$X_{1}$ and $X_{2}$ represent the independent exogenous variables in (1) and (2)

$b_{2}$ and $c_{2}$ are vectors of parameters in (1) and (2)

$b_{1}$ and $c_{1}$ are the parameters of the endogenous variables in (1) and (2), $\gamma_{1}$ and $\gamma_{2}$ are the error terms of (1) and (2). 
For this model, I use control variables similar to those applied by the other researchers in the manner suggested by Titman and Wessels (1988) and Opler and Titman (1996). In the first equation of the model, $L E V E R A G E^{*}$ is the predicted value derived from the second equation. Equation (1) captures the simultaneous effect of capital structure in the decisions to use derivatives. $X_{1}$ comprise the control variables: investment growth; size, volatility, derivatives, and profitability. The second equation uses a probit regression model with derivatives as the dependent variable and $D E R^{*}$ is the predicted value derived from the first equation. $X_{2}$ represents the independent variables for corporate governance as discussed in Section 5.7 and the control variables described in Section 5.9. A definition of all explanatory variables are provided in Tables 5.3 and 5.4.

I use CDSIMEQ model developed by Keshk (2003) to extrapolate the results of the equation. The CDSIMEQ model is unique in that it is able to handle simultaneous equations models, where one endogenous variable is dichotomous and the other endogenous variable is continuous, unlike other models that require both endogenous variables to be continuous.

\section{Controlling for Potential Heteroscedasticity, Time-series Correlations of Pooled Data, and Year and Industry Effects.}

One of the Gauss-Markov assumptions regarding homoscedasticity infers that, error variance is not related to the explanatory variables. The constant error variance implies that the conditional variance of the dependent variable is also constant. However, heteroscedasticity is frequently encountered in cross-sectional regression models when the dependent variable is related to either one or more of the explanatory variables (Chai and Hayes, 2008). Though the failure of this assumption does not cause bias or inconsistency in the OLS estimators, however they are now inefficient and standard errors are not valid (Wooldridge, 2012). 
My study uses panel data in which companies are observed over an eight-year period from 2004-2011 and therefore there is the possibility of serial correlation of residuals. Fama and French (2002) indicate that cross-correlation problem and standard errors bias in regression slopes occur when the residuals are correlated across years. To handle this problem, I include industry and year fixed effects. Year and industry dummies control for correlations across observations of firms related to both time periods and industry effects.

Further, I also use the Newey-West (1987) estimator. The Huber White sandwich robust variance estimator (White 1980) produces consistent standard errors for OLS regression coefficient estimates in the presence of heteroscedasticity. The NeweyWest (1987) variance estimator is an extension of the above and produces consistent estimates for possible autocorrelation and heteroscedasticity. Therefore, this estimator handles autocorrelation up to and including a lag of $\mathrm{m}$ and thus, it assumes that any autocorrelation at lags greater than m can be ignored. I use Newey and West (1987) robust standard errors to correct for potential problems of heteroscedasticity and serial correlation and take lags up to 3 levels in my estimates.

The study period includes the financial crisis period which could influence the risk and value effects of financial derivatives in relation to corporate governance. Hence a dummy variable has been included to control for the financial crisis period with value 1 in years 2007 and 2008 and 0 in all other years. Similarly with respect to industry effects, the energy and utility industry is heavily regulated and generally exhibits a higher level of firm performance than the other industries. Therefore, to control for this the regression equations use a dummy variable with value 1 for the energy and utilities industry, and 0 otherwise. 


\section{Controlling for Potential Multicollinearity in Variables and Data Skewness and}

\section{Kurtosis.}

Another assumption of the OLS regression model requires that there is no perfect collinearity - or multicollinearity, in the sample. For example, if any one independent variable could be expressed as a linear combination of another independent variable, this assumption would be rejected. If the matrix displays perfect collinearity in any of the regressors, then the OLS estimates cannot be computed as mathematically, these do not exist (Wooldridge, 2012).

To assess for the potential problem of multicollinearity in my samples, I examine the variance inflation factors (VIF) and Tolerance factor with regard to my regression models. Further in order to reduce skewness and kurtosis in the continuous variables, I use the arsinh transformations for variables that have a large number of negative or zero numbers. The inverse hyperbolic sine function also expressed as: arsinh (x) or

$\sinh ^{-1}(x)$ and is defined as $\left[\log \left(x+\sqrt{\left.x^{2}+1\right)}\right.\right.$. Sokal and Rohlf (1981, p. 859) use this function to correct variance in the error term of their regressions. The arsinh function has a benefit over the log function as it also transforms and retains negative and zero values. Therefore, the arsinh function transforms large positive values of $\mathrm{x}$ to approach the $\log (2 x)$ (Anscombe, 1948; Laubscher, 1961; Sokal and Rohlf, 1981). This will ensure a comparatively larger sample of normalized data. In addition, I also use natural logarithm transformations for other variables, where necessary.

\subsection{Sensitivity Analyses and Alternative Tests}

The results for the model related to the firm value and risk effects, of the relationship of corporate governance and financial derivatives, are provided in Chapter 6. In order 
to check the robustness of my results, I conduct additional regression models on alternative dependent variables and also apply bootstrapping models. In order to achieve consistency with the main regression models, I use the Newey-West estimator in all the sensitivity analyses as well. This corrects for effects of serial correlation and heteroscedasticity to provide robust standard errors.

The results for the model that examines derivatives and corporate governance is provided in Chapter 7. In order to examine the robustness of these results, I conduct sensitivity analyses. These sensitivity tests examine whether other/additional measures for financing contracting costs and financing constraints; growth effects; investment opportunities and underinvestment problems; various levels of leverage; firm size effects and finally alternative measures for all the control variables; change my results.

Additional robustness tests are conducted to examine the effects of the global financial crises (GFC) on my results. I divide the sample into two groups: one for the GFC period and the other for the non-GFC period and apply the Iterated Seemingly Unrelated Regression Model (ISUR), discussed below, to all the value and risk models. The results are similar across the two groups. However, this model was not included, due to a space limitation in reporting the results of the thesis.

\section{Alternative tests - Iterated Seemingly Unrelated Regression Model (ISUR)}

I conduct alternative tests in order to assess the hedging effectiveness of corporate governance by examining both the value and risk effects of the derivatives-corporate governance relationship simultaneously, as depicted in Appendix 6. Typically, in a simultaneous equation the endogenous regressor in one equation forms the predicted dependent variable in the other equation and vice versa. This is not the case in the 
ISUR model, which enables the simultaneous examination of the value and risk without forcing an endogenous relation between the two equations. In this model the two equations are exogenous but have the errors correlated across the equations arising from the common factors that exist due to the derivatives environment.

Therefore, I examine the simultaneity of value and risk effect of derivatives through the Iterated Seemingly Unrelated Regressions (ISUR) (Zellner 1962; Zellner 1963). "For conditions generally encountered, I propose an estimation procedure which yields coefficient estimators at least asymptotically more efficient than single-equation least squares estimators". (Zellner, 1962, p. 348). The ISUR model uses the asymptotically efficient, feasible generalized least-squares algorithm. The regressions are related because the contemporaneous errors associated with the dependent variables may be correlated. Additionally, Zellner's (1962) seemingly unrelated regression will refuse to compute the estimators if the same equation is named more than once or the covariance matrix of the residuals is singular, also known as the cross-equation restrictions (or linear restrictions). Under the Zellner's ISUR methodology, the estimator process continues to iterate until convergence is achieved. Convergence is achieved when the change in parameter estimates is very small. Iteration will make the estimates be equivalent to maximum likelihood estimates of the system and therefore has additional advantages over the simple seemingly unrelated regression (SUR) model.

Therefore, the ISUR model I use to examine the value and risk effects of hedging together, while treating both equations as exogenous is:

$$
\begin{aligned}
& \mathrm{y}_{1}=\beta_{0}+\sum \beta_{1} \mathrm{~b}_{1}+\sum \mathrm{X}_{1}+\varepsilon_{1} \\
& \mathrm{y}_{2}=\gamma_{0}+\sum \gamma_{2} \mathrm{~B}_{2}+\sum \boldsymbol{\lambda}_{2}+\varepsilon_{2}
\end{aligned}
$$


where equation (3a) represents the value equation with and (3b) is the risk equation. $\mathrm{y}_{1}$ depicts value and $\mathrm{y}_{2}$ firm risk; $\mathrm{b}_{1}$ and $\mathrm{B}_{2}$ are the corporate governance variables and $\sum \mathrm{X}_{1}$ and $\sum \boldsymbol{\lambda}_{2}$ reflect all the control variables in each respective equation.

Table 5. 9: Specifications for ISUR Models

\begin{tabular}{|c|c|}
\hline Model 6 & 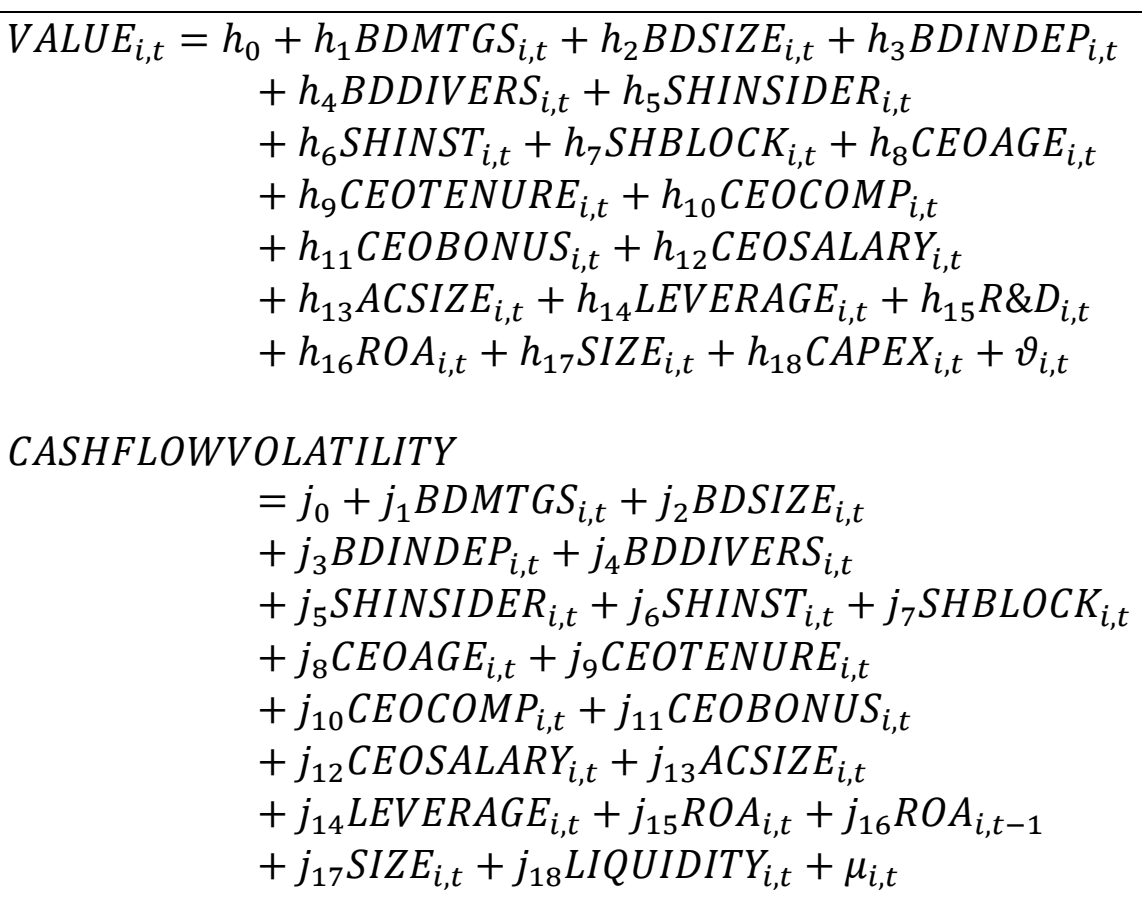 \\
\hline Model 7 & $\begin{aligned} \text { VALUE }_{i, t}=k_{0} & +k_{1} \text { BDMTGS }_{i, t}+k_{2} \text { BDSIZE }_{i, t}+k_{3} \text { BDINDEP }_{i, t} \\
& +k_{4} \text { BDDIVERS }_{i, t}+k_{5} \text { SHINSIDER }_{i, t} \\
& +k_{6} \text { SHINST }_{i, t}+k_{7} \operatorname{SHBLOCK}_{i, t}+k_{8} \text { CEOAGE }_{i, t} \\
& +k_{9} \text { CEOTENURE }_{i, t}+k_{10} \text { CEOCOMP }_{i, t} \\
& +k_{11} \text { CEOBONUS }_{i, t}+k_{12} \text { CEOSALARY }_{i, t} \\
& +k_{13} \text { ACSIZE }_{i, t}+k_{14} \text { LEVERAGE }_{i, t}+k_{15} R \& D_{i, t} \\
& +k_{16} \text { ROA }_{i, t}+k_{17} \text { SIZE }_{i, t}+k_{18} C A P E X_{i, t}+\pi_{i, t}\end{aligned}$ \\
\hline
\end{tabular}




\begin{tabular}{|c|c|}
\hline & $\begin{aligned} \text { STOCKRETURNVOLATILITY } & \\
& =l_{0}+l_{1} \text { BDMTG }_{i, t}+l_{2} \text { BDSIZE }_{i, t} \\
& +l_{3} \text { BDINDEP }_{i, t}+l_{4} \text { BDDIVERS }_{i, t} \\
& +l_{5} \text { SHINSIDER }_{i, t}+l_{6} \text { SHINST }_{i, t}+l_{7} \text { SHBLOCK }_{i, t} \\
& +l_{8} \text { CEOAGE }_{i, t}+l_{9} \text { CEOTENURE }_{i, t} \\
& +l_{10} \text { CEOCOMP }_{i, t}+l_{11} \text { CEOBONUS }_{i, t} \\
& +l_{12} \text { CEOSALARY }_{i, t}+l_{13} \text { ACSIZE }_{i, t} \\
& +l_{14} \text { LEVERAGE }_{i, t}+l_{15} \text { ROA }_{i, t}+l_{16} \text { ROA }_{i, t-1} \\
& +l_{17} \text { SIZE }_{i, t}+l_{18} \text { LIQUIDITY }_{i, t}+\rho_{i, t}\end{aligned}$ \\
\hline Model 8 & 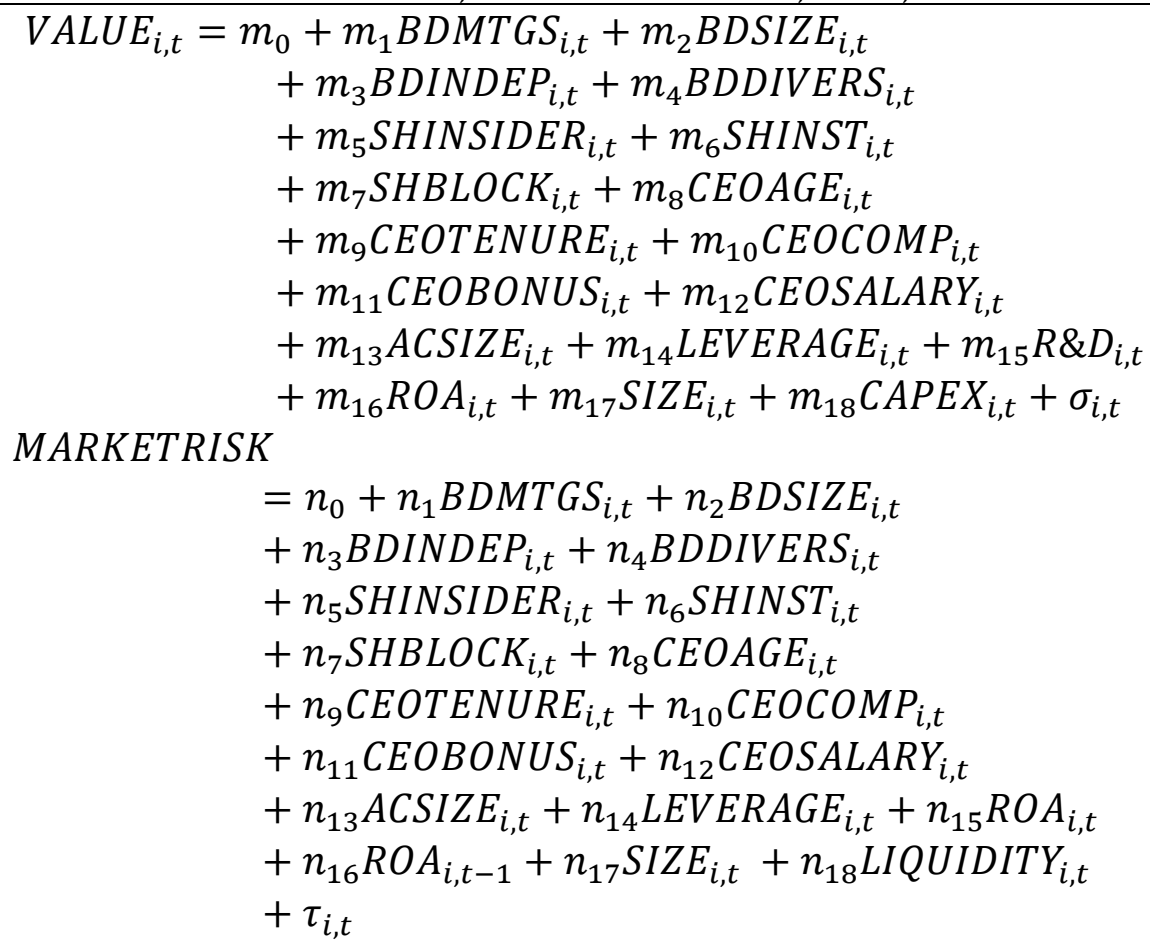 \\
\hline
\end{tabular}

\subsection{Chapter Summary}

This chapter builds on the theoretical framework and proposed hypotheses that are discussed in Chapter 4. This section elaborates on the sample selection and data collection processes of the study. There are basically two sample data-sets. The first data set comprises 6234 firm year observations and is used for all the regression 
models related to firm value and firm risk. The second data set of 6900 firm year observations provides the basis for testing corporate governance impact on derivatives.

Further, I describe measures used as proxies for the variables in the models: derivatives; firm value; systematic and unsystematic firm risks; and corporate governance variables. I follow this with details of control variables for each model and draw support for the proxies used and their measurements, from literature.

My investigation involves six regression models that test the hypotheses developed in the earlier chapter. I also include variable definitions extracted from the databases: Bloomberg, Compustat, Corporate Library and Direct Edgar.

The research methodology provides a description of the various methods used to test the hypotheses described in Chapter 4. Model 1a uses probit regression and Model 1b applies a simultaneous equations model to capture the simultaneity of hedging and capital structure/financing decisions within the firm. Models 2 to 5 employ the OLS regression with Newey-West corrected robust standard errors.

At the end I discuss the sensitivity analyses performed to confirm the validity of my results. I also provide a discussion of the alternative tests conducted to assess corporate governance effectiveness by examining both the value and risk effects of derivatives together. 


\section{CHAPTER SIX: RESULTS I: FIRM VALUE, FIRM RISK, DERIVATIVES AND CORPORATE GOVERNANCE}

\subsection{Introduction}

In this study I conduct two sets of tests to examine the hypotheses developed in Chapter 4. The first set of analyses examines the impact of corporate governance on the effect of derivatives on firm performance, specifically firm value and firm risk. I present results of this analyses in Chapter Six as Results I. The second group of tests examines the hypotheses related to the impact of corporate governance on derivatives. These tests investigate whether corporate governance is a determinant in the derivatives hedging decisions by the firm and I present the findings as Results II in Chapter Seven.

In this chapter I present the results for the value and risk models. Section 6.2 provides a summary of descriptive statistics of the sample variables that are employed in the empirical analyses. It includes sub-sections that investigate the differences in characteristics between derivative user and non user firms, including a review of the time-series effects. Section 6.3 presents the correlation analysis, variance inflation factors and tolerance indices of the variables examined in the study.

This is followed by the results of the empirical analyses. In Section 6.4, I provide findings of the empirical results pertaining to analysis of the impact of corporate governance mechanisms on firm value, with the sample split into derivative users and non users. Section 6.5 presents the results for the cash flow volatility model, in which I split the model into two regression models for derivative users and non users. Similarly, in Section 6.6, I provide the regression results for the split models related 
to the stock return volatility risk model and finally in Section 6.7 results for the two regression split models pertaining to market risk are provided. Each section has four regression models: base model, fixed effects model, White (1980) robust model and the Newey West (1987) robust model that corrects for heteroscedasticity and serial correlation.

In section 6.8, I provide the sensitivity tests performed relating to the empirical procedures applied in this chapter. The tests employ alternative specifications for the dependent variables and alternative methodology to support the robustness of the results. In section 6.9, I present alternative tests to examine the derivatives-corporate governance relationship on the simultaneous effects of firm value and firm risk. Finally, in Section 6.10 I present a summary of the chapter.

\subsection{Descriptive Statistics}

In Panel A of Table 6.1, I present summary statistics of the dependent variables related to firm value and firm risk. As reported in the table, the mean values for firm value, market risk, stock return volatility and cash flow volatility are $0.249,0.127,3.815$ and 1.630 respectively and the median values are $0.153,0.141,3.814$ and 0.040 respectively.

Panel B of Table 6.1 provides the descriptive statistics for the corporate governance variables. With respect to meetings (BDMTGS) held by boards, the statistics show that the number of meetings held by sample firms at the 5 percentile is 4 , and at the 95

percentile the number recorded is 15 meetings. However, on average firms hold 7.969 
meetings per year ${ }^{6}$. Board size (BDSIZE) statistics indicate that at the lowest (highest) percentile recorded boards have 6 members (13) and a mean and median of 8.867 and 9 members respectively, with a standard deviation of $2.154 .^{7}$ The composition of independent members on the board (BDINDEP) exhibit that on average boards have 6.47 independent members on their boards, with some boards containing 3 independent members at the 5 percentile and 10 members at the 95 percentile levels. ${ }^{8}$.

Board diversity (BDDIVERS) does not appear to be an important criterion for boards in my sample composition with an average of 1 female member on most boards and at a minimum some boards do not have any female members. Even at the 75 percentile, boards only have 2 female members, while at the highest percentile there are 3 members. ${ }^{9}$

With regard to CEOAGE, the table shows that the average age of CEOs is 55.34 years, with 50 years reported in the $1^{\text {st }}$ quartile and 60 years in the third quartile. The average duration of CEO service (CEOTENURE) for my sample is 8.68 years and with 3 years'

\footnotetext{
${ }^{6}$ This is in line with the findings of Vafaes (1999) and others (Karamanou and Vafeas, 2005) whose results indicate a mean of 7.45 meetings and median at 7 meetings. However, my sample has a larger deviation of 3.583 compared to 2.66 for Vafeas (1999).

${ }^{7}$ The sample dispersion is similar of Adams and Ferreira (2009) who also record a mean of 9.38 board size with a 2.68 standard deviation. However, it is lower than for others (Yermack, 1996; Karamanou and Vafeas, 2005) who report a mean in the range of 11.60 to 12.25.

${ }^{8}$ The whole sample shows a minimum of 1 member and maximum size of 16 . Overall it is similar to board size statistics for Adams and Ferreira (2009) and Karamanou and Vafeas (2005)

${ }^{9}$ Adams and Ferreira (2009) study gender diversity and provide support for my results, with a mean of 0.61 number of female directors, a minimum of 0 and maximum of 1 female member.
} 
tenure recorded the 1 st quartile and 11.25 years' tenure in the $3^{\text {rd }}$ quartile ${ }^{10}$. All CEO compensation variables have been transformed to the natural logarithm form. The natural logarithm value of mean CEOCOMP is $\$ 14.071$ and the $25^{\text {th }}$ and $75^{\text {th }}$ percentiles are $\$ 13.44$ and $\$ 14.74$ respectively ${ }^{11}$. The CEOCOMP is $\$ 15.861$ at the 95 percentile, which appears quite high for some of the larger companies in the sample ${ }^{12}$. CEOBONUS represents the cash and cash equivalent of all incentives paid to the CEO and the natural logarithm mean is $\$ 4.856$. This figure has been influenced by a large number of firms that record a zero bonus. The CEOSALARY represents CEO base salary, which can include non -cash elements and salary taken as deferred

${ }^{10}$ Coles et al. (2006) report a mean CEO age of 54 years, with 49 years in the $1^{\text {st }}$ quartile and 59 years in the $3^{\text {rd }}$ quartile. With respect to CEO tenure they report a mean CEO tenure of 7 years, with 2 years in the 1 st quartile and 10 years in the $3^{\text {rd }}$ quartile.

${ }^{11}$ In Table 6.1, the mean total compensation (CEOCOMP) is equivalent to $\$ 1.29$ million (Ln retransformed back to raw data). This is similar to Rogers (2002) who reports a mean total compensation of $\$ 1.76$ million. (Also see: Frydman and Jenter, 2010, p. 41), and Cyert et al. (2002) also reports a mean total compensation of $\$ 1.011$ million.

12 Adams and Ferreira (2009) report a very high maximum total compensation of $\$ 580.64$ million while Kang et al. (2006) show an even a higher maximum figure of $\$ 600.30$ million for total compensation, with mean of $\$ 2.98$ million. There is great variation in reported compensation figures and Cyert et al. (2002) reports $\$ 23.875$ million highest total compensation. 
compensation and the mean of sample is $\$ 13.38 .^{13}$ At the highest level reported the base salary is $\$ 14.127$ for some firms. ${ }^{14}$

In the literature there appears to be great variation in the reported CEO compensation descriptive statistics. This is mainly due to the different time periods employed in the various studies, diverse valuation methods applied, different firm structures (e.g. S\&P 100, NYSE, S\&P 500, etc.) and compositions in the samples, and different compensation dollar-year employed, to name a few differences. Other elements have also had an impact on compensation, such as the financial crisis period, various systemic factors, Troubled Asset Relief Program (TARP), among others.

The mean percentage for insider shareholding (SHINSIDER) is $13.8 \%$ and with $60.8 \%$ at the 95 percentile level. This appears in line with Wright et al. (1996) who record a mean insider ownership of $12.7 \%$ and a maximum of insider ownership of $80 \%$, and it also supports the statistics reported by others. ${ }^{15}$ Generally, it is surprising to see a low percentage of insider ownership in view of the recent focus on payment of larger

\footnotetext{
${ }^{13}$ In Table 6.1, the sum of mean bonus (CEOBONUS) and mean salary (CEOSALARY) is equivalent to $\$ 0.648$ million (Ln retransformed back). This is in line with Cyert et al. (2002) who indicate a mean bonus of $\$ 0.190$ million and mean base salary of $\$ 0.366$ million. Rajgopal and Shevlin (2002) study CEO bonus for the period from 1993-1997 and also report a mean bonus of $\$ 0.188$ million and salary of $\$ 0.372$ million. Guay (1999) reports a mean salary + bonus of $\$ 1.10$ million. Brick et al. (2006) and Coles et al. (2006) use a proxy "cash compensation" as sum of salary and bonus and report CEO mean cash compensation of $\$ 1.14$ million and \$1.60million respectively. However, Cornett et al. (2008) finds a higher mean at $\$ 2.72$ million but uses an S\&P 100 Index sample.
}

${ }^{14}$ In Table 6.1, the highest base salary (CEOSALARY) is equivalent to $\$ 1.365$ million (Ln retransformed back). Dittmann and Maug (2007) report a mean base salary $\$ 1.72$ million, while Cyert et al. (2002) has a mean base salary of $\$ 0.366$ million with a maximum of $\$ 2.693$ million.

${ }^{15}$ Borokhovich et al. (2004) have a mean managerial ownership percentage of $7.25 \%$, but a higher maximum of $72.90 \%$. Barnhart \& Rosenstein (1998) indicate a mean insider shareholding of $6 \%$ and maximum of $66 \%$. 
stock and stock option payouts to align managerial objectives with those of the shareholders.

Majority institutional shareholding (SHINST) is a binary variable of 1 where a firm has a majority percentage of institutional shareholding and otherwise 0 . The mean of 0.722 indicates that $72.2 \%$ of the firms in the sample have a majority of institutional shareholders which is in line with others that report a high institutional shareholding. For example, Wright et al. (1996) report a mean of 51\% institutional shareholding in their sample of firms, and record the highest level of shareholding at 96.9 percentage shareholding. Similarly, Graham and Rogers (2002) indicate a mean institutional percentage of 41.97 and a maximum of 90.38 percentage. ${ }^{16}$

The statistics for block shareholders (SHBLOCK) variable indicates those shareholders who own $5 \%$ or greater shareholding. The mean for block shareholders is $23.6 \%$, with $54.0 \%$ at the 95 percentile. There is some variation in the range of descriptive statistics for some researchers such as Wright et al. (1996) show a mean of $17.3 \%$, with a maximum of $76 \%$. Linck et al. (2008) report a higher mean percentage of $40.08 \%$ while Borokhovich et al. (2004) indicate an average percentage of $12.78 \%$ and a maximum of $65.25 \%$ for their sample of firms. In line with the measure used in this study, both authors use a similar definition of block holders as having $5 \%$ or greater ownership.

Finally, an examination of audit committee size (ACSIZE) indicates that the committees in my sample firms have a mean of 5.17 members, with 3 members at the

\footnotetext{
${ }^{16}$ With regard to institutional shareholding, Barnhart and Rosenstein (1998) report mean of $53.89 \%$ with a maximum reported at $98 \%$ ownership; Linck et al. (2008) indicate a mean of $34.16 \%$, while Hartzell and Starks (2003) observe mean of $53.1 \%$, and $77.3 \%$ at the 90 percentile.
} 
5 percentile and 10 members in the 95 percentile. Audit Committees appear to have a robust number of members and at the 75 percentile audit committee have 6 members, while some firms may have all board members sitting on the audit committee. Xie et al. (2003) also indicate a mean of 4.53 members for their sample.

Panel C of Table 6.1 provide the descriptive statistics for the control variables. An examination reveals that the sample have mean (median) return of assets (ROA) 1.295 (2.234); the mean (median) of firm leverage (LEVERAGE), as measured by total debt scaled by total firm size is $21.8 \%$ (15.9\%) with a standard deviation of 0.218 ; the mean (median) of firm size (SIZE) is measured as the natural logarithm of total sales is 7.088 (7.086) with a standard deviation of 1.862. The mean values for the one-year lag of return on assets $\left(\mathrm{ROA}_{(\mathrm{t}-1)}\right)$, capital expenditure (CAPEX), research and development expenditure (R\&D) and liquidity (LIQUIDITY) are 1.275, 0.052, 0.498, and 0.180 respectively. 
Table 6. 1: Descriptive Statistics for Value, Risk, Derivatives and Corporate Governance

\begin{tabular}{|c|c|c|c|c|c|c|c|c|}
\hline \multirow[b]{2}{*}{ Variables } & \multirow[b]{2}{*}{$\mathrm{N}$} & \multirow[b]{2}{*}{ Mean } & \multirow[b]{2}{*}{ Median } & \multirow{2}{*}{$\begin{array}{l}\text { Standard } \\
\text { deviation }\end{array}$} & \multicolumn{4}{|c|}{ Percentiles } \\
\hline & & & & & 5 & 25 & 75 & 95 \\
\hline \multicolumn{9}{|l|}{ Panel A: Dependent Variables } \\
\hline VALUE(Ln) & 6234 & 0.249 & 0.153 & 0.596 & -0.575 & -0.156 & 0.608 & 1.332 \\
\hline MARKET RISK(Ln) & 6234 & 0.127 & 0.141 & 0.354 & -0.439 & -0.090 & 0.363 & 0.659 \\
\hline STOCK RETURN VOLATILITY(Ln) & 6234 & 3.815 & 3.814 & 0.479 & 3.015 & 3.492 & 4.131 & 4.614 \\
\hline CASH FLOW VOLATILITY(ratio) & 6234 & 1.630 & 0.040 & 30.331 & 0.010 & 0.023 & 0.073 & 0.394 \\
\hline \multicolumn{9}{|l|}{ Panel B: Corporate Governance Variables } \\
\hline BDMTGS(no.) & 6234 & 7.969 & 7.000 & 3.583 & 4.000 & 6.000 & 9.000 & 15.000 \\
\hline BDSIZE(no.) & 6234 & 8.867 & 9.000 & 2.154 & 6.000 & 7.000 & 10.000 & 13.000 \\
\hline BDINDEP(no.) & 6234 & 6.466 & 6.000 & 2.174 & 3.000 & 5.000 & 8.000 & 10.000 \\
\hline BDDIVERS(no.) & 6234 & 1.003 & 1.000 & 0.990 & 0.000 & 0.000 & 2.000 & 3.000 \\
\hline CEOAGE(no.) & 6234 & 55.335 & 55.000 & 7.319 & 44.000 & 50.000 & 60.000 & 67.000 \\
\hline CEOTENURE(no.) & 6234 & 8.686 & 6.500 & 7.518 & 1.000 & 3.000 & 11.250 & 24.000 \\
\hline SHINSIDER(\%) & 6234 & 0.138 & 0.054 & 0.194 & 0.000 & 0.023 & 0.161 & 0.608 \\
\hline SHINST(\%) & 6234 & 0.722 & 1.000 & 0.448 & 0.000 & 0.000 & 1.000 & 1.000 \\
\hline SHBLOCK $(\%)$ & 6234 & 0.236 & 0.211 & 0.166 & 0.000 & 0.114 & 0.330 & 0.540 \\
\hline ACSIZE(no.) & 6234 & 5.175 & 5.000 & 2.184 & 3.000 & 4.000 & 6.000 & 10.000 \\
\hline CEOBONUS(Ln) & 6234 & 4.856 & 0.000 & 6.316 & 0.000 & 0.000 & 12.495 & 14.372 \\
\hline CEOSALARY(Ln) & 6234 & 13.382 & 13.396 & 0.500 & 12.612 & 13.060 & 13.741 & 14.127 \\
\hline CEOCOMP (Ln) & 6234 & 14.071 & 14.029 & 1.085 & 12.460 & 13.442 & 14.739 & 15.861 \\
\hline \multicolumn{9}{|l|}{ Panel C: Control Variables } \\
\hline ROA(as) & 6234 & 1.295 & 2.234 & 2.355 & -3.811 & 0.647 & 2.878 & 3.598 \\
\hline $\mathrm{ROA}_{\mathrm{t}-1}(\mathrm{as})$ & 6234 & 1.275 & 2.254 & 2.391 & -3.940 & 0.611 & 2.884 & 3.563 \\
\hline LEVERAGE(ratio) & 6234 & 0.218 & 0.159 & 0.218 & 0.000 & 0.026 & 0.342 & 0.665 \\
\hline CAPEX(ratio) & 6234 & 0.052 & 0.034 & 0.064 & 0.006 & 0.018 & 0.063 & 0.161 \\
\hline SIZE(Ln) & 6234 & 7.088 & 7.086 & 1.829 & 4.264 & 5.987 & 8.269 & 10.054 \\
\hline R\&D(dummy) & 6234 & 0.498 & 0.000 & 0.500 & 0.000 & 0.000 & 1.000 & 1.000 \\
\hline LIQUIDITY(Ln) & 6234 & 0.180 & 0.167 & 0.866 & -1.235 & -0.326 & 0.681 & 1.655 \\
\hline
\end{tabular}




\subsubsection{Analysis of Differences between Derivative User and Non User Firms}

In Table 6.2, I provide results of a univariate analysis of mean differences in value, risk, corporate governance and firm characteristics between derivative user and derivative non user firms. I use the Wilcoxon (1945) rank sum tests to examine differences in variables in both the groups. The Wilcoxon (1945) test examines the null hypothesis that there is no difference between the two test statistics and I need to reject the hypothesis in order to accept the alternate hypothesis that there is a difference in the two groups.

In Panel A of Table 6.2, I report the mean differences in the continuous dependent variables for derivative users and derivative non user firms. As reported in the table, the mean and median for VALUE is 0.1572 and 0.069; MARKET RISK is 0.128 and 0.141; STOCK RETURN VOLATILITY is 3.797 and 3.778; and CASH FLOW VOLATILITY is 1.461 and 0.040 respectively for derivative users. On the other hand, the mean (median) for derivative non user is 0.3283 (0.229), 0.126 (0.141), 3.831(3.835), 1.778 (0.0396) for VALUE, MARKET RISK, STOCK RETURN VOLATILILTY and CASH FLOW VOLATILITY, respectively.

The univariate analysis shows that the mean difference between firm value of derivative user and non user is statistically different at 0.01 percent level. Surprisingly, the value measure indicates that on an average the Tobin's $Q$ is lower for the derivative user firms. It is generally expected that hedging increases value and therefore derivative user firms should have higher values. However, my results are in line with Fauver and Naranjo (2010) who find that firms not using derivatives have a larger mean Q compared to users with a difference of 0.390. Allayannis et al. (2012) also record a higher Tobin's Q for derivative non user with a mean of 2.627 and median of 1.809 compared to derivative users of 1.976 and 1.436 respectively. Bartram et al. 
(2011) report a mean Tobin's Q of -0.099 for derivative users and 0.154 for non users exhibiting a similar trend in value measures for both the groups.

In respect of the risk measures, the results indicate that cash flow volatility and stock return volatility have statistically different mean values between derivative user and non user firms at a 0.01 percent level while market risk does not indicate any significant differences in the means between the two groups. The mean differences are 0.002 for market risk, -0.034 for stock return volatility and -0.317 for cash flow risk, indicating that unsystematic risks are lower for derivative users while systematic risk is higher. This is similar to Bartram et al. (2011) who also find cash flow and stock return volatility is lower for derivative users. Though Bartram et al. (2011) find a lower market risk for their corporate risk model, however for their country corporate risk model the market risk is higher for derivative users which reflects the mean difference for my results. As anticipated, a comparison between the two groups indicates that firms that use derivatives have a greater reduction in firm risk over firms not hedging with derivatives.

Panel B provides the univariate statistics for the corporate governance variables. Of the thirteen governance variables, BDMTGS, BDSIZE, BDINDEP, BDDIVERS, CEOAGE, CEOTENURE, SHINSIDER, SHINST, SHBLOCK, ACSIZE, CEOBONUS, CEOSALARY, CEOCOMP, all have statistically different mean values between the two groups at $1 \%$ level of significance, only CEOAGE differences do not appear to be significant. While derivative user firms have a larger mean for nearly all the governance variables, the mean differences for CEOTENURE, SHINSIDER and SHBLOCK is negative indicating that derivative non user firms on average have a larger number of managerial shareholders and block shareholders. Also CEOs in this group retain their positions for a longer period averagely. Surprisingly, the CEOs are paid higher salaries and bonuses in firms that use derivatives. The results thus indicate 
that firms hedging with derivatives appear to have a larger corporate governance structure, or this could simply be related to the larger firm size.

The other firm characteristics are provided in Panel C. The mean differences for return on asset (ROA) and lagged return on asset, $\operatorname{ROA}(\mathrm{t}-1)$ are higher for derivative users by 0.173 and 0.295 respectively. This is as expected however the differences are not statistically significant. Mean LEVERAGE is statistically higher for derivative users in line with theory that more financially distressed firms use hedging to increase debt capacity. Capital expenditure (CAPEX) and size (SIZE) mean values are larger for users and this is statistically significant for the one-tailed test at $10 \%$. It indicates that firms using derivatives are larger in size and also have higher investment growth opportunities on average. Theory suggests that lower liquidity reserves would be required for derivative users and this is reflected in the negative 0.299 difference in means between the two groups. However, the research and development (R\&D) variable is not significantly different for the two groups.

Overall the results of the univariate analysis are in line with the expected theories of derivatives. 
Table 6. 2: Mean Differences in Characteristics for Derivative User \& Non User Firms

\begin{tabular}{|c|c|c|c|c|c|c|c|c|c|}
\hline \multirow[b]{2}{*}{ Variables } & \multicolumn{3}{|c|}{ DER USER } & \multicolumn{3}{|c|}{ NON USER } & \multirow{2}{*}{$\begin{array}{l}\text { Difference } \\
\text { in Means }\end{array}$} & \multirow{2}{*}{$\begin{array}{l}\text { Wilcoxon } \\
p \text {-value }\end{array}$} & \\
\hline & $\mathrm{N}$ & Mean & Median & $\mathrm{N}$ & Mean & Median & & & \\
\hline \multicolumn{10}{|c|}{ Panel A: Dependent variables } \\
\hline VALUE & 2904 & 0.1572 & 0.069 & 3330 & 0.3283 & 0.229 & -0.1711 & 0.000 & \\
\hline MARKET RISK & 2904 & 0.128 & 0.141 & 3330 & 0.126 & 0.141 & 0.002 & 0.909 & \\
\hline STOCK RETURN VOL & 2904 & 3.797 & 3.778 & 3330 & 3.831 & 3.835 & -0.034 & 0.001 & \\
\hline CASH FLOW VOL & 2904 & 1.461 & 0.040 & 3330 & 1.778 & 0.0396 & -0.317 & 0.000 & \\
\hline \multicolumn{10}{|c|}{ Panel B: Corporate Governance Variables } \\
\hline BDMTGS & 2904 & 7.990 & 7.000 & 3330 & 7.952 & 7.000 & 0.038 & 0.000 & \\
\hline BDSIZE & 2904 & 9.183 & 9.000 & 3330 & 8.591 & 8.000 & 0.592 & 0.000 & \\
\hline BDINDEP & 2904 & 6.770 & 7.000 & 3330 & 6.200 & 6.000 & 0.570 & 0.000 & \\
\hline BDDIVERS & 2904 & 1.085 & 1.000 & 3330 & 0.932 & 1.000 & 0.153 & 0.000 & \\
\hline CEOAGE & 2904 & 55.515 & 55.000 & 3330 & 55.177 & 55.000 & 0.338 & 0.233 & \\
\hline CEOTENURE & 2904 & 8.574 & 6.000 & 3330 & 8.784 & 7.000 & -0.210 & 0.000 & \\
\hline SHINSIDER & 2904 & 0.123 & 0.044 & 3330 & 0.151 & 0.067 & -0.028 & 0.000 & \\
\hline SHINST & 2904 & 0.760 & 1.000 & 3330 & 0.689 & 1.000 & 0.071 & 0.012 & \\
\hline SHBLOCK & 2904 & 0.230 & 0.204 & 3330 & 0.240 & 0.217 & -0.010 & 0.003 & \\
\hline ACSIZE & 2904 & 5.275 & 5.000 & 3330 & 5.087 & 5.000 & 0.188 & 0.000 & \\
\hline CEOBONUS & 2904 & 5.084 & 0.000 & 3330 & 4.658 & 0.000 & 0.426 & 0.000 & \\
\hline CEOSALARY & 2904 & 13.468 & 13.494 & 3330 & 13.307 & 13.305 & 0.161 & 0.000 & \\
\hline CEOCOMP & 2904 & 14.166 & 14.159 & 3330 & 13.988 & 13.917 & 0.178 & 0.000 & \\
\hline \multicolumn{10}{|c|}{ Panel C: Control Variables } \\
\hline ROA & 2904 & 1.388 & 2.216 & 3330 & 1.215 & 2.255 & 0.173 & 0.257 & \\
\hline $\operatorname{ROA}(\mathrm{t}-1)$ & 2904 & 1.433 & 2.250 & 3330 & 1.138 & 2.260 & 0.295 & 0.531 & \\
\hline LEVERAGE & 2904 & 0.263 & 0.212 & 3330 & 0.178 & 0.106 & 0.085 & 0.000 & \\
\hline CAPEX & 2904 & 0.055 & 0.036 & 3330 & 0.050 & 0.032 & 0.005 & 0.189 & \# \\
\hline SIZE & 2904 & 7.496 & 7.458 & 3330 & 6.732 & 6.710 & 0.764 & 0.142 & \# \\
\hline $\mathrm{R} \& \mathrm{D}$ & 2904 & 0.488 & 0.000 & 3330 & 0.507 & 1.000 & -0.019 & 0.307 & \\
\hline LIQUIDITY & 2904 & 0.021 & 0.034 & 3330 & 0.320 & 0.291 & -0.299 & 0.000 & \\
\hline
\end{tabular}

The p-values are for asymptotic two-tailed Wilcoxon rank mean tests between derivative users and non users. \# indicates significant p-values for a one-tailed test. Variable form is the same as in Table 6.1. 


\section{Time Series Evidence for Mean Differences}

In Table 6.3, I provide time series results of a univariate analysis of mean differences in value, and risk characteristics between derivative user and derivative non user firms. I use the Wilcoxon rank sum tests to examine differences in both the groups over the period. The results record the mean values for each year along with the mean differences. Further, the Wilcoxon test p-values for the asymptotic two-tailed rank mean tests are provided to indicate the significance of the differences between the two groups.

In Panel A of Table 6.3, I present year-wise summary statistics for period from 2005 to 2011 for firm value and profit measures. With respect to VALUE, the mean differences are statistically significant for all the years. The largest difference is recorded in 2010, and is quite substantial for each year. However, the derivative users consistently have lower Q than non users showing a negative difference. Bartram et al. (2011) achieve a lower Tobin's Q for three years and the overall mean measure is approximately $17 \%$ lower than that for average firm that does not use derivatives. They suggest that derivative users tend to be larger and older firms than non users and this could be part of the reason. The larger firm size may also be evidenced in the higher values for market equity values and total firm size for derivative users in my results. However, the authors achieve a higher measure for their alpha (annualized) value measure value for a majority of the years.

In order to examine differences in performances between the two groups, I examine the earnings yield for each year. The mean differences for each year is largely positive and significant at $1 \%$ level, which indicates that derivative user firms consistently perform better than non users. The highest earnings yield is achieved in 2005 and 2009 and there is a negative difference for 2008, which may reflect the impact of the 
financial crisis on derivative user firms. This is similar to Bartram et al. (2011) who also observe higher performance of derivative users through return on assets, cash flow and earnings yield.

In Panel B, I present the time series effects of the risk measures. The results for CASH FLOW VOLATILITY show a statistically significant difference between the means for years from 2006 through 2010. However, for the years 2005 and 2011 that there is no significant difference between the two groups. Except for the years, 2006 and 2011, all the years indicate that the cash flow volatility risk for derivative users is lower than for the firms that do not use derivatives. The univariate results for STOCK RETURN VOLATILITY indicates the years, 2005 and 2008 do not display any significant differences in the means between derivative users and non users. All other years report significant differences between the two groups and the statistics indicate that for all the years, the stock return risk is lower for the derivative user firms. With respect to MARKET RISK only four years show statistically significant differences: 2006, 2008, 2009 and 2010. And, except for 2006, 2010 and 2011, all the years indicate a positive mean difference related to larger market risk for derivative user firms. Except for market risk, overall the results for the risk measures are similar to that evidenced by Bartram, et al. (2011) for their sample years from 1998 to 2003.

Panel C presents statistics for the mean differences in firm characteristics between derivative user and non user firms. Derivative user firms have a larger total firm size, higher sales turnover, larger growth opportunities and undertake more projects. As indicated by theory, derivative users also have higher leverage and lower liquidity. The mean differences for each year are generally statistically significant and support derivatives theory. However, derivative users appear to have lower Z-Scores which would indicate higher bankruptcy risk. This finds support in Bartram et al. (2011) who 
find that the mean Z-Scores for their sample of derivative users is lower by -3.373 than that for non users.

The univariate analysis shows that derivatives user firms generally have higher performance, lower risk, higher leverage, higher investment growth opportunities and lower liquidity which is in line with derivatives theory discussed under Section 3.2. 
Table 6. 3: Time Series Effects for Mean Differences in Derivative User and Non User Firms

\begin{tabular}{|c|c|c|c|c|c|c|c|}
\hline & 2005 & 2006 & 2007 & 2008 & 2009 & 2010 & 2011 \\
\hline \multicolumn{8}{|c|}{ Panel A: Value \& Profit Measures } \\
\hline \multicolumn{8}{|c|}{ Tobins Q (Ln) } \\
\hline Non User & 0.46 & 0.52 & 0.53 & 0.10 & 0.26 & 0.39 & 0.30 \\
\hline Difference & -0.14 & -0.15 & -0.10 & -0.13 & -0.17 & -0.20 & -0.18 \\
\hline$p$-value & 0.01 & 0.00 & 0.27 & 0.00 & 0.00 & 0.00 & 0.00 \\
\hline \multicolumn{8}{|c|}{ Market Value of Equity (Ln) } \\
\hline User & 7.90 & 7.96 & 7.67 & 7.21 & 7.21 & 7.52 & 7.48 \\
\hline Non User & 7.74 & 7.23 & 6.89 & 6.81 & 6.65 & 7.15 & 7.09 \\
\hline Difference & 0.16 & 0.73 & 0.78 & 0.4 & 0.56 & 0.37 & 0.39 \\
\hline p-value & 0.07 & 0.00 & 0.00 & 0.00 & 0.00 & 0.00 & 0.00 \\
\hline \multicolumn{8}{|c|}{ Earnings Yield (as) } \\
\hline User & 0.54 & 0.08 & 0.04 & 0.03 & 0.39 & 0.04 & 0.03 \\
\hline Non User & 0.05 & -0.01 & 0.00 & -0.02 & 0.00 & 0.02 & 0.01 \\
\hline Difference & 0.50 & 0.09 & 0.04 & 0.04 & 0.39 & 0.01 & 0.02 \\
\hline$p$-value & 0.13 & 0.00 & 0.70 & 0.03 & 0.00 & 0.01 & 0.00 \\
\hline \multicolumn{8}{|c|}{ Panel B: Risk Measures } \\
\hline \multicolumn{8}{|c|}{ Cash Flow Volatility(Ratio) } \\
\hline User & 1.90 & 0.87 & 0.08 & 0.91 & 0.48 & 0.14 & 0.23 \\
\hline Non User & 1.88 & 2.79 & 0.32 & 1.76 & 2.34 & 1.43 & 2.43 \\
\hline Difference & 0.02 & -1.92 & -0.24 & -0.85 & -1.86 & -1.29 & -2.2 \\
\hline$p$-value & 0.68 & 0.06 & 0.02 & 0.09 & 0.00 & 0.00 & 0.98 \\
\hline
\end{tabular}




\section{Stock Return Volatility(Ln)}

User

Non User

Difference

$p$-value

Market Risk(Ln)

User

Non User

Difference

p-value

\section{Panel C: Other Firm Measures}

\section{Z-Score (Ln)}

User

Non User

Difference

p-value

\section{Liquidity (Ln)}

User

Non User

Difference

p-value

Capex (ratio)

User

Non User

Difference

p-value

$\begin{array}{rrrrrrr}3.38 & 3.41 & 3.56 & 4.21 & 4.02 & 3.57 & 3.74 \\ 3.42 & 3.53 & 3.64 & 4.23 & 4.10 & 3.67 & 3.83 \\ -0.04 & -0.12 & -0.08 & -0.02 & -0.08 & -0.10 & -0.09 \\ 0.21 & 0.00 & 0.07 & 0.30 & 0.00 & 0.00 & 0.00 \\ & & & & & & \\ 0.11 & 0.16 & 0.04 & 0.13 & 0.14 & 0.12 & 0.14 \\ 0.08 & 0.24 & 0.02 & 0.08 & 0.09 & 0.14 & 0.15 \\ 0.03 & -0.08 & 0.02 & 0.05 & 0.05 & -0.02 & -0.01 \\ 0.37 & 0.02 & 0.87 & 0.01 & 0.05 & 0.12 @ & 0.66\end{array}$

$\begin{array}{rrrrrrr}1.29 & 1.28 & 1.43 & 0.90 & 0.79 & 1.16 & 0.08 \\ 1.41 & 1.41 & 1.52 & 1.11 & 1.12 & 1.21 & 1.02 \\ -0.11 & -0.13 & -0.09 & -0.21 & -0.33 & -0.05 & -0.94 \\ 0.01 & 0.00 & 0.03 & 0.00 & 0.00 & 0.01 & 0.00 \\ & & & & & & \\ 0.03 & -0.04 & -0.02 & -0.01 & 0.07 & 0.11 & 0.04 \\ 0.23 & 0.35 & 0.43 & 0.14 & 0.41 & 0.34 & 0.32 \\ -0.21 & -0.39 & -0.45 & -0.15 & -0.34 & -0.24 & -0.27 \\ 0.02 & 0.00 & 0.00 & 0.00 & 0.00 & 0.00 & 0.00 \\ & & & & & & \\ 0.05 & 0.63 & 0.05 & 0.72 & 0.05 & 0.04 & 0.06 \\ 0.05 & 0.06 & 0.05 & 0.06 & 0.04 & 0.05 & 0.05 \\ 0.00 & 0.57 & 0.00 & 0.67 & 0.00 & -0.01 & 0.01 \\ 0.92 & 0.42 & 0.45 & 0.00 & 0.00 & 0.73 & 0.01\end{array}$




\begin{tabular}{|c|c|c|c|c|c|c|c|}
\hline \multicolumn{8}{|l|}{ Sales (Ln) } \\
\hline User & 7.74 & 7.65 & 7.51 & 7.63 & 7.27 & 7.49 & 7.47 \\
\hline Non User & 7.32 & 6.63 & 6.23 & 7.01 & 6.41 & 6.72 & 6.84 \\
\hline Difference & 0.42 & 1.02 & 1.28 & 0.62 & 0.86 & 0.78 & 0.63 \\
\hline$p$-value & 0.02 & 0.00 & 0.00 & 0.00 & 0.00 & 0.00 & 0.00 \\
\hline \multicolumn{8}{|c|}{ Leverage (ratio) } \\
\hline User & 0.20 & 0.19 & 0.18 & 0.35 & 0.28 & 0.23 & 0.29 \\
\hline Non User & 0.14 & 0.13 & 0.11 & 0.24 & 0.18 & 0.18 & 0.18 \\
\hline Difference & 0.06 & 0.05 & 0.07 & 0.11 & 0.10 & 0.05 & 0.12 \\
\hline$p$-value & 0.00 & 0.00 & 0.00 & 0.00 & 0.00 & 0.00 & 0.00 \\
\hline \multicolumn{8}{|c|}{ Total Firm Size (Ln) } \\
\hline User & 7.94 & 7.97 & 7.84 & 7.71 & 7.54 & 7.77 & 7.78 \\
\hline Non User & 7.74 & 7.19 & 6.89 & 7.09 & 6.83 & 7.26 & 7.22 \\
\hline Difference & 0.20 & 0.78 & 0.95 & 0.61 & 0.72 & 0.51 & 0.56 \\
\hline$p$-value & 0.01 & 0.00 & 0.00 & 0.00 & 0.00 & 0.00 & 0.00 \\
\hline
\end{tabular}


Further I conduct an analysis on the maximum and minimum statistics for the risk and value measures pertaining to derivative users and non users for each year. Figures 6.1, 6.2 , and 6.3 show that the fluctuations in cash flow volatility, stock return volatiity and market risk are much larger in firms that do not use derivatives during each year of observation. It is in keeping with expectations that the use of derivatives stabilize cash flow, equity volatilies and market risk to minimize risk. The results for firm value also show that the profit fluctuations are lower for derivative users. However, though non-users are achieving higher value at each point in Figure 6.4 , the losses are also larger. This supports hedging theory that derivatives reduce fluctuations in profits and cash flows, which enables a more stable flow of liquidity, lower tax payments and reduction in financial distress, thereby increasing firm value.

Appendix 6 presents a set of figures that captures variations in the mean governance characteristics between derivative user and non user firms. From this year-wise analyses, it is very noticeable that derivative user firms have more robust corporate governance structures throughout the period. The board size, audit committee size, board diversity and board independence are larger in derivative users all through the period. However, the number of board meetings are the same for both groups. It appears that after 2007, derivative user firms have older CEOs, while the compensation characteristics are nearly the same, with a noticeable dip in the bonuses component after 2007 for both. While insider shareholding is larger for non users, the institutional shareholding is higher for derivative users.

Overall derivative users exhibit all the elements of a more robust corporate governance structure for each year. 
Figure 6.1 Year wise Cash Flow Volatility Graph

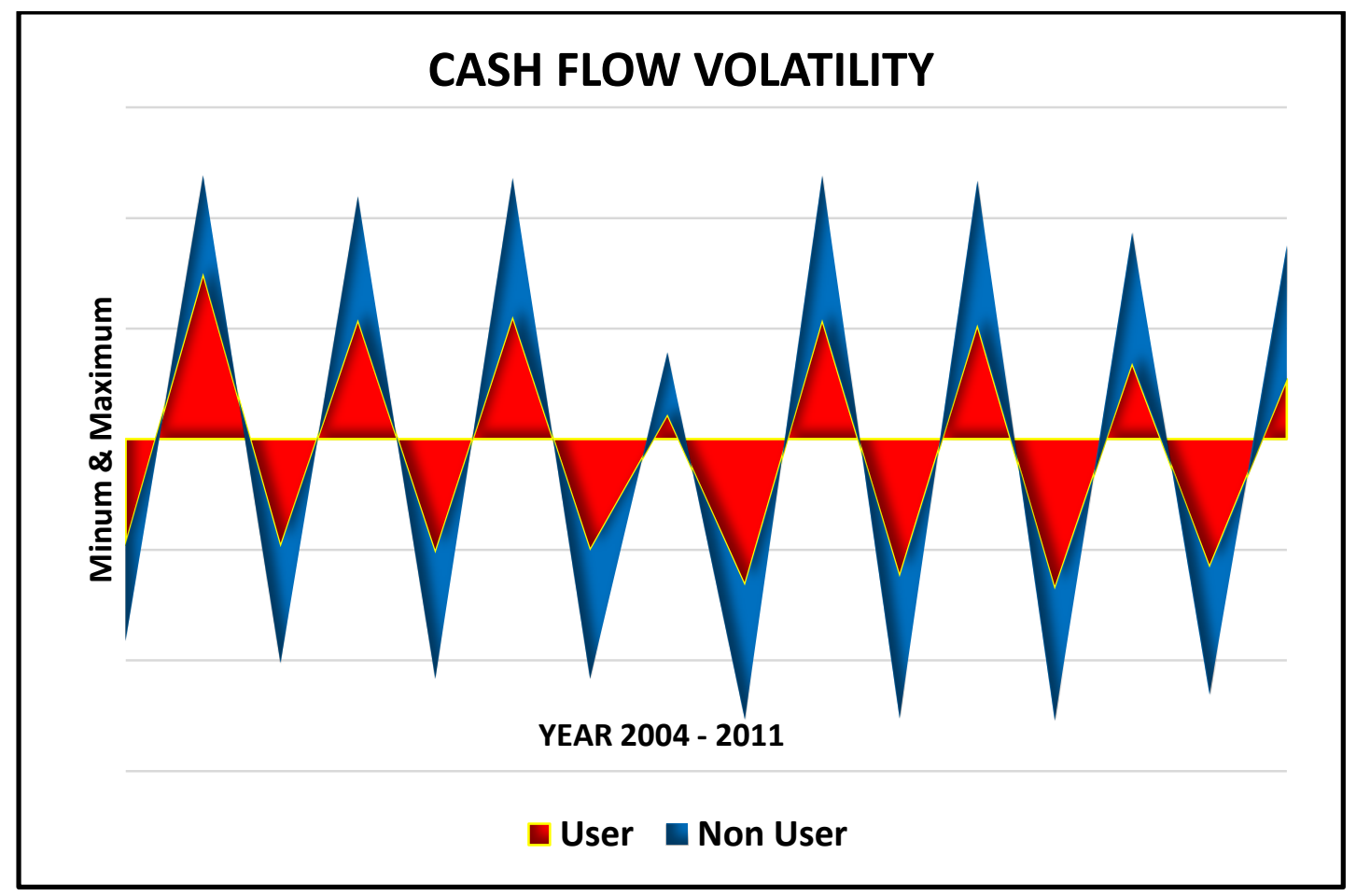

Figure 6.2 Year wise Stock Return Volatility Graph

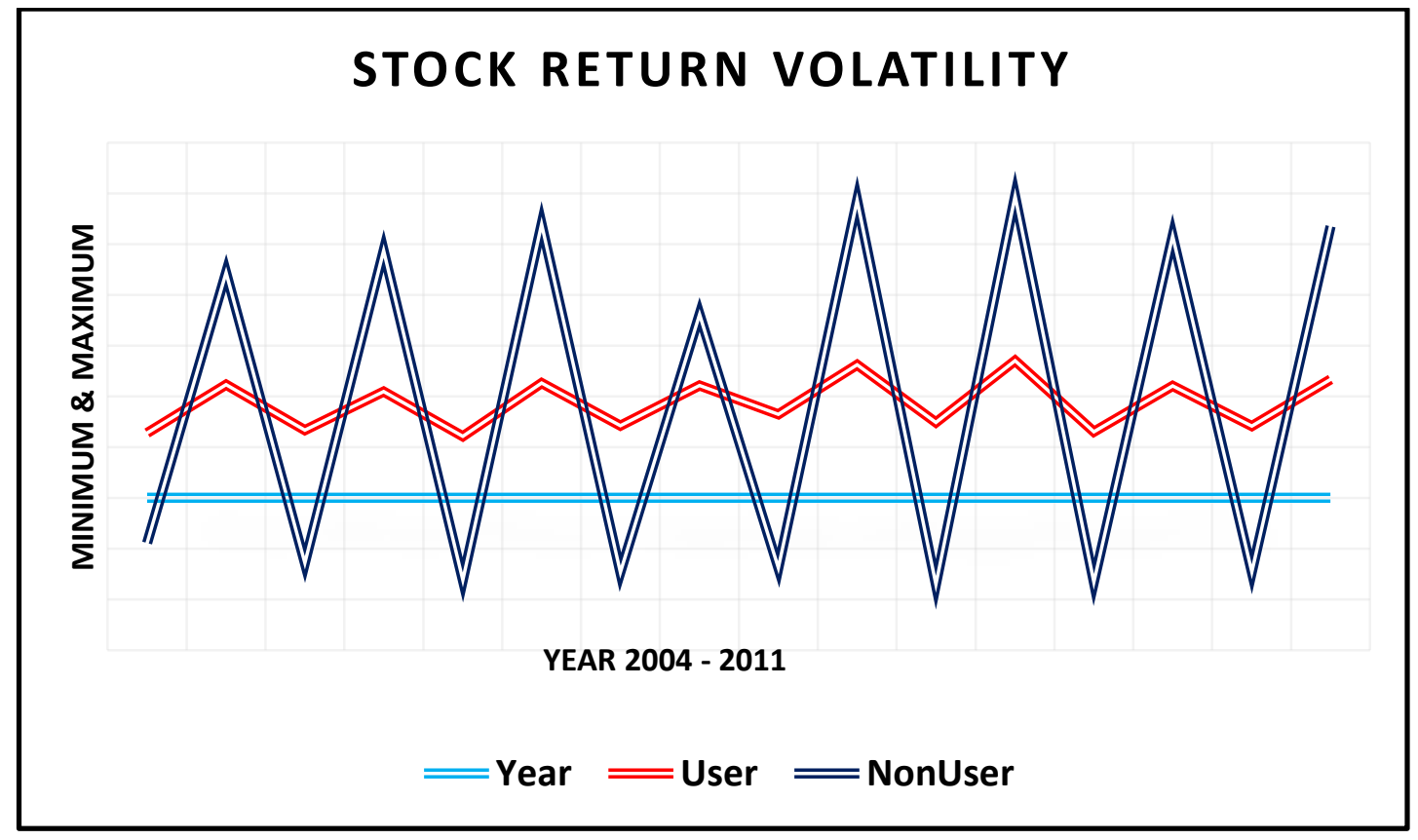


Figure 6.3 Year wise Market Risk Graph

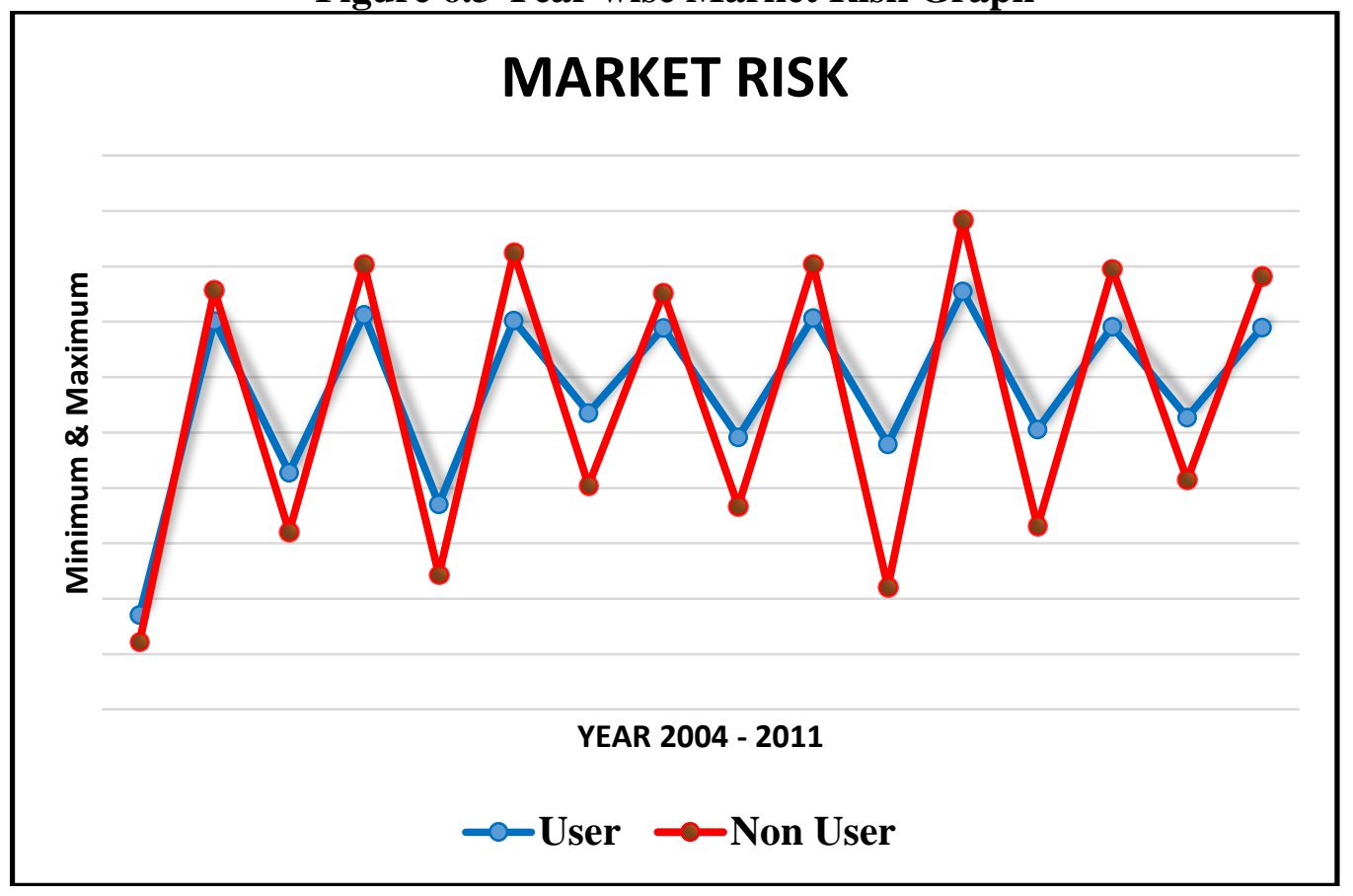

Figure 6.4 Year wise Value Graph

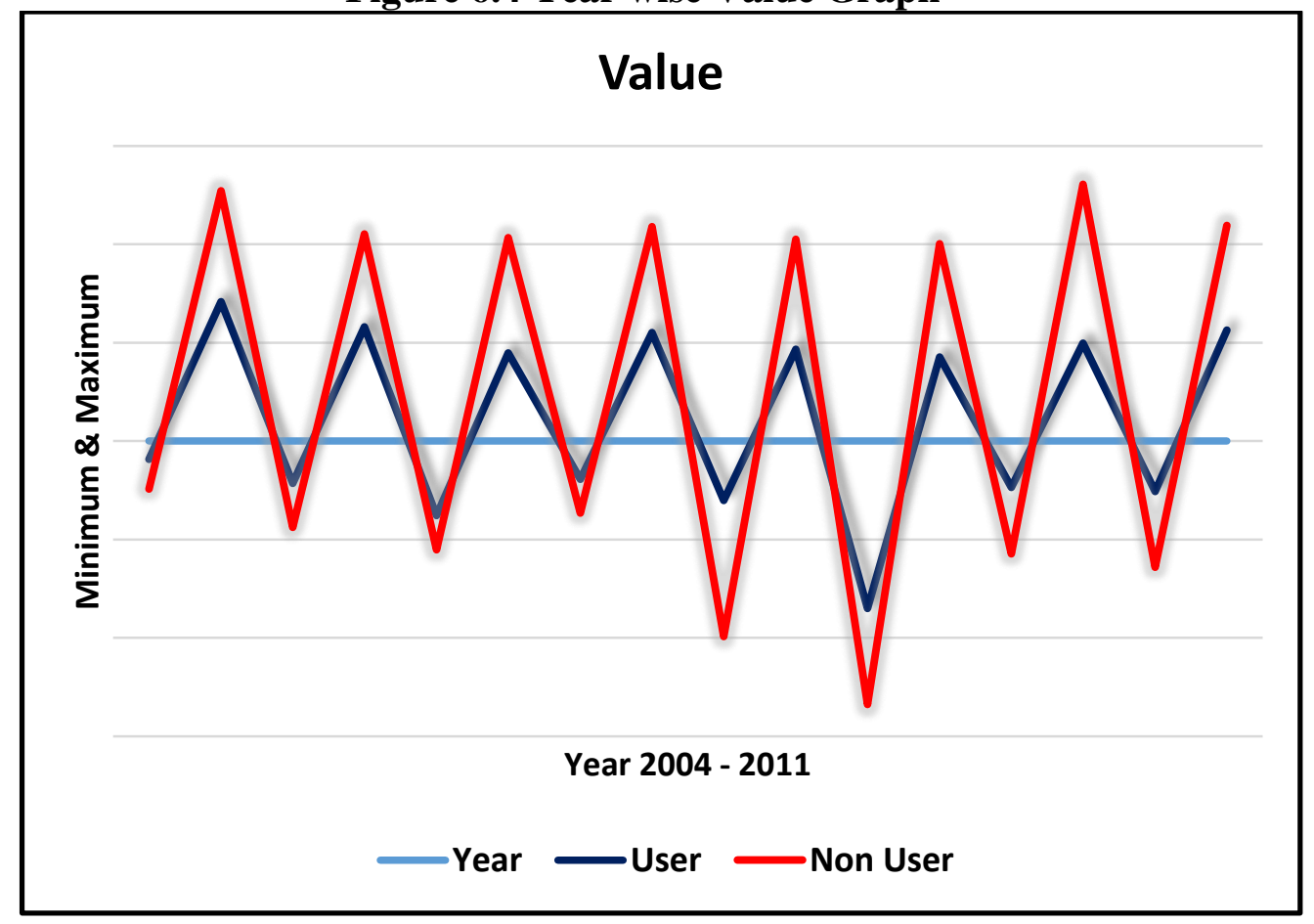




\subsection{Correlation Analysis of Variables}

Prior to the regression analyses, I conduct a correlation analysis to examine the correlation between all the dependent and independent variables in the regression models for Models 2-5. Through the correlation tests I examine whether there is any problem of correlations between the independent variables.

\subsubsection{Correlation Analysis of Variables - Value and Risk Model}

The Pearson product momentum correlations and the Spearman rank correlation coefficients for the regression with Value as the dependent variable are reported in Table 6.4A and 6.4B respectively. All the correlations among the independent variables are less than the generally accepted rule of thumb which is that a correlation greater than 0.80 indicates risk of multicollinearity problems ${ }^{17}$. Most of the correlations are statistically significant and do not show any very large associations, except for board independence (BDINDEP) and board size (BDSIZE) which indicate correlation coefficients of 0.791 and 0.788 for the Pearson and Spearman correlations respectively.

The correlation matrix in Tables 6.4A and Table 6.4B indicates that all the independent variables are statistically significantly correlated with VALUE, except for CEOTENURE, insider shareholders (SHINSIDER). The Correlation statistics show that VALUE has a positive correlation with CEOBONUS, CEOCOMP, CEOTENURE, and SHINSIDER, and a negative correlation with the other corporate

${ }^{17}$ Pallant (2005) suggests that: "Multicollinearity exists when the independent variables are highly correlated ( $r=.9$ and above)" (p. 142). 
governance variables. With respect to the control variables, ROA, R\&D, CAPEX have a positive correlation with VALUE, however the other control variables, LEVERAGE and SIZE show a negative correlation.

The Pearson product momentum correlations for the risk models: cash flow volatility, stock return volatility and market risk are provided in Table $6.4 \mathrm{C}$ presented below. All the correlations among the independent variables are less than the generally accepted rule of thumb which is discussed above. Further most of the correlations are statistically significant and do not show any very large associations. 
Table 6. 4A: Pearson Correlation Matrix for Value, Corporate Governance, Control Variables

\begin{tabular}{|c|c|c|c|c|c|c|c|c|c|c|c|c|c|c|c|c|c|c|c|}
\hline & ROA & LEV & SIZE & $\begin{array}{l}\text { BD } \\
\text { MTGS }\end{array}$ & $\begin{array}{l}\text { BD } \\
\text { SIZE }\end{array}$ & \begin{tabular}{|l} 
BD \\
INDEP
\end{tabular} & $\begin{array}{l}\text { BD } \\
\text { DIVERS }\end{array}$ & $\begin{array}{l}\text { CEO } \\
\text { AGE }\end{array}$ & \begin{tabular}{|l} 
CEO \\
TENURE
\end{tabular} & $\begin{array}{l}\text { SH } \\
\text { INSIDER }\end{array}$ & SHINST & $\begin{array}{l}\text { SH } \\
\text { BLOCK }\end{array}$ & $\begin{array}{l}\text { AC } \\
\text { SIZE }\end{array}$ & $\begin{array}{l}\text { CEO } \\
\text { BONUS }\end{array}$ & $\begin{array}{l}\text { CEO } \\
\text { SALARY }\end{array}$ & $\begin{array}{l}\text { CEO } \\
\text { COMP }\end{array}$ & $\mathrm{R} \& \mathrm{D}$ & VALUE & CAPEX \\
\hline ROA & 1 & & & & & & & & & & & & & & & & & & \\
\hline LEV & $-.268^{* * *}$ & 1 & & & & & & & & & & & & & & & & & \\
\hline SIZE & $.360^{* *}$ & $.245^{* *}$ & 1 & & & & & & & & & & & & & & & & \\
\hline \begin{tabular}{|l} 
BD \\
MTGS
\end{tabular} & $-.178^{* *}$ & $.096^{* *}$ & -.020 & 1 & & & & & & & & & & & & & & & \\
\hline BDSIZE & $.119^{* *}$ & $.189^{* * *}$ & $.559^{* *}$ & -.011 & 1 & & & & & & & & & & & & & & \\
\hline \begin{tabular}{|l} 
BD \\
INDEP
\end{tabular} & $.126^{* *}$ & $.126^{* *}$ & $.530^{* *}$ & $.031^{*}$ & $.791^{* *}$ & 1 & & & & & & & & & & & & & \\
\hline $\begin{array}{l}\text { BD } \\
\text { DIVERS }\end{array}$ & $.104^{* *}$ & $.119^{* *}$ & $.416^{* *}$ & .015 & $.540^{* *}$ & $.532^{* *}$ & 1 & & & & & & & & & & & & \\
\hline $\begin{array}{l}\mathrm{CEO} \\
\mathrm{AGE}\end{array}$ & .010 & $.065^{* *}$ & $.082^{* *}$ & $-.072^{* *}$ & $.060^{* *}$ & $.029^{*}$ & .014 & 1 & & & & & & & & & & & \\
\hline \begin{tabular}{|l} 
CEO \\
TENURE
\end{tabular} & .014 & -.004 & $-.050^{* *}$ & $-.112^{* *}$ & $-.087^{* *}$ & $-.118^{* *}$ & $-.102^{* *}$ & $.386^{* *}$ & 1 & & & & & & & & & & \\
\hline \begin{tabular}{|l} 
SH \\
INSIDER \\
\end{tabular} & $-.067^{* *}$ & $.044^{* * *}$ & $-.186^{* *}$ & $-.102^{* *}$ & $-.133^{* *}$ & $-.376^{* *}$ & $-.115^{* *}$ & $.080^{* *}$ & $.174^{* *}$ & 1 & & & & & & & & & \\
\hline SHINST & $.111^{* *}$ & -.017 & $.217^{* *}$ & $-.045^{* *}$ & $.162^{* *}$ & $.183^{* *}$ & $.091^{* *}$ & .012 & .007 & $-.175^{* *}$ & 1 & & & & & & & & \\
\hline \begin{tabular}{|l} 
SH \\
BLOCK \\
\end{tabular} & $-.158^{* *}$ & $.072^{* *}$ & $-.165^{* *}$ & $.062^{* *}$ & $-.141^{* *}$ & $-.121^{* *}$ & $-.115^{* *}$ & $\begin{array}{c}- \\
.079^{* *}\end{array}$ & $-.072^{* *}$ & $-.277^{* *}$ & $-.083^{* *}$ & 1 & & & & & & & \\
\hline ACSIZE & $.072^{* *}$ & $.116^{* *}$ & $.334^{* *}$ & $.091^{* *}$ & $.368^{* * *}$ & $.440^{* *}$ & $.311^{* *}$ & $103^{* *}$ & $-.135^{* *}$ & $-.196^{* *}$ & $.104^{* * *}$ & $-.053^{* *}$ & 1 & & & & & & \\
\hline \begin{tabular}{|l} 
CEO \\
BONUS
\end{tabular} & $.095^{* *}$ & $-.059^{* *}$ & $.032^{*}$ & $-.040^{* *}$ & -.013 & $-.083^{* *}$ & $-.049^{* *}$ &.- & $.044^{* *}$ & $.033^{* *}$ & $.051^{* *}$ & $-.069^{* *}$ & $\begin{array}{c}- \\
227^{* *}\end{array}$ & 1 & & & & & \\
\hline $\begin{array}{l}\text { CEO } \\
\text { SALARY }\end{array}$ & $.139^{* *}$ & $.247^{* *}$ & $.645^{* *}$ & -.014 & $.489^{* *}$ & $.473^{* *}$ & $.384^{* *}$ & $164^{* *}$ & -.002 & $-.124^{* *}$ & $.127^{* *}$ & $-.118^{* *}$ & $327^{* *}$ & $-.027^{*}$ & 1 & & & & \\
\hline $\begin{array}{l}\mathrm{CEO} \\
\text { COMP }\end{array}$ & $.215^{* *}$ & $.096^{* *}$ & $.541^{* *}$ & .008 & $.391^{* *}$ & $.389^{* *}$ & $.294^{* *}$ & $.124^{* *}$ & $-.033^{* *}$ & $-.174^{* *}$ & $.165^{* *}$ & $-.123^{* *}$ & $381^{\text {** }}$ & $.055^{* *}$ & $.634^{* *}$ & 1 & & & \\
\hline $\mathrm{R} \& \mathrm{D}$ & $-.066^{* *}$ & $-.305^{* *}$ & $-.178^{* *}$ & $.040^{* * *}$ & $-.047^{* *}$ & $.041^{* *}$ & $-.072^{* *}$ & $.078^{* *}$ & $-.051^{* *}$ & $-.144^{* *}$ & $.073^{* *}$ & .020 & $-.030^{*}$ & $-.033^{*}$ & $-.081^{* *}$ & $-.034^{* *}$ & 1 & & \\
\hline VALUE & $.232^{* *}$ & $-.505^{* *}$ & $-.264^{* *}$ & $-.111 * *$ & $-.129^{* *}$ & $-.132^{* *}$ & $-.095^{* *}$ & $\begin{array}{c}- \\
.093^{* *}\end{array}$ & .023 & .013 & $-.047^{* *}$ & $-.059^{* *}$ & $-\overline{-}$ & $.090^{* * *}$ & $-.190^{* *}$ & $-.053^{* *}$ & $243^{* *}$ & 1 & \\
\hline CAPEX & $.026^{*}$ & $.072^{* * *}$ & .012 & -.004 & -.020 & $-.040^{* *}$ & $-.055^{* *}$ & .009 & $.044^{* *}$ & -.019 & .000 & $-.033^{* *}$ & $\begin{array}{c}- \\
.060^{* *}\end{array}$ & $.095^{* *}$ & $-.047^{* * *}$ & -.003 & ${ }^{-}-5^{* *}$ & $.056^{* *}$ & 1 \\
\hline
\end{tabular}


Table 6.4B: Spearman Correlation Matrix for Value, Corporate Governance, Control Variables

\begin{tabular}{|c|c|c|c|c|c|c|c|c|c|c|c|c|c|c|c|c|c|c|c|}
\hline & ROA & $\begin{array}{l}\text { LEVER- } \\
\text { AGE }\end{array}$ & SIZE & $\begin{array}{l}\text { BD } \\
\text { MTGS }\end{array}$ & $\begin{array}{l}\text { BD } \\
\text { SIZE }\end{array}$ & $\begin{array}{l}\text { BD } \\
\text { INDEP }\end{array}$ & $\begin{array}{l}\text { BD } \\
\text { DIVER } \\
\text { S }\end{array}$ & $\begin{array}{l}\text { CEO } \\
\text { AGE }\end{array}$ & $\begin{array}{l}\text { CEO } \\
\text { TENUR } \\
\text { E }\end{array}$ & $\begin{array}{l}\text { SH } \\
\text { INSIDE } \\
\mathrm{R}\end{array}$ & $\begin{array}{l}\text { SH } \\
\text { INST }\end{array}$ & $\begin{array}{l}\text { SH } \\
\text { BLOCK }\end{array}$ & ACSIZE & $\begin{array}{l}\text { CEO } \\
\text { BONUS }\end{array}$ & $\begin{array}{l}\text { CEOSA } \\
\text { LARY }\end{array}$ & $\begin{array}{l}\text { CEO } \\
\text { COMP }\end{array}$ & $R \& D$ & VALUE & CAPEX \\
\hline ROA & 1 & $.353^{* *}$ & $213^{* *}$ & $.192^{* *}$ & $.055^{* *}$ & $.066^{* *}$ & $.063^{* *}$ & -.010 & .008 & $-.079^{* * *}$ & $.102^{* *}$ & $-.155^{* *}$ & .010 & $.124^{* *}$ & $.096^{* * *}$ & $.197^{* *}$ & .022 & $.457^{* * *}$ & $.121^{* *}$ \\
\hline \begin{tabular}{|l} 
LEV- \\
ERAGE
\end{tabular} & & 1 & $351^{* *}$ & $109^{* *}$ & $271^{* * *}$ & $207^{* *}$ & $170^{* * *}$ & $.075^{* *}$ & -.013 & $-.138^{* * *}$ & .006 & .021 & $.150^{* * *}$ & $-.033^{* *}$ & $.329^{* * *}$ & $.194^{* *}$ & $-.304^{* *}$ & $-.555^{* *}$ & $.112^{* *}$ \\
\hline SIZE & & & 1 & $.031^{*}$ & $590^{* *}$ & $.548^{* *}$ & $451^{* *}$ & $.096^{* *}$ & $-.045^{* *}$ & $-.425^{* *}$ & $.199^{* *}$ & $-.185^{* *}$ & $.328^{* *}$ & $.071^{* *}$ & $.732^{* *}$ & $.618^{* *}$ & $-.178^{* *}$ & $-.231^{* *}$ & $.158^{* *}$ \\
\hline BDMTGS & & & & 1 & $.029^{*}$ & $.078^{* *}$ & $.058^{* *}$ & $-.078^{* *}$ & $-.124^{* *}$ & $-.163^{* *}$ & -.024 & $.050^{* *}$ & $.123^{* *}$ & $-.049^{* *}$ & $.028^{*}$ & $.033^{* *}$ & $.047^{* *}$ & $-.126^{* *}$ & -.023 \\
\hline BDSIZE & & & & & 1 & $.788^{* *}$ & $542^{* *}$ & $.070^{* *}$ & $-.086^{* *}$ & $-.294^{* * *}$ & $.163^{* *}$ & $-.151^{* *}$ & $.365^{* *}$ & .012 & $.515^{* *}$ & $.418^{* * *}$ & $-.053^{* *}$ & $-.137^{* *}$ & $.105^{* *}$ \\
\hline \begin{tabular}{|l} 
BD \\
INDEP
\end{tabular} & & & & & & 1 & $536^{* *}$ & $.038^{* *}$ & $-.091^{* *}$ & $-.501^{* *}$ & $.178^{* *}$ & $-.079^{* *}$ & $.422^{* * *}$ & $-.052^{* *}$ & $.497^{* *}$ & $.412^{* *}$ & $.033^{*}$ & $-.133^{* *}$ & $.076^{* *}$ \\
\hline \begin{tabular}{|l} 
BD \\
DIVERS
\end{tabular} & & & & & & & 1 & $.032^{*}$ & $-.096^{* *}$ & $-.278^{* * *}$ & $.087^{* *}$ & $-.116^{* *}$ & $.305^{* *}$ & $-.031^{*}$ & $.420^{* *}$ & $.319^{* *}$ & $-.066^{* *}$ & $-.098^{* *}$ & $.062^{* *}$ \\
\hline CEOAGE & & & & & & & & 1 & $.330^{* *}$ & .010 & .024 & $-.082^{* *}$ & $.112^{* *}$ & $-.050^{* *}$ & $.175^{* *}$ & $.125^{* *}$ & $-.083^{* *}$ & $-.101^{* *}$ & $.027^{*}$ \\
\hline \begin{tabular}{|l|} 
CEO \\
TENURE \\
\end{tabular} & & & & & & & & & 1 & $.169^{* *}$ & .005 & $-.047^{* *}$ & $-.103^{* *}$ & $.026^{*}$ & $.026^{*}$ & -.005 & $-.036^{* *}$ & $.028^{*}$ & .017 \\
\hline \begin{tabular}{|l} 
SH \\
INSIDER
\end{tabular} & & & & & & & & & & 1 & $.130^{* * *}$ & $.105^{* *}$ & $-.289^{* *}$ & $.026^{*}$ & $-.314^{* *}$ & $-.322^{* *}$ & $-.069^{* *}$ & $.097^{* *}$ & $-.111^{* *}$ \\
\hline \begin{tabular}{|l} 
SH \\
INST \\
\end{tabular} & & & & & & & & & & & 1 & $.048^{* *}$ & $.094^{* *}$ & $.062^{* *}$ & $.134^{* *}$ & $.172^{* *}$ & $.073^{* *}$ & $-.033^{* *}$ & .024 \\
\hline \begin{tabular}{|l} 
SH \\
BLOCK \\
\end{tabular} & & & & & & & & & & & & 1 & $-.033^{* *}$ & $-.085^{* *}$ & $-.141^{* *}$ & $-.130^{* *}$ & $.047^{* *}$ & $-.077^{* *}$ & $-.093^{* *}$ \\
\hline ACSIZE & & & & & & & & & & & & & 1 & $-.226^{* *}$ & $.349^{* *}$ & $.390^{* *}$ & -.023 & $-.133^{* *}$ & -.020 \\
\hline \begin{tabular}{|l} 
CE \\
BONUS \\
\end{tabular} & & & & & & & & & & & & & & 1 & .011 & $.126^{* *}$ & $-.035^{* *}$ & $.098^{* *}$ & $.081^{* *}$ \\
\hline \begin{tabular}{|l} 
CEO \\
SALARY
\end{tabular} & & & & & & & & & & & & & & & 1 & $.708^{* *}$ & $-.091^{* *}$ & $-.178^{* *}$ & $.042^{* *}$ \\
\hline $\begin{array}{l}\text { CEO } \\
\text { COMP }\end{array}$ & & & & & & & & & & & & & & & & 1 & $-.048^{* *}$ & $-.057^{* *}$ & $.054^{* *}$ \\
\hline $\mathrm{R} \& \mathrm{D}$ & & & & & & & & & & & & & & & & & 1 & $.257^{* *}$ & $-.245^{* *}$ \\
\hline VALUE & & & & & & & & & & & & & & & & & & 1 & $.154^{* *}$ \\
\hline CAPEX & & & & & & & & & & & & & & & & & & & 1 \\
\hline
\end{tabular}


Table 6.4C: Pearson Correlation Matrix for Risk, Corporate Governance, Control Variables

\begin{tabular}{|c|c|c|c|c|c|c|c|c|c|c|c|c|c|c|c|c|c|c|c|c|c|}
\hline & 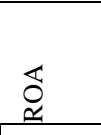 & 死 & $\begin{array}{l}0 \\
0 \\
2 \\
\text { U }\end{array}$ & $\begin{array}{l}0 \\
0 \\
> \\
\text { s }\end{array}$ & 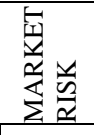 & 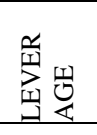 & v̂n & 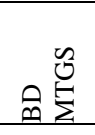 & คิ & 会寅 & $\stackrel{\substack{n \\
\infty}}{\sum^{\frac{n}{1}}}$ & 입뭔 & 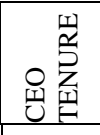 & 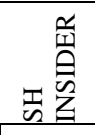 & 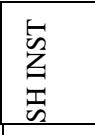 & 跑苞 & 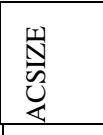 & o: & 일 & 일 & 总光 \\
\hline ROA & 1 & & & & & & & & & & & & & & & & & & & & \\
\hline $\mathrm{ROA}_{(\mathrm{t}-1)}$ & $.595^{* *}$ & 1 & & & & & & & & & & & & & & & & & & & \\
\hline CFVOL & $-.367^{* *}$ & $-.414^{* *}$ & 1 & & & & & & & & & & & & & & & & & & \\
\hline SRVOL & $-.472^{* *}$ & $-.389^{* *}$ & $.234^{* *}$ & 1 & & & & & & & & & & & & & & & & & \\
\hline $\begin{array}{l}\text { MARKE } \\
\text { TRISK } \\
\end{array}$ & $-.209^{* * *}$ & $-.231^{* *}$ & $.112^{* *}$ & $.460^{* * *}$ & 1 & & & & & & & & & & & & & & & & \\
\hline $\begin{array}{l}\text { LEVER } \\
\text { AGE } \\
\end{array}$ & $-.268^{* * *}$ & $-.184^{* *}$ & $-.097^{* *}$ & $.199^{* * *}$ & $.129^{* *}$ & 1 & & & & & & & & & & & & & & & \\
\hline SIZE & $.360^{* *}$ & $.361^{* * *}$ & $-.545^{* *}$ & $-.411^{* *}$ & $-.124^{* * *}$ & $.245^{* *}$ & 1 & & & & & & & & & & & & & & \\
\hline BDMTG & $-.178^{* *}$ & $-.184^{* * *}$ & $.129^{* *}$ & $.121^{* *}$ & .017 & $.096^{* *}$ & -.020 & 1 & & & & & & & & & & & & & \\
\hline BDSIZE & $.119^{* *}$ & $.130^{* *}$ & $-.195^{* *}$ & $-.295^{* *}$ & $-.135^{* *}$ & $.189^{* *}$ & $.559^{* *}$ & -.011 & 1 & & & & & & & & & & & & \\
\hline \begin{tabular}{|l} 
BD \\
INDEP \\
\end{tabular} & $.126^{* *}$ & $.145^{* *}$ & $-.192^{* *}$ & $-.289^{* *}$ & $-.146^{* *}$ & $.126^{* *}$ & $.530^{* *}$ & $.031^{*}$ & $.791^{* *}$ & 1 & & & & & & & & & & & \\
\hline \begin{tabular}{|l} 
BDDIV \\
ERS \\
\end{tabular} & $.104^{* *}$ & $.116^{* *}$ & $-.179^{* *}$ & $-.248^{* *}$ & $-.166^{* *}$ & $.119^{* * *}$ & $.416^{* *}$ & .015 & $.540^{* * *}$ & $.532^{* *}$ & 1 & & & & & & & & & & \\
\hline $\begin{array}{l}\text { CEO } \\
\text { AGE }\end{array}$ & .010 & .014 & $-.066^{* *}$ & $-.029^{*}$ & $.039^{* *}$ & $.065^{* *}$ & $.082^{* * *}$ & $-.072^{* *}$ & $.060^{* *}$ & $.029^{*}$ & .014 & 1 & & & & & & & & & \\
\hline \begin{tabular}{|l} 
CEOTE \\
NURE
\end{tabular} & . 014 & $.043^{* *}$ & -.003 & .020 & .015 & -.004 & $-.050^{* * *}$ & $-.112^{* *}$ & $-.087^{* *}$ & $-.118^{* *}$ & $-.102^{* *}$ & $.386^{* *}$ & 1 & & & & & & & & \\
\hline $\begin{array}{l}\text { SHINSI } \\
\text { DER }\end{array}$ & $-.067^{* * *}$ & $-.065^{* *}$ & .008 & $.157^{* *}$ & $.045^{* *}$ & $.044^{* * *}$ & $-.186^{* *}$ & $-.102^{* *}$ & $-.133^{* *}$ & $-.376^{* *}$ & $-.115^{* *}$ & $.080^{* * *}$ & $.174^{* *}$ & 1 & & & & & & & \\
\hline SHINST & $.111^{* *}$ & $.116^{* *}$ & $-.104^{* *}$ & $-.142^{* *}$ & .019 & -.017 & $.217^{* *}$ & $-.045^{* *}$ & $.162^{* *}$ & $.183^{* *}$ & $.091^{* *}$ & .012 & .007 & $-.175^{* *}$ & 1 & & & & & & \\
\hline $\begin{array}{l}\text { SH } \\
\text { BLOCK }\end{array}$ & $-.158^{* * *}$ & $-.174^{* *}$ & $.077^{* *}$ & $.214^{* *}$ & $.116^{* *}$ & $.072^{* *}$ & $-.165^{* *}$ & $.062^{* *}$ & $-.141^{* *}$ & $-.121^{* *}$ & $-.115^{* *}$ & $-.079^{* *}$ & $-.072^{* *}$ & $-.277^{* *}$ & $-.083^{* *}$ & 1 & & & & & \\
\hline ACSIZE & $.072^{* *}$ & .003 & $-.141^{* *}$ & $-.195^{* *}$ & $-.053^{* *}$ & $.116^{* *}$ & $.334^{* *}$ & $.091^{* *}$ & $.368^{* *}$ & $.440^{* * *}$ & $.311^{* *}$ & $.103^{* *}$ & $-.135^{* *}$ & $-.196^{* *}$ & $.104^{* *}$ & $-.053^{* *}$ & 1 & & & & \\
\hline \begin{tabular}{|l} 
CEO \\
BONUS \\
\end{tabular} & $.095^{* *}$ & $.101^{* * *}$ & $.049^{* *}$ & $-.185^{* *}$ & .025 & $-.059^{* *}$ & $.032^{*}$ & $-.040^{* *}$ & -.013 & $-.083^{* *}$ & $-.049^{* *}$ & $-.048^{* *}$ & $.044^{* * *}$ & $.033^{* *}$ & $.051^{* *}$ & $-.069^{* *}$ & $-.227^{* *}$ & 1 & & & \\
\hline $\begin{array}{l}\text { CEOSA } \\
\text { LARY }\end{array}$ & $.139^{* *}$ & $.152^{* *}$ & $-.258^{* *}$ & $-.228^{* *}$ & $-.076^{* *}$ & $.247^{* *}$ & $.645^{* *}$ & -.014 & $.489^{* * *}$ & $.473^{* *}$ & $.384^{* *}$ & $.164^{* * *}$ & -.002 & $-.124^{* *}$ & $.127^{* *}$ & $-.118^{* * *}$ & $.327^{* *}$ & $-.027^{*}$ & 1 & & \\
\hline \begin{tabular}{|l} 
CEO \\
COMP \\
\end{tabular} & $.215^{* *}$ & $.201^{* *}$ & $-.181^{* *}$ & $-.330^{* *}$ & $-.070^{* *}$ & $.096^{* *}$ & $.541^{* *}$ & .008 & $.391^{* *}$ & $.389^{* *}$ & $.294^{* *}$ & $.124^{* *}$ & $-.033^{* *}$ & $-.174^{* *}$ & $.165^{* *}$ & $-.123^{* *}$ & $.381^{* *}$ & $.055^{* *}$ & $.634^{* *}$ & 1 & \\
\hline $\begin{array}{l}\text { LIQUID } \\
\text { ITY }\end{array}$ & $-.061^{* * *}$ & $-.100^{* *}$ & $.308^{* *}$ & $.125^{* *}$ & $.061^{* *}$ & $-.417^{* *}$ & $-.450^{* * *}$ & .000 & $-.284^{* *}$ & $-.232^{* * *}$ & $-.238^{* *}$ & $-.043^{* *}$ & $.047^{* *}$ & .020 & $-.037^{* *}$ & $.079^{* *}$ & $-.138^{* *}$ & -.022 & $-.318^{* *}$ & $-.199^{* *}$ & 1 \\
\hline
\end{tabular}




\subsubsection{Multicollinearity Tests for Value and Risk Models}

Pallant (2005) suggests that the absence of a high correlation does not guarantee that there is no multicollinearity between the independent variables in a regression model. Collinearity may occur as a result of the combined effect of independent variables in the regression and, therefore, the author recommends additional tests of Tolerance or Variance Inflation Factor (VIF) which identify any multicollinearity problems that may not be evidenced through the correlation matrix. The author indicates cut offs at tolerance value of less than 0.10 , or a VIF value of above 10

I conduct tests to examine whether there are any problems of multicollinearity in my regression models depicted in Table 5.8 for derivative users and non users. I present results of the Tolerance and Variance Inflation Factor (VIF) tests for the value model variables in Table 6.5. I also test for collinearity in the risk regression models 3, 4 and 5 (Table 5.8) related to cash flow volatility, stock return volatility and market risk respectively. I present the Tolerance and VIF results in Table 6.6 for the derivative user and derivative non user risk regression models.

The largest VIF in Table 6.5 for derivative users and non users is 3.73 and 3.94 respectively. In Table 6.6 the largest VIF is 3.61 and 3.85 for derivative users and non users respectively. The tolerance value is the inverse of VIF and any difference in figures is due to decimals used.

All the statistics displayed in the two tables show that the statistics are well within the collinearity limits. All Tolerance levels are above 0.10 and VIF values are below the VIF 10 limit and therefore provide assurance that there is no problem of multicollinearity in the regression models. 
Table 6. 5: Multicollinearity Tests - Value Model

\begin{tabular}{|c|c|c|c|c|}
\hline \multirow[b]{2}{*}{ Variables } & \multicolumn{2}{|c|}{ DER USER } & \multicolumn{2}{|c|}{ NON USER } \\
\hline & $\begin{array}{c}\text { Variance } \\
\text { Inflation Factor } \\
\text { (VIF) }\end{array}$ & $\begin{array}{c}\text { Tolerance } \\
\text { (1/VIF) }\end{array}$ & $\begin{array}{c}\text { Variance } \\
\text { Inflation } \\
\text { Factor } \\
\text { (VIF) }\end{array}$ & $\begin{array}{c}\text { Tolerance } \\
(1 / \mathrm{VIF})\end{array}$ \\
\hline BDMTGS & 1.07 & 0.937 & 1.10 & 0.912 \\
\hline BDSIZE & 3.23 & 0.309 & 3.34 & 0.299 \\
\hline BDINDEP & 3.73 & 0.268 & 3.94 & 0.253 \\
\hline BDDIVERS & 1.59 & 0.631 & 1.52 & 0.660 \\
\hline SHINSIDER & 1.63 & 0.613 & 1.64 & 0.610 \\
\hline SHINST & 1.11 & 0.904 & 1.11 & 0.904 \\
\hline SHBLOCK & 1.29 & 0.774 & 1.28 & 0.782 \\
\hline CEOAGE & 1.28 & 0.781 & 1.24 & 0.806 \\
\hline CEOTENURE & 1.29 & 0.773 & 1.24 & 0.808 \\
\hline CEOCOMP & 2.04 & 0.490 & 2.23 & 0.448 \\
\hline CEOBONUS & 1.16 & 0.861 & 1.11 & 0.901 \\
\hline CEOSALARY & 2.40 & 0.416 & 2.39 & 0.433 \\
\hline ACSIZE & 1.73 & 0.577 & 1.70 & 0.590 \\
\hline LEVERAGE & 1.56 & 0.639 & 1.42 & 0.703 \\
\hline SIZE & 2.48 & 0.403 & 2.73 & 0.366 \\
\hline ROA & 1.47 & 0.682 & 1.46 & 0.684 \\
\hline$R \& D$ & 1.30 & 0.771 & 1.31 & 0.766 \\
\hline CAPEX & 1.14 & 0.874 & 1.06 & 0.940 \\
\hline
\end{tabular}

Der User and Non User signify firms that use derivatives and those that do not use derivatives, respectively. 
Table 6. 6: Multicollinearity Tests - Risk Models

\begin{tabular}{|c|c|c|c|c|}
\hline \multirow[b]{2}{*}{ Variables } & \multicolumn{2}{|c|}{ DER USER } & \multicolumn{2}{|c|}{ NON USER } \\
\hline & $\begin{array}{c}\text { Variance } \\
\text { Inflation Factor } \\
\text { (VIF) }\end{array}$ & $\begin{array}{c}\text { Tolerance } \\
(1 / \text { VIF })\end{array}$ & $\begin{array}{c}\text { Variance } \\
\text { Inflation } \\
\text { Factor (VIF) } \\
\end{array}$ & $\begin{array}{c}\text { Tolerance } \\
(1 / \mathrm{VIF})\end{array}$ \\
\hline BDMTGS & 1.07 & 0.939 & 1.11 & 0.905 \\
\hline BDSIZE & 3.24 & 0.309 & 3.33 & 0.300 \\
\hline BDINDEP & 3.61 & 0.277 & 3.85 & 0.260 \\
\hline BDDIVERS & 1.57 & 0.638 & 1.50 & 0.666 \\
\hline SHINSIDER & 1.58 & 0.633 & 1.59 & 0.631 \\
\hline SHINST & 1.09 & 0.914 & 1.10 & 0.908 \\
\hline SHBLOCK & 1.25 & 0.801 & 1.25 & 0.800 \\
\hline CEOAGE & 1.28 & 0.784 & 1.23 & 0.812 \\
\hline CEOTENURE & 1.29 & 0.774 & 1.24 & 0.804 \\
\hline CEOCOMP & 1.87 & 0.535 & 1.99 & 0.503 \\
\hline CEOBONUS & 1.14 & 0.879 & 1.10 & 0.906 \\
\hline CEOSALARY & 2.31 & 0.433 & 2.32 & 0.432 \\
\hline ACSIZE & 1.46 & 0.683 & 1.50 & 0.666 \\
\hline LEVERAGE & 1.53 & 0.652 & 1.46 & 0.684 \\
\hline SIZE & 2.58 & 0.388 & 2.95 & 0.339 \\
\hline ROA & 1.69 & 0.591 & 1.89 & 0.528 \\
\hline $\operatorname{ROA}_{(t-1)}$ & 1.52 & 0.659 & 1.85 & 0.542 \\
\hline LIQUIDITY & 1.32 & 0.759 & 1.52 & 0.659 \\
\hline
\end{tabular}

Der User and Non User signify firms that use derivatives and those that do not use derivatives, respectively. 


\subsection{Multivariate Analysis for Effect of Corporate Governance on the Value Effect of Derivatives.}

In Table 6.7, I present results for the tests of the hypotheses related to firm value that are presented in Chapter 4. In order to examine the effect of these corporate governance factors on the value effect of derivatives, I partition the full sample into two sub-sample of firms. One sample consists of firms that use derivatives and are termed as derivative users or users, while the other sub-sample consists of firms that do not use any derivatives and are termed as derivative non users or non users. Another method employed by some studies to examine the different effects between users and non users is to use a joint effect between the derivative user variable and the independent variables, as is used by Fauver and Naranjo (2010). However, this method has some shortcomings, especially when the examination involves thirteen corporate governance variables. Taking the joint effect of derivatives with each governance variable would entail at least 32 variables (excluding the control variables) in one model and give rise to a serious problem of multicollinearity. On the other hand, if separate regressions are taken for each governance variable to overcome this multicollinearity problem, then it would give rise to problems of omitted variables bias. Therefore, this study follows the methodology used in the derivatives literature (Bartram et al., 2009; Gay and Nam, 1998; Jin and Jorion, 2006; Petersen and Thiagarajan, 2000) of splitting the sample into two groups of derivative users and derivative non users.

Regressions for the first sub-sample of derivative user firms are provided in Table 6.8. Column 1 presents the results from basic regression in estimation of equation (Model 2 in Table 5.8) where firm value (VALUE) is regressed on measures of corporate governance and other control variables for firms that use derivatives. The corporate governance variables are size of board of directors (BDSIZE), board meetings 
(BDMTGS), board independence (BDINDEP), board diversity (BDDIVERS), insider shareholders (SHINSIDER), institutional shareholding (SHINST), block shareholders (SHBLOCK), CEO age (CEOAGE), CEO numbers of years of service (CEOTENURE), CEO total compensation (CEOCOMP), bonus provided to CEO (CEOBONUS), CEO basic salary (CEOSALARY) and size of the audit committee (ACSIZE).

The second column of Table 6.7 provides the regression results similar to the basic regression model (in column 1), but after controlling for industry and year fixed effects; the third column contains results of regression estimates after adjusting for heteroscedasticity using White's (1980) consistent covariance matrix, and the fourth column presents the results of regression estimates of the equation using the NeweyWest (1987) procedure to mitigate the potential times-series correlations of panel data taken up to three lags.

The values of the F-statistics for all four regression models are statistically significant at the $1 \%$ level. The $\mathrm{R}^{2}$ for the basic, industry and year adjusted, White adjusted and Newey-West adjusted regressions are in the range of 35\%. A review of the derivatives literature shows that the explanatory power of these models is high and is greater than that reported by Fauver and Naranjo (2010) where the $\mathrm{R}^{2}$ ranges from $5 \%$ to $17.7 \%$ for their models. However, $\mathrm{R}^{2}$ of $35 \%$ but is lower than achieved by Allayannis et al. (2012) that varies from $64 \%$ to $71 \%$, but this could be due to the much higher global sample size. Both the studies examine governance features in a derivatives environment through their impact on Tobin's Q taken as firm value. ${ }^{18}$

${ }^{18}$ Governance literature also indicates a lower $\mathrm{R}^{2}$ for models that examine relationships between governance and firm value/firm performance: Klein (1998) records $\mathrm{R}^{2}$ between $3 \%$ - 
The results from the regressions reported in Table 6.7 pertain to the firms that use derivatives for hedging. Eight of the thirteen corporate governance variables are found to be associated with firm value. The coefficient for number of board meetings (BDMTGS) is -0.001 and insignificant with a t-value of -0.50 and p-value of 0.620 . This suggests that increased board meetings do not impact firm value and resounds the findings of Jensen (1993) and Vafeas (1999) that boards increase activity in face of poor performance. And, boards that meet more frequently are valued less by the market (Karamanou and Vafeas, 2005; Vafeas, 1999). ${ }^{19}$

As predicted, the results for board size (BDSIZE) are positive at the $1 \%$ level of significance with t-value of 3.19. The coefficient indicates that with the addition of one board member, firm value increases by $3 \%$. This is in line with Dalton et al. (1999) and Beiner et al. (2006) who find a positive relation for all their models. Coles et al. (2008) concedes that one board size is not optimal for all companies and finds that Tobin's Q increases (decreases) in board size for complex (simple) firms ${ }^{20}$. While Adams and Mehran (2012) find a positive relationship between value and board size at $5 \%$ significance, for all their models related to bank holding companies ${ }^{21}$.

54\%; Beiner et al. (2006) record a range between 42\% to 47\%; and Ammann et al. (2011) achieve $\mathrm{R}^{2}$ from $6 \%$ - $31 \%$ for their value models.

19 Vafeas (1999) and Adams (2005) board's meetings is inversely related to prior year experience, as boards increase the number of meetings in response to poor performance. Zhang et al. (2007) suggest more meetings in response to firm internal control weaknesses.

${ }^{20}$ Coles et al. (2008) suggests that rules and regulations prohibiting large boards and insiders on boards could destroy value. Gillian, Hartzell, and Starks (2003) and Bainbridge (2003) also support the arguments that regulations mandating a one-size-fits-all criteria can damage some firms.

${ }^{21}$ Guest (2009) also finds a positive association for board size in the UK. Cheng (2008) suggests that board size reduce corporate performance variability and others (Kogan and Wallach, 1996; Moscovici and Zavalloni, 1969; Sah and Stiglitz, 1986, 1991) suggest that it 
With respect to board independence (BDINDEP), the results indicate a negative association with firm value which is significant at $5 \%$ level. The result coefficient indicates that for one additional independent board member, the value decreases by 2\%. Board diversity (BDDIVERS) increases firm value with coefficient of 0.03 and $\mathrm{t}$-statistic of 2.90 that is significant at $1 \%$ level, indicating an additional female director on the board increases $\mathrm{Q}$ ratio by $3 \%$. This is in line with the findings of Brammer et al. (2009) who find a positive relationship of gender diversity with firm reputation at coefficients ranging from 3.80 to 8.74 at $1 \%$ to $5 \%$ significance levels for their models. One factor in firm reputation is firm performance. My findings are in line with Carter et al. (2003) who find a positive coefficient of 1.679 for the dummy diversity variable and 9.426 for the diversity percentage model and both are significant at $5 \%{ }^{22}$.

As predicted (Table 5.7), the results for CEO age (CEOAGE) exhibit short-term horizon problems. The coefficient shows a negative relationship between CEO age and firm value which is significant at $1 \%$ level, with t-statistic of -2.99 , indicating that a one-year increase in CEO age reduces firm value by $0.5 \%$. As discussed under Section 4.6, CEO age acts as a proxy for the entrenchment problem and my results are in line with Hermalin and Weisbach (1998) who find that CEOs with more than 15 years of service, reduce profitability with each additional year on the job and therefore

reduces performance variability because they take less extreme decisions. Brammer, et al. (2009) find that board size increases a firm's reputation. While Coles et al. (2006), Raheja (2005), and Harris and Raviv (2008) find a negative relationship and they attribute to some exogenous factors. When Yermack (1996) and Coles et al. (2008) combine complexity with board size, they find that firm performance increases with board size for more complex firms. They suggest that the negative correlations could be due to more simple firms in the sample, where the costs would surpass the benefits of larger boards.

${ }^{22}$ Adler (2001) find that women friendly boards perform better as compared to the industry with: $34 \%$ higher profits/revenues; $18 \%$ higher profits/assets; $69 \%$ higher as a measure of profits/equity. However, Adams and Ferreira (2009) on board gender diversity suggest that women on boards decrease performance, though they perform better in relation to other factors: board meetings attendance and board monitoring. 
with every additional increase in age. The results for CEO tenure (Table 6.7) show a coefficient of 0.003 , but it is weakly significant at $10 \%$ level.

The results for CEO compensation show a positive association with firm value only for CEOBONUS, with a coefficient of 0.004 and significant at $1 \%$ level. Thus, a one percent increase in CEO bonus translates into a $0.004 \%$ increase in value. Though CEO total compensation (CEOCOMP) and CEO basic salary (CEOSALARY) results also show a positive correlation with value these are not significant. The direction of the result is in line with Mehran (1995) who finds a positive association between percentage of CEO's equity-based compensation and CEO's percentage of shares and stock options outstanding when examined against value and firm performance at $1 \%$ and 5\% respectively. Brick et al. (2006) also find a positive relation. This supports the findings of McConnell and Servaes (1990) when they examine apiece-wise linear relationship of variations of CEO compensation sensitivity with firm value. Larcker et al. (2007) use a principal component analysis to derive a compensation mix for CEO and they also achieve positive results at $1 \%$ level of significance. Similarly, some researchers examine the effect of value on CEO compensation components. Adams and Ferreira (2009) indicate a positive and significant association of CEO incentive pay, and total CEO compensation with value, at $1 \%$ level of significance. ${ }^{23}$

\footnotetext{
${ }^{23}$ There are two types of studies that examine the association between CEO compensation and firm value/performance. The first type that is more popular investigate the effect of value and/or performance on CEO compensation and find strong and significant results (Aggarwal and Samwick, 1999; and Hartzell and Starks, 2003; to name a few). The second type study the impact of pay on performance and many find a strong effect of pay on firm performance (Core and Larcker, 2002; Anderson et al., 2000; Makri, et al., 2006). Ashbaugh-Skaife et al. (2006) examine basic salary, salary plus bonus and total compensation and find a positive association of basic salary with sales at $1 \%$ level of significance; for salary plus bonus they record a positive association with sales and stock return at $1 \%$ significance, and also obtain a positive association with sales, market-to-book ratio at $1 \%$ and $10 \%$ significance level for total compensation.
} 
With respect to the results related to firm shareholders, only block holders (SHBLOCK) comprising those with 5\% and more shareholding, are negatively associated with value and significant at $5 \%$ level $^{24}$. This indicates that that an increase in percentage of block holders reduces firm value. However, institutional shareholding and insider shareholding do not have any significant impact on value. This is in line with Allayannis et al. (2012) who use a governance index and find that firms with no insider or block shareholders increase the value of derivatives at 5\% significance level, while firms with insiders and block shareholdings have no impact on firm value.

The coefficient for audit committee size is negative and significant at $1 \%$ level with a $\mathrm{t}$-statistic of -2.73 . This indicates that an increase in the number of committee members reduces value of derivatives, where the increase of one additional member would decrease firm value by $1.4 \%$ as predicted (Table 5.7). This draws support from Chan and $\mathrm{Li}$ (2008) who find a negative association between audit committee size and Q for four of their models at $5 \%$ level of significance. It may indicate that there is an optimal number above which the audit committee effectiveness would decrease.

The control variables are all significant at the $1 \%$ level. In accordance with my predictions, CAPEX and R\&D show a positive effect of investment growth opportunities on firm value; ROA indicates that profitability increases value; and LEVERAGE reduces firm value. It appears that smaller firm size increases firm value which supports the bankruptcy theory that larger firms have higher bankruptcy costs and financial distress costs and would therefore reduce firm value.

\footnotetext{
${ }^{24}$ Erkens et al. (2012) also show a negative correlation with stock return as a proxy for firm performance, however their results are not significant. 
Table 6. 7: Value Regression Models for Derivative User Firms

\begin{tabular}{|c|c|c|c|c|c|c|c|c|}
\hline & Basic & Regression & Industry \& & r Effects & White & $(1980)$ & Newey West & (1987) \\
\hline & coeff & $t$-stat & Coeff & $t$-stat & Coeff & $t$-stat & coeff & $t$-stat \\
\hline BDMTGS & $\begin{array}{c}-0.00 \\
(0.002)\end{array}$ & -1.09 & $\begin{array}{c}-0.00 \\
(0.002)\end{array}$ & -0.55 & $\begin{array}{c}-0.00 \\
(0.002)\end{array}$ & -0.54 & $\begin{array}{c}-0.00 \\
(0.003)\end{array}$ & -0.50 \\
\hline BDSIZE & $\begin{array}{c}0.03 * * * \\
(0.007)\end{array}$ & 3.98 & $\begin{array}{c}0.03 * * * \\
(0.007)\end{array}$ & 3.82 & $\begin{array}{c}0.03 * * * \\
(0.007)\end{array}$ & 3.70 & $\begin{array}{c}0.03 * * * \\
(0.008)\end{array}$ & 3.19 \\
\hline BDINDEP & $\begin{array}{c}-0.03 * * * \\
(0.007)\end{array}$ & -3.95 & $\begin{array}{c}-0.02 * * * \\
(0.007)\end{array}$ & -2.95 & $\begin{array}{c}-0.02 * * * \\
(0.007)\end{array}$ & -2.90 & $\begin{array}{c}-0.02 * * \\
(0.008)\end{array}$ & -2.54 \\
\hline BDDIVERS & $\begin{array}{c}0.03 * * * \\
(0.010)\end{array}$ & 2.80 & $\begin{array}{c}0.03 * * * \\
(0.010)\end{array}$ & 3.37 & $\begin{array}{c}0.03 * * * \\
(0.009)\end{array}$ & -3.49 & $\begin{array}{c}0.03 * * * \\
(0.011)\end{array}$ & 2.90 \\
\hline SHINSIDER & $\begin{array}{c}-0.01 \\
(0.053)\end{array}$ & -0.24 & $\begin{array}{c}-0.06 \\
(0.053)\end{array}$ & -1.10 & $\begin{array}{c}-0.06 \\
(0.058)\end{array}$ & -1.01 & $\begin{array}{c}-0.06 \\
(0.069)\end{array}$ & -0.84 \\
\hline SHINST & $\begin{array}{c}-0.03 \\
(0.019)\end{array}$ & -1.50 & $\begin{array}{l}-0.03^{*} \\
(0.019)\end{array}$ & -1.78 & $\begin{array}{l}-0.03^{*} \\
(0.021)\end{array}$ & -1.65 & $\begin{array}{c}-0.03 \\
(0.023)\end{array}$ & -1.51 \\
\hline SHBLOCK & $\begin{array}{l}-0.14 * * \\
(0.054)\end{array}$ & -2.56 & $\begin{array}{c}-0.18 * * * \\
(0.054)\end{array}$ & -3.31 & $\begin{array}{c}-0.18 * * * \\
(0.059)\end{array}$ & -3.03 & $\begin{array}{c}-0.18 * * * \\
(0.070)\end{array}$ & -2.58 \\
\hline CEOAGE & $\begin{array}{c}-0.00 * * * \\
(0.001)\end{array}$ & -3.46 & $\begin{array}{c}-0.00 * * * \\
(0.001)\end{array}$ & -3.66 & $\begin{array}{c}-0.00 * * * \\
(0.001)\end{array}$ & -3.48 & $\begin{array}{c}-0.005 * * * \\
(0.002)\end{array}$ & -2.99 \\
\hline CEOTENURE & $\begin{array}{l}0.00 * * \\
(0.001)\end{array}$ & 2.07 & $\begin{array}{l}0.00 * * \\
(0.001)\end{array}$ & 2.14 & $\begin{array}{l}0.00 * * \\
(0.001)\end{array}$ & 2.06 & $\begin{array}{l}0.003^{*} \\
(0.001)\end{array}$ & 1.90 \\
\hline СЕОСОМР & $\begin{array}{l}0.02 * * \\
(0.010)\end{array}$ & 2.37 & $\begin{array}{c}0.01 \\
(0.011)\end{array}$ & 1.03 & $\begin{array}{c}0.01 \\
(0.012)\end{array}$ & 0.93 & $\begin{array}{c}0.01 \\
(0.012)\end{array}$ & 0.89 \\
\hline
\end{tabular}




\begin{tabular}{|c|c|c|c|c|c|c|c|c|}
\hline & \multicolumn{2}{|c|}{ Basic Regression } & \multicolumn{2}{|c|}{ Industry \& Year Effects } & \multicolumn{2}{|c|}{ White (1980) } & \multirow{2}{*}{$\frac{\text { Newey West }}{\text { coeff }}$} & \multirow{2}{*}{$\frac{(1987)}{t \text {-stat }}$} \\
\hline & coeff & $t$-stat & Coeff & $t$-stat & Coeff & $t$-stat & & \\
\hline \multirow[t]{2}{*}{ CEOBONUS } & $0.00 * * *$ & 3.41 & $0.00 * * *$ & 2.92 & $0.00 * * *$ & 2.95 & $0.004 * * *$ & 2.66 \\
\hline & $(0.001)$ & & $(0.001)$ & & $(0.001)$ & & $(0.001)$ & \\
\hline \multirow[t]{2}{*}{ CEOSALARY } & 0.04 & 1.39 & 0.04 & 1.54 & 0.04 & 1.24 & 0.04 & 1.14 \\
\hline & $(0.026)$ & & $(0.026)$ & & $(0.033)$ & & $(0.036)$ & \\
\hline \multirow[t]{2}{*}{ ACSIZE } & $-0.01 *$ & -1.87 & $-0.01 * * *$ & -3.04 & $-0.01 * * *$ & -3.22 & $-0.014 * * *$ & -2.73 \\
\hline & $(0.004)$ & & $(0.005)$ & & $(0.004)$ & & $(0.005)$ & \\
\hline \multirow[t]{2}{*}{$L E V E R A G E$} & $-0.91 * * *$ & -20.71 & $-0.85 * * *$ & -19.23 & $-0.85 * * *$ & -17.03 & $-0.85 * * *$ & -14.81 \\
\hline & $(0.044)$ & & $(0.044)$ & & $(0.050)$ & & $(0.058)$ & \\
\hline \multirow[t]{2}{*}{$R \& D$} & $0.10 * * *$ & 5.91 & $0.09 * * *$ & 5.08 & $0.09 * * *$ & 5.22 & $0.09 * * *$ & 4.13 \\
\hline & $(0.018)$ & & $(0.018)$ & & $(0.017)$ & & $(0.022)$ & \\
\hline \multirow[t]{2}{*}{ ROA } & $0.05 * * *$ & 11.35 & $0.05 * * *$ & 11.75 & $0.05 * * *$ & 8.95 & $0.05 * * *$ & 8.37 \\
\hline & $(0.004)$ & & $(0.004)$ & & $(0.006)$ & & $(0.006)$ & \\
\hline \multirow[t]{2}{*}{ SIZE } & $-0.07 * * *$ & -8.93 & $-0.07 * * *$ & -8.92 & $-0.07 * * *$ & -6.61 & $-0.07 * * *$ & -5.82 \\
\hline & $(0.008)$ & & $(0.008)$ & & $(0.010)$ & & $(0.012)$ & \\
\hline \multirow[t]{2}{*}{ CAPEX } & $0.55 * * *$ & 4.12 & $0.61 * * *$ & 4.53 & $0.61 * * *$ & 4.46 & $0.61 * * *$ & 3.59 \\
\hline & $(0.133)$ & & $(0.134)$ & & $(0.136)$ & & $(0.169)$ & \\
\hline Year effects & & & yes & & yes & & yes & \\
\hline Industry effects & & & yes & & yes & & yes & \\
\hline \multirow[t]{2}{*}{ Constant } & 0.15 & 0.53 & 0.32 & 1.10 & 0.32 & 0.87 & 0.32 & 0.78 \\
\hline & $(0.288)$ & & $(0.288)$ & & $(0.364)$ & & $(0.407)$ & \\
\hline Observations & 2,904 & & 2,904 & & 2,904 & & 2,904 & \\
\hline$R^{2}$ & 0.34 & & 0.35 & & 0.35 & & 0.35 & \\
\hline$F$-statistic & $82.10 * * *$ & & $76.64 * * *$ & & $75.27 * * *$ & & $49.84 * * *$ & \\
\hline
\end{tabular}

The p-value for the one-tailed test of the null hypothesis that the coefficient is zero is indicated as $* * *, * *, *$ to show statistical significance at the 0.01 , 0.05 and 0.10 levels respectively, and robust standard errors are provided in parentheses. User and Non User signify firms that use derivatives and those that do not. See Tables 5.3 and 5.4 for definitions of dependent and independent variables. 


\subsubsection{Multivariate Analysis on Value for Derivatives Non User Firms.}

Table 6.8 presents regression estimates of the association between corporate governance variables and firm value for the second sub-sample comprising only derivatives non user firms. This is the estimation of the value regression model and similar to those depicted in Table 6.8, that is, the basic regression, industry and year effects controlled regression, White (1980) regression model and the Newey-West (1987) regression model.

All the regression models have significant F-statistics at the $1 \%$ level. The $\mathrm{R}^{2}$ values for this sample are 35\% and similar to those for the derivative user firms (Table 6.8). Generally, the results for the corporate governance variables are similar across the two samples. With respect to the corporate governance variables, BDMTGS, CEOAGE, SHINST and ACSIZE have a negative association with Tobin's $Q$ indicating a reducing effect on value at $1 \%$ level of significance. BDSIZE and CEOCOMP are significant at $1 \%$ and exhibit a positive relationship with VALUE. However, the coefficients for board independence, board diversity, CEO tenure, block holders, and CEO bonus are insignificant ( $p>0.10$ ), in this sub-sample.

All the control variables are significant at $1 \%$ level and in the direction of my predictions provided in Table 5. 7 and SIZE indicates a negative relationship with VALUE. The control variables are significant and exhibit the same directional relationship as exhibited in the derivative user sample. A detailed comparison of the results for the two groups is provided in the next section. 
Table 6. 8: Value Regression Models for Derivative Non User Firms

\begin{tabular}{|c|c|c|c|c|c|c|c|c|}
\hline & \multicolumn{2}{|c|}{ Basic Regression } & \multicolumn{2}{|c|}{ Industry \& Year Effects } & \multicolumn{2}{|c|}{ White (1980) } & \multicolumn{2}{|c|}{ Newey West (1987) } \\
\hline & coeff & t-stat & Coeff & t-stat & Coeff & t-stat & coeff & t-stat \\
\hline BDMTGS & $\begin{array}{c}-0.01 * * * \\
(0.003)\end{array}$ & -4.67 & $\begin{array}{c}-0.01 * * * \\
(0.003)\end{array}$ & -4.62 & $\begin{array}{c}-0.01 * * * \\
(0.003)\end{array}$ & -4.16 & $\begin{array}{c}-0.01 * * * \\
(0.003)\end{array}$ & -3.69 \\
\hline$B D S I Z E$ & $\begin{array}{c}0.04 * * * \\
(0.008)\end{array}$ & 4.98 & $\begin{array}{c}0.04 * * * \\
(0.008)\end{array}$ & 4.96 & $\begin{array}{c}0.04 * * * \\
(0.008)\end{array}$ & 4.91 & $\begin{array}{c}0.04 * * * \\
(0.010)\end{array}$ & 4.03 \\
\hline BDINDEP & $\begin{array}{l}-0.02 * * \\
(0.008)\end{array}$ & -2.10 & $\begin{array}{l}-0.02^{*} \\
(0.008)\end{array}$ & -1.82 & $\begin{array}{l}-0.02^{*} \\
(0.008)\end{array}$ & -1.87 & $\begin{array}{c}-0.02 \\
(0.010)\end{array}$ & -1.58 \\
\hline BDDIVERS & $\begin{array}{c}0.01 \\
(0.011)\end{array}$ & 0.54 & $\begin{array}{c}0.01 \\
(0.011)\end{array}$ & 0.48 & $\begin{array}{c}0.01 \\
(0.012)\end{array}$ & 0.46 & $\begin{array}{c}0.01 \\
(0.015)\end{array}$ & 0.38 \\
\hline SHINSIDER & $\begin{array}{l}-0.12 * * \\
(0.058)\end{array}$ & -2.02 & $\begin{array}{l}-0.11^{*} \\
(0.058)\end{array}$ & -1.95 & $\begin{array}{l}-0.11^{*} \\
(0.059)\end{array}$ & -1.92 & $\begin{array}{c}-0.11 \\
(0.072)\end{array}$ & -1.56 \\
\hline SHINST & $\begin{array}{c}-0.09 * * * \\
(0.021)\end{array}$ & -4.36 & $\begin{array}{c}-0.09 * * * \\
(0.020)\end{array}$ & -4.48 & $\begin{array}{c}-0.09 * * * \\
(0.021)\end{array}$ & -4.33 & $\begin{array}{c}-0.09 * * * \\
(0.024)\end{array}$ & -3.77 \\
\hline SHBLOCK & $\begin{array}{l}-0.12 * \\
(0.060)\end{array}$ & -1.95 & $\begin{array}{c}-0.09 \\
(0.061)\end{array}$ & -1.56 & $\begin{array}{c}-0.09 \\
(0.066)\end{array}$ & -1.43 & $\begin{array}{c}-0.09 \\
(0.081)\end{array}$ & -1.17 \\
\hline CEOAGE & $\begin{array}{c}-0.01 * * * \\
(0.001)\end{array}$ & -4.52 & $\begin{array}{c}-0.01 * * * \\
(0.001)\end{array}$ & -4.82 & $\begin{array}{c}-0.01 * * * \\
(0.001)\end{array}$ & -4.70 & $\begin{array}{c}-0.01 * * * * \\
(0.002)\end{array}$ & -3.84 \\
\hline CEOTENURE & $\begin{array}{c}0.00 \\
(0.001)\end{array}$ & 1.62 & $\begin{array}{c}0.00 * \\
(0.001)\end{array}$ & 1.73 & $\begin{array}{c}0.00 * \\
(0.001)\end{array}$ & 1.77 & $\begin{array}{c}0.00 \\
(0.001)\end{array}$ & 1.55 \\
\hline СЕОСОМР & $\begin{array}{c}0.08 * * * \\
(0.012)\end{array}$ & 7.18 & $\begin{array}{c}0.07 * * * \\
(0.012)\end{array}$ & 5.52 & $\begin{array}{c}0.07 * * * \\
(0.012)\end{array}$ & 5.69 & $\begin{array}{c}0.07 * * * \\
(0.013)\end{array}$ & 5.35 \\
\hline
\end{tabular}




\begin{tabular}{|c|c|c|c|c|c|c|c|c|}
\hline & \multicolumn{2}{|c|}{ Basic Regression } & \multicolumn{2}{|c|}{ Industry \& Year Effects } & \multicolumn{2}{|c|}{ White (1980) } & \multicolumn{2}{|c|}{ Newey West (1987) } \\
\hline & coeff & t-stat & Coeff & t-stat & Coeff & t-stat & coeff & t-stat \\
\hline CEOBONUS & $\begin{array}{c}0.00 \\
(0.002)\end{array}$ & 1.34 & $\begin{array}{c}0.00 \\
(0.002)\end{array}$ & 1.15 & $\begin{array}{c}0.00 \\
(0.001)\end{array}$ & 1.17 & $\begin{array}{c}0.00 \\
(0.002)\end{array}$ & 1.02 \\
\hline CEOSALARY & $\begin{array}{c}-0.01 \\
(0.026)\end{array}$ & -0.33 & $\begin{array}{c}0.01 \\
(0.027)\end{array}$ & 0.54 & $\begin{array}{c}0.01 \\
(0.031)\end{array}$ & 0.46 & $\begin{array}{c}0.01 \\
(0.040)\end{array}$ & 0.36 \\
\hline ACSIZE & $\begin{array}{c}-0.02 * * * \\
(0.005)\end{array}$ & -3.16 & $\begin{array}{c}-0.02 * * * \\
(0.006)\end{array}$ & -4.37 & $\begin{array}{c}-0.02 * * * \\
(0.005)\end{array}$ & -4.66 & $\begin{array}{c}-0.02 * * * \\
(0.006)\end{array}$ & -4.06 \\
\hline LEVERAGE & $\begin{array}{c}-0.96 * * * \\
(0.052)\end{array}$ & -18.72 & $\begin{array}{c}-0.96 * * * \\
(0.052)\end{array}$ & -18.58 & $\begin{array}{c}-0.96 * * * \\
(0.053)\end{array}$ & -18.13 & $\begin{array}{c}-0.96 * * * \\
(0.068)\end{array}$ & -14.28 \\
\hline$R \& D$ & $\begin{array}{c}0.18 * * * \\
(0.021)\end{array}$ & 8.82 & $\begin{array}{c}0.19 * * * \\
(0.021)\end{array}$ & 9.16 & $\begin{array}{c}0.19 * * * \\
(0.020)\end{array}$ & 9.31 & $\begin{array}{c}0.19 * * * \\
(0.027)\end{array}$ & 7.10 \\
\hline ROA & $\begin{array}{c}0.06 * * * \\
(0.004)\end{array}$ & 14.28 & $\begin{array}{l}0.06 * * * \\
(0.004)\end{array}$ & 14.23 & $\begin{array}{c}0.06 * * * \\
(0.005)\end{array}$ & 11.77 & $\begin{array}{c}0.06 * * * \\
(0.006)\end{array}$ & 10.18 \\
\hline SIZE & $\begin{array}{c}-0.12 * * * \\
(0.008)\end{array}$ & -15.77 & $\begin{array}{l}-0.12 * * * \\
-0.01 * * *\end{array}$ & -15.01 & $\begin{array}{c}-0.12 * * * \\
(0.009)\end{array}$ & -13.14 & $\begin{array}{c}-0.12 * * * \\
(0.011)\end{array}$ & -10.24 \\
\hline CAPEX & $\begin{array}{c}0.44 * * * \\
(0.142)\end{array}$ & 3.06 & $\begin{array}{c}0.45^{* * * *} \\
(0.142)\end{array}$ & 3.71 & $\begin{array}{c}0.45^{* * * *} \\
(0.138)\end{array}$ & 3.27 & $\begin{array}{c}0.45^{* * * *} \\
(0.168)\end{array}$ & 2.68 \\
\hline $\begin{array}{l}\text { Year effects } \\
\text { Industry effects }\end{array}$ & & & $\begin{array}{l}\text { yes } \\
\text { yes }\end{array}$ & & $\begin{array}{l}\text { yes } \\
\text { yes }\end{array}$ & & $\begin{array}{l}\text { yes } \\
\text { yes }\end{array}$ & \\
\hline Constant & $\begin{array}{c}0.44 \\
(0.292)\end{array}$ & 1.50 & $\begin{array}{c}0.37 \\
(0.293)\end{array}$ & 1.26 & $\begin{array}{c}0.37 \\
(0.350)\end{array}$ & 1.06 & $\begin{array}{c}0.37 \\
(0.456)\end{array}$ & 0.81 \\
\hline Observations & 3,330 & & 3,330 & & 3,330 & & 3,330 & \\
\hline$R^{2}$ & 0.35 & & 0.35 & & 0.35 & & 0.35 & \\
\hline$F$-static & $99.13 * * *$ & & $90.78 * * *$ & & $94.56 * * *$ & & $64.79 * * *$ & \\
\hline
\end{tabular}

The p-value for the one-tailed test of the null hypothesis that the coefficient is zero is indicated as ***,**, * to show statistical significance at the $0.01,0.05$ and 0.10 levels respectively, and robust standard errors are provided in parentheses. User and Non User signify firms that use derivatives and those that do not. See Tables 5.3 and 5.4 for definitions of dependent and independent variables. 


\subsubsection{Comparison of Results from the Multivariate Analysis}

A comparison of the results indicates some marked differences between the two groups with regard to corporate governance responses. There are some corporate governance variables such as managerial shareholders, CEO basic salary, CEO age, board size, and audit committee size that exhibit similar results for both groups. For example, SHINSIDERS and CEOSALARY are insignificant across the samples indicating that both managerial ownership and the CEO basic salary are not strong governance tools and do not have any impact on firm value. BDSIZE is significant in both group of firms, however the impact is larger in non-derivative users where an increase of one board member would have a $1 \%$ greater impact on the firm value for non users. CEOAGE reduces firm value, the negative impact is greater for non users. Audit Committee Size (ACSIZE) has a negative relationship with firm value, however, an increase of one member reduces value by $1 \%$ more in derivative non user firms compared to derivative users.

Other corporate governance variables that impact non users but have no impact on derivative users are board meetings, institutional shareholders and CEO total compensation. BDMTGS and SHINST reduce Tobin's Q, and CEOCOMP increases value. This would indicate that total compensation is an important factor for non user firms, however, the other corporate governance variables do not have any impact on firm value for derivative non users.

To summarize, derivative user firms show that BDDIVERS, CEOTENURE, CEOBONUS, BDINDEP and SHBLOCK are important corporate governance mechanisms for derivative users but not for non user firms. BDDIVERS, CEOTENURE, and CEOBONUS increase firm value and BDINDEP and SHBLOCK reduce value for derivative users. BDSIZE increases value in both groups, however, 
the magnitude is higher for non users. With respect to CEOAGE and ACSIZE both have a value reducing effect for derivative users but the reduction is smaller than that observed in non users. BDMTGS and SHINST have a negative association and CEOCOMP has a positive relationship, with firm value only in non users, but has no impact in derivative users.

Overall it shows that corporate governance is more effective in firms using derivatives. Four governance mechanisms increase value for users as compared to only two for derivative non users. While four of the governance variables reduce value in both firms, however for two of these the value reduction is higher in non user firms. Therefore, generally derivative users show more value enhancing activity by corporate governance as compared to derivative non users.

\subsection{Multivariate Analysis on the Effect of Corporate Governance on the Relationship between Derivatives and Cash Flow Volatility Risk.}

In this section I present results of the tests of hypotheses related to cash flow volatility which are discussed in Chapter 4. In order to examine the effect of these corporate governance factors on the risk effect of derivatives, I partition the full sample into two sub-samples of firms. One sample consists of firms that use derivatives for hedging, while the other subsample consists of firms that do not use any derivatives for hedging.

Table 6.9 presents the results for the regression of cash flow volatility (CASH FLOW VOLATILITY) on corporate governance for derivative user $(\mathrm{DER}=1)$ firms and estimates the regression equation Model 3 provided in Table 5.8. As discussed under Section 5.6, the first risk measure relates to operating cash flow volatility and captures the effect of net risk exposure in the manner of Bartram et al. (2011). The independent 
variables are related to corporate governance and are the size of board of directors (BDSIZE), board meetings (BDMTGS), board independence (BDINDEP), board diversity (BDDIVERS), insider shareholders (SHINSIDER), institutional shareholding (SHINST), block shareholders (SHBLOCK), CEO age (CEOAGE), CEO years of service (CEOTENURE), CEO total compensation (CEOCOMP), bonus provided to CEO (CEOBONUS), CEO basic salary (CEOSALARY) and size of the audit committee (ACSIZE). The corporate governance variables are described in Table 5.3. The control variables, return on assets (ROA), one-year prior return on assets $\left(\mathrm{ROA}_{(\mathrm{t}-1)}\right)$, leverage (LEVERAGE), firm size (SIZE) and quick ratio (LIQUIDITY) are defined in Table 5.4.

Column 1 of Table 6.9 presents the results of the baseline regression where the risk measure is regressed on measures of corporate governance and other control variables for firms that use derivatives. The first column presents the basic Ordinary Least Squares (OLS) regression results. The second column shows the regression results for the same equation after controlling for industry and year fixed effects; the third column presents the results of regression estimates after adjusting for heteroscedasticity using White's (1980) consistent covariance matrix, and the fourth column presents the results of regression estimates of the equation using the Newey-West (1987) procedure to correct effects of any potential times-series correlations of panel data taken up to three lags.

With respect to Table 6.9, the values for the F-statistics for all four regression models are statistically significant at the $1 \%$ level. The $\mathrm{R}^{2}$ for the industry and year adjusted, White adjusted and Newey-West adjusted regressions and the basic regression is $29 \%$. A review of the literature shows that the explanatory power of these models is comparatively higher than that for similar risk models used by Huang (2009), Miller et al. (2002) and Cheng (2008) who report $\mathrm{R}^{2}$ ranging from $2 \%$ to $13 \%$; in the range 
of $25 \%$; and from $14.4 \%$ to $28.6 \%$, respectively. However, it is lower than for others using similar risk models: the $\mathrm{R}^{2}$ for John et al. (2008) ranges from $35.2 \%$ to $39.0 \%$ for their US risk models; and for Allayannis et al (2012) the $\mathrm{R}^{2}$ falls in the range of $64 \%$ to $71 \%$ for their global sample.

Results for board meetings and board size ${ }^{25}$ show a positive relation with cash flow volatility and are significant at $1 \%$ level with t-statistics of 3.57 and 3.35 respectively. This is in line with predictions provided in Table 5.6. It indicates that with an addition of one board member, the cash flow risk increases by $0.06 \%$ and the increase in one board meeting enhances risk by $0.02 \%$. Similarly, as predicted CEO total compensation and CEO bonus increase cash flow volatility and both are significant at $1 \%$ level. ${ }^{26}$ This is in line with the findings of Miller et al. (2002) who find that total CEO compensation and variable pay mix both increase unsystematic (income) firm risk at $1 \%$ level, however they suggest that at extreme risk levels, the effect diminishes.

\footnotetext{
${ }^{25}$ Abbott, Parker and Peters (2004) find that board size increases firm restatements that have a higher probability of fraud and which could relate to firm risk.

${ }^{26}$ Gray and Cannella (1997) suggest that "because increased firm risk means increased variability in performance outcomes, executives employed by high risk firms may require a risk premium as poor performance (regardless of the cause) will be attributed to them" (p. 519). Cheng (2004) find a positive relation for change in CEO total pay and change in CEO cash compensation with the change (variability) in earnings.
} 
With respect to managerial shareholding (SHINSIDER) ${ }^{27}$ and audit committee size $(\mathrm{ACSIZE})^{28}$, the coefficients show a negative association with firm risk and are significant at $1 \%$ level. This indicates that larger audit committees and increased insider shareholding reduce firm risk. The coefficients for the other corporate governance variables, BDINDEP, BDDIVERS, CEOAGE, CEOTENURE, SHINST, SHBLOCK and CEOSALARY are not significant ( $p>0.10$ ), providing no evidence for the existence of associations between these variables and cash flow volatility. The results show that all the control variables, ROA, ROA(t-1), LEVERAGE, SIZE have significant negative associations with cash flow volatility, and LIQUIDITY has a significant positive relationship with risk. It indicates that firms with higher profitability in the current and prior year, higher debt utilization and larger size reduce cash flow variability, while liquidity is an increasing function of cash flow fluctuations.

Contrary to predictions, leverage shows a negative association with risk. This is in line with the findings of Cheng (2008) and Keefe and Yaghoubi (2014) who observe a negative relationship between leverage and firm risk. This may be capturing the effect of higher total firm risk inducing more debt utilization. Titman and Wessels (1988) also examine the effect of leverage on standard deviation of percentage change in operating income. "Many authors have also suggested that a firm's debt level is a decreasing function of the volatility of earnings" (Titman and Wessels, 1988, p. 6),

\footnotetext{
${ }^{27}$ Wright et al. (1996) results show a negative relationship between managerial shareholding and corporate risk taking at $5 \%$ level of significance for all samples, but this becomes positive when they examine low managerial ownership. This is also supported by Miller et al. (2002) findings where they find that CEO ownership reduces both systematic and unsystematic risk. Similar to my results, Wright et al. (1996) do not find any significant results for institutional shareholding and block holder ownership.

${ }^{28}$ Lin, Li and Yang (2006) find a negative relation between audit committee size and earnings restatements where the restatement of earnings is more likely to be associated with fraud and subsequent bankruptcy. (Also see: DeZoort and Salterio, 2001).
} 
however though the authors observe a negative relationship between volatility and leverage, the results are not significant. ${ }^{29}$

\footnotetext{
${ }^{29}$ While DeAngelo and Masulius (1980) suggest that "firm leverage (debt-asset ratio) should also differ across industries with differing non-debt tax shields relative to EBIT .....(and) as the ratio of non-debt tax shield to EBIT rises, leverage should fall" (DeAngelo and Masulis, 1980, p. 23-24). Literature on capital structure under asymmetric information show that proponents of the signaling theory suggest a positive relation between leverage and cash flow, while the pecking order behavior implies a negative relationship. (Shenoy and Koch, 1996), with most cross-sectional studies finding a negative relationship, as opposed to event studies that observe a positive relationship between cash flow and leverage.
} 
Table 6. 9: Cash Flow Volatility Regression Models for Derivative User Firms

CASH FLOW VOLATILITY

$=e_{0}+e_{1} B D M T G S_{i, t}+e_{2}$ BDSIZE $_{i, t}+e_{3}$ BDINDEP $_{i, t}+e_{4}$ BDDIVERS $_{i, t}+e_{5}$ SHINSIDER $_{i, t}+e_{6}$ SHINST $_{i, t}$

$+e_{7}$ SHBLOCK $_{i, t}+e_{8}$ CEOAGE $_{i, t}+e_{9}$ CEOTENURE $_{i, t}+e_{10}$ CEOCOMP $_{i, t}+e_{11}$ CEOBONUS $_{i, t}+e_{12}$ CEOSALARY $_{i, t}$

$+e_{13}$ ACSIZE $_{i, t}+e_{14}$ LEVERAGE $_{i, t}+e_{15}$ ROA $_{i, t}+e_{16}$ ROA $_{i, t-1}+e_{17}$ SIZE $_{i, t}+e_{18}$ LIQUIDITY $_{i, t}+\varepsilon_{i, t}$

\begin{tabular}{|c|c|c|c|c|c|c|c|c|}
\hline & \multicolumn{2}{|c|}{ Basic Regression } & \multicolumn{2}{|c|}{ Industry \& Year Effects } & \multicolumn{2}{|c|}{ White (1980) } & \multicolumn{2}{|c|}{ Newey West (1987) } \\
\hline & Coeff & t-stat & Coeff & t-stat & coeff & t-stat & coeff & t-stat \\
\hline$B D M T G S$ & $\begin{array}{c}0.02 * * * \\
(0.005)\end{array}$ & 3.72 & $\begin{array}{c}0.02 * * * \\
(0.005)\end{array}$ & 3.51 & $\begin{array}{c}0.02 * * * \\
(0.005)\end{array}$ & 3.85 & $\begin{array}{c}0.02 * * * \\
(0.005)\end{array}$ & 3.57 \\
\hline$B D S I Z E$ & $\begin{array}{c}0.06 * * * \\
(0.015)\end{array}$ & 3.84 & $\begin{array}{c}0.06 * * * \\
(0.015)\end{array}$ & 3.86 & $\begin{array}{c}0.06 * * * \\
(0.015)\end{array}$ & 3.79 & $\begin{array}{c}0.06 * * * \\
(0.017)\end{array}$ & 3.35 \\
\hline BDINDEP & $\begin{array}{c}-0.01 \\
(0.015)\end{array}$ & -0.44 & $\begin{array}{c}-0.01 \\
(0.016)\end{array}$ & -0.58 & $\begin{array}{c}-0.01 \\
(0.015)\end{array}$ & -0.61 & $\begin{array}{c}-0.01 \\
(0.017)\end{array}$ & -0.54 \\
\hline BDDIVERS & $\begin{array}{c}-0.02 \\
(0.022)\end{array}$ & -0.93 & $\begin{array}{c}-0.03 \\
(0.022)\end{array}$ & -1.35 & $\begin{array}{c}-0.03 \\
(0.021)\end{array}$ & -1.41 & $\begin{array}{c}-0.03 \\
(0.025)\end{array}$ & -1.22 \\
\hline SHINSIDER & $\begin{array}{c}-0.65 * * * \\
(0.119)\end{array}$ & -5.48 & $\begin{array}{c}-0.59 * * * \\
(0.120)\end{array}$ & -4.92 & $\begin{array}{c}-0.59 * * * \\
(0.118)\end{array}$ & -5.02 & $\begin{array}{c}-0.59 * * * \\
(0.135)\end{array}$ & -4.38 \\
\hline SHINST & $\begin{array}{c}0.02 \\
(0.044)\end{array}$ & 0.46 & $\begin{array}{c}0.02 \\
(0.044)\end{array}$ & 0.45 & $\begin{array}{c}0.02 \\
(0.045)\end{array}$ & 0.44 & $\begin{array}{c}0.02 \\
(0.048)\end{array}$ & 0.40 \\
\hline SHBLOCK & $\begin{array}{l}-0.28 * * \\
(0.122)\end{array}$ & -2.29 & $\begin{array}{c}-0.19 \\
(0.123)\end{array}$ & -1.51 & $\begin{array}{c}-0.19 \\
(0.123)\end{array}$ & -1.51 & $\begin{array}{c}-0.19 \\
(0.139)\end{array}$ & -1.34 \\
\hline CEOAGE & $\begin{array}{c}-0.00 \\
(0.003)\end{array}$ & -1.47 & $\begin{array}{c}-0.00 \\
(0.003)\end{array}$ & -1.55 & $\begin{array}{c}-0.00 \\
(0.003)\end{array}$ & -1.44 & $\begin{array}{c}-0.00 \\
(0.003)\end{array}$ & -1.30 \\
\hline CEOTENURE & $\begin{array}{l}0.01 * * \\
(0.003)\end{array}$ & 2.02 & $\begin{array}{c}0.01 * \\
(0.003)\end{array}$ & 1.93 & $\begin{array}{c}0.01 \\
(0.003)\end{array}$ & 1.53 & $\begin{array}{c}0.01 \\
(0.004)\end{array}$ & 1.44 \\
\hline СЕОСОМР & $\begin{array}{c}0.11^{* * * *} \\
(0.023)\end{array}$ & 4.76 & $\begin{array}{c}0.11 * * * \\
(0.024)\end{array}$ & 4.42 & $\begin{array}{c}0.11 * * * \\
(0.025)\end{array}$ & 4.25 & $\begin{array}{c}0.11^{* * *} * \\
(0.025)\end{array}$ & 4.16 \\
\hline CEOBONUS & $\begin{array}{c}0.02 * * * \\
(0.003)\end{array}$ & 5.51 & $\begin{array}{c}0.02 * * * \\
(0.003)\end{array}$ & 5.39 & $\begin{array}{c}0.02 * * * \\
(0.003)\end{array}$ & 5.31 & $\begin{array}{c}0.02 * * * \\
(0.003)\end{array}$ & 4.93 \\
\hline
\end{tabular}




\begin{tabular}{|c|c|c|c|c|c|c|c|c|}
\hline & \multicolumn{2}{|c|}{ Basic Regression } & \multicolumn{2}{|c|}{ Industry \& Year Effects } & \multicolumn{2}{|c|}{ White (1980) } & \multicolumn{2}{|c|}{ Newey West (1987) } \\
\hline & Coeff & t-stat & Coeff & t-stat & coeff & t-stat & coeff & t-stat \\
\hline CEOSALARY & $\begin{array}{c}0.09 \\
(0.059)\end{array}$ & 1.53 & $\begin{array}{l}0.12 * * \\
(0.059)\end{array}$ & 2.01 & $\begin{array}{c}0.12^{*} \\
(0.070)\end{array}$ & 1.71 & $\begin{array}{c}0.12 \\
(0.074)\end{array}$ & 1.61 \\
\hline$A C S I Z E$ & $\begin{array}{c}-0.03 * * * \\
(0.010)\end{array}$ & -3.03 & $\begin{array}{c}-0.04 * * * \\
(0.010)\end{array}$ & -3.41 & $\begin{array}{c}-0.04 * * * \\
(0.009)\end{array}$ & -3.77 & $\begin{array}{c}-0.04 * * * \\
(0.011)\end{array}$ & -3.34 \\
\hline LEVERAGE & $\begin{array}{l}-0.22 * * \\
(0.100)\end{array}$ & -2.21 & $\begin{array}{c}-0.28 * * * \\
(0.102)\end{array}$ & -2.78 & $\begin{array}{c}-0.28 * * * \\
(0.108)\end{array}$ & -2.63 & $\begin{array}{l}-0.28 * * \\
(0.126)\end{array}$ & -2.25 \\
\hline$R O A$ & $\begin{array}{c}-0.03 * * * \\
(0.011)\end{array}$ & -3.00 & $\begin{array}{c}-0.04 * * * \\
(0.011)\end{array}$ & -3.43 & $\begin{array}{c}-0.04 * * * \\
(0.012)\end{array}$ & -3.18 & $\begin{array}{c}-0.04 * * * \\
(0.012)\end{array}$ & -3.09 \\
\hline$R O A_{(t-1)}$ & $\begin{array}{c}-0.10 * * * \\
(0.010)\end{array}$ & -9.51 & $\begin{array}{c}-0.10 * * * \\
(0.010)\end{array}$ & -9.32 & $\begin{array}{c}-0.10 * * * \\
(0.012)\end{array}$ & -7.71 & $\begin{array}{c}-0.10 * * * \\
(0.012)\end{array}$ & -7.78 \\
\hline SIZE & $\begin{array}{c}-0.35 * * * \\
(0.018)\end{array}$ & -19.29 & $\begin{array}{c}-0.34 * * * \\
(0.018)\end{array}$ & -18.71 & $\begin{array}{c}-0.34 * * * \\
(0.027)\end{array}$ & -12.46 & $\begin{array}{c}-0.34 * * * \\
(0.030)\end{array}$ & -11.17 \\
\hline LIQUIDITY & $\begin{array}{c}0.11 * * * \\
(0.026)\end{array}$ & 4.23 & $\begin{array}{c}0.12 * * * \\
(0.027)\end{array}$ & 4.70 & $\begin{array}{c}0.12 * * * \\
(0.029)\end{array}$ & 4.32 & $\begin{array}{c}0.12 * * * \\
(0.033)\end{array}$ & 3.77 \\
\hline $\begin{array}{l}\text { Year effects } \\
\text { Industry effects }\end{array}$ & & & $\begin{array}{l}\text { yes } \\
\text { yes }\end{array}$ & & $\begin{array}{l}\text { yes } \\
\text { yes }\end{array}$ & & $\begin{array}{l}\text { yes } \\
\text { yes }\end{array}$ & \\
\hline Constant & $\begin{array}{c}-3.33 * * * \\
(0.647)\end{array}$ & -5.15 & $\begin{array}{c}-3.69 * * * \\
(0.651)\end{array}$ & -5.67 & $\begin{array}{c}-3.69 * * * \\
(0.820)\end{array}$ & -4.50 & $\begin{array}{c}-3.69 * * * \\
(0.891)\end{array}$ & -4.14 \\
\hline Observations & 2,904 & & 2,904 & & 2,904 & & 2,904 & \\
\hline$R^{2}$ & 0.29 & & 0.29 & & 0.29 & & 0.29 & \\
\hline$F$-statistic & $65.64 * * *$ & & $60.38 * * *$ & & $34.13 * * *$ & & $26.47 * * *$ & \\
\hline
\end{tabular}

The p-value for the one-tailed test of the null hypothesis that the coefficient is zero is indicated as $* * *, * * *$ to show statistical significance at the $0.01,0.05$ and 0.10 levels respectively, and robust standard errors are provided in parentheses. User and Non User signify firms that use derivatives and those that do not. See Tables 5.3 and 5.4 for definitions of dependent and independent variables. 


\section{Multivariate Analysis for Cash Flow Volatility in Non User Firms.}

Table 6.10 presents regression estimates of the association between corporate governance variables and cash flow volatility firm risk for the second sub-sample comprising only derivative non user firms $(\mathrm{DER}=0)$. This is an estimation of regression Model 3 and the regression models are the same as used earlier shown in Table 6.10, for the derivative user firms sample. The first column represents results of the basic regression, followed by industry and year effects controlled regression, White (1980) regression model and the Newey-West (1987) regression model.

All the regression models have significant F-statistics at the $1 \%$ level, however these F-statistics are significantly larger than those presented in Table 6.9 for derivative users. The $\mathrm{R}^{2}$ values for this sample are $49 \%$ and higher than $29 \%$ observed for the derivative user firms (Table 6.9) and indicates that these models are more robust. This can also be evidenced in the larger coefficient values compared to derivative users. Generally, the results for the corporate governance variables are similar across the two samples, however there are some differences for some of the governance variables.

Unlike the results for derivative user firms, these results indicate that CEOAGE and SHINSIDER are significantly negative and CEOSALARY is significantly positive at $10 \%, 1 \%$ and $5 \%$ levels, respectively. It indicates that CEO age and managerial ownership have a greater impact in reducing risk in firms not using derivatives. But in contrast CEO base salary has a risk enhancing effect. In contrast to the other sample (Table 6.9), coefficient for audit committee is now insignificant in this sub-sample indicating that for firms not using derivatives, the number of audit committee members is irrelevant. The coefficients for the other corporate governance variables, BDINDEP, BDDIVERS, SHINST and CEOTENURE remain the same and are 
insignificant ( $>>0.10)$. All control variables are significant at $1 \%$ level and in same direction as for derivative users, except for LEVERAGE which is now insignificant. 
Table 6. 5: Cash Flow Volatility Regression Models for Derivative Non User Firms

CASH FLOW VOLATILITY

$=e_{0}+e_{1} B D M T G S_{i, t}+e_{2}$ BDSIZE $_{i, t}+e_{3}$ BDINDEP $_{i, t}+e_{4}$ BDDIVERS $_{i, t}+e_{5}$ SHINSIDER $_{i, t}+e_{6}$ SHINST $_{i, t}$

$+e_{7}$ SHBLOCK $_{i, t}+e_{8}$ CEOAGE $_{i, t}+e_{9}$ CEOTENURE $_{i, t}+e_{10}$ CEOCOMP $_{i, t}+e_{11}$ CEOBONUS $_{i, t}+e_{12}$ CEOSALARY $_{i, t}$

$+e_{13}$ ACSIZE $_{i, t}+e_{14}$ LEVERAGE $_{i, t}+e_{15}$ ROA $_{i, t}+e_{16}$ ROA $_{i, t-1}+e_{17}$ SIZE $_{i, t}+e_{18}$ LIQUIDITY $_{i, t}+\varepsilon_{i, t}$

\begin{tabular}{|c|c|c|c|c|c|c|c|c|}
\hline & \multicolumn{2}{|c|}{ Basic Regression } & \multicolumn{2}{|c|}{ Industry \& Year Effects } & \multicolumn{2}{|c|}{ White (1980) } & \multicolumn{2}{|c|}{ Newey West (1987) } \\
\hline & Coeff & t-stat & coeff & t-stat & coeff & t-stat & coeff & t-stat \\
\hline$B D M T G S$ & $\begin{array}{c}0.03 * * * \\
(0.005)\end{array}$ & 5.07 & $\begin{array}{c}0.03 * * * \\
(0.005)\end{array}$ & 5.06 & $\begin{array}{c}0.03 * * * \\
(0.006)\end{array}$ & 4.80 & $\begin{array}{c}0.03 * * * \\
(0.006)\end{array}$ & 4.34 \\
\hline$B D S I Z E$ & $\begin{array}{c}0.10 * * * \\
(0.016)\end{array}$ & 6.45 & $\begin{array}{c}0.10 * * * \\
(0.016)\end{array}$ & 6.45 & $\begin{array}{c}0.10^{* * * *} \\
(0.020)\end{array}$ & 5.08 & $\begin{array}{c}0.10^{* * *} \\
(0.023)\end{array}$ & 4.43 \\
\hline BDINDEP & $\begin{array}{c}-0.03 * \\
(0.017)\end{array}$ & -1.97 & $\begin{array}{l}-0.03^{*} \\
(0.017)\end{array}$ & -1.95 & $\begin{array}{c}-0.03 * \\
(0.019)\end{array}$ & -1.73 & $\begin{array}{c}-0.03 \\
(0.022)\end{array}$ & -1.53 \\
\hline BDDIVERS & $\begin{array}{c}0.01 \\
(0.023)\end{array}$ & 0.49 & $\begin{array}{c}0.01 \\
(0.023)\end{array}$ & 0.43 & $\begin{array}{c}0.01 \\
(0.021)\end{array}$ & 0.47 & $\begin{array}{c}0.01 \\
(0.025)\end{array}$ & 0.40 \\
\hline SHINSIDER & $\begin{array}{c}-0.73 * * * \\
(0.115)\end{array}$ & -6.36 & $\begin{array}{c}-0.72 * * * \\
(0.116)\end{array}$ & -6.25 & $\begin{array}{c}-0.72 * * * \\
(0.127)\end{array}$ & -5.72 & $\begin{array}{c}-0.72 * * * \\
(0.147)\end{array}$ & -4.92 \\
\hline SHBLOCK & $\begin{array}{c}-0.72 * * * \\
(0.121)\end{array}$ & -5.98 & $\begin{array}{c}-0.71 * * * \\
(0.122)\end{array}$ & -5.77 & $\begin{array}{c}-0.71 * * * \\
(0.146)\end{array}$ & -4.81 & $\begin{array}{c}-0.71 * * * \\
(0.165)\end{array}$ & -4.26 \\
\hline SHINST & $\begin{array}{c}-0.05 \\
(0.041)\end{array}$ & -1.11 & $\begin{array}{c}-0.05 \\
(0.041)\end{array}$ & -1.10 & $\begin{array}{c}-0.05 \\
(0.043)\end{array}$ & -1.05 & $\begin{array}{c}-0.05 \\
(0.050)\end{array}$ & -0.91 \\
\hline CEOAGE & $\begin{array}{l}-0.01 * * \\
(0.003)\end{array}$ & -2.13 & $\begin{array}{l}-0.01 * * \\
(0.003)\end{array}$ & -2.19 & $\begin{array}{c}-0.01 * * \\
(0.003)\end{array}$ & -2.08 & $\begin{array}{l}-0.01 * \\
(0.003)\end{array}$ & -1.74 \\
\hline CEOTENURE & $\begin{array}{c}-0.00 \\
(0.003)\end{array}$ & -0.56 & $\begin{array}{c}-0.00 \\
(0.003)\end{array}$ & -0.54 & $\begin{array}{c}-0.00 \\
(0.003)\end{array}$ & -0.56 & $\begin{array}{c}-0.00 \\
(0.003)\end{array}$ & -0.48 \\
\hline СЕОСОМР & $\begin{array}{c}0.17 * * * \\
(0.023)\end{array}$ & 7.22 & $\begin{array}{c}0.16 * * * \\
(0.025)\end{array}$ & 6.65 & $\begin{array}{c}0.16^{* * * *} \\
(0.026)\end{array}$ & 6.37 & $\begin{array}{c}0.16^{* * * *} \\
(0.028)\end{array}$ & 5.78 \\
\hline CEOBONUS & $\begin{array}{c}0.02 * * * \\
(0.003)\end{array}$ & 5.64 & $\begin{array}{c}0.02 * * * \\
(0.003)\end{array}$ & 5.61 & $\begin{array}{c}0.02 * * * \\
(0.003)\end{array}$ & 5.37 & $\begin{array}{c}0.02 * * * \\
(0.004)\end{array}$ & 4.75 \\
\hline
\end{tabular}




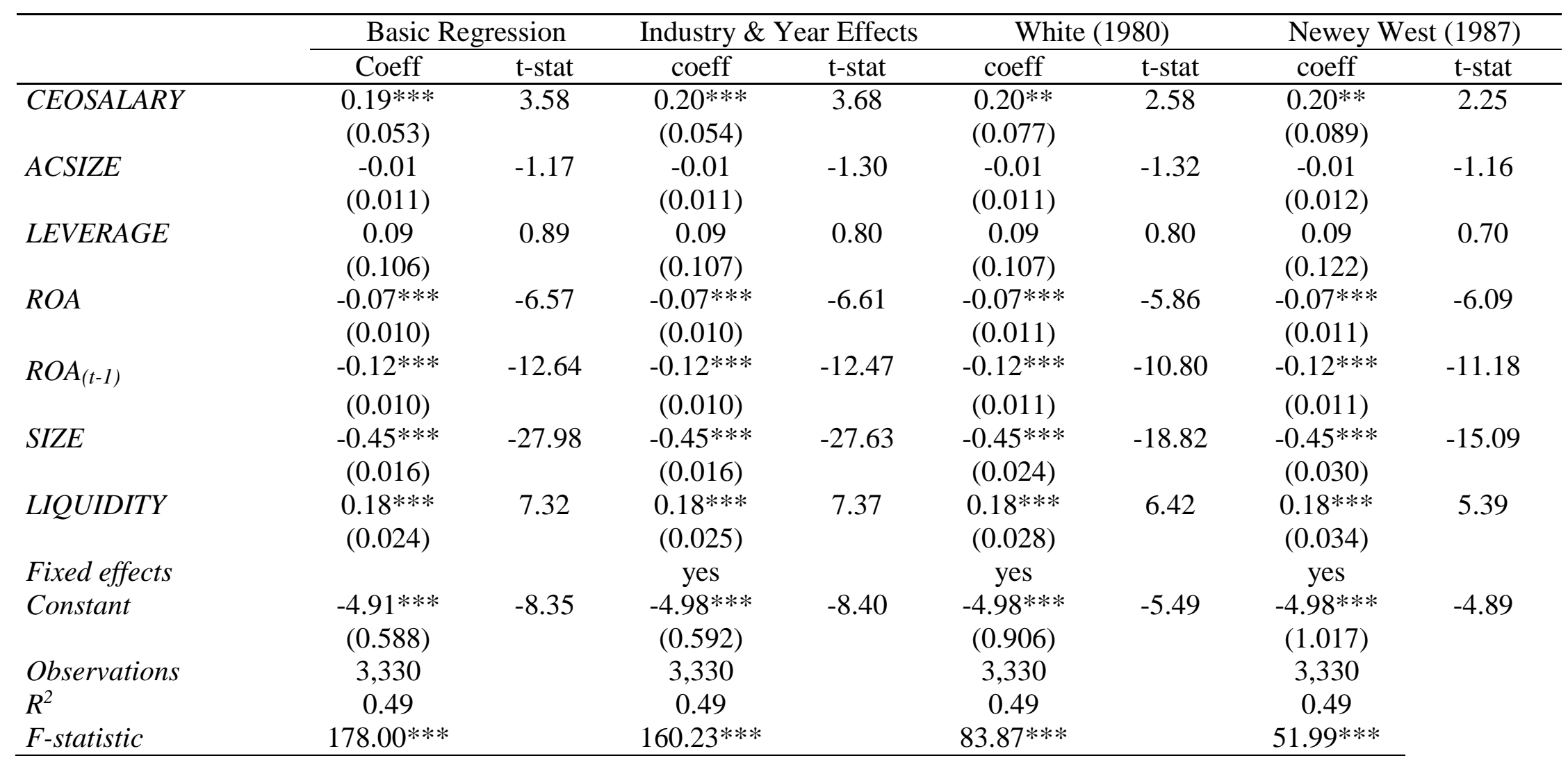

The p-value for the one-tailed test of the null hypothesis that the coefficient is zero is indicated as ***, **, * to show statistical significance at the $0.01,0.05$ and 0.10 levels respectively, and robust standard errors are provided in parentheses. User and Non User signify firms that use derivatives and those that do not. See Tables 5.3 and 5.4 for definitions of dependent and independent variables. 


\section{Comparison of Cash Flow Volatility Results for Derivative Users and Non Users}

A comparison of derivative user firms with derivative non user firms indicates that are many similarities between the groups. To start with BDINDEP, BDDIVERS, CEOTENURE and SHINST exhibit similar results in both groups to indicate that they do not have any impact on cash flow volatility. While the coefficients for BDMTGS, BDSIZE, CEOCOMP and CEOBONUS show a significant positive effect and SHINSIDER has a significant negative impact in both the groups. Though these corporate governance mechanisms show similar directions, the magnitude of the impact differs for derivative users and non user.

A comparison of the coefficients indicates that derivative non user firms have a larger impact on firm risk. For example, the governance variables that have a larger impact on cash flow risk in non user firms over derivative users are: BDMTGS has a $1 \%$ larger increase; BDSIZE shows a $6 \%$ greater increase on risk and CEOCOMP has a $0.04 \%$ larger impact on risk. While SHINSIDER indicates a larger reduction of risk with a significant coefficient of -0.72 compared to -0.59 for derivative users. When we view the coefficients for CEOBONUS there is a larger impact of non user firms at 0.0172 compared to that of 0.0161 for derivative users, showing a higher impact of $0.11 \%$ on cash flow volatility.

There are some differences in the two groups such as ACSIZE reduces risk by $4 \%$ and which is significant at $1 \%$ level in derivative user firms. However, audit committee size does not have an effect on non users. On the other hand, SHBLOCK and CEOAGE reduces risk and CEOSALARY increases risk only in firms that do not use derivatives. 
To summarize, derivative user firms show that ACSIZE and SHINSIDER are important in reducing risk, while BDMTGS, BDSIZE, CEOCOMP and CEOBONUS do increase risk but the increase in risk is higher for derivative non users. This would indicate that even though many of the governance mechanisms are increasing cash flow volatility, there is better control in firms that use derivatives. And ACSIZE is important in reducing risk only for derivative users. 


\subsection{Multivariate Analysis of the Effect of Corporate Governance on the Relationship between Derivatives and Stock Return Volatility}

This section presents the results from the estimation of regression equation that examines the effect of corporate governance on the stock return volatility effect of derivatives. These models test the hypotheses related to stock return volatility developed in Chapter 4. I partition the full sample into two subsamples of firms. One sample consists of firms that use derivatives for hedging, while the other subsample consists of firms that do not use any derivatives for hedging.

Table 6.11 presents results for the regression of stock returns volatility (STOCK RETURN VOLATILITY) on corporate governance for derivative user firms (DER=1) that estimates the regression Model 4 provided in Table 5.8. As discussed under Section 5.6, the second risk measure relates to stock returns volatility and represents the standard deviation of day-to-day logarithmic price changes for each firm for each year in the manner of Bartram et al. (2011).

The F-statistical values for all regression models are statistically significant at the $1 \%$ level. The $\mathrm{R}^{2}$ for the models range from $42 \%$ to $55 \%$, with the lowest pertaining to the basic regression. A review of the literature shows that the explanatory power of these models is in line with equity risk model $\mathrm{R}^{2}$ of: Cheng (2008) that is around $55.8 \%$; Hentschel and Kothari (2001) that ranges from 34.3\% to 49.47\%; and Sila et al. (2014). However, my results are higher than other studies that report a lower goodness-of-fit ranging from $15.91 \%$ to $27.88 \%$ (Guay, 1999; Rajgopal and Shevlin, 2002) for stock return volatility risk. 
Ten of the thirteen corporate governance variables are found to be associated with stock return volatility. BDMTGS is found to be significantly positively related with stock return variation at $5 \%$ level with t-statistics of 2.53 , that is an additional board meeting increases stock return variation by $0.01 \%$. The coefficients for BDSIZE and BDDIVERS are negative and statistically significant at $1 \%$ level. Both results are in line with findings of Sila et al. (2014) $)^{30}$ and Elbadry, et al. (2015) who find a negative relationship for board size and board diversity with stock return volatility risk measure at $1 \%$ to $5 \%$ level of significance. This indicates that larger board size and women on the boards effectively reduce stock return volatility.

The results for the shareholders indicate that they influence the risk management activities of the firm. As discussed in Section 4.5, insider shareholding (SHINSIDER) shows a coefficient of 0.15 indicating a positive association with Stock Return Volatility at $1 \%$ level of significance. As predicted in Table 5.6, the results of institutional shareholders (SHINST) ${ }^{31}$ and block shareholders (SHBLOCK) are positive and significant at the 5\% level. This is similar to results of Himmelberg et al. (1999) when they take a dummy variable to capture stock price risk.

CEO age (CEOAGE) captures the effects of CEO short-term horizon problems. The result shows a significantly positive association with stock return volatility at the $1 \%$ level of significance. This indicates that older CEOs increase risk with the use of

\footnotetext{
${ }^{30}$ However, Sila, Gonzalez and Hagendorff (2014) contend that this negative relationship disappears when they use more sophisticated identification strategies and suggest there is no impact of women directors on risk measures.

${ }^{31}$ David et al. (2015) indicate that Institutional Investors exhibit a granular effect, with largest investors having a positive effect and the bottom tier of institutional investors having a negative effect on stock return volatility. However, their variable for all investors shows a positive relationship with stock return volatility at $1 \%$ level of significance.
} 
derivatives. However, counter to predictions the coefficients for CEOTENURE ${ }^{32}$ and CEOBONUS $^{33}$ are negative and significant at $1 \%$, level indicating that CEO bonus and CEOs with longer years of service reduce Stock Return Volatility risk.

With respect to audit committee size (ACSIZE), the results indicate that large audit committees reduce Stock Return Volatility risk and are an important governance mechanism. The coefficient is positive and statistically significant at $5 \%$ level.

The other coefficients for corporate governance variables, board independence (BDINDEP), CEO total compensation (CEOCOMP) and CEO base salary $($ CEOSALARY) are not significant $(\mathrm{p}>0.10)$, providing no evidence for the existence of associations between these variables and risk management through increased derivatives.

With respect to the control variables, ROA, ROA(t-1), SIZE have negative association and LEVERAGE has a positive association with Stock Return Volatility risk at $1 \%$ significant level. The coefficient for LIQUIDITY is insignificant and all the other control variables are according to predictions (Table 5.6). This indicates that firms

\footnotetext{
${ }^{32}$ Coles et al. (2006) find a negative relationship between tenure and firm risk taken as stock return volatility and Cohen et al. (2004) also find a negative association of tenure with investment risk.

${ }^{33}$ Jin, (2002) find a negative relationship between firm specific risk and pay-performance sensitivities. Research suggests that stock-based incentives might not increase CEO risktaking (Carpenter, 2000; Ross, 2004). Sila, et al. (2014) find a negative relationship with stock return volatility for CEO tenure in their IV model; negative CEO cash compensation in their GMM model; and negative CEO delta and vega compensation sensitivities at 10\%, 5\% and $1 \%$ level of significance, respectively. My results also support the finding of Bloom and Milkovich (1998) who observe that firm risk is positively related to base salary and negatively related to incentive pay.
} 
with higher profitability in the current and prior year, higher debt utilization and larger size reduce stock return volatility. 


\section{Table 6. 6: Stock Return Volatility Regression Models for Derivative User Firms}

STOCK RETURN VOLATILITY

$=e_{0}+e_{1} B D M T G S_{i, t}+e_{2} B_{D S I Z E_{i, t}}+e_{3}$ BDINDEP $_{i, t}+e_{4}$ BDDIVERS $_{i, t}+e_{5}$ SHINSIDER $_{i, t}+e_{6}$ SHINST $_{i, t}$

$+e_{7}$ SHBLOCK $_{i, t}+e_{8}$ CEOAGE $_{i, t}+e_{9}$ CEOTENURE $_{i, t}+e_{10}$ CEOCOMP $_{i, t}+e_{11}$ CEOBONUS $_{i, t}+e_{12}$ CEOSALARY $_{i, t}$

$+e_{13} \operatorname{ACSIZE}_{i, t}+e_{14}$ LEVERAGE $_{i, t}+e_{15}$ ROA $_{i, t}+e_{16} \operatorname{lagROA}_{i, t}+e_{17} \operatorname{SIZE}_{i, t}+e_{18} \operatorname{LIQUIDITY}_{i, t}+\varepsilon_{i, t}$

\begin{tabular}{|c|c|c|c|c|c|c|c|c|}
\hline & \multicolumn{2}{|c|}{ Basic Regression } & \multicolumn{2}{|c|}{ Industry \& Year Effects } & \multicolumn{2}{|c|}{ White (1980) } & \multicolumn{2}{|c|}{ Newey West (1987) } \\
\hline & coeff & t-stat & coeff & t-stat & Coeff & t-stat & coeff & t-stat \\
\hline \multirow[t]{2}{*}{$B D M T G S$} & $0.01 * * *$ & 2.92 & $0.01 * * *$ & 3.00 & $0.01 * * *$ & 2.77 & $0.01 * *$ & 2.53 \\
\hline & $(0.002)$ & & $(0.002)$ & & $(0.002)$ & & $(0.002)$ & \\
\hline \multirow[t]{2}{*}{ BDSIZE } & $-0.02 * * *$ & -4.11 & $-0.02 * * *$ & -4.28 & $-0.02 * * *$ & -4.01 & $-0.02 * * *$ & -3.44 \\
\hline & $(0.006)$ & & $(0.005)$ & & $(0.006)$ & & $(0.006)$ & \\
\hline \multirow[t]{2}{*}{$B D I N D E P$} & 0.01 & 1.62 & 0.00 & 0.04 & 0.00 & 0.04 & 0.00 & 0.03 \\
\hline & $(0.006)$ & & $(0.005)$ & & $(0.006)$ & & $(0.007)$ & \\
\hline \multirow[t]{2}{*}{ BDDIVERS } & $-0.05 * * *$ & -5.90 & $-0.04 * * *$ & -4.79 & $-0.04 * * *$ & -4.79 & $-0.04 * * *$ & -4.10 \\
\hline & $(0.009)$ & & $(0.008)$ & & $(0.008)$ & & $(0.009)$ & \\
\hline \multirow[t]{2}{*}{ SHINSIDER } & $0.21 * * *$ & 4.45 & $0.15 * * *$ & 3.64 & $0.15 * * *$ & 3.38 & $0.15 * * *$ & 3.00 \\
\hline & $(0.047)$ & & $(0.042)$ & & $(0.045)$ & & $(0.051)$ & \\
\hline \multirow[t]{2}{*}{ SHBLOCK } & $0.27 * * *$ & 5.67 & $0.11 * * *$ & 2.61 & $0.11 * *$ & 2.47 & $0.11 * *$ & 2.17 \\
\hline & $(0.048)$ & & $(0.043)$ & & $(0.045)$ & & $(0.052)$ & \\
\hline \multirow[t]{2}{*}{ SHINST } & 0.02 & 1.26 & $0.04 * * *$ & 2.66 & $0.04 * * *$ & 2.61 & $0.04 * *$ & 2.42 \\
\hline & $(0.017)$ & & $(0.015)$ & & $(0.016)$ & & $(0.017)$ & \\
\hline \multirow[t]{2}{*}{ CEOAGE } & $0.00 * *$ & 2.04 & $0.00 * * *$ & 3.38 & $0.00 * * *$ & 3.33 & $0.00 * * *$ & 2.94 \\
\hline & $(0.001)$ & & $(0.001)$ & & $(0.001)$ & & $(0.001)$ & \\
\hline \multirow[t]{2}{*}{ CEOTENURE } & $-0.00 * *$ & -2.43 & $-0.00 * *$ & -2.29 & $-0.00 * *$ & -2.19 & $-0.00 * *$ & -1.99 \\
\hline & $(0.001)$ & & $(0.001)$ & & $(0.001)$ & & $(0.001)$ & \\
\hline \multirow[t]{2}{*}{ СЕОСОМР } & $-0.05 * * *$ & -5.23 & -0.00 & -0.11 & -0.00 & -0.11 & -0.00 & -0.11 \\
\hline & $(0.009)$ & & $(0.008)$ & & $(0.008)$ & & $(0.008)$ & \\
\hline \multirow[t]{2}{*}{ CEOBONUS } & $-0.01 * * *$ & -11.01 & $-0.01 * * *$ & -9.97 & $-0.01 * * *$ & -9.62 & $-0.01 * * *$ & -8.73 \\
\hline & $(0.001)$ & & $(0.001)$ & & $(0.001)$ & & $(0.001)$ & \\
\hline
\end{tabular}




\begin{tabular}{|c|c|c|c|c|c|c|c|c|}
\hline & \multicolumn{2}{|c|}{ Basic Regression } & \multicolumn{2}{|c|}{ Industry \& Year Effects } & \multicolumn{2}{|c|}{ White (1980) } & \multicolumn{2}{|c|}{ Newey West (1987) } \\
\hline & coeff & t-stat & coeff & t-stat & Coeff & t-stat & coeff & t-stat \\
\hline CEOSALARY & $\begin{array}{l}0.09 * * * \\
(0.023)\end{array}$ & 3.86 & $\begin{array}{c}-0.01 \\
(0.021)\end{array}$ & -0.37 & $\begin{array}{c}-0.01 \\
(0.022)\end{array}$ & -0.36 & $\begin{array}{c}-0.01 \\
(0.026)\end{array}$ & -0.30 \\
\hline$A C S I Z E$ & $\begin{array}{c}-0.02 * * * \\
(0.004)\end{array}$ & -6.46 & $\begin{array}{c}0.01 * * * \\
(0.004)\end{array}$ & 2.84 & $\begin{array}{c}0.01 * * * \\
(0.004)\end{array}$ & 2.82 & $\begin{array}{l}0.01 * * \\
(0.004)\end{array}$ & 2.51 \\
\hline LEVERAGE & $\begin{array}{c}0.42 * * * \\
(0.040)\end{array}$ & 10.69 & $\begin{array}{c}0.45 * * * \\
(0.036)\end{array}$ & 12.52 & $\begin{array}{c}0.45 * * * \\
(0.037)\end{array}$ & 12.19 & $\begin{array}{c}0.45 * * * \\
(0.041)\end{array}$ & 10.87 \\
\hline$R O A$ & $\begin{array}{c}-0.06^{* * * *} \\
(0.004)\end{array}$ & -13.81 & $\begin{array}{c}-0.05 * * * \\
(0.004)\end{array}$ & -12.32 & $\begin{array}{c}-0.05 * * * \\
(0.004)\end{array}$ & -12.37 & $\begin{array}{c}-0.05 * * * \\
(0.004)\end{array}$ & -12.67 \\
\hline$R O A_{(t-1)}$ & $\begin{array}{c}-0.01 * * * \\
(0.004)\end{array}$ & -3.71 & $\begin{array}{c}-0.03 * * * \\
(0.004)\end{array}$ & -7.35 & $\begin{array}{c}-0.03 * * * \\
(0.004)\end{array}$ & -6.99 & $\begin{array}{c}-0.03 * * * \\
(0.004)\end{array}$ & -6.97 \\
\hline SIZE & $\begin{array}{c}-0.04 * * * \\
(0.007)\end{array}$ & -6.24 & $\begin{array}{c}-0.07 * * * \\
(0.006)\end{array}$ & -10.56 & $\begin{array}{c}-0.07 * * * \\
(0.007)\end{array}$ & -9.74 & $\begin{array}{c}-0.07 * * * \\
(0.008)\end{array}$ & -8.49 \\
\hline LIQUIDITY & $\begin{array}{c}0.03 * * * \\
(0.010)\end{array}$ & 2.93 & $\begin{array}{c}0.02 * \\
(0.009)\end{array}$ & 1.67 & $\begin{array}{c}0.02 * \\
(0.009)\end{array}$ & 1.68 & $\begin{array}{c}0.02 \\
(0.010)\end{array}$ & 1.52 \\
\hline $\begin{array}{l}\text { Year effects } \\
\text { Industry effects }\end{array}$ & & & $\begin{array}{l}\text { yes } \\
\text { yes }\end{array}$ & & $\begin{array}{l}\text { Yes } \\
\text { Yes }\end{array}$ & & $\begin{array}{l}\text { yes } \\
\text { yes }\end{array}$ & \\
\hline Constant & $\begin{array}{c}3.73 * * * \\
(0.256)\end{array}$ & 14.57 & $\begin{array}{c}4.30 * * * \\
(0.227)\end{array}$ & 18.95 & $\begin{array}{c}4.30 * * * \\
(0.240)\end{array}$ & 17.89 & $\begin{array}{c}4.30 * * * \\
(0.299)\end{array}$ & 14.37 \\
\hline Observations & 2,904 & & 2,904 & & 2,904 & & 2,904 & \\
\hline$R^{2}$ & 0.42 & & 0.55 & & 0.55 & & 0.55 & \\
\hline$F$-statistic & $114.61 * * *$ & & $176.69 * * *$ & & $174.44 * * *$ & & $158.66 * * *$ & \\
\hline
\end{tabular}




\section{Multivariate Analysis for Stock Return Volatility in Derivative Non User Firms.}

Table 6.12 presents regression estimates of the association between corporate governance variables and stock return volatility risk for the second sub-sample comprising only non user firms $(\mathrm{DER}=0)$. This is an estimation of regression equation depicted in Model 4 (Table 5.8), and similar to the regression models for derivative user firms presented in Table 6.11, that is, the basic regression model, industry and year effects controlled regression model, White (1980) regression model and the Newey-West (1987) regression model.

All the regression models have significant F-statistics at the 1\% level, however these F-statistics are significantly smaller than those presented in Table 6.11 for derivative users. The $\mathrm{R}^{2}$ values for this sample range from $39 \%$ to $50 \%$, which is lower than those observed for the derivative users. Most of the corporate governance variables, such as BDMTGS, BDSIZE, CEOBONUS, SHINSIDE, SHBLOCK and ACSIZE are similar across the two samples and with the same direction of association. However, the coefficients for the insider shareholders and block holders are much higher in this sample indicating a greater risk-enhancing effect on the non user firms.

Unlike results for derivative users, the coefficients for BDDIVERS, CEOAGE, CEOTENURE and SHINST are insignificant. It appears that women directors on the board, CEO age or tenure and institutional shareholders become irrelevant when firms do not hedge with derivatives. The coefficients for the other corporate governance variables, BDINDEP, SHINST and CEOTENURE and for control variable, LIQUIDITY remain the same in both samples and are insignificant $(p>0.10)$. All the other control variables are significant at $1 \%$ level and in same direction for both the samples. 


\section{Table 6. 7: Stock Return Volatility Regression Models for Derivative Non User Firms}

STOCK RETURN VOLATILITY

$=e_{0}+e_{1}$ BDMTGS $_{i, t}+e_{2}$ BDSIZE $_{i, t}+e_{3}$ BDINDEP $_{i, t}+e_{4}$ BDDIVERS $_{i, t}+e_{5}$ SHINSIDER $_{i, t}+e_{6}$ SHINST $_{i, t}$

$+e_{7}$ SHBLOCK $_{i, t}+e_{8}$ CEOAGE $_{i, t}+e_{9}$ CEOTENURE $_{i, t}+e_{10}$ CEOCOMP $_{i, t}+e_{11}$ CEOBONUS $_{i, t}+e_{12}$ CEOSALARY $_{i, t}$

$+e_{13} A_{C S I Z E_{i, t}}+e_{14} L E V E R A G E_{i, t}+e_{15} R_{0 A} A_{i, t}+e_{16} R O A_{i, t-1}+e_{17} \operatorname{SIZE}_{i, t}+e_{18} \operatorname{LIQUIDITY}_{i, t}+\varepsilon_{i, t}$

\begin{tabular}{|c|c|c|c|c|c|c|c|c|}
\hline & \multicolumn{2}{|c|}{ Basic Regression } & \multicolumn{2}{|c|}{ Industry \& Year Effects } & \multicolumn{2}{|c|}{ White (1980) } & \multicolumn{2}{|c|}{ Newey West (1987) } \\
\hline & coeff & t-stat & coeff & t-stat & coeff & t-stat & coeff & t-stat \\
\hline \multirow[t]{2}{*}{ BDMTGS } & $0.01 * * *$ & 4.12 & $0.01 * * *$ & 3.92 & $0.01 * * *$ & 3.39 & $0.01 * * *$ & 3.09 \\
\hline & $(0.002)$ & & $(0.002)$ & & $(0.002)$ & & $(0.002)$ & \\
\hline \multirow[t]{2}{*}{$B D S I Z E$} & $-0.02 * * *$ & -4.61 & $-0.02 * * *$ & -4.95 & $-0.02 * * *$ & -4.91 & $-0.02 * * *$ & -4.37 \\
\hline & $(0.005)$ & & $(0.005)$ & & $(0.005)$ & & $(0.006)$ & \\
\hline \multirow[t]{2}{*}{ BDINDEP } & 0.01 & 1.07 & -0.00 & -0.39 & -0.00 & -0.39 & -0.00 & -0.36 \\
\hline & $(0.006)$ & & $(0.005)$ & & $(0.005)$ & & $(0.006)$ & \\
\hline \multirow[t]{2}{*}{ BDDIVERS } & $-0.02 * *$ & -2.06 & -0.01 & -1.63 & -0.01 & -1.56 & -0.01 & -1.36 \\
\hline & $(0.008)$ & & $(0.007)$ & & $(0.008)$ & & $(0.009)$ & \\
\hline \multirow[t]{2}{*}{ SHINSIDER } & $0.27 * * *$ & 6.84 & $0.26 * * *$ & 7.24 & $0.26^{* * *}$ & 6.92 & $0.26^{* * *}$ & 6.09 \\
\hline & $(0.040)$ & & $(0.036)$ & & $(0.038)$ & & $(0.043)$ & \\
\hline \multirow[t]{2}{*}{ SHINST } & -0.00 & -0.19 & 0.00 & 0.31 & 0.00 & 0.31 & 0.00 & 0.29 \\
\hline & $(0.014)$ & & $(0.013)$ & & $(0.013)$ & & $(0.014)$ & \\
\hline \multirow[t]{2}{*}{ SHBLOCK } & $0.34 * * *$ & 8.10 & $0.25 * * *$ & 6.50 & $0.25 * * *$ & 6.31 & $0.25 * * *$ & 5.76 \\
\hline & $(0.042)$ & & $(0.038)$ & & $(0.039)$ & & $(0.043)$ & \\
\hline \multirow[t]{2}{*}{$C E O A G E$} & $-0.00 * * *$ & -2.79 & -0.00 & -1.27 & -0.00 & -1.30 & -0.00 & -1.17 \\
\hline & $(0.001)$ & & $(0.001)$ & & $(0.001)$ & & $(0.001)$ & \\
\hline \multirow[t]{2}{*}{ CEOTENURE } & 0.00 & 1.48 & 0.00 & 1.20 & 0.00 & 1.22 & 0.00 & 1.12 \\
\hline & $(0.001)$ & & $(0.001)$ & & $(0.001)$ & & $(0.001)$ & \\
\hline \multirow[t]{2}{*}{ СЕОСОМР } & $-0.05 * * *$ & -5.92 & 0.01 & 0.97 & 0.01 & 1.02 & 0.01 & 0.99 \\
\hline & $(0.008)$ & & $(0.008)$ & & (0.007) & & $(0.008)$ & \\
\hline CEOBONUS & $-0.01 * * *$ & -8.68 & $-0.01 * * *$ & -8.44 & $-0.01 * * *$ & -8.45 & $-0.01 * * *$ & -7.78 \\
\hline
\end{tabular}




\begin{tabular}{|c|c|c|c|c|c|c|c|c|}
\hline & \multicolumn{2}{|c|}{ Basic Regression } & \multicolumn{2}{|c|}{ Industry \& Year Effects } & \multicolumn{2}{|c|}{ White (1980) } & \multicolumn{2}{|c|}{ Newey West (1987) } \\
\hline & coeff & t-stat & coeff & t-stat & coeff & t-stat & coeff & t-stat \\
\hline & $(0.001)$ & & $(0.001)$ & & $(0.001)$ & & $(0.001)$ & \\
\hline \multirow[t]{2}{*}{ CEOSALARY } & $0.07 * * *$ & 3.90 & -0.01 & -0.85 & -0.01 & -0.85 & -0.01 & -0.79 \\
\hline & $(0.018)$ & & $(0.017)$ & & $(0.017)$ & & $(0.018)$ & \\
\hline \multirow[t]{2}{*}{ ACSIZE } & $-0.01 * * *$ & -3.68 & $0.01 * * *$ & 3.87 & $0.01 * * *$ & 3.83 & $0.01 * * *$ & 3.50 \\
\hline & $(0.004)$ & & $(0.004)$ & & $(0.004)$ & & $(0.004)$ & \\
\hline \multirow{2}{*}{$L E V E R A G E$} & $0.34 * * *$ & 9.41 & $0.34 * * *$ & 10.27 & $0.34 * * *$ & 9.71 & $0.34 * * *$ & 8.67 \\
\hline & $(0.037)$ & & $(0.034)$ & & $(0.036)$ & & $(0.040)$ & \\
\hline \multirow[t]{2}{*}{$R O A$} & $-0.04 * * *$ & -11.10 & $-0.03 * * *$ & -10.30 & $-0.03 * * *$ & -9.97 & $-0.03 * * *$ & -9.91 \\
\hline & $(0.003)$ & & $(0.003)$ & & $(0.003)$ & & $(0.003)$ & \\
\hline \multirow[t]{2}{*}{$R O A_{(t-1)}$} & $-0.02 * * *$ & -4.70 & $-0.02 * * *$ & -7.65 & $-0.02 * * *$ & -7.36 & $-0.02 * * *$ & -7.44 \\
\hline & $(0.003)$ & & $(0.003)$ & & $(0.003)$ & & $(0.003)$ & \\
\hline \multirow[t]{2}{*}{ SIZE } & $-0.05 * * *$ & -9.61 & $-0.07 * * *$ & -13.62 & $-0.07 * * *$ & -12.94 & $-0.07 * * *$ & -11.60 \\
\hline & $(0.006)$ & & $(0.005)$ & & $(0.005)$ & & $(0.006)$ & \\
\hline \multirow[t]{2}{*}{ LIQUIDITY } & 0.01 & 1.21 & 0.00 & 0.03 & 0.00 & 0.03 & 0.00 & 0.03 \\
\hline & $(0.008)$ & & $(0.008)$ & & $(0.008)$ & & $(0.009)$ & \\
\hline Year effects & & & yes & & Yes & & Yes & \\
\hline Industry effects & & & yes & & Yes & & Yes & \\
\hline \multirow[t]{2}{*}{ Constant } & $4.16^{* * *}$ & 20.47 & $4.45^{* * *}$ & 23.93 & $4.45^{* * *}$ & 23.55 & $4.45 * * *$ & 21.31 \\
\hline & $(0.203)$ & & $(0.186)$ & & $(0.189)$ & & $(0.209)$ & \\
\hline Observations & 3,330 & & 3,330 & & 3,330 & & 3,330 & \\
\hline$R^{2}$ & 0.39 & & 0.50 & & 0.50 & & 0.50 & \\
\hline$F$-statistic & $117.85^{* * *}$ & & $163.48 * * *$ & & $148.68 * * *$ & & $121.36^{* * *}$ & \\
\hline
\end{tabular}

The p-value for the one-tailed test of the null hypothesis that the coefficient is zero is indicated as $* * *, * *, *$ to show statistical significance at the $0.01,0.05$ and 0.10 levels respectively, and robust standard errors are provided in parentheses. User and Non User signify firms that use derivatives and those that do not. See Tables 5.3 and 5.4 for definitions of dependent and independent variables. 
A comparison of the results indicates some marked differences between the two groups with regard to corporate governance responses. CEOSALARY, BDINDEP and CEOCOMP do not have any impact on stock return volatility in both groups. Other variables such as board meetings, board size, insider shareholders, block holders, audit committee size and CEO bonus are significant in both groups and have same directional relationship with stock return volatility. However, the coefficients indicate that there is a difference in the magnitude of the results, for example, for non users (users) the coefficients are: BDMTGS 0.0065 (0.0055); BDSIZE -0.0242 (-0.0222); CEOBONUS -0.008 (-0.010); and ACSIZE 0.0136 (0.0103). Though the differences appear minimal, however even a $0.01 \%$ increase would have a less than negligible impact on stock return volatility and stock price. SHINSIDER increases risk in both firm samples, however the increase is much larger in non users showing a coefficient of 0.26 compared to 0.15 for derivative user firms and both are significant at $1 \%$ level. The results for SHBLOCK also show a higher positive impact on stock return volatility for non users.

Some corporate governance mechanisms are only significant for derivative users such as BDDIVERS and CEOTENURE and indicate negative relationship with equity risk, while CEOAGE and SHINST increase risk. However, these governance variables do not show any significant results in firms that do not use derivatives.

Therefore, to summarize, most of the corporate governance variables play an important role in firms that use derivatives. BDDIVERS, CEOTENURE, BDSIZE and CEOBONUS reduce stock return volatility, while the two former variables are not relevant and the reduction in risk are lower in BDSIZE and CEOBONUS for non user firms. Several variables increase risk such as BDMTGS, SHINSIDER, SHBLOCK and ACSIZE however the increase in risk is greater for non users. Overall a comparison indicates that corporate governance is more effective in handling equity 
in firms using derivatives: the risk reduction effects are larger and the risk enhancing effects are smaller as compared to non user firms.

\subsection{Multivariate Analysis of the Effect of Corporate Governance on the Relationship between Derivatives and Market Risk}

Table 6.13 presents the results from estimation of equation (Model 5) where market risk is regressed on measures of corporate governance and other control variables, for a sample of firms using derivatives (DER=1) for hedging. The first column provides the basic regression model, the second column presents the results after controlling for industry and year fixed effects. The third column shows the regression estimates after adjusting for heteroscedasticity using White's (1980) consistent covariance matrix and the fourth column presents results of the regression estimates using Newey West (1987) procedure to correct the potential time-series correlations of panel data.

These models test the hypotheses related to firm risk that is developed in Chapter 4. I partition the full sample into two subsamples of firms. One sample consists of firms that use derivatives for hedging, while the other subsample consists of firms that do not use any derivatives for hedging. As discussed under Section 5.6, the third risk measure examined relates to market risk. Market risk is a proxy for systematic risk and measured as beta through the market model following Bartram et al. (2011).

The F-statistics for all regression models are statistically significant at the $1 \%$ level. The $\mathrm{R}^{2}$ for the models are quite low ranging from $14 \%$ to $18 \%$ for the four models. Only four out of the thirteen corporate governance variables are found to be 
significant. Specifically, CEOAGE, $\mathrm{SHINST}^{34}$, and CEOBONUS ${ }^{35}$ are positive and statistically significant at $1 \%$ level with t-statistic of 2.86, 2.75 and 3.07 respectively, and BDDIVERS ${ }^{36}$ is negative and statistically significant at $1 \%$ with t-statistic of 3.74. Thus older CEOs, increase in institutional shareholding and CEO bonus increase systematic risk of the firm and women on the board decreases market risk.

The other coefficients for corporate governance variables, BDMTGS, BDSIZE, BDINDEP, CEOTENURE, SHINDIDER, SHBLOCK, ACSIZE, CEOCOMP and CEOSALARY are not significant $(\mathrm{p}>0.10)$, providing no evidence for the existence of associations between these variables and market risk through increased use of derivatives by the firm.

${ }^{34}$ David et al. (2015) suggest that Institutional Investors exhibit a granular effect, with largest investors having a positive effect and the bottom tier of institutional investors having a negative effect on market risk. However, when all investors are taken it shows a positive relationship with market risk at $1 \%$ level of significance.

35 This supports Miller, Wiseman and Gomez-Meija (2002) findings where they find that CEO Total Compensation and CEO Variable Pay Mix have a positive relation with both systematic and unsystematic market risk. Jin (2002) also find that the pay-performance sensitivity is positively associated with market risk for the full sample at $10 \%$ level of significance. However, others suggest that stock-based incentives might not increase CEO risk-taking (Carpenter, 2000; Ross, 2004).

${ }^{36}$ Sila, et al. (2014) find a negative relationship for some of their models but contend that this negative relationship disappears when they use more sophisticated identification strategies and suggest there is no impact of women directors on risk measures. Sila, Gonzalez and Hagendorff (2014) find a negative relationship with market risk for CEO cash compensation and CEO delta and vega compensation. They also find a positive impact between market risk and CEO tenure. 
Table 6. 8: Market Risk Regression Models for Derivative User Firms

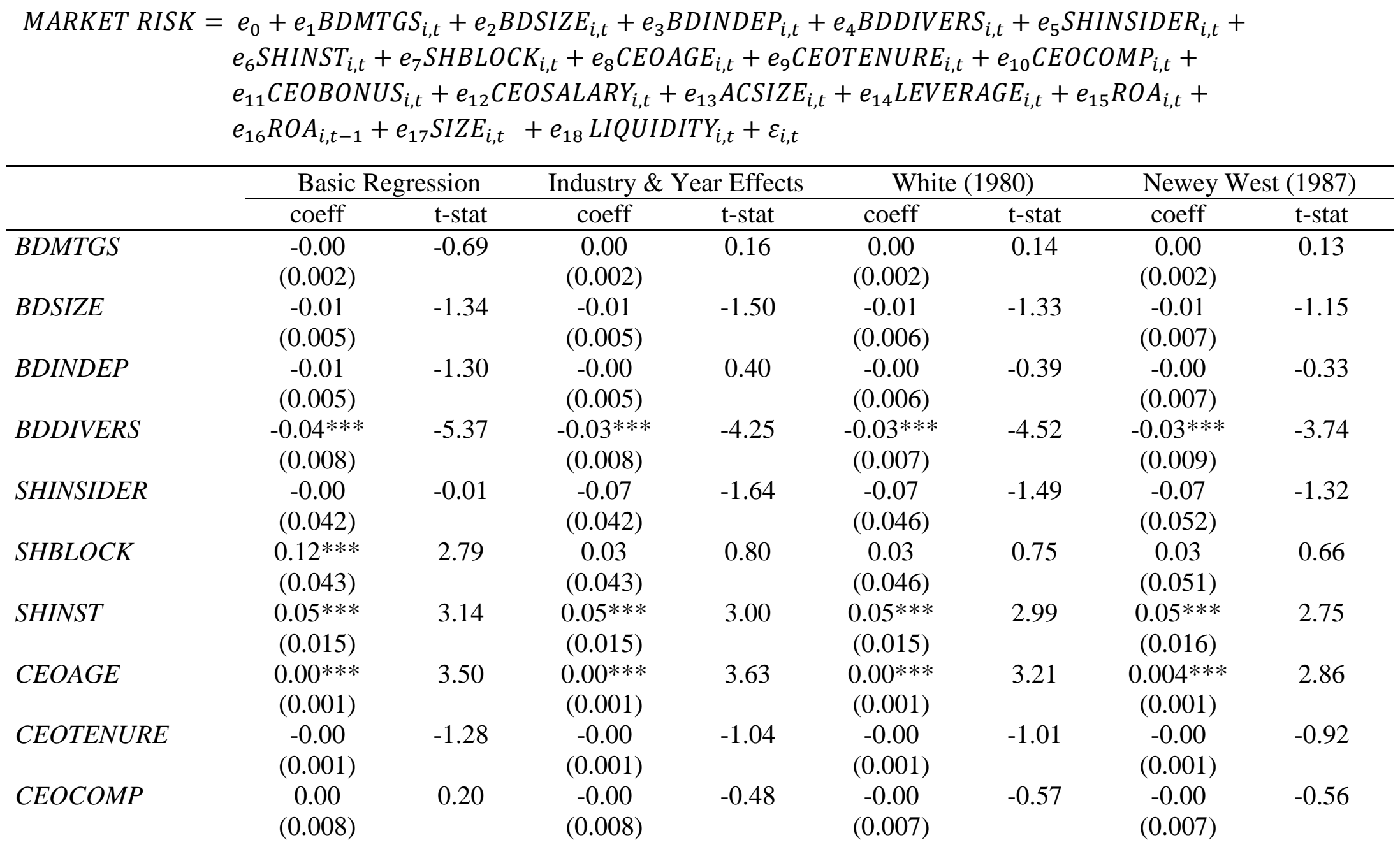




\begin{tabular}{|c|c|c|c|c|c|c|c|c|}
\hline & \multicolumn{2}{|c|}{ Basic Regression } & \multicolumn{2}{|c|}{ Industry \& Year Effects } & \multicolumn{2}{|c|}{ White (1980) } & \multicolumn{2}{|c|}{ Newey West (1987) } \\
\hline & coeff & t-stat & coeff & t-stat & coeff & t-stat & coeff & t-stat \\
\hline \multirow[t]{2}{*}{ CEOBONUS } & $0.00 * * *$ & 3.42 & 0.00 *** & 3.32 & $0.00 * * *$ & 3.30 & $0.00 * * *$ & 3.07 \\
\hline & $(0.001)$ & & $(0.001)$ & & $(0.001)$ & & $(0.001)$ & \\
\hline \multirow[t]{2}{*}{ CEOSALARY } & 0.01 & 0.52 & -0.01 & -0.34 & -0.01 & -0.34 & -0.01 & -0.31 \\
\hline & $(0.021)$ & & $(0.021)$ & & $(0.021)$ & & $(0.023)$ & \\
\hline \multirow[t]{2}{*}{$A C S I Z E$} & -0.00 & -0.97 & -0.00 & -0.65 & -0.00 & -0.68 & -0.00 & -0.61 \\
\hline & $(0.003)$ & & $(0.004)$ & & $(0.003)$ & & $(0.004)$ & \\
\hline \multirow[t]{2}{*}{ LEVERAGE } & $0.20 * * *$ & 5.63 & $0.28 * * *$ & 7.80 & $0.28 * * *$ & 6.73 & $0.28 * * *$ & 6.09 \\
\hline & $(0.035)$ & & $(0.035)$ & & $(0.041)$ & & $(0.045)$ & \\
\hline \multirow[t]{2}{*}{$R O A$} & $-0.01 * * *$ & -3.36 & $-0.01 * *$ & -2.47 & $-0.01 * *$ & -2.00 & $-0.01 * *$ & -1.99 \\
\hline & $(0.004)$ & & $(0.004)$ & & $(0.005)$ & & $(0.005)$ & \\
\hline \multirow[t]{2}{*}{$R O A_{(t-1)}$} & $-0.03 * * *$ & -8.39 & $-0.03 * * *$ & -8.13 & $-0.03 * * *$ & -8.06 & $-0.03 * * *$ & -7.89 \\
\hline & $(0.004)$ & & $(0.004)$ & & $(0.004)$ & & $(0.004)$ & \\
\hline \multirow[t]{2}{*}{ SIZE } & 0.00 & 0.51 & -0.00 & -0.58 & -0.00 & -0.56 & -0.00 & -0.50 \\
\hline & $(0.006)$ & & $(0.006)$ & & (0.006) & & $(0.007)$ & \\
\hline \multirow[t]{2}{*}{ LIQUIDITY } & $0.05 * * *$ & 5.13 & $0.03 * * *$ & 3.74 & $0.03 * * *$ & 3.54 & $0.03 * * *$ & 3.07 \\
\hline & $(0.009)$ & & $(0.009)$ & & $(0.010)$ & & $(0.011)$ & \\
\hline Year effects & & & yes & & yes & & yes & \\
\hline Industry effects & & & yes & & yes & & yes & \\
\hline \multirow[t]{2}{*}{ Constant } & -0.14 & -0.59 & 0.21 & 0.92 & 0.21 & 0.89 & 0.21 & 0.78 \\
\hline & $(0.228)$ & & $(0.225)$ & & $(0.233)$ & & $(0.266)$ & \\
\hline Observations & 2,904 & & 2,904 & & 2,904 & & 2,904 & \\
\hline$R^{2}$ & 0.14 & & 0.18 & & 0.18 & & 0.18 & \\
\hline$F$-statistic & $26.46 * * *$ & & $31.95 * * *$ & & $37.50 * * *$ & & $27.04 * * *$ & \\
\hline
\end{tabular}

The p-value for the one-tailed test of the null hypothesis that the coefficient is zero is indicated as $* * *, * *, *$ to show statistical significance at the $0.01,0.05$ and 0.10 levels respectively, and robust standard errors are provided in parentheses. User and Non User signify firms that use derivatives and those that do not. See Tables 5.3 and 5.4 for definitions of dependent and independent variables. 


\section{Multivariate Analysis of the Effect of Corporate Governance on Market Risk for Derivative Non User Firms.}

Table 6.14 presents regression estimates of the association between corporate governance variables and market risk for the second sub-sample comprising only non user firms $(\mathrm{DER}=0)$. This is an estimation of regression equation (Model 5 in Table 5.8). The regression models are the same as used earlier for the derivative user sample, that is, the basic regression, industry and year effects controlled regression, White (1980) model and the Newey-West (1987) model.

All the regression models have significant F-statistics at the 1\% level, however these F-statistics are significantly smaller than those presented in Table 6.13 for derivative users. The $\mathrm{R}^{2}$ values for this sample range from $9 \%$ to $11 \%$, which is lower than those observed for the derivative users. Most of the corporate governance variables, such as BDMTGS, BDSIZE, CEOBONUS, SHINSIDE, SHBLOCK and ACSIZE are similar across the two samples and with the same direction of association. However, the coefficients for the insider shareholders and block holders are much higher in this sample indicating a greater risk-enhancing effect for non user firms.

Unlike results for derivative users, the coefficients for BDDIVERS, CEOAGE, CEOTENURE, SHINSIDER and LIQUIDITY are insignificant. It appears that women directors on the board, CEO age or tenure, institutional shareholders and liquidity considerations become irrelevant when firms do not hedge with derivatives. The coefficients for the other corporate governance variables, BDINDEP, SHINIDER and CEOTENURE remain the same in both samples and are insignificant ( $>0.10)$. All the other control variables are significant at $1 \%$ level and in same direction for both the samples, while SIZE is insignificant in both group of firms. 
Table 6.14: Market Risk Regression Models for Derivative Non User Firms

MARKET RISK

$=e_{0}+e_{1} B_{D M T G S} S_{i, t}+e_{2}$ BDSIZE $_{i, t}+e_{3}$ BDINDEP $_{i, t}+e_{4}$ BDDIVERS $_{i, t}+e_{5}$ SHINSIDER $_{i, t}$

$+e_{6}$ SHINST $_{i, t}+e_{7}$ SHBLOCK $_{i, t}+e_{8}$ CEOAGE $_{i, t}+e_{9}$ CEOTENURE $_{i, t}+e_{10}$ CEOCOMP $_{i, t}$

$+e_{11}$ CEOBONUS $_{i, t}+e_{12}$ CEOSALARY $_{i, t}+e_{13}$ ACSIZE $_{i, t}+e_{14}$ LEVERAGE $_{i, t}+e_{15} R_{0 A} A_{i, t}$

$+e_{16} R O A_{i, t-1}+e_{17}$ SIZE $_{i, t}+e_{18}$ LIQUIDITY $_{i, t}+\varepsilon_{i, t}$

\begin{tabular}{|c|c|c|c|c|c|c|c|c|}
\hline & \multicolumn{2}{|c|}{ Basic Regression } & \multicolumn{2}{|c|}{ Industry \& Year Effects } & \multicolumn{2}{|c|}{ White (1980) } & \multicolumn{2}{|c|}{ Newey West (1987) } \\
\hline & coeff & t-stat & coeff & t-stat & coeff & t-stat & coeff & t-stat \\
\hline BDMTGS & $\begin{array}{c}-0.00 * * * \\
(0.002)\end{array}$ & -2.64 & $\begin{array}{c}-0.00 * * \\
(0.002)\end{array}$ & -2.26 & $\begin{array}{l}-0.00 * * \\
(0.002)\end{array}$ & -2.03 & $\begin{array}{l}-0.00 * \\
(0.002)\end{array}$ & -1.91 \\
\hline$B D S I Z E$ & $\begin{array}{c}-0.01 * * \\
(0.005)\end{array}$ & -2.40 & $\begin{array}{c}-0.01 * * * \\
(0.005)\end{array}$ & -2.58 & $\begin{array}{c}-0.01 * * \\
(0.005)\end{array}$ & -2.46 & $\begin{array}{c}-0.01 * * \\
(0.006)\end{array}$ & -2.24 \\
\hline$B D I N D E P$ & $\begin{array}{c}-0.00 \\
(0.005)\end{array}$ & -0.26 & $\begin{array}{c}0.00 \\
(0.005)\end{array}$ & 0.50 & $\begin{array}{c}0.00 \\
(0.006)\end{array}$ & 0.47 & $\begin{array}{c}0.00 \\
(0.006)\end{array}$ & 0.44 \\
\hline BDDIVERS & $\begin{array}{c}-0.03 * * * \\
(0.007)\end{array}$ & -4.64 & $\begin{array}{c}-0.03 * * * \\
(0.007)\end{array}$ & -4.11 & $\begin{array}{c}-0.03 * * * \\
(0.007)\end{array}$ & -4.21 & $\begin{array}{c}-0.03 * * * \\
(0.008)\end{array}$ & -3.67 \\
\hline SHINSIDER & $\begin{array}{l}0.09 * * \\
(0.036)\end{array}$ & 2.37 & $\begin{array}{c}0.05 \\
(0.036)\end{array}$ & 1.48 & $\begin{array}{c}0.05 \\
(0.042)\end{array}$ & 1.28 & $\begin{array}{c}0.05 \\
(0.045)\end{array}$ & 1.18 \\
\hline SHINST & $\begin{array}{c}0.06 * * * \\
(0.013)\end{array}$ & 4.47 & $\begin{array}{c}0.05 * * * \\
(0.013)\end{array}$ & 4.15 & $\begin{array}{c}0.05^{* * *} \\
(0.013)\end{array}$ & 4.04 & $\begin{array}{c}0.05 * * * \\
(0.014)\end{array}$ & 3.78 \\
\hline SHBLOCK & $\begin{array}{c}0.16 * * * \\
(0.038)\end{array}$ & 4.13 & $\begin{array}{c}0.12 * * * \\
(0.038)\end{array}$ & 3.09 & $\begin{array}{c}0.12 * * * \\
(0.037)\end{array}$ & 3.22 & $\begin{array}{c}0.12 * * * \\
(0.041)\end{array}$ & 2.89 \\
\hline CEOAGE & $\begin{array}{c}0.00 \\
(0.001)\end{array}$ & 1.48 & $\begin{array}{c}0.00 \\
(0.001)\end{array}$ & 1.60 & $\begin{array}{c}0.00 * \\
(0.001)\end{array}$ & 1.65 & $\begin{array}{c}0.00 \\
(0.001)\end{array}$ & 1.50 \\
\hline CEOTENURE & $\begin{array}{c}-0.00 \\
(0.001)\end{array}$ & -0.95 & $\begin{array}{c}-0.00 \\
(0.001)\end{array}$ & -0.95 & $\begin{array}{c}-0.00 \\
(0.001)\end{array}$ & -0.90 & $\begin{array}{c}-0.00 \\
(0.001)\end{array}$ & -0.82 \\
\hline
\end{tabular}




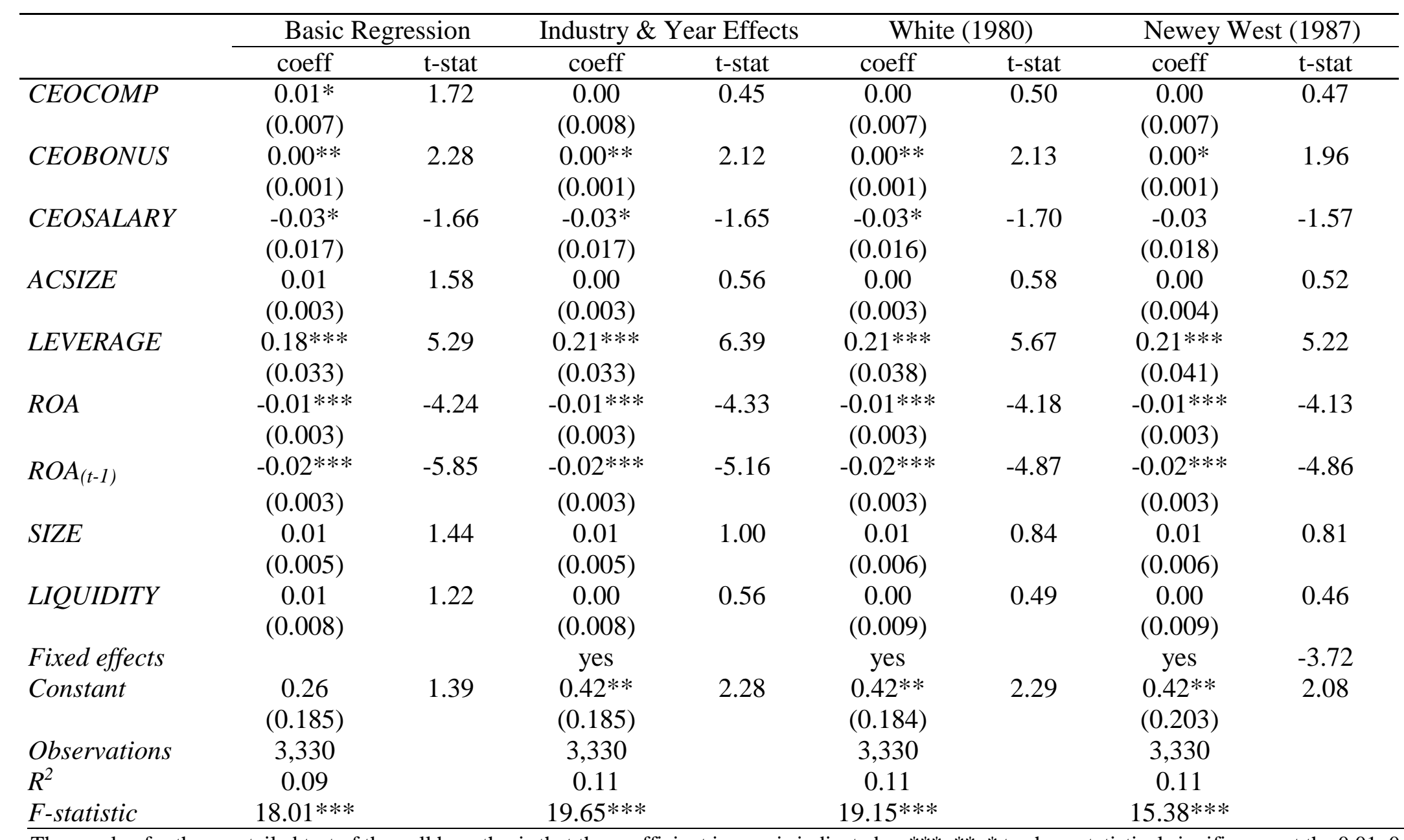

The p-value for the one-tailed test of the null hypothesis that the coefficient is zero is indicated as $* * *, * *, *$ to show statistical significance at the $0.01,0.05$ and 0.10 levels respectively, and robust standard errors are provided in parentheses. User and Non User signify firms that use derivatives and those that do not. See Tables 5.3 and 5.4 for definitions of dependent and independent variables. 
A comparison of the results indicates some similarities and differences between the two groups with regard to corporate governance. CEOSALARY, BDINDEP, CEOTENURE, CEOCOMP, SHINSIDER and ACSIZE do not have any impact on market risk in both groups. Some corporate governance variables such as board diversity, CEO bonus and institutional shareholders exhibit significant results in both groups and have same directional relationship with market risk, however, the coefficients indicate that there is a difference in the magnitude of the results. For example, for non users (users) the coefficients are: BDDIVERS -0.0295 (-0.0327); CEOBONUS 0.0020 (0.0034); and SHINST 0.0533 (0.0453). While CEOAGE increases risk only for derivative users. Some corporate governance mechanisms are only significant for non user firms for example BDMTGS and BDSIZE reduce market risk and SHBLOCK increase market risk but have no impact in derivative user firms.

Therefore, in summary, the results for market risk generally indicate weak results, with most of the corporate governance variables not having any effect on market risk for derivative user firms. While non user firms show that a larger number of governance variables have a risk reducing impact. Overall, when compared to derivative non users, corporate governance appears to be less effective in firms that use derivatives with respect to market risk.

\subsection{Sensitivity Analysis and Robustness Tests}

Sensitivity tests are important to show that the results cannot be attributed to model misspecification, measurement errors or alternative definitions of the control variables (Barton, 2001). Geczy et al. (1997) suggest that test results may be criticized as the independent variables used are selected variables of choice. Therefore, they suggest

robustness checks of the variable specifications, by using alternative specifications and procedures to show that the conclusions remain unaffected. Similarly, I conduct 
sensitivity analyses by using alternative test specifications and alternative test methodology to examine the consistency to my results for all the value and risk models.

\subsubsection{Robustness Tests for Value Model}

First, in order to show that my results are largely invariant to the choice of the dependent variable, I use different measures for firm value. In the manner of Allayannis and Weston (2001), the first measure uses a variation of the VALUETobin's Q ratio that is applied in the main regression models, and is described in Table 5.4. This measure captures the market value of the firm to replacement cost of assets taken at the end of the fiscal year for each firm and closely follows the Lewellen and Badrinath (1997) Q. A second measure for the VALUE dependent variable is the market-to-book ratio (simple Q), following Allayannis and Weston (2001). In both models I use the Newey-West (1987) procedure to correct for any problems of heteroscedasticity and time-series correlations in panel data taken up to three lags. The results for both derivative user firms and derivative non user firms are presented alongside each other.

Table 6.15 presents the regression model for the first measure of Tobin's Q and a comparison of the results for the derivative user firms indicates that all the corporate governance variables and the control variables are similar to the main regression. However, the weak association of CEOTENURE at 10\% level of significance (Table 6.8) now disappears and though BDINDEP maintains the same directional relationship with value, the level of significance disappears. 
Table 6.16 presents the regression model for the market-to-book ratio, as the dependent variable. A comparison of the results for the derivative user firms indicates that all the corporate governance variables and the control variables are similar to the main regression results depicted in Table 6.8. Though there are some differences in the magnitude of the coefficients and level of significance, the direction and significance is similar to the main value regression model, for firms using derivatives. However, though ACSIZE, CEOBONUS and CEOTENURE effects show the same directional relationship, they are not significant. The reasons for the diluted results could stem from the fact that market-to-book ratio is also a strong proxy for investment growth and this effect may be influencing the relationship for these corporate governance variables.

Secondly, I use a bootstrapping method with 10,000 iterations as a robustness check. Many researchers use the bootstrapping methodology and some apply this method in their main investigations (Kosowski et al., 2006). To illustrate, in a sample dataset of $\mathrm{N}$ observations, the bootstrapping methodology would draw, with replacement, $\mathrm{N}$ observations from the N-observation dataset. In this random drawing, some of the original observations will appear once, some more than once, and some not at all. This process is repeated many times; each time, a new random sample is drawn and the statistics are recalculated. This process builds a dataset of replicated statistics, to arrive at the final results after the specified number of replications. Lim and Loh (1996) conduct a comparison of the tests of equality of variances and find that the bootstrapping methodology of the tests provide more robust results. Table 6.17 presents results of the bootstrapping regression model for derivative users and non users. Though there is some variation in the coefficients and level of significance, all the results for the corporate governance variables and control variables indicate the same direction and significance impact as the main regression models for firm value. The goodness of fit is also similar to the main regression models shown in Tables 6.7 and 6.8 . 


\section{Table 6. 9: Robustness Tests - Q Ratio,}

$$
\begin{aligned}
Q_{i, t}=v_{0} & +v_{1} \text { BDMTGS }_{i, t}+v_{2} \text { BDSIZE }_{i, t}+v_{3} \text { BDINDEP }_{i, t}+v_{4} \text { BDDIVERS }_{i, t} \\
& +v_{5} \operatorname{SHINSIDER}_{i, t}+v_{6} \operatorname{SHINST}_{i, t}+v_{7} \operatorname{SHBLOCK}_{i, t}+v_{8} \text { CEOAGE }_{i, t} \\
& +v_{9} \operatorname{CEOTENURE}_{i, t}+v_{10} \text { CEOCOMP }_{i, t}+v_{11} \operatorname{CEOBONUS}_{i, t} \\
& +v_{12} \text { CEOSALARY }_{i, t}+v_{13} \text { ACSIZE }_{i, t}+v_{14} \text { LEVERAGE }_{i, t}+v_{15} R \& D_{i, t} \\
& +v_{16} \text { ROA }_{i, t}+v_{17} \operatorname{SIZE}_{i, t}+v_{18} \text { CAPEX }_{i, t}+\vartheta_{i, t}
\end{aligned}
$$

\begin{tabular}{|c|c|c|c|c|}
\hline \multirow[b]{2}{*}{ VARIABLES } & \multicolumn{2}{|c|}{ DER USER } & \multicolumn{2}{|c|}{ NON USER } \\
\hline & Coeff & t-stat & coeff & t-stat \\
\hline BDMTGS & $\begin{array}{c}-0.00 \\
(0.002)\end{array}$ & -0.54 & $\begin{array}{c}-0.01 * * * \\
(0.003)\end{array}$ & -3.87 \\
\hline BDSIZE & $\begin{array}{l}0.01 * * \\
(0.006)\end{array}$ & 2.09 & $\begin{array}{c}0.03^{* * *} \\
(0.008)\end{array}$ & 3.70 \\
\hline$B D I N D E P$ & $\begin{array}{c}-0.01 \\
(0.007)\end{array}$ & -1.60 & $\begin{array}{c}-0.01 \\
(0.008)\end{array}$ & -1.37 \\
\hline BDDIVERS & $\begin{array}{c}0.04 * * * \\
(0.009)\end{array}$ & 4.16 & $\begin{array}{c}0.02 \\
(0.012)\end{array}$ & 1.43 \\
\hline SHINSIDER & $\begin{array}{c}-0.03 \\
(0.056)\end{array}$ & -0.63 & $\begin{array}{c}-0.08 \\
(0.059)\end{array}$ & -1.42 \\
\hline SHINST & $\begin{array}{l}-0.03^{*} \\
(0.018)\end{array}$ & -1.87 & $\begin{array}{c}-0.08 * * * \\
(0.021)\end{array}$ & -3.86 \\
\hline SHBLOCK & $\begin{array}{l}-0.11^{*} \\
(0.058)\end{array}$ & -1.84 & $\begin{array}{c}-0.07 \\
(0.069)\end{array}$ & -1.02 \\
\hline CEOAGE & $\begin{array}{c}-0.00^{* * * *} \\
(0.001)\end{array}$ & -3.29 & $\begin{array}{c}-0.00 * * * \\
(0.001)\end{array}$ & -3.27 \\
\hline CEOTENURE & $\begin{array}{c}0.00 \\
(0.001)\end{array}$ & 1.01 & $\begin{array}{c}0.00 \\
(0.001)\end{array}$ & 0.19 \\
\hline СЕОСОМР & $\begin{array}{c}0.01 \\
(0.010)\end{array}$ & 0.84 & $\begin{array}{c}0.04 * * * \\
(0.011)\end{array}$ & 4.15 \\
\hline CEOBONUS & $\begin{array}{l}0.00^{* *} \\
(0.001)\end{array}$ & 2.54 & $\begin{array}{c}0.00 \\
(0.001)\end{array}$ & 1.42 \\
\hline CEOSALARY & $\begin{array}{c}0.03 \\
(0.029)\end{array}$ & 1.13 & $\begin{array}{c}0.04 \\
(0.035)\end{array}$ & 1.11 \\
\hline ACSIZE & $\begin{array}{c}-0.01^{* * *} \\
(0.004)\end{array}$ & -2.65 & $\begin{array}{c}-0.02 * * * \\
(0.005)\end{array}$ & -4.12 \\
\hline LEVERAGE & $\begin{array}{c}-0.79 * * * \\
(0.045)\end{array}$ & -17.37 & $\begin{array}{c}-0.87 * * * \\
(0.053)\end{array}$ & -16.35 \\
\hline$R \& D$ & $\begin{array}{c}0.09 * * * \\
(0.018)\end{array}$ & 4.93 & $\begin{array}{c}0.15^{* * * *} \\
(0.022)\end{array}$ & 7.02 \\
\hline
\end{tabular}




\begin{tabular}{lcccc}
\hline \multirow{2}{*}{ VARIABLES } & \multicolumn{2}{c}{ DER USER } & \multicolumn{2}{c}{ NON USER } \\
\cline { 2 - 5 } ROA & Coeff & t-stat & coeff & t-stat \\
SIZE & $0.03^{* * *}$ & 6.11 & $0.04 * * *$ & 7.77 \\
& $(0.005)$ & & $(0.005)$ & \\
CAPEX & $-0.03^{* * *}$ & -3.17 & $-0.08^{* * *}$ & 8.00 \\
& $(0.010)$ & & $(0.010)$ & \\
Year effects & $0.45^{* * *}$ & 3.08 & $0.39 * *$ & 2.53 \\
Industry effects & $(0.146)$ & & $(0.153)$ & \\
Constant & Yes & & yes & \\
& Yes & & yes & \\
& 0.44 & 1.37 & 0.29 & 0.71 \\
Observations & $(0.324)$ & & $(0.401)$ & \\
$R$-squared & & & & \\
$F$ statistic & 2,904 & & 3,330 & \\
\hline
\end{tabular}

The p-value for the one-tailed test of the null hypothesis that the coefficient is zero is indicated as $* * *, * *, *$ to show statistical significance at the $0.01,0.05$ and 0.10 levels respectively, and robust standard errors are provided in parentheses. DER USER and NON USER signify firms that use derivatives and those that do not. See Tables 5.3 and 5.4 for definitions of dependent and independent variables. 


\section{Table 6.10: Robustness Tests - Market-Book Ratio}

$$
\begin{aligned}
& M B_{i, t}=v_{0}+v_{1} B D M T G S_{i, t}+v_{2} B D S I Z E_{i, t}+v_{3} B D I N D E P_{i, t}+v_{4} B D D I V E R S_{i, t} \\
& +v_{5} \text { SHINSIDER }_{i, t}+v_{6} \text { SHINST }_{i, t}+v_{7} \text { SHBLOCK }_{i, t}+v_{8} \text { CEOAGE }_{i, t} \\
& +v_{9} \text { CEOTENURE }_{i, t}+v_{10} \text { CEOCOMP }_{i, t}+v_{11} \text { CEOBONUS }_{i, t} \\
& +v_{12} \operatorname{CEOSALARY~}_{i, t}+v_{13} \text { ACSIZE }_{i, t}+v_{14} \text { LEVERAGE }_{i, t}+v_{15} R \& D_{i, t} \\
& +v_{16} R O A_{i, t}+v_{17} S I Z E_{i, t}+v_{18} C A P E X_{i, t}+\vartheta_{i, t}
\end{aligned}
$$

\begin{tabular}{|c|c|c|c|c|}
\hline \multirow[b]{2}{*}{ VARIABLES } & \multicolumn{2}{|c|}{ DER USER } & \multicolumn{2}{|c|}{ NON USER } \\
\hline & Coeff & t-stat & Coeff & t-stat \\
\hline$B D M T G S$ & $\begin{array}{c}-0.00 \\
(0.005)\end{array}$ & -0.40 & $\begin{array}{c}-0.02 * * * \\
(0.004)\end{array}$ & -4.46 \\
\hline BDSIZE & $\begin{array}{l}0.03 * * \\
(0.014)\end{array}$ & 2.29 & $\begin{array}{l}0.03 * * \\
(0.012)\end{array}$ & 2.56 \\
\hline BDINDEP & $\begin{array}{l}-0.03^{*} \\
(0.015)\end{array}$ & -1.85 & $\begin{array}{c}-0.01 \\
(0.014)\end{array}$ & -0.91 \\
\hline BDDIVERS & $\begin{array}{c}0.07 * * * \\
(0.018)\end{array}$ & 3.69 & $\begin{array}{c}0.03 \\
(0.020)\end{array}$ & 1.33 \\
\hline SHINSIDER & $\begin{array}{c}-0.14 \\
(0.105)\end{array}$ & -1.32 & $\begin{array}{c}-0.25 * * * \\
(0.095)\end{array}$ & -2.61 \\
\hline SHINST & $\begin{array}{l}-0.06^{*} \\
(0.036)\end{array}$ & -1.71 & $\begin{array}{c}-0.14 * * * \\
(0.033)\end{array}$ & -4.09 \\
\hline SHBLOCK & $\begin{array}{c}-0.25 * * \\
(0.119)\end{array}$ & -2.12 & $\begin{array}{c}-0.30^{* * * *} \\
(0.113)\end{array}$ & -2.64 \\
\hline CEOAGE & $\begin{array}{c}-0.01 * * * \\
(0.002)\end{array}$ & -3.92 & $\begin{array}{c}-0.01 * * \\
(0.002)\end{array}$ & -2.46 \\
\hline CEOTENURE & $\begin{array}{l}-0.00 \\
(0.002)\end{array}$ & -0.61 & $\begin{array}{c}-0.00 \\
(0.002)\end{array}$ & -1.15 \\
\hline СЕОСОМР & $\begin{array}{c}0.03 \\
(0.020)\end{array}$ & 1.37 & $\begin{array}{c}0.07 * * * \\
(0.017)\end{array}$ & 4.19 \\
\hline CEOBONUS & $\begin{array}{c}0.00 \\
(0.002)\end{array}$ & 1.44 & $\begin{array}{c}0.00 \\
(0.002)\end{array}$ & 0.80 \\
\hline CEOSALARY & $\begin{array}{c}0.03 \\
(0.048)\end{array}$ & 0.59 & $\begin{array}{c}0.04 \\
(0.058)\end{array}$ & 0.67 \\
\hline ACSIZE & $\begin{array}{c}-0.01 \\
(0.009)\end{array}$ & -0.81 & $\begin{array}{c}-0.03 * * * \\
(0.008)\end{array}$ & -3.15 \\
\hline LEVERAGE & $\begin{array}{c}-0.93 * * * \\
(0.104)\end{array}$ & -8.91 & $\begin{array}{c}-1.01 * * * \\
(0.098)\end{array}$ & -10.31 \\
\hline
\end{tabular}




\begin{tabular}{lcccc}
\hline \multirow{2}{*}{ VARIABLES } & \multicolumn{2}{c}{ DER USER } & \multicolumn{2}{c}{ NON USER } \\
\cline { 2 - 5 }$R \& D$ & Coeff & t-stat & Coeff & t-stat \\
\hline \multirow{2}{*}{$R O A$} & $0.15^{* * *}$ & 4.43 & $0.23^{* * *}$ & 6.74 \\
& $(0.035)$ & & $(0.034)$ & \\
SIZE & $0.05^{* * *}$ & 4.88 & $0.05^{* * *}$ & 5.93 \\
& $(0.009)$ & & $(0.008)$ & \\
CAPEX & -0.01 & -0.41 & $-0.06^{* * *}$ & -3.71 \\
& $(0.017)$ & & $(0.016)$ & \\
Year effects & $0.61 * *$ & 2.48 & $0.54 * * *$ & 2.61 \\
Industry effects & $(0.244)$ & & $(0.207)$ & \\
Constant & yes & & Yes & \\
& yes & & Yes & \\
& 0.59 & 1.11 & 0.27 & 0.41 \\
Observations & $(0.536)$ & & $(0.654)$ & \\
$R$-squared & & & & \\
$F$ statistic & 2,904 & & 3330 & \\
\hline
\end{tabular}

The p-value for the one-tailed test of the null hypothesis that the coefficient is zero is indicated as $* * *, * *, *$ to show statistical significance at the $0.01,0.05$ and 0.10 levels respectively, and robust standard errors are provided in parentheses. DER USER and NON USER signify firms that use derivatives and those that do not. See Tables 5.3 and 5.4 for definitions of dependent and independent variables. 


\section{Table 6.11: Robustness Model - Value Bootstrap (10,000)}

$$
\begin{aligned}
\operatorname{VALUE}_{i, t}= & h_{0}+h_{1} \text { BDMTGS }_{i, t}+h_{2} \text { BDSIZE }_{i, t}+h_{3} \text { BDINDEP }_{i, t}+h_{4} \text { BDDIVERS }_{i, t} \\
& +h_{5} \operatorname{SHINSIDER}_{i, t}+h_{6} \text { SHINST }_{i, t}+h_{7} \operatorname{SHBLOCK}_{i, t}+h_{8} \text { CEOAGE }_{i, t} \\
& +h_{9} \text { CEOTENURE }_{i, t}+h_{10} \text { CEOCOMP }_{i, t}+h_{11} \text { CEOBONUS }_{i, t} \\
& +h_{12} \text { CEOSALARY Y }_{i, t}+h_{13} \text { ACSIZE }_{i, t}+h_{14} \text { LEVERAGE }_{i, t}+h_{15} R \& D_{i, t} \\
& +h_{16} \text { ROA }_{i, t}+h_{17} \operatorname{SIZE}_{i, t}+h_{18} \text { CAPEX }_{i, t}+\vartheta_{i, t}
\end{aligned}
$$

\begin{tabular}{|c|c|c|c|c|}
\hline \multirow[b]{2}{*}{ VARIABLES } & \multicolumn{2}{|c|}{ DER USER } & \multicolumn{2}{|c|}{ NON USER } \\
\hline & Coeff & z-stat & Coeff & z-stat \\
\hline$B D M T G S$ & $\begin{array}{c}-0.00 \\
(0.002)\end{array}$ & -0.53 & $\begin{array}{c}-0.01 * * * \\
(0.003)\end{array}$ & -4.12 \\
\hline BDSIZE & $\begin{array}{c}0.03^{* * * *} \\
(0.007)\end{array}$ & 3.68 & $\begin{array}{c}0.04 * * * \\
(0.008)\end{array}$ & 4.88 \\
\hline$B D I N D E P$ & $\begin{array}{c}-0.02 * * * \\
(0.007)\end{array}$ & -2.88 & $\begin{array}{l}-0.02^{*} \\
(0.008)\end{array}$ & -1.88 \\
\hline BDDIVERS & $\begin{array}{c}0.03 * * * \\
(0.009)\end{array}$ & 3.51 & $\begin{array}{c}0.01 \\
(0.012)\end{array}$ & 0.46 \\
\hline SHINSIDER & $\begin{array}{c}-0.06 \\
(0.059)\end{array}$ & -1.00 & $\begin{array}{l}-0.11^{*} \\
(0.059)\end{array}$ & -1.91 \\
\hline SHINST & $\begin{array}{l}-0.03^{*} \\
(0.021)\end{array}$ & -1.65 & $\begin{array}{c}-0.09 * * * \\
(0.021)\end{array}$ & -4.33 \\
\hline SHBLOCK & $\begin{array}{c}-0.18 * * * \\
(0.060)\end{array}$ & -3.02 & $\begin{array}{c}-0.09 \\
(0.066)\end{array}$ & -1.42 \\
\hline CEOAGE & $\begin{array}{c}-0.00 * * * \\
(0.001)\end{array}$ & -3.45 & $\begin{array}{c}-0.01 * * * \\
(0.001)\end{array}$ & -4.68 \\
\hline CEOTENURE & $\begin{array}{c}0.003^{* * *} \\
(0.001)\end{array}$ & 2.06 & $\begin{array}{l}0.002^{*} \\
(0.001)\end{array}$ & 1.77 \\
\hline СЕОСОМР & $\begin{array}{c}0.01 \\
(0.012)\end{array}$ & 0.91 & $\begin{array}{c}0.07^{* * *} \\
(0.012)\end{array}$ & 5.67 \\
\hline CEOBONUS & $\begin{array}{c}0.00^{* * * *} \\
(0.001)\end{array}$ & 2.96 & $\begin{array}{c}0.00 \\
(0.001)\end{array}$ & 1.17 \\
\hline CEOSALARY & $\begin{array}{c}0.04 \\
(0.033)\end{array}$ & 1.23 & $\begin{array}{c}0.01 \\
(0.031)\end{array}$ & 0.46 \\
\hline ACSIZE & $\begin{array}{c}-0.01 * * * \\
(0.004)\end{array}$ & -3.18 & $\begin{array}{c}-0.02 * * * \\
(0.005)\end{array}$ & -4.67 \\
\hline
\end{tabular}




\begin{tabular}{lcccc}
\hline \multirow{2}{*}{ VARIABLES } & \multicolumn{2}{c}{ DER USER } & \multicolumn{2}{c}{ NON USER } \\
\cline { 2 - 5 } LEVERAGE & Coeff & z-stat & Coeff & z-stat \\
R\&D & $-0.85^{* * *}$ & -17.22 & $-0.96^{* * *}$ & -18.08 \\
& $(0.050)$ & & $(0.053)$ & \\
ROA & $0.09^{* * *}$ & 5.20 & $0.19^{* * *}$ & 9.40 \\
& $(0.017)$ & & $(0.020)$ & \\
SIZE & $0.05^{* * *}$ & 9.02 & $0.06^{* * *}$ & 11.71 \\
& $(0.006)$ & & $(0.005)$ & \\
CAPEX & $-0.07^{* * *}$ & -6.54 & $-0.12^{* * *}$ & -13.12 \\
& $(0.010)$ & & $(0.009)$ & \\
Year effects & $0.61^{* * *}$ & 4.42 & $0.45^{* * *}$ & 3.17 \\
Industry effects & $(0.137)$ & & $(0.142)$ & \\
Constant & yes & & yes & \\
& yes & & yes & \\
& 0.32 & 0.87 & 0.37 & 1.05 \\
Observations & $(0.365)$ & & $(0.353)$ & \\
R-squared & & & 3,330 & \\
Wald $\chi^{2}$ & 2,904 & & 0.35 & \\
\hline
\end{tabular}

The $\mathrm{p}$-value for the one-tailed test of the null hypothesis that the coefficient is zero is indicated as $* * *, * *, *$ to show statistical significance at the $0.01,0.05$ and 0.10 levels respectively, and robust standard errors are provided in parentheses. DER USER and NON USER signify firms that use derivatives and those that do not. See Tables 5.3 and 5.4 for definitions of dependent and independent variables. 


\subsubsection{Robustness Tests for Risk Models}

Empirical research indicates that there is a positive association between financial distress and hedging for firms. The strong financial distress results might be due to the fact that it includes another form of hedging. If the hedging motives for firms using only non -derivative techniques are similar to those using derivatives, then the classification of non -derivative users as separate from derivative users for the purposes of hedging would bias results (Judge, 2006). Other forms of hedging against financial distress may be captured through leverage, with the variations in leverage impacting on the hedging effects of derivatives. Purnanandum (2004) suggests that there exists a strong positive relationship between leverage and hedging for firms with high deadweight losses, so that derivatives effects would vary with the levels of financial distress and leveraging. However, this relationship reverses for very high levels of leverage, while there exists a positive relationship for firms with moderate levels of debt. To test this the author includes leverage squared to capture the effect of high financial distress. In order to investigate whether the variations in the levels of leverage would have an influence on my results with respect to firm risk, I follow Purnanandum (2004) and perform an additional sensitivity analysis using leverage squared $\left(\mathrm{LEV}^{2}\right)$. The results for the derivative user firms are presented in Table 6.18 and for non -derivative users are provided in Table 6.19.

A review of the results for the corporate governance variables show there is no change from my main regression results (presented in Tables from 6.9 to 6.14 with respect to the corporate governance variables. They are statistically significant and exhibit the same association with Risk in keeping with my results. Interestingly, this variable of financial leverage square $\left(\mathrm{LEV}^{2}\right)$ increases firm risk and LEVERAGE decreases risk to exhibit a non -monotonic effect as discussed by Purnanandum (2004). 


\section{Table 6. 18: Robustness Tests - Levels of Leverage in Derivative User Firms}

\begin{tabular}{|c|c|c|c|c|c|c|}
\hline \multirow[b]{2}{*}{ VARIABLES } & \multicolumn{2}{|c|}{ Cash Flow Volatility } & \multicolumn{2}{|c|}{ Stock Return Volatility } & \multicolumn{2}{|c|}{ Market Risk } \\
\hline & coeff & t-stat & coeff & t-stat & coeff & t-stat \\
\hline BDMTGS & $\begin{array}{c}0.02 * * * \\
(0.005)\end{array}$ & 3.34 & $\begin{array}{c}0.005 * * \\
(0.002)\end{array}$ & 2.21 & $\begin{array}{c}0.00 \\
(0.002)\end{array}$ & 0.02 \\
\hline BDSIZE & $\begin{array}{c}0.06 * * * \\
(0.017)\end{array}$ & 3.41 & $\begin{array}{c}-0.02 * * * \\
(0.006)\end{array}$ & -3.31 & $\begin{array}{l}-0.01 \\
(0.007)\end{array}$ & -1.10 \\
\hline BDINDEP & $\begin{array}{c}-0.01 \\
(0.017)\end{array}$ & -0.53 & $\begin{array}{c}0.00 \\
(0.007)\end{array}$ & 0.07 & $\begin{array}{c}-0.00 \\
(0.007)\end{array}$ & -0.32 \\
\hline BDDIVERS & $\begin{array}{c}-0.03 \\
(0.025)\end{array}$ & -1.23 & $\begin{array}{c}-0.04 * * * \\
(0.009)\end{array}$ & -4.12 & $\begin{array}{c}-0.03 * * * \\
(0.009)\end{array}$ & -3.75 \\
\hline SHINSIDER & $\begin{array}{c}-0.62 * * * \\
(0.137)\end{array}$ & -4.53 & $\begin{array}{l}0.12 * * \\
(0.049)\end{array}$ & 2.35 & $\begin{array}{c}-0.08 \\
(0.051)\end{array}$ & -1.55 \\
\hline SHINST & $\begin{array}{c}0.01 \\
(0.049)\end{array}$ & 0.28 & $\begin{array}{l}0.03 * * \\
(0.017)\end{array}$ & 2.05 & $\begin{array}{c}0.04 * * * \\
(0.016)\end{array}$ & 2.63 \\
\hline SHBLOCK & $\begin{array}{c}-0.19 \\
(0.139)\end{array}$ & -1.38 & $\begin{array}{l}0.10^{* *} \\
(0.051)\end{array}$ & 2.05 & $\begin{array}{c}0.03 \\
(0.051)\end{array}$ & 0.62 \\
\hline CEOAGE & $\begin{array}{c}-0.00 \\
(0.003)\end{array}$ & -1.34 & $\begin{array}{c}0.00 * * * \\
(0.001)\end{array}$ & 2.90 & $\begin{array}{c}0.00 * * * \\
(0.001)\end{array}$ & 2.84 \\
\hline CEOTENURE & $\begin{array}{c}0.01 \\
(0.004)\end{array}$ & 1.44 & $\begin{array}{l}-0.00 * * \\
(0.001)\end{array}$ & -1.98 & $\begin{array}{c}-0.00 \\
(0.001)\end{array}$ & -0.91 \\
\hline СЕОСОМР & $\begin{array}{c}0.11 * * * \\
(0.025)\end{array}$ & 4.25 & $\begin{array}{c}0.00 \\
(0.008)\end{array}$ & 0.22 & $\begin{array}{c}-0.00 \\
(0.007)\end{array}$ & -0.45 \\
\hline CEOBONUS & $\begin{array}{c}0.02 * * * \\
(0.003)\end{array}$ & 4.84 & $\begin{array}{c}-0.01 * * * \\
(0.001)\end{array}$ & -9.04 & $\begin{array}{c}0.00 * * * \\
(0.001)\end{array}$ & 3.01 \\
\hline
\end{tabular}




\begin{tabular}{|c|c|c|c|c|c|c|}
\hline \multirow[b]{2}{*}{ VARIABLES } & \multicolumn{2}{|c|}{ Cash Flow Volatility } & \multicolumn{2}{|c|}{ Stock Return Volatility } & \multicolumn{2}{|c|}{ Market Risk } \\
\hline & coeff & t-stat & coeff & t-stat & coeff & t-stat \\
\hline \multirow[t]{2}{*}{ CEOSALARY } & $0.12 *$ & 1.67 & -0.00 & -0.13 & -0.01 & -0.25 \\
\hline & $(0.074)$ & & $(0.025)$ & & $(0.022)$ & \\
\hline \multirow[t]{2}{*}{$A C S I Z E$} & $-0.03 * * *$ & -3.29 & $0.01 * * *$ & 2.67 & -0.00 & -0.55 \\
\hline & $(0.011)$ & & $(0.004)$ & & $(0.004)$ & \\
\hline \multirow[t]{2}{*}{ LEVERAGE } & $-0.85 * *$ & -2.54 & $-0.21 * *$ & -2.19 & 0.07 & 0.69 \\
\hline & $(0.334)$ & & $(0.096)$ & & $(0.105)$ & \\
\hline \multirow[t]{2}{*}{$R O A$} & $-0.03 * * *$ & -2.91 & $-0.04 * * *$ & -11.96 & $-0.01 *$ & -1.84 \\
\hline & $(0.012)$ & & $(0.004)$ & & $(0.005)$ & \\
\hline \multirow{2}{*}{$R O A_{(t-1)}$} & $-0.10 * * *$ & -7.82 & $-0.03 * * *$ & -7.06 & $-0.03 * * *$ & -7.92 \\
\hline & $(0.012)$ & & $(0.004)$ & & $(0.004)$ & \\
\hline \multirow[t]{2}{*}{ SIZE } & $-0.34 * * *$ & -11.17 & $-0.07 * * *$ & -8.70 & -0.00 & -0.52 \\
\hline & $(0.030)$ & & $(0.008)$ & & $(0.007)$ & \\
\hline \multirow[t]{2}{*}{ LIQUIDITY } & $0.12 * * *$ & 3.40 & 0.01 & 0.52 & $0.03 * * *$ & 2.75 \\
\hline & $(0.034)$ & & $(0.010)$ & & $(0.011)$ & \\
\hline \multirow{2}{*}{$L E V 2$} & $0.77 *$ & 1.81 & $0.89 * * *$ & 7.99 & $0.28 * *$ & 2.17 \\
\hline & $(0.426)$ & & $(0.111)$ & & $(0.128)$ & \\
\hline Fixed effects & yes & & yes & & yes & \\
\hline \multirow[t]{2}{*}{ Constant } & $-3.70 * * *$ & -4.16 & $4.28 * * *$ & 14.73 & 0.20 & 0.77 \\
\hline & $(0.889)$ & & $(0.291)$ & & $(0.263)$ & \\
\hline Observations & 2,904 & & 2,904 & & 2,904 & \\
\hline$R$-squared & 29.66 & & 56.05 & & 18.32 & \\
\hline F-Statistic & $25.60 * * *$ & & $170.05 * * *$ & & $25.96 * * *$ & \\
\hline
\end{tabular}

The p-value for the one-tailed test of the null hypothesis that the coefficient is zero is indicated as ***, **, * to show statistical significance at the $0.01,0.05$ and 0.10 levels respectively, and robust standard errors are provided in parentheses. DER USER and NON USER signify firms that use derivatives and those that do not. See Tables 5.3 and 5.4 for definitions of dependent and independent variables. 


\section{Table 6.19: Robustness Tests - Levels of Leverage in Derivative Non User Firms}

\begin{tabular}{|c|c|c|c|c|c|c|}
\hline \multirow[b]{2}{*}{ VARIABLES } & \multicolumn{2}{|c|}{ Cash Flow Volatility } & \multicolumn{2}{|c|}{ Stock Return Volatility } & \multicolumn{2}{|c|}{ Market Risk } \\
\hline & coeff & t-stat & coeff & t-stat & coeff & t-stat \\
\hline$B D M T G S$ & $\begin{array}{c}0.03 * * * \\
(0.006)\end{array}$ & 4.30 & $\begin{array}{c}0.01 * * * \\
(0.002)\end{array}$ & 3.38 & $\begin{array}{c}-0.00 * \\
(0.002)\end{array}$ & -1.89 \\
\hline$B D S I Z E$ & $\begin{array}{c}0.10 * * * \\
(0.023)\end{array}$ & 4.38 & $\begin{array}{c}-0.02 * * * \\
(0.005)\end{array}$ & -4.06 & $\begin{array}{l}-0.01 * * \\
(0.006)\end{array}$ & -2.15 \\
\hline BDINDEP & $\begin{array}{c}-0.03 \\
(0.022)\end{array}$ & -1.55 & $\begin{array}{c}-0.00 \\
(0.006)\end{array}$ & -0.22 & $\begin{array}{c}0.00 \\
(0.006)\end{array}$ & 0.47 \\
\hline BDDIVERS & $\begin{array}{c}0.01 \\
(0.025)\end{array}$ & 0.41 & $\begin{array}{c}-0.01 \\
(0.008)\end{array}$ & -1.46 & $\begin{array}{c}-0.03 * * * \\
(0.008)\end{array}$ & -3.68 \\
\hline SHINSIDER & $\begin{array}{c}-0.71 * * * \\
(0.149)\end{array}$ & -4.80 & $\begin{array}{c}0.24 * * * \\
(0.043)\end{array}$ & 5.66 & $\begin{array}{c}0.05 \\
(0.045)\end{array}$ & 1.09 \\
\hline SHINST & $\begin{array}{c}-0.05 \\
(0.050)\end{array}$ & -0.92 & $\begin{array}{c}0.01 \\
(0.014)\end{array}$ & 0.39 & $\begin{array}{c}0.05 * * * \\
(0.014)\end{array}$ & 3.79 \\
\hline SHBLOCK & $\begin{array}{c}-0.70 * * * \\
(0.166)\end{array}$ & -4.18 & $\begin{array}{c}0.23 * * * \\
(0.043)\end{array}$ & 5.47 & $\begin{array}{c}0.11 * * * \\
(0.041)\end{array}$ & 2.81 \\
\hline CEOAGE & $\begin{array}{l}-0.01 * \\
(0.003)\end{array}$ & -1.77 & $\begin{array}{c}-0.00 \\
(0.001)\end{array}$ & -0.95 & $\begin{array}{c}0.00 \\
(0.001)\end{array}$ & 1.54 \\
\hline CEOTENURE & $\begin{array}{c}-0.00 \\
(0.003)\end{array}$ & -0.47 & $\begin{array}{c}0.00 \\
(0.001)\end{array}$ & 1.03 & $\begin{array}{c}-0.00 \\
(0.001)\end{array}$ & -0.84 \\
\hline СЕОСОМР & $\begin{array}{c}0.16^{* * * *} \\
(0.028)\end{array}$ & 5.79 & $\begin{array}{c}0.01 \\
(0.008)\end{array}$ & 0.90 & $\begin{array}{c}0.00 \\
(0.007)\end{array}$ & 0.46 \\
\hline CEOBONUS & $\begin{array}{c}0.02 * * * \\
(0.004)\end{array}$ & 4.72 & $\begin{array}{c}-0.01 * * * \\
(0.001)\end{array}$ & -7.76 & $\begin{array}{l}0.00 * * \\
(0.001)\end{array}$ & 1.98 \\
\hline
\end{tabular}




\begin{tabular}{|c|c|c|c|c|c|c|}
\hline \multirow[b]{2}{*}{ VARIABLES } & \multicolumn{2}{|c|}{ Cash Flow Volatility } & \multicolumn{2}{|c|}{ Stock Return Volatility } & \multicolumn{2}{|c|}{ Market Risk } \\
\hline & coeff & t-stat & coeff & t-stat & coeff & t-stat \\
\hline \multirow[t]{2}{*}{ CEOSALARY } & $0.20 * *$ & 2.23 & -0.01 & -0.61 & -0.03 & -1.53 \\
\hline & $(0.089)$ & & $(0.018)$ & & $(0.018)$ & \\
\hline \multirow[t]{2}{*}{ ACSIZE } & -0.01 & -1.20 & $0.01 * * *$ & 3.75 & 0.00 & 0.57 \\
\hline & $(0.012)$ & & $(0.004)$ & & $(0.004)$ & \\
\hline \multirow[t]{2}{*}{ LEVERAGE } & 0.43 & 1.36 & $-0.36 * * *$ & -3.78 & 0.08 & 0.69 \\
\hline & $(0.315)$ & & $(0.094)$ & & $(0.110)$ & \\
\hline \multirow[t]{2}{*}{$R O A$} & $-0.07 * * *$ & -6.10 & $-0.03 * * *$ & -9.96 & $-0.01 * * *$ & -4.10 \\
\hline & $(0.011)$ & & $(0.003)$ & & $(0.003)$ & \\
\hline \multirow{2}{*}{$R O A_{(t-1)}$} & $-0.12 * * *$ & -11.18 & $-0.02 * * *$ & -7.45 & $-0.02 * * *$ & -4.85 \\
\hline & $(0.011)$ & & $(0.003)$ & & $(0.003)$ & \\
\hline \multirow[t]{2}{*}{ SIZE } & $-0.45 * * *$ & -15.18 & $-0.07 * * *$ & -11.64 & 0.01 & 0.87 \\
\hline & $(0.030)$ & & $(0.006)$ & & $(0.006)$ & \\
\hline \multirow[t]{2}{*}{ LIQUIDITY } & $0.19 * * *$ & 5.36 & -0.01 & -1.24 & 0.00 & 0.22 \\
\hline & $(0.035)$ & & $(0.009)$ & & $(0.010)$ & \\
\hline \multirow[t]{2}{*}{$L E V 2$} & -0.52 & -1.14 & $1.06^{* * *}$ & 8.54 & 0.21 & 1.21 \\
\hline & $(0.454)$ & & $(0.124)$ & & $(0.171)$ & \\
\hline Fixed effects & yes & & yes & & yes & \\
\hline \multirow[t]{2}{*}{ Constant } & $-4.96 * * *$ & -4.87 & $4.41 * * *$ & 21.25 & $0.41 * *$ & 2.04 \\
\hline & $(1.017)$ & & $(0.208)$ & & $(0.203)$ & \\
\hline Observations & 3,330 & & 3,330 & & 3,330 & \\
\hline$R$-squared & 49.23 & & 50.95 & & 10.70 & \\
\hline$F$-statistic & $49.74 * * *$ & & $133.79 * * *$ & & $14.74 * * *$ & \\
\hline
\end{tabular}

The p-value for the one-tailed test of the null hypothesis that the coefficient is zero is indicated as ***, **,* to show statistical significance at the $0.01,0.05$ and 0.10 levels respectively, and robust standard errors are provided in parentheses. DER USER and NON USER signify firms that use derivatives and those that do not use derivatives, respectively. See Tables 5.3 and 5.4 for definitions of dependent and independent variables. 
Further, in the context of the risk models, I present other robustness tests for the main risk models (Tables 6.9 - 6.14). Firstly, in order to show that my results are largely invariant to the choice of the dependent variable, I use different measures for firm risk. The first measure examines the Altman Z-Score (ZSCORE) as an additional risk variable taken as the dependent variable and is described in Table 5.4. This variable captures bankruptcy risk and may be another proxy of unsystematic risk. Many researchers examine this measure, for example Brockman and Turtle (2003) study Zscores in relation to security valuation, and Chava and Purnanandam (2010) investigate the relationship in respect of stock returns. The results for my sensitivity tests are presented in Table 6.20 and show similar results to that of the stock return volatility main regression results (Tables 6.11 and 6.12), specifically for the corporate governance independent variables.

For my second risk measure, I use the variance of return on equity (VROE). This variable follows the measure used by Ferreira and Laux (2007) and is described in Table 5.4. VROE captures profitability volatility and provides an additional proxy for unsystematic firm risk in my analysis. In both models I use the Newey-West (1987) procedure to correct for any problems of heteroscedasticity and time-series correlations in panel data taken up to three lags. The results for both derivative user firms and derivative non user firms are presented alongside each other in Table 6.21. 
Table 6. 12: Robustness Tests - Z-Score

$$
\begin{aligned}
\text { ZSCOREi } \boldsymbol{t}=_{=} & z_{0}+z_{1} \text { BDMTGS }_{i, t}+z_{2} \text { BDSIZE }_{i, t}+z_{3} \text { BDINDEP }_{i, t}+z_{4} \text { BDDIVERS }_{i, t} \\
& +z_{5} \text { SHINSIDER }_{i, t}+z_{6} \text { SHINST }_{i, t}+z_{7} \text { SHBLOCK }_{i, t}+z_{8} \text { CEOAGE }_{i, t} \\
& +z_{9} \text { CEOTENURE }_{i, t}+z_{10} \text { CEOCOMP }_{i, t}+z_{11} \text { CEOBONUS }_{i, t} \\
& +z_{12} \text { CEOSALARY }_{i, t}+z_{13} \text { ACSIZE }_{i, t}+z_{14} \text { LEVERAGE }_{i, t}+z_{15} \text { ROA }_{i, t} \\
& +z_{16} \text { lagROA }_{i, t}+z_{17} \text { SIZE }_{i, t}+z_{18} \text { LIQUIDITY }_{i, t}+\varepsilon_{i, t}
\end{aligned}
$$

\begin{tabular}{|c|c|c|c|c|}
\hline \multirow[b]{2}{*}{ VARIABLES } & \multicolumn{2}{|c|}{ DER USER } & \multicolumn{2}{|c|}{ NON USER } \\
\hline & coeff & t-stat & coeff & t-stat \\
\hline BDMTGS & $\begin{array}{c}-0.01 * * * \\
(0.003)\end{array}$ & -2.85 & $\begin{array}{c}-0.01 * * \\
(0.004)\end{array}$ & -2.43 \\
\hline BDSIZE & $\begin{array}{c}-0.01 \\
(0.011)\end{array}$ & -0.71 & $\begin{array}{c}-0.02 \\
(0.012)\end{array}$ & -1.40 \\
\hline BDINDEP & $\begin{array}{c}-0.02 * * \\
(0.011)\end{array}$ & -1.99 & $\begin{array}{c}0.01 \\
(0.013)\end{array}$ & 0.88 \\
\hline BDDIVERS & $\begin{array}{c}0.06^{* * * *} \\
(0.016)\end{array}$ & 3.76 & $\begin{array}{c}-0.01 \\
(0.019)\end{array}$ & -0.31 \\
\hline SHINSIDER & $\begin{array}{c}0.02 \\
(0.102)\end{array}$ & 0.15 & $\begin{array}{c}0.17 * \\
(0.093)\end{array}$ & 1.82 \\
\hline SHINST & $\begin{array}{l}-0.06 * * \\
(0.028)\end{array}$ & -2.22 & $\begin{array}{c}-0.04 \\
(0.033)\end{array}$ & -1.20 \\
\hline SHBLOCK & $\begin{array}{c}0.10 \\
(0.084)\end{array}$ & 1.22 & $\begin{array}{c}0.16 \\
(0.107)\end{array}$ & 1.52 \\
\hline CEOAGE & $\begin{array}{l}-0.00 \\
(0.002)\end{array}$ & -0.31 & $\begin{array}{c}0.00 \\
(0.002)\end{array}$ & 0.52 \\
\hline CEOTENURE & $\begin{array}{l}0.00 * * \\
(0.002)\end{array}$ & 2.01 & $\begin{array}{l}0.00 * * \\
(0.002)\end{array}$ & 2.14 \\
\hline СЕОСОМР & $\begin{array}{c}-0.09 * * * \\
(0.016)\end{array}$ & -5.60 & $\begin{array}{c}-0.06 * * * \\
(0.018)\end{array}$ & -3.10 \\
\hline CEOBONUS & $\begin{array}{c}-0.00 \\
(0.002)\end{array}$ & -0.32 & $\begin{array}{c}-0.00 \\
(0.002)\end{array}$ & -0.62 \\
\hline CEOSALARY & $\begin{array}{l}-0.01 \\
(0.049)\end{array}$ & -0.26 & $\begin{array}{c}-0.07 \\
(0.046)\end{array}$ & -1.53 \\
\hline ACSIZE & $\begin{array}{c}-0.02 * * * \\
(0.007)\end{array}$ & -2.73 & $\begin{array}{c}-0.03 * * * \\
(0.008)\end{array}$ & -3.32 \\
\hline
\end{tabular}




\begin{tabular}{|c|c|c|c|c|}
\hline \multirow[b]{2}{*}{ VARIABLES } & \multicolumn{2}{|c|}{ DER USER } & \multicolumn{2}{|c|}{ NON USER } \\
\hline & coeff & t-stat & coeff & t-stat \\
\hline LEVERAGE & $\begin{array}{c}-1.46 * * * \\
(0.078)\end{array}$ & -18.74 & $\begin{array}{c}-1.56 * * * \\
(0.084)\end{array}$ & -18.64 \\
\hline$R O A$ & $\begin{array}{c}0.05 * * * \\
(0.007)\end{array}$ & 7.71 & $\begin{array}{c}0.08 * * * \\
(0.008)\end{array}$ & 10.55 \\
\hline$R O A_{(t-1)}$ & $\begin{array}{c}0.06 * * * \\
(0.007)\end{array}$ & 8.20 & $\begin{array}{c}0.05^{* * *} * \\
(0.007)\end{array}$ & 7.10 \\
\hline SIZE & $\begin{array}{l}0.10 * * * \\
(0.018)\end{array}$ & 5.52 & $\begin{array}{c}0.08 * * * \\
(0.015)\end{array}$ & 5.29 \\
\hline LIQUIDITY & $\begin{array}{l}0.19 * * * \\
(0.022)\end{array}$ & 8.71 & $\begin{array}{c}0.24 * * * \\
(0.023)\end{array}$ & 10.32 \\
\hline $\begin{array}{l}\text { Year effects } \\
\text { Industry effects }\end{array}$ & $\begin{array}{l}\text { yes } \\
\text { yes }\end{array}$ & & $\begin{array}{l}\text { yes } \\
\text { yes }\end{array}$ & \\
\hline Constant & $\begin{array}{c}2.40 * * * \\
(0.531)\end{array}$ & 4.51 & $\begin{array}{c}2.64 * * * \\
(0.512)\end{array}$ & 5.16 \\
\hline $\begin{array}{l}\text { Observations } \\
R \text {-squared } \\
F \text { statistic }\end{array}$ & $\begin{array}{c}2,904 \\
49.60 \\
93.78 * * *\end{array}$ & & $\begin{array}{c}3,330 \\
42.78 \\
67.96 * * * \\
\end{array}$ & \\
\hline
\end{tabular}

The p-value for the one-tailed test of the null hypothesis that the coefficient is zero is indicated as $* * *, * * * *$ to show statistical significance at the $0.01,0.05$ and 0.10 levels respectively, and robust standard errors are provided in parentheses. DER USER and NON USER signify firms that use derivatives and those that do not. See Tables 5.3 and 5.4 for definitions of dependent and independent variables. 


\section{Table 6. 13: Robustness Tests - VROE}

$$
\begin{aligned}
& \text { VROEi, } t=z_{0}+z_{1} B D M T G S_{i, t}+z_{2} \text { BDSIZE }_{i, t}+z_{3} \text { BDINDEP }_{i, t}+z_{4} B D D I V E R S_{i, t} \\
& +z_{5} \text { SHINSIDER }_{i, t}+z_{6} \text { SHINST }_{i, t}+z_{7} \text { SHBLOCK }_{i, t}+z_{8} \text { CEOAGE }_{i, t} \\
& +z_{9} \text { CEOTENURE }_{i, t}+z_{10} \text { CEOCOMP }_{i, t}+z_{11} \text { CEOBONUS }_{i, t} \\
& +z_{12} \operatorname{CEOSALARY}_{i, t}+z_{13} \text { ACSIZE }_{i, t}+z_{14} \text { LEVERAGE }_{i, t}+z_{15} M_{i, t} \\
& +z_{17} \text { TOTALFIRMSIZE }_{i, t}+z_{18} \text { LIQUIDITY }_{i, t}+\varepsilon_{i, t}
\end{aligned}
$$

\begin{tabular}{lcccc}
\hline \multirow{2}{*}{ VARIABLES } & \multicolumn{2}{c}{ DER USER } & NON & USER \\
\cline { 2 - 5 } BDMTGS & coeff & t-stat & coeff & t-stat \\
& $0.06^{* * *}$ & 4.57 & $0.11^{* * *}$ & 8.44 \\
BDSIZE & $(0.013)$ & & $(0.013)$ & \\
& -0.04 & -0.96 & $-0.12^{* * *}$ & -3.06 \\
BDINDEP & $(0.041)$ & & $(0.039)$ & \\
& -0.01 & -0.25 & $0.08^{*}$ & 1.94 \\
BDDIVERS & $(0.041)$ & & $(0.042)$ & \\
& $-0.12^{* *}$ & -2.00 & -0.04 & -0.80 \\
SHINSIDER & $(0.058)$ & & $(0.056)$ & \\
& -0.51 & -1.56 & $0.54^{*}$ & 1.86 \\
SHINST & $(0.327)$ & & $(0.290)$ & \\
& 0.08 & 0.70 & 0.09 & 0.84 \\
SHBLOCK & $(0.115)$ & & $(0.103)$ & \\
& $0.56^{*}$ & 1.72 & $0.83^{* * *}$ & 2.69 \\
CEOAGE & $(0.326)$ & & $(0.309)$ & \\
& 0.01 & 1.60 & -0.00 & -0.04 \\
CEOTENURE & $(0.007)$ & & $(0.007)$ & \\
& -0.01 & -1.46 & -0.01 & -1.31 \\
CEOCOMP & $(0.007)$ & & $(0.006)$ & \multirow{2}{*}{0.17} \\
CEOBONUS & $-0.15^{* *}$ & -2.39 & 0.01 & 0.17 \\
& $(0.065)$ & & $(0.059)$ & \\
CEOSALARY & $-0.02^{* * *}$ & -3.10 & $-0.02^{* * *}$ & -2.79 \\
ACSIZE & $(0.008)$ & & $(0.008)$ & \multirow{2}{*}{3.18} \\
& $0.55^{* * *}$ & 3.55 & $0.29^{* *}$ & 2.18 \\
& $(0.155)$ & & $(0.132)$ & \\
& -0.01 & -0.30 & $0.06^{* *}$ & 2.17 \\
& $(0.027)$ & & $(0.027)$ & \\
& & & &
\end{tabular}




\begin{tabular}{|c|c|c|c|c|}
\hline \multirow[b]{2}{*}{ VARIABLES } & \multicolumn{2}{|c|}{ DER USER } & \multicolumn{2}{|c|}{ NON USER } \\
\hline & coeff & t-stat & coeff & t-stat \\
\hline LEVERAGE & $\begin{array}{c}2.69 * * * \\
(0.302)\end{array}$ & 8.91 & $\begin{array}{c}2.20 * * * \\
(0.304)\end{array}$ & 7.24 \\
\hline MB & $\begin{array}{c}0.61 * * * \\
(0.087)\end{array}$ & 6.94 & $\begin{array}{c}0.49 * * * \\
(0.077)\end{array}$ & 6.40 \\
\hline LIQUIDITY & $\begin{array}{c}0.30 * * * \\
(0.074)\end{array}$ & 4.08 & $\begin{array}{c}0.21 * * * \\
(0.058)\end{array}$ & 3.63 \\
\hline TOTALFIRMSIZE & $\begin{array}{c}-0.20 * * * \\
(0.037)\end{array}$ & -5.58 & $\begin{array}{c}-0.29 * * * \\
(0.033)\end{array}$ & -8.72 \\
\hline Year effects & yes & & yes & \\
\hline Industry effects & yes & & yes & \\
\hline Constant & $\begin{array}{c}-1.72 \\
(1.744)\end{array}$ & -0.99 & $\begin{array}{c}-0.08 \\
(1.471)\end{array}$ & -0.05 \\
\hline Observations & 2,904 & & 3,330 & \\
\hline$R$-squared & 0.12 & & 0.11 & \\
\hline$F$-static & $17.22 * * *$ & & $18.22 * * *$ & \\
\hline
\end{tabular}

The p-value for the one-tailed test of the null hypothesis that the coefficient is zero is indicated as $* * *, * *, *$ to show statistical significance at the $0.01,0.05$ and 0.10 levels respectively, and robust standard errors are provided in parentheses. DER USER and NON USER signify firms that use derivatives and those that do not. See Tables 5.3 and 5.4 for definitions of dependent and independent variables. 
Further, for the risk models, I use a bootstrapping method with 10,000 iterations as a robustness test that are presented in Tables 6.22, 6.23 and 6.24. This is similar to the bootstrapping technique applied in the sensitivity analysis of the value models discussed in Section 6.8.1 and presented in Table 6.17. Though there is some variation in the coefficients and level of significance, bootstrapping risk results for the corporate governance variables and control variables indicate the same direction and significance impact as the main regression models for firm risk. 


\section{Table 6. 14: Robustness Tests -Cash Flow Volatility Bootstrap (10,000)}

$$
\begin{aligned}
\text { CASH FLOW } & \text { VOLATILITY } \\
& =z_{0}+z_{1} \text { BDMTGS }_{i, t}+z_{2} \text { BDSIZE }_{i, t}+z_{3} \text { BDINDEP }_{i, t}+z_{4} \text { BDDIVERS }_{i, t} \\
& +z_{5} \text { SHINSIDER }_{i, t}+z_{6} \operatorname{SHINST}_{i, t}+z_{7} \operatorname{SHBLOCK}_{i, t}+z_{8} \text { CEOAGE }_{i, t} \\
& +z_{9} \text { CEOTENURE }_{i, t}+z_{10} \text { CEOCOMP }_{i, t}+z_{11} \text { CEOBONUS }_{i, t} \\
& +z_{12} \text { CEOSALARY }_{i, t}+z_{13} \text { ACSIZE }_{i, t}+z_{14} \text { LEVERAGE }_{i, t}+z_{15} \text { ROA }_{i, t} \\
& +z_{16} \operatorname{lagROA}_{i, t}+z_{17} \operatorname{SIZE}_{i, t}+z_{18} \text { LIQUIDITY }_{i, t}+\varepsilon_{i, t}
\end{aligned}
$$

\begin{tabular}{|c|c|c|c|c|}
\hline \multirow[b]{2}{*}{ VARIABLES } & \multicolumn{2}{|c|}{ DER USER } & \multicolumn{2}{|c|}{ NON USER } \\
\hline & coeff & z-stat & Coeff & z-stat \\
\hline$B D M T G S$ & $\begin{array}{c}0.02 * * * \\
(0.005)\end{array}$ & 3.86 & $\begin{array}{c}0.03 * * * \\
(0.006)\end{array}$ & 4.81 \\
\hline$B D S I Z E$ & $\begin{array}{c}0.06 * * * \\
(0.015)\end{array}$ & 3.75 & $\begin{array}{c}0.10 * * * \\
(0.020)\end{array}$ & 5.09 \\
\hline BDINDEP & $\begin{array}{c}-0.01 \\
(0.015)\end{array}$ & -0.61 & $\begin{array}{l}-0.03^{*} \\
(0.019)\end{array}$ & -1.74 \\
\hline BDDIVERS & $\begin{array}{c}-0.03 \\
(0.021)\end{array}$ & -1.40 & $\begin{array}{c}0.01 \\
(0.021)\end{array}$ & 0.47 \\
\hline SHINSIDER & $\begin{array}{c}-0.59 * * * \\
(0.119)\end{array}$ & -4.96 & $\begin{array}{c}-0.72 * * * \\
(0.127)\end{array}$ & -5.68 \\
\hline SHINST & $\begin{array}{c}0.02 \\
(0.045)\end{array}$ & 0.44 & $\begin{array}{c}-0.05 \\
(0.043)\end{array}$ & -1.05 \\
\hline SHBLOCK & $\begin{array}{c}-0.19 \\
(0.123)\end{array}$ & -1.51 & $\begin{array}{c}-0.70 * * * \\
(0.148)\end{array}$ & -4.77 \\
\hline CEOAGE & $\begin{array}{c}-0.00 \\
(0.003)\end{array}$ & -1.45 & $\begin{array}{c}-0.01 * * \\
(0.003)\end{array}$ & -2.05 \\
\hline CEOTENURE & $\begin{array}{c}0.01 \\
(0.003)\end{array}$ & 1.54 & $\begin{array}{c}-0.00 \\
(0.003)\end{array}$ & -0.56 \\
\hline СЕОСОМР & $\begin{array}{c}0.11 * * * \\
(0.025)\end{array}$ & 4.22 & $\begin{array}{c}0.16 * * * \\
(0.026)\end{array}$ & 6.41 \\
\hline CEOBONUS & $\begin{array}{c}0.02 * * * \\
(0.003)\end{array}$ & 5.28 & $\begin{array}{c}0.02 * * * \\
(0.003)\end{array}$ & 5.42 \\
\hline CEOSALARY & $\begin{array}{c}0.12 * \\
(0.070)\end{array}$ & 1.72 & $\begin{array}{c}0.20 * * * \\
(0.077)\end{array}$ & 2.60 \\
\hline
\end{tabular}




\begin{tabular}{|c|c|c|c|c|}
\hline \multirow[b]{2}{*}{ VARIABLES } & \multicolumn{2}{|c|}{ DER USER } & \multicolumn{2}{|c|}{ NON USER } \\
\hline & coeff & Z-stat & Coeff & Z-stat \\
\hline$A C S I Z E$ & $\begin{array}{c}-0.04 * * * \\
(0.009)\end{array}$ & -3.74 & $\begin{array}{c}-0.01 \\
(0.011)\end{array}$ & -1.32 \\
\hline$L E V E R A G E$ & $\begin{array}{l}-0.28 * * * \\
(0.107)\end{array}$ & -2.65 & $\begin{array}{c}0.09 \\
(0.107)\end{array}$ & 0.80 \\
\hline$R O A$ & $\begin{array}{c}-0.04 * * * \\
(0.012)\end{array}$ & -3.17 & $\begin{array}{c}-0.07 * * * \\
(0.011)\end{array}$ & -5.86 \\
\hline$R O A_{(t-1)}$ & $\begin{array}{c}-0.10 * * * \\
(0.013)\end{array}$ & -7.63 & $\begin{array}{c}-0.12 * * * \\
(0.011)\end{array}$ & -10.94 \\
\hline$S I Z E$ & $\begin{array}{c}-0.34 * * * \\
(0.027)\end{array}$ & -12.52 & $\begin{array}{c}-0.45 * * * \\
(0.024)\end{array}$ & -18.78 \\
\hline LIQUIDITY & $\begin{array}{c}0.12 * * * \\
(0.029)\end{array}$ & 4.33 & $\begin{array}{c}0.18 * * * \\
(0.028)\end{array}$ & 6.47 \\
\hline $\begin{array}{l}\text { Year effects } \\
\text { Industry effects }\end{array}$ & $\begin{array}{l}\text { yes } \\
\text { yes }\end{array}$ & & $\begin{array}{l}\text { yes } \\
\text { yes }\end{array}$ & \\
\hline Constant & $\begin{array}{c}-3.69 * * * \\
(0.817)\end{array}$ & -4.51 & $\begin{array}{c}-4.98 * * * \\
(0.900)\end{array}$ & -5.53 \\
\hline $\begin{array}{l}\text { Observations } \\
R \text {-squared } \\
\text { Wald } \chi^{2}\end{array}$ & $\begin{array}{c}2,904 \\
29.52 \\
690.40 * * * \\
\end{array}$ & & $\begin{array}{c}3,330 \\
49.20 \\
1689.86 * * *\end{array}$ & \\
\hline
\end{tabular}

The p-value for the one-tailed test of the null hypothesis that the coefficient is zero is indicated as $* * *, * *, *$ to show statistical significance at the $0.01,0.05$ and 0.10 levels respectively, and robust standard errors are provided in parentheses. DER USER and NON USER signify firms that use derivatives and those that do not. See Tables 5.3 and 5.4 for definitions of dependent and independent variables. 


\section{Table 6. 15: Robustness Tests - Stock Return Volatility Bootstrap $(10,000)$}

\begin{tabular}{|c|c|c|c|c|}
\hline $\begin{array}{l}= \\
+ \\
+ \\
+ \\
+ \\
+\end{array}$ & $\begin{array}{l}t+z_{2} B D \\
z_{5} S H I N S \\
\text { CEOTEN } \\
+z_{12} C E O \\
+z_{15} R O A_{i} \\
+\varepsilon_{i, t}\end{array}$ & $\begin{array}{l}i, t+z_{3} \\
R_{i, t}+z_{\epsilon} \\
{ }_{t}+z_{10} \\
4 R Y_{i, t} \\
z_{16} \text { lagl }\end{array}$ & $\begin{array}{l}N D E P_{i, t} \\
N S T_{i, t}+z \\
C O M P_{i, t} \\
A C S I Z E_{i, t} \\
i, t+z_{17} S I\end{array}$ & $3 L O C K_{i, t}$ \\
\hline \multirow[b]{2}{*}{ VARIABLES } & \multicolumn{2}{|c|}{ DER USER } & \multicolumn{2}{|c|}{ NON USER } \\
\hline & coeff & z-stat & coeff & Z-stat \\
\hline$B D M T G S$ & $\begin{array}{c}0.01 * * * \\
(0.002)\end{array}$ & 2.77 & $\begin{array}{c}0.01 * * * \\
(0.002)\end{array}$ & 3.40 \\
\hline$B D S I Z E$ & $\begin{array}{c}-0.02 * * * \\
(0.005)\end{array}$ & -4.06 & $\begin{array}{c}-0.02 * * * \\
(0.005)\end{array}$ & -4.94 \\
\hline BDINDEP & $\begin{array}{c}0.00 \\
(0.006)\end{array}$ & 0.04 & $\begin{array}{c}-0.00 \\
(0.005)\end{array}$ & -0.39 \\
\hline BDDIVERS & $\begin{array}{c}-0.04 * * * \\
(0.008)\end{array}$ & -4.76 & $\begin{array}{c}-0.01 \\
(0.007)\end{array}$ & -1.57 \\
\hline SHINSIDER & $\begin{array}{c}0.15 * * * \\
(0.045)\end{array}$ & 3.36 & $\begin{array}{c}0.26 * * * \\
(0.038)\end{array}$ & 6.87 \\
\hline SHINST & $\begin{array}{c}0.04 * * * \\
(0.015)\end{array}$ & 2.63 & $\begin{array}{c}0.00 \\
(0.013)\end{array}$ & 0.31 \\
\hline SHBLOCK & $\begin{array}{l}0.11 * * \\
(0.045)\end{array}$ & 2.47 & $\begin{array}{c}0.25 * * * \\
(0.040)\end{array}$ & 6.27 \\
\hline$C E O A G E$ & $\begin{array}{c}0.00 * * * \\
(0.001)\end{array}$ & 3.35 & $\begin{array}{c}-0.00 \\
(0.001)\end{array}$ & -1.30 \\
\hline CEOTENURE & $\begin{array}{c}-0.00 * * \\
(0.001)\end{array}$ & -2.19 & $\begin{array}{c}0.00 \\
(0.001)\end{array}$ & 1.22 \\
\hline СЕОСОМР & $\begin{array}{c}-0.00 \\
(0.008)\end{array}$ & -0.11 & $\begin{array}{c}0.01 \\
(0.007)\end{array}$ & 1.01 \\
\hline CEOBONUS & $\begin{array}{c}-0.01 * * * \\
(0.001)\end{array}$ & -9.55 & $\begin{array}{c}-0.01 * * * \\
(0.001)\end{array}$ & -8.50 \\
\hline
\end{tabular}




\begin{tabular}{|c|c|c|c|c|}
\hline \multirow[b]{2}{*}{ VARIABLES } & \multicolumn{2}{|c|}{ DER USER } & \multicolumn{2}{|c|}{ NON USER } \\
\hline & coeff & z-stat & coeff & Z-stat \\
\hline CEOSALARY & $\begin{array}{c}-0.01 \\
(0.022)\end{array}$ & -0.35 & $\begin{array}{c}-0.01 \\
(0.017)\end{array}$ & -0.84 \\
\hline ACSIZE & $\begin{array}{c}0.01 * * * \\
(0.004)\end{array}$ & 2.83 & $\begin{array}{c}0.01 * * * \\
(0.004)\end{array}$ & 3.82 \\
\hline LEVERAGE & $\begin{array}{c}0.45^{* * *} * \\
(0.037)\end{array}$ & 12.09 & $\begin{array}{c}0.34 * * * \\
(0.035)\end{array}$ & 9.73 \\
\hline$R O A$ & $\begin{array}{c}-0.05 * * * \\
(0.004)\end{array}$ & -12.37 & $\begin{array}{c}-0.03 * * * \\
(0.003)\end{array}$ & -9.80 \\
\hline$R O A_{(t-1)}$ & $\begin{array}{c}-0.03 * * * \\
(0.004)\end{array}$ & -7.03 & $\begin{array}{c}-0.02 * * * \\
(0.003)\end{array}$ & -7.26 \\
\hline$S I Z E$ & $\begin{array}{c}-0.07 * * * \\
(0.007)\end{array}$ & -9.73 & $\begin{array}{c}-0.07 * * * \\
(0.005)\end{array}$ & -12.96 \\
\hline LIQUIDITY & $\begin{array}{l}0.02 * \\
(0.009)\end{array}$ & 1.68 & $\begin{array}{c}0.00 \\
(0.008)\end{array}$ & 0.03 \\
\hline $\begin{array}{l}\text { Year effects } \\
\text { Industry effects }\end{array}$ & $\begin{array}{l}\text { yes } \\
\text { yes }\end{array}$ & & $\begin{array}{l}\text { Yes } \\
\text { Yes }\end{array}$ & \\
\hline Constant & $\begin{array}{c}4.30 * * * \\
(0.242)\end{array}$ & 17.76 & $\begin{array}{c}4.45 * * * \\
(0.190)\end{array}$ & 23.37 \\
\hline $\begin{array}{l}\text { Observations } \\
R \text {-squared } \\
\text { Wald } \chi^{2}\end{array}$ & $\begin{array}{c}2,904 \\
55.07 \\
3428.32 * * *\end{array}$ & & $\begin{array}{c}3,330 \\
49.70 \\
2994.99 * * *\end{array}$ & \\
\hline
\end{tabular}

The p-value for the one-tailed test of the null hypothesis that the coefficient is zero is indicated as $* * *, * * * *$ to show statistical significance at the $0.01,0.05$ and 0.10 levels respectively, and robust standard errors are provided in parentheses. DER USER and NON USER signify firms that use derivatives and those that do not use derivatives, respectively. See Tables 5.3 and 5.4 for definitions of dependent and independent variables. 
Table 6. 16: Robustness Tests - Market Risk Bootstrap (10,000) MARKET RISK

$$
\begin{aligned}
& =z_{0}+z_{1} \text { BDMTGS }_{i, t}+z_{2} \text { BDSIZE }_{i, t}+z_{3} \text { BDINDEP }_{i, t} \\
& +z_{4} \text { BDDIVERS }_{i, t}+z_{5} \text { SHINSIDER }_{i, t}+z_{6} \text { SHINST }_{i, t} \\
& +z_{7} \text { SHBLOCK }_{i, t}+z_{8} \text { CEOAGE }_{i, t}+z_{9} \text { CEOTENURE }_{i, t} \\
& +z_{10} \text { CEOCOMP }_{i, t}+z_{11} \text { CEOBONUS }_{i, t}+z_{12} \text { CEOSALARY }_{i, t} \\
& +z_{13} \text { ACSIZE }_{i, t}+z_{14} \text { LEVERAGE }_{i, t}+z_{15} \text { ROA }_{i, t}+z_{16} \text { lagROA }_{i, t} \\
& +z_{17} \text { SIZE }_{i, t}+z_{18} \text { LIQUIDITY }_{i, t}+\varepsilon_{i, t}
\end{aligned}
$$

\begin{tabular}{|c|c|c|c|c|}
\hline \multirow[b]{2}{*}{ VARIABLES } & \multicolumn{2}{|c|}{ DER USER } & \multicolumn{2}{|c|}{ NON USER } \\
\hline & coeff & Z-stat & coeff & z-stat \\
\hline BDMTGS & $\begin{array}{c}0.00 \\
(0.002)\end{array}$ & 0.14 & $\begin{array}{c}-0.00 * * \\
(0.002)\end{array}$ & -2.02 \\
\hline$B D S I Z E$ & $\begin{array}{c}-0.01 \\
(0.006)\end{array}$ & -1.32 & $\begin{array}{l}-0.01 * * \\
(0.005)\end{array}$ & -2.48 \\
\hline BDINDEP & $\begin{array}{c}-0.00 \\
(0.006)\end{array}$ & -0.39 & $\begin{array}{c}0.00 \\
(0.006)\end{array}$ & 0.47 \\
\hline BDDIVERS & $\begin{array}{c}-0.03 * * * \\
(0.007)\end{array}$ & -4.51 & $\begin{array}{c}-0.03 * * * \\
(0.007)\end{array}$ & -4.17 \\
\hline SHINSIDER & $\begin{array}{c}-0.07 \\
(0.046)\end{array}$ & -1.49 & $\begin{array}{c}0.05 \\
(0.042)\end{array}$ & 1.26 \\
\hline SHINST & $\begin{array}{c}0.05 * * * \\
(0.015)\end{array}$ & 3.03 & $\begin{array}{c}0.05 * * * \\
(0.013)\end{array}$ & 4.02 \\
\hline SHBLOCK & $\begin{array}{c}0.03 \\
(0.046)\end{array}$ & 0.74 & $\begin{array}{c}0.12 * * * \\
(0.036)\end{array}$ & 3.23 \\
\hline$C E O A G E$ & $\begin{array}{c}0.00 * * * \\
(0.001)\end{array}$ & 3.19 & $\begin{array}{c}0.00 * \\
(0.001)\end{array}$ & 1.66 \\
\hline CEOTENURE & $\begin{array}{c}-0.00 \\
(0.001)\end{array}$ & -1.01 & $\begin{array}{c}-0.00 \\
(0.001)\end{array}$ & -0.89 \\
\hline СЕОСОМР & $\begin{array}{c}-0.00 \\
(0.007)\end{array}$ & -0.56 & $\begin{array}{c}0.00 \\
(0.007)\end{array}$ & 0.49 \\
\hline CEOBONUS & $\begin{array}{c}0.00 * * * \\
(0.001)\end{array}$ & 3.30 & $\begin{array}{l}0.00 * * \\
(0.001)\end{array}$ & 2.12 \\
\hline CEOSALARY & $\begin{array}{c}-0.01 \\
(0.021)\end{array}$ & -0.34 & $\begin{array}{l}-0.03^{*} \\
(0.017)\end{array}$ & -1.69 \\
\hline ACSIZE & $\begin{array}{c}-0.00 \\
(0.003)\end{array}$ & -0.67 & $\begin{array}{c}0.00 \\
(0.003)\end{array}$ & 0.58 \\
\hline$L E V E R A G E$ & $\begin{array}{c}0.28 * * * \\
(0.041)\end{array}$ & 6.76 & $\begin{array}{c}0.21 * * * \\
(0.038)\end{array}$ & 5.66 \\
\hline
\end{tabular}




\begin{tabular}{|c|c|c|c|c|}
\hline \multirow[b]{2}{*}{ VARIABLES } & \multicolumn{2}{|c|}{ DER USER } & \multicolumn{2}{|c|}{ NON USER } \\
\hline & coeff & Z-stat & coeff & Z-stat \\
\hline$R O A$ & $\begin{array}{c}-0.01 * * \\
(0.005)\end{array}$ & -1.98 & $\begin{array}{c}-0.01 * * * \\
(0.003)\end{array}$ & -4.18 \\
\hline$R O A_{(t-1)}$ & $\begin{array}{c}-0.03 * * * \\
(0.004)\end{array}$ & -7.99 & $\begin{array}{c}-0.02 * * * \\
(0.003)\end{array}$ & -4.85 \\
\hline$S I Z E$ & $\begin{array}{c}-0.00 \\
(0.007)\end{array}$ & -0.56 & $\begin{array}{c}0.01 \\
(0.006)\end{array}$ & 0.86 \\
\hline LIQUIDITY & $\begin{array}{c}0.03 * * * \\
(0.010)\end{array}$ & 3.52 & $\begin{array}{c}0.00 \\
(0.009)\end{array}$ & 0.49 \\
\hline $\begin{array}{l}\text { Year effects } \\
\text { Industry effects }\end{array}$ & $\begin{array}{l}\text { yes } \\
\text { yes }\end{array}$ & & $\begin{array}{l}\text { yes } \\
\text { yes }\end{array}$ & \\
\hline Constant & $\begin{array}{c}0.21 \\
(0.235)\end{array}$ & 0.88 & $\begin{array}{l}0.42 * * \\
(0.186)\end{array}$ & 2.26 \\
\hline $\begin{array}{l}\text { Observations } \\
R \text {-squared } \\
\text { Wald } \chi^{2}\end{array}$ & $\begin{array}{c}2,904 \\
18.14 \\
749.62 * * *\end{array}$ & & $\begin{array}{c}3,330 \\
10.62 \\
384.44 * * *\end{array}$ & \\
\hline
\end{tabular}

The p-value for the one-tailed test of the null hypothesis that the coefficient is zero is indicated as $* * *, * * * *$ to show statistical significance at the $0.01,0.05$ and 0.10 levels respectively, and robust standard errors are provided in parentheses. DER USER and NON USER signify firms that use derivatives and those that do not. See Tables 5.3 and 5.4 for definitions of dependent and independent variables. 


\subsection{Alternative Tests on the Relationship between Derivatives, Corporate Governance, Firm Value and Firm Risk for Derivative Users and Derivative Non Users}

In this section I conduct alternative tests to examine the effects of corporate governance on firm value and firm risks simultaneously. Zellner's (1962) Iterated Seemingly Unrelated Regression (ISUR) model enables an examination of both the value and risk effects of the corporate governance-derivatives relationship. There are two requirements for Zellner's ISUR model: a) the errors in both equations need to be correlated and b) there should be no serial correlation between the independent variables in both the equations. In my ISUR alternative tests, I use the Breusch-Pagan Lagrange test to confirm that the errors are correlated. The null hypothesis for the Breusch Pagan Lagrange test is that there is no correlation in the errors of both equations and this needs to be rejected. For the second requirement (b), I use the Wald test to examine the cross-equation restrictions. The Wald test works by testing the null hypothesis that a set of parameters is equal to some value. In this model being tested here, the null hypothesis is that the two coefficients of interest (in the two equations) are simultaneously equal to zero. And this needs to be rejected. I provide results for these tests at the end of each ISUR model. Further, in order to evaluate the goodness of fit of both the regression models, I examine the system weighted $\mathrm{R}^{2}$, which is also reported at the end of each ISUR model. Additionally, I provide results of the correlation of the residuals for both the equations.

\section{ISUR Analysis of Corporate Governance and Derivatives Relationship for both Value and Cash Flow Volatility.}

Table 6.25 presents results of the Iterated Seemingly Unrelated Regression (ISUR) model. The dependent variables for this model are value and cash flow volatility. The 
independent variables related to corporate governance are the size of board of directors (BDSIZE), board meetings (BDMTGS), board independence (BDINDEP), board diversity (BDDIVERS), insider shareholders (SHINSIDER), institutional shareholding (SHINST), block shareholders (SHBLOCK), CEO age (CEOAGE), CEO years of service (CEOTENURE), CEO total compensation (CEOCOMP), bonus provided to CEO (CEOBONUS), CEO basic salary (CEOSALARY) and size of the audit committee (ACSIZE). The corporate governance variables are described in Table 5.3. The control variables, for the two equations are: return on assets (ROA), one-year prior return on assets $\left(\mathrm{ROA}_{(\mathrm{t}-1)}\right)$, leverage (LEVERAGE), firm size (SIZE), quick ratio (LIQUIDITY), research and development expenditure (R\&D) and capital expenditure (CAPEX) and these are defined in Table 5.4.

In the first ISUR model, I segregate the sample into two groups: derivative users and non users based on the full sample for 8 years, from 2004-2011. Model 1 presents the ISUR results of the first group of derivative users and the model 2 captures the ISUR results for derivative non users. The correlation of residuals for value and cash flow volatility is 0.1230 with the Breusch-Pagan $\chi^{2}$ of 41.93 which is significant at $1 \%$ level. The Wald $\chi^{2}$ is 592.75 and significant at $1 \%$ level, indicating that both requirements a) \& b) above are met. The system $\mathrm{R}^{2}$ is $54 \%$. For the VALUE model the results for BDSIZE, BDINDEP, BDDIVERS, SHINST, SHBLOCK, CEOAGE, CEOTENURE, CEOBONUS, and ACSIZE are significant and generally exhibit the same directional relationship with VALUE as exhibited in Table 6.7. Similarly, in keeping with the main results BDMTGS, SHINSIDER, CEOCOMP and CEOSALARY are insignificant. However, SHINST is now significant at $10 \%$ level.

With respect to the cash flow volatility risk equation, the results for corporate governance variables and control variables are significant and in the same direction as the main cash flow risk results for derivative users (Table 6.9). However, now 
CEOTENURE and CEOSALARY have a positive correlation with risk and are significant at $10 \%$ and $5 \%$ respectively. Generally, the results indicate that the findings for value and risk are similar to those of the main results, but ISUR provides the added advantage of examination of both the value and risk effects simultaneously.

A comparison between Model 1 and Model 2 for cash flow volatility results shows that SHINSIDER reduces risk and BDMTGS, BDSIZE, CEOCOMP, CEOBONUS and CEOSALARY increase risk for both groups of firms. However, the increase in risk is higher for Model 2 for non -derivative user firms. In respect of SHINSIDER, Model 2 shows a greater reduction in cash flow volatility in comparison to Model 1.

Some variables only effect one of the models, for example ACSIZE and CEOTENURE impact derivative users, and BDINDEP, CEOTENURE, SHBLOCK show an influence on the non -derivative user group to decrease risk. In summary, ACSIZE has an important impact for derivative users, indicating that an increase in 1 member in the audit committee reduces risk by $4 \%$ for derivative users. Though there is an increase in risk, due to BDMTGS, BDSIZE, CEOCOMP, CEOBONUS and CEOSALARY, however the derivatives users show lower risk increases. With respect of derivative user group a comparison shows there is lower risk increase for this group by: $0.9 \%$ for every unit increase in BDMTGS; $4.2 \%$ for every unit increase in BDSIZE; while for $100 \%$ increase in CEOCOMP, CEOBONUS and CEOSALARY the risk increase is lower by $5.89 \%, 1 \%$ and $7.7 \%$, respectively. 
Table 6. 17:Alternative Tests (ISUR): Value and Cash Flow Volatility in Derivative User and Non User Firms

\begin{tabular}{|c|c|c|c|c|}
\hline \multirow[b]{2}{*}{ VARIABLES } & \multicolumn{2}{|c|}{ Value } & \multicolumn{2}{|c|}{ Cash Flow Volatility } \\
\hline & coeff & z-stat & coeff & z-stat \\
\hline \multicolumn{5}{|l|}{ Model 1} \\
\hline BDMTGS & $\begin{array}{c}-0.00 \\
(0.002)\end{array}$ & -0.55 & $\begin{array}{c}0.02 * * * \\
(0.005)\end{array}$ & 3.51 \\
\hline$B D S I Z E$ & $\begin{array}{c}0.03 * * * \\
(0.007)\end{array}$ & 3.84 & $\begin{array}{c}0.06 * * * \\
(0.015)\end{array}$ & 3.87 \\
\hline BDINDEP & $\begin{array}{c}-0.02 * * * \\
(0.007)\end{array}$ & -2.98 & $\begin{array}{c}-0.01 \\
(0.016)\end{array}$ & -0.57 \\
\hline BDDIVERS & $\begin{array}{c}0.03 * * * \\
(0.010)\end{array}$ & 3.32 & $\begin{array}{c}-0.03 \\
(0.022)\end{array}$ & -1.39 \\
\hline SHINSIDER & $\begin{array}{c}-0.06 \\
(0.053)\end{array}$ & -1.20 & $\begin{array}{c}-0.59 * * * \\
(0.120)\end{array}$ & -4.96 \\
\hline SHINST & $\begin{array}{c}-0.19 * * * \\
(0.054)\end{array}$ & -3.42 & $\begin{array}{c}-0.19 \\
(0.123)\end{array}$ & -1.52 \\
\hline SHBLOCK & $\begin{array}{l}-0.03 * \\
(0.019)\end{array}$ & -1.77 & $\begin{array}{c}0.02 \\
(0.044)\end{array}$ & 0.46 \\
\hline CEOAGE & $\begin{array}{c}-0.00 * * * \\
(0.001)\end{array}$ & -3.62 & $\begin{array}{c}-0.00 \\
(0.003)\end{array}$ & -1.55 \\
\hline CEOTENURE & $\begin{array}{l}0.00 * * \\
(0.001)\end{array}$ & 2.16 & $\begin{array}{c}0.01 * \\
(0.003)\end{array}$ & 1.95 \\
\hline СЕОСОМР & $\begin{array}{c}0.01 \\
(0.010)\end{array}$ & 1.12 & $\begin{array}{c}0.11 * * * \\
(0.024)\end{array}$ & 4.45 \\
\hline CEOBONUS & $\begin{array}{c}0.00 * * * \\
(0.001)\end{array}$ & 3.03 & $\begin{array}{c}0.02 * * * \\
(0.003)\end{array}$ & 5.39 \\
\hline CEOSALARY & $\begin{array}{c}0.04 \\
(0.026)\end{array}$ & 1.43 & $\begin{array}{l}0.12 * * \\
(0.059)\end{array}$ & 2.03 \\
\hline ACSIZE & $\begin{array}{c}-0.01 * * * \\
(0.005)\end{array}$ & -3.03 & $\begin{array}{c}-0.04 * * * \\
(0.010)\end{array}$ & -3.43 \\
\hline LEVERAGE & $\begin{array}{c}-0.85 * * * \\
(0.044)\end{array}$ & -19.29 & $\begin{array}{c}-0.30 * * * \\
(0.102)\end{array}$ & -2.93 \\
\hline$R \& D$ & $\begin{array}{c}0.09 * * * \\
(0.018)\end{array}$ & 4.84 & & \\
\hline$R O A$ & $\begin{array}{c}0.05 * * * \\
(0.004)\end{array}$ & 11.79 & $\begin{array}{c}-0.04 * * * \\
(0.011)\end{array}$ & -3.40 \\
\hline$S I Z E$ & $\begin{array}{c}-0.07 * * * \\
(0.008)\end{array}$ & -8.99 & $\begin{array}{c}-0.34 * * * \\
(0.018)\end{array}$ & -18.86 \\
\hline
\end{tabular}




\begin{tabular}{lcccc}
\hline \multirow{2}{*}{ VARIABLES } & \multicolumn{2}{c}{ Value } & \multicolumn{2}{c}{ Cash Flow Volatility } \\
\cline { 2 - 5 } CAPEX & coeff & z-stat & coeff & Z-stat \\
& $(0.132)$ & 3.54 & & \\
ROA $(t-1)$ & & & & \\
& & & $(0.010)$ & \\
LIQUIDITY & & $0.11^{* * * *}$ & 4.32 \\
& & & $(0.026)$ & \\
Fixed Effects & yes & & yes & \\
Constant & 0.36 & 1.24 & $-3.68^{* * *}$ & -5.68 \\
& $(0.287)$ & & $(0.648)$ & \\
Observations & & 2,904 & & \\
Correlation of Residuals & & 0.1230 & & \\
Breusch-Pagan $\chi^{2}$ & & 43.931 & & \\
p-value & & 0.000 & & \\
Wald $\chi^{2}$ & & 592.75 & & \\
p-value & & 0.000 & & \\
Systems $R_{2}$ & & 53.55 & & \\
\hline
\end{tabular}

\begin{tabular}{|c|c|c|c|c|}
\hline \multicolumn{5}{|l|}{ Model 2} \\
\hline$B D M T G S$ & $\begin{array}{c}-0.01 * * * \\
(0.003)\end{array}$ & -4.56 & $\begin{array}{c}0.03 * * * \\
(0.005)\end{array}$ & 5.13 \\
\hline \multirow[t]{2}{*}{$B D S I Z E$} & $0.04 * * *$ & 4.99 & $0.10 * * *$ & 6.44 \\
\hline & $(0.008)$ & & $(0.016)$ & \\
\hline \multirow[t]{2}{*}{ BDINDEP } & $-0.01 *$ & -1.75 & $-0.03^{*}$ & -1.91 \\
\hline & $(0.008)$ & & $(0.017)$ & \\
\hline \multirow[t]{2}{*}{ BDDIVERS } & 0.00 & 0.36 & 0.01 & 0.39 \\
\hline & $(0.011)$ & & $(0.023)$ & \\
\hline \multirow[t]{2}{*}{ SHINSIDER } & $-0.13 * *$ & -2.18 & $-0.73 * * *$ & -6.29 \\
\hline & $(0.058)$ & & $(0.115)$ & \\
\hline \multirow[t]{2}{*}{ SHINST } & $-0.09 * * *$ & -4.40 & -0.04 & -1.07 \\
\hline & $(0.020)$ & & $(0.041)$ & \\
\hline \multirow[t]{2}{*}{ SHBLOCK } & $-0.10^{*}$ & -1.68 & $-0.70 * * *$ & -5.74 \\
\hline & $(0.060)$ & & $(0.122)$ & \\
\hline \multirow[t]{2}{*}{ CEOAGE } & $-0.01 * * *$ & -4.93 & $-0.01 * *$ & -2.22 \\
\hline & $(0.001)$ & & $(0.003)$ & \\
\hline \multirow[t]{2}{*}{ CEOTENURE } & $0.00 *$ & 1.79 & -0.00 & -0.51 \\
\hline & $(0.001)$ & & $(0.003)$ & \\
\hline \multirow[t]{2}{*}{ СЕОСОМР } & $0.07 * * *$ & 5.64 & $0.17 * * *$ & 6.70 \\
\hline & $(0.012)$ & & $(0.025)$ & \\
\hline \multirow[t]{2}{*}{ CEOBONUS } & 0.00 & 1.18 & $0.02 * * *$ & 5.61 \\
\hline & $(0.002)$ & & $(0.003)$ & \\
\hline CEOSALARY & 0.01 & 0.49 & $0.20 * * *$ & 3.65 \\
\hline
\end{tabular}




\begin{tabular}{|c|c|c|c|c|}
\hline \multirow[b]{2}{*}{ VARIABLES } & \multicolumn{2}{|c|}{ Value } & \multicolumn{2}{|c|}{ Cash Flow Volatility } \\
\hline & coeff & Z-stat & coeff & z-stat \\
\hline & $(0.027)$ & & $(0.054)$ & \\
\hline$A C S I Z E$ & $\begin{array}{c}-0.02 * * * \\
(0.006)\end{array}$ & -4.40 & $\begin{array}{c}-0.01 \\
(0.011)\end{array}$ & -1.28 \\
\hline LEVERAGE & $\begin{array}{c}-0.98 * * * \\
(0.052)\end{array}$ & -18.90 & $\begin{array}{c}0.06 \\
(0.107)\end{array}$ & 0.58 \\
\hline$R \& D$ & $\begin{array}{c}0.16 * * * \\
(0.020)\end{array}$ & 7.97 & & \\
\hline$R O A$ & $\begin{array}{c}0.06 * * * \\
(0.004)\end{array}$ & 14.19 & $\begin{array}{c}-0.07 * * * \\
(0.010)\end{array}$ & -6.74 \\
\hline SIZE & $\begin{array}{c}-0.12 * * * \\
(0.008)\end{array}$ & -15.27 & $\begin{array}{c}-0.45 * * * \\
(0.016)\end{array}$ & -28.05 \\
\hline$C A P E X$ & $\begin{array}{l}0.30 * * \\
(0.140)\end{array}$ & 2.11 & & \\
\hline$R O A_{(t-1)}$ & & & $\begin{array}{c}-0.12 * * * \\
(0.010)\end{array}$ & -12.46 \\
\hline LIQUIDITY & & & $\begin{array}{c}0.16^{* * *} * \\
(0.024)\end{array}$ & 6.62 \\
\hline Fixed Effects & yes & & yes & \\
\hline Constant & $\begin{array}{c}0.41 \\
(0.292)\end{array}$ & 1.39 & $\begin{array}{c}-4.92 * * * \\
(0.590)\end{array}$ & -8.33 \\
\hline Observations & & 3,330 & & \\
\hline Correlation of Residuals & & 0.1649 & & \\
\hline Breusch-Pagan $\chi^{2}$ & & 90.578 & & \\
\hline p-value & & 0.000 & & \\
\hline Wald $\chi^{2}$ & & 974.19 & & \\
\hline$p$-value & & 0.000 & & \\
\hline Systems $R_{2}$ & & 65.98 & & \\
\hline $\begin{array}{l}\text { The p-value for the one-ta } \\
\text { indicated as } * * *, * *, * \text { to } \\
\text { respectively, and the ISt } \\
\text { indicates those firms that } \\
\text { derivatives. The regressio } \\
\text { for definitions of depende }\end{array}$ & $\begin{array}{l}\text { est of the r } \\
\text { tatistical } \\
\text { andard err } \\
\text { rivatives a } \\
\text { lels are pro } \\
\text { independ }\end{array}$ & $\begin{array}{l}\text { pothesi } \\
\text { cance at } \\
\text { e provi } \\
\text { del } 2 \text { si } \\
\text { in Tabl } \\
\text { iables. }\end{array}$ & $\begin{array}{l}\text { the coeffic } \\
.01,0.05 \text { a } \\
\text { n parenthe } \\
\text { the firms } t \\
\text { See Tabl }\end{array}$ & $\begin{array}{l}\text { is zero } \\
.10 \text { leve } \\
\text { Model } \\
\text { do not us } \\
.3 \text { and } 5 .\end{array}$ \\
\hline
\end{tabular}




\section{ISUR Analysis on the Corporate Governance and Firm Value and Stock Return}

Volatility.

Table 6.26 presents results of the seemingly unrelated regression iteration model (ISUR). The dependent variables for this model are value and stock return volatility and the independent variables and control variables are the same as explained in Section 6.9 above. Model 1 presents the ISUR results of the first group of derivative users and the model 2 captures the ISUR results for derivative non users. The correlation of residuals for value and stock return volatility is -0.1593 , with the Breusch-Pagan $\chi^{2}$ of 73.72 and is significant at $1 \%$ level. The Wald $\chi^{2}$ is 2329.18 and significant at $1 \%$ level, indicating that both requirements of the ISUR methodology are met. The system $\mathrm{R}^{2}$ is 69.3. For the VALUE model the results for BDSIZE, BDINDEP, BDDIVERS, SHINST, SHBLOCK, CEOAGE, CEOTENURE, CEOCOMP, CEOBONUS, ACSIZE are significant and exhibit the same directional relationship with VALUE as exhibited in Table 6.7. Similarly, BDMTGS, SHINSIDER and CEOCOMP are insignificant. However, SHINST is now weakly significant at $10 \%$ level.

In respect of the stock return volatility equation, the results for BDMTGS, BDSIZE, BDINDEP, BDDIVERS, SHINST, SHBLOCK, CEOAGE, CEOTENURE, CEOBONUS and ACSIZE are significant. BDSIZE, BDDIVERS, and CEOBONUS have a negative correlation with risk that is significant at $1 \%$ and CEOTENURE is negative and significant at $5 \%$ level, while the other corporate governance variables are positively correlated with stock return volatility. Overall, the results for corporate governance variables and control variables are significant and in the same direction as the main stock return risk results. 
A comparison between Model 1 and Model 2 for stock return volatility results shows that: BDSIZE and CEOBONUS have a negative significant correlation; BDMTGS, SHINSIDER, SHBLOCK and ACSIZE have a positive significant correlation; and BDINDEP, CEOCOMP and CEOSALARY have no significant correlation with risk for both derivative users and nonusers. Other corporate governance variables for BDDIVERS, CEOAGE, CEOTENURE, and SHINST are only significant in the first group of firms. A comparison of the magnitude of the coefficients in both the Models 1 and 2, indicates that the reduction in stock return volatility for BDSIZE is greater and for CEOBONUS is lower for derivative non user firms. The increase in risk is also higher for derivative non users for BDMTGS, SHINSIDER, SHBLOCK and ACSIZE. Of the corporate governance variables that only impact derivative users, BDDIVERS and CEOAGE reduce risk and CEOTENURE and SHINST increase risk. 
Table 6. 18: Alternative Tests (ISUR) Value and Stock Return Volatility

\begin{tabular}{|c|c|c|c|c|}
\hline \multirow[b]{2}{*}{ Variables } & \multicolumn{2}{|c|}{ Value } & \multicolumn{2}{|c|}{ Stock Return Volatility } \\
\hline & coeff & z-stat & coeff & z-stat \\
\hline \multicolumn{5}{|l|}{ Model 1} \\
\hline$B D M T G S$ & $\begin{array}{c}-0.00 \\
(0.002)\end{array}$ & -0.55 & $\begin{array}{c}0.01 * * * \\
(0.002)\end{array}$ & 3.01 \\
\hline BDSIZE & $\begin{array}{c}0.03^{* * *} \\
(0.007)\end{array}$ & 3.83 & $\begin{array}{c}-0.02^{* * * *} \\
(0.005)\end{array}$ & -4.28 \\
\hline BDINDEP & $\begin{array}{c}-0.02 * * * \\
(0.007)\end{array}$ & -2.92 & $\begin{array}{c}0.00 \\
(0.005)\end{array}$ & 0.03 \\
\hline BDDIVERS & $\begin{array}{c}0.03^{* * *} \\
(0.010)\end{array}$ & 3.44 & $\begin{array}{c}-0.04 * * * \\
(0.008)\end{array}$ & -4.77 \\
\hline SHINSIDER & $\begin{array}{c}-0.05 \\
(0.053)\end{array}$ & -1.03 & $\begin{array}{c}0.15^{* * *} \\
(0.042)\end{array}$ & 3.67 \\
\hline SHINST & $\begin{array}{l}-0.03^{*} \\
(0.019)\end{array}$ & -1.77 & $\begin{array}{c}0.04 * * * \\
(0.015)\end{array}$ & 2.65 \\
\hline SHBLOCK & $\begin{array}{c}-0.17 * * * \\
(0.054)\end{array}$ & 3.22 & $\begin{array}{c}0.11 * * * \\
(0.043)\end{array}$ & 2.63 \\
\hline CEOAGE & $\begin{array}{c}-0.00 * * * \\
(0.001)\end{array}$ & -3.73 & $\begin{array}{c}0.00^{* * * *} \\
(0.001)\end{array}$ & 3.38 \\
\hline CEOTENURE & $\begin{array}{l}0.00 * * \\
(0.001)\end{array}$ & 2.11 & $\begin{array}{l}-0.00 * * \\
(0.001)\end{array}$ & -2.31 \\
\hline СЕОСОМР & $\begin{array}{c}0.01 \\
(0.010)\end{array}$ & 0.94 & $\begin{array}{c}-0.00 \\
(0.008)\end{array}$ & -0.13 \\
\hline CEOBONUS & $\begin{array}{c}0.00^{* * *} \\
(0.001)\end{array}$ & 2.82 & $\begin{array}{c}-0.01 * * * \\
(0.001)\end{array}$ & -9.98 \\
\hline CEOSALARY & $\begin{array}{c}0.04^{*} \\
(0.026)\end{array}$ & 1.69 & $\begin{array}{c}-0.01 \\
(0.021)\end{array}$ & -0.38 \\
\hline ACSIZE & $\begin{array}{c}-0.01 * * * \\
(0.005)\end{array}$ & -3.08 & $\begin{array}{c}0.01 * * * \\
(0.004)\end{array}$ & 2.85 \\
\hline LEVERAGE & $\begin{array}{c}-0.86^{* * * *} \\
(0.044)\end{array}$ & -19.45 & $\begin{array}{c}0.45^{* * *} \\
(0.035)\end{array}$ & 12.79 \\
\hline$R \& D$ & $\begin{array}{c}0.09^{* * *} \\
(0.018)\end{array}$ & 5.08 & & \\
\hline$R O A$ & $\begin{array}{c}0.05^{* * *} \\
(0.004)\end{array}$ & 11.76 & $\begin{array}{c}-0.05^{* * * *} \\
(0.004)\end{array}$ & -12.43 \\
\hline SIZE & $\begin{array}{c}-0.07 * * * \\
(0.008)\end{array}$ & -8.97 & $\begin{array}{c}-0.07 * * * \\
(0.006)\end{array}$ & -10.50 \\
\hline CAPEX & $\begin{array}{c}0.74 * * * \\
(0.132)\end{array}$ & 5.65 & & \\
\hline & & 270 & & \\
\hline
\end{tabular}




\begin{tabular}{lcccc}
\hline \multirow{2}{*}{ Variables } & coeff & Z-stat & \multicolumn{2}{c}{ Stock Return Volatility } \\
\cline { 2 - 5 } & & & $-0.03^{* * *}$ & Z-stat \\
\hline ROA $(t-1)$ & & $(0.004)$ & -7.30 \\
LIQUIDITY & & $0.02^{* *}$ & 2.33 \\
& & & $(0.009)$ & \\
Fixed effects & yes & & yes & 19.00 \\
Constant & 0.28 & 0.97 & $4.30^{* * *}$ & \\
& $(0.287)$ & & $(0.226)$ & \\
Observations & & 2,904 & & \\
Correlation of Residuals & & -0.1593 & & \\
Breusch-Pagan $\chi^{2}$ & & 73.72 & & \\
p-value & & 0.000 & & \\
Wald $\chi^{2}$ & & 2329.18 & & \\
p-value & 0.000 & & \\
Systems $R_{2}$ & 69.29 & & \\
\hline
\end{tabular}

\begin{tabular}{|c|c|c|c|c|}
\hline \multicolumn{5}{|l|}{ Model 2} \\
\hline$B D M T G S$ & $\begin{array}{c}-0.01 * * * \\
(0.003)\end{array}$ & -4.63 & $\begin{array}{c}0.01 * * * \\
(0.002)\end{array}$ & 3.88 \\
\hline$B D S I Z E$ & $\begin{array}{c}0.04 * * * \\
(0.008)\end{array}$ & 4.96 & $\begin{array}{c}-0.02 * * * \\
(0.005)\end{array}$ & -4.94 \\
\hline BDINDEP & $\begin{array}{l}-0.02 * \\
(0.008)\end{array}$ & -1.81 & $\begin{array}{c}-0.00 \\
(0.005)\end{array}$ & -0.44 \\
\hline BDDIVERS & $\begin{array}{c}0.01 \\
(0.011)\end{array}$ & 0.48 & $\begin{array}{c}-0.01 \\
(0.007)\end{array}$ & -1.60 \\
\hline SHINSIDER & $\begin{array}{c}-0.11 * * \\
(0.058)\end{array}$ & -1.96 & $\begin{array}{c}0.26 * * * \\
(0.036)\end{array}$ & 7.28 \\
\hline SHINST & $\begin{array}{c}-0.09 * * * \\
(0.020)\end{array}$ & -4.48 & $\begin{array}{c}0.00 \\
(0.013)\end{array}$ & 0.28 \\
\hline SHBLOCK & $\begin{array}{c}-0.09 \\
(0.060)\end{array}$ & -1.57 & $\begin{array}{c}0.25 * * * \\
(0.038)\end{array}$ & 6.47 \\
\hline CEOAGE & $\begin{array}{c}-0.01 * * * \\
(0.001)\end{array}$ & -4.83 & $\begin{array}{c}-0.00 \\
(0.001)\end{array}$ & -1 . \\
\hline CEOTENURE & $\begin{array}{c}0.00 * \\
(0.001)\end{array}$ & 1.73 & $\begin{array}{c}0.00 \\
(0.001)\end{array}$ & 1.17 \\
\hline CEOCOMP & $\begin{array}{c}0.07 * * * \\
(0.012)\end{array}$ & 5.54 & $\begin{array}{c}0.01 \\
(0.008)\end{array}$ & 0.94 \\
\hline CEOBONUS & $\begin{array}{c}0.00 \\
(0.002)\end{array}$ & 1.14 & $\begin{array}{c}-0.01 * * * \\
(0.001)\end{array}$ & -8.45 \\
\hline CEOSALARY & $\begin{array}{c}0.01 \\
(0.027)\end{array}$ & 0.55 & $\begin{array}{c}-0.01 \\
(0.017)\end{array}$ & -0.81 \\
\hline
\end{tabular}




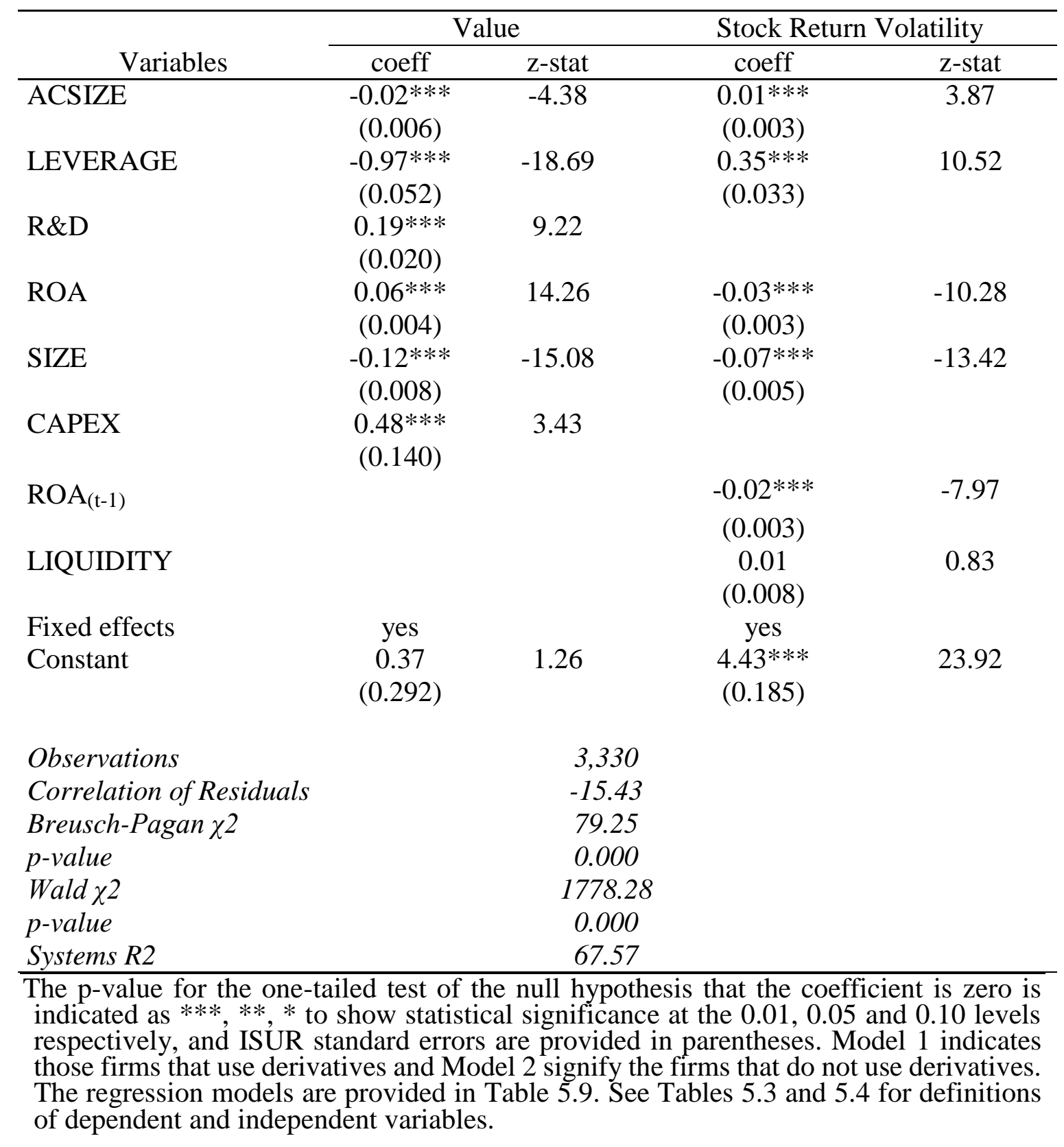




\section{ISUR Analysis on the relationship of Corporate Governance and Derivatives on Firm Value and Market Risk}

Table 6.27 presents results of the seemingly unrelated regression iteration model (ISUR). The dependent variables for this model are value and market risk and the independent variables and control variables are the same as explained in Section 6.9.

Model 1 presents the ISUR results of the first group of derivative users and the model 2 captures the ISUR results for derivative non users. The correlation of residuals for value and market risk is $-0.093 \%$, with the Breusch-Pagan $\chi^{2}$ of 25.07 and is significant at $1 \%$ level. The Wald $\chi^{2}$ is 1008.80 and significant at $1 \%$ level, indicating that both requirements of the seemingly unrelated regression methodology are met. The system $\mathrm{R}^{2}$ is $46.09 \%$. For the VALUE model the results for BDSIZE, BDINDEP, BDDIVERS, SHBLOCK, CEOAGE, CEOTENURE, CEOBONUS and ACSIZE are significant and exhibit the same directional relationship with VALUE as exhibited in Table 6.7. SHINST is now weakly significant at $10 \%$ level, while BDMTGS, SHINSIDER, CEOCOMP and CEOSALARY are insignificant as exhibited in the main regressions.

In respect of the market risk, the results for BDDIVERS, SHINST, CEOAGE, and CEOBONUS are significant in both the models. BDDIVERS has a negative correlation and SHINST, CEOAGE, and CEOBONUS have a positive correlation with risk, at a significance level of $1 \%$. Overall, the results for corporate governance variables and control variables are significant and in the same direction as the main market risk results. 
A comparison between Model 1 and Model 2 for market risk shows that: BDDIVERS has a negative correlation and SHINST and CEOBONUS have a positive significant correlation with market risk in both the models. Some corporate governance variables are only significant for derivative non users for example, BDMTGS and BDSIZE have a negative association and CEOSALARY and SHBLOCK have a positive association with market risk. While CEOAGE only has a positive impact on risk in derivative users. Generally, the results for market risk show better risk management by corporate governance in firms that do not use derivatives. However, BDDIVERS has a larger risk reduction effect for derivative users as an increase of one female director on the board reduces market risk by $3.25 \%$, and reduces risk by $2.95 \%$ in non users. 
Table 6. 19: Alternative Tests (ISUR): Value and Market Risk, in Derivative User and Non User Firms

\begin{tabular}{|c|c|c|c|c|}
\hline \multirow[b]{2}{*}{ Variables } & \multicolumn{2}{|c|}{ Value } & \multicolumn{2}{|c|}{ Market Risk } \\
\hline & coeff & z-stat & coeff & z-stat \\
\hline \multicolumn{5}{|l|}{ Model 1} \\
\hline$B D M T G S$ & $\begin{array}{c}-0.00 \\
(0.002)\end{array}$ & -0.56 & $\begin{array}{c}0.00 \\
(0.002)\end{array}$ & 0.16 \\
\hline$B D S I Z E$ & $\begin{array}{c}0.03 * * * \\
(0.007)\end{array}$ & 3.84 & $\begin{array}{c}-0.01 \\
(0.005)\end{array}$ & -1.50 \\
\hline BDINDEP & $\begin{array}{c}-0.02 * * * \\
(0.007)\end{array}$ & -2.95 & $\begin{array}{c}-0.00 \\
(0.005)\end{array}$ & 0.41 \\
\hline BDDIVERS & $\begin{array}{c}0.03 * * * \\
(0.010)\end{array}$ & 3.42 & $\begin{array}{c}-0.03 * * * \\
(0.008)\end{array}$ & -4.24 \\
\hline SHINSIDER & $\begin{array}{c}-0.06 \\
(0.053)\end{array}$ & -1.05 & $\begin{array}{c}-0.07 \\
(0.041)\end{array}$ & -1.64 \\
\hline SHINST & $\begin{array}{l}-0.03^{*} \\
(0.019)\end{array}$ & -1.78 & $\begin{array}{c}0.05 * * * \\
(0.015)\end{array}$ & 3.00 \\
\hline SHBLOCK & $\begin{array}{c}-0.18 * * * \\
(0.054)\end{array}$ & -3.26 & $\begin{array}{c}0.03 \\
(0.042)\end{array}$ & 0.81 \\
\hline CEOAGE & $\begin{array}{c}-0.00 * * * * \\
(0.001)\end{array}$ & -3.71 & $\begin{array}{c}0.00 * * * \\
(0.001)\end{array}$ & 3.64 \\
\hline CEOTENURE & $\begin{array}{l}0.00 * * \\
(0.001)\end{array}$ & 2.13 & $\begin{array}{c}-0.00 \\
(0.001)\end{array}$ & -1.05 \\
\hline СЕОСОМР & $\begin{array}{c}0.01 \\
(0.010)\end{array}$ & 0.98 & $\begin{array}{c}-0.00 \\
(0.008)\end{array}$ & -0.49 \\
\hline CEOBONUS & $\begin{array}{c}0.00 * * * \\
(0.001)\end{array}$ & 2.87 & $\begin{array}{c}0.00 * * * \\
(0.001)\end{array}$ & 3.34 \\
\hline CEOSALARY & $\begin{array}{c}0.04 \\
(0.026)\end{array}$ & 1.63 & $\begin{array}{c}-0.01 \\
(0.020)\end{array}$ & -0.35 \\
\hline ACSIZE & $\begin{array}{c}-0.01 * * * \\
(0.005)\end{array}$ & -3.06 & $\begin{array}{c}-0.00 \\
(0.004)\end{array}$ & -0.65 \\
\hline LEVERAGE & $\begin{array}{c}-0.85 * * * \\
(0.044)\end{array}$ & -19.35 & $\begin{array}{c}0.28 * * * \\
(0.035)\end{array}$ & 7.95 \\
\hline$R \& D$ & $\begin{array}{c}0.09 * * * \\
(0.018)\end{array}$ & 5.19 & & \\
\hline$R O A$ & $\begin{array}{c}0.05^{* * * *} \\
(0.004)\end{array}$ & 11.78 & $\begin{array}{l}-0.01 * * \\
(0.004)\end{array}$ & -2.51 \\
\hline$S I Z E$ & $\begin{array}{c}-0.07 * * * * \\
(0.008)\end{array}$ & -8.95 & $\begin{array}{c}-0.00 \\
(0.006)\end{array}$ & -0.53 \\
\hline
\end{tabular}




\begin{tabular}{|c|c|c|c|c|}
\hline \multirow[b]{2}{*}{ Variables } & \multicolumn{2}{|c|}{ Value } & \multicolumn{2}{|c|}{ Market Risk } \\
\hline & coeff & Z-stat & coeff & Z-stat \\
\hline CAPEX & $\begin{array}{c}0.69 * * * \\
(0.133)\end{array}$ & 5.20 & & \\
\hline$R O A_{(t-1)}$ & & & $\begin{array}{c}-0.03 * * * \\
(0.004)\end{array}$ & -8.09 \\
\hline LIQUIDITY & & & $\begin{array}{c}0.04 * * * \\
(0.009)\end{array}$ & 4.13 \\
\hline Fixed effects & yes & & yes & \\
\hline Constant & $\begin{array}{c}0.30 \\
(0.287)\end{array}$ & 1.03 & $\begin{array}{c}0.21 \\
(0.224)\end{array}$ & 0.92 \\
\hline $\begin{array}{l}\text { Observations } \\
\text { Correlation of Residuals } \\
\text { Breusch-Pagan } \chi^{2} \\
\text { p-value } \\
\text { Wald } \chi^{2} \\
\text { p-value } \\
\text { Systems } R_{2}\end{array}$ & & $\begin{array}{c}2,904 \\
-0.0929 \\
25.072 \\
0.000 \\
1008.80 \\
0.000 \\
46.09 \\
\end{array}$ & & \\
\hline \multicolumn{5}{|l|}{ Model 2} \\
\hline$B D M T G S$ & $\begin{array}{c}-0.01 * * * \\
(0.003)\end{array}$ & -4.64 & $\begin{array}{c}-0.004 * * \\
(0.002)\end{array}$ & -2.28 \\
\hline$B D S I Z E$ & $\begin{array}{c}0.04 * * * \\
(0.008)\end{array}$ & 4.97 & $\begin{array}{l}-0.01 * * \\
(0.005)\end{array}$ & -2.59 \\
\hline BDINDEP & $\begin{array}{l}-0.02 * \\
(0.008)\end{array}$ & -1.82 & $\begin{array}{c}-0.00 \\
(0.005)\end{array}$ & 0.49 \\
\hline BDDIVERS & $\begin{array}{c}0.01 \\
(0.011)\end{array}$ & 0.48 & $\begin{array}{c}-0.03 * * * \\
(0.007)\end{array}$ & -4.12 \\
\hline SHINSIDER & $\begin{array}{l}-0.11^{*} \\
(0.058)\end{array}$ & -1.96 & $\begin{array}{c}0.05 \\
(0.036)\end{array}$ & 1.49 \\
\hline SHINST & $\begin{array}{c}-0.09 * * * \\
(0.020)\end{array}$ & -4.49 & $\begin{array}{c}0.05 * * * \\
(0.013)\end{array}$ & 4.15 \\
\hline SHBLOCK & $\begin{array}{c}-0.09 \\
(0.060)\end{array}$ & -1.56 & $\begin{array}{c}0.12 * * * \\
(0.038)\end{array}$ & 3.10 \\
\hline CEOAGE & $\begin{array}{c}-0.01 * * * \\
(0.001)\end{array}$ & -4.83 & $\begin{array}{c}0.00 \\
(0.001)\end{array}$ & 1.61 \\
\hline CEOTENURE & $\begin{array}{c}0.00 * \\
(0.001)\end{array}$ & 1.73 & $\begin{array}{c}-0.00 \\
(0.001)\end{array}$ & -0.96 \\
\hline СЕОСОМР & $\begin{array}{c}0.07 * * * \\
(0.012)\end{array}$ & 5.53 & $\begin{array}{c}0.00 \\
(0.008)\end{array}$ & 0.45 \\
\hline CEOBONUS & $\begin{array}{c}0.00 \\
(0.002)\end{array}$ & 1.14 & $\begin{array}{l}0.00 * * \\
(0.001)\end{array}$ & 2.13 \\
\hline CEOSALARY & 0.01 & 0.54 & $-0.03 *$ & -1.65 \\
\hline & & 276 & & \\
\hline
\end{tabular}




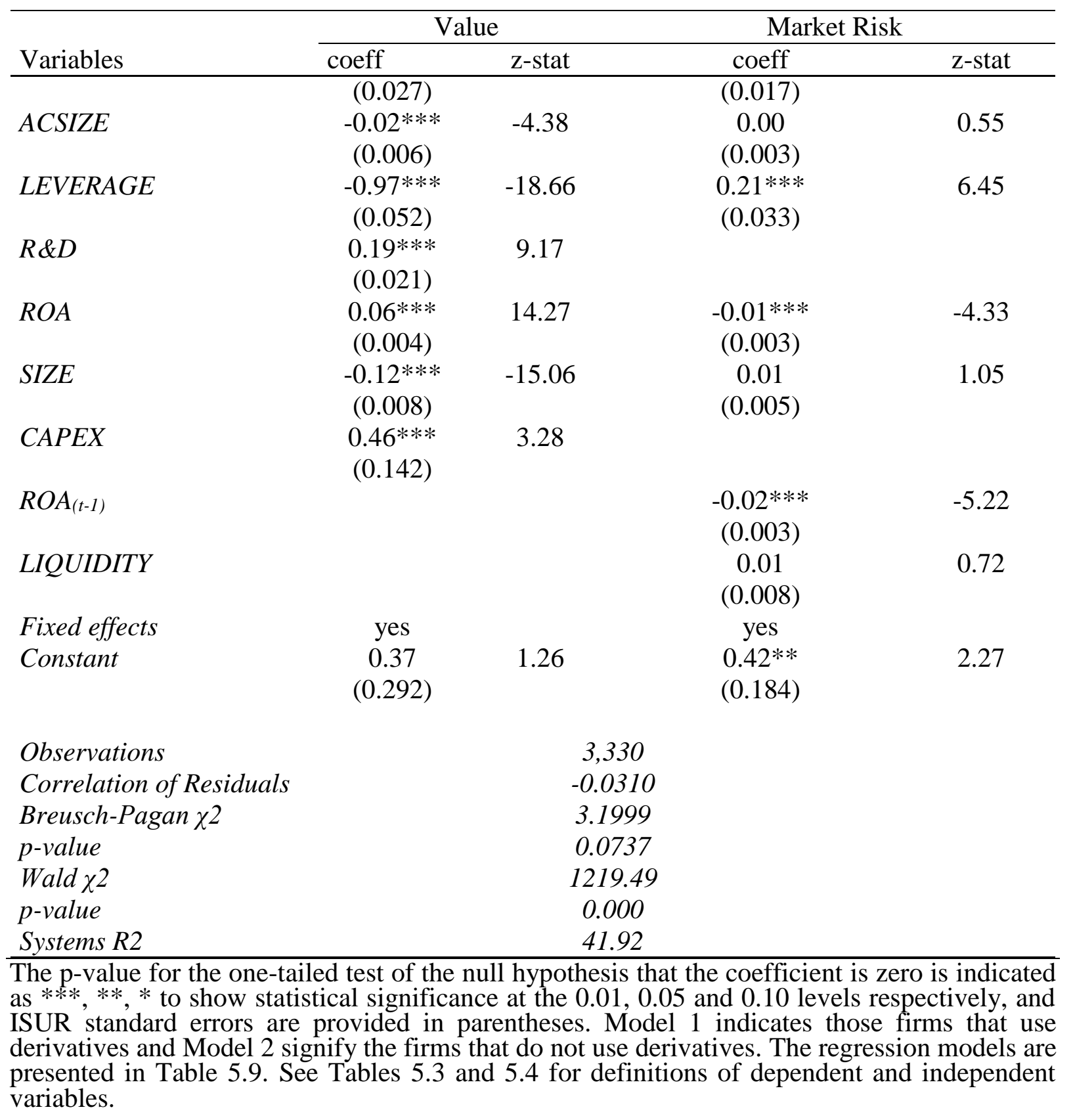




\section{Comparison of the Value Differences between Derivative Users and Non Users in the ISUR Models}

This section discusses a comparison of the ISUR Value results between Model 1 and Model 2 as presented in Tables 6.25, 6.26 and 6.27. In respect of Value in all the models, BDSIZE, BDINDEP, CEOAGE, CEOTENURE, SHINST, and ACSIZE are significant and CEOSALARY is not significant in both the groups. The direction of the coefficients indicates that BDSIZE and CEOTENURE increase value, while BDINDEP, CEOAGE, SHINST, and ACSIZE have a negative correlation with value.

There are some corporate governance variables that only have an impact on derivative users, for example BDDIVERS and CEOBONUS increase value and SHBLOCK decreases value in firms that use derivatives, while CEOCOMP, SHINSIDER and BDMTGS are insignificant. And, CEOSALARY has a weak positive relationship with Value in the Value-Stock Return Volatility model (Table 6.26) at a 10\% level of significance.

In respect of non users, BDMTGS, SHINSIDER reduce value and CEOCOMP increases value only for this group while BDDIVERS, SHBLOCK and CEOBONUS are insignificant. However, SHBLOCK indicates a weak negative correlation with value in the Value-Cash Flow Volatility model at 10\% level of significance.

The overall results for corporate governance variables and firm value are robust. Though there may be some variations in the magnitude of the coefficients and the levels of significance, the direction and significance of all the independent and control variables are the same across all the models for firm value, cash flow volatility, stock 
return volatility and market risk, that additionally provides support for the robustness of the results of the main regression models.

\subsection{Chapter Summary}

In this chapter I perform the tests for the regression models 2, 3, 4, and 5 which are presented in Table 5.8. Initially I examine descriptive statistics for the variables employed in the risk and value models. This is followed with a univariate analysis of the differences in firm characteristics for derivative users and non users. In keeping with literature and as expected firms that use derivatives are larger in size, have higher

profitability, higher sales turnover and lower risk. Also the majority of corporate governance variables are larger in number for derivative users indicating a larger governance structure.

I examine the effects of corporate governance and derivatives on firm value and firm risk. Therefore, I split the sample firms into derivative users and non users and examine the effect that corporate governance has on the value effect of these firms. I conduct four separate regressions: Ordinary Least Squares (OLS) base regression, with industry and year adjustments, with White (1980) adjustments and finally with Newey West (1987) adjustments. Overall the results are similar for the regressions, excluding the base regression.

Subsequently, I split the sample data again into derivative users and non users and investigate the effect that corporate governance has on cash flow volatility, stock return volatility and market risk in both types of firms. In the same manner as above I conduct four separate regressions for each type of risk. Here again the results are 
similar, excluding the base regression. And the $\mathrm{R}^{2}$ statistics are also similar for the four regressions models under each individual risk.

An analysis of the results indicates that overall firms better manage risk with derivatives indicating a higher level of risk reduction. Where there is an increase in risk, the magnitude of increase is higher for non -derivative user firms as compared to derivative users. With respect to value, the corporate governance mechanisms show a better performance in firms that use derivatives.

Subsequently, to test the robustness of my results I use alternative specification tests for value and risk and also alternative methodology. I use two other measures of Tobin's Q as alternative measures for value and Z-Score and ROE variance (VROE) as alternative measures for risk. One alternative method employed in the sensitivity analyses is the bootstrapping methodology with 10,000 replications which I apply on the value and risk models. The second alternative test comprises the iterated seemingly unrelated regression (ISUR) models. The ISUR enables a simultaneous examination of corporate governance on of the risk and value impact of derivatives and it has the added advantage as an alternative test of robustness. Overall the sensitivity analyses indicate that the results across all the value models and the cash flow volatility, stock return volatility and market risk models are similar, which supports the robustness of my results. 


\section{CHAPTER SEVEN RESULTS II: DERIVATIVES AND CORPORATE GOVERNANCE}

\subsection{Introduction}

This chapter deals with the second set of analyses and utilizes the second data set of 6900 firm year observations. In this chapter I present the results for the derivatives model that examines whether corporate governance influences the firm's decisions to use derivatives. Section 7.2 provides a summary of the descriptive statistics of the sample variables that are employed in the empirical analyses. It includes sub-sections that investigate differences in industry structure between derivative user and non user firms. Section 7.3 presents the correlation analysis, variance inflation factors and tolerance indices of the variables examined in the study.

This is followed by the results of the empirical analyses. In Section 7.4, I provide findings of the analyses pertaining to the impact of corporate governance mechanisms on derivatives. The main tests employ the probit regression model and a simultaneous equations methodology. In Section 7.5, I provide the sensitivity tests performed relating to the empirical procedures applied in this chapter. The tests use alternative specifications for the dependent variables and for the other explanatory variables to support the robustness of the results. These tests relate to: the levels of leveraging; financial contracting costs and financial constraints; investment growth opportunities and underinvestment hypothesis, among other robustness tests. Finally, in Section 7.6 I present a summary of the chapter. 


\subsection{Descriptive Statistics}

Table 7.1 presents the descriptive statistics for the variables examined in this chapter. It reports the mean values of derivatives, where derivatives are measured as a binary variable indicating 1 if a firm uses derivatives and 0 otherwise. This information is provided across industries and across years for the sample period from 2004 to 2011. In general, the mean value for derivatives does not vary greatly between the years for any one industry. Similarly, the average means for each industry are not very different, except for the manufacturing and service provider industries. 
Table 7. 1: Description of Derivative Users by Industry and Year

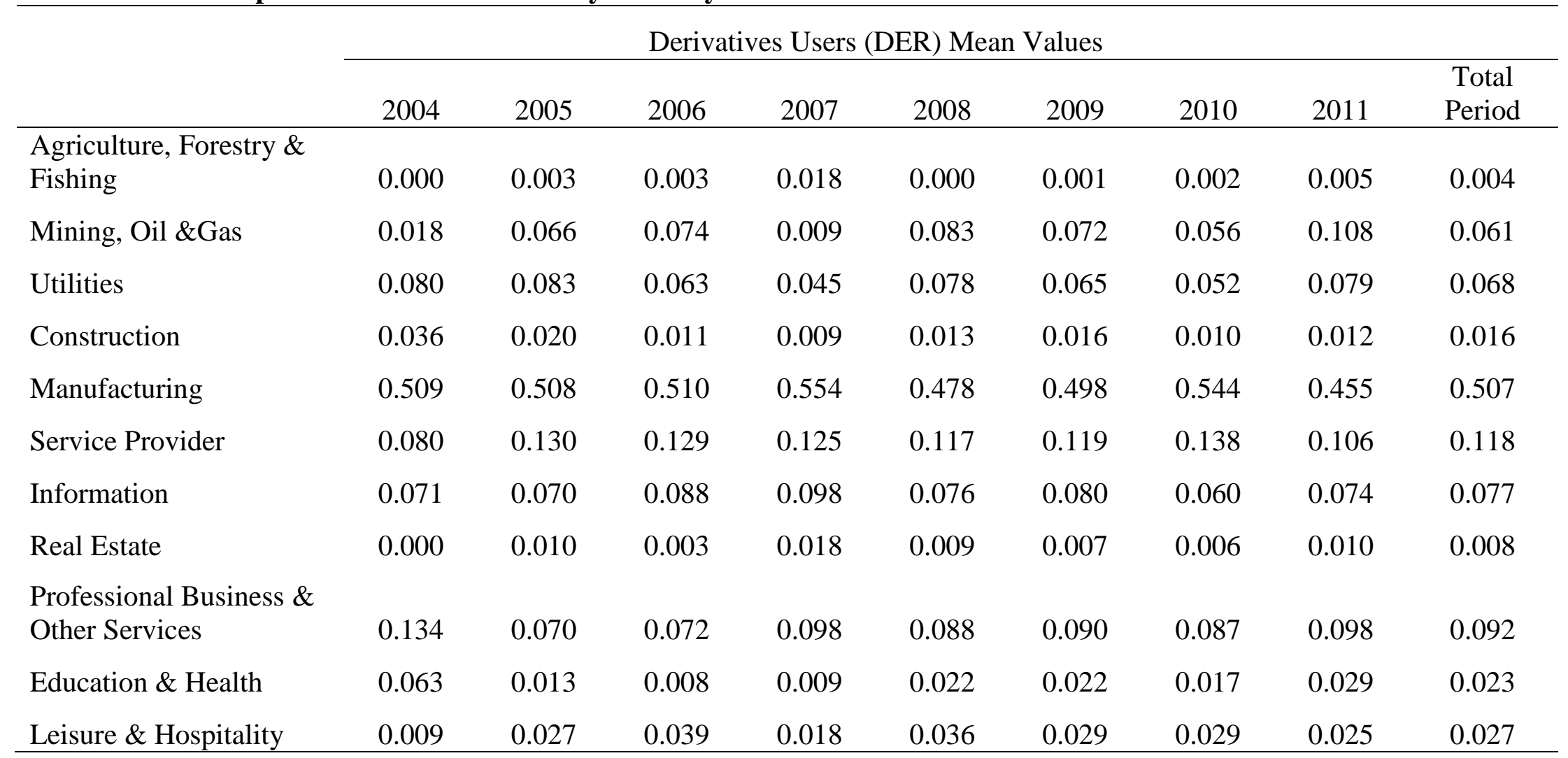


Across industries, the table shows that on average, the manufacturing sector has the highest derivatives while the agriculture, fishing and forestry sector has the lowest derivatives during the sample period. Overall the highest industry mean value of DER for the total period is recorded at 0.507 , with the lowest overall mean at 0.004. In particular, the highest mean has been achieved in 2007 and the lowest in 2004 and 2008.

With regard to derivative user and derivative non-user firms, the industry-wise breakdown based on the North American Industry Classification System (NAICS) is provided in Table 7.2. The table shows that generally both groups of firms have similar distributions within an industry. The proportion of derivative users are lower than derivative non-user firms in all sectors, other than for mining, oil and gas, and utilities sectors where they are marginally higher. While derivative non user firms are proportionally much higher in the services sectors. In the total sample, the percentage of derivative user firms is $46.13 \%$, which is slightly higher than the samples employed by Graham and Rogers (2002) at $35.15 \%$ for interest rate derivatives and $43.39 \%$ for foreign currency derivatives, and slightly lower than (Guay and Kothari, 2003) at $56.66 \%$. Both studies utilize USA based sample firms. My sample contains a more balanced proportion of derivative users and non-users which minimizes the possibility of selection bias. 
Table 7. 2: Description of Derivative User and Non-User Firms by Industry

\begin{tabular}{lccc} 
& \multicolumn{3}{c}{ Derivative User and Non-User firms } \\
\cline { 2 - 4 } Industry & $\begin{array}{c}\text { No. of } \\
\text { derivative non- } \\
\text { user firms }\end{array}$ & $\begin{array}{c}\text { No. of } \\
\text { derivative user } \\
\text { firms }\end{array}$ & $\begin{array}{c}\text { Percentage of } \\
\text { derivative user } \\
\text { firms }\end{array}$ \\
\hline $\begin{array}{l}\text { Agriculture, Forestry \& } \\
\text { Fishing } \\
\text { Mining, Oil \&Gas }\end{array}$ & 16 & 8 & 33.33 \\
Utilities & 177 & 228 & 56.30 \\
Construction & 154 & 217 & 58.49 \\
Manufacturing & 76 & 45 & 37.19 \\
Service Provider & 1679 & 1595 & 48.72 \\
Information & 538 & 386 & 41.77 \\
Real Estate & 348 & 240 & 40.82 \\
Professional Business \& & 46 & 24 & 34.29 \\
Other Services & 450 & 280 & 38.36 \\
Education \& Health & 116 & 66 & 36.26 \\
Leisure \& Hospitality & 117 & 94 & 44.55 \\
Total & 3717 & 3183 & 6900 \\
Total (percentage) & $53.87 \%$ & $46.13 \%$ & $100 \%$ \\
\hline
\end{tabular}


In Panel A of Table 7.3, I present summary statistics of the dependent variables: derivatives and leverage in the regression models used in the study. As reported in the table, the mean and median values of derivatives (DER) is 0.461 and 0.00 respectively, and 0.205 and 0.148 for LEVERAGE respectively. This indicates that sample firms on an average carry a debt of $20.5 \%$ as a percentage of firm value.

Panel B of Table 7.3 provides descriptive statistics for the corporate governance variables. For meetings (BDMTGS) held by boards, it appears that the least number of meetings held by any firm is 1 and maximum number is 46 . However, on average firms hold 8 meetings per year. This is in line with the findings of Vafaes (1999) and others (Karamanou and Vafeas, 2005) whose results indicate a mean of 7.45 meetings and median of 7 meetings. However, my sample has a larger deviation of 3.699 compared to 2.66 for Vafeas (1999), which seems justifiable as my sample comprises 6900 observations compared to 307 for Vafaes (1999) and also my sample covers a larger period of 8 years, compared to his study period of 4 years.

Board size (BDSIZE) statistics indicate that on a minimum (maximum) boards have 4 members (17) and a mean and median of 8.8 and 9 members respectively, with a standard deviation of 2.1. My sample dispersion seems similar of Adams and Ferreira (2009) who also record a mean of 9.38 board size with a 2.68 standard deviation. However, this is lower than recorded by others (Karamanou and Vafeas, 2005; Yermack, 1996) who report a mean in the range of 11.60 to 12.25 .

With respect to composition of independent members on the board (BDINDEP), on average boards have 6 independent members on their boards, with some boards having a minimum of 1 independent member and others having a maximum 16 of independent members. This is similar to Adams and Ferreira (2009) board composition that indicates a minimum of $0 \%$ and maximum of $94 \%$ of total board size. My sample 
statistics (examining number of independent members as a percentage of total board size) at both the mean level and at the $75^{\text {th }}$ percentile show that my results are in line with others (Adams and Ferreira, 2009; Karamanou and Vafeas, 2005) who indicate a mean board independence ranging from $63 \%$ to $80 \%$ of total board size.

Board diversity (BDDIVERS) does not appear to be an important criterion for boards in my sample composition with an average of 0.98 female members on most boards and at a minimum some boards do not have any female members. Even at the 75 percentile, boards only have 2 female members, while at a maximum there are 6 members. Adams and Ferreira (2009) study gender diversity and provide support for my results, with a mean of 0.61 number of female directors, a minimum of 0 and maximum of 1 female member.

Further, with regard to CEOAGE, the table shows that the average age of CEOs is 55.26 years, with 50 years reported in the $1^{\text {st }}$ quartile and 60 years in the third quartile. This is in line with Coles et al. (2006) study who report a mean CEO age of 54 years, with 49 years in the $1^{\text {st }}$ quartile and 59 years in the $3^{\text {rd }}$ quartile. The average duration of CEO service (CEOTENURE) for my sample is 8.68 years and the maximum tenure of 54 years: with 3 years' tenure recorded the 1st quartile and 12 years' tenure in the $3^{\text {rd }}$ quartile. This is a little higher than that for Coles et al. (2006) who report a mean CEO tenure of 7 years, with 2 years in the 1 st quartile and 10 years in the $3^{\text {rd }}$ quartile.

All CEO compensation variables have been transformed to the natural logarithm form. CEO Compensation (CEOCOMP) represents the natural logarithm of the base salary, annual bonus and other annual compensation to CEO. The natural logarithm value of mean CEOCOMP is 14.06 and the $25^{\text {th }}$ and $75^{\text {th }}$ percentiles are 13.44 and 14.74 
respectively $^{37}$. The maximum CEOCOMP is $\$ 18.79$, which appears quite high for some of the larger companies in the sample ${ }^{38}$. CEOBONUS represents the cash and cash equivalent of all incentives paid to the CEO and the natural logarithm mean is 5.08. This figure has been influenced by a great number of firms that record a zero bonus. The CEOSALARY represents CEO base salary, which can include non-cash elements and salary taken as deferred compensation and the mean of sample is $13.34 .^{39}$ The maximum base salary is 16.84 and also quite high. ${ }^{40}$

In the literature there appears to be a great variation in the reported CEO compensation descriptive statistics. This is mainly due to the different time periods employed in the various studies, different valuation methods applied, different firm structures (e.g.

${ }^{37}$ In Table 7.3, the mean total compensation (CEOCOMP) is equivalent to $\$ 1.28$ million (Ln retransformed back to raw data). This is similar to Rogers (2002) who reports a mean total compensation of $\$ 1.76$ million. (Also see: Frydman and Jenter, 2010, p. 41), and Cyert et al. (2002) also reports a mean total compensation of $\$ 1.011$ million.

${ }^{38}$ In Table 7.3, the maximum total compensation (CEOCOMP) is equivalent to $\$ 145.27$ million (Ln retransformed back to raw data). Adams and Ferreira (2009) report a very high maximum total compensation of \$ 580.64 million while Kang et al. (2006) show an even higher maximum figure of $\$ 600.30$ million for total compensation, with mean of $\$ 2.98$ million. There is great variation in reported compensation figures and Cyert et al. (2002) reports $\$ 23.875$ million highest total compensation.

${ }^{39}$ In Table 7.3, the sum of mean bonus (CEOBONUS) and mean salary (CEOSALARY) is equivalent to $\$ 0.620$ million (Ln retransformed back). This is in line with Cyert et al. (2002) who indicate a mean bonus of $\$ 0.190$ million and mean base salary of $\$ 0.366$. Rajgopal and Shevlin (2002) study CEO bonus for the period from 1993-1997 and also report a mean bonus of $\$ 0.188$ million and salary of $\$ 0.372$ million. Guay (1999) reports a mean salary + bonus of $\$ 1.10$ million. Brick et al. (2006) and Coles et al. (2006) use a proxy "cash compensation" as sum of salary and bonus and report CEO mean cash compensation of \$1.14 million and \$1.60 million respectively. However, Cornett et al. (2008) finds a higher mean at \$2.72 million but use an S\&P 100 Index sample.

${ }^{40}$ In Table 7.3 , the maximum base salary (CEOSALARY) is equivalent to $\$ 10.79$ million (Ln retransformed back). Dittmann and Maug (2007) report a mean base salary $\$ 1.72$ million and maximum base salary of $\$ 90$ million. Cyert et al. (2002) has a mean base salary of $\$ 0.366$ million with a maximum of $\$ 2.693$ million. 
S\&P 100, NYSE, S\&P 500, etc.) and compositions in the samples, and different compensation dollar-year employed, to name a few. Other elements have also had an impact such as the financial crisis period, various systemic factors, Troubled Asset Relief Program (TARP), among others.

With regard to insider shareholding (SHINSIDER) the mean percentage of their shareholding is $13.7 \%$ and with a maximum of $96.3 \%$. This appears to be in line with Wright et al. (1996) who record a mean insider ownership of $12.7 \%$ and maximum of insider ownership of $80 \%$. However, some others report a lower percentage. ${ }^{41}$ Generally, I would expect to see a larger percentage of insider ownership with the recent focus on pay for performance centering on larger stock and stock option payouts.

Majority institutional shareholding (SHINST) is a binary variable of 1 where a firm has a majority percentage of institutional shareholding and otherwise 0 . The mean of 0.675 indicates that $67.5 \%$ of the firms in the sample have a majority of institutional shareholders. Wright et al. (1996) also shows a mean of 51\% shareholding held by institutions in their sample of firms, and report a highest shareholding of 96.9 percentage, which is close to the maximum figure in my data sample. Similarly, Graham and Rogers (2002) indicate a mean institutional percentage of 41.97 and max of $90.38 .^{42}$

\footnotetext{
${ }^{41}$ Borokhovich et al. (2004) have a mean managerial ownership percentage of $7.25 \%$, but a higher maximum of $72.90 \%$. Barnhart and Rosenstein (1998) indicate a mean insider shareholding of $6 \%$ and maximum of $66 \%$.

42 With regard to institutional shareholding, Barnhart \& Rosenstein (1998) report mean of $53.89 \%$ with a maximum reported at $98 \%$ ownership; Linck et al. (2008) indicate a mean of $34.16 \%$, while Hartzell and Starks (2003) observe mean of $53.1 \%$ and $77.3 \%$ at the 90 percentile.
} 
The SHBLOCK variable indicates those shareholders who own $5 \%$ or greater shareholding. The mean for block shareholders is $23.6 \%$ with a maximum of $97.9 \%$ and this appears in line with other studies. Wright et al. (1996) show a mean of $17.3 \%$ with maximum of $76 \%$. Linck et al. (2008) report a higher mean percentage of 40.08 , while Borokhovich et al. (2004) indicate an average $12.78 \%$ and maximum of $65.25 \%$ for their sample of firms. Both authors use the same definition of block holders as having $5 \%$ or greater ownership.

Finally, an examination of audit committee size (ACSIZE) indicates that the committees in my sample firms have a mean of 5 members, minimum of 1 member and a maximum of 16 members. Audit Committees appear to have a robust number of members and at the 75 percentile audit committees have 6 members, while some firms may have all board members sitting on the audit committee. Similarly, Xie et al. (2003) also indicate a mean of 4.53 audit committee members for their sample.

Panel C of Table 7.3 provide the descriptive statistics for the control variables. An examination reveals that the sample have mean (median) tax loss carry forward of 0.617 (1.000) indicating that around 62 percent in the sample exhibit tax loss carry forward; the mean (median) of firms leverage, as measured by total debts to firm value is $20.5 \%(14.8 \%)$ with a standard deviation of 0.208 ; the mean (median) of firm size measured as the natural logarithm of total sales is 7.041 (7.057) with a standard deviation of 1.862; the mean values for the arsinh of return on assets, natural logarithm of stock volatility, the natural logarithm of liquidity, and research and development are $0.205,1.322,3.803$ and 0.497 respectively. 
Table 7. 3: Descriptive Statistics for Derivatives, Leverage and Corporate Governance

\begin{tabular}{|c|c|c|c|c|c|c|c|}
\hline & & & & Standard & & Percentiles & \\
\hline Variables & $\mathrm{N}$ & Mean & Median & Deviation & Minimum & 25 & Maximum \\
\hline
\end{tabular}

Panel A: Dependent variables

$\begin{array}{lllllllll}\text { DER } & 6900 & 0.461 & 0.000 & 0.499 & 0.000 & 0.000 & 1.000 & 1.000 \\ \text { LEVERAGE } & 6900 & 0.205 & 0.148 & 0.208 & 0.000 & 0.019 & 0.323 & 0.980\end{array}$

Panel B: Corporate Governance variables

$\begin{array}{lrrrrrrrr}\text { BDMTGS } & 6900 & 8.007 & 7.000 & 3.699 & 1.000 & 6.000 & 9.000 & 46.000 \\ \text { BDSIZE } & 6900 & 8.815 & 9.000 & 2.129 & 4.000 & 7.000 & 10.000 & 17.000 \\ \text { BDINDEP } & 6900 & 6.411 & 6.000 & 2.156 & 1.000 & 5.000 & 8.000 & 16.000 \\ \text { BDDIVERS } & 6900 & 0.981 & 1.000 & 0.980 & 0.000 & 0.000 & 2.000 & 6.000 \\ \text { CEOAGE } & 6900 & 55.263 & 55.000 & 7.323 & 30.000 & 50.000 & 60.000 & 89.000 \\ \text { CEOTENURE } & 6900 & 8.683 & 7.000 & 7.527 & 1.000 & 3.000 & 12.000 & 54.000 \\ \text { SHINSIDER } & 6900 & 0.137 & 0.055 & 0.191 & 0.000 & 0.024 & 0.161 & 0.963 \\ \text { SHINST } & 6900 & 0.675 & 1.000 & 0.468 & 0.000 & 0.000 & 1.000 & 1.000 \\ \text { SHBLOCK } & 6900 & 0.236 & 0.213 & 0.164 & 0.000 & 0.115 & 0.330 & 0.979 \\ \text { ACSIZE } & 6900 & 5.111 & 5.000 & 2.181 & 1.000 & 3.000 & 6.000 & 16.000 \\ \text { CEOCOMP } & 6900 & 14.060 & 14.023 & 1.181 & 2.303 & 13.440 & 14.741 & 18.794 \\ \text { CEOBONUS } & 6900 & 5.080 & 0.000 & 6.374 & 0.000 & 0.000 & 12.612 & 18.159 \\ \text { CEOSALARY } & 6900 & 13.337 & 13.383 & 0.753 & 2.303 & 13.037 & 13.722 & 16.194\end{array}$




\begin{tabular}{|c|c|c|c|c|c|c|c|c|}
\hline \multirow[b]{2}{*}{ Variables } & \multirow[b]{2}{*}{$\mathrm{N}$} & \multirow[b]{2}{*}{ Mean } & \multirow[b]{2}{*}{ Median } & \multirow{2}{*}{$\begin{array}{c}\text { Standard } \\
\text { Deviation }\end{array}$} & \multirow[b]{2}{*}{ Minimum } & \multicolumn{2}{|c|}{ Percentiles } & \multirow[b]{2}{*}{ Maximum } \\
\hline & & & & & & 25 & 75 & \\
\hline \multicolumn{9}{|c|}{ Panel C: Control variables } \\
\hline TLCF & 6900 & 0.617 & 1.000 & 0.486 & 0.000 & 0.000 & 1.000 & 1.000 \\
\hline LIQUIDITY & 6900 & 0.205 & 0.188 & 0.875 & -4.083 & -0.303 & 0.716 & 4.210 \\
\hline ROA & 6900 & 1.322 & 2.245 & 2.333 & -6.293 & 0.759 & 2.875 & 5.581 \\
\hline SIZE & 6900 & 7.041 & 7.057 & 1.862 & -3.912 & 5.967 & 8.216 & 12.980 \\
\hline VOL & 6900 & 3.803 & 3.800 & 0.472 & 2.427 & 3.487 & 4.114 & 5.640 \\
\hline $\mathrm{R} \& \mathrm{D}$ & 6900 & 0.497 & 0.000 & 0.500 & 0.000 & 0.000 & 1.000 & 1.000 \\
\hline LEVERAGE & 6900 & 0.205 & 0.148 & 0.208 & 0.000 & 0.019 & 0.323 & 0.980 \\
\hline
\end{tabular}




\subsection{Correlation Analysis of Variables}

Prior to the regression analyses, I conduct a correlation analysis to examine the correlation between all the dependent and independent variables in the regression Models 1a and 1b depicted in Table 5.8. However, Pallant (2005) indicates that the absence of a high correlation does not guarantee that there is no multicollinearity. Collinearity may occur as a result of the combined effect of independent variables in the regression and, therefore, the author recommends additional tests of Tolerance or Variance Inflation Factor (VIF) which identify any multicollinearity problems that may not be evidenced through the correlation matrix.

The Pearson product momentum correlations and the Spearman rank correlation coefficients are reported in Table 7.4. All the correlations among the independent variables are less than the generally accepted rule of thumb that $r$ greater than 0.80 indicates risk of multicollinearity problems ${ }^{43}$. Most of the correlations are statistically significant and do not show very large relationships, except for Board Independence (BDINDEP) and Boards Size (BDSIZE) which indicate correlation coefficients of 0.789 and 0.783 for the Pearson and Spearman Correlations respectively.

The correlation matrix in Table 7.4 indicates that all the board variables are positively correlated with derivatives. Except for board meetings (BDMTGS) and CEOTENURE, all the variables are statistically significant in relation to derivatives (DER).

${ }^{43}$ Pallant (2005) suggests that: "Multicollinearity exists when the independent variables are highly correlated ( $\mathrm{r}=.9$ and above). (p. 142). 
With respect to the other corporate governance variables, the coefficients indicate that all variables for CEO compensation (CEOCOMP, CEOBONUS and CEOSALARY) are statistically significant and increase derivatives. Similarly, CEO age (CEOAGE), audit committee size (ACSIZE) and majority institutional shareholding (SHINST) have a positive and significant association with derivatives. In contrast block holders (SHBLOCK) and inside shareholders (SHINSIDER) appear to decrease the use of derivatives hedging. CEO tenure (CEOTENURE) is the other governance variable that is not significant and has a negative association with derivatives (DER). There is a dearth of literature in the area of derivatives and corporate governance and of the few existing studies, most do not report the correlation matrix to provide a basis for comparison. However, variations of total CEO compensation (CEOCOMP) and CEO bonus (CEOBONUS) have been used in the literature to proxy for managerial risk aversion and the results vary depending on the incentive portfolio. ${ }^{44}$

The control variables for derivatives, leverage (LEVERAGE), firm size (SIZE), quick ratio (LIQUIDITY) are all significant and in line with derivatives theory and literature, and consistent with the predicted signs shown in Table 5.5. However, tax loss carry forwards (TLCF) and research and development expenditure (R\&D) are negative and counter to the expected sign. One of the main reasons is that the correlation test is being conducted between two dichotomous variables and both the Spearman and Pearson correlation tests are not geared to test correlation between two binary variables. $^{45}$

\footnotetext{
${ }^{44}$ Details of these conflicting results are explained in Chapter 4.

45 "Note: The bivariate Pearson Correlation only reveals associations among continuous variables. The bivariate Pearson Correlation does not provide any inferences about causation, no matter how large the correlation coefficient is." (Kent State University, 2015) http://libguides.library.kent.edu/SPSS.
} 
With respect to the independent and control variables for the model with Leverage (LEVERAGE) as the dependent variable, derivative (DER), return on assets (ROA), research and development (R\&D), volatility (VOL), and size (SIZE) are all statistically significant and in the direction of my predictions provided in Table 5.5. 
Table 7. 4A: Correlation Matrix for Derivatives, Corporate Governance and Control Variables

\begin{tabular}{|c|c|c|c|c|c|c|c|c|c|c|c|c|}
\hline & DER & BDMTGS & BDSIZE & BDINDEP & BDDIVERS & CEOAGE & CEOTENURE & SHINSIDER & SHINST & SHBLOCK & ACSIZE & CEOCOMP \\
\hline DER & 1 & & & & & & & & & & & \\
\hline BDMTGS & 0.005 & 1 & & & & & & & & & & \\
\hline BDSIZE & $0.146 * *$ & -0.01 & 1 & & & & & & & & & \\
\hline BDINDEP & $0.132 * *$ & $0.031^{*}$ & $0.789 * *$ & 1 & & & & & & & & \\
\hline BDDIVERS & $0.085 * *$ & 0.009 & $0.529 * *$ & $0.528 * *$ & 1 & & & & & & & \\
\hline CEOAGE & $0.034 * *$ & $-0.069^{* * *}$ & $\mathbf{0 . 0 5 3}^{* *}$ & 0.022 & 0.009 & 1 & & & & & & \\
\hline CEOTENURE & $\begin{array}{c}-0.002 \\
-\end{array}$ & $-0.109 * *$ & $-0.089 * *$ & $-0.112 * *$ & $-0.101 * *$ & $0.385^{* * *}$ & 1 & & & & & \\
\hline SHINSIDER & $0.087 * *$ & $-0.103 * *$ & $-0.133^{* *}$ & $-0.371 * *$ & $-0.111 * *$ & $0.074 * *$ & $0.151 * *$ & 1 & & & & \\
\hline SHINST & $0.090^{* *}$ & $-0.053^{* *}$ & $0.173^{* *}$ & $0.181 * *$ & $0.105^{* *}$ & 0.014 & -0.002 & $-0.147 * *$ & 1 & & & \\
\hline SHBLOCK & $-0.024 *$ & $0.067^{* *}$ & $-0.135 * *$ & $-0.106 * *$ & $-0.117 * *$ & $-0.075^{* *}$ & $-0.073 * *$ & $-0.276 * *$ & $-0.113 * *$ & 1 & & \\
\hline ACSIZE & $0.043^{* *}$ & $0.098 * *$ & $0.373^{* *}$ & $0.444 * *$ & $0.297 * *$ & $0.091 * *$ & $-0.128 * *$ & $-0.192 * *$ & $0.092 * *$ & $-0.042 * *$ & 1 & \\
\hline СЕОСОМР & $0.080^{* *}$ & 0.002 & $0.352 * *$ & $0.349 * *$ & $0.257^{* *}$ & $0.106 * *$ & -0.019 & $-0.172 * *$ & $0.111 * *$ & $-0.083 * *$ & $0.343^{* *}$ & 1 \\
\hline CEOBONUS & $0.042 * *$ & $-0.045^{* *}$ & -0.004 & $-0.074 * *$ & $-0.037 * *$ & $-0.047^{* * *}$ & $0.056^{* *}$ & 0.019 & $0.047^{* * *}$ & $-0.068 * *$ & $-0.238 * *$ & $0.069 * *$ \\
\hline CEOSALARY & $\begin{array}{c}0.122^{* *} \\
-\end{array}$ & -0.02 & $0.331 * *$ & 0.331 ** & $0.258 * *$ & $0.109 * *$ & 0.008 & $-0.139 * *$ & $0.088^{* *}$ & $-0.041 * *$ & $0.219^{* *}$ & $0.634 * *$ \\
\hline TLCF & $\mathbf{0 . 0 3 3}^{* *}$ & $-0.029 *$ & $-0.075^{* *}$ & $-0.077 * *$ & $-0.049 * *$ & $-0.026^{*}$ & 0.000 & $0.073 * *$ & $-0.038 * *$ & 0.023 & $-0.025^{*}$ & -0.016 \\
\hline LIQUIDITY & $0.176^{* *}$ & -0.005 & $-0.277^{* *}$ & $-0.235 * *$ & $-0.231 * *$ & $-0.054 * *$ & $0.033 * *$ & $0.027 *$ & $-0.053^{* *}$ & 0.078** & $-0.142 * *$ & $-0.185^{* *}$ \\
\hline LEVERAGE & $0.201 * *$ & $0.104 * *$ & $0.284^{* *}$ & $0.223^{* *}$ & $0.171 * *$ & $0.078 * *$ & -0.015 & $-0.166 * *$ & 0.024 & 0.012 & $0.155^{* *}$ & $0.216^{* *}$ \\
\hline ROA & $0.049 * *$ & $-0.185^{* *}$ & $0.051^{* *}$ & $0.064 * *$ & $0.051 * *$ & -0.004 & 0.023 & $-0.070 * *$ & $0.108 * *$ & $-0.162 * *$ & 0.006 & $0.193 * *$ \\
\hline SIZE & $\begin{array}{c}0.221 * * \\
-\end{array}$ & $0.033^{* *}$ & $0.579 * *$ & $0.535 * *$ & $0.438 * *$ & $0.098 * *$ & $-0.041 * *$ & $-0.429 * *$ & $0.208 * *$ & $-0.175^{* *}$ & $0.326 * *$ & $0.608 * *$ \\
\hline VOL & $0.055^{* *}$ & $0.105 * *$ & $-0.286^{* *}$ & $-0.263^{* *}$ & $-0.246 * *$ & $-0.039 * *$ & -0.003 & $0.222 * *$ & $-0.146 * *$ & $0.208^{* *}$ & $-0.142 * *$ & $-0.323 * *$ \\
\hline R\&D & $-0.026 *$ & $0.043^{* *}$ & $-0.067 * *$ & 0.009 & $-0.069 * *$ & $-0.094 * *$ & $-0.030 *$ & $-0.054 * *$ & $0.066^{* *}$ & $0.040 * *$ & $-0.031 *$ & $-0.071 * *$ \\
\hline
\end{tabular}


Table 7. 4A: Pearson Correlation Matrix for Derivatives, Corporate Governance and Control Variables (continued)

\begin{tabular}{|c|c|c|c|c|c|c|c|c|c|}
\hline & CEOBONUS & CEOSALARY & TLCF & LIQUIDITY & LEVERAGE & ROA & SIZE & VOL & $\mathbf{R} \& \mathbf{D}$ \\
\hline CEOBONUS & 1 & & & & & & & & \\
\hline CEOSALARY & 0.014 & 1 & & & & & & & \\
\hline TLCF & $-0.048 * *$ & 0.004 & 1 & & & & & & \\
\hline LIQUIDITY & -0.023 & $-0.226 * *$ & $0.064 * *$ & 1 & & & & & \\
\hline LEVERAGE & -0.024 & $0.341^{* *}$ & $-0.065 * *$ & $-0.504 * *$ & $\mathbf{1}$ & & & & \\
\hline ROA & $0.133^{* * *}$ & $0.098^{* *}$ & 0.022 & $0.051^{* *}$ & $-0.229 * *$ & 1 & & & \\
\hline SIZE & $0.085^{* * *}$ & $0.730^{* *}$ & $-0.077 * *$ & $-0.473 * *$ & $0.282^{* *}$ & $0.375^{* *}$ & 1 & & \\
\hline VOL & $-0.242 * *$ & $-0.267 * *$ & $0.134 * *$ & 0.170 ** & $0.140 * *$ & $-0.454 * *$ & $-0.416 * *$ & 1 & \\
\hline R\&D & $-0.043 * *$ & $-0.114 * *$ & $0.044 * *$ & $0.351 * *$ & $-0.311 * *$ & $-0.081 * *$ & $-0.198 * *$ & $0.049 * *$ & 1 \\
\hline
\end{tabular}

Table 7. 4B: Spearman Correlation Matrix for Derivatives, Corporate Governance and Control Variables

\begin{tabular}{|c|c|c|c|c|c|c|c|c|c|c|c|c|c|}
\hline & DER & $\begin{array}{l}\text { BD } \\
\text { MTGS }\end{array}$ & $\begin{array}{l}\text { BD } \\
\text { SIZE }\end{array}$ & $\begin{array}{l}\text { BD } \\
\text { INDEP }\end{array}$ & $\begin{array}{l}\text { BD } \\
\text { DIVERS }\end{array}$ & $\begin{array}{l}\text { CEO } \\
\text { AGE } \\
\end{array}$ & $\begin{array}{l}\text { CEO } \\
\text { TENURE } \\
\end{array}$ & $\begin{array}{l}\text { SH } \\
\text { INSIDER }\end{array}$ & $\begin{array}{l}\text { SH } \\
\text { INST } \\
\end{array}$ & $\begin{array}{l}\text { SH } \\
\text { BLOCK } \\
\end{array}$ & ACSIZE & $\begin{array}{l}\text { CEO } \\
\text { COMP } \\
\end{array}$ & $\begin{array}{l}\text { CEO } \\
\text { BONUS } \\
\end{array}$ \\
\hline DER & 1 & 0.017 & $0.154 * *$ & $0.136 * *$ & $0.090 * *$ & 0.029* & -0.005 & $-0.142 * *$ & $0.090 * *$ & $-0.033 * *$ & $0.043 * *$ & $0.112 * *$ & $0.054 * *$ \\
\hline BDMTGS & & 1 & $0.025 *$ & $0.072 * *$ & $0.052 * *$ & $-0.074 * *$ & $-0.123 * *$ & $-0.161 * *$ & $-0.036 * *$ & $0.052 * *$ & $0.120 * *$ & $0.036 * *$ & -0.050 ** \\
\hline BDSIZE & & & 1 & $\mathbf{0 . 7 8 3} * *$ & $0.530 * *$ & $0.061^{* *}$ & $-0.088 * *$ & $-0.283 * *$ & $0.174 * *$ & $-0.144 * *$ & $0.367 * *$ & $0.407 * *$ & $0.027 *$ \\
\hline BDINDEP & & & & 1 & $0.532 * *$ & $0.031 * *$ & $-0.086 * *$ & $-0.492 * *$ & $0.174 * *$ & $-0.067 * *$ & $0.428 * *$ & $0.401 * *$ & $-0.039 * *$ \\
\hline BDDIVERS & & & & & 1 & $0.028 *$ & $-0.093 * *$ & $-0.263 * *$ & $0.102 * *$ & $-0.115 * *$ & $0.294 * *$ & $0.304 * *$ & -0.016 \\
\hline $\begin{array}{l}\text { CEOAGE } \\
\text { CEO }\end{array}$ & & & & & & 1 & $0.326^{* *}$ & 0.006 & $0.024 *$ & $-0.081 * *$ & $0.099 * *$ & $0.118 * *$ & $-0.046^{* *}$ \\
\hline TENURE & & & & & & & 1 & $0.153^{* *}$ & -0.006 & $-0.049 * *$ & $-0.093 * *$ & 0.001 & $0.040 * *$ \\
\hline SHINSIDER & & & & & & & & 1 & $-0.122 * *$ & $-0.112 * *$ & $-0.290 * *$ & $-0.328 * *$ & 0.015 \\
\hline SHINST & & & & & & & & & 1 & $-0.087 * *$ & $0.086^{* * *}$ & $0.136 * *$ & $0.062 * *$ \\
\hline SHBLOCK & & & & & & & & & & 1 & -0.023 & $-0.107 * *$ & $-0.085^{* *}$ \\
\hline ACSIZE & & & & & & & & & & & 1 & $0.382 * *$ & $-0.232 * *$ \\
\hline СЕОСОМР & & & & & & & & & & & & 1 & $0.142 * *$ \\
\hline CEOBONUS & & & & & & & & & & & & & 1 \\
\hline
\end{tabular}


Table 7. 4B: Spearman Correlation Matrix for Derivatives, Corporate Governance and Control Variables (continued)

\begin{tabular}{|c|c|c|c|c|c|c|c|c|}
\hline & CEOSALARY & TLCF & LIQUIDITY & LEVERAGE & ROA & SIZE & VOL & $\mathbf{R} \& \mathbf{D}$ \\
\hline DER & $0.171^{* * *}$ & $-0.033 * *$ & $-0.184 * *$ & $0.240 * *$ & -0.008 & $0.230 * *$ & $-0.060 * *$ & $-0.026^{*}$ \\
\hline BDMTGS & $0.030 *$ & $-0.037 * *$ & $-0.026 *$ & $0.090 * *$ & $-0.158 * *$ & -0.011 & $0.119 * *$ & $0.041 * *$ \\
\hline BDSIZE & $0.512 * *$ & $-0.074 * *$ & $-0.300 * *$ & $0.207 * *$ & $0.118 * *$ & $0.544 * *$ & $-0.293 * *$ & -0.059 ** \\
\hline BDINDEP & $0.494 * *$ & $-0.072 * *$ & $-0.258 * *$ & $0.152 * *$ & $0.126 * *$ & $0.515 * *$ & $-0.279 * *$ & 0.018 \\
\hline BDDIVERS & $0.416^{* * *}$ & $-0.053 * *$ & $-0.249 * *$ & $0.127 * *$ & $0.091 * *$ & $0.400 * *$ & $-0.243 * *$ & $-0.075^{* * *}$ \\
\hline CEOAGE & $0.168^{* * *}$ & $-0.038 * *$ & $-0.058 * *$ & $0.070^{* *}$ & 0.015 & $0.084 * *$ & $-0.033 * *$ & $-0.087^{* * *}$ \\
\hline CEOTENURE & 0.02 & -0.004 & $0.031 *$ & -0.008 & $0.026^{*}$ & $-0.036 * *$ & 0.003 & $-0.046 * *$ \\
\hline SHINSIDER & $-0.323 * *$ & $0.108 * *$ & $0.172 * *$ & 0.003 & $-0.064 * *$ & $-0.191 * *$ & $0.148 * *$ & $-0.122 * *$ \\
\hline SHINST & $0.146 * *$ & $-0.038 * *$ & $-0.062 * *$ & $\mathbf{0}$ & $0.116 * *$ & $0.227 * *$ & $-0.154 * *$ & $0.066 * *$ \\
\hline SHBLOCK & $-0.125^{* *}$ & $0.028 *$ & $0.101 * *$ & $0.062 * *$ & $-0.154 * *$ & $-0.151 * *$ & $0.209 * *$ & 0.018 \\
\hline ACSIZE & $0.351 * *$ & -0.003 & $-0.133 * *$ & $0.131 * *$ & $0.065^{* *}$ & $\mathbf{0 . 3 3 3} * *$ & $-0.165 * *$ & $-0.038 * *$ \\
\hline СЕОСОМР & $0.711 * *$ & $-0.035 * *$ & $-0.248 * *$ & $0.118 * *$ & $0.188 * *$ & $0.471 * *$ & $-0.282 * *$ & $-0.061 * *$ \\
\hline CEOBONUS & $0.028 *$ & $-0.054 * *$ & $-0.059 * *$ & $-0.063 * *$ & $0.102 * *$ & $0.032 * *$ & $-0.211 * *$ & $-0.036 * *$ \\
\hline CEOSALARY & 1 & $-0.036 * *$ & $-0.357 * *$ & $0.197 * *$ & $\mathbf{0 . 0 7 7 * *}$ & $0.396 * *$ & $-0.142 * *$ & $-0.097 * *$ \\
\hline TLCF & & 1 & $0.075 * *$ & $-0.062 * *$ & -0.01 & $-0.075 * *$ & $0.135 * *$ & $0.044 * *$ \\
\hline LIQUIDITY & & & 1 & $-0.420 * *$ & $-0.082 * *$ & $-0.471 * *$ & $0.146 * *$ & $0.360 * *$ \\
\hline LEVERAGE & & & & 1 & $-0.335 * *$ & $0.383 * *$ & $0.031 * *$ & $-0.307 * *$ \\
\hline ROA & & & & & 1 & $0.213 * *$ & $-0.363 * *$ & 0.014 \\
\hline SIZE & & & & & & 1 & $-0.405 * *$ & $-0.197 * *$ \\
\hline VOL & & & & & & & 1 & $0.052 * *$ \\
\hline R\&D & & & & & & & & 1 \\
\hline
\end{tabular}

All variables are as defined in Tables 5.3 and 5.4. 
There are a large number of independent variables and therefore there exists the possibility of multicollinearity due to collective correlations in the regressions. In addition to the Pearson and Spearman correlation tests, I also conduct tests to check for the Variance Inflation Factor (VIF) and Tolerance indicator. The results for the Tolerance indicator and VIF are reported in Table 7.5 and the variables do not show any signs of multicollinearity as they are within the specified limit. A VIF greater than 10 and a tolerance indicator less than 0.10 indicates a severe multicollinearity problem. 
Table 7. 5: Multicollinearity Tests for Derivatives Model

\begin{tabular}{|c|c|c|}
\hline & Variance Inflation Factor (VIF) & Tolerance (1/VIF) \\
\hline$B D M T G S$ & 1.08 & 0.928 \\
\hline$B D S I Z E$ & 3.26 & 0.307 \\
\hline BDINDEP & 3.79 & 0.263 \\
\hline BDDIVERS & 1.52 & 0.658 \\
\hline SHINSIDER & 1.55 & 0.643 \\
\hline SHINST & 1.11 & 0.902 \\
\hline SHBLOCK & 1.25 & 0.798 \\
\hline CEOAGE & 1.24 & 0.808 \\
\hline CEOTENURE & 1.24 & 0.804 \\
\hline СЕОСОМР & 2.17 & 0.461 \\
\hline CEOBONUS & 1.15 & 0.871 \\
\hline CEOSALARY & 1.84 & 0.542 \\
\hline$A C S I Z E$ & 1.67 & 0.597 \\
\hline LEVERAGE $E^{a}$ & 2.48 & 0.404 \\
\hline SIZE & 2.40 & 0.417 \\
\hline$B V / M V$ & 1.34 & 0.746 \\
\hline$T L C F$ & 1.05 & 0.949 \\
\hline LIQUIDITY & 1.49 & 0.673 \\
\hline$L E V \phi_{-} 1 /(B V / M V)$ & 1.14 & 0.875 \\
\hline$R \& D$ & 1.59 & 0.628 \\
\hline
\end{tabular}




\subsection{Multivariate Analysis on the Effect of Corporate Governance Variables on Derivatives.}

This section presents the results from the estimation of Model 1a and Model 1b shown in Table 5.8 that examine the relations between derivatives and corporate governance.

Table 7.6 shows the results of Model 1a and utilizes a probit regression technique, in order to capture the dichotomous nature of derivatives. DER is a categorical variable that takes on a 1 for firms using derivatives and 0 otherwise. The corporate governance variables are size of the board of directors (BDSIZE), board independence (BDINDEP), board diversity (BDDIVERS), board meetings (BDMTGS), insider shareholding (SHINSIDER), institutional shareholding (SHINST), block-holders (SHBLOCK), CEO age (CEOAGE), CEO tenure (CEOTENURE), CEO total compensation (CEOCOMP), CEO bonus (CEOBONUS), CEO base salary (CEOSALARY) and audit committee size (ACSIZE). Wald $\chi^{2}$ test results, the pseudo

$\mathrm{R}^{2}$ and the $\mathrm{z}$ statistics are provided alongside the results. The $\mathrm{prob}>\chi^{2}$ of 0.000 indicates the hypothesis that all coefficients are equal to zero are rejected at the $1 \%$ significance level and supports the fitness of the model. 


\section{Table 7. 6: Probit Regression for Derivatives Model}

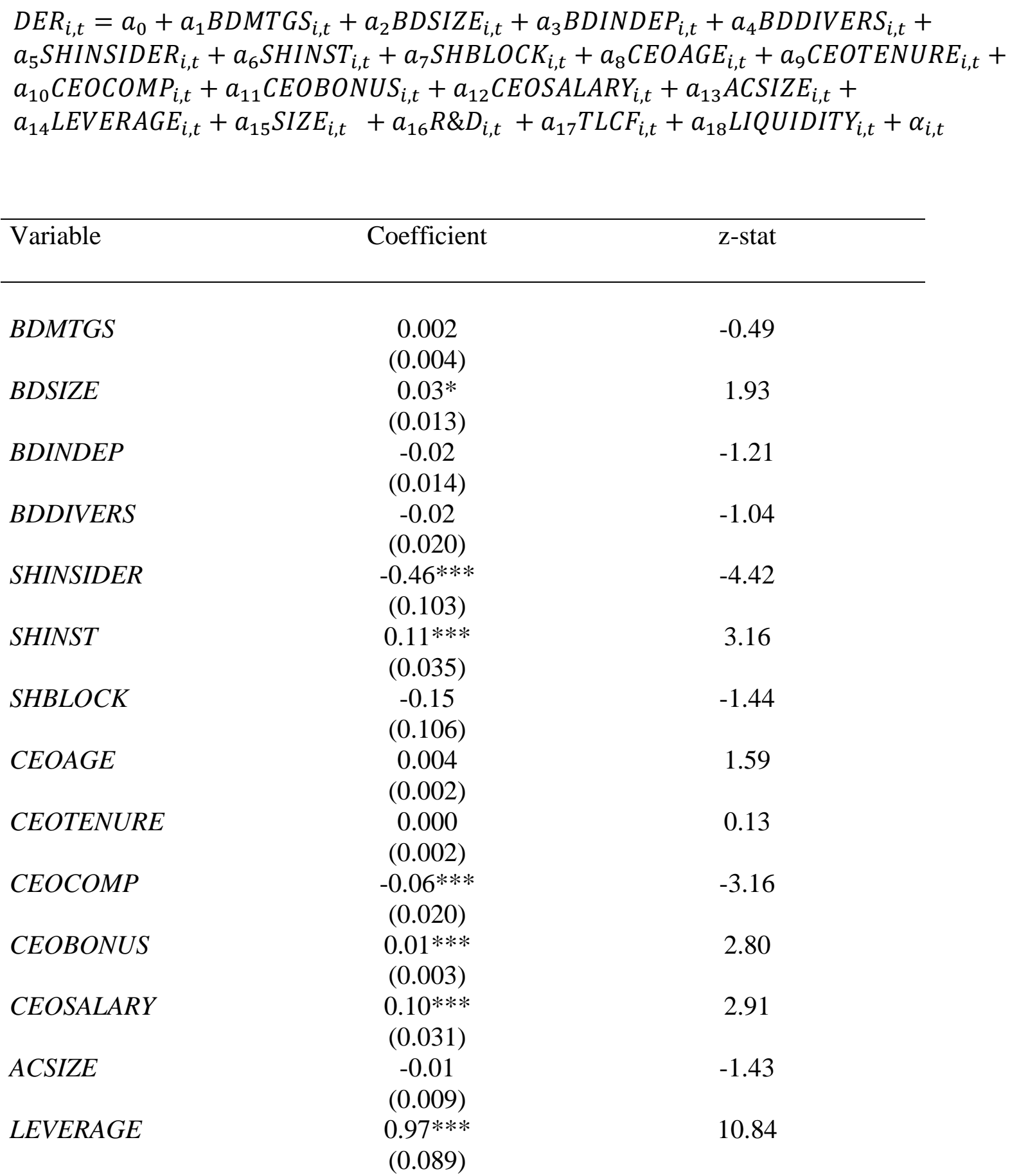




\begin{tabular}{lcc}
\hline Variable & Coefficient & Z-stat \\
\hline & & \\
SIZE & $-0.11 * * *$ & 5.18 \\
$R \& D$ & $(0.013)$ & \\
& $0.18^{* * *}$ & -0.53 \\
TLCF & $(0.035)$ & -4.11 \\
& -0.02 & -5.07 \\
LIQUIDITY & $(0.033)$ & \\
Constant & $-0.10^{* * *}$ & \\
& $(0.022)$ & \\
Year effects & $-1.69 * *$ & \\
Industry effects & $(0.333)$ & \\
Observations & yes & \\
Wald $\chi^{2}$ & yes & \\
Prob> $\chi^{2}(p-v a l u e)$ & 6900 & \\
Pseudo $R^{2}$ & 583.71 & \\
& 0.000 & \\
\hline
\end{tabular}

The p-value for the one-tailed test of the null hypothesis that the coefficient is zero, is indicated as $* * *, * *, *$ to show statistical significance at the $0.01,0.05$ and 0.10 levels respectively and the robust standard errors are given in parentheses. Z statistics are also provided. See Tables 5.3 and 5.4 for definitions of dependent and independent variables. 
There is a problem of endogeneity due to the simultaneity of capital structure (debt) and derivatives decisions that is discussed in detail in Section 5.11. Therefore, I conduct a simultaneous equations regression with debt (LEVERAGE) and derivatives (DER) as the endogenous dependent variables in the two equations. Results from the CDSIMEQ simultaneous equations model developed by Keshak (2003) are presented in Table 7.7.

A comparison of the single equation probit model (Table 7.6) and the simultaneous equations model (Table 7.7) show a difference in the z-statistics coefficient values. When reducing the effects of endogeneity through the consideration of capital structure and hedging decisions simultaneously, CEOAGE becomes statistically significant and has a positive association with DER and the coefficient for LEVERAGE is reduced from 0.97 to 0.59 . The most significant change is in the direction of SIZE variable, which changes from a negative to a positive statistically significant association with DER. Under the probit model a one-unit increase in SIZE decreases the z-statistics by 0.11 , however under the simultaneous equations model, an additional unit of SIZE increases the z-statistic by 0.11. As discussed in Section 5.8 , my results appear to be inclined to the economies of scale theory of size rather than the bankruptcy theory. It is in keeping with Geczy et al. (1997) and Berkman and Bradbury (1996), which suggests that larger firms are more likely to use derivatives, have effective hedging programs in place and reflect increased value.

The results from the first regression in Table 7.7 (columns 2 and 3) show that derivatives (DER) has a significant positive association with debt (LEVERAGE) at the $1 \%$ level with a t-statistics of 9.29 . The positive and significant relationship is consistent with literature (Graham and Rogers, 2002; Lin and Smith, 2007) and supports the contention that an increase in leverage would increase the need to hedge with derivatives in order to increase debt capacity. It supports the simultaneity of 
capital structure and hedging decisions for the firm. All the controls for the leverage equation (column 2) are statistically significant at the $1 \%$ level and in the directions of my predictions provided in Table 5.5. This regression utilizes the ordinary least squares (OLS) technique and shows a comparatively high $\mathrm{R}^{2}$ of $35 \%$. This is larger than Borokhovich et al. (2004) results for their models ranging from $16.7 \%$ to $25.2 \%$, but less than achieved by Graham and Rogers (2002) who report a higher $\mathrm{R}^{2}$ ranging from $48.56 \%$ to $59.5 \%$. Both use a simultaneous equations model and US sample.

Table 7.7 columns 4 and 5, show results of the derivatives (DER) equation, and here all control variables are significant and in line with predictions depicted in Table 5.5. All the determinants of derivatives: financial distress (LEVERAGE), investment growth opportunities (R\&D), and managerial risk aversion are significant and in line with literature, including liquidity. However, tax convexity, captured through a dichotomous variable as 1 for tax loss carry forward (TLCF) and otherwise 0 , is not significant. Fok et al. (1997) use a similar measure to capture tax convexity and do not find any significant results for the two different proxies used. This is similar to the results obtained by Graham and Rogers (2002) in their simultaneous equations model. In Table 7.7, the DER Model (columns 4 and 5) show a prob>chi2 as 0.000. This indicates the hypothesis that all coefficients are equal to zero are rejected at the $1 \%$ significance level and supports the fitness of the model.

Only seven out of the thirteen corporate governance variables are found to be associated with derivatives. Board size is found to be significantly positively related with derivatives at $5 \%$ level with z-statistics of 2.16. BDSIZE captures the effects of board influence and involvement in the risk management decisions of the firm and the result indicates that larger boards increase derivatives. The results for the other board characteristics - independence, diversity and meetings, do not indicate any significant influence on derivatives. These results are consistent with the findings of Borokhovich 
et al. (2004) who examine the effect of board characteristics on interest rate derivatives. They do not obtain significant results for any of the board characteristics examined, except for board independence which has a positive and significant impact on the derivatives. There are no other studies that examine the impact of a comprehensive set of board characteristics on derivatives and none that investigate board gender diversity (BDDIVERS) or board diligence (BDMTGS) with respect to derivatives.

The results indicate that shareholders are actively involved in risk management of the firm. However, as discussed in Section 4.5 and as predicted (Table 5.5) insider shareholding (SHINSIDER) by management and directors show a -0.42 coefficient indicating a negative association with derivatives at $1 \%$ level of significance. This is in keeping with others (Allayannis et al., 2009; Lel, 2012) who find that insiders reduce derivatives. Allayannis et al. (2009) attribute this characteristic to a well governed firm where they do not have the power to manipulate the derivatives decisions for their own benefit and Lel (2012) also finds a negative association for strongly governed firms.

Institutional shareholders (SHINST) appear to increase derivatives. The coefficient is positive and significant at the $1 \%$ level. Allayannis et al. (2009) obtain a positive relationship between institutional shareholders and derivatives and they attribute this to strong governance.

CEO age (CEOAGE) captures the effects of CEO short-term problems. The result shows a significantly positive association with derivatives at the $10 \%$ level of significance. This indicates that older CEOs increase derivatives. The results for CEO total compensation (CEOCOMP) is negative and statistically significant at $1 \%$ level with z-statistics of -3.24 , which indicates that the total CEO compensation tends to 
reduce the amount of derivatives. This is in keeping with the literature which indicates that stock options seem to have a dominating effect (Sections 4.6) and tend to cause CEOs to increase risk and volatility in order to derive gains in their options portfolios. The other components for CEO base salary (CEOSALARY) and cash bonus (CEOBONUS) show positive coefficients that are statistically significant at the $1 \%$ level. As predicted, in keeping with literature, the other compensation components: CEOBONUS and CEOSALARY, display CEO risk aversion and therefore induce an increase in the use of derivatives.

The other coefficients for corporate governance variables, audit committee size (ACSIZE), block holders (SHBLOCK) and CEO tenure (CEOTENURE) are not significant $(\mathrm{p}>0.10)$, providing no evidence for the existence of associations between these variables and risk management through increased derivatives. 


\section{Table 7. 7: Simultaneous Equations Model - Derivatives, Leverage and Corporate Governance}

$$
\begin{aligned}
& \text { LEVERAGE } \underset{i, t}{\boldsymbol{a}}=b_{0}+b_{1} D E R_{i, t}^{b}+b_{2} R \& D_{i, t}+b_{3} R O A_{i, t}+b_{4} S I Z E_{i, t}+b_{5} V O L_{i, t}+\beta_{i, t} \\
& \boldsymbol{D E R}_{\boldsymbol{i , t}}^{\boldsymbol{b}}=c_{0}+c_{1} \text { BDMTGS }_{i, t}+c_{2} \text { BDSIZE }_{i, t}+c_{3} \text { BDINDEP }_{i, t}+c_{4} \text { BDDIVERS }_{i, t}+ \\
& c_{5} \text { SHINSIDER }_{i, t}+c_{6} \text { SHINST }_{i, t}+c_{7} \text { SHBLOCK }_{i, t}+c_{8} \text { CEOAGE }_{i, t}+ \\
& c_{9} \text { CEOTENURE } E_{i, t}+c_{10} \text { CEOCOMP }_{i, t}+c_{11} \text { CEOBONUS } S_{i, t}+c_{12} \text { CEOSALARY }_{i, t}+ \\
& c_{13} A_{C S I Z E_{i, t}}+c_{14} L E V E R A G E_{i, t}^{a}+c_{15} S_{I Z E_{i, t}}+c_{16} R \& D_{i, t}+c_{17} T L C F_{i, t}+ \\
& c_{18} L_{I Q U I D I T Y}, t+\gamma_{i, t}
\end{aligned}
$$

\begin{tabular}{|c|c|c|c|c|}
\hline \multirow[b]{2}{*}{ VARIABLE } & \multicolumn{2}{|c|}{ LEVERAGE } & \multicolumn{2}{|c|}{ DERIVATIVES } \\
\hline & coefficient & t-stat & coefficient & z-stat \\
\hline$D E R^{b}$ & $\begin{array}{c}0.17 * * * \\
(0.018)\end{array}$ & 9.29 & & \\
\hline$R O A$ & $\begin{array}{c}-0.03^{* * * *} \\
(0.002)\end{array}$ & -16.22 & & \\
\hline SIZE & $\begin{array}{c}0.02 * * * \\
(0.004)\end{array}$ & 5.25 & & \\
\hline$V O L$ & $\begin{array}{l}0.09^{* * * *} \\
(0.009)\end{array}$ & 9.98 & & \\
\hline$R \& D$ & $\begin{array}{c}-0.11^{* * * *} \\
(0.006)\end{array}$ & -16.67 & $\begin{array}{c}0.15^{* * * *} \\
(0.037)\end{array}$ & 3.95 \\
\hline$B D M T G S$ & & & $\begin{array}{l}-0.000 \\
(0.004)\end{array}$ & -0.08 \\
\hline BDSIZE & & & $\begin{array}{l}0.03 * * \\
(0.013)\end{array}$ & 2.16 \\
\hline BDINDEP & & & $\begin{array}{c}-0.02 \\
(0.014)\end{array}$ & -1.34 \\
\hline BDDIVERS & & & $\begin{array}{c}-0.02 \\
(0.019)\end{array}$ & -1.23 \\
\hline SHINSIDER & & & $\begin{array}{c}-0.42 * * * \\
(0.102)\end{array}$ & -4.09 \\
\hline SHINST & & & $\begin{array}{c}0.11 * * * \\
(0.035)\end{array}$ & 3.09 \\
\hline SHBLOCK & & & $\begin{array}{c}-0.09 \\
(0.110)\end{array}$ & -0.79 \\
\hline CEOAGE & & & $\begin{array}{l}0.004 * \\
(0.002)\end{array}$ & 1.71 \\
\hline
\end{tabular}




\begin{tabular}{|c|c|c|c|c|}
\hline \multirow[b]{2}{*}{ VARIABLE } & \multicolumn{2}{|c|}{ LEVERAGE } & \multicolumn{2}{|c|}{ DERIVATIVES } \\
\hline & coefficient & t-stat & coefficient & z-stat \\
\hline CEOTENURE & & & $\begin{array}{c}0.000 \\
(0.002)\end{array}$ & 0.13 \\
\hline СЕОСОМР & & & $\begin{array}{c}-0.06 * * * \\
(0.020)\end{array}$ & -3.24 \\
\hline CEOBONUS & & & $\begin{array}{l}0.01 * * * \\
(0.003)\end{array}$ & 3.18 \\
\hline CEOSALARY & & & $\begin{array}{c}0.10 * * * \\
(0.031)\end{array}$ & 3.21 \\
\hline$A C S I Z E$ & & & $\begin{array}{c}-0.01 \\
(0.009)\end{array}$ & -1.16 \\
\hline LEVERAGE $E^{a}$ & & & $\begin{array}{l}0.59 * * \\
(0.230)\end{array}$ & 2.56 \\
\hline SIZE & & & $\begin{array}{c}0.11 * * * \\
(0.013)\end{array}$ & 8.61 \\
\hline$T L C F$ & & & $\begin{array}{c}-0.02 \\
(0.032)\end{array}$ & -0.62 \\
\hline LIQUIDITY & & & $\begin{array}{l}-0.12 * * * \\
(0.026)\end{array}$ & -4.41 \\
\hline Constant & $\begin{array}{c}-0.16 * * * \\
(0.050)\end{array}$ & -3.17 & $\begin{array}{l}-1.81 * * * \\
(0.341)\end{array}$ & -5.31 \\
\hline Year effects & Yes & & yes & \\
\hline Industry effects & Yes & & yes & \\
\hline $\begin{array}{l}\text { Observations } \\
R^{2} / \text { Pseudo } R^{2}\end{array}$ & $\begin{array}{l}6900 \\
0.35\end{array}$ & & $\begin{array}{c}6900 \\
0.05\end{array}$ & \\
\hline
\end{tabular}

The p-value for the one-tailed test of the null hypothesis that the coefficient is zero is indicated as $* * *, * *, *$ to show statistical significance at the $0.01,0.05$ and 0.10 levels respectively, and robust standard errors are given in parentheses. The $\mathrm{t}$ and $\mathrm{z}$ values are also provided. See Tables 5.3 and 5.4 for definitions of dependent and independent variables. 


\subsection{Sensitivity Analyses and Robustness Tests}

Geczy et al. (1997) suggest that test results may be criticized as the independent variables used to capture the incentives for derivatives are selected variables of choice. Therefore, they perform robustness checks of the variable specifications, by using alternative specifications and procedures to show that their conclusions remain unaffected. Similarly, I conduct a sensitivity analyses on the important variables that inform hedging theory by using alternative measures and specifications to test the consistency of my results.

\section{The Effects of Financial Contracting Costs and Financial Constraint}

Researchers contend that hedging reduces expected bankruptcy costs. By decreasing the probability of default, hedging increases investors' incentives to invest and therefore improves the contracting rates and terms with creditors (Haulshalter, 2000). Therefore, if a firm is faced with decreased cash flows it would need to increase their reliance on costlier external financing, reduce investments in profitable projects and decrease growth.

In the literature various different measures have been used to capture this aspect of financial constraint. Gay and Nam (1998) use a dummy variable with a value of 1 for those firms with a cash stock lower than average and the growth measure being greater than the mean. I use a similar measure (FINCONSTR1) to capture financial constraint.

Haulshalter (2000) uses an indicator variable that takes on a measure of 1 if the debt ratio is greater than the median debt ratio for the sample and also the current ratio is less than the median of the sample. I use a similar variable in Table 7.8, as financial 
constraint (FINCONSTR2) variable using Haulshalter's measure. Another measure popularly used to capture financial constraint is the ratio of book value to market value ratio and I also use this as my FINCONSTR3 measure. In Table 7.8 the simultaneous equations model is used for all the models and the first stage regression has not been included for convenience of space, however these are available on request.

The overall results for the corporate governance variables are consistent across the models and do not vary from the main results depicted in Table 7.7. 
Table 7. 8: Derivatives Robustness Tests - Financial Constraint Measures

\begin{tabular}{|c|c|c|c|c|c|c|}
\hline \multicolumn{7}{|c|}{ 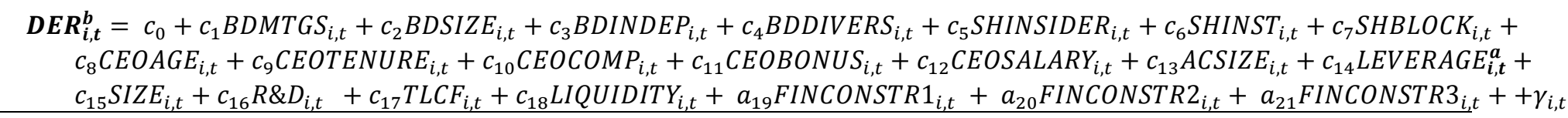 } \\
\hline \multirow[b]{2}{*}{ VARIABLE } & \multicolumn{2}{|c|}{ Model 1} & \multicolumn{2}{|c|}{ Model 2} & \multicolumn{2}{|c|}{ Model 3} \\
\hline & coefficient & z-stat & coefficient & z-stat & coefficient & z-stat \\
\hline$B D M T G S$ & $\begin{array}{c}-0.00 \\
(0.004)\end{array}$ & -0.17 & $\begin{array}{c}-0.00 \\
(0.004)\end{array}$ & -0.07 & $\begin{array}{c}-0.00 \\
(0.004)\end{array}$ & -0.07 \\
\hline$B D S I Z E$ & $\begin{array}{l}0.03 * * \\
(0.013)\end{array}$ & 2.14 & $\begin{array}{l}0.03 * * \\
(0.013)\end{array}$ & 2.11 & $\begin{array}{l}0.03 * * \\
(0.013)\end{array}$ & 2.39 \\
\hline BDINDEP & $\begin{array}{c}-0.02 \\
(0.014)\end{array}$ & -1.38 & $\begin{array}{c}-0.02 \\
(0.014)\end{array}$ & -1.33 & $\begin{array}{c}-0.02 \\
(0.014)\end{array}$ & -1.49 \\
\hline BDDIVERS & $\begin{array}{c}-0.02 \\
(0.020)\end{array}$ & -1.27 & $\begin{array}{c}-0.02 \\
(0.019)\end{array}$ & -1.20 & $\begin{array}{l}-0.02 \\
(0.19)\end{array}$ & -1.15 \\
\hline SHINSIDER & $\begin{array}{c}-0.41 * * * \\
(0.104)\end{array}$ & -4.00 & $\begin{array}{c}-0.41 * * * \\
(0.103)\end{array}$ & -4.01 & $\begin{array}{c}-0.42 * * * \\
(0.102)\end{array}$ & -4.15 \\
\hline SHINST & $\begin{array}{c}0.11 * * * \\
(0.035)\end{array}$ & 3.12 & $\begin{array}{c}0.11 * * * \\
(0.035)\end{array}$ & 3.06 & $\begin{array}{c}0.10 * * * \\
(0.035)\end{array}$ & 2.88 \\
\hline SHBLOCK & $\begin{array}{c}-0.09 \\
(0.111)\end{array}$ & -0.81 & $\begin{array}{c}-0.08 \\
(0.111)\end{array}$ & -0.75 & $\begin{array}{c}-0.09 \\
(0.111)\end{array}$ & -0.80 \\
\hline$C E O A G E$ & $\begin{array}{l}0.002^{*} \\
(0.004)\end{array}$ & 1.67 & $\begin{array}{l}0.002^{*} \\
(0.004)\end{array}$ & 1.67 & $\begin{array}{c}0.004 \\
(0.002)\end{array}$ & 1.60 \\
\hline CEOTENURE & $\begin{array}{c}0.00 \\
(0.002)\end{array}$ & 0.10 & $\begin{array}{c}0.00 \\
(0.002)\end{array}$ & 0.08 & $\begin{array}{c}0.000 \\
(0.002)\end{array}$ & 0.11 \\
\hline СЕОСОМР & $\begin{array}{c}-0.06^{* * * *} \\
(0.020)\end{array}$ & -3.28 & $\begin{array}{c}-0.06 * * * \\
(0.020)\end{array}$ & -3.21 & $\begin{array}{c}-0.06 * * * \\
(0.020)\end{array}$ & -3.06 \\
\hline CEOBONUS & $\begin{array}{c}0.01 * * * \\
(0.003)\end{array}$ & 3.18 & $\begin{array}{c}0.01 * * * \\
(0.003)\end{array}$ & 3.07 & $\begin{array}{c}0.008 * * * \\
(0.003)\end{array}$ & 3.22 \\
\hline CEOSALARY & $0.10 * * *$ & 3.19 & $\begin{array}{l}0.10 * * * \\
312\end{array}$ & 3.21 & $0.10 * * *$ & 3.21 \\
\hline
\end{tabular}




\begin{tabular}{|c|c|c|c|c|c|c|}
\hline \multirow[b]{2}{*}{ VARIABLE } & \multicolumn{2}{|c|}{ Model 1} & \multicolumn{2}{|c|}{ Model 2} & \multicolumn{2}{|c|}{ Model 3} \\
\hline & coefficient & z-stat & coefficient & z-stat & coefficient & z-stat \\
\hline \multirow{3}{*}{$A C S I Z E$} & $(0.031)$ & & $(0.031)$ & & $(0.03)$ & \\
\hline & -0.01 & -1.26 & -0.01 & -1.18 & -0.01 & -1.19 \\
\hline & $(0.009)$ & & $(0.009)$ & & $(0.009)$ & \\
\hline \multirow[t]{2}{*}{$L E V E R A G E^{a}$} & $0.51 * * *$ & 1.84 & $0.60 * * *$ & 2.67 & 0.38 & 1.40 \\
\hline & $(0.279)$ & & $(0.227)$ & & $(0.273)$ & \\
\hline \multirow[t]{2}{*}{$S I Z E$} & 0.110 & 8.56 & $0.11 * * *$ & 8.64 & $0.11 * * *$ & 8.61 \\
\hline & $(0.013)$ & & $(0.013)$ & & $(0.013)$ & \\
\hline \multirow[t]{2}{*}{$R \& D$} & $0.71 * * *$ & 16.88 & $0.16^{* * *}$ & 4.27 & $0.15 * * *$ & 4.10 \\
\hline & $(0.042)$ & & $(0.037)$ & & $(0.037)$ & \\
\hline \multirow[t]{2}{*}{$T L C F$} & -0.02 & -0.54 & -0.02 & -0.58 & -0.02 & -0.62 \\
\hline & $(0.032)$ & & $(0.032)$ & & $(0.032)$ & \\
\hline \multirow[t]{2}{*}{ LIQUIDITY } & $-0.08 * * *$ & -3.29 & $-0.10 * * *$ & -3.93 & $-0.13^{* * *}$ & -4.61 \\
\hline & $(0.024)$ & & $(0.026)$ & & $(0.028)$ & \\
\hline \multirow[t]{2}{*}{ FINCONSTRI } & $0.14 *$ & 1.82 & & & & \\
\hline & $(0.076)$ & & & & & \\
\hline \multirow[t]{2}{*}{ FINCONSTR2 } & & & 0.05 & 1.30 & & \\
\hline & & & $(0.041)$ & & & \\
\hline \multirow[t]{2}{*}{ FINCONSTR3 } & & & & & $0.07 * *$ & 2.44 \\
\hline & & & & & $(0.027)$ & \\
\hline \multirow[t]{2}{*}{ Constant } & $-1.81 * * *$ & -5.29 & $-1.84 * * *$ & -4.93 & $-1.76^{* * *}$ & -5.19 \\
\hline & $(0.34)$ & & $(0.33)$ & & $(0.34)$ & \\
\hline Fixed effects & yes & & yes & & yes & \\
\hline Observations & 6900 & & 6900 & & 6900 & \\
\hline$R^{2} /$ Pseudo $R^{2}$ & 0.06 & & 0.05 & & 0.06 & \\
\hline
\end{tabular}




\section{The Effects of Growth Opportunities}

Gay and Nam (1998) suggest that two conditions should be prevalent to motivate firms to hedge. Firstly, a firm must have access to positive NPV projects and secondly there must be the probability that the firm will have a cash flow constraint. Researchers have used multiple proxies with varying results and Gay and Nam (1998) indicate that this may be due to weak proxies that contain substantial noise. Therefore, the authors use five different proxies to test the hypothesis.

In order to control for the growth opportunities, I follow Gay and Nam (1998) and use three alternative proxies for growth opportunities: Tobins Q (Q), Capital Expenditure (CAPEX1) and market-to-book ratio (MB). The results for the three models are reported in Table 7.9. The coefficients for the corporate governance variables are consistent across the three models and similar to that depicted in the main simultaneous equations model exhibited in Table 7.7. 
Table 7.9: Derivatives Robustness Tests - Growth Measures

\begin{tabular}{|c|c|c|c|c|c|c|}
\hline \multicolumn{7}{|c|}{ 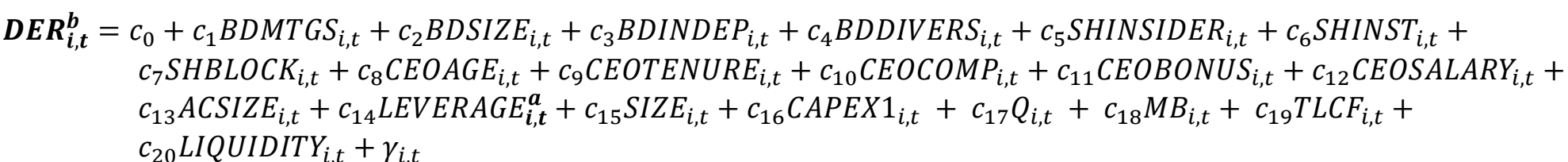 } \\
\hline \multirow[b]{2}{*}{ VARIABLE } & \multicolumn{2}{|c|}{ Model 1} & \multicolumn{2}{|c|}{ Model 2} & \multicolumn{2}{|c|}{ Model 3} \\
\hline & Coefficient & t-stat & Coefficient & z-stat & Coefficient & z-stat \\
\hline$B D M T G S$ & $\begin{array}{c}-0.00 \\
(0.004)\end{array}$ & 0.27 & $\begin{array}{c}-0.00 \\
(0.004)\end{array}$ & 0.23 & $\begin{array}{c}-0.00 \\
(0.004)\end{array}$ & 0.47 \\
\hline$B D S I Z E$ & $\begin{array}{c}0.02 * \\
(0.013)\end{array}$ & 1.70 & $\begin{array}{c}0.04 * * * \\
(0.014)\end{array}$ & 3.12 & $\begin{array}{c}0.04 * * * \\
(0.013)\end{array}$ & 2.65 \\
\hline$B D I N D E P$ & $\begin{array}{c}-0.01 \\
(0.014)\end{array}$ & -0.76 & $\begin{array}{c}0.021 \\
(0.014)\end{array}$ & -1.46 & $\begin{array}{c}0.018 \\
(0.014)\end{array}$ & -1.30 \\
\hline BDDIVERS & $\begin{array}{c}-0.03 \\
(0.020)\end{array}$ & -1.61 & $\begin{array}{c}-0.02 \\
(0.020)\end{array}$ & -1.22 & $\begin{array}{c}-0.03 \\
(0.019)\end{array}$ & -1.35 \\
\hline SHINSIDER & $\begin{array}{c}-0.35 * * * \\
(0.104)\end{array}$ & -3.39 & $\begin{array}{c}-0.44 * * * \\
(0.104)\end{array}$ & -4.26 & $\begin{array}{c}-0.44 * * * \\
(0.103)\end{array}$ & -4.26 \\
\hline SHINST & $\begin{array}{c}0.11 * * * \\
(0.035)\end{array}$ & 3.26 & $\begin{array}{c}0.01 * * * \\
(0.036)\end{array}$ & 2.76 & $\begin{array}{c}0.11 * * * \\
(0.035)\end{array}$ & 3.10 \\
\hline$S H B L O C K$ & $\begin{array}{c}0.00 \\
(0.113)\end{array}$ & 0.03 & $\begin{array}{c}-0.07 \\
(0.112)\end{array}$ & -0.65 & $\begin{array}{c}-0.06 \\
(0.111)\end{array}$ & -0.51 \\
\hline CEOAGE & $\begin{array}{c}0.004 \\
(0.002)\end{array}$ & 1.54 & $\begin{array}{c}0.003 \\
(0.002)\end{array}$ & 1.34 & $\begin{array}{c}0.004 \\
(0.002)\end{array}$ & 1.57 \\
\hline CEOTENURE & $\begin{array}{l}-0.000 \\
(0.002)\end{array}$ & -0.01 & $\begin{array}{c}0.000 \\
(0.002)\end{array}$ & 0.22 & $\begin{array}{c}0.000 \\
(0.002)\end{array}$ & 0.05 \\
\hline СЕОСОМР & $\begin{array}{c}-0.07 * * * \\
(0.021)\end{array}$ & -3.62 & $\begin{array}{c}-0.05^{* *} \\
(0.020)\end{array}$ & -2.58 & $\begin{array}{c}-0.06 * * * \\
(0.020)\end{array}$ & -2.99 \\
\hline CEOBONUS & $0.01 * * *$ & 2.65 & $\begin{array}{l}0.01 * * * \\
315\end{array}$ & 2.82 & $0.01 * * *$ & 2.87 \\
\hline
\end{tabular}




\begin{tabular}{|c|c|c|c|c|c|c|}
\hline \multirow[b]{2}{*}{ VARIABLE } & \multicolumn{2}{|c|}{ Model 1} & \multicolumn{2}{|c|}{ Model 2} & \multicolumn{2}{|c|}{ Model 3} \\
\hline & Coefficient & t-stat & Coefficient & z-stat & Coefficient & z-stat \\
\hline & $(0.003)$ & & $(0.003)$ & & $(0.003)$ & \\
\hline \multirow[t]{2}{*}{ CEOSALARY } & $0.11^{* * *}$ & 3.66 & $0.10^{* * *}$ & 3.17 & $0.10^{* * *}$ & 3.38 \\
\hline & $(0.031)$ & & $(0.031)$ & & $(0.031)$ & \\
\hline \multirow[t]{2}{*}{$A C S I Z E$} & -0.01 & -1.08 & -0.01 & -1.37 & -0.01 & -1.04 \\
\hline & $(0.009)$ & & (0.009) & & $(0.009)$ & \\
\hline \multirow[t]{2}{*}{$L E V E R A G E^{a}$} & 0.24 & 1.14 & $-0.69 * *$ & -2.10 & -0.02 & -0.10 \\
\hline & $(0.215)$ & & $(0.331)$ & & $(0.256)$ & \\
\hline \multirow[t]{2}{*}{ SIZE } & $0.057 * * *$ & 3.56 & $0.10 * * *$ & 8.05 & $0.11 * * *$ & 8.45 \\
\hline & $(0.016)$ & & $(0.013)$ & & $(0.013)$ & \\
\hline \multirow[t]{2}{*}{ CAPEXI } & $0.66 * * *$ & 4.77 & & & & \\
\hline & $(0.014)$ & & & & & \\
\hline \multirow[t]{2}{*}{$Q$} & & & $-0.47 * * *$ & -5.77 & & \\
\hline & & & $(0.081)$ & & & \\
\hline \multirow{2}{*}{$M B$} & & & & & $-0.08 * * *$ & -2.94 \\
\hline & & & & & $(0.027)$ & \\
\hline \multirow[t]{2}{*}{$T L C F$} & -0.01 & -0.42 & 0.03 & -0.88 & 0.02 & -0.68 \\
\hline & $(0.033)$ & & 0.033 & & 0.033 & \\
\hline \multirow[t]{2}{*}{ LIQUIDITY } & $-0.10 * * *$ & -3.91 & $-0.14 * * *$ & -4.95 & $-0.13 * * *$ & -4.73 \\
\hline & $(0.026)$ & & $(0.28)$ & & $(0.28)$ & \\
\hline \multirow[t]{2}{*}{ Constant } & $-1.64 * * *$ & -4.82 & $-1.04 * * *$ & -2.97 & $-1.74 * * *$ & -5.12 \\
\hline & $(0.34)$ & & $(0.35)$ & & $(0.34)$ & \\
\hline Fixed effects & yes & & yes & & yes & \\
\hline Observations & 6900 & & 6900 & & 6900 & \\
\hline Pseudo $R^{2}$ & 0.06 & & 0.06 & & 0.05 & \\
\hline
\end{tabular}




\section{Investment Opportunities and Underinvestment Hypothesis}

Froot et al. (1993) indicate that hedging helps a firm by reducing the underinvestment problem. They suggest that external funds are costlier than internally generated funds. Therefore, risk-management can increase firm value by mitigating the underinvestment problem. Their model predicts a positive relationship between proxies for underinvestment costs and the extent of hedging by the firm. Bartram et al. (2009) and Geczy et al. (1997) prefer to use a different variable to capture the underinvestment constraints by an interaction between investment opportunities and leverage. I use the same methodology in Table 7.10 where I include an additional variable $\left(R \& D \_L E V\right.$ a $)$ to capture effects of the underinvestment problem.

The results for the corporate governance variables, BDSIZE, SHINSIDER, SHINST, CEOCOMP, and CEOBONUS are statistically significant and exhibit the same association with DER. It appears that the additional effect of increased underinvestment problems removes the effect of the CEOSALARY which is now insignificant. However, it appears that the additional constraint provides a stimulus for the other corporate governance mechanisms and BDMTGS, SHBLOCK, and ACSIZE now induce a reduction of hedging activities. Coefficients for all these variables become negative and statistically significant. 
Table 7.5: Derivatives Robustness Tests - Investment Opportunities and Underinvestment Costs

\begin{tabular}{|c|c|c|c|c|}
\hline \multicolumn{5}{|c|}{ 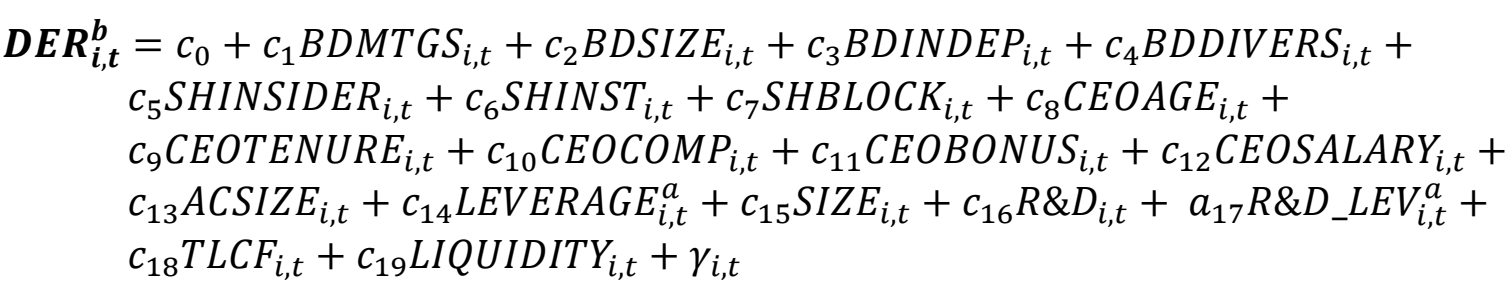 } \\
\hline \multirow[b]{2}{*}{ VARIABLE } & \multicolumn{2}{|c|}{ LEVERAGE } & \multicolumn{2}{|c|}{ DER } \\
\hline & coefficient & z-stat & coefficient & z-stat \\
\hline$\overline{D E R^{b}}$ & $\begin{array}{c}0.05^{* * * *} \\
(0.004)\end{array}$ & 12.40 & & \\
\hline$R O A$ & $\begin{array}{c}-0.03 * * * \\
(0.001)\end{array}$ & -25.55 & & \\
\hline SIZE & $\begin{array}{c}0.05 * * * \\
(0.001)\end{array}$ & 34.43 & & \\
\hline$V O L$ & $\begin{array}{c}0.10 * * * \\
(0.006)\end{array}$ & 15.34 & & \\
\hline$R \& D$ & $\begin{array}{c}-0.10 * * * \\
(0.004)\end{array}$ & -23.29 & $\begin{array}{c}0.76 * * * \\
(0.081)\end{array}$ & 9.36 \\
\hline$B D M T G S$ & & & $\begin{array}{c}-0.02 * * * \\
(0.005)\end{array}$ & -4.80 \\
\hline BDSIZE & & & $\begin{array}{c}0.03 * \\
(0.014)\end{array}$ & 1.96 \\
\hline BDINDEP & & & $\begin{array}{l}-0.020 \\
(0.015)\end{array}$ & -1.37 \\
\hline BDDIVERS & & & $\begin{array}{c}-0.02 \\
(0.020)\end{array}$ & -1.08 \\
\hline SHINSIDER & & & $\begin{array}{c}-0.62 * * * \\
(0.109)\end{array}$ & -5.73 \\
\hline SHINST & & & $\begin{array}{c}0.12 * * * \\
(0.036)\end{array}$ & 3.20 \\
\hline SHBLOCK & & & $\begin{array}{c}-0.43 * * * \\
(0.111)\end{array}$ & -3.84 \\
\hline CEOAGE & & & $\begin{array}{c}0.002 \\
(0.002)\end{array}$ & 0.72 \\
\hline CEOTENURE & & & $\begin{array}{c}0.002 \\
(0.002)\end{array}$ & 0.75 \\
\hline
\end{tabular}




\begin{tabular}{|c|c|c|c|c|}
\hline \multirow[b]{2}{*}{ VARIABLE } & \multicolumn{2}{|c|}{ LEVERAGE } & \multicolumn{2}{|c|}{ DER } \\
\hline & coefficient & z-stat & coefficient & z-stat \\
\hline СЕОСОМР & & & $\begin{array}{l}-0.04 * \\
(0.021)\end{array}$ & -1.78 \\
\hline CEOBONUS & & & $\begin{array}{c}0.018 * * * \\
(0.003)\end{array}$ & 6.56 \\
\hline CEOSALARY & & & $\begin{array}{c}0.04 \\
0.029\end{array}$ & 1.47 \\
\hline$A C S I Z E$ & & & $\begin{array}{c}-0.02 * * * \\
(0.010)\end{array}$ & -2.60 \\
\hline LEVERAGE $E^{a}$ & & & $\begin{array}{c}6.20 * * * \\
(0.283)\end{array}$ & 21.88 \\
\hline$S I Z E$ & & & $\begin{array}{l}-0.006 \\
(0.014)\end{array}$ & -0.45 \\
\hline$T L C F$ & & & $\begin{array}{c}-0.03 \\
(0.034)\end{array}$ & -0.93 \\
\hline LIQUIDITY & & & $\begin{array}{c}-0.09 * * * \\
(0.023)\end{array}$ & -3.87 \\
\hline$R \& D \_L E V^{a}$ & & & $\begin{array}{c}-0.25 \\
(0.353)\end{array}$ & -0.70 \\
\hline Constant & $\begin{array}{c}-0.43 * * * \\
(0.029)\end{array}$ & -14.95 & $\begin{array}{c}-1.54 * * * \\
(0.33)\end{array}$ & -4.69 \\
\hline Year effects & yes & & yes & \\
\hline Industry effects & yes & & yes & \\
\hline Observations & 6900 & & 6900 & \\
\hline$R^{2} /$ Pseudo $R^{2}$ & 0.34 & & 0.14 & \\
\hline $\begin{array}{l}a, b \text { denote the prec } \\
\text { test of the null hy } \\
\text { show statistical } \\
\text { robust standard e } \\
\text { See Tables } 5.3 \\
\text { Dependent Varia }\end{array}$ & $\begin{array}{l}\text { value from } t \\
\text { sis that the } \\
\text { cance at the } \\
\text { e given in } p \\
\text { for definit } \\
\text { all the mod }\end{array}$ & $\begin{array}{l}\text { ler equat } \\
\text { icient is } \\
1,0.05 \text { a } \\
\text { heses. Tl } \\
\text { of depe } \\
\text { DER }\end{array}$ & $\begin{array}{l}\text { ne p-value } f \\
\text { s indicated } \\
10 \text { levels re } \\
\text { z values at } \\
\text { and indepe }\end{array}$ & $\begin{array}{l}\text { one-tai } \\
\text { k, **, } * \\
\text { pely, a } \\
\text { provid } \\
\text { variabl }\end{array}$ \\
\hline
\end{tabular}




\section{The Effects of Varying Levels of Leverage}

Financial distress is an important motivation for hedging. Empirical research indicates that there is a positive association between financial distress and hedging for firms. However, this may vary with the levels of financial distress. Purnanandum (2004) indicates that there exists a strong positive relationship between leverage and hedging for firms with high deadweight losses ${ }^{46}$. However, this relationship reverses for very high levels of leverage, while there exists a positive relationship for firms with moderate levels of debt. To test this, the author includes a leverage squared variable for financial distress. He also includes: an interaction variable between leverage ratio and squared leverage with the inverse of book to market ratio. In line with earlier empirical work, he suggests that low book-to-market firms experience higher deadweight losses of distress and expects to find a positive coefficient on the leverage*1/BM ratio and a negative coefficient on leverage ${ }^{2 *} 1 / \mathrm{BM}^{47}$

In order to investigate whether the levels of leverage would have an influence on my results, I follow Purnanandum (2004) and perform an additional sensitivity analysis using the author's model specifications. In Table 7.11, I include square of predicted leverage as LEVERAGE2 ${ }^{c}$ in the model in addition to LEVERAGEa, where both are the predicted value from the first equation. Additionally, I take the interaction

\footnotetext{
${ }^{46}$ Purnanandam (2004) provide anecdotal evidence of deadweight loss existing amongst some firms.

${ }^{47}$ To gain further insight into the non-monotonicity of leverage and hedging activities, the author conducts spline regression across three groups - (i) low leverage group (firms in deciles 1-5); (ii) moderate-to-high leverage group (deciles 6-9) and (iii) extremely leveraged group (decile 10). For the first group (low leverage) the marginal effect of leverage on hedging is positive (0.0325). Their results show a positive effect for the second group (moderate-to-high leverage) with marginal effect of 0.1085 , and the marginal effect of leverage on hedging becomes negative $(-0.044)$ for the firms in top decile. This confirms the non-monotonic relation between leverage and hedging and indicates that it becomes negative for firms in top $10 \%$ of financial distress likelihood (Purnanandam, 2004; Purnanandam, 2008).
} 
variables of leverage and leverage squared, with the inverse book-to-market ratio taken as LEVERAGE ${ }_{-}^{\mathrm{a}} 1 /(\mathrm{BV} / \mathrm{MV})$ and LEVERAGE2 ${ }^{\mathrm{c}} \_1 /(\mathrm{BV} / \mathrm{MV})$ respectively.

As expected, in keeping with Purnanandum (2004, 2008), I find a negative effect of leverage squared which is significant at $1 \%$ level. However, both interaction variables for leverage are not significant.

When we look at the results for corporate governance variables there is no change in my results for SHINSIDER, SHINST, CEOCOMP, CEOBONUS and CEOSALARY. They are statistically significant and exhibit the same association with DER as per predictions. However, the introduction of high financial distress through higher leverage takes away the effects of BDSIZE which is now insignificant. Interestingly, the results for BDMTGS, SHBLOCK, and ACSIZE become negative and statistically significant. Interestingly, it appears that this higher financial leverage seems to motivate these governance mechanisms to reduce derivatives. The results are aligned with Purananandum's (2008) contention of a non-monotonic relation between higher levels of leverage and hedging, which also seems to have an impact on the governance variables.

\section{The Effects of Alternative Measures}

In Table 7.12, I further change measures for all the control variables: investment growth is now CAPEX1, size is depicted as a percentage of firm value (SALES/VALUE) and the quick ratio is now taken as the ratio of cash-to-total assets to proxy for liquidity. The results for corporate governance are consistent with the main regression results. 


\section{Table 7.6: Derivatives Robustness Tests - Levels of Leverage}

$$
\begin{aligned}
& \text { LEVERAGE } \boldsymbol{E}_{\mathrm{i}, \mathrm{t}}^{\mathrm{a}}=b_{0}+b_{1} D E R_{i, t}^{\mathrm{b}}+b_{2} R \& D_{i, t}+b_{3} R O A_{i, t}+b_{4} S_{I Z E_{i, t}}+b_{5} V O L_{i, t}+\beta_{i, t} \\
& \boldsymbol{D E} \boldsymbol{R}_{\boldsymbol{i}, \boldsymbol{t}}^{\boldsymbol{b}}=c_{0}+c_{1} \text { BDMTGS }_{i, t}+c_{2} \text { BDSIZE }_{i, t}+c_{3} \text { BDINDEP }_{i, t}+c_{4} \text { BDDIVERS }_{i, t}+ \\
& c_{5} \text { SHINSIDER }_{i, t}+c_{6} \text { SHINST }_{i, t}+c_{7} \text { SHBLOCK }_{i, t}+c_{8} \text { CEOAGE }_{i, t}+ \\
& c_{9} \text { CEOTENURE }_{i, t}+c_{10} \text { CEOCOMP }_{i, t}+c_{11} \text { CEOBONUS }_{i, t}+c_{12} \text { CEOSALARY }_{i, t}+ \\
& c_{13} A_{C S I Z E_{i, t}}+c_{14} L E V E R A G E_{i, t}^{a}+c_{15} L E V E R A G E 2_{i, t}^{c}+c_{16} \operatorname{SIZE}_{i, t}+ \\
& c_{16} R \& D_{i, t}+a_{17} B V / M V_{i, t}+c_{18} T L C F_{i, t}+c_{19} L_{I Q U I D I T Y} Y_{i, t}+a_{20} L E V E R A G E^{a}{ }_{-1} \\
& (B V / M V)_{i, t}+a_{21} L_{E V E R A G E 2^{c}{ }_{-} 1 /(B V / M V)_{i, t}}+\gamma_{i, t}
\end{aligned}
$$

\begin{tabular}{|c|c|c|c|c|}
\hline \multirow[b]{2}{*}{ VARIABLE } & \multicolumn{2}{|c|}{ LEVERAGE } & \multicolumn{2}{|c|}{ DER } \\
\hline & Coefficient & t-stat & Coefficient & z-stat \\
\hline$D E R^{b}$ & $\begin{array}{c}0.05^{* * * *} \\
(0.004)\end{array}$ & 12.40 & & \\
\hline$R O A$ & $\begin{array}{c}-0.03 * * * \\
(0.001)\end{array}$ & -25.55 & & \\
\hline SIZE & $\begin{array}{c}0.05^{* * * *} \\
(0.001)\end{array}$ & 34.43 & & \\
\hline$V O L$ & $\begin{array}{c}0.10^{* * * *} \\
(0.006)\end{array}$ & 15.34 & & \\
\hline$R \& D$ & $\begin{array}{c}-0.10 * * * \\
(0.004)\end{array}$ & -23.29 & $\begin{array}{c}0.74 * * * \\
(0.043)\end{array}$ & 17.33 \\
\hline$B D M T G S$ & & & $\begin{array}{c}-0.02 * * * \\
(0.005)\end{array}$ & -4.64 \\
\hline BDSIZE & & & $\begin{array}{c}0.02 \\
(0.014)\end{array}$ & 1.38 \\
\hline BDINDEP & & & $\begin{array}{c}-0.01 \\
(0.015)\end{array}$ & -1.07 \\
\hline BDDIVERS & & & $\begin{array}{c}-0.02 \\
(0.020)\end{array}$ & -1.03 \\
\hline SHINSIDER & & & $\begin{array}{c}-0.60 * * * \\
(0.108)\end{array}$ & -5.55 \\
\hline SHINST & & & $\begin{array}{c}0.12 * * * * \\
(0.037)\end{array}$ & 3.35 \\
\hline SHBLOCK & & & $\begin{array}{c}-0.38 * * * \\
(0.113)\end{array}$ & -3.39 \\
\hline CEOAGE & & & $\begin{array}{c}0.002 \\
(0.002)\end{array}$ & 0.90 \\
\hline CEOTENURE & & & $\begin{array}{c}0.002 \\
(0.002)\end{array}$ & 0.86 \\
\hline
\end{tabular}




\begin{tabular}{|c|c|c|c|c|}
\hline \multirow[b]{2}{*}{ VARIABLE } & \multicolumn{2}{|c|}{ LEVERAGE } & \multicolumn{2}{|c|}{ DER } \\
\hline & Coefficient & t-stat & Coefficient & z-stat \\
\hline CEOCOMP & & & $\begin{array}{l}-0.04 * * \\
(0.021)\end{array}$ & -1.97 \\
\hline CEOBONUS & & & $\begin{array}{l}0.02 * * * \\
(0.003)\end{array}$ & 6.44 \\
\hline CEOSALARY & & & $\begin{array}{c}0.06^{*} \\
(0.031)\end{array}$ & 1.84 \\
\hline$A C S I Z E$ & & & $\begin{array}{l}-0.02 * * \\
(0.010)\end{array}$ & -2.59 \\
\hline$L E V E R A G E^{a}$ & & & $\begin{array}{c}8.07 * * * \\
(0.732)\end{array}$ & 11.03 \\
\hline LEVERAGE2 $2^{c}$ & & & $\begin{array}{c}-5.00 * * * \\
(1.288)\end{array}$ & -3.88 \\
\hline SIZE & & & $\begin{array}{l}-0.016 \\
(0.014)\end{array}$ & -1.14 \\
\hline$B V / M V$ & & & $\begin{array}{l}0.13 * \\
(0.070\end{array}$ & -1.86 \\
\hline$T L C F$ & & & $\begin{array}{l}-0.05 \\
(0.034)\end{array}$ & -1.34 \\
\hline LIQUIDITY & & & $\begin{array}{c}-0.08 * * * \\
(0.023)\end{array}$ & -3.54 \\
\hline LEVERAGE $E^{a} 1 /(B V / M V)$ & & & $\begin{array}{c}1.10 * \\
(0.587)\end{array}$ & 1.87 \\
\hline LEVERAGE2 ${ }^{c} \_1 /(B V / M V)$ & & & $\begin{array}{c}-0.69 \\
(1.134)\end{array}$ & -0.61 \\
\hline Constant & $\begin{array}{c}-0.43 * * * \\
(0.029)\end{array}$ & -14.94 & $\begin{array}{c}-1.72 * * * \\
(0.34)\end{array}$ & -5.05 \\
\hline Year effects & yes & & yes & \\
\hline Industry effects & yes & & yes & \\
\hline Observations & 6900 & & 6900 & \\
\hline$R^{2} /$ Pseudo $R^{2}$ & 0.34 & & 0.15 & \\
\hline
\end{tabular}


Table 7.7: Derivatives Robustness Tests - Alternative Variables

$\operatorname{LEVERAGE}{ }_{i, t}^{\mathrm{a}}=b_{0}+b_{1} D E R_{i, t}^{\boldsymbol{b}}+b_{2} R_{0 A} A_{i, t}+b_{3} \operatorname{SALES}_{\mathrm{V} A L U E_{i, t}}+b_{4} C A P E X 1_{i, t}+\beta_{i, t}$

$$
\begin{aligned}
& \boldsymbol{D E} \boldsymbol{R}_{\boldsymbol{i}, \boldsymbol{t}}^{\boldsymbol{b}}=c_{0}+c_{1} B D M T G S_{i, t}+c_{2} \text { BDSIZE }_{i, t}+c_{3} \text { BDINDEP }_{i, t}+c_{4} \text { BDDIVERS }_{i, t}+ \\
& c_{5} \text { SHINSIDER }_{i, t}+c_{6} \text { SHINST }_{i, t}+c_{7} \text { SHBLOCK }_{i, t}+c_{8} \text { CEOAGE }_{i, t}+ \\
& c_{9} \text { CEOTENURE }_{i, t}+c_{10} \text { CEOCOMP }_{i, t}+c_{11} \text { CEOBONUS }_{i, t}+c_{12} \text { CEOSALARY }_{i, t}+
\end{aligned}
$$

\begin{tabular}{|c|c|c|c|c|}
\hline \multirow[b]{2}{*}{ VARIABLE } & \multicolumn{2}{|c|}{ LEVERAGE } & \multicolumn{2}{|c|}{ DER } \\
\hline & Coefficient & z-stat & Coefficient & z-stat \\
\hline$D E R^{b}$ & $\begin{array}{c}0.21 * * * \\
(0.019)\end{array}$ & 10.81 & & \\
\hline$R O A$ & $\begin{array}{c}-0.03 * * * \\
(0.002)\end{array}$ & -16.33 & & \\
\hline SALES/VALUE & $\begin{array}{c}0.01 * * * \\
(0.003)\end{array}$ & 5.92 & & \\
\hline CAPEXI & $\begin{array}{c}-0.10 * * * \\
(0.004)\end{array}$ & 2.61 & & \\
\hline$B D M T G S$ & & & $\begin{array}{c}0.00 \\
(0.004)\end{array}$ & 0.41 \\
\hline BDSIZE & & & $\begin{array}{c}0.02 * \\
(0.013)\end{array}$ & 1.74 \\
\hline BDINDEP & & & $\begin{array}{c}0.007 \\
(0.014)\end{array}$ & -0.48 \\
\hline BDDIVERS & & & $\begin{array}{c}-0.01 \\
(0.020)\end{array}$ & -0.61 \\
\hline SHINSIDER & & & $\begin{array}{c}-0.35^{* * * *} \\
(0.107)\end{array}$ & -3.28 \\
\hline SHINST & & & $\begin{array}{c}0.11 * * * \\
(0.035)\end{array}$ & 3.31 \\
\hline SHBLOCK & & & $\begin{array}{c}0.01 \\
(0.118)\end{array}$ & 0.07 \\
\hline CEOAGE & & & $\begin{array}{c}0.003 \\
(0.002)\end{array}$ & 1.33 \\
\hline CEOTENURE & & & $\begin{array}{l}-0.000 \\
(0.002)\end{array}$ & -0.22 \\
\hline СЕОСОМР & & & $\begin{array}{c}-0.06^{* * * *} \\
(0.020)\end{array}$ & -2.97 \\
\hline
\end{tabular}

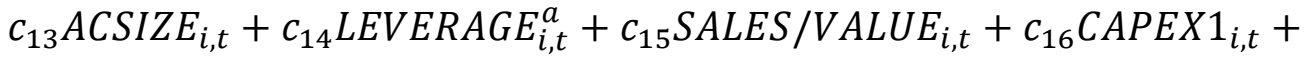

$$
\begin{aligned}
& c_{17} T_{L C F_{i, t}}+c_{18} C A S H / T A+\gamma_{i, t}
\end{aligned}
$$




\begin{tabular}{|c|c|c|c|c|}
\hline \multirow[b]{2}{*}{ VARIABLE } & \multicolumn{2}{|c|}{ LEVERAGE } & \multicolumn{2}{|c|}{ DER } \\
\hline & Coefficient & z-stat & Coefficient & z-stat \\
\hline \multirow[t]{2}{*}{ CEOBONUS } & & & $0.01 * *$ & 2.34 \\
\hline & & & $(0.003)$ & \\
\hline \multirow[t]{2}{*}{ CEOSALARY } & & & $0.12 * * *$ & 3.76 \\
\hline & & & $(0.032)$ & \\
\hline \multirow[t]{2}{*}{$A C S I Z E$} & & & -0.01 & -0.71 \\
\hline & & & $(0.009)$ & \\
\hline \multirow[t]{2}{*}{$L E V E R A G E^{a}$} & & & 0.30 & 1.10 \\
\hline & & & $(0.272)$ & \\
\hline \multirow{2}{*}{ SALES/VALUE } & & & -0.012 & -1.07 \\
\hline & & & $(0.012)$ & \\
\hline \multirow[t]{2}{*}{$C A P E X 1$} & & & $0.09 * * *$ & 7.40 \\
\hline & & & $(0.012)$ & \\
\hline \multirow[t]{2}{*}{$T L C F$} & & & -0.02 & -0.67 \\
\hline & & & $(0.034)$ & \\
\hline \multirow[t]{2}{*}{ CASH/TA } & & & -1.11 & -5.99 \\
\hline & & & $(0.185)$ & \\
\hline \multirow[t]{2}{*}{ Constant } & $0.21 * * *$ & 13.44 & $-1.49 * * *$ & -4.30 \\
\hline & $(0.015)$ & & $(0.348)$ & \\
\hline Year effects & yes & & yes & \\
\hline Industry effects & yes & & yes & \\
\hline Observations & 6900 & & 6900 & \\
\hline$R^{2} /$ Pseudo $R^{2}$ & 0.34 & & 0.12 & \\
\hline
\end{tabular}

${ }^{a, b}$ denote the predicted value from the other equation. The $\mathrm{p}$-value for the onetailed test of the null hypothesis that the coefficient is zero is indicated as $* * *$, $* *$, * to show statistical significance at the $0.01,0.05$ and 0.10 levels respectively, and robust standard errors are given in parentheses. The $t$ and $z$ values are also provided. See Tables 5.3 and 5.4 for definitions of dependent and independent variables. 


\section{The Effects of Small and Large Firm Size on Risk Management}

Firm size is a strong determinant of a firm's hedging activities. Purnanandam (2004) suggests that despite the control for effects of size, the pooled regression analysis for all firms may hide the hedging behavior of large and small firms if they have significant different characteristics and hedging motivations. Therefore, I perform a sensitivity test to examine whether such a size differences could affect hedging activities.

In the manner of Purnanandam (2004) I divide the full sample into two groups based on whether the firm size, taken as total assets, is above or below the sample median. The results are provided in Table 7.13. Both samples support the theories of investment growth opportunities related to hedging activities. For both groups, I find a positive and significant coefficient on the $R \& D$ variable. These findings are consistent with the underinvestment cost model of Froot et al. (1993). The large-firm sample provides evidence in support of the underinvestment cost theories and financial distress theories of hedging. On the other hand, the hedging behavior of small firms is explained primarily by economies of scale. Also, smaller firms use liquid assets as a substitute for hedging which is evidenced through the negative sign on the quick ratio which is significant at $1 \%$ level.

With respect to the corporate governance variables the results are similar between the two groups and in keeping with my findings. However, while board size is insignificant for the larger firms, the smaller firms show significant results for board size. Largely, the results do not show significant differences in the governance mechanisms for large and small firms. 
Table 7.8: Derivatives Robustness Tests - Firm Size Sub-Samples

$$
\begin{aligned}
& \boldsymbol{L E V E R A G E} \underset{i, t}{\boldsymbol{a}}=b_{0}+b_{1} D E R_{i, t}^{\mathrm{b}}+b_{2} R \& D_{i, t}+b_{3} R O A_{i, t}+b_{4} S I Z E_{i, t}+b_{5} V O L_{i, t}+\beta_{i, t} \\
& \boldsymbol{D E} \boldsymbol{R}_{\boldsymbol{i}, \boldsymbol{t}}^{\boldsymbol{b}}=c_{0}+c_{1} B D M T G S_{i, t}+c_{2} \text { BDSIZE }_{i, t}+c_{3} \text { BDINDEP }_{i, t}+c_{4} \text { BDDIVERS }_{i, t}+ \\
& c_{5} \text { SHINSIDER }_{i, t}+c_{6} \text { SHINST }_{i, t}+c_{7} \text { SHBLOCK }_{i, t}+c_{8} C_{2} O A G E_{i, t}+ \\
& c_{9} \text { CEOTENURE } E_{i, t}+c_{10} \text { CEOCOMP }{ }_{i, t}+c_{11} \text { CEOBONUS } S_{i, t}+c_{12} \text { CEOSALARY } Y_{i, t}+ \\
& c_{13} A_{C S I Z E_{i, t}}+c_{14} L E V E R A G E_{i, t}^{a}+c_{15} \operatorname{SIZE}_{i, t}+c_{16} R \& D_{i, t}+c_{17} T L C F_{i, t}+ \\
& c_{18} \text { LIQUIDITY }_{i, t}+c_{19} \text { FINCONSTR }_{i, t}+\gamma_{i, t}
\end{aligned}
$$

\begin{tabular}{|c|c|c|c|c|}
\hline \multirow[b]{2}{*}{ VARIABLE } & \multicolumn{2}{|c|}{$\begin{array}{c}\text { TA>median } \\
\text { DER }\end{array}$} & \multicolumn{2}{|c|}{$\begin{array}{c}\text { TA }<\text { median } \\
\text { DER }\end{array}$} \\
\hline & coefficient & z-stat & coefficient & z-stat \\
\hline$B D M T G S$ & $\begin{array}{c}0.00 \\
(0.007)\end{array}$ & 0.11 & $\begin{array}{l}-0.000 \\
(0.006)\end{array}$ & -0.43 \\
\hline$B D S I Z E$ & $\begin{array}{c}0.02 \\
(0.02)\end{array}$ & 0.93 & $\begin{array}{l}0.04 * * \\
(0.021)\end{array}$ & 2.12 \\
\hline BDINDEP & $\begin{array}{c}-0.01 \\
(0.018)\end{array}$ & -0.55 & $\begin{array}{c}-0.03 \\
(0.022)\end{array}$ & -1.21 \\
\hline BDDIVERS & $\begin{array}{c}0.02 \\
(0.026)\end{array}$ & -0.84 & $\begin{array}{c}-0.00 \\
(0.031)\end{array}$ & 0.01 \\
\hline SHINSIDER & $\begin{array}{l}-0.35^{* *} \\
(0.151)\end{array}$ & -2.34 & $\begin{array}{c}-0.52 * * * \\
(0.147)\end{array}$ & -3.55 \\
\hline SHINST & $\begin{array}{c}0.11 * * \\
(0.05)\end{array}$ & 2.09 & $\begin{array}{c}0.13 * * * \\
(0.047)\end{array}$ & 2.72 \\
\hline SHBLOCK & $\begin{array}{c}-0.20 \\
(0.164)\end{array}$ & -1.23 & $\begin{array}{c}-0.17 \\
(0.155)\end{array}$ & -1.11 \\
\hline$C E O A G E$ & $\begin{array}{c}0.00 \\
(0.003)\end{array}$ & 0.84 & $\begin{array}{c}0.005 \\
(0.003)\end{array}$ & 1.63 \\
\hline CEOTENURE & $\begin{array}{c}0.00 \\
(0.003)\end{array}$ & 0.15 & $\begin{array}{c}0.000 \\
(0.003)\end{array}$ & 0.08 \\
\hline СЕОСОМР & $\begin{array}{c}-0.08 * * * \\
(0.026)\end{array}$ & -2.97 & $\begin{array}{c}-0.06 * * \\
(0.020)\end{array}$ & -3.24 \\
\hline CEOBONUS & $\begin{array}{c}0.01 * * * \\
(0.004)\end{array}$ & 2.86 & $\begin{array}{l}0.01 * * \\
(0.004)\end{array}$ & 2.26 \\
\hline CEOSALARY & $\begin{array}{c}0.10^{* * * *} \\
(0.036)\end{array}$ & 2.68 & $\begin{array}{c}0.12 * \\
(0.064)\end{array}$ & 1.88 \\
\hline
\end{tabular}




\begin{tabular}{|c|c|c|c|c|}
\hline \multirow[b]{2}{*}{ VARIABLE } & \multicolumn{2}{|c|}{$\begin{array}{c}\text { TA>median } \\
\text { DER }\end{array}$} & \multicolumn{2}{|c|}{$\begin{array}{c}\text { TA }<\text { median } \\
\text { DER }\end{array}$} \\
\hline & coefficient & z-stat & coefficient & z-stat \\
\hline$A C S I Z E$ & $\begin{array}{c}0.011 \\
(0.012)\end{array}$ & -0.96 & $\begin{array}{c}-0.00 \\
(0.015)\end{array}$ & -0.24 \\
\hline LEVERAGE $E^{a}$ & $\begin{array}{c}0.54^{*} \\
(0.289)\end{array}$ & 1.88 & $\begin{array}{c}0.71 \\
(0.472)\end{array}$ & 1.51 \\
\hline$S I Z E$ & $\begin{array}{c}-0.01 \\
(0.022)\end{array}$ & -0.39 & $\begin{array}{c}0.14 * * * \\
(0.021)\end{array}$ & 6.46 \\
\hline$R \& D$ & $\begin{array}{c}0.17 * * * \\
(0.053)\end{array}$ & 3.25 & $\begin{array}{l}0.20 * * * \\
(0.053)\end{array}$ & 3.74 \\
\hline$T L C F$ & $\begin{array}{c}0.02 \\
(0.047)\end{array}$ & 0.33 & $\begin{array}{c}-0.06 \\
(0.047)\end{array}$ & -1.36 \\
\hline LIQUIDITY & $\begin{array}{c}0.036 \\
(0.038)\end{array}$ & 0.96 & $\begin{array}{c}-0.14 * * * \\
(0.034)\end{array}$ & -4.18 \\
\hline FINCONSTR1 & $\begin{array}{c}0.14^{*} \\
(0.080)\end{array}$ & 1.76 & $\begin{array}{c}0.11 \\
0.136\end{array}$ & 0.80 \\
\hline Constant & $\begin{array}{c}-0.53 \\
(0.421)\end{array}$ & -1.26 & $\begin{array}{c}-2.36 * * * \\
(0.737)\end{array}$ & -3.20 \\
\hline $\begin{array}{l}\text { Year effects } \\
\text { Industry effects }\end{array}$ & $\begin{array}{l}\text { yes } \\
\text { yes }\end{array}$ & & $\begin{array}{l}\text { yes } \\
\text { yes }\end{array}$ & \\
\hline $\begin{array}{l}\text { Observations } \\
\text { Pseudo } R^{2}\end{array}$ & $\begin{array}{l}3451 \\
0.02\end{array}$ & & $\begin{array}{c}3449 \\
0.05\end{array}$ & \\
\hline
\end{tabular}

${ }^{a, b}$ denote the predicted value from the other equation. The $\mathrm{p}$-value for the one-tailed test of the null hypothesis that the coefficient is zero is indicated as ***,**, * to show statistical significance at the $0.01,0.05$ and 0.10 levels respectively, and robust standard errors are given in parentheses. The $t$ and $z$ values are also provided. See Tables 5.3 and 5.4 for definitions of dependent and independent variables. 


\subsection{Chapter Summary}

This chapter provides findings of the empirical analysis including the descriptive, multivariate and sensitivity analyses. The descriptive analysis reported in this chapter presents statistics for firms that use derivatives and highlights differences based on the various industries and time periods. It also presents the quantitative characteristics of the extent of corporate governance practices as well as the other independent variables following from hedging theories.

The multivariate analysis provides evidence of the association between corporate governance and risk management in firms that use derivatives. The risk-management activities incorporated in this analysis accepts that the firm's capital structure decisions are endogenous to the decisions to use derivatives. Therefore, both aspects need to be examined together and the empirical analysis in this study uses a simultaneous equation methodology to study the effects of leverage and derivatives simultaneously.

The results show that board size, insider shareholders, institutional shareholders, CEO total compensation, CEO base salary and CEO cash bonus are important determinants of derivatives decisions and influence the firm's risk management decisions. The results suggest that larger board size is associated with increase in derivatives. While managerial and director ownership reduces derivatives, institutional shareholding promotes higher level of derivatives use by the firm. The results for CEO compensation indicate that all are strong corporate governance components. CEO bonus and salary increase derivatives and in accordance with theory they are aligned with the managerial risk aversion theory. However, CEO total compensation has a negative association with derivatives, which could be due to a dominating influence of stock options that induces increased risk volatility. The other board characteristics, 
block shareholding, CEO tenure and audit committee size do not impact derivatives hedging decisions.

The sensitivity analyses include tests on the effects of: financial contracting costs, investment growth opportunities and underinvestment problems, the varying levels of leverage, firms size differences and use of alternative measures. All the tests support the main findings and show a consistency across the models. These tests also reveal that in the face of higher leverage and increased underinvestment costs, the other corporate governance mechanisms such as board meetings, block shareholders and audit committee induce reduction in derivatives activities in response to the heightened financial distress.

The findings are consistent with agency-hedging theory expectations and the prior findings in the literature, where available. 


\section{CHAPTER EIGHT: DISCUSSION OF FINDINGS}

\subsection{Introduction}

In this chapter I provide a discussion of the results from my analyses. Section 8.2 provides an overall summary of the findings and conclusions drawn from the empirical work contained in the thesis. This section discusses results of the corporate governance variables with respect to derivatives (Chapter 7), and in relations to the value and risk effects of derivatives (Chapter 6). The section comprises six sub-sections: Corporate Governance and Hedging; Corporate Governance and Speculation; Corporate Governance and Selective Hedging, Corporate Governance as a Determinant of Derivatives, and finally, in Section 8.2.5, I provide a conclusion for the summary and evaluation of the findings.

In Section 8.3 I present a detailed discussion of the results in respect of each corporate governance variable. This section comprises four subsections for board of directors, shareholders, CEO and audit committee size. Finally, in Section 8.4, I conclude with a summary of the chapter.

\subsection{Summary of Findings}

The objective of my study has been to examine the impact of corporate governance on the use of derivatives, and on the value and risk effects of derivatives in non-financial firms. The main purpose for the use of derivatives in non-financial firms is to hedge risk exposure that arises from their operational and financial activities in relation to their business. Unlike financial institutions, trading in derivatives is not part of the business for non-financial firms and as such they are expected to declare to this effect 
in their financial statements. Thus an analysis of corporate governance in non-financial firms must address whether the derivatives were employed to hedge risks and/or to speculate for profits, in order to evaluate the governance effectiveness. Therefore, I evaluate the results of my analyses for the risk and value effects of derivatives, within the context of hedging and speculation as discussed in the framework in Chapter 4 (Section 4.2.3 and Table 4.1).

\subsubsection{Corporate Governance and Hedging}

Risks are bundled together such that a variation in one type of risk may concurrently affect other risks such that management are involved in risk allocation (Schrand and Unal, 1998). This concept is explained in Section 5.6. This suggests that crosspurposes exist with respect to different risks and hedging, so that one risk component could act as a substitute or complement for another or have indirect effects with respect to other risk exposures. Hence, this cross purpose or risk allocation would drive the hedging programs and strategies employed in respect of derivatives. Petersen and Thiarajan (2000) suggest that it is not whether managers manage risk but what types of risks they choose to manage and the tools they use, that is important. My results indicate that corporate governance response varies for the different types of risks examined and it does not provide overly strong support for corporate governance effecting successful hedging strategies within firms that use derivatives.

A summary of the results are provided in Appendix 7 and reveals that of the thirteen corporate governance variables examined, board size, board diversity, CEO tenure, CEO bonus, insider shareholders and audit committee indicate some levels of hedging effectiveness. Board diversity, Board size, CEO tenure and CEO bonus indicate a hedging effect against stock return volatility risk with an accompanying increase in value. Additionally, board diversity hedges for market risk. Insider shareholders 
exhibit a decrease in cash flow volatility, without any increase in value, to indicate a hedging impact. Increase in value is not an objective of hedging and may not be achieved (See Section 4.2.3). Therefore, these results provide evidence of corporate governance hedging behavior. On the other hand, audit committee size reduces cash flow volatility but with an accompanying decrease in value, to indicate ineffective hedging. One reason for this could be that the hedging strategy put in place may have been achieved at excessively high transaction costs to adversely affect profits.

Board diversity is the only corporate governance mechanism that achieves hedging effectiveness. Women directors consistently reduce risk in both equity risk and market risk models, and enhance firm value without showing any signs of speculation. This is in keeping with relevant literature discussed in Section 4.4.

\subsubsection{Corporate Governance and Speculation}

Some of the corporate governance variables in my study show an effect of speculation with accompanying increase in firm risk and firm value. The results for board size, CEO tenure, CEO bonus, CEO salary, institutional shareholders, CEO age, audit committee size, insider shareholders, and block shareholders exhibit speculating activities with derivatives.

CEO age, board meetings, and audit committee size motivate an increase in stock return volatility without any increase in firm value, and CEO age also increases market risk. These corporate governance variables exhibit attempts at speculation but without any accompanying increase in firm value (Appendix 7). This appears to reflect the findings of Adams et al. (2012) who do not find evidence of any positive relations between speculation and shareholder value, and they suggest that the value- 
maximizing drivers postulated by Stulz (1996) are not visible in their sample of firms. The fact of corporate governance in non-financial firms engaging in speculation is in line with the findings of other researchers (Geczy et al., 2007; Weller and Reidenbach, 2011; Zeidan and Mullner, 2015).

With respect to cash flow volatility, board meetings, board size, CEO tenure, CEO compensation, CEO bonus and CEO salary, encourage higher risk taking which may stem from motives to increase profits and income. Cash flow volatility captures earnings volatility (Barton, 2001; Lang et al., 2003; Leuz et al., 2003; Rountree et al., 2008) that managers may want to impact. Li and Stammerjohan (2004) examine the effect of hedge accounting on earnings volatility and find increased effect of earnings volatility with derivatives users. While Puwalski (2003) suggests that firms use derivatives to sort out different types of risk and trade to assist the management in adjusting exposure to specific risk. My results support Geczy et al. (2007) findings that if compensation structure is aligned to profits rather than risk, then it would induce more risk taking.

In respect of corporate governance shareholder characteristics: institutional shareholders, insider shareholders and block shareholding, the results show that they encourage risk taking with respect of stock return volatility and generally have no effect or a reducing effect in respect of cash flow volatility. This supports the findings of David et al. (2015) who suggest that the increase in stock price volatilities are evidenced in relation to the trading shocks of large institutions (and large investors). Due to the granular nature of their portfolios and their market presence, large institutions trade less with the objective to diversify risk than other smaller firms and have a strong positive impact on stock return volatility in firms (David et al., 2015). Institutions and larger block holders have well diversified portfolios and therefore, would not like to incur additional costs of hedging risks when they are already well 
protected. The theory of granularity also suggests that these investors are able to play the markets in their own favor. The firm may be of little importance in the larger investor portfolio, and investors would be more interested in increasing risks in the markets to benefit from shifts in prices. My results support the argument that larger shareholders are impervious to firm risk for their own portfolio gains. Therefore, due to this granular nature and their market presence, large institutions trade less with the objective to diversify risk and increase stock return volatility in firms (David et al., 2015).

Large institutions can also effect asset prices (Barberis et al., 2005; Coval and Stafford, 2007; Greenwood, 2005; Shleifer, 1986; Baker et al., 2011) through their trading strategies. Ferreira and Laux (2007) find evidence of institutions trading activities through merger arbitrage and speculation that increases idiosyncratic risk for firms. ${ }^{48}$ Studies indicate that block holders are well informed about the firm and implement this information into stock price trading and so they may negatively affect stock prices through block selling of shares (Kraus and Stoll, 1972; Mikkelson and Partch, 1985; Scholes, 1972; Sias et al., 2006). The decline in value reflected in my study, could be a result of block holders off-loading firm's shares which sends a signal to the markets that these informed investors consider firm value to be lower (Dou et al., 2014). Further, institutional block holders engender higher information asymmetry in the markets, as they lower the degree of informed trading (Belghitar et al., 2011; Heflin and Shaw, 2000; O'Neill and Swisher, 2003). Elbadry et al. (2015) suggest that while large shareholders can closely monitor management, at the same time they have the power to get managers to act in their best interest to the detriment of other shareholders. This creates uncertainty and insecurity among shareholders that could

\footnotetext{
${ }^{48}$ Others also suggest that institutions cannot easily diversify their idiosyncratic risk (Gabaix, 2011); increase market volatility (Gabaix et al., 2006); impact CDS contracts prices when financially constrained (Siriwardane, 2015); and impact the behavior of small traders (Corsetti et al., 2004).
} 
lead of uncertainty in share prices and higher volatility. Their results show a significant positive relation between asymmetry and ownership concentration. Erkens et al. (2012) also find that large shareholders positively impact stock return volatility and do not effect firm value.

Institutional shareholders, $\mathrm{CEO}$ age and $\mathrm{CEO}$ bonus also speculate in respect of market risk. Overall, board meetings, CEO age, institutional shareholders, block shareholders, CEO compensation and CEO salary only show signs of speculation, without any risk reduction hedging behavior.

\subsubsection{Corporate Governance and Selective Hedging}

The term selective hedging suggests the display of both hedging and speculation through the shifting of derivatives positions in response to market price considerations. I use the term selective hedging when any one corporate governance mechanism exhibits both hedging and speculation.

This study finds a display of both hedging and speculative activities for board size, insider shareholders, CEO tenure, CEO bonus and audit committee that indicate the signs of selective hedging. There are many reasons why firms may engage in selective hedging stemming from asset substitution motives, driven by objectives of wealth transfer or other financial constraint motives (Adam et al., 2012).

My results for corporate governance selective hedging behavior is supported by researchers who find strong support for the selective hedging behavior by nonfinancial firms in the markets. Dolde (1993) reports that almost $90 \%$ of the 244 firms in Fortune 500 firms surveyed sometimes based their hedging on future market 
movements; and Bodnar et al. (1998) use survey data and find that of the 399 US nonfinancial firms around half of them admit to sometimes hedging based on the markets. While Glaum (2002) finds that the risk management practices of their sample of German firms followed risk management strategies oriented to profit increase. Brown et al. (2002) indicate that for their sample of non-financial firms comprising 44 gold producers, managers market views influence the broader financial policies and decisions. This is further supported by Adam and Fernando (2006) who finds that $62 \%$ of the firms in their sample gold mining industry took hedging positions according to future metal prices. Others also find support for the view that selective hedging is a common practice for nonfinancial firms in the financial markets (Baker and Wurgler, 2002; Faulkender, 2005; Graham and Harvey, 2001). These studies observe that nonfinancial firms use derivatives not only to hedge but also for speculation and may vary their derivatives positions in accordance with their market expectations. They provide evidence that the prices in the markets influence derivatives users to switch from hedging to speculation or vice versa.

\subsubsection{Corporate Governance as a Determinant of Derivatives}

With regard to whether there is a relationship between corporate governance and derivatives, the findings show that corporate governance does influence hedging decisions and therefore is an important determinant for the use of derivatives in nonfinancial firms. Of the thirteen corporate governance variables examined, board size, institutional shareholders, older CEOs, CEO bonus and CEO salary increase the amount of derivatives. However, insider shareholders and total CEO compensation decrease the use of derivatives in firms and the results for managerial shareholders, block shareholders, CEO tenure, board independence, board diversity and audit committee size do not exhibit any significant relationship with derivatives. 
The increased derivatives for board size, institutional shareholders, CEO age, CEO bonus and CEO salary has a multidimensional impact. For example: board size achieves hedging effectiveness with respect to stock return volatility, but appears to over-hedge in respect to cash flow volatility to increase risk; institutional shareholders exhibit problems of over-hedging that results in an increase in both equity and market risk, but with a reduction in firm value; CEO age also motivate over hedging to increase both equity and market risk and reduced value; while CEO bonus appears to achieve hedging effectiveness with respect to stock return volatility, but increase both equity and market risk. While CEO salary exhibits speculation with respect to cash flow volatility along with an increase in firm value. Insider shareholders achieve hedging effectiveness with reduction in cash flow volatility. However, they exhibit under-hedging, mismatched risk exposure to increase stock return volatility risk without any increase in value. CEO total compensation also exhibit under-hedging risk exposure to increase cash flow volatility, without any value effect.

The results for derivatives, indicate that corporate governance mechanisms have an impact on derivatives decisions within the firm and therefore are an important determinant of derivatives in the firm's. hedging decisions. Though there is strong support for the association between governance and derivatives, the hedging effectiveness appears quite weak. Corporate governance largely achieves over and/or under hedging outcomes.

\subsubsection{Conclusion}

The study provides strong evidence that corporate governance is an important determinant of derivatives within the firm and therefore, should be included in any study of derivatives. The conflicting and weak results related to derivatives studies may be due to this omitted factor. An important observation following from the 
analyses highlights that an increase in the amount of derivatives does not automatically mean enhanced hedging. Likewise, a reduction in the amount of derivatives may not undermine hedging effectiveness. The increase or the decrease in derivatives may simply indicate over-hedging or under-hedging activities to result in mismatched risk exposures. Therefore, any study of derivatives needs to additionally examine for hedging effectiveness if the researcher is to draw a conclusion regarding the hedging impact.

The results of this study show that corporate governance largely hedges with respect to stock return volatility. Board size, board diversity, CEO tenure and CEO bonus exhibit hedging effectiveness. The findings support the contention that when the stocks (diversifiable risk) component in CEO bonus dominates they would tend to reduce stock return volatility. Fluctuations in stock price reduce stock portfolio gains and studies indicate that greater shareholdings compensation tends to decrease risk (Schrand and Unal, 1998; Tufano, 1996; Geczy, et al., 1997; Gay and Nam, 1998; Guay, 1999). My study finds that board size, CEO bonus, CEO tenure and board diversity influence effective hedging which may stem from a personal motive to protect stock portfolios by reducing equity volatility. It could also stem from purposeful risk management strategies in the process of risk allocation for the benefit of the firm.

Corporate governance mechanisms related to shareholding indicate a different response with respect to equity risk. Insider shareholders, institutional shareholders and block shareholders increase stock return volatility. While institutional shareholders (insider shareholders) also increase (reduce) market risk (cash flow volatility). None of the shareholder components exhibit any increase in firm value. All the shareholder governance mechanisms encourage risk taking with respect to stock return volatility and generally have no or a reducing effect in respect of cash flow 
volatility. This supports the findings of market granularity by institutional and other larger block holders (David et al., 2015) to indicate that institutional investors increase stock price volatilities that is specifically related to the trading shocks of large institutions (See Section 8.2.2).

With respect to cash flow volatility, corporate governance: board meetings, board size, CEO tenure, CEO total compensation, CEO bonus and CEO salary, exhibits increased speculative behavior. It supports the thinking that the performance and reputation of directors, CEOs and top management alike are gauged and rewarded based on the growth in profits, earnings and cash flows. Boards and CEOs would be more concerned to show higher earnings and cash flows to increase reputation, protect jobs/positions and enhance compensation. Firm earnings are more directly associated with board and CEO performance and therefore it would be expected that they would endeavor to increase earnings performance. Likewise, CEOs nearing the end of their tenure (CEO tenure) would try to increase earnings to increase their cash wealth and position in the firm. As these measures are more transparent and more easily understood by management, managers have more incentives and are able to more easily manipulate these financial statement measures. (While stock price volatility is more opaque and less understood by managers and therefore more difficult to manipulate). Managers have their bonuses, awards, promotions, reputation and jobs linked to firm performance. Similarly, the markets gauge directors' reputations primarily on firm performance through the financial reports. Therefore, there is a strong motivation to manipulate earnings by both managers and directors

Additionally, board meetings and CEO age indicate an increase in stock return volatility. This also finds support in the literature that increase in board meetings reflect trouble shooting when the firm is faced with financial distress and poor performance (Section 8.3.1). Where it could result in accelerated efforts to increase 
profits through speculation, or provide the semblance of a vigilant board. My results for CEO age captures the problems related to short term horizon, job insecurity and wealth myopia (Section 8.3.3) due to CEOs nearing the end of their tenure. Surprisingly, all the governance variables that effect speculation through stock return volatility do not find any accompanying increase in value.

The results for audit committee size exhibits a reduction in cash flow volatility and increase in stock return volatility, with an accompanying decrease in value. It would indicate a monitoring and disciplining role of the audit committee with respect to cash flow risk. The increase in equity risk and reduction in value is in line with studies which suggest that an excessively large group becomes incompetent in taking decisions effectively and in a timely manner (Jensen, 1993; Lipton and Lorsch,1992; Yermack, 1996). This suggests that there may be an optimum number over which effectiveness suffers and that the audit committees comprising all (or large number) of board members may suffer from deficiencies.

With regard to market risk, institutional shareholders, CEO bonus and CEO age appear to increase systematic risk, while only board diversity effects a reduction in risk. A majority of the corporate governance variables do not indicate any effect on systematic risk. This is similar to the results for Huang et al. (2013) who does not find any significant results for his market risk models in his study of board independence and hedging. Likewise, Guay (1999) finds no relationship between derivatives and market risk in his models. This may reflect the observations of researchers who suggest that the capital asset pricing model (CAPM) is a weak measure to capture the market effects of trading actions in the derivatives markets. They indicate that CAPM market model is more consumer focused with the underlying assumption that all individuals hold a small amount of all the marketable assets for diversification reasons (Hirshleifer, 1988). Others suggest that other models are better in that they also 
incorporate producers as important participants in commodity futures market who influence the markets and impact on prices (Carter et al., 1983; Chang, 1985; Marcus, 1984).

The findings of the selective hedging literature that non-financial firms exhibit concurrent (or switching) hedging and speculation positions, provides strong support for my results. In the final analyses my results show the individual corporate governance variables exhibit hedging, speculation and, both hedging and speculation behavior. This could be due to the aligning of derivatives positions to vary with market prices for profits, as indicated by the research on selective hedging. Or this behavior could stem from the motive of risk allocation to hedge one type of risk in order to enhance another business risk where more benefits are to be derived (Schrand and Unal, 1998). Another plausible reason could be speculation due to weak governance, which allows for managers to use derivatives for personal motives and gains (Geczy et al., 2007). Weller et al. (2011) suggest that corporate governance "prioritizes shortterm speculative investments, impedes productive investments and jeopardizes" (title page). They attribute this largely to institutional investors and their short term focus and also suggest that board of directors provide only limited counterbalance to managers' activities which could fail to curb management speculative activities. Zeidan and Mullner (2015) indicate that the lack of adequate hedging policy, inefficient management of top management, overconfidence, personal motives and compensation add to ineffective hedging strategies. Geczy et al. (2007) find evidence of speculative activities within non-financial firms and attribute it generally to weakly governed firms who are more prone to speculation. They find these firms encourage managers to speculate through specific bonding and incentive-aligning compensation contracts but at the same time discover that these firms may use strong internal controls related to derivatives to control for the possibility of abuse. Therefore, the concurrent hedging and speculation activities evidenced in my study could also be part of purposeful risk management strategy where the speculation may be accompanied with 
effective internal controls in place to monitor derivatives and deter their abuse (Geczy, et al., 2007).

\subsection{Detailed Discussion of Findings}

This study had three main objectives. The study aimed (1) to examine the association between derivatives and corporate governance, (2) to examine the relationship between derivatives and corporate governance on firm value, and (3) to examine whether the influence of corporate governance mitigates the risk effects of derivatives within the firm. The following subsections provide further discussions on the results that are summarized in Appendices 3 and 4. Further they address the hypotheses that have been in chapter 4 .

\subsubsection{Board of Directors (Board)}

\section{Board Meetings}

This section relates to:

H01a: Board meetings has no relationship with the value effect of derivatives

H1b: Board meetings increase the risk effect of derivatives

H05b: There is no relationship between board meetings and derivatives

Though there is an argument to suggest that frequent board meetings promote greater diligence and effectiveness of the board in monitoring activities, this study does not find any association of board meeting (BDMTGS) frequency with the use of derivatives, and does not influence the effect of derivatives on firm value and market risk. The result, which is consistent in all regressions and sensitivity analyses, leads 
to the conclusion that there is no basis to reject the null hypothesis that there is no association of board meeting frequency with derivatives, and with the value effect of derivatives which is in accordance with my predictions. With respect to firm risk, the results indicate that there is a positive relationship of board meetings with cash flow volatility and stock return volatility and this is supported by the tests of robustness. Therefore, this study rejects the null hypothesis that there is no association between board meetings and firm risk, and accepts the alternate hypothesis that board meetings have a positive relationship with cash flow volatility and stock return volatility.

The result of this study is consistent with the findings of Vafeas (1999) and Adams (2005) who suggest that boards appear to increase their activities through more meetings in the face of poor performance. Further, excess board meetings may be an inkling of the boards own deficiencies (Karamanou and Vafeas, 2005; Vafeas, 1999) and internal control weaknesses (Zhang et al., 2007), suggesting that increased meetings are associated with an increase in risk. Additionally, the findings support Erkens et al. (2009) contention that over monitoring may be putting excessive pressure on management to increase short term profits resulting in higher firm risk. Brick and Chidambaran (2010) highlight that the board's activities just for the purpose of fulfilling regulatory requirements would only increase costs, without any related benefits. This finding suggests that boards use meetings either to send a signal to the markets or as a trouble shooting device. Therefore, enhanced board meetings do not have any value enhancing benefits but result in heightened firm risk, suggesting speculative behaviour.

\section{Board Size}

This section relates to:

H02a: Board size has no relationship with the value effect of derivatives 
H02b: Board size has no relationship with the risk effect of derivatives H05a: There is no relationship between board size and derivatives

The results indicate that larger boards manage stock price fluctuations in order to protect their reputations in the stock markets. They may also hedge to protect their own stock portfolios by reducing equity volatility. This is in line with Cheng (2008) who finds that larger board size reduces stock return volatility for both the idiosyncratic and unsystematic components.

Based on the results, this study fails to reject the null hypotheses that board size has no effect on firm value, firm risk and derivatives. The study supports the argument that larger board size increases derivatives and enhances firm value. The greater the number of directors, the more experience they bring to the board and the more they appear to compensate for one another's deficiencies in adding value. Consistent with evidence from previous studies, greater numbers make it possible for more vigilance and alertness and therefore contribute to higher performance (Adams and Mehran, 2012; Coles et al. 2008; Dalton et al, 1999), lower risk and more hedging effectiveness. Researchers provide a general consensus that directors provide important linkages and affiliations and this advantage is reinforced with larger boards (Korac-Kakabadse et al., 2001; Zahra and Pearce, 1989) and this would impact firm performance. This hedging advantage is evidenced with respect to stock return volatility where board size reduces risk. The increase in cash flow volatility could stem from the board's personal motives related to earnings risk, as discussed in Section 8.2.5 above. The results of the study are robust to sensitivity analyses.

\section{Board Independence}

This section relates to:

H03a: Board independence has no relationship with the value effect of derivatives 
H03b: Board independence has no relationship with the risk effect of derivatives H05c: There is no relationship between board independence and derivatives

The results of this study do not support the theory that greater participation of independent directors on boards would lead to higher monitoring of managerial activities to result in higher firm performance. The results indicate that there is no association between: board independence and derivatives, and board independence and risk effect of derivatives, and therefore I do not find a basis to reject the null hypotheses. However, the results indicate a significant negative association of board independence with firm value and therefore I reject the null hypothesis of no relationship.

These findings are consistent with the evidence obtained by Erkens et al. (2012) who find a negative relationship between board independence and stock returns. Bhagat and Black (1999) do not find any correlation between board independence and longterm firm performance. Similarly, Klein (1998) finds little association between board composition and firm performance. While Hermalin and Weisbach (2003) suggest that board independence may not be very important for the day-to-day actions and may only be more important in certain crisis situations. It may also support the findings of Mace (1971) and Vancil (1987) that insiders are important in their ability to advise the CEOs regarding the day-to-day operations of the company, which external directors cannot do. Thus, suggesting a balance of both outside and inside directors on the board.

This suggests that board independence may not be an important corporate governance factor for firms that use derivatives. The ineffectiveness of independent directors in carrying out their monitoring function may be due to their lack of expertise and the lack of required knowledge that is essential to a more complex derivatives environment. It reinforces the findings of Kirkpatrick (2009) who suggest that board 
independence may have resulted in undermining the competence on boards during the financial crisis. Another reason for the weak results could be that the appointments of independent directors may have been influenced by controlling shareholders to protect their interests, which would have undermined independence on the boards.

\section{Board Diversity}

This section relates to:

$\mathrm{H} 4 \mathrm{a}$ : Female representation on boards increases the value effect of derivatives $\mathrm{H} 4 \mathrm{~b}$ : Female representation on boards reduces the risk effect of derivatives H05d: There is no relationship between board diversity and derivatives

My results show that women play an important role on the boards in hedging risk, both market risk and stock return volatility. This could be attributed to the fact that women generally have a higher level of risk aversion. It supports past studies in that women are effective risk managers on boards in a derivatives environment.

Despite the argument that more gender diversity on the boards does not enhance firm performance (Adams and Ferreira, 2009; Sila et al., 2014) with respect to both firm value and firm risk, this study does not find support for this contention. In accordance with my predictions, results of the study suggest that gender diversity has a negative correlation with the risk effect of derivatives (stock return volatility and market risk) and this is consistent in all the regressions and sensitivity analyses, therefore I reject the null hypothesis that there is no relationship between board diversity and the risk effects of derivatives. The results are robust to the sensitivity analyses. However, in respect of the results for cash flow volatility, the results are not significant.

My results are consistent with the findings of others that board diversity decreases risk: 
women are more risk averse than men (Byrnes et al., 1999); when delving in money matters women show an inclination to discourage risk taking (Fehr-Duda, et. al., 2006; Levin et al., 1988; Powell and Ansic, 1997); and the number of women directors on boards is negatively related to firm bankruptcy (Wilson and Altanlar, 2011). Adams and Ferreira (2004) also find that firms that exhibit higher stock return volatility have lower proportion of female directors (Farrell and Hersch, 2005; Hillman et al., 2007). Harjoto et al. (2014) also find that board diversity (including gender diversity) exhibits more risk aversion. However, Barber and Odean (2001) attribute the negative correlation to women shirking from taking decisions involving risk or from a lack of confidence. The positive relationship between board diversity and firm value is in line with others who find that women on boards: enhance firm performance (Adler, 2001; Carter et al., 2003;); increase the reputation of the firm (Bernardi et al., 2006; Brammer et al., 2009); have a positive effect on board decisions (Burgess and Tharenou, 2002; Campbell et. al 2008; Carter et al. 2003; Kang et al., 2007); and generally diversity impacts firm performance positively (Kramer et al., 2006; Ramirez, 2003; Sellers, 2007).

The findings suggest that a more gender-diverse board is more effective in their monitoring and disciplining roles. This stems from their caution in taking excessive risk and providing more objectivity and balance to an all-male member board. They also have incentives to avoid activities that would damage their reputation. Women directors are better monitors and play an important role in reducing risk and implementing effective hedging strategies in firms that use derivatives.

\subsubsection{Shareholders}

\section{Insider Shareholders}

This section relates to: 
H6a: Higher percentage of insider shareholding reduces the value effect of derivatives H06b:Percentage of insider shareholding has no relationship with the risk effect of derivatives

H9c: Lower concentration of insider shareholders increases derivatives

The study finds significant correlations of insider shareholders with the risk effects of derivatives and between insider shareholders and use of derivatives. Therefore it provides the basis for rejection of the null hypothesis that there is a no association between insider shareholders and derivatives, and between insider shareholders and firm risk (cash stock volatility and stock return volatility). On the other hand, the findings in respect of firm value, does not allow for rejection of the null hypothesis that there is no association of insider shareholding with firm value.

The results show that increased insider shareholding encourages a reduction in derivatives. It also influences the decrease in cash flow volatility, indicating hedging effectiveness. However, the increased risk in respect of stock return volatility shows evidence of speculation activities by insider shareholders. The findings are in line with many researchers who do not see the advantages of increased insider shareholding for example, Fauver and Naranjo (2010) find that insider ownership impacts derivatives to reduce firm value. Others indicate that more managerial shareholding contribute to entrenchment problems (McConnell and Servaes, 1990; Short and Keasey, 1999) and therefore risk. When insiders own significant shareholding they become entrenched and are able to exert substantial influence (Demsetz, 1983; Fama and Jensen, 1983a \& 1983b; Gibbs, 1992) to undermine board decisions and performance. Managerial shareholding also enables managers to implement hedging programs out of their own personal objectives at the cost of other shareholders (Beber and Fabbri, 2005; Dhanajarata et al., 2010; Dolde, 1993; Faulkender, 2005; Geczy et al., 2007). 
Firms that do not use derivatives exhibit similar findings for insider shareholders to show no impact on firm value and market risk, an increase in stock return volatility and a decrease in cash flow volatility. However, the magnitude of the impact differs between user and non user firms, where the reduction in cash flow risk is higher and the increase in stock return volatility is lower for derivative non user firms.

\section{Institutional Shareholders}

This section relates to:

H7a: Higher percentage of institutional shareholding reduces the value effect of derivatives

H7b: Higher percentage of institutional shareholding increases the risk effect of derivatives

H9a: Larger concentration of institutional shareholders increases derivatives

The results show a detrimental impact of large institutional shareholding. The results show a positive association with derivatives, stock return volatility and market risk and an accompanying reduction in firm value. Therefore, there is evidence to allow me to reject the null hypotheses of no association for institutional shareholders. However, the results for cash flow volatility do not show any significant results.

The results are consistent with the findings of Erkens et al. (2007) who find a value reducing effect of institutional shareholders on stock returns and a risk increasing effects with respect to expected default probability (EDF), to suggest that they encourage managers to take greater risks in their investment policies. Erkens et al. (2007) suggests that that due to institutional shareholders' focus on short-term performance and bonus plans, as opposed to long-term strategies, corporate managers have taken more risk, resulting in larger losses. Fauver and Naranjo (2010) also find (for their linear variable) a negative effect for institutional shareholders on Tobin's Q 
with respect to derivatives. (See Section 8.2.5 for a detailed discussion on institutional granularity and risk diversification behavior).

\section{Block Shareholders}

This section relates to:

H8a: Higher concentration of ownership reduces the value effect of derivatives H8b: Higher concentration of ownership increases the risk effect of derivatives H9b: Larger concentration of block shareholders increases derivatives

With respect to block shareholding, the results of this analyses provide evidence to reject the null hypothesis of no association of block shareholding on the value effect of derivatives, and between block shareholding and risk effect of derivatives (stock return volatility). However, with regard to the relationship of corporate and derivatives, the results are insignificant.

The results of this study indicate an increase in stock return volatility and a reduction in value. It supports the theory that block holders are well informed about the firm and implement this information into stock price trading. They use this information to negatively affect stock prices through block selling of shares (Kraus and Stoll, 1972; Mikkelson and Partch, 1985; Scholes, 1972; Sias et al., 2006). This decline in value could also stem from the fact that the off-loading of the firm's shares sends a signal to the markets that these informed investors consider firm value to be lower (Dou et al., 2014).

The results support the contention that more institutional block holders engender higher information asymmetry in the markets, as they lower the degree of informed trading (Belghitar et al., 2011; Heflin and Shaw, 2000; O’Neill and Swisher, 2003). 
Elbadry et al. (2015) suggests that though large shareholders can closely monitor management, at the same time they have the power to get managers to act in their best interest to the detriment of other shareholders. This creates uncertainty and insecurity among shareholders that could lead to uncertainty in share prices and higher volatility.

\subsubsection{Chief Executive Officer (CEO)}

\section{CEO Age}

\section{This section relates to:}

H10a: Older CEOs reduce the value effect of derivatives

H10b: Older CEOs increase the risk effect of derivatives

H010e: There is no relationship between CEO age and derivatives.

The results for CEO age show significant associations and provide evidence in support of the argument that older CEOs exhibit problems related to short term horizon job insecurity and wealth/income myopia. Therefore, I cannot reject the null hypotheses that there is no association between: CEO age and value effect of derivatives; CEO age and risk effect of derivatives; and CEO age and use of derivatives by the firm. Older CEOs increase the use of derivatives by the firm, decrease value effect of derivatives, and increase both market risk and stock return volatility to undermine hedging effectiveness. However, there is no impact of older CEOs on the cash flow volatility effect of derivatives.

My results support the findings of others (Berger et al., 1997; Lewellen et al., 1987) that older CEOs engross in more unethical and biased behavior. CEO's who are near retirement cannot be disciplined and therefore have a greater incentive to look for ways to increase their income through increased compensation (Gibbons and Murphy, 
1992). Lewellen et al. (1987) observes that older CEOs may have more personal wealth in the form of stocks and options and therefore would be more prone to take additional risk as they lack the incentives available to younger CEOs in the job market. Thus, this would contribute to more myopic decision-making. In contrast younger CEOs are more concerned with career growth and so would be more aligned with shareholders' objectives (Fama, 1980; Gibbons and Murphy, 1992). Similarly, the results show a speculative effect of CEO age with respect to increase in stock return volatility and market risk effects of derivatives.

\section{CEO Tenure}

This section relates to:

H010c: CEO tenure has no relationship with the value effect of derivatives

H010d: CEO tenure has no relationship with the risk effect of derivatives

H010f: There is no relationship between CEO tenure and derivatives

Further from the analysis it is found that CEO tenure has a risk enhancing impact on cash flow volatility (in the ISUR results). It lends support to the theory that CEOs with longer tenures and therefore shorter term horizons, exhibit behavioral problems related to wealth myopia and job insecurity. Thus CEOs with larger tenures would delve in speculative activities with respect to cash flow volatility. It is in line with findings of several researchers who suggest CEO tenure captures an entrenchment effect. Hermalin and Weisbach (1991) use different levels of CEO tenure to examine their effect on Tobin's Q. They find that at lower levels, CEO tenure does not affect profitability, however, when CEO's have been in service for more than 15 years, it reduces profitability. CEO tenure has a stronger association with compensation (and therefore performance) when the CEO is approaching retirement (Cheng, 2004). The results of the study are also in line with $\mathrm{Xu}$ (2011) who finds a variation of CEO risk 
behavior with respect to CEO tenure, where CEOs with a short-term horizon reduce investments and the opposite is evidenced for CEOs with longer term horizons.

The results do not show any association of CEO tenure with market risk and derivatives decisions. In respect of stock return volatility, longer tenured CEOs reduce risk to contribute to hedging effectiveness and exhibit an increase in value. Alderfer (1986) suggests that it takes time to understand the company and therefore longer tenured CEOs display a greater understanding of the firm and industry which therefore translates to higher performance. Cornett et al. (2008) also indicate that CEO tenure discourages managed performance which indicates that CEO tenure captures the CEO effectiveness in managing the firm, as officials with little experience would have limited effectiveness. The reduction in stock return volatility is in keeping with the trend evidenced by the board who reduce stock return volatility to protect their personal stock portfolios without having to incur the costs of hedging.

The results indicate a variation in CEO behavior with respect to the different risks. Older CEOs speculate cash flow volatility to increase their income (cash wealth) and reduce stock return volatility to increase stock portfolio wealth. There is a difference in the results for CEO age and tenure and it may capture the effects that Dechow and Sloan (1991) discuss, that older CEOs may enhance performance, but there is the possibility that CEOs in their final years of service are more prone to manage shortterm earnings. Therefore, the authors suggest that CEO horizon would be a better proxy than age or tenure. This might explain why the results for CEO age vary from the results of CEO tenure. A difference in results between CEO age and tenure is also observed by Cornett et al. (2008). The authors suggest that the horizon proxy is a better measure as it captures differences in position of CEOs with respect to their horizon. Those nearing retirement would be prone to manipulate earnings more than those CEOs toward the beginning of their horizon which may not be captured by age or 
tenure. It may also reflect Hermalin and Weisbach (1991) who suggest that ownership is an important factor so that at lower levels of ownership, stock ownership and CEO tenure performance improves with an increase in ownership. However, beyond the $1 \%$ of ownership, performance declines because they are more insulated against disciplining devices and less aligned to shareholders' interests.

A comparison reveals that $\mathrm{CEO}$ tenure achieves hedging effectiveness with respect to stock return volatility and encourages speculation with respect to cash flow volatility in firms that use derivatives. However, CEO tenure has no effect on the firm measures in the firms that do not use derivatives. Additionally, for derivative user firms, CEO tenure shows marked similarities with CEO bonus in relation to firm value, cash flow volatility and stock return volatility. This suggests that CEO bonus portfolio is an important factor for retiring CEOs, or at least those near the end of their tenure.

\section{CEO Compensation, CEO Bonus and CEO Salary}

This section relates to:

H11a: CEO total compensation increases the value effect of derivatives

H11b: CEO total compensation increases the risk effect of derivatives

$\mathrm{H} 11 \mathrm{c}$ CEO bonus increases the value effect of derivatives

H011d CEO bonus has no relationship with the risk effect of derivatives

H11e: CEO salary increases the value effect of derivatives

H11f CEO salary increases the risk effect of derivatives

H12a: There is a positive relationship between CEO salary and derivatives

H012b: There is no relationship between CEO bonus and derivatives

H012c: There is no relationship between CEO total compensation and derivatives 
The findings of this study show that CEO compensation (CEOCOMP), CEO bonus (CEOBONUS) and CEO salary have a significant impact on derivatives. CEO total compensation effects a reduction in the amount of derivatives used by the firm, while both CEO salary and CEO bonus motivate managers to increase derivatives. These results provide enough evidence to reject the null hypotheses that CEO compensation, CEO bonus and CEO salary have no association with derivatives.

The most significant results are displayed in respect of CEO bonus. CEO bonus has an enhancing effect on firm value, cash flow volatility and market risk, and a risk decreasing effect on stock return volatility. With respect to $\mathrm{CEO}$ compensation (CEOCOMP), generally, the results are weak without any significant correlations for most of the dependent variables and therefore I do not reject the null hypothesis that CEO compensation has no association with firm value, stock return risk and market risk. CEO compensation only indicates a positive correlation with cash flow volatility. Most research that examine stock bonuses separately, find that firms tend to reduce stock price fluctuation to increase their stock wealth When the stocks (diversifiable risk) component in CEO bonus dominates they would tend to reduce stock return volatility. This is because fluctuations in stock price reduce stock portfolio gains and Guay (1999) finds a reduction in stock return volatility for new users of derivatives. Many researchers suggest that greater shareholdings compensation tend to decrease risk, while managerial options holdings would encourage increase in risk (Gay and Nam, 1998; Geczy et al., 1997; Schrand and Unal, 1998; Tufano, 1996).

In keeping with the general consensus, my results for CEO salary (CEOSALARY) do not indicate any significant relationships in any of the main regressions. This is in line with the growing emphasis on stocks, options and other bonus instruments to manage the performance of managers through alignment of pay with performance. However, an examination of the system of equations model (ISUR) indicates a positive effect of 
CEO salary with firm value and cash flow volatility. This would imply that in firms that use derivatives there is a tendency for executives to manage their base salaries through speculation of cash flow volatility to enhance income and profits.

This response to cash flow risk is in line with Murphy's (1999) findings that suggests CEOs would naturally devote their efforts on increasing accounting bonuses (through income risk) which they understand, rather than focus their efforts to increase stock price. Most executive compensation comprises four main components: a basic salary, annual bonus which is linked to accounting performance and then there is stock options and long-term incentive plans. Murphy (1999) suggests that base salary is a key component of contracts, mainly because components of compensation are measured in relation to base salary levels. Most companies use accounting measures to gauge the CEO performance and it would therefore indicate that CEOs would try to increase profits. The results for cash flow volatility support the findings of Geczy et al., (2007), who observe that derivative users indulge in speculation if compensation is benchmarked against profits rather than risk management.

On the other hand, CEO bonus has a negative effect on stock return volatility and a positive effect on market risk. It seems to indicate a strategy of reducing equity risk (diversifiable risk) to protect wealth and speculating market risk, that is undiversifiable, to increase profits. These differences appear to reflect CEO bonus sensitivity due to the stocks and options within their incentive structure. It appears that CEOs would tend to reduce stock price volatility to gain on their stock portfolios. Researchers suggest that stock ownership encourages reduction of volatility, while options increase volatility (Rajgopal and Shevlin, 2002; Schrand and Unal, 1998). Stronger equity incentives are associated with less risk taking, whereas portfolio convexity due to options encourages more risk taking (Coles et al., 2006; Lewellen, 2006; Guay, 1999; Rajgopal and Shevlin, 2002; Tufano, 1996). Risk tolerance in 
executives is positively related to incentive pay levels and there is also a concern that incentive compensation encourages managers to manipulate performance measures (Benmelech et al., 2010; Bolton et al., 2006; Goldman and Slezak, 2006) and some attribute it to the options component and some to the stock component of compensation. Chesney and Asner (2004) also indicate that managers will always have an incentive to cheat and stock options provide a greater incentive to cheat than a compensation structure comprising cash equivalent remuneration and stocks.

The findings show that only CEO bonus increases the use of derivatives to achieve hedging effectiveness through an increase in firm value and reduction in stock return volatility. CEO bonus however, displays speculation through the increase in cash flow volatility and market risk. CEO salary also shows evidence of speculation through the increase in derivatives, resulting in an increase in firm value and cash flow volatility. CEO compensation appears to induce a reduction in derivatives to achieve an increase in cash flow volatility. All three compensation components increase cash flow volatility to speculate which may stem from personal motives. This is similar to nonusers who also show that CEO compensation, CEO bonus and CEO salary are correlated to an increase in cash flow volatility and there is only an increase in value for CEO compensation.

Overall a comparison for the risk measures shows that derivatives users exhibit lower risk increase in cash flow volatility for all the compensation components; and a greater reduction in stock return volatility for CEO bonus, over derivative non-users. Further, the CEO bonus and CEO salary increase value in derivatives users, while CEO compensation increases value for derivatives non-users. Though there is a trend of the compensation elements to encourage risk taking, however it is to a lesser magnitude in firms that use derivatives. While, only CEO bonus shows hedging effectiveness for 
derivatives users with respect of stock return volatility. This would indicate that compensation structures are more effective for derivative users.

\subsubsection{Audit Committee Size}

This section relates to:

H13a: Smaller audit committees increase the value effect of derivatives

H013b: Audit committee size has no relationship with the risk effect of derivatives

H13d There is no relationship between audit committee size and derivatives

Audit committee size appears to be the most important audit committee characteristic as it synthesizes all the other attributes (Dhaliwal et. al., 2006) to capture financial expertise, resources, and independence of the committee members. The results of this study do not support the argument of others that larger audit committees enhance firm performance through quality of financial reporting (Lin et al., 2006; Yang and Krishnan, 2005). This study does not find a positive association audit committee size and firm value, but indicate a significant negative association between audit committee size and value, and a positive association of audit committee size with the equity risk effect of derivatives. Audit committee size has no effect the derivatives impact on market risk and on the amount of derivatives. However, audit committee size is instrumental in reducing the cash flow volatility risk for derivatives users.

The results support the findings of some researchers, for example Chan and $\mathrm{Li}$ (1996) indicate a negative association between audit committee size and Tobin's Q. Others show that smaller groups provide better group dynamics and synergy, and higher firm value (Yermack, 1996) evidenced through more conducive communication and coordination (Jensen, 1993). Baraiotta (1999) and DeZoort et al. (2002) also suggest that audit committees should be contained enough to enable valuable dialogue and 
deliberation between members, but large enough to benefit from their resources. Though Mangena and Pike (2005) do not find any relationship between number of members on the audit committee and interim financial disclosures, however, the sign of the coefficient is negative which they suggest may weakly support the fact that smaller committees improve financial reporting.

Despite audit committees size indicating a reduction in firm value and an increase in stock return volatility, overall findings indicate that audit committees perform better within firms that use derivatives in comparison to non-users. Firstly, the findings suggest that a larger audit committee is more effective in performing its oversight role with respect to risk management. The larger sized audit committee provides the expertise and resources to reduce cash flow volatility only in firms that use derivatives. Here the risk reduction plays a vital role in risk management to provide a disciplining effect to the other corporate governance variables that are motivated to increase cash flow volatility risk. One of the primary roles of audit committees in non-financial firms is risk reduction and risk management, and not necessarily value enhancement. It is evident that audit committees fulfill this role more effectively for derivatives user firms as they reduce cash flow volatility.

Secondly, audit committees are able to lower the risk enhancement in stock return volatility compared to non-user firms. Additionally, the value reduction effect of audit committees is lower for derivatives users. Overall audit committees indicate a higher reduction in firm value and a higher increase in stock return volatility, with no effect on cash flow volatility in firms not using derivatives. Therefore, this leads to the conclusion that larger audit committees perform better within firms that use derivatives, even though they are not able to increase firm value or reduce stock return volatility. 


\subsection{Chapter Summary}

In this chapter I discuss the results of my study. The overall results indicate that corporate governance responds differently to the types of risks being examined. There is evidence of hedging, speculation and selective hedging behavior.

Generally, the board and CEO corporate governance mechanisms exhibit effective hedging behavior with respect to stock return volatility. Largely, the results for cash flow volatility show speculative corporate governance behavior, While, the results for market risk are quite weak, and where significant, exhibit an increase in risk. However, board independence does not impact risk measures, and has a value decreasing effect on derivatives.

All three components of shareholder governance mechanisms exhibit a propensity to speculate with respect to stock return volatility. This agrees with research findings that large block holders and institutional shareholders have well diversified portfolios and would not want to incur additional costs of hedging. They would therefore prefer to increase stock return volatility and play markets for financial gain.

Results for audit committee size indicate that smaller audit committees would result in a value increase in firms that use derivatives. This would suggest that larger size has an adverse impact and there may be an optimum number, over which the value decreases for audit committees. 


\section{CHAPTER NINE: SUMMARY AND CONCLUSION}

\subsection{Introduction}

This is the last chapter in the thesis. It provides a summary of the results, highlights the limitations and contributions of the study, and provides suggestions for future research. This chapter is organized as follows. Section 9.2 presents a summary of the research and implications of the findings. Section 9.3 examines corporate governance hedging/speculative behavior with respect to the results of the study. Section 9.4 discusses limitations of the research, followed by Section 9.5 that provides suggestions for future research. Finally, Section 9.6 concludes the thesis by outlining the contributions of the study.

\subsection{Summary of the Research}

The thesis is motivated by the limited research on the relationship of corporate governance and risk management in non-financial firms. Further the study is prompted by the role of corporate governance in the global financial crisis. There are three main questions examined in the thesis that underscores the main research objectives. These are: 1) Does corporate governance influence decisions related to derivatives in firms that manage their risk with derivative instruments? 2) Does corporate governance have an impact on the effect of derivatives on firm value? 3) Does corporate governance have an impact on the effect of derivatives on firm risk? Finally, this study has attempted to assess corporate governance hedging and/or speculative behavior in the context of the findings. 


\subsubsection{Is Corporate Governance a Determinant of Derivatives?}

This examination uses a sample of NYSE listed firms comprising 6900 firm-year observations for the period from 2004-2011. There is a potential problem of endogeneity between capital structure and derivatives in their relationship to the firm's financing and capital structure decisions. Therefore, both elements need to be examined together and the study employs a simultaneous equations model to examine the effects of debt utilization and derivatives hedging simultaneously.

Consistent with the results from previous studies on derivatives and corporate governance (Lel, 2012; Dionne and Trikki, 2005), this study finds significant associations between corporate governance variables and the use of derivatives by the firm. Specifically, the study documents that larger boards, higher institutional shareholding, older CEOs, larger award of CEO bonus, larger CEO basic salary, a smaller percentage of insider shareholders and lower CEO total compensation increase the use of derivatives. (See Appendix 3). Therefore, the research finds support for the influence of corporate governance on derivatives to suggest that corporate governance is a determinant of derivatives. In keeping with these findings, it is suggested that future studies should include corporate governance as a determinant of derivatives alongside tax convexity, financial distress, investment growth opportunity and managerial risk aversion.

\subsubsection{Does Corporate Governance Impact the Value Effects of Derivatives?}

For examination of this objective, I use a second sample of NYSE listed firms with 6234 firm-year observations for the period from 2004-2011. The sample is split into two groups comprising firms that use derivatives and those that do not. To ensure the 
robustness of results, the study includes the White (1980) adjusted t-statistics, uses industry and year dummies to control for industry and year fixed effects and estimates Newey-West (1987) regressions to mitigate potential time-series correlations of pooled data. Additionally, it uses alternative measures for firm value and alternative techniques of bootstrapping and Iterated Seemingly Unrelated Regression (ISUR).

Consistent with studies on corporate governance and firm value, this study documents significant associations between corporate governance variables and derivatives to support the view that corporate governance provides value enhancing monitoring and control over risk management in firms using derivatives. Specifically, the study documents that a higher proportion of board diversity, higher award of CEO bonus, larger CEO tenure, higher CEO basic salary, lower block shareholding and lower board independence enhances firm value. However, the significant association between these corporate governance variables and firm value exists only in derivative user firms. Further smaller audit committees, larger board size, younger CEOs and lower percentage of institutional shareholding, enhance firm value in both group of firms. Overall, in keeping with Allayannis et al. (2012) and Fauver and Naranjo (2010), the study provides support for the value enhancing effects of corporate governance on derivatives in the firm.

\subsubsection{Does Corporate Governance Impact the Risk Effects of Derivatives?}

Contrary to my expectations, an examination of the risk effects indicates that corporate governance has a varying impact on the different types of risk examined. This appears to support the concept of risk allocation expounded by Schrand and Unal (1998) and the selective hedging behavior of non-financial firms evidenced by others (Adam et al., 2012; Baker and Wurgler, 2002; Brown et al., 2002; Faulkender, 2005; Glaum, 
2002; Graham and Harvey, 2001). I discuss the effects of corporate governance on derivatives for each risk type separately.

Cash Flow Volatility: The results of this study indicate significant associations between corporate governance variables and cash flow volatility in firms that use derivatives. Specifically, this study documents that board meetings, board size, CEO tenure, CEO total compensation, CEO bonus, CEO salary, smaller percentage of insider shareholders and smaller audit committee size have a risk enhancing impact on cash flow volatility. However, the increase in risk is generally larger for derivative non-users. In respect of the research objective for derivative user firms, the findings provide evidence of a risk enhancing effect of corporate governance on derivatives in relation to cash flow volatility.

Stock Return Volatility: By considering the split sample groups for derivative users and non-users, I examine the relationship between stock return volatility and corporate governance. The results show that board diversity, CEO tenure, institutional shareholding and CEO age have a significant association with equity risk. However, the significant association between these corporate governance variables and stock return volatility exists only in derivative user firms. On the other hand, board meetings, board size, insider shareholders, block shareholders, CEO bonus and audit committee size show a significant association with stock return volatility for both group of firms (See Appendix 3).

These results indicate that larger board size, more board diversity, larger CEO bonus and CEO tenure reduce stock return volatility and the reduction in risk is higher for derivative user firms (except in the case of board size). Conversely, the coefficients for institutional shareholding and CEO age document a positive association with stock return volatility only for derivative users. While board meetings, insider shareholders, 
block shareholders, and audit committee size increase equity risk in both group of firms with a larger increase displayed by derivative non-user firms. These results highlight the effectiveness of corporate governance in managing and hedging equity risk in firms that use derivatives. Where the results evidence an increase in risk, the coefficients are smaller for derivative users to show a greater disciplining effect of the corporate governance mechanisms.

Market Risk: The market risk model generally exhibits less significant results than the other two risk models. Further, the results for derivative users in this model are less significant than those reported for non-derivative users. This is similar to the findings of Guay (1999) and Huang et al. (2013) who do not observe any significant results for their market risk models. The results indicate that older CEOs increase market risk, while board diversity has a higher risk reduction effect, institutional shareholders report a lower risk enhancing effect, and CEO bonus report a larger risk enhancing effect for derivative users when compared to nonusers. While board meetings, board size, and block shareholding are only significant for non-users (See Appendix 3).

\subsection{Derivatives and Corporate Governance: Hedging, Speculation, and Selective Hedging}

This systems of equations model - ISUR, simultaneously examines the risk and value effects of the corporate governance-derivatives relationship. The overall objective of this study has been to examine whether corporate governance mechanisms are effective monitors for non-financial firms in their use of derivatives. As explained in Section 8.2, the primary purpose for non-financial firms in using derivatives is to hedge their risk exposure. Therefore, in order to assess corporate governance impact, the examination needs to establish whether the primary objective has been achieved in 
relation to hedging effectiveness. As discussed in Section 4.2.3, I assume that a reduction in risk indicates hedging and an increase in risk shows speculation. Table 4.1 depicts the risk-value relationship for hedging and speculation.

Hedging: The study documents that hedging is largely evidenced with respect to stock return volatility and for the corporate governance mechanisms related to the board and CEO. There is a reduction in stock return volatility and increase in firm value evidenced by: larger board size, larger board diversity, larger tenured CEOs, and larger CEO bonus. There is also evidence of hedging of market risk due to larger board diversity.

The motivation to reduce stock return volatility is supported by many (Schrand and Unal, 1998; Tufano, 1996; Geczy, et al., 1997; Gay and Nam, 1998; Guay, 1999) who contend that fluctuations in stock price reduce stock portfolio gains and therefore greater shareholding (compensation) tends to motivate a decrease risk. Managers are prone to increase derivatives in order to hedge their portfolios against stock return fluctuations. Therefore, the influence of corporate governance on hedging may stem from personal motives to protect their own stock portfolios through reduction of equity volatility. It could also stem from purposeful risk management strategies in the process of risk allocation for the benefit of the firm.

Speculation: Corporate governance mechanisms consistently exhibit speculative behavior with respect to cash flow volatility. The results for board size, larger tenured CEOs, larger CEO bonus, larger CEO salary, and smaller audit committee size show an increase in cash flow volatility with an accompanying increase in firm value, while board meetings, smaller percentage of insider shareholding and CEO total compensation increase cash flow volatility without any impact on value. Board 
meetings and audit committee size also show an increase in stock return risk. Additionally, CEO bonus, CEO age and institutional shareholding enhance market risk

The findings suggest these corporate governance mechanisms prefer to use derivatives to speculate cash flow risk with an accompanying increase in value. It supports the thinking that the performance and reputation of directors, CEOs and top management alike are gauged and rewarded based on the growth in profits, earnings and cash flows. As these measures are more transparent and more easily understood by management, managers have more incentives and are able to more easily manipulate these financial statement measures. (While stock price volatility is more opaque and less understood by managers and therefore more difficult to manipulate). Managers have their bonuses, awards, promotions, reputation and jobs linked to firm performance. Similarly, the markets gauge directors' reputations primarily on firm performance through the financial reports. Therefore, there is a strong motivation to manipulate earnings by both managers and directors. This reasoning appears logical as boards and CEOs would be more concerned to show higher earnings and cash flows to increase reputation, protect jobs/positions and enhance compensation. Firm earnings are more directly associated with board and CEO performance and therefore it would be expected that they would endeavor to increase earnings performance. Likewise, CEOs nearing the end of their tenure would try to increase earnings to enhance their cash wealth and position in the firm.

Insider shareholders, institutional shareholders, block shareholders show a speculating impact on stock return volatility. The tendency of shareholders to speculate stock return volatility appears plausible in light of their already well diversified portfolios and their hesitance to incur any additional costs of risk management (See Section 8.2.2 for more details). 
Selective Hedging: Following the selective hedging literature, this study uses the term selective hedging to capture the concurrent hedging and speculation behavior exhibited by corporate governance. The remaining corporate governance mechanisms: board size, insider shareholding, CEO tenure, CEO bonus and audit committee size exhibit selective hedging behavior. The findings of the selective hedging literature indicate that non-financial firms exhibit concurrent (or switching between) hedging and speculation positions and they provide support for my results. The reason for this selective hedging behavior could be due to the aligning of derivatives positions to vary with market prices for profits (Adam and Fernando, 2004). Or the selective hedging behavior may be a result of risk allocation to hedge one type of risk in order to enhance another risk where more benefits are to be derived (Schrand and Unal, 1998). Another plausible reason could be speculation by managers that use derivatives for personal motives and gains (Geczy, et al., 2007). Lastly, it is possible that the concurrent hedging and speculation activities evidenced could be part of a purposeful risk management strategy where there are effective internal controls to monitor derivatives and to deter their misuse (Geczy, et al., 2007). For more detailed discussion of results see Section 8.2.

In summary, of the thirteen corporate governance variables examined in the study only board diversity shows consistent hedging effectiveness, with accompanying increase in firm value. While board meetings, institutional shareholders, block shareholders, CEO age, CEO base salary and CEO compensation are associated exclusively with speculative behavior. The remaining corporate governance mechanisms, board size, insider shareholding, CEO tenure, CEO bonus and audit committee size exhibit selective hedging behavior. Board Independence reduces firm value but has no impact on firm risk. 


\subsection{Limitations of the Study}

This study is subject to a number of limitations. First, the research does not segregate corporate governance behavior into weak and strong governance, as is done by some researchers. The main objective here was to see corporate governance as a whole and to throw light on their hedging behavior.

Second, the corporate governance mechanisms are examined without consideration of other elements in the corporate governance framework. Geczy et al. (2007) suggest that when corporate governance speculation behavior is viewed in isolation of other governance structures, it could misleadingly indicate corporate governance failure. While in actuality there may be very strong internal controls over speculative trading activities. The authors suggest that generally weakly governed firms are more prone to speculation and they find evidence to suggest that firms take these positions actively out of their information and cost advantages. The authors find that these firms in actuality encourage managers to speculate through specific bonding and incentivealigning compensation contracts and use strong internal controls to control for the possibility of abuse with derivatives.

It is likely that the high costs of the internal control structures may be balanced with purposive profit-enhancing speculation activities as part of the risk management strategy. Larger firms that use derivatives would have elaborate controls and systems and therefore would naturally better monitor management. With the additional costs of maintaining elaborate internal control systems that are mandatory under legislation and stock exchange rulings, speculation may not indicate corporate governance weaknesses at all, but could be intentional to balance the costs and benefits to the firm. These firms would therefore encourage risk taking to better align management objectives with those of investors toward increased profits and wealth. The intentional 
speculation by corporate governance has also been indicated by Geczy et al. (2007). Therefore, this study does not make any assumptions regarding weak or strong governance, without also examining other governance structures.

In this study, a 1/0 dummy variable has been used to capture derivatives. This was necessitated by the non-availability of consistent data on derivatives over the eightyear study period. Such a problem arose primarily due to the variation in disclosure requirements for derivatives under the numerous and frequently changing accounting standards on derivative financial instruments (See Section 5.4). Additionally, the use of a dummy variable reflects the wide diversity in the types of derivatives and their reporting. The approach taken is one commonly used in the literature

Finally, the corporate governance variables used in this study may be endogenously related to firm value and firm risk. This endogeneity could be eliminated by applying a two stage least squares method and using instrument variables (2 SLS IV) for the corporate governance mechanisms. However, there are no available instrumental variables in the literature that consistently apply for all thirteen corporate governance variables. Neither was I able to develop any to fulfill this requirement.

In this study, the firms are included based on the availability of data for the corporate governance and firm measures. The data might suffer from selection bias as firms in the derivatives user samples are larger and more profitable than firms not using derivatives. However, both groups have a similar number of firm year observations, e.g. 2904 for derivative users and 3330 for derivative non-users and this may minimize any potential selection bias. Further the robustness test for firm size does not indicate any difference in results due to larger size which would provide some confidence against selection bias in the results. 
The issues examined in this study are related to a broad range of jurisdictions and the results should be generalizable to countries, other than the US, depending on any institutional and other differences prevalent in those countries.

\subsection{Future Research Suggestions}

Future research could provide an extension to this study by examining corporate governance along-side other structures within the whole corporate governance framework. This is especially important with respect to the internal control structures and other board committees. Further, the study examines thirteen corporate governance variables which could be extended to encompass a more comprehensive range of governance controls. It would be interesting to investigate the impact of board expertise on other board characteristics such as board size and board diversity. As data on board expertise is not readily available on databases it would need to be collected manually. For that reason, this study did not include this variable and leaves it for future examination.

Many new accounting standards have been introduced with respect to derivatives. The rapid progression of these standards is to improve the transparency and accountability with regard to derivatives. The standards show a progression from mere disclosure to the materializing and quantifying the derivatives effects in financial reports. Future studies could conduct a similar study to examine corporate governance effectiveness over reporting of derivatives and their impact on firm performance.

My research uses a derivative variable to capture all types of derivatives. It is suggested that future research could examine the value and risk effects directly with respect to the different derivative types: interest rate, foreign currency, commodity, 
etc. If research is able to isolate the individual effects of each governance mechanisms specifically with respect to each type of derivative and quantify the impact, this would greatly add value. It may highlight specific governance mechanisms that are relevant in the monitoring of specific types of derivatives. Additionally, a similar study may be conducted with a global sample. This would throw light on global governance practices in respect of the use of financial derivatives.

This study reinforces the importance of examining the risk and value effects of derivatives simultaneously and uses a fairly simplistic systems of equations model: Iterated Seemingly Unrelated Regression (ISUR) model. It is possible that in future a more sophisticated model could be applied to examine the value and risk effects of the firms simultaneously. Such an application would further add to the insights of the hedging-corporate governance relationship.

Another area that needs to be investigated is with respect to the arbitraging behavior of corporate governance in non-financial firms, both from the perspective of the firm and markets. There is a gap as no studies have examined the arbitraging impact of the derivatives -corporate governance relationship. Additionally, the capital asset pricing model (CAPM) and related market risk models do not seem to adequately capture stock related market risk (See Section 8.2.5) and therefore this needs to be addressed in studying the market impact of corporate governance on derivatives.

\subsection{Contributions}

There is extensive literature on derivatives that examines the effects of derivatives on firm performance and provides support for the benefits of risk management. However, there is a dearth of studies that investigate the relationship of corporate governance 
and derivatives. A few studies have investigated this relationship (Borokhovich et al., 2004; Dionne and Trikki, 2005; Huang et al., 2014; Lel, 2012), however the governance mechanisms examined are limited. Additionally, an examination of a comprehensive range of governance mechanisms taken together has been ignored. In respect of firm value, there are around two studies that examine the governancederivatives relationship with respect to firm value: Allayannis, et al. (2009) and Fauver and Naranjo (2010), while the former pertains to a global sample, the latter investigates only a few components of shareholding in a US sample. There is only one (recent working paper) that examines the relationship of board independence with respect to firm risk. There are no studies ( to the knowledge of the author that look at the hedging impact by examination of firm value and risk simultaneously.

My research contributes to the literature in a number of ways. Firstly, I contribute to the derivatives risk management literature. I provide new insights by measuring hedging effectiveness through an examination of both value and risk effects simultaneously. I contend that hedging and speculation activities cannot be gauged by viewing only one of these factors. An increase in firm value through the use of derivatives could indicate an accompanying increase in risk, reflecting inadvertent or deliberate speculation. Similarly, a reduction in risk may mean inefficient hedging if it also causes a reduction in firm value. Therefore, an examination of corporate governance hedging and speculative activities needs to analyze the derivatives impact on both firm value and firm risk. This is the first study to conduct such a simultaneous analysis.

Secondly, my research extends the literature on the determinants of derivatives. Results of such studies have produced quite conflicting findings and this could be due to the result of omitted factors (Geczy et al., 2001; Guay and Kothari, 2003; Pantzalis et al., 2001). Lel (2012) emphasizes the importance of including corporate governance 
in any study of derivatives because in his view it affects the risk management decisions of the firm. This is the first study to examine a comprehensive list of governance variables together in one model. Additionally, the inclusion of board meetings, board diversity, CEO base salary, CEO age and CEO tenure and audit committee size is innovative.

Thirdly, the method employed in the study is innovative and is the first application in a study of the derivatives-corporate governance relationship. Zellner's (1962) Iterated Seemingly Unrelated Regression (ISUR) methodology is suitable for an investigation of the hedging effect, where both value and risk need to be examined simultaneously, without forcing an endogenous relationship in the model. ISUR enables the simultaneous examination, with inclusion of some exogenous correlations in the error terms that exist as a result of the common derivatives environment in both the equations.

Fourthly, the study makes a contribution to corporate finance literature by providing unique insights of the varying responses to the types of risk being managed: with more hedging activities evidenced in respect to stock return volatility and higher speculation in respect to cash flow volatility. And a minimal effect of management of market risk. The research insights indicate the importance of examining the individual components of systematic and unsystematic risks separately, in relation to the firm's risk management strategies.

Finally, the study contributes to the corporate governance literature. There are few studies that examine corporate governance risk management activities in non-financial firms, though there is an abundance of research on the financial sector. This study contributes in the area of non-financial firms and provides insights to a comprehensive set of corporate governance mechanisms related to the board of directors, 
shareholders, compensation, audit committee and CEO/management characteristics, with respect to their risk management functioning. It is the first study to document corporate governance selective hedging behaviour.

\section{Implications for Corporations, Regulation and Legislation.}

The study builds awareness of firms exhibiting speculative behavior in response to cash flow volatility. This suggests that such activities may be discouraged through better compensation structures that would link cash based bonuses less with profits and more aligned with the overall firm risk management policies. On the other hand, if the speculation activity is intentional, then management needs to be aware of this and ensure that strong controls related to derivatives are in place and operational to deter their misuse.

There exists a paradox in the literature related to compensation objectives. Researchers and theorists maintain that compensation structures need to be framed to encourage risk-taking by risk-averse managers in order to align the objectives of management with those of the shareholders to increase firm value and wealth and therefore reduce agency conflict. If this is true, then it would indicate that compensation structures should encourage high risk taking and speculation. This feature needs to be reviewed by legislative bodies to determine what the overall objectives of compensation structures should be, especially with regard to hedging and risk management. It may suggest that compensation structures for derivative users may need to be tailored to the hedging objectives.

The study highlights that there are some gaps with respect to the relationship between

corporate governance and risk management. Specifically, it underscores that 
governance mechanisms and compensation requirement under the current system is too general and not customized toward efficient risk management. There is a need for more derivatives-hedging specific governance tools to provide direction for derivatives risk management activities within non-financial firms. This would enable corporate governance to be more focused and effective in a derivatives environment. 


\section{REFERENCES}

Abbott, L., Parker, S., \& Peters, G. (2004). Audit committee characteristics and restatements. Auditing: A Journal of Practice \& Theory, 23(1), 69-87.

Adam, T. (2002). Do firms use derivatives to reduce their dependence on external capital markets. European Finance Review, 6, 163-187.

Adam, T., \& Fernando, C. (2004). Hedging, speculation and shareholder value. Working Paper, Michael F. Price College of Business, University of Oklahoma.

Adam, T., \& Fernando, C. (2006). Hedging, speculation and shareholder value. Journal of Financial Economics, 81, 283-309

Adam, T., Fernando, S., \& Salas, J. (2012). Why do firms engage in selective hedging? Working Paper, Economic Risk, School of Business and Economics, Humboldt University of Berlin Dorotheenstr. 1, 10117 Berlin, Germany.

Adams, R., \& Ferreira, D. (2008). Do directors perform for pay? Journal of Accounting and Economics, 46(1), 154-171.

Adams, R., \& Ferreira, D. (2004). Gender diversity in the boardroom. ECGI Working Paper Series in Finance. Stockholm School of Economics, Department of Finance, Stockholm, Sweden.

Adams, R., \& Ferreira, D. (2007). A theory of friendly boards. The Journal of Finance, $62,217-250$.

Adams, R., \& Ferreira, D. (2009). Women in the boardroom and their impact on governance and performance. Journal of Financial Economics, 94, 291-309.

Adams, R., \& Mehran, H. (2012). Bank board structure and performance: evidence for large bank holding companies. Journal of Financial Intermediation, 21, 243267.

Adams, R. (2005). What do boards do? Evidence from board committee and director compensation data. Working Paper. Stockholm School of Economics.

Adams, R. (2009). Governance and the financial crisis. ECGI Working Paper Series in Finance. European Corporate Governance Institute. No. 248/2009. April 2009.

Adams, R., \& Ferreira, D. (2012). Regulatory pressure and bank directors' incentives to attend board meetings. International Review of Finance. 12(1), 227-248.

Adler, R.D. (2001), "Women in the Executive Suite Correlate to High Profits", Working Paper, European Project on Equal Pay, Pepperdine University. 
Aggarwal, R., \& Samwick, A. (1999). The other side of the trade-off: the impact of risk on executive compensation. Journal of Political Economy, 107, 65-105.

Agrawal A., \& Chadha, S. (2005). Corporate governance and accounting scandals. Journal of Law and Economics, 48(2), 371-406.

Alderfer, C. (1986). The invisible director on corporate boards. Harvard Business Review, 64(6), 38-52.

Allayannis, G., \& Mozumdar, A. (2000). Cash flow, investment and hedging. Paper presented at the annual meeting of the American Finance Association, New Orleans, Louisiana.

Allayannis, G., \& Ofek, E. (2001). Exchange rate exposure, hedging and the use of foreign currency derivatives. Journal of International Money and Finance, 20, 273-296.

Allayannis, G., \& Weston, J. (2001). The use of foreign currency derivatives and firm value. The Review of Financial Studies, 14(1), 243-276.

Allayannis, G., Brown, G., \& Klapper, L. (2003) Capital structure and financial risk: Evidence from foreign debt use in East Asia. The Journal of Finance, 58 (6), 2667-2710.

Allayannis, G., Ihrig, J., \& Weston, J.P. (2001). Exchange-rate hedging: financial versus operational strategies. The American Economic Review, 91(2), 391-395.

Allayannis, G., Lel, L., \& Miller, D. (2012). The use of foreign currency derivatives, corporate governance, and firm value around the world. Journal of International Economics, 87, 65-79.

Allayannis, G., Lel, L., \& Miller, D.P. (2009). Corporate governance and the hedging premium around the world. Working Paper, Darden Graduate School of Business.

Almazan A., \& Suarez, J. (2003). Entrenchment and severance pay in optimal governance structures. The Journal of Finance, 58(2), 519-547.

Almeida, H., Campello, M. \& Weisbach, M. (2004). The cash flow sensitivity of cash. The Journal of Finance, 59 (4), 1777-1804.

Amihud, Y. \& Lev, B., (1981). Risk reduction as a managerial motive for conglomerate mergers. Bell Journal of Economics, 12, 605-617.

Ammann, M., Oesch, D., \& Schmid, M. (2011). Corporate governance and firm value: international evidence. Journal of Empirical Finance, 18, 36-55. 
Anderson, R., Bates, T., Bizjak, T., \& Lemmon, M. (2000). Corporate governance and firm diversification. Financial Management, 78, 5-22.

Anderson, R., Mansi, S., \& Reeb, D. (2004). Board characteristics, accounting report integrity, and the cost of debt. Journal of Accounting and Economics, 37 (3), 315-342.

Ang, J. S., Chua, J. H., \& McConnell, J. J. (1982). The administrative costs of corporate bankruptcy: a note. Journal of Finance, 37, 219-226.

Anscombe, F. (1948). The transformation of Poisson, binomial and negative-binomial data. Biometrika, 35 (3/4), 246-254.

Antle, R., \& Smith, A. (1986). An empirical investigation into the relative performance evaluation of corporate executives. Journal of Accounting Research, 24, 139.

Archambeault, D., \& DeZoort, T. (2001). Auditor opinion shopping and the audit committee: an analysis of suspicious auditor switches. International Journal of Auditing, 5, 33-52

Aretz, K., \& Bartram, S. (2010). Corporate hedging and shareholder value. Journal of Financial Research. 33 (4), 317-371.

Ashbaugh-Skaife, H., Collins, D. \& LaFond, R. (2006). The effects of corporate governance on firms' credit ratings. Journal of Accounting and Economics, 42 (1-2), 203-243.

Baber, W., Kang, S., \& Kumar, K. (1998). Accounting earnings and executive compensation: the role of earnings persistence. Journal of Accounting and Economics, 25, 169-193.

Bainbridge, S. (2003). The business judgment rule as abstention doctrine. University of California, Los Angeles (UCLA), School of Law, Law and Econ. Research Paper No. 03-18.

Baker, A., Bradley, B., \& Wurgler, J. (2011). Benchmarks as limits to arbitrage: understanding the low-volatility anomaly. Financial Analysts Journal, 67(1), 40-54.

Baker, A. \& Wurgler, J. (2002). Market Timing and Capital Structure. The Journal of Finance, 57 (1), 1-32

Barber, B., \& Lyon, J. (1996). Detecting abnormal operating performance; the empirical power and specification of test statistics. Journal of Financial Economics, 41, 359-399. 
Barber, B., \& Odean, T. (2001). Boys will be boys: gender, overconfidence and common stock investment. The Quarterly Journal of Economics, 116 (1), 261-292.

Barberis, N., Shleifer, A., \& Wurgler, J. (2005). Comovements. Journal of Financial Economics, 75, 283-317

Bargeron, L., Lehn, K., \& Zutter, C. (2010). Sarbanes-Oxley and corporate risk-taking. Journal of Accounting and Economics, 49, 34-52.

Barnhart S., \& Rosenstein, S. (1998). Board composition, managerial ownership, and firm performance: an empirical analysis. Eastern Finance Association, 33 (4), $1-16$.

Barton, J. (2001). Does the use of financial derivatives affect earnings management decisions? The Accounting Review, 76 (1), 1-26.

Bartram, S. M., Brown, G. W., \& Fehle, F. R. (2009). International evidence on financial derivatives usage. Financial Management, 185-206.

Bartram, S.M., Brown, G. W., \& Conrad, J. (2011). The Effects of Derivatives on Firm Risk and Value. Journal of Financial and Quantitative Analysis,46 (4), 967999.

Beaumont, S. (2015). An investigation of the short-and long-run relations between executive cash bonus payments and firm financial performance: a pitch. Accounting and Finance, 55 (2), 337-343.

Bebchuk, L. \& Fried, J. (2003). Executive compensation as an agency problem. Journal of Economic Perspectives, 17(3), 71-92.

Bebchuk, L. \& Fried, J. (2004). Pay without performance: the unfulfilled promise of executive compensation. Harvard University Press, Cambridge, MA.

Bebchuk, L. \& Weisbach M. (2010). The state of corporate governance research. The Review of Financial Studies, 23(3), 939-961.

Beber, A. \& Fabbri, D. (2005). Who times the foreign exchange market? Corporate speculation and CEO characteristics. Working paper, University of Lausanne and FAME.

Bedard, J., Chtourou, S., \& Courteau, L. (2004). The effect of audit committee expertise, independence, and activity on aggressive earnings management. Auditing: A Journal of Practice \& Theory, 23(2), 13-35.

Beiner, S., Drobetz, W., Schmid, M \& Zimmermann, H. (2006). An integrated framework of corporate governance and firm valuation. European Financial Management, 12 (2), 249-283. 
Belghitar, Y., Clark, E., \& Judge, A. (2008). The value effects of foreign currency and interest rate hedging: the UK evidence. International Journal of Business, 13(1), 23-60.

Belghitar, Y., Clark, E., \& Kassimatis, K. (2011). The prudential effect of strategic institutional ownership on stock performance. International Review of Financial Analysis, 20(4), 191-199.

Benmelech, E., Berrebi, C., \& Klor, E. (2010). The economic cost of harboring terrorism. Journal of Conflict Resolution, 54(2), 331-353.

Berger, P., Ofek, E., \& Yermack., D. (1997). Managerial entrenchment and capital structure decisions. Journal of Finance, 52, 1411-1438.

Berk, J., (1997) Necessary conditions for the CAPM. Journal of Economic Theory, 73 (1), 245-257

Berkman, H., \& Bradbury, M. E. (1996). Empirical evidence on the corporate use of derivatives. Financial Management, 25(2), 5-13.

Berle, A. \& Means, G. (1932). The modern corporation and private property. Macmillian, New York.

Bernardi, R., Bosco, S., \& Vassill, K. (2006). Does female representation on boards of directors associate with Fortune's 100 best companies to work for list? Business \& Society, 45 (2), 235-248.

Bernasek A., \& Shwiff, S. (2001). Gender, risk, and retirement. Journal of Economic Issues, 35 (2), 345-356

Bertrand, M., \& Mullainathan, S. (2000) Do CEOs set their own pay? The ones without principals do. Working Paper 7604, National Bureau of Economic Research, 1050 Massachusetts Avenue Cambridge, MA 02138.

Bessembinder, H. (1991). Forward contract and firm value: investment incentive and contracting effects. The Journal of Financial and Quantitative Analysis, 26(4), 519-532.

Beyer, S. (1990). Gender differences in the Accuracy of self-evaluations of performance. Journal of Personality and Social Psychology, 59, 960-970.

Bhagat, S., \& Black, B. (1999). The uncertain relationship between board composition and firm performance. Business Lawyer, 54, 921-963.

Bhagat, S., \& Black, B., (2001). The non-correlation between board independence and long-term firm performance. Journal of Corporation Law, 27, 231. 
Bhalla, V.K. (2009). Global financial turmoil containment and resolution. Journal of Management Research, 9(1), 43-56.

Birt, J., Rankin, M., \& Chen S. (2012). Derivatives use and financial instrument disclosure in the extractives industry. Accounting and Finance, 1-29.

BIS (2013). Bank for International Settlements, Statistical Release OTC Derivatives Statistics at end-June 2013, Monetary and Economic Department, November 2013.

BIS (2015). Bank for International Settlements, BIS Quarterly Review, March 2015.

Block, S. B., \& Gallagher, T. J. (1986). The use of interest rate futures and operations by corporate financial managers. Financial Management, 15(3), 73-78.

Bloom, M., \& Milkovich, G. (1998). Relationships among risk, incentive pay, and organizational performance. Academy of Management Journal, 41(3), 283297.

Bodnar, G., Graham, J., Harvey, C., \& Marston, R. (2011). Managing Risk Management. Working Paper.

Bodnar, G.M., Hayt, G.S., \& Marston, R.C. (1998). 1998 Wharton survey of financial risk management by US non-financial firms. Financial Management, 27(4), 70-91.

Bolton, P., Scheinkman, J., \& Xiong, W. (2006). Executive compensation and shorttermist behaviour in speculative markets Review of Economic Studies, 73 (3), 577-610.

Boone, A., Field, L., Karpoff, J., \& Raheja, C. (2007). The determinants of corporate board size and composition: an empirical analysis. Journal of Financial Economics, 85, 65-101.

Booth, J. R., Smith, L., \& Stolz, R. W. (1984). The use of interest futures by financial institutions. Journal of Bank Research, 15, 15-20.

Borokhovich, K., Brunarski, K., Crutchley, C., \& Simkins, B. J. (2004). Board interest and corporate use of interest rate derivatives. Journal of Financial Research, 27, 199-216.

Borokhovich, K., Parrino, R., \& Trapani, T. (1996). Outside directors and CEO selection. Journal of Financial and Quantitative Analysis, 31, 189-220.

Boschen, J., \& Smith, K. (1995). You can pay me now and you can pay me later: the dynamic response of executive compensation to firm performance. The Journal of Business, 68 ( 4 ), pp. 577-608. 
Boschen, J., Duru, A., Gordon, L., \& Smith, K. (2003). Accounting and stock price performance in dynamic CEO compensation arrangements. The Accounting Review, 78 (1), 143-168.

Bozec, Y., \& Laurin, C. (2008). Large shareholder entrenchment and performance: Empirical evidence from Canada. Journal of Business Finance \& Accounting, $35,25-49$.

Braiotta, L. (1999). The audit committee handbook. Third edition, published by John Wiley \& Sons, 1999.

Brammer, S., Millington, A., \& Pavelin, S. (2009). Corporate reputation and women on the board', British Journal of Management 20 (1), 17-29.

Breeden, D., \& Viswanathan, S. (1998).Why do firms hedge? An asymmetric information model. Working Paper, University of Pennsylvania.

Breeden, D., \& Viswanathan, S. (1999). Why do firms hedge? An asymmetric information model. Working Paper, Duke University, Durham, NC.

Brick, I., \& Chidambaram, N. (2010). Board meetings, committee structure and firm value. Journal of Corporate Finance. 16, 533-553.

Brick, I., \& Chidambaran, N. (2008). Board monitoring, firm risk, and external regulation. Journal of Regulatory Economics, 33 (1), 87-116.

Brick, I., Palmon, O., Wald, J. (2006), CEO compensation, director compensation, and firm performance: evidence of cronyism? Journal of Corporate Finance, 12, 403-423.

Brockman, P., \& Turtle, H. 2003. A barrier option framework for corporate security valuation. Journal of Financial Economics, 67 (3), 511-529

Brown, J., \& Otsuki, T. (1993). Risk premia in Pacific-Basin capital markets. PacificBasin Finance Journal, 1 (3), 235-261.

Brown, G., Crabb, P., and Haulshalter, D. (2002). Are firms successful at selective hedging? Journal of Business, 79, 2925-2950.

Bryant, H., Bessler, D., \& Haigh, M. "Causality in Futures Markets." The Journal of Futures Markets, 26, 1039-1057.

Buffett, W. (2003). Warren Buffet's letters to Berkshire shareholders 1977-2002.

Retrieved 1/12/2011

<http://www.berkshirehathaway.com/letters/2002.html >

Burgess, Z., \& Tharenou, P. (2002). Women board directors: characteristics of the few. 
Journal of Business Ethics, 37 (1), 39-49.

Burt, R. (1983). Corporate profits and cooptation. Administrative Science Quarterly, 29 (4), 633-636.

Bushee, B. (1998). The influence of institutional investors on myopic R\&D investment behaviour. The Accounting Review, 73,303-333.

Buyuksahin, B., \& Harris, J. (2011). Do speculators drive crude oil futures prices? The Energy Journal, 32 (2), 167-202.

Byrd, J. \& Hickman, A. (1992). Do outside directors monitor managers? Evidence from tender offer bids. Journal of Financial Economics, 32, 195-221.

Byrnes, J., Miller, D., \& Schafer, W. (1999). Gender differences in risk taking: a metaanalysis. Psychological Bulletin, 125, 367-383.

Callahan, M. (2002). To hedge or not to hedge that is the question. Empirical evidence from the North American gold mining industry 1996-2000. Working Paper. The Leonard N. Stern School of Business.

Campbell, K., \& Minguez-Vera, A. (2008). Gender diversity in the boardroom and firm financial performance. Journal of Business Ethics, 83 (3), 435-451.

Campbell, J., Hilscher, J., \& Szilagyi, J. (2008). In search of distress risk. Journal of Finance, 63, 2899- 2939.

Campello, M., Lin, C., Ma, Y., \& Hong, Z. (2011). The real and financial implications of corporate hedging. The Journal of Finance, 66(5), 1615-1647.

Carpenter, J. (2000). Does option compensation increase managerial risk appetite? The Journal of Finance, 55 (5), 2311-2331

Carter, D., D’Souza, F., Simkins, B., \& Simpson, G. (2010). The Gender and Ethnic Diversity of US Boards and Board Committees and Firm Financial Performance. Corporate Governance: An International Review, 2010, 18(5), 396-414.

Carter, D., Simkins, B., \& Simpson, W., (2003). Corporate governance, board diversity, and firm value. Financial Review, 38, 33-53.

Carter, D.A., Rogers, D.A., \& Simkins, B.J. (2006). Does hedging add value. evidence from global airline industry. Financial Management, 35(2), 53-86.

Carter,C., Rausser, G., \& Schmitz, A. (1983). Efficient asset portfolios and the theory of normal backwardation. Journal of Political Economy, 91, 319-331. 
Chai, L., \& Hayes, A. (2008). A new test of linear hypotheses in OLS regression under heteroscedasticity of unknown form. Journal of Educational and Behavioral Statistics, 33(1), 21-40.

Chan, K., \& Li, J. (2008). Audit Committee and Firm Value: Evidence on outside top executives as expert-independent directors. Corporate Governance: An International Review, 16(1), 16-31.

Chang, E. (1985). Returns to speculators and the theory of normal backwardation. Journal of Finance, 40, 193-208.

Chava, S., \& Purnanandam, A. (2010). CEOs versus CFOs: incentives and corporate policies. Journal of Financial Economics, 97 (2), 263-278.

Chen, H., Wang, H., \& Zhou, H. (2014). Stock return volatility and capital structure decisions. Working Paper, Massachusetts Institute of Technology; National Bureau of Economic Research (NBER), USA

Cheng, S. (2004). R\&D expenditures and CEO compensation. The Accounting Review, 79 (2), 305-328.

Cheng, S. (2008). Board size and the variability of corporate performance. Journal of Financial Economics, 87, 157-176.

Chesney, M. \& Asner, R. (2004). Stock options and managers' incentives to cheat. Working Paper, Swiss Banking Institute, University of Zurich, Zurich, Switzerland.

Chow, G. (1960). Tests of equality between sets of coefficients in two linear regressions. Econometrica, 28 (3) 591-605.

Chung, K. \& Pruitt, S. (1994). A simple approximation of Tobin's q. Financial Management, 23 (3), 70-74.

Coase, R. (1937). The nature of the firm. Economica, 4, 386-405.

Coase, R. (1960). The problem of social cost. Journal of Law and Economics, 3, 1-44.

Cohen, D., Dey, A., \& Lys, T. (2004). The Sarbanes Oxley Act of 2002: Implications for compensation contracts and managerial risk-taking. NYU Working Paper No. $2451 / 27546$

Coles, J., Daniel, N., \& Naveen, L. (2006). Managerial incentives and risk-taking. Journal of Financial Economics, 79, 431-468.

Coles, J., Daniel, N., \& Naveen, L. (2008). Boards: does one size fit all? Journal of Financial Economics, 87, 329-356. 
Conyon, M., \& Peck, S. (1998). Board size and corporate performance: evidence from European countries. The European Journal of Finance, 4, 291-304.

Conyon, M., Peck, S., Sadler, G. (2001). Corporate tournaments and executive compensation: evidence from the U.K. Strategic Management Journal, 22 (8), 805-815.

Core J. \& Guay, W. (1999). The use of equity grants to manage optimal equity incentive levels. Journal of Accounting and Economics, 18, 151-184.

Core, J., \& Guay, W. (2010). Is there a case for regulating executive pay in the financial services industry. Working paper. The Wharton School, University of Pennsylvania.

Core, J., \& Larcker, D. (2002). Performance consequences of mandatory increases in executive stock ownership. Journal of Financial Economics, 64(3), 317- 340.

Core, J., Holthausen, R., \& Larcker, D. (1999). Corporate governance, chief executive officer compensation and firm performance. Journal of Financial Economics, 51, 371-406.

Cornett, M., Marcus, A., Tehranian, H. (2008). Corporate governance and pay-forperformance: the impact of earnings management. Journal of Financial Economics, 87, 357-373.

Corsetti, G., Dasgupta, A., Morris, S., \& Shin, H. (2004). Does one soros make a difference? A theory of currency crises with large and small traders. The Review of Economic Studies, 71 (1), 87-113.

Cotter, J., Shivdasani, A., \& Zenner, M. (1997). Do independent directors enhance target shareholder wealth during tender offers? Journal of Financial Economics, 43, 195-218.

Coval, J., \& Stafford, E. (2007). Asset fire sales (and purchases) in equity markets. Journal of Financial Economics, 86 (2), 479-512.

Crutchley, C., Garner, J., \& Marshall, B. (2004). Does one size fit all? A comparison of boards between newly public and mature firms. Working Paper, Drexel University.

Cyert, R., Kang, S., \& Kumar, P. (2002). Corporate governance, takeovers, and top management compensation: theory and evidence. Management Science, 48, 453-469.

Dalton, D., Daily, C., Johnson, J., \& Ellstrand, A. (1999). Number of directors and financial performance: a meta-analysis. Academy of Management Journal, 42, 674-686. 
David, I., Franzoni, F., Moussawi, R., \& Sedunov, J. (2015). The granular nature of large institutional investors. Working Paper, Fisher College of Business Working Paper Series. The Ohio State University.

Davies, A. (2011). Women on boards February 2011. Report by the Equality and Human Rights Commission (2008) presented by Lord Davies of Abersoch, on $24^{\text {th }}$ February, 2011.

DeAngelo, H. \& Masulis, R. (1980). Optimal capital structure under corporate and personal taxation. Journal of Financial Economics, 8 (1), 3-29

Deaux, K., \& Farris, E. (1977). Attributing causes for one's own performance: The effects of sex, norms, and outcome. Journal of Research in Personality. 11 (1), 59-72.

Dechow, P., Hutton, A., \& Sloan, R. (1998). An empirical assessment of the residual income valuation model. Journal of Accounting and Economics, 26, 1-34

Dechow, P., Sloan, R., \& Sweeney, A. (1996). Causes and consequence of earnings manipulation: an analysis of firms subject to enforcement actions by the SEC. Contemporary Accounting Research, 13, 1-36.

Dechow, P., \& Sloan, R. (1991). Executive incentives and the horizon problem: An empirical investigation. Journal of Accounting and Economics, 14(1), 51-89.

DeMarzo, P., \& Duffie, D. (1995). Corporate incentives for hedging and hedge accounting. Review of Financial Studies, 8, 743-772.

Demsetz, H. \& Villalonga, B. (2001). Ownership structure and corporate performance. Journal of Corporate Finance, 7, 209-233.

Demsetz, H. (1983). The structure of ownership and the theory of the firm. Journal of Law and Economics, 26, 375-390.

Denis, D., \& McConnell, J. (2003). International corporate governance. Journal of Financial and Quantitative Analysis, 38, 1-36.

DeZoort, F., Hermanson, D., Archambeault, D., \& Reed, S. (2002). Audit committee effectiveness: A synthesis of the empirical audit committee literature. Journal of Accounting Literature, 21, 38-75.

DeZoort, F., \& Salterio, S. (2001). The effects of corporate governance experience and financial-reporting and audit knowledge on audit committee members' judgments. Auditing: A Journal of Practice \& Theory, 20 (2), 31-47. 
Dhaliwal, D., Naiker, V., \& Navissi, F. (2006). Audit committee financial expertise, corporate governance and accruals quality: an empirical analysis. Working Paper. University of Arizona, Department of Accounting.

Dhanajarata, S., Kumar, P., \& Rabinovitch, R. (2010). Hedging and risk-management in the oil and gas industry. Working Paper, University of Houston.

Dionne, G. \& Garand, M. (2003). On risk management determinants affecting firms' values in the gold mining industry: new empirical evidence. Economic Letters, 79, 43-52.

Dionne, G., \& Triki, T. (2005). Risk management and corporate governance: the importance of independence and financial knowledge for the board and the audit committee. Working Paper 05-15. Department of Finance and Canada Research Chair in Risk Management, HEC Montreal.

Dionne, G., \& Trikki, T. (2013). On risk management determinants: what really matters? The European Journal of Finance, 19(2), 145-164.

DiTomaso, N., \& Post, C. (2007). Diversity, in S. R. Clegg and J. Bailey (eds.), International Encyclopedia of Organization Studies (Sage, Thousand Oaks), pp. 397-401.

Dittman, I., \& Maug, E. (2007). Lower salaries and no options? On the optimal structure of executive pay. The Journal of Finance, 62 (1), 303-343.

Dodd-Frank (2010). Corporate Governance Issues, Including Executive Compensation Disclosure and Related SRO Rules. Dodd-Frank Home Spotlight. US Securities Exchange Commission. Available at: http://www.sec.gov/spotlight/dodd-frank/ corporate governance .shtml.

Dolde, W. (1993). The trajectory of corporate financial risk management. Journal of Applied Corporate Finance, 6(3), 33-41.

Dolde, W. (1995). Hedging, leverage and primitive risk. Journal of Financial Engineering, 4, 187-216.

Donohoe, M. (2015). The economic effects of financial derivatives on corporate tax avoidance. Journal of Accounting and Economics. 59, 1-24

Dou, Y., Hope, O., Thomas, W., \& Zou, Y. (2014). Blockholder exit threats and financial reporting quality. Working Paper, Stern School of Business, New York University.

Dybvig, P., \& Zender, J. (1991). Capital structure and dividend irrelevance with asymmetric information. The Review of Financial Studies, 4 (1), 201-219. 
Eisenberg, T., Sundgren, S., \& Wells, M. (1998). Larger board size and decreasing firm value in small firms. Journal of Financial Economics, 48, 35-54.

Elbadry, A., Gounopoulos, D., \& Skinner, F. (2015). Governance Quality and information Asymmetry. Financial Markets, Institutions \& Instruments, Vol. 24, Issue 2-3, pp. 127-157, 2015.

Ely, K. (1991). Interindustry differences in the relation between compensation and firm performance variables. Journal of Accounting Research, 29, 37-58.

Erkens, D., Hung, M., \& Matos, P. (2009). Corporate governance in the 2007-2008 financial crisis: evidence from financial institutions worldwide. Working Paper, University of Southern California.

Erkens, D., Hung, M., \& Matos, P. (2012). Corporate governance in the 2007-2008 financial crisis: evidence from financial institutions worldwide. Journal of Corporate Finance, 18, 389-411

Faleye, O., Hoitash, R. \& Hoitash, U. (2011). The costs of intense board monitoring. Journal of Financial Economics. 101, 160-181.

Fama, E. \& Jensen, M. (1983a). Separation of ownership and control. Journal of Law and Economics, 26, 301-325.

Fama, E. \& Jensen, M. (1983b). Agency problems and residual claims. Journal of Law and Economics, 26, 327-349.

Fama, E. (1980). Agency problems and the theory of the firm. Journal of Political Economy, 88, 288-307.

Fama, E. (1984). Forward and spot exchange rates. Journal of Monetary Economics, 14, 319-338.

Fama, E., \& French, K. (1998). Taxes, financing decisions, and firm value. The Journal of Finance, 53 (3), 819-843.

Fama, E., \& French, K. (2002). The Equity Premium. The Journal of Finance, 57 (2), 637-659.

Farrell, K., \& Hersch, P. (2005). Additions to corporate boards: the effect of gender. Journal of Corporate Finance, 11 (1-2), 85-106.

Faulkender, M. (2005). Hedging or market timing? Selecting the interest rate exposure of corporate debt. The Journal of Finance, 60 (2), 931-962.

Faulkender, M., \& Petersen, M. (2006). Does the source of capital affect capital structure? Review of Financial Studies, 19(1), 45-79. 
Fauver, F., \& Naranjo, A. (2010). Derivative usage and firm value: The influence of agency costs and monitoring problems. Journal of Corporate Finance, 16, 719-735.

Fazzari, S., Hubbard, R. G., \& Petersen, B. (1988). Financing constraints and corporate investment. Brookings Papers on Economic Activity, 1, 141-195.

FCIR (2011). The Financial Crisis Inquiry Report. Final Report of the National Commission on the Causes of the Financial and Economic Crisis in the United States, February 25, 2011. http://www.gpo.gov/fdsys/pkg/GPO-FCIC/pdf/ GPO-FCIC.pdf.

Fehr-Duda, H., Gennaro, M., \& Schubert, R. (2006). Gender, financial risk, and probability weights. Theory and Decision, 60 (2), 283-313.

Ferreira, M., \& Laux, P. (2007). Corporate governance, idiosyncratic risk and information flow. The Journal of Finance. 62 (2), 951-989.

Fields, A., \& Keys, P. (2003). The emergence of corporate governance from Wall St. to Main St.: outside directors, board diversity, earnings management, and managerial incentives to bear risk. The Financial Review, 38(1), 1-24.

Figlewski, S. (2009). Viewing the financial crisis from 20,000 feet up. Journal of Derivatives, 16(3), 53-61.

Firth, M., Lin, C., Wong, S., \& Zhao, X. (2014). Hello, is anybody there? Corporate accessibility for outside shareholders as a signal of agency problem. Working Paper, Lingnan University, Hong Kong.

Florackis, E., \& Ozkan, A. (2009). The impact of managerial entrenchment on agency costs: an empirical investigation using UK panel data. European Financial Management, 15, 497-528.

Fok, R., Carroll, C., \& Chiou, M. (1997). Determinants of corporate hedging and derivatives: a revisit. Journal of Economics and Business, 49(6), 569-585.

Freeman, R., \& Evan, W. (1990). Corporate governance: a stakeholder interpretation. Journal of Behavioural Economics, 19, 337-359.

Frooman, J. (1999). Stakeholder influence strategies. Academy of Management Review, 24, 191-205.

Froot, K. A., Scharfstein, D. S., \& Stein, J. C. (1993). Risk management: coordinating corporate investment and financing policies. The Journal of Finance, 48(5), 1629-1658. 
Frydman, C., \& Jenter, D. (2010). CEO Compensation. Working Paper 16585, National Bureau of Economic Research, 1050 Massachusetts Avenue Cambridge, MA 02138 .

Gabaix, X. (2011). The granular origins of aggregate fluctuations. Econometrica, 79, 733-772.

Gabaix, X., Gopikrishnan, P., Plerou, V., \& Stanley, E. (2006). Institutional investors and stock market volatility. The Quarterly Journal of Economics, 121 (2), 461-504.

Garen, J. E. (1994). Executive compensation and principal-agent theory. The Journal of Political Economy, 102(6), 1175-1199.

Gay, G. D., \& Nam, J. (1998). The underinvestment problem and corporate derivatives use. Financial Management, 27(4), 53-69.

Geczy, C., Minton, B. A., \& Schrand, C. (1997). Why firm use currency derivatives. The Journal of Finance, 52(4), 1323-1354.

Geczy, C., Minton, B. A., \& Schrand, C. (2007). Taking a view: corporate speculation, governance and compensation. The Journal of Finance, 62(5), 2405-2443.

Geczy, C., Minton, B., \& Schrand, C. (2001). Choices among alternative risk management strategies: evidence from the natural gas industry. Working Paper, University of Pennsylvania.

Gervais, S. \& Odean, T. (1999). Learning to be overconfident. Working Paper, University of Pennsylvania.

Gibbons, R. \& Murphy, K. (1992). Does executive compensation affect investment? NBER Working Paper 4135. National Bureau of Economic Research.

Gibbs, P. (1992). Determinants of corporate restructuring: the relative importance of corporate governance, takeover threat, and free cash flow. Strategy Management Journal, 14, 51-68.

Gillian, S., Hartzell, J., \& Starks, L. 2003. Explaining Corporate Governance Boards: Bylaws and Charter Provisions. Working paper, University of Delaware, Newark, DE and University of Texas, Austin, TX

Gillian, S., \& Starks, L. (2007). The evolution of shareholder activism in the United States. Journal of Applied Corporate Finance, 19, 55-73.

Gillette, A., Noe, T., \& Rebello, M. (2003). Corporate board composition, protocol and voting behaviour: experimental evidence. The Journal of Finance, 58 (5), 1997-2031. 
Glaum, M. (2002). The determinants of selective exchange risk management-evidence from German non-financial corporations. Journal of Applied Corporate Finance, 14 (4), 108-121.

Goldman, E., \& Slezak, S. (2006). An equilibrium model of incentive contracts in the presence of information manipulation. Journal of Financial Economics, 80 (3), 603-626.

Gompers, P., Ishii, J., \& Metrick, A. (2003) Corporate Governance and Equity Prices. The Quarterly Journal of Economics, 118 (1): 107-156.

Gonzalez, F. P., \& Yun, H. (2013). Risk management and firm value: evidence from weather derivatives. The Journal of Finance, 68(5), 2143-2176.

Graham, J., \& Harvey, C. (2001) The theory and practice of corporate finance: evidence from the field. Journal of Financial Economics, 60 (2-3), 187-243.

Graham J., \& Rogers, D. (1999). Is corporate hedging consistent with value maximization? An empirical analysis. Working Paper, Northeastern University, Boston, USA.

Graham, J., \& Rogers, D. (2002). Do firms hedge in response to tax incentives, Journal of Finance, 57, 815-839.

Graham, J., \& Smith, C. (1999). Tax incentives to hedge. Journal of Finance, 54, 22412263.

Gray S. \& Cannella, A. (1997). The role of risk in executive compensation. Journal of Management, 23, 517-540.

Greenwood, R. (2005). Short- and long-term demand curves for stocks: theory and evidence on the dynamics of arbitrage. Journal of Financial Economics, 75 (3), 607-649.

Grossman, S. \& Hart, O. (1986). The costs and benefits of ownership: A theory of vertical and lateral integration. Journal of Political Economy, 94, 691-719.

Grossman, S., \& Hart, O. (1983). An analysis of the principal agent problem, Econometrica, 51, 7-45.

Guay, W., \& Kothari, S. P. (2003). How much do firms hedge with derivatives. Journal of Financial Economics, 70, 423-461.

Guay. W.R. (1999). The impact of derivatives on firm risk: an empirical examination of new derivative users. Journal of Accounting and Economics, 26, 319-351. 
Gul, R., Kim, J., \& Qiu, A. (2010). Ownership concentration, foreign shareholding, audit quality, and stock price synchronicity: Evidence from China. Journal of Financial Economics, 95, 425-442.

Guest, P. (2009). The impact of board size on firm performance: evidence from the UK. The European Journal of Finance, 15 (4), 385-404.

Harford, J. (2003). Takeover bids and target directors' incentives: the impact of a bid on directors' wealth and board seats. Journal of Financial Economics, 69 (1), 51-83.

Harjoto, M., Laksmana, I., \& Yang, Y. (2014). Board Diversity and Corporate Risk Taking. Working Paper. Pepperdine University - Graziadio School of Business and Management, Malibu, CA.

Harris J., \& Bromiley, P. (2007). Incentives to cheat: the influence of executive compensation and firm performance on financial misrepresentation. Organization Science, 18 (3), 350-367.

Harris, M., \& Raviv, A. (1979). Optimal incentive contracts with imperfect information. Journal of Economic Theory, 20 (2), 231-259.

Harris, M., \& Raviv, A. (1993). Differences of opinion make a horse race. The Review of Financial Studies, 6 (3), 473-506.

Harris, M., \& Raviv, A. (2008). A theory of board control and size. The Review of Financial Studies. 21 (4), 1797-1832.

Hartzell, J. \& Starks, L. (2003). Institutional investors and executive compensation. The Journal of Finance, 58 (6), 2351-2374.

Harvey, K., \& Shrieves, R. (2001). Executive compensation structure and corporate governance choices. The Journal of Financial Research, 24 (4), 495-512.

Haushalter, D. G. (2000). Financing policy, basis risk and corporate hedging:evidence from oil and gas producers. The Journal of Finance, 55(1), 107-152.

Heflin, F., \& Shaw, K. (2000). Blockholder ownership and market liquidity. Journal of Financial and Quantitative Analysis, 35 (4), 621-633.

Hentschel, L. \& Kothari, S.P. (2001). Are Corporations Reducing or Taking Risks with Derivatives? The Journal of Financial and Quantitative Analysis, 36 (1), 93118.

Hermalin, B. \& Weisbach, M. (1991). The effects of board composition and direct incentives on firm performance. Financial Management, 20 (4), 101-112. 
Hermalin, B. \& Weisbach, M. (1998). Endogenously chosen boards of directors and their monitoring of the CEO. The American Economic Review, 88 (1) 96-118.

Hermalin, B., \& Weisbach, M. (2003) Board of directors as an endogenously determined institution. Federal Reserve Bank of New York Economic Policy Review, 9, $1-20$.

Hermalin, B., \& Weisbach, M., (2007). Transparency and Corporate Governance. NBER Working Paper Series. Working Paper 12875. National Bureau of Economic Research, Massachusetts, Cambridge.

Hermalin, H., \& Weisbach, M. (1988). The determinants of board composition. Rand Journal of Economics, 19, 589-606.

Hill, C., \& Snell, S. (1988). External control, corporate strategy, and firm performance in research-intensive industries. Strategic Management Journal, 9, 577-590

Hillman, A., Shropshire, C., \& Cannella, A. (2007). Organizational predictors of women of corporate boards. Academy of Management Journal, 50 (4), 941-952.

Himmelberg, C., Hubbard, R., \& Palia, D. (1999). Understanding the determinants of managerial ownership and the link between ownership and performance. Journal of Financial Economics. 53, 353-84.

Hirshleifer, D. (1988). Residual risk, trading costs, and commodity futures risk premia. The Review of Financial Studies, 1 (2), 173-193.

Hogan, C., \& Lewis, C. (2005).Long-run investment decisions, operating performance, and shareholder value creation of firms adopting compensation plans based on economic profits. Journal of Financial and Quantitative, 40 (4), 721-745.

Holmstrom, B. (1979). Moral hazard and observability. Bell Journal of Economics, 10, 4-29.

Howton, S., \& Perfect, S. (1998). Currency and interest-rate derivatives use in US firms. Financial Management, 27 (4) 111-121.

Hovakimian, A., Opler, T., \& Titman, S. (2001). The debt-equity choice. The Journal of Financial and Quantitative Analysis, 36 (1), 1-24.

Huang, A. (2009). The cross section of cashflow volatility and expected stock returns. Journal of Empirical Finance, 16, 409-429.

Huang, S., Peyer, U., \& Segal, B. (2013). Do firms hedge optimally? Evidence from an exogenous governance change. Working Paper, INSEAD, Singapore. 
Hull, J. (2011). Fundamentals of futures and options markets. Seventh edition, Prentice Hall, Pearson Education, Inc. publishing as Prentice Hall, 2011.

Jensen, M. (1993). The modern industrial revolution, exit, and the failure of internal control systems. Journal of Finance, 48, 831-880.

Jensen, M., \& Meckling, W. (1976). Theory of the firm: managerial behaviour, agency costs, and ownership structure. Journal of Financial Economics, 3 (4), 305360 .

Jensen, M., \& Murphy, K. (1990). Performance pay and top management incentives. Journal of Political Economy, 98, 225-264.

Jin, L. (2002). CEO compensation, diversification and incentives. Journal of Financial Economics, 66, 29-63.

Jin, Y. \& Jorion, P. (2006). Firm value and hedging: Evidence form US oil and gas producers. Journal of Finance, 61(2), 893-919.

John, K., Litov, L., \& Yeung, B. (2008). Corporate governance and risk-taking. The Journal of Finance, 63 (4), 1679-1728.

Joskow, P., \& Rose, N. (1994). CEO pay and firm performance: dynamics, asymmetries, and alternative performance measures. NBER Working Paper No. 4976. National Bureau of Economic Performance.

Judge, A. (2002). Hedging and the use of derivatives: evidence from UK non-financial firms. Working Paper, Middlesex University, London.

Judge, A. (2006). Why and how UK firms hedge? European Financial Management, 12 (3), 407-441.

Kalbers, L., \& Fogarty, T. (1993). Audit committee effectiveness: an empirical investigation of the contribution of power. Auditing: A Journal of Practice \& Theory 12, 24-49.

Kang, H., Cheng, M., \& Gray, S. (2007). Corporate governance and board composition: diversity and independence of Australian boards. Corporate Governance: An International Review, 15(2), 194-207.

Kang, S. Kumar, P, Lee, H. (2006). Agency and corporate investment: the role of executive compensation and corporate governance. The Journal of Business. 79 (3), 1127-1147.

Kanter, R. (1977). The impact of hierarchical structures on the work behavior of women and men. Source: Social Problems, 23 (4), Feminist Perspectives: The Sociological Challenge, p. 415-430. 
Kapitsinas, S. (2008). The impact of derivative usage on firm value: evidence from Greece. Working Paper, National and Kapodistrian University of Athens.

Kaplan, S. (2012). Executive compensation and corporate governance in the U.S.: perceptions, facts and challenges. Working Paper, Chicago Booth Research Paper No. 12-42.

Kaplan, S., \& Zingales, L. (1997). Do investment sensitivities provide useful measures of financing constraints. Quarterly Journal of Ecnonomics, 112, 169-215.

Karamanou, I., \& Vafeas, N. (2005). The association between corporate boards, audit committees, and management earnings forecasts: an empirical analysis. Journal of Accounting Research, 43 (3), 453-486.

Kashyap, A. K., Rajan, R.G., \& Stein, J. (2008). Rethinking Capital Regulation. Conference Draft. Federal Reserve Bank of Kansas.

Kato, H., Lemmon, M., Luo, M., \& Schallheim, J. (2005). An empirical examination of the costs and benefits of executive stock options: evidence of Japan. Journal of Financial Economics, 78 (2), 435-461.

Keefe, M., \& Yaghoubi, M. (2014). Does cash flow volatility affect firm capital structure? Working Paper, Victoria University of Wellington.

Keshk , O. (2003). CDSIMEQ: A program to implement two-stage probit least squares. The Stata Journal, 3 (2), 157-167.

Kogan, N. \& Wallach, M. (1966). Modification of a judgmental style through group interaction. Journal of Personality and Social Psychology, 4(2), 165-174.

Kim, K., Patro, S., \& Pereira, R. (2014). Option incentives, leverage and risk-taking. Working Paper, University of Missouri, Columbia, Missouri 65211.

Kim, Y.S., Mathur, I. \& Nam, J. (2006). Is operational hedging a substitute for or a complement to financial hedging? Journal of Corporate Finance, 12(4), 834853

Kirkpatrick, G. (2009). The corporate governance lessons from the financial crisis. Financial Market Trends, 2009/1.

Klein, A. (1998). Firm performance and board committee structure. The Journal of Law \& Economics, 41 (1), 275-304

Klein, A. (2002). Audit committee, board of director characteristics, and earnings management. Journal of Accounting and Economics 33, 375-400. 
Knopf, J., Nam, J., \& Thornton, J. (2002). The volatility and price sensitivities of managerial stock option portfolios and corporate hedging. The Journal of Finance, 57 (2), 801-813.

Kogan, N., \& Wallach, M. (1996). Modification of judgement style through group interaction. Journal of Personality and Social Psychology, 4, 165-174.

Korac-Kakabadse, N., Kakabadse, A., \& Kouzmin, A. (2001). Board governance and company performance: any correlations? Corporate Governance, 1, 24-30.

Koski, J.L., \& Pontiff, J. (1999). How are derivatives used? Evidence from the mutual fund industry. Journal of Finance, 54 (2), 791-816.

Kosowski, R., Timmermann, A., \& Wermers, R., (2006) Can mutual fund "stars" really pick stocks? New evidence from a bootstrap analysis. The Journal of Finance, 61 (6), 2551-2595.

Kosowski, R. (2011). Do mutual funds perform when it matters most to investors? US mutual fund performance and risk in recessions and expansions. Quarterly Journal of Finance, 1(3), 607.

Kramer, V., Conrad, A., \& Erkut, S. (2006). Critical mass on corporate boards: why three or more women enhance governance. Report No. WCW 11, Wellesley Centers for Women, Wellesley, MA.

Kraus, A., \& Stoll, H. (1972). Price impacts of block trading on the New Stock Exchange. The Journal of Finance, 27 (3), 569-588.

Laeven, L., \& Levine, R. (2009). Bank governance, regulation, and risk taking. Journal of Financial Economics, 93, 259-275.

Lambert, R.A., David F. Larcker, D. F., \& Verrecchia, R. E. (1991). Portfolio considerations in valuing executive compensation. Journal of Accounting Research, 29 (1), 129-149.

Lang, M., Raedy, J., \& Yetman, M. (2003). How representative are firms that are crosslisted in the United States? An analysis of accounting quality. Journal of Accounting Research, 41, 363-386.

Lang, L., \& Stulz, R., (1994). Tobin's Q, corporate diversification, and firm performance. Journal of Political Economy, 102, 1248-1280.

Larcker, D., \& Balkcom, J. (1984). Executive compensation contracts and investment behaviour: an analysis of mergers. Working Paper, Northwestern University, Evanston, Illinois.

Larcker, D., Richardson, S., \& Tuna, I. (2007). Corporate governance, accounting 
outcomes and organizational performance. Accounting Review, 82, 9631008 .

Laubscher, N. (1961). On stabilizing the binomial and negative binomial variances. Journal of the American Statistical Association, 56 (293), 143-150.

Lee, C., Rosenstein, S., Rangan, N., \& Davidson, W. (1992). Board composition and shareholder wealth. The case of management buyouts. Financial Management, 21, 58-72.

Lehn, K., Patro, S., Zhao, M. (2005). Determinants of the size and structure of corporate boards: 1935-2000. Working Paper, University of Pittsburgh.

Lel, U. (2006). Currency hedging and corporate governance: a cross-country analysis. Working Paper, International Finance Discussion Papers, Board of Governors of the Federal Reserve System.

Lel, U. (2012). Currency hedging and corporate governance: a cross-country analysis. Journal of Corporate Finance. 18, 221-237.

Leland, H. (1998). Agency costs, risk management, and capital structure. Journal of Finance, 53, 1213-1243.

Leone, A., Wu, J., \& Zimmerman, J. (2006). Asymmetric sensitivity of CEO cash compensation to stock returns. Journal of Accounting and Economics, 42 (12), 167-192

Lessard, D. (1990). Global competition and corporate in the 1990s. Continental Bank Journal of Applied Corporate Finance, 1, 59-72.

Leuz, C., Nanda, D., \& Wysocki, P. (2003). Earnings management and investor protection: an international comparison. Journal of Financial Economics, 69, 505-527.

Levin, I., Snyder, M., \& Chapman, D. (1988). The Interaction of experiential and situational factors and gender in a simulated risky decision-making task. The Journal of Psychology: Interdisciplinary and Applied, 122 (2), 173-181.

Lewellen, K. (2006). Financing decisions when managers are risk averse. Journal of Financial Economics, 82(3), 551-589.

Lewellen, W., \& Badrinath, S. (1997). On the measurement of Tobin's Q. Journal of Financial Economics, 77-122.

Lewellen, W., Loderer, C., \& Martin, K. (1987). Executive compensation and executive incentive problems: an empirical analysis. Journal of Accounting and Economics, 9(3), 287-310. 
Li, W., \& Stammerjohan, W. (2004). Empirical analysis of effects of SFAS No. 133 on derivative use and earnings smoothing. Working Paper, Washington State University.

Li, J. \& Tang, Y. (2010). CEO hubris and firm risk taking in China: the moderating role of managerial discretion. Academy of Management Journal, 53(1), 45-68.

Lim, T., \& Loh, W. (1996). A comparison of tests of equality of variances. Computational Statistics \& Data Analysis. 22(3), 287-301

Lin, C., \& Smith, S. (2007). Hedging, financing and investment decisions: A simultaneous equations framework. The Financial Review, 42, 191-209.

Lin, J., Li, J., \& Yang, J. (2006). The effect of audit committee performance on earnings quality. Managerial Auditing Journal, 21(9), 921-933.

Linck, J., Netter, J., \& Yang, T. (2008). The determinants of board structure. Journal of Financial Economics. 87, 308-328.

Lindenberg, B. \& Ross, S. (1981). Tobin's q ratio and industrial organization. Journal of Business. January, 1-32.

Lippert, R., \& Moore, W. (1994). Compensation contracts of Chief Executive: determinants of pay-performance sensitivity. Journal of Financial Research, 17(3), 321-332.

Lipton, M., \& Lorsch, J. (1992). A modest proposal for improved corporate governance. Business Lawyer, 48, 59-77.

Lookman, A. (2004). Does hedging increase firm value? Comparing premia for hedging 'big' versus 'small' risks. Working Paper, University of Pittsburgh.

Lundberg M., Fox, P. \& Puncochar, J. (1994). Highly confident but wrong: gender differences and similarities in confidence judgments. Journal of Educational Psychology, 86, 114-121.

MacAvoy, P. \& Millstein, I. (1999). The active board of directors and its effect on the performance of the large publicly traded corporation. Journal of Applied Corporate Finance, 11 (4), 8-20.

Mackay, P., \& Moeller, S. (2007). The value of corporate risk management. The Journal of Finance, 62 (3), 1379-1419.

Mace, M. (1971). Directors: Myth and reality. Harvard University Press, Boston, MA.

Maddala, G. (1983). Limited-dependent and qualitative variables in econometrics. Cambridge University Press, New York. 
Magee, S. (2008). Foreign currency hedging and firm value: a dynamic panel approach. Working Paper, Macquarie University.

Magee, S. (2013). The effect of foreign currency hedging on the probability of financial distress. Accounting and Finance, (53) 1107-1127.

Mak, Y. \& Kusnadi, Y. (2005). Size really matters: further evidence on the negative relationship between size and firm value. Pacific-Basin Finance Journal, 13, 301-318.

Makri, M., Lane, P., \& Gomez-Mejia, G. (2006). CEO incentives, innovation, and performance in technology-intensive firms: a reconciliation of outcome and behavior-based incentive schemes. Strategic Management Journal, 27(11), 1057-1080.

Mallin, C. Yong, K.O., \& Reynolds, M. (2001). Derivatives usage in UK non-financial listed companies. The European Journal of Finance. 7(1), 63-91.

Manchiraju, H., Pierce, S., \& Sridharan, S. (2014). Do firms use derivatives for hedging or non-hedging purposes? Evidence based on SFAS 161 disclosures. Working Paper, Kellog School of Management, Northwestern University.

Mangena, M., \& Pike, R. (2005). The effect of audit committee shareholding, financial expertise and size on interim financial disclosures. Accounting and Business Research, 35(4), 327-349.

Mann H., \& Whitney, D. (1947). On a test of whether one of two random variables is stochastically larger than the other. Annals of Mathematical Statistics;18(1), $50-60$.

Marcus, A. (1984). Efficient asset portfolios and the theory of normal backwardation: a comment. Journal of Political Economy, 92(1), 162-164.

Marsden A., \& Prevost, A. (2005). Derivatives use, corporate governance and legislative change: An empirical analysis of New Zealand listed companies. Journal of Business Finance \& Accounting, 32 (1) \& (2), 255-295.

Marshall, B., \& Young, M. (2003). Liquidity and stock returns in pure order-driven markets: evidence from the Australian stock market. International Review of Financial Analysis, 12, 173-188.

Masulis, R. (1980). The effects of capital structure changes on security prices: a study of exchange offers. Journal of Financial Economics, 8, 139-177.

Mayers, D., \& Smith, C. W. (1982). On the corporate demand for insurance. Journal of Business Finance and Accounting, 55, 281-296. 
Mayers, D., \& Smith, C. W. (1987). Corporate insurance and the underinvestment problem. Journal of Risk and Insurance, 54, 45-54.

Mayers, D. \& Smith, C. (1990). On the corporate demand for insurance: evidence from the reinsurance market. Journal of Business, 63(1), 19-40.

Mayers, D., Shivdasani, A., \& Smith, C. (1997). Board composition in the insurance industry. Journal of Business, 70, 33-63.

Maznevski, M. (1994). Understanding our differences: performance in decision-making groups with diverse members. Human Relations, 47(5), 531-552.

McConnell, J., \& Servaes, H. (1990). Additional evidence on equity ownership and corporate value, Journal of Financial Economics, 20, 293-315.

Meehan, A., \& Overton, W. (1986). Gender differences in expectancies for success and performance on piagetian spatial tasks. Merrill-Palmer Quarterly, 32, 427441.

Mehran, H. (1995). Executive compensation structure, ownership, and firm performance. Journal of Financial Economics, 29, 315-355.

Merton, R. (1974). On the pricing of corporate debt: the risk structure of interest rates. Journal of Finance, 29, 449-470.

Mian, S. L. (1996). Evidence on corporate hedging policy. The Journal of Financial and Quantitative Analysis, 31(3), 419-439.

Mikkelson, W., \& Partch, M. (1985). Stock price effects and costs of secondary distributions. Journal of Financial Economics, 14, 165-194.

Miller, M. (1977). Debt and taxes. Journal of Finance, 32, 261-275.

Miller, M., \& Modigliani, F. (1961). Dividend policy, growth and the valuation of shares. Journal of Business, 411-432.

Miller, S., Wiseman, R., \& Gomez, L. (2002). The fit between CEO compensation design and firm risk. Academy of Management Journal, 45 (4), 745-756.

Minton, B. (1997). An empirical examination of basic valuation models for plain vanilla U.S. interest rate swaps. Journal of Financial Economics, 44 (2), 251-277

Mizruchi, M., \& Stearns, L. (1988). A longitudinal study of the formation of interlocking directorates. Administrative Science Quarterly, 33, 194-210.

Modigliani, F., \& Miller, M. H. (1958). The cost of capital, corporation finance and the theory of investment. The American Economic Review, 48(3), 261-297. 
Morck, R., Shleifer, A., \& Vishny, R. (1988). Management ownership and market valuation: An empirical analysis. Journal of Financial Economics, 20, (JanMar), 293-315.

Moscovici, S., \& Zavalloni, M. (1969). The group as a polarizer of attitudes. Journal of Personality and Social Psychology, 12 (2), 125-135.

Murphy, K. (1999). Chapter 38 Executive compensation, Handbook of Labor Economics, 3 (B), 1999, 2485-2563.

Myers, S. (1984). The capital structure puzzle. Journal of Financial Economics, 5, 147175.

Myers, S. C. (1977). Determinants of corporate borrowing. Journal of Financial and Economics, 5, 147-175.

Myers, S., \& Maljuf, N. (1984). Corporate financing and investment decisions when firm have information that investors do not have. Journal of Financial and Economics, 3, 187-221.

NAICS (2007). North American Industry Classification System. United States Census Bureau, 2007.

Nain, A. (2004). The strategic motives for corporate risk management. Job market paper. Working Paper, University of Michigan.

Nance, D. R., Smith, C. W., \& Smithson, C. W. (1993). On the determinants of corporate hedging. The Journal of Finance, 48(1), 267-284.

Nelson, J., Moffitt, J., \& Alleck-Graves, J. (2005). The impact of hedging on the market value of equity. Journal of Corporate Finance, 11, 851-881

Newey, W., \& West, N. (1987). A simple, semi-definite, heteroscedasticity and autocorrelation consistent covariance matrix. Econometrica, 55 (3), 703- 708.

Nguyen, H. V. (2011). Why do non-financial firms select one type of derivatives over others. Journal of Applied Business and Economics, 12(3), 91-109.

Nguyen, H., \& Faff, R. (2002). On the Determinants of Derivative Usage by Australian Companies. Australian Journal of Management, 27(1), 1-24.

NYSE (2009). New York Stock Exchange Listing. Amended November 25, 2009 (NYSE-2009-89) and amended January 11, 2013 (NYSE-2012-49). http://nysemanual.nyse.com/LCMTools/PlatformViewer.asp?selectednode= chp_1_4_3\&manual=\%2Flcm\%2Fsections $\% 2$ Flcm-sections $\% 2 \mathrm{~F}$. 
O’Neill, M., \& Swisher, J. (2003). Institutional investors and information asymmetry: An event study of self-tender offers. Financial Review, 38, 197-211.

Odean, T. (1998). Volume, volatility, price and profit when all traders are above average. Journal of Finance, 53, 1887-1934.

OECD (2009). Corporate governance and the financial crisis: key findings and main messages. OECD Report, June 2009.

Opler, T., \& Titman, S. (1996). The debt-equity choice. Working Paper, Ohio State University.

Ozkan, N. (2011). CEO compensation and firm performance: an empirical investigation of UK panel data. European Financial Management, 17 (2), 260-285.

Pallant (2005). SPSS Survival Guide. http://www.academia.dk/BiologiskAntropologi /Epidemiologi/ PDF/SPSS_Survival_Manual_Ver12.pdf

Pantzalis, C., Simmkins, B., \& Laux, P. (2001). Operational hedges and the foreign exchange exposure of US multinational corporations. Journal of International Business Studies, 32, 793-812.

Perfect, S., \& Wiles, K. (1994). Alternative construction of Tobin's q - an empirical comparison. Journal of Empirical Finance, 1, 313-341

Petersen, M., \& Thiagarajan, S. (2000). Risk measurement and hedging: with and without derivatives. Financial Management, 29 (4), 5-29.

Peterson, P. (1980). A re-examination of seemingly unrelated regressions methodology applied to estimation of financial relationships. The Journal of Financial Research, 3(3), 297-308.

Pincus, K., Rusbarsky, M., \& Wong, J. (1989). Voluntary formation of corporate audit committees among NASDAQ firms. Journal of Accounting and Public Policy, 8 (4), 239-265.

Pincus, M., \& Rajgopal, S. (2002). The interaction between accrual management and hedging: Evidence from oil and gas firms, The Accounting Review, 77 (1), $127-160$.

Powell, M., \& Ansic, D. (1997). Gender differences in risk behaviour in financial decision-making: an experimental analysis. Journal of Economic Psychology, 18 (6), 605-628.

Prendergst, S. (2000). Reconceptualizing women's agency and empowerment. Women \& Criminal Justice. 12 (1), 75-89. 
Price III, R., Nathan, S. \& Wood, D. (2011). Detecting and predicting accounting irregularities: A comparison of commercial and academic risk measures. SSRN Working Paper.

Prince, M. (1993). Women, men and money styles. Journal of Economic Psychology, 14, 175-182.

Pulvino, T. (1998). Do asset fire-sales exist: An empirical investigation of commercial aircraft transactions. Journal of Finance, 53, 939-978.

Purnanandam, A. (2008). Financial distress and corporate risk management: theory and evidence. Journal of Financial Economics, 87 (3), 706-739

Purnanandam, A. (2004). Financial distress and corporate risk management: theory and evidence. Working Paper, Cornell University, Ithaca, NY 14853.

Puwalski, A. (2003). Derivatives risk in commercial banking. Federal Deposit Insurance Corp. (FDIC), For Your Information, March 26, 2003. www.fdic.gov/bank/analytical/fyi/ index.html.

Raghunandan, K., \& Rama, D. (2007). Determinants of audit committee diligence. Accounting Horizons, 21 (3), 265-279.

Raheja, C. (2005). Determinants of board size and composition. A theory of corporate boards. Journal of Financial Quantitative Analysis, 40, 283-306.

Rajan, R. \& Zingales, L. (1995). What do we know about capital structure? Some evidence from international data. The Journal of Finance, 50 (5), 1421-1460.

Rajgopal, S., \& Shevlin, T. (2000). Stock option compensation and risk taking: the case of oil and gas producers. Working Paper, University of Washington.

Rajgopal, S., \& Shevlin, T. (2002). Empirical evidence on the relation between stock option compensation and risk taking. Journal of Accounting and Economics, 33 (2), 145-171.

Ramirez, S. (2003). A flaw in the Sarbanes-Oxley reform: can diversity in the boardroom quell corporate corruption?, St. John's Law Review 77 (4), 837-866.

Ravina, E. \& Sapienza, P. (2009). What do independent directors know? Evidence from their trading. Review of Financial Studies, 23 (3), 962-1003.

Ricol, R. (2008). Report to the President of the French Republic on the Financial Crisis, Paris.

Rogers, D. (2002). Does executive portfolio structure affect risk management? CEO risktaking incentives and corporate derivatives usage. Journal of Banking \& 
Finance, 26(2-3), 271-295.

Roll, R. (2011). The possible misdiagnosis of a crisis. Financial Analysts Journal. 67(2), 12-17.

Rosenstein, S., \& Wyatt, J. (1990). Outside directors, board independence, and shareholder wealth. Journal of Financial Economics, 20, 293-315.

Rosenstein, S., \& Wyatt, J. (1997). Inside directors, board effectiveness, and shareholder wealth. Journal of Financial Economics, 44, 229-250.

Ross, S. (2004). Compensation, incentives, and the duality of risk aversion and riskiness. The Journal of Finance, 59 (1), 207-225

Rossi, J. (2012). Hedge or Speculation? Evidence of the use of derivatives by Brazilian firms during the financial crisis. Insper Working Paper Series.

Rountree, B., Weston, J., \& Allayannis, G. (2008). Do investors value smooth performance? Journal of Financial Economics, 90, 237-251.

Sah, R., \& Stiglitz, J. (1986). The architecture of economic systems: hierarchies and polyarchies. The American Economic Review, 76 (4), 716 - 727.

Sah, R., \& Stiglitz, J. (1991). The quality of managers in centralized versus decentralized organizations. The Quarterly Journal of Economics, 106 (1), 289-295.

Sanders, D., Boris, K., \& Manfredo, M. (2004). Hedgers, funds, and small speculators in the energy futures markets: an analysis of the CFTC's commitments of traders reports. Energy Economics, 26, 425-445.

Sanders, D., Irwin, S., \& Merrin, R. (2009). Smart money: the forecasting ability of CFTC large traders in agricultural futures markets.", Journal of Agricultural and Resource Economics, 34, 276-296.

Scholes, M. (1972). The market for securities: substitution versus price pressure and the effects of information on share prices. The Journal of Business. 45, (2), 179211.

Schrand, C., \& Unal, H. (1998). Hedging and coordinated risk management: evidence from thrift conversions. Journal of Finance, 53, 979-1014.

Sellers, P. ( 2007). Women on boards (not!)', Fortune 156 (8), 105.

Servaes, H. (1996). The value of diversification during the conglomerate merger waves. Journal of Finance, 51, 1201-1225.

Shapiro, A. C., \& Titman, S. (Eds.). (1986). An integrated approach to corporate risk management. New York: Basil Blackwell. 
Sharma, V., Naiker, V., \& Lee, B. (2009). Determinants of audit committee meeting frequency: evidence from a voluntary governance system. Accounting Horizons, 23 (3), 245-263.

Shenoy, C., \& Koch, P. (1996). The firm's leverage-cash flow relationship. Journal of Empirical Finance, 2 (4), 307-331.

Shivdasani, A. (1993). Board composition, ownership structure and hostile takeovers. Journal of Accounting and Economics, 16 (1-3), 167-198.

Shleifer, A. (1986). Do demand curves for stocks slope down? The Journal of Finance, 41 (3), 579-590.

Shleifer, A., \& Vishny, R. (1997). A survey of corporate governance. Journal of Finance, $52,737-783$

Short, H., \& Keasey, K. (1999). Managerial ownership and the performance of firms: evidence from UK. Journal of Corporate Finance, 5, 79-101.

Sias, R., Starks, L., \& Titman, S. (2006). Changes in institutional ownership and stock returns: assessment and methodology. The Journal of Business, 79 (6), 2869-2910.

Sila, V., Gonzalez, A., \& Hasgendorff, J. (2014). Women on board: does gender diversity really affect firm risk? Working Paper. University of Edinburgh Business School.

Siriwardane, E. (2015). Concentrated capital losses and the pricing of corporate credit risk. Working Paper. Harvard Business School Finance Working Paper No. 16-007.

Skaife, H., Collins, D., \& LaFond, R. (2006). The effects of corporate governance on firms' credit ratings. Journal of Accounting and Economics, 42 (1-2), $203-$ 243.

Sloan, R. (1993). Accounting earnings and top executive compensation. Journal of Accounting and Economics, 16, 55-100.

Smith, C. W., \& Stulz, R. M. (1985). The determinants of firms' hedging policies. The Journal of Financial and Quantitative Analysis, 20(4), 391-405.

Smith, C. W., \& Watts, R. L. (1992). The investment opportunity set and corporate financing, dividend and compensation policies. Journal of Financial and Economics, 32, 263-292.

Sokal, R., \& Rohlf, J. (1981). Biometry: the principles and practice of statistics in biological research. 2nd ed., San Francisco, W.H. Freeman and Company, p 
859.

Stulz, R. (1988). Managerial control of voting rights: financing policies and the market for corporate control. Journal of Financial Economics, 20 (1-2), 25-54

Stulz, R. (1996). Rethinking risk management. Journal of Applied Corporate Finance, 9(3), 8-25.

Stulz, R. M. (1984). Optimal hedging policies. Journal of Financial and Quantitative Analysis, 19, 127-140.

Stulz, R. M. (1990). Managerial discretion and optimal hedging policies. Journal of Financial Economics, 26, 3-27.

Subrahmanyam, V., Rangan, N., \& Rosenstein, S. (1997). The role of outside directors in bank acquisitions. Financial Management, 26 (3), 23-36.

Sunden, E., \& Surette, B. (1998). Gender differences in the allocation of assets in retirement savings plans. The American Economic Review. 88 (2), 207-211.

Titman, S. (1992). Interest rate swaps and corporate financing choices. The Journal of Finance, 47 (4), 1503 - 1516.

Titman, S., \& Wessels, R., (1988). The determinants of capital structure choice. The Journal of Finance, 43 (1), 1-19.

Tufano, P. (1996). Who manages risk? An empirical examination of risk management practices in the gold mining industry. The Journal of Finance, 51(4), 10971137.

Tufano, P. (1998). Agency costs of corporate risk management. Financial Management, 27, 67-77.

Vafeas, N. 2005. Audit committees, boards, and the quality of reported earnings. Contemporary Accounting Research, 22 (4), 1093-1122.

Vafeas, N. (1999). Board meeting frequency and firm performance. Journal of Financial Economics, 53, 113-142.

Vancil, R. (1987). Passing the baton: managing the process of CEO succession. Harvard Business School Press, Boston, MA.

Varian, H. (1989). Differences of opinion in financial markets. Financial Risk: Theory, Evidence and Implications, Courtenay C. Stone, ed. (Proceedings of the Eleventh Annual Economic Policy Conference of the Federal Reserve Bank of St. Louis, Boston, 1989). 
Veliota, D. (2014). Accounting for derivative instruments and hedging activities. Journal of Financial Risk Management, 3, 151-165.

Visvanathan, G. (1998). Who uses interest rate swaps? A cross-sectional analysis. Journal of Accounting, Auditing and Finance, 13, 173-200.

Wang, C. (2003). The behavior and performance of major types of futures traders. Journal of Futures Markets, 23 (1), 1-31.

Warner, J. B. (1977). Bankruptcy costs: some evidence. [Papers and Proceedings of the 35th Annual Meeting of the American Finance Association, Atlantic City, New Jersey, September 16-18, 1976]. The Journal of Finance, 32(2), 337347.

Wei, S., \& Zhang, C. (2006). Why did individual stocks become more volatile? Journal of Business, 79, 259-292.

Weisbach, M. (1988). Outside directors and CEO turnover. Journal of Financial Economics, 20, 431-460.

Weller, C., \& Reidenbach, L. (2011). On uneven ground: how corporate governance prioritizes short-term speculative investments, impedes productive investments, and jeopardizes productivity growth. Working Paper, Political Economy Research Institute, Amherst, MA 01002.

White, H., (1980). A heteroscedasticity-consistent covariance matrix estimator and a direct test of heteroscedasticity. Econometrica: Journal of the Econometric Society, 48 (4), 817-838.

Wilcoxon F. (1945). Individual comparisons by ranking methods. Biometrics Bulletin; 1, $80-83$.

Wilson, N., \& Altanlar, A. (2011). The survival of newly incorporated companies and the impact of founding director characteristics. Working Paper. Credit Management Research Centre, University of Leeds - Division of Accounting and Finance.

Wooldridge, J. (2012). Introductory Econometrics: A modern approach. ( $5^{\text {th }}$ edition).

Wright, P., \& Ferris, S. (1997). Agency conflict and corporate strategy: The effect of divestment on corporate value. Strategic Management Journal, Strategic Management Journal, 18 (1), 77-83.

Wright, P., Ferris, S., Sarin, A., \& Vidya, A. (1996). Impact of corporate insider, blockholder, and institutional equity ownership on firm risk taking. The Academy of Management Journal, 39 (2), 441-463. 
Xie, B., Davidson, W., \& DaDalt, P. (2003). Earnings management and corporate governance: the role of the board and the audit committee. Journal of Corporate Finance, 9 (3), 295-316.

$\mathrm{Xu}$, M. (2011). CEO contract horizon and investment. INSEAD Faculty and Research Working Paper, June 2011.

Yang, J., \& Krishnan, J. (2005) Audit committees and quarterly earnings management. International Journal of Auditing, 9(3), 201-219.

Yermack, D. (1996). Higher market valuation of companies with a small board of directors. Journal of Financial Economics, 40, 185-213.

Yermack, D. (2006). Flights of fancy: corporate jets, CEO perquisites, and inferior shareholder returns. Journal of Financial Economics, 80, 211-242.

Zahra, S.A., \& Pearce, J. (1989). Boards of directors and corporate financial performance: a review and integrative model. Journal of Management, 15, 291-334.

Zaman, M., Hudaib, M., \& Haniffa, R. (2011). Corporate governance quality, audit fees and non-audit services fees. Journal of Business Finance \& Accounting, 38(1) \& (2), 165-197.

Zeidan, R., \& Mullner, J. (2015). Firm, market and top management antecedents of speculation: Lessons for corporate governance. Journal of Multinational Financial Management, 32-33, 42-58.

Zeidan, R. \& Rodriques, B. (2013). The failure of risk management for nonfinancial companies in the context of the financial crisis:lessons from Aracruz Cellulose and hedging with derivatives. Applied Financial Economics, 23(3), 241-250.

Zellner, A. (1962). An efficient method of estimating seemingly unrelated regressions and tests for aggregation bias. Journal of the American Statistical Association, 57 (298), 348-368.

Zellner, A. (1963). Estimators for seemingly unrelated regression equations: some exact finite sample results. Journal of the American Statistical Association, 58 (304), 977-992.

Zhang, Y., Zhou, J., \& Zhou, N. (2007). Audit committee quality, auditor independence, and internal control weaknesses. Journal of Accounting and Public Policy, $26,300-327$. 
Appendix 1: Derivatives Traded on Organized Exchanges

\begin{tabular}{|c|c|c|c|c|c|c|c|c|c|c|}
\hline \multicolumn{11}{|c|}{ By instrument and location (Notional principal in billions of US dollars) } \\
\hline \multirow[b]{2}{*}{ Instrument / location } & \multicolumn{4}{|c|}{ Amounts outstanding } & \multicolumn{6}{|c|}{ Turnover } \\
\hline & Dec 2012 & Dec 2013 & Sep 2014 & Dec 2014 & 2013 & 2014 & Q1 2014 & Q2 2014 & Q3 2014 & Q4 2014 \\
\hline Futures: All & $24,071.4$ & $25,787.9$ & $30,154.0$ & $27,169.3$ & $1,415,393.1$ & $1,450,464.3$ & $364,314.7$ & $353,242.5$ & $356,854.6$ & $376,052.5$ \\
\hline Interest rate & $22,626.9$ & $24,165.1$ & $28,327.4$ & $25,348.4$ & $1,244,191.2$ & $1,266,579.0$ & $321,617.3$ & $314,317.4$ & $312,921.6$ & $317,722.7$ \\
\hline Currency & 231.7 & 243.9 & 257.5 & 249.3 & $32,615.6$ & $28,837.2$ & $7,262.8$ & $6,094.6$ & $7,286.6$ & $8,193.3$ \\
\hline Equity index & $1,212.8$ & $1,378.9$ & $1,569.1$ & $1,571.6$ & $138,586.3$ & $155,048.1$ & $35,434.7$ & $32,830.5$ & $36,646.4$ & $50,136.5$ \\
\hline North America & $12,904.0$ & $14,261.4$ & $18,349.4$ & $16,245.7$ & $721,033.1$ & $888,556.0$ & $203,322.4$ & $204,992.9$ & $231,042.2$ & $249,198.5$ \\
\hline Interest rate & $12,297.0$ & $13,592.5$ & $17,630.9$ & $15,553.7$ & $644,883.7$ & $809,509.7$ & $183,728.6$ & $187,725.0$ & $211,742.1$ & $226,314.0$ \\
\hline Currency & 157.6 & 155.0 & 171.0 & 151.1 & $25,589.1$ & $22,010.7$ & $5,579.5$ & $4,598.7$ & $5,496.5$ & $6,336.0$ \\
\hline Equity index & 449.3 & 513.9 & 547.4 & 540.8 & $50,560.4$ & $57,035.6$ & $14,014.3$ & $12,669.2$ & $13,803.6$ & $16,548.5$ \\
\hline Europe & $8,024.1$ & $8,522.7$ & $8,696.9$ & $7,664.7$ & $540,914.8$ & $427,978.9$ & $130,697.1$ & $119,820.2$ & $92,114.0$ & $85,347.6$ \\
\hline Interest rate & $7,560.2$ & $7,956.5$ & $8,061.1$ & $7,076.9$ & $509,975.0$ & $390,821.1$ & $121,172.7$ & $111,312.3$ & $83,248.9$ & $75,087.1$ \\
\hline Currency & 3.2 & 3.4 & 5.1 & 3.4 & 497.6 & 774.0 & 177.0 & 121.9 & 188.6 & 286.5 \\
\hline Equity index & 460.8 & 562.8 & 630.7 & 584.4 & $30,442.2$ & $36,383.8$ & $9,347.4$ & $8,385.9$ & $8,676.5$ & $9,974.0$ \\
\hline Asia and Pacific & $2,119.7$ & $2,105.4$ & $2,104.5$ & $2,204.0$ & $127,113.4$ & $112,883.2$ & $24,775.8$ & $23,796.9$ & $27,839.4$ & $36,471.1$ \\
\hline Interest rate & $1,824.2$ & $1,809.1$ & $1,721.4$ & $1,764.6$ & $68,802.1$ & $51,168.9$ & $12,654.1$ & $12,000.4$ & $13,658.5$ & $12,855.9$ \\
\hline Currency & 11.3 & 10.4 & 11.7 & 10.7 & $2,056.6$ & $1,474.4$ & 355.6 & 330.7 & 390.3 & 397.8 \\
\hline Equity index & 284.3 & 285.9 & 371.4 & 428.7 & $56,254.7$ & $60,239.9$ & $11,766.1$ & $11,465.8$ & $13,790.6$ & $23,217.4$ \\
\hline Other Markets & $1,023.6$ & 898.4 & $1,003.2$ & $1,054.9$ & $26,331.8$ & $21,046.2$ & $5,519.5$ & $4,632.4$ & $5,859.0$ & $5,035.4$ \\
\hline Interest rate & 945.5 & 807.1 & 914.0 & 953.2 & $20,530.4$ & $15,079.4$ & $4,061.8$ & $3,279.6$ & $4,272.1$ & $3,465.8$ \\
\hline Currency & 59.7 & 75.1 & 69.7 & 84.1 & $4,472.4$ & $4,578.1$ & $1,150.7$ & $1,043.3$ & $1,211.2$ & $1,173.0$ \\
\hline Equity index & 18.4 & 16.2 & 19.5 & 17.6 & $1,329.0$ & $1,388.8$ & 306.9 & 309.5 & 375.7 & 396.6 \\
\hline Options: All & $30,037.4$ & $38,310.2$ & $47,718.0$ & $37,688.9$ & $467,383.8$ & $486,004.5$ & $123,435.1$ & $117,543.7$ & $123,286.0$ & $121,739.6$ \\
\hline Interest rate & $25,895.8$ & $32,786.2$ & $41,024.2$ & $31,874.0$ & $354,368.4$ & $334,809.3$ & $91,513.8$ & $86,907.4$ & $83,091.6$ & $73,296.6$ \\
\hline Currency & 105.6 & 142.6 & 183.8 & 143.4 & $3,023.1$ & $3,069.7$ & 700.3 & 596.5 & 835.9 & 936.9 \\
\hline Equity index & $4,036.0$ & $5,381.4$ & $6,510.0$ & $5,671.4$ & $109,992.2$ & $148,125.5$ & $31,220.9$ & $30,039.8$ & $39,358.5$ & $47,506.2$ \\
\hline North America & $12,321.7$ & $20,890.2$ & $33,166.0$ & $28,329.0$ & $224,248.7$ & $314,803.4$ & $72,468.2$ & $70,345.9$ & $83,282.3$ & $88,706.9$ \\
\hline Interest rate & $10,280.3$ & $17,769.9$ & $29,223.2$ & $24,589.8$ & $164,604.6$ & $232,199.2$ & $54,091.4$ & $52,815.1$ & $62,741.0$ & $62,551.7$ \\
\hline Currency & 68.9 & 94.6 & 122.7 & 98.0 & $2,051.2$ & $2,246.7$ & 480.3 & 425.5 & 650.9 & 690.0 \\
\hline Equity index & $1,972.5$ & $3,025.7$ & $3,820.2$ & $3,641.3$ & $57,593.0$ & $80,357.4$ & $17,896.6$ & $17,105.2$ & $19,890.4$ & $25,465.2$ \\
\hline Europe & $15,637.4$ & $15,806.8$ & $13,068.8$ & $8,141.2$ & $200,020.7$ & $116,075.6$ & $40,733.9$ & $37,023.0$ & $23,281.4$ & $15,037.2$ \\
\hline Interest rate & $14,225.4$ & $14,274.0$ & $11,226.0$ & $6,771.6$ & $184,581.9$ & $98,761.3$ & $36,113.7$ & $33,194.6$ & $19,327.3$ & $10,125.7$ \\
\hline Currency & 0.6 & 0.7 & 1.3 & 3.1 & 6.4 & 45.9 & 2.3 & 1.2 & 2.7 & 39.6 \\
\hline Equity index & $1,411.4$ & $1,532.2$ & $1,841.6$ & $1,366.4$ & $15,432.3$ & $17,268.4$ & $4,617.9$ & $3,827.2$ & $3,951.4$ & $4,871.9$ \\
\hline Asia and Pacific & 618.0 & 791.2 & 816.1 & 648.8 & $37,591.9$ & $49,985.2$ & $8,544.6$ & $9,065.9$ & $15,354.4$ & $17,020.3$ \\
\hline Interest rate & 1.8 & 4.1 & 14.3 & 17.0 & $2,143.8$ & $1,274.8$ & 319.5 & 347.3 & 291.4 & 316.7 \\
\hline Currency & 1.4 & 0.4 & 1.0 & 1.4 & 354.1 & 154.6 & 36.6 & 23.0 & 43.3 & 51.7 \\
\hline Equity index & 614.8 & 786.6 & 800.8 & 630.4 & $35,094.0$ & $48,555.7$ & $8,188.5$ & $8,695.6$ & $15,019.7$ & $16,651.9$ \\
\hline Other Markets & $1,460.3$ & 822.1 & 667.0 & 569.9 & $5,522.5$ & $5,140.4$ & $1,688.3$ & $1,109.0$ & $1,368.0$ & 975.1 \\
\hline Interest rate & $1,388.4$ & 738.2 & 560.8 & 495.6 & $3,038.2$ & $2,573.9$ & 989.2 & 550.4 & 731.9 & 302.5 \\
\hline Currency & 34.6 & 47.0 & 58.8 & 41.0 & 611.4 & 622.5 & 181.2 & 146.8 & 139.1 & 155.5 \\
\hline Equity index & 37.3 & 36.9 & 47.4 & 33.3 & $1,872.9$ & $1,944.0$ & 518.0 & 411.8 & 497.0 & 517.1 \\
\hline
\end{tabular}

(BIS, March 2015) 
Appendix 2: Global OTC Derivatives Market

\begin{tabular}{|c|c|c|c|c|c|c|}
\hline \multirow[t]{2}{*}{ (amounts outstanding, in billions US\$) } & \multicolumn{3}{|c|}{ Notional amounts outstanding } & \multicolumn{3}{|c|}{ Gross market value } \\
\hline & $\begin{array}{c}\text { end-June } \\
2007 \\
\end{array}$ & $\begin{array}{c}\text { end-June } \\
2010\end{array}$ & $\begin{array}{c}\text { end-June } \\
2013\end{array}$ & \begin{tabular}{|c|} 
end-June \\
2007
\end{tabular} & $\begin{array}{c}\text { end-June } \\
2010 \\
\end{array}$ & \begin{tabular}{|c} 
end-June \\
2013
\end{tabular} \\
\hline GRAND TOTAL & 507,907 & 582,655 & 692,908 & 11,118 & 24,673 & 20,158 \\
\hline A. Foreign exchange contracts & 57,604 & 62,933 & 81,025 & 1,613 & 3,158 & 2,613 \\
\hline Forwards and swaps & 29,775 & 31,935 & 39,575 & 668 & 1,330 & 1,082 \\
\hline Currency swaps & 14,130 & 18,890 & 26,318 & 666 & 1,372 & 1,170 \\
\hline Total options & 13,662 & 12,107 & 15,077 & 279 & 456 & 362 \\
\hline Other & 37 & 1 & 56 & $\ldots$ & $\ldots$ & $\ldots$ \\
\hline B. Interest rate contracts & 381,357 & 478,093 & 577,269 & 6,730 & 18,508 & 15,683 \\
\hline Forward rate agreements & 25,607 & 60,028 & 89,434 & 145 & 204 & 276 \\
\hline Interest rate swaps & 299,155 & 367,541 & 437,066 & 5,818 & 16,703 & 14,054 \\
\hline Total options & 56,587 & 50,519 & 50,191 & 767 & 1,600 & 1,352 \\
\hline Other & 7 & 5 & 579 & $\ldots$ & $\ldots$ & $\ldots$ \\
\hline C. Equity-linked contracts & 9,518 & 6,868 & 6,963 & 1,212 & 796 & 707 \\
\hline Forwards and swaps & 2,668 & 1,854 & 2,350 & 262 & 202 & 209 \\
\hline Total options & 6,850 & 5,013 & 4,614 & 950 & 595 & 498 \\
\hline D. Commodity contracts & 8,255 & 3,273 & 2,727 & 656 & 492 & 394 \\
\hline Gold & 1,051 & 669 & 610 & 56 & 52 & 83 \\
\hline Other & 7,204 & 2,604 & 2,117 & 600 & 439 & 312 \\
\hline Forwards and swaps & 3,481 & 1,686 & 1,403 & $\ldots$ & $\cdots$ & $\ldots$ \\
\hline Options & 3,724 & 918 & 715 & $\ldots$ & $\ldots$ & $\ldots$ \\
\hline E. Credit derivatives & 51,095 & 31,416 & 24,845 & 906 & 1,708 & 732 \\
\hline Forwards and swaps & 49,974 & 31,331 & 24,497 & ... & ... & $\cdots$ \\
\hline CDS & 45,179 & 31,057 & 24,470 & 768 & 1,694 & 728 \\
\hline Single-name instruments & 25,104 & 18,806 & 13,211 & 430 & 1,012 & 432 \\
\hline Multi-name instruments & 20,075 & 12,251 & 11,259 & 338 & 682 & 296 \\
\hline Index products & 0 & 7,614 & 10,170 & $\ldots$ & $\ldots$ & $\ldots$ \\
\hline Options & 1,121 & 85 & 348 & $\ldots$ & $\ldots$ & $\ldots$ \\
\hline F. Other derivatives & 78 & 72 & 78 & 1 & 12 & 29 \\
\hline Forwards and swaps & 73 & 38 & 63 & $\ldots$ & $\ldots$ & $\ldots$ \\
\hline Options & 6 & 34 & 15 & $\cdots$ & $\ldots$ & $\cdots$ \\
\hline GROSS CREDIT EXPOSURE & ... & $\ldots$ & $\ldots$ & 2,672 & 3,578 & 3,900 \\
\hline Exchange-traded contracts & 95,097 & 75,418 & 66,311 & $\ldots$ & $\ldots$ & $\ldots$ \\
\hline
\end{tabular}

Source: OTC derivatives statistics at end-June 2013 
Appendix 3: Hedging vs Non-Hedging with Put Options

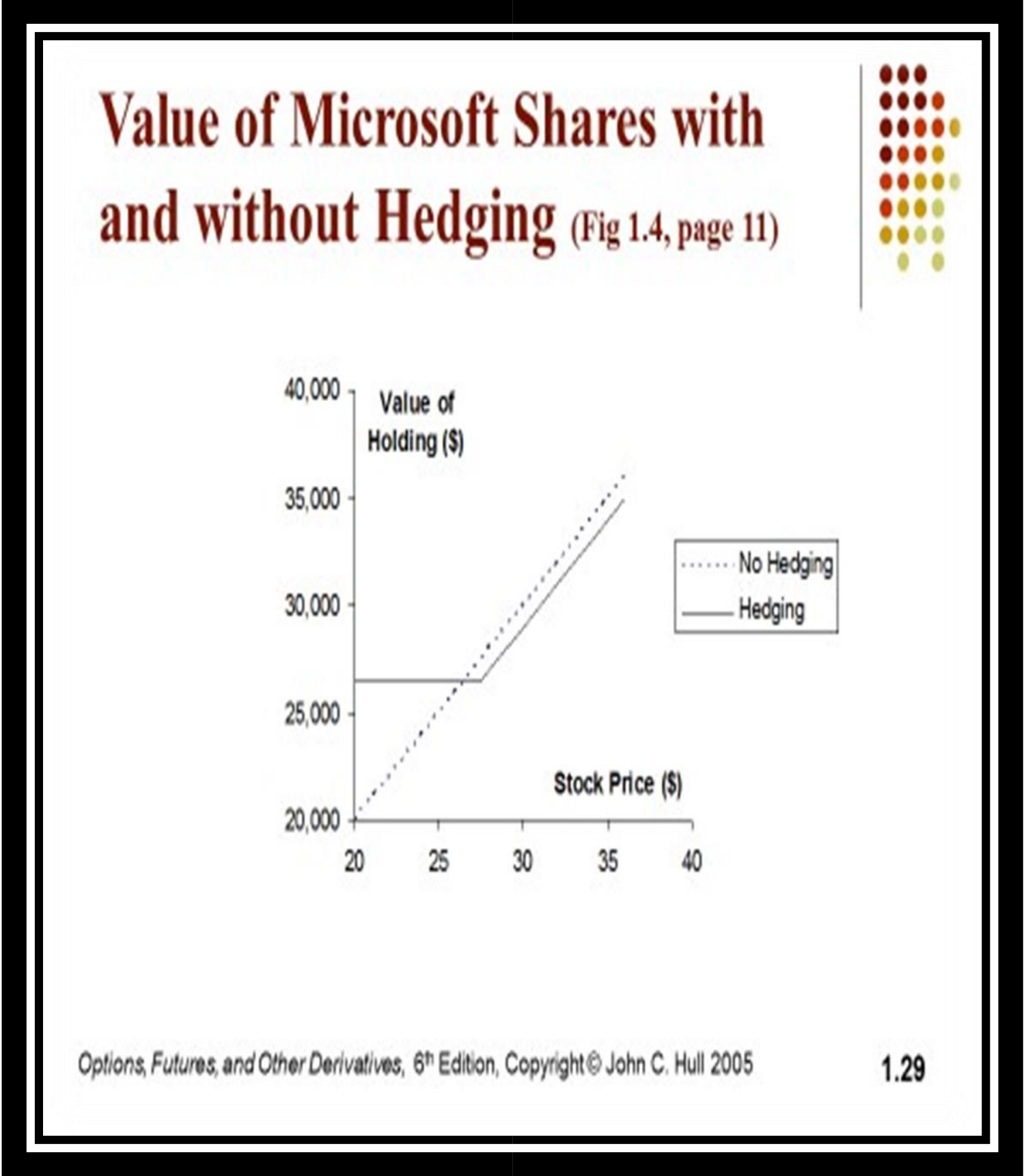


Appendix 4: Derivative User and Non User Comparison of Results

\begin{tabular}{|c|c|c|c|c|c|}
\hline Variable & Group & Value & $\mathrm{CFV}$ & SRV & MR \\
\hline \multirow[t]{2}{*}{ BDMTGS } & DERUSER & NS & +0.02 & +0.006 & NS \\
\hline & NONUSER & - & +0.03 & +0.007 & - \\
\hline \multirow[t]{2}{*}{ BDSIZE } & DERUSER & +0.03 & +0.06 & -0.022 & NS \\
\hline & NONUSER & +0.04 & +0.10 & -0.024 & - \\
\hline \multirow[t]{2}{*}{ BDINDEP } & DERUSER & - & NS & NS & NS \\
\hline & NONUSER & $\mathrm{NS}(-)$ & $\mathrm{NS}(-)$ & NS & NS \\
\hline \multirow[t]{2}{*}{ BDDIVERS } & DERUSER & + & NS & - & -0.033 \\
\hline & NONUSER & NS & NS & NS & -0.029 \\
\hline \multirow[t]{2}{*}{ SHINSIDER } & DERUSER & NS & -0.59 & +0.152 & NS \\
\hline & NONUSER & $\mathrm{NS}(-)$ & -0.72 & +0.263 & NS \\
\hline \multirow[t]{2}{*}{ SHINST } & DERUSER & NS (-0.19) & NS & + & +0.045 \\
\hline & NONUSER & -0.09 & NS & NS & +0.053 \\
\hline \multirow[t]{2}{*}{ SHBLOCK } & DERUSER & -0.18 & NS & +0.11 & NS \\
\hline & NONUSER & $\mathrm{NS}(-0.10)$ & - & +0.25 & + \\
\hline \multirow[t]{2}{*}{ CEOAGE } & DERUSER & -0.005 & NS & + & + \\
\hline & NONUSER & -0.007 & - & NS & NS \\
\hline \multirow[t]{2}{*}{ CEOTENURE } & DERUSER & + & NS (+) & - & NS \\
\hline & NONUSER & $\mathrm{NS}(+)$ & NS & NS & NS \\
\hline \multirow[t]{2}{*}{ CEOCOMP } & DERUSER & NS & +0.11 & NS & NS \\
\hline & NONUSER & + & +0.16 & NS & NS \\
\hline \multirow[t]{2}{*}{ CEOBONUS } & DERUSER & + & +0.016 & -0.010 & +0.003 \\
\hline & NONUSER & NS & +0.017 & -0.008 & +0.002 \\
\hline \multirow[t]{2}{*}{ CEOSALARY } & DERUSER & $\mathrm{NS}(+)$ & $\begin{array}{c}\mathrm{NS} \\
(+0.12) \\
\end{array}$ & NS & NS \\
\hline & NONUSER & NS & +0.20 & NS & $\mathrm{NS}(-)$ \\
\hline \multirow[t]{2}{*}{ ACSIZE } & DERUSER & -0.01 & - & +0.010 & NS \\
\hline & NONUSER & -0.02 & NS & +0.014 & NS \\
\hline
\end{tabular}

CFV is cash flow volatility; SRV is stock return volatility; MR is market risk; DERUSER is derivatives user; NONUSER is derivatives non-user; NS is not significant; ( ) bracket shows the significant, coefficient sign from the ISUR tests (where it is different); + indicates positive coefficient; - indicates negative coefficient. Coefficients are provided only where the directional results are the same for derivatives users and non-users. 
Appendix 5: Summary of Results for Derivative Users

\begin{tabular}{|c|c|c|c|c|c|}
\hline Variable & DERUSE & Value & CFV & SRV & MR \\
\hline BDMTGS & NS & NS & + & + & $\mathrm{NS}$ \\
\hline BDSIZE & + & + & + & - & NS \\
\hline BDINDEP & NS & - & NS & NS & $\mathrm{NS}$ \\
\hline BDDIVERS & NS & + & NS & - & - \\
\hline SHINSIDER & - & NS & - & + & NS \\
\hline SHINST & + & NS (-) & NS & + & + \\
\hline SHBLOCK & NS & - & NS & + & NS \\
\hline CEOAGE & + & - & NS & + & + \\
\hline CEOTENURE & NS & + & $\mathrm{NS}(+)$ & - & $\mathrm{NS}$ \\
\hline CEOCOMP & - & NS & + & NS & NS \\
\hline CEOBONUS & + & + & + & - & + \\
\hline CEOSALARY & + & $\mathrm{NS}(+)$ & $\mathrm{NS}(+)$ & NS & NS \\
\hline ACSIZE & NS & - & - & + & $\mathrm{NS}$ \\
\hline
\end{tabular}

CFV is cash flow volatility; SRV is stock return volatility; MR is market risk; DERUSE is derivative use; NS is not significant; ( ) bracket shows the significant, coefficient sign from the ISUR tests (where it is different); + indicates positive coefficient; - indicates negative coefficient. 
Appendix 6: Year-wise Comparison of Mean Corporate Governance Characteristics for Derivative User and Non User Firms
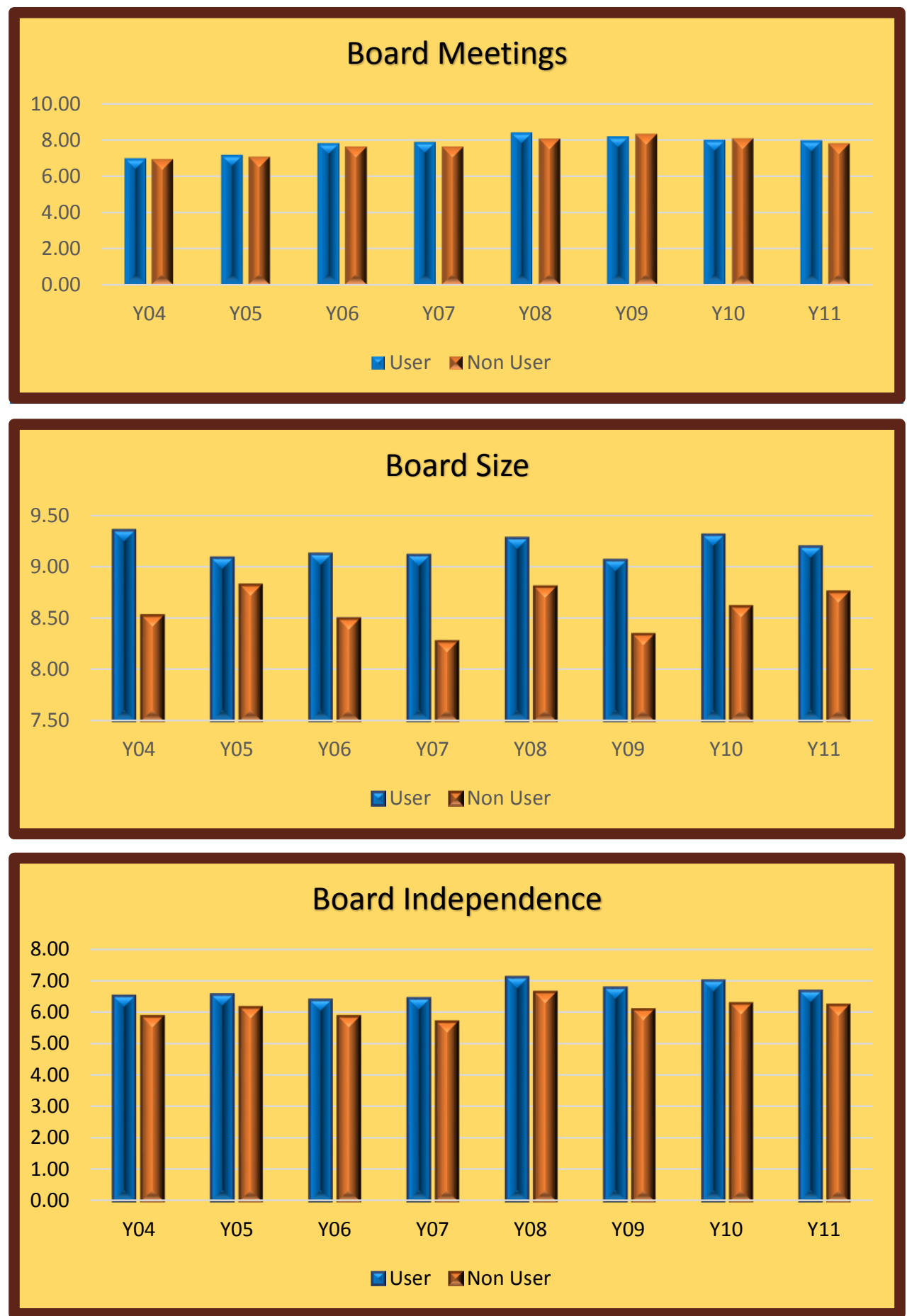

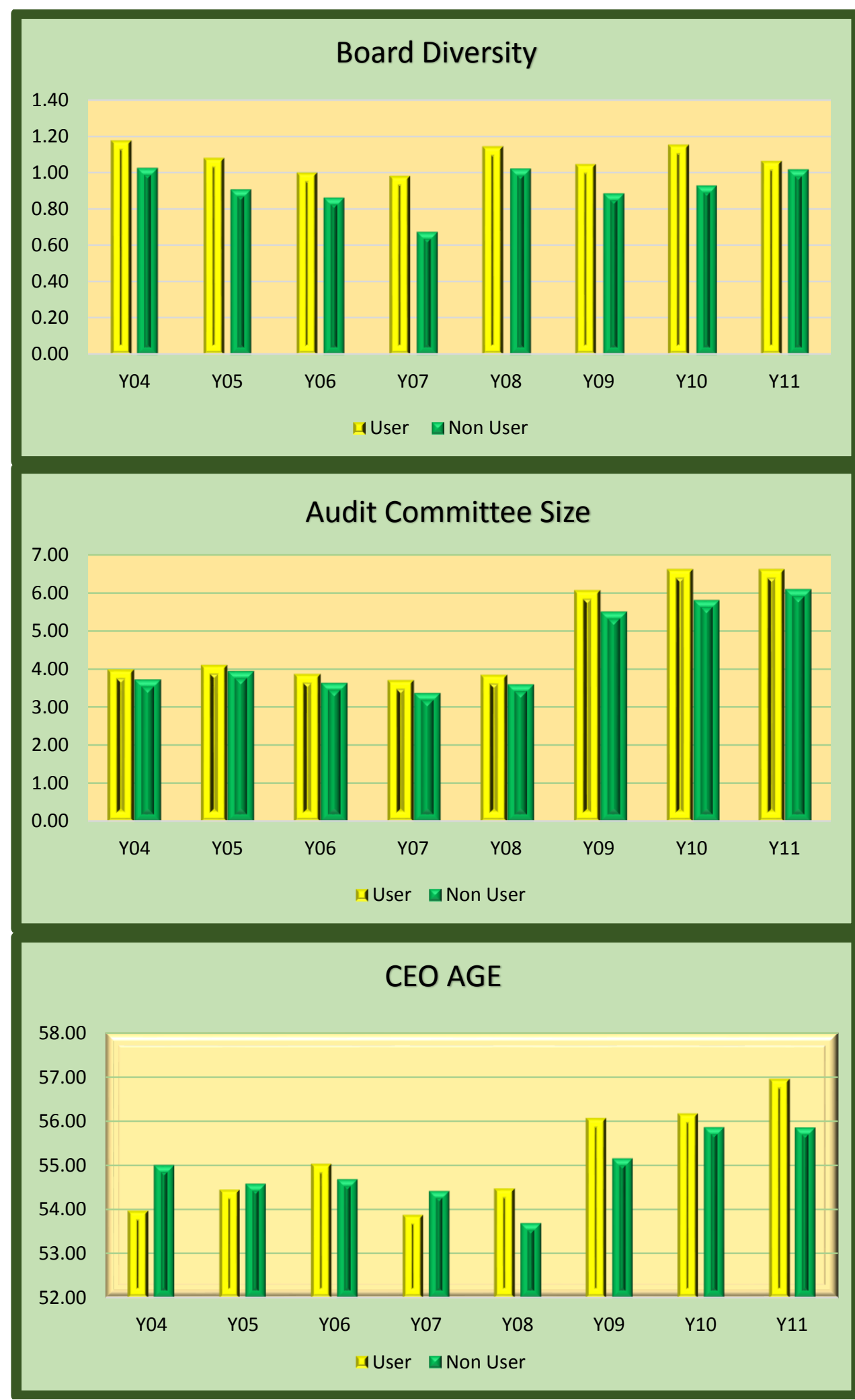

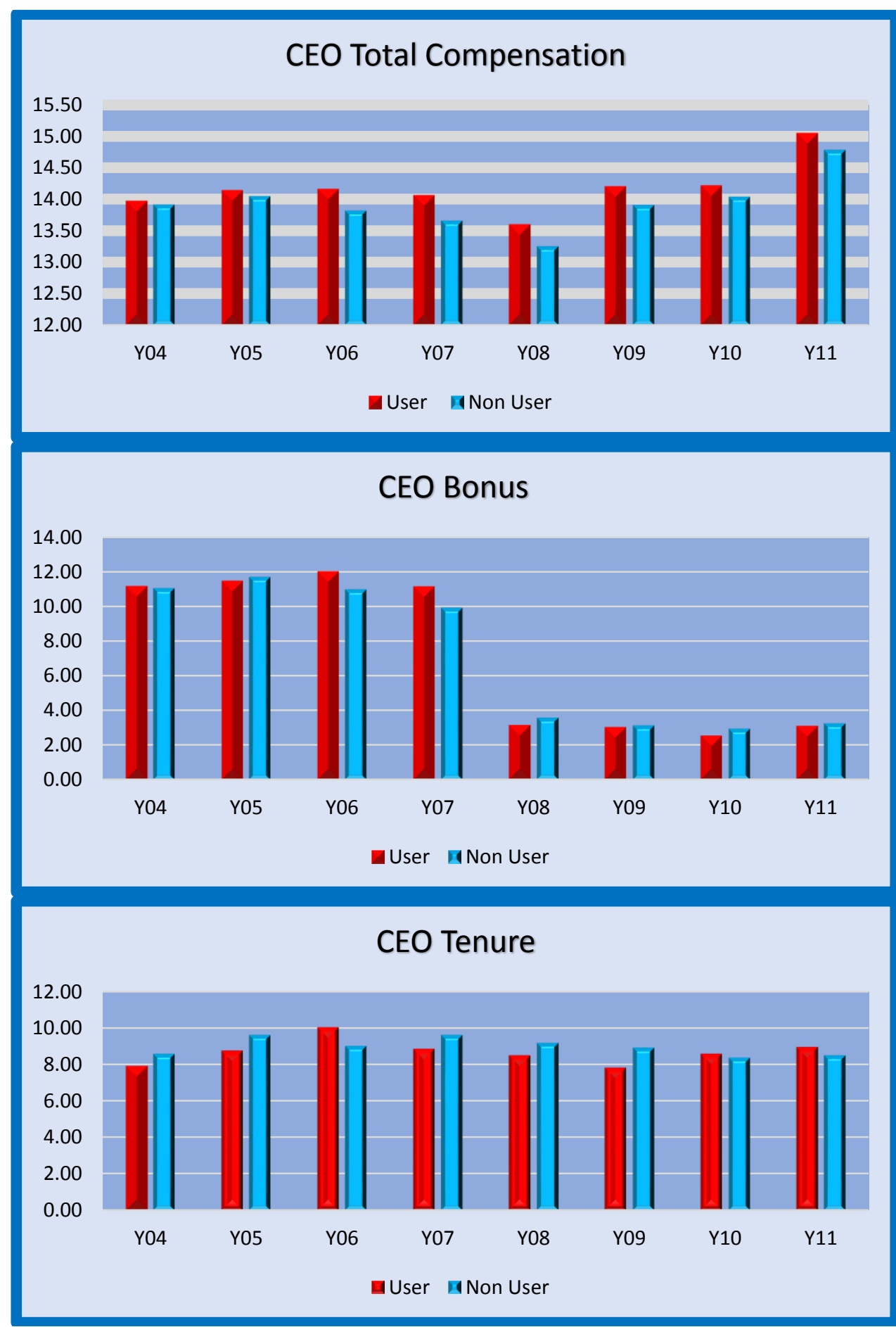


\section{Insider Shareholders}
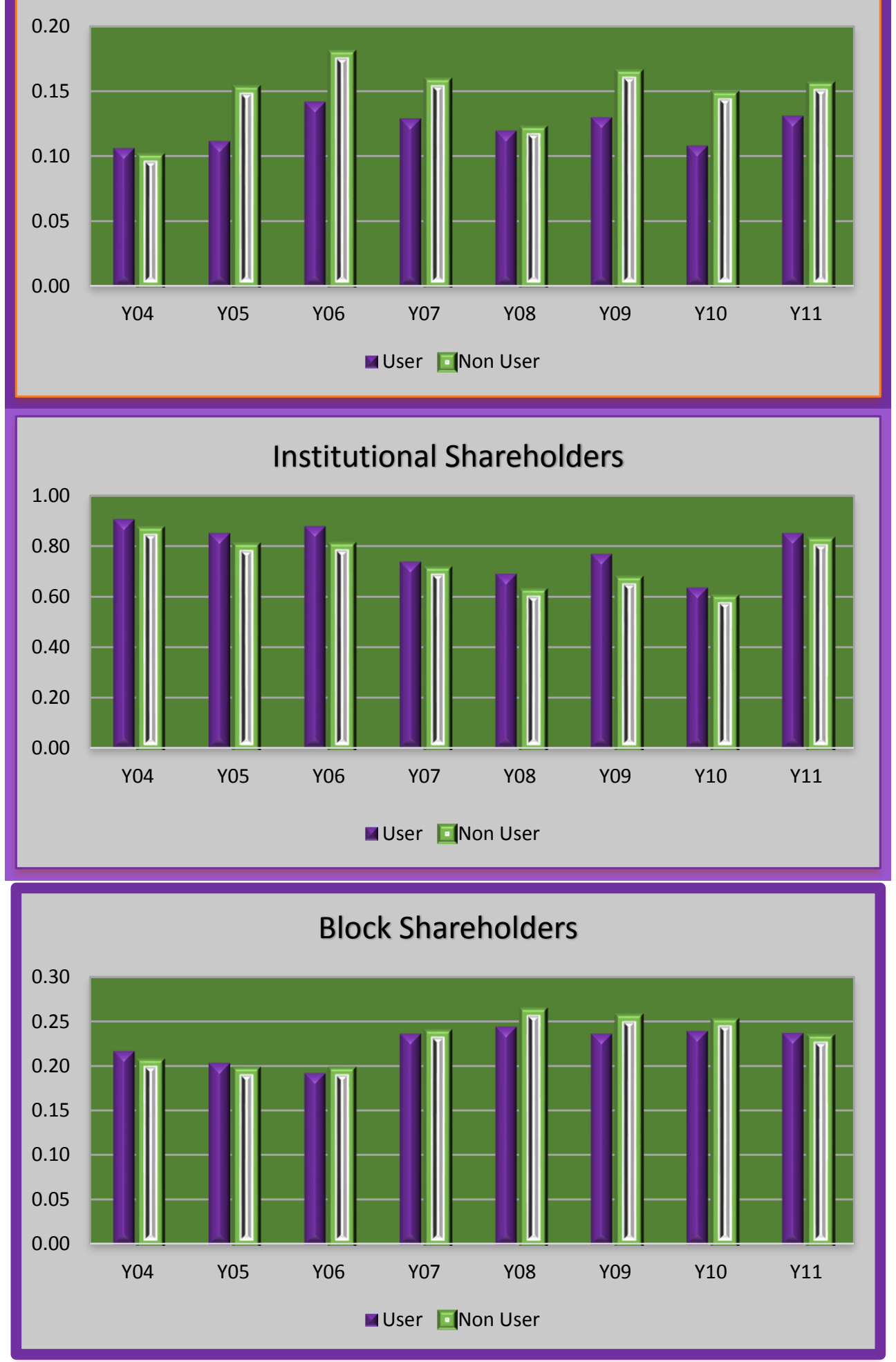